(1)

i. 


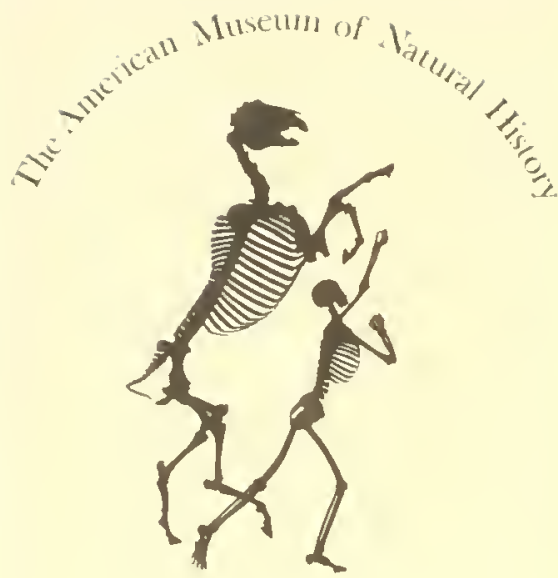

1869

THE LIBRARY 




STUDIES IN CANCER AND ALLIED SUBJECTS

CONTRIBUTIONS

TO THE ANATOMY AND DEVELOPMENT

OF THE SALIVARY GLANDS

IN THE MAMMALIA 
STLDIES IN CANCER AND ALLIED SUBJECTS

Conducted under the George Crocker Special Research Fund at Columbia University

VOL. I. THE ST U D Y O F E X P E R I M N T A L C A N C E R. A Review. By Willam H. Woglom, M.D. Illustrated with many plates. In two bindings, Quarto, boards, or $8 v o$, cloth. In press.

VOL. I I. PATHOLOGY. Illustrated with many plates and charts. Quarto, boards, pp. $2 i+267$. Price, $\$ 5.00$ net.

VOL. III. FROM THE DEPARTMENTS OF ZOÖLOGY, SURGERY, CLINICAL PATHOLOGY, AND BIOL O G I CA L C HEM ISTRY. Illustrated with many plates. Quarto, boards. In press.

VOL. IV. CONTRIBUTIONS TO THE ANATOMY AND DEVELOPMENT OF THE SALIVARY GLANDS IN THE MAMALIA. lilustrated with many plates. Quarto, boards, $p p .0+366$. Price $\$ 5.00$ net.

COLUMBIA UNIYERSITY PRESS

Sales Agents

Lovpon:

NEW YORK:

Toronto:

HENRY FROWDE LEMCKE \& BUECHNER HENRY FROWDE

Amen Corner, E.C. 30-32 West $27 \mathrm{Th}$ St. 25 Richmond $\mathrm{St}_{\text {t. }}, \mathrm{W}$. 


\title{
STUDIES IN CANCER
}

AND ALLIED SUBJECTS

\author{
CONTRIBUTIONS \\ TO THE ANATOMY AND DEVELOPMENT \\ OF THE SALIVARY GLANDS \\ IN THE MAMMALIA \\ CONDUCTED UNDER THE GEORGE CROCKER \\ SPECIAL RESEARCH FUND AT \\ COLUMBIA UNIVERSITY
}

VOLUME IV

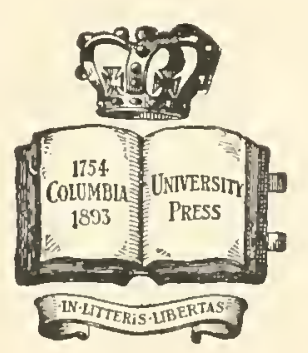

Xrow Dorts

COLUMBIA UNIVERSITY PRESS

1913

All rights reserved 
COPYRIGHT, I9I3

BY COLUMBIA LNIVERSITY PRESS

Set up and electrotyped. Published May, s9r3.

Xorbood 翟ress

1. S. Cushing Co - Berwick of smith (w. 


\section{CONTENTS}

I.NTRODLCTION

$P \wedge R T$

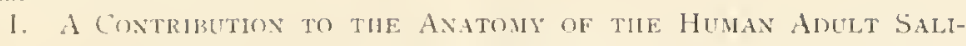
YARI Giaxds. By Churchill Carmalt . . . . . . 5

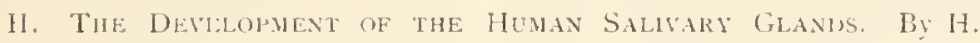
ron $\mathrm{W}^{\circ}$. Schulte. . . . . . . . 25

111. The Axatomy of the Salivarg Glands in the Lower Prinites. By George S. Huntington . . . . . . . 73

17. Tize Ginetic Tsterpretation of the Prialate Alieolinglal SAliVARY AREA. By George S. Huntington . . . . I I

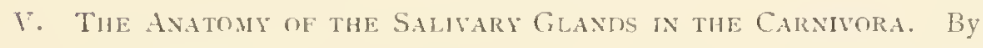
Churçhill Carmalt . . . . . . . . . I55

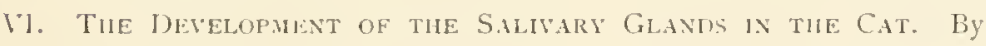
H. von IV. Schulte . . . . . . . . 191

VII. THE AxATMMY OF THE SAlikary Gland IN SOME MEMHER OF

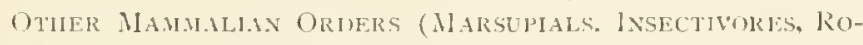
DExts, AND (UxGulates). B! Churchill Carmalt . . . 315

Vill. The Mammalax Alveolangul Salivary Area. with Special REFERENCE TO THE DEvelopMext OF THE Greater SubLiNGUal GLAND OF THE PIg. TOGETHER WITH a R゚EVEW OF THE Literature. By H. von IV. Schulte . . . . . 325 


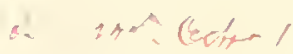




\section{INTRODUCTION}

At the eighteenth session of the Association of American Anatomists, held in Philadelphia December-January, I905, our late colleague and friend, Dr. Churchilt Carmalt, presented the results of an extensive research, occupying several years, on the comparative morphology of the vertebrate salivary structures, with especial reference to the mammalia. Dr. Carmalt died suddenly on Jan. 8, I905, within a week of the time at which he presented his communication to the Association.

As his close friends and associates of many years, and as the scientific executors of the material he left to the University he served so well, and honored by his services, we undertook to preserve the results of the careful and brilliant work he performed in the cause of American scientific anatomy. Unfortunately, his paper was presented orally, with numerous photographic lantern slides, but without even a written synopsis. In undertaking the publication of Carmalt's work we found oursetves confronted by a large amount of carefully and beautifully prepared material, and a number of rough and disconnected notes which evidently formed, for him, the basis of a future finished publication, but which we, only moderately familiar with the general trend and results of his researches, could not edit. In anticipation of the forthcoming publication the artist of the Anatomical Department, Mr. Petersen, had prepared a large number of illustrations, under Dr. Carmalt's directions. The present editors wish here to express their sense of obligation to Mr. Petersen for his aid in classifying and identifying this illustrative material. We were, in other words, in possession of an extremely complete set of preparations and illustrations for publication, but lacked the accompanying manuscript, and were devoid of the personal knowledge of the material which would have enabled us to group Carmalt's notes into a consecutive account. Moreover, in addition to his own extensive comparative material, Carmalt had, through the courtesy of Professor C. F. IV. 
McClure, based many of his illustrations on the preparations of vertebrate salivary structures contained in the Morphological Museum of Princeton University, and prepared by Mr. C. F. Silvester.

It was therefore necessary for us to become, from the beginning, familiar with the material we proposed to handle, and this involved a number of years of careful study. Furthermore, we knew that Carmalt was extremely anxious to enlarge his observations in certain important groups, and that he proposed to control his results by the study of the ontogenetic conditions in forms in which the embryos could be secured. Consequently it became necessary for us to satisfy: both of these additional demands. We offer this statement in explanation of the unavoidable delay which has attended the publication of our colleague's work. While we have reconducted this investigation on the lines above defined together and with constant comparison of our respective results, one of us (Huntington) has been charged chiefly with the preparation and study of the adult macroscopic anatomy of the forms examined and reported, while the other (Schulte) has mainly undertaken the embryological investigations which we considered necessary in order to complete and round out the work which Carmalt had set himself to perform. We have now arrived at the point where we can begin to publish the results. It was our purpose to primarily cover the very extensive and complicated ground of this research in a series of separate papers, published in the current journals, in which subdepartments of the entire problem could be handled. We proposed to continue the publication of these chapters until we had covered the entire problem as far as our material permitted. When this had been accomplished, the series of individual publications, with such addenda as might have accrued in the interval, were to be published in book form. Arrangements for such a publication had already been completed. and we intended that the resulting volume should represent a tangible proof of the honor in which his University holds the memory of our late colleague. Fortunately at this time the George Crocker Research Fund enabled Columbia University to provide for the publication of various researches conducted in the several laboratories and bearing on the subject of Cancer Research and allied subjects. A portion of the investigation of salivary morphogenesis has been supported during the past two years 
by grants from the Crocker Fund. We also wish to here acknowledge the assistance received in the prosecution of this work through a grant of $\$ 250$ received during the year 1907-1908 from the Rockefeller Institute for Medical Research.

It was considered proper to include all the results heretofore attained in this research in a single volume, published through the Columbia University Press. This procedure seemed all the more desirable to us because one of Carmalt's principal purposes in undertaking the salivary research was to furnish a sound morphological basis for the development of neoplasms of this region. We feel, therefore, that this aspect of his work is fully entitled to participate in the opportunity for publication offered by the Trustees of the University through the Crocker Research Fund.

The studies contained in the present volume are offered in the hope that they may afford a morphological and developmental basis for the investigation of the epithelial structures directly or indirectly involved in the mammalian salivary apparatus, and perhaps further throw light on the phylogenetic aspect of the epithelial neoplasms of this area.

It was unavoidable that the individual chapters should, to a greater or lesser extent, represent the viewpoints of their respective authors. While we have endeavored to assimilate the work as far as possible into a consecutive whole, and to provide extensive cross-references between the individual parts of this volume, each main chapter represents, as a matter of fact, an independent piece of work. This necessitates a certain amount of repetition, especially in reference to terminology, which could have been avoided if the book were the work of a single author.

We desire to express our grateful appreciation of the work of Mr. Petersen, who made the drawings here published, and to thank Dr. A. J. Brown for the great care and skill with which he prepared the photomicrographs.

Colemibia University,

February, 1912.

Geo. S. Huntington

H. voN W. SCHULte 



\section{PART I}

\section{CONTRIBUTION TO THE ANATOMY OF THE ADULT HUMAN SALIVARY GLANDS}

\section{By Churchill Carmalt}

TIIE adult human salivary apparatus is structurally composed of two separate and distinct glandlular areas. In one of these divisions the individual glandular anlages are united to form definite major glands, with distinct ducts, conveying the secretion of each gland to a terminal orifice. This group comprises the submaxillary and greater sublingual glands in the alveolingual field, and the parotid in the area of the superior alveobuccal sulcus.

The second group is characterized by the retention of a more primitive type of salivary organization. Certain areas of the oral, faucial, palatine, pharyngeal, and alveobuccal mucous membrane carry the minute orifices of numerous small separate and distinct glands. This glandiferous mucosa is topographically divided into districts. Thus the group of the lesser sublingual, or - in Chievitz's sense - "alveolingual" glands occupies the lateral district of the oral floor proper. Similar separate elements, mesarl of the line of the submaxillary duct, form in all probability the Blindlin-Nuhn or "apical" gland of the tongue, and the so-called "gland of Weber."

Further caudad this type of numerous separate minute glands. each with its individual orifice, invales the arcus palatinus and the soft palate, forming the groups of the isthmian and palatine glands.

Similar elements are encountered in the pharyngeal region. They are topographically united into the set of the pharyngeal glands.

The neighborhood of the terminal of the parotid gland shows in many adult human individuals several small separate glandular masses, opening by independent ducts upon the retroparotid oral mucosa, trending in their general line of development toward the cntal surface of the massetcr muscle, while the parotid glandular 
unfolding is cctomasselcric. These elements represent the reduced homologues of the orbital series of glands, which in some of the lower mammalia (Carnivora) reach a relatively high degree of development.

The superior and inferior alveobuccal and alveolabial sulci, which in certain of the lower mammalia yield distinct groups of molar and labial glands, are in the adult human the site of more or less reduced glandular development (alveobuccal or molar glands). Their forward extension, however, into the lips is responsible for the development of the distinct masses of separate superior and inferior labial glands, especially pronounced in the negroid races and largely responsible for the characteristic bulging and protruding lips of these human racial types.

No attempt has been made in the following pages to repeat the stereotyped descriptions of the human salivary glands, current in the general anatomical text-books. Only those conditions which seem to me worthy of special mention have been treated in any detail.

[Many new and important facts in reference to the parotid gland have recently been described by Mr. Parsons,* and the topographical anatomy of the human salivary glands has been treated by Professor Symington, to whose admirable paper the reader is referred. $\dagger$ ]

On the other hand I have endeavored to furnish a series of illustrations of the adult human salivary apparatus which, I hope, will prove of some service.

They represent accurately the actual conditions encountered in a large series of carefully injected and prepared subjects. I have been impressed, in the prosecution of this portion of the general research, with the inaccuracy and incompleteness of the illustrations which, especially in the alveolingual district, accompany the reading matter of the majority of accepted anatomical text-books. They seem to have been handed down, unchanged, or in some cases further obscured by reduction in the reproduction, from the earliest decades of descriptive anatomical knowledge. Much of the uncertainty which reveals itself, both in the descriptions of the individual glands and in the accompanying illustrations, is due to the fact that, without injection of the individual major glands, it is practically impossible

* On the form of the parotid gland. Jour. of Anat. \& Phys. April, IgI I.

f The topographical anatomy of the salivary glands. Jour. Anat. E Phys., Vol. xlvi. 
to unravel the constitution of a conglomerate salivary group, such as is offered by the sublingual mass. The individual elements are so closely interlocked, and the ducts so small and delicate in structure, that their relation to the entire glandular body can only be demonstrated by careful differential injection of the main efferent ducts.

The facts here recorded can be grouped under three main headlings:- -

I. Parotid gland and paraparotid separate glandular elements.

II. Glands of the alveolingual area, arcus palatinus, and soft palate.

III. Separate small glands of the lingual, labial, and pharyngeal regions.

I. THE PAROTID GLAND, AND THE SMALLER SEPARATE (ORBITAL)

GLANDS IN TIIE NEIGHBORHOOD OF TIIE PAROTID BUCCAL ORIFICE

The human parotid gland in the earlier fetal stages possesses a very short terminal duct in the submucous and buccinator segments. The transmasseteric portion of the duct is enveloped by a gradually increasing periductular glandular proliferation, which is indirectly continuous with the main body of the gland. The latter is chiefly subauricular in position, its caudal margin in close contact with the submaxillary gland.

Figure I shows, in a lateral superficial exposure, the parotid and submaxillary glands in a human fetus of approximately five months.

Figure 2 gives the same exposure in a fetus of approximately seven months.

In the latter preparation the duct of Stenson has differentiated as a clean transmasseteric canal, without lateral derivatives, while the main parotid gland is retromasseteric in position and has begun to elongate in the vertical diameter, producing a distinct preauricular process.

The oblique position of the caudal mandibular margin of Fig. I has been exchanged for the more horizontal line of the same shown in Fig. 2, indicating the attainment of a greater vertical value of the ramus.

Comparison with adult conditions suggests that the development of the ectomasseteric parotid duct and the localization of the main parotid gland in a retromasseteric position is, on the one hand, due 
to further growth and topographical changes in the mandible, producing an angular transition between ramus and body of the lower jaw, with coincident elongation of the earlier premasseteric segment of Stenson's duct (Fig. I), while, on the other hand, reduction of the earlier continuous periductular efflorescence may also help to clear the masseteric segment of the duct and define more sharply its relation to the retromasseteric parotid gland proper. This view would reasonably account for the adult retention of the accessory parotid glands (socice parotidis) on the basis of unusual persistence and further development of certain of the earlier periductular glandular sprouts.

Thus no better illustration of the persistence of earlier developmental conditions could be afforded than by the comparison of Figs. I and 3. In the latter adult individual the secondary or associate parotid elements, indicated in Fig. I by the periductular efflorescence, have developed into distinct glandular masses (6) emptying into both dorsal and ventral borders of Stenson's duct (5) and surrounding the same nearly to the cephalic margin of the masseter. In this case practically all of the glandular elements surrounding the masseteric segment of the parotid duct in the earlier fetal stage (Fig. I) have been carried over into the adult organization.

The same type of profuse parotid development along the course of the masseteric segment of the duct is characteristic, among the lower primates, chiefly in certain genera of the group of the Old World Cercopithecide. Thus Fig. 4 shows the parotid complex of one of the Cynocephalida (Cynocephalus porcarius) in which the hammershaped parotid glandular prolongation accompanies and nearly envelops Stenson's duct up to the point of its engagement in the buccinator.

In contradistinction, a specimen of Macacus rhcsus (Fig. 5), from the Morphological Museum of Princeton University (No. 9o6), shows the opposite type of general parotid development in primates, in which the entire parotid gland proper has receded into a retromassetcric position, surrounding the caudal margin of the external auditory meatus and extending thence into submandibular and sternomastoid regions. On the other hand, in the adult human individual instance shown in Fig. 6, the ventral circumference of the parotid duct is free, while its dorsal border is incrusted by a fully 
developed accessory glandular mass extending from the main gland across the masseter to the point of engagement of Stenson's duct in the buccinator muscle $(6)$.

In this instance only the dorsal members of the earlier periductular group of accessory parotid glands (Fig. I) have been retained in the adult organization, and have produced the extensive prolongation of the main gland along the dorsal border of the duct, while the earlier ventral periductular elements have disappeared, thus frecing this aspect of the duct in its entire transmasseteric course.

[Further confirmation of the above-expressed views in regard to the human associate or secondary parotid glands is furnished by these structures in some of the lower primates. Thus the human adult of Fig. 3, Part I, corresponds closely in its parotid organization to the specimens of Simia satyrus of Fig. I, Part III, and of Cynocephalus hamadryas, Fig. 5, Part I11. It is not dificult to see in the glandiferous parotid ducts of Cynocephalus sphinx (Fig. 3, Part III), and Macacus ncmestrinus (Fig. 7, Part III) a persistence and further development of the conditions presented in the early human fetal stages (Fig. I, Part I), while the buman adult shown in Fig. 6, Part I, has carried this periductular efflorescence only along the dorsal border of Stenson's duct. Note by the EDitors.]

This latter type of prolongation of the associate parotid lobules along the clorsal border of Stenson's duct is also seen in the human adult shown in Fig. 7 .

The individual represented, on the other hand, in Fig. 8, possesses a parotid which is shortened in the transverse and elongated in the vertical diameter. Stenson's duct, formed by the union of two branches emerging from the ventral margin of the main gland, carries no accessory elements throughout its entire transmasseteric course.

In Fig. 9 the parotid has the more typical adult shape with the dorsocephalic angle of the irregularly rectangular mass projecting slightly along the dorsal border of the duct, marking the first stage of the more extensive periductular development of associated gland masses seen in the previously described instances (Figs. 3, 6, and 7). The rest of the duct is, however, entirely free to its termination, and its formation by confluence of two main branches emerging from the ventral border of the gland is again clearly seen.

Figure ro shows an exposure in the human adult of the mesat surface of the gland, with its relations to internal ( 15 ) and external (If) pterygoid muscles, external carotid (29) and internal maxillary (30) arteries, and to the temperomaxillary vein (35). 
The ventral view of the two parotid glands is given in Fig. I I, with the divided pharynx between them. The preparation shows the deep preauricular glandular process extending mesad of the internal maxillary (3o) and superficial temporal (3I) arteries in front of the cartilagenous meatus, in relation to the stylopharyngeus (25) and styloglossus (24) muscles. The transverse width of the ventral portion of the gland is also better realized in this exposure.

Scparate glandular masses in relation with the terminal (intramural and buccinator) portion of the parotid duct. - Occasionally these elements are found in the adult human subject. They are characterized by the following features:--

I. They do not communicate with the parotid duct, but open by small independent and separate orifices on the oral mucosa, caudal to the parotid duct opening.

2. When well developed, a series of these little glands (6 to 7 in number) extends caudad from the parotid duct terminal, turning to the cutal side of the masseter muscle, while the parotid duct diverges to the ectal surface of the muscle. The cephalic masseteric border thus separates the caudal members of this group from the parotid duct.

3. The glands, when present, are for the most part embedded in the entomasseteric fat mass of the "sucking-pad."

4. The little bodies of the glands lie on the latcral surface of the buccinator muscle, which is pierced by the small ducts on their way to the oral mucous surface.

5. The majority of the glands lie ventral as well as mesal to the parotid duct terminal. Occasionally a few nodules are found dorsal to the parotid duct, close to the point of its engagement in the mucosa.

6. These latter glands appear to be scattered caudal members of the incomplete and feebly developed series of glandular elements occupying the superior alveobuccal sulcus and occasionally continued cephalad into the superior labial glands. They should, I believe, be distinguished from the first-mentioned series, lying ventral and mesal to the parotid duct, which separates them from each other.

7. The entomasseteric series of separate small glands clearly are the human reduced representatives of the group of the orbital glands which are so highly developed in some of the carnivora. I have hence so 
designated them in the figures. The most cephalic member of the group was described (1722) by Nuck in the dog, and is hence sometimes called the Glandula Nuckii. The little series of glands was also recognized by Ward, who described them under the name of "molar glands" in Todd's "Encyclopedia of Anatomy and Physiology" (Vol. IV, Part I, P. 426).

[For the details of the adult anatomy of these structures in the carnivora, see Carnalt's account and illustrations in Part $V$; the ontogeny of the structures in carnivora and their relation to the orbital inclusion is treated by Schulte in cxlenso in Part VI.]

One of the best examples of the full development of the orbital series which I have encountered in the series of adult human subjects examined is shown in Fig. 9.

Caudomesad of the terminal segment of the parotid duct a series of six little spherical glands extends dorsad along the buccinator muscle into the entomasseteric recess. These are the orbital glands (7). A few scattered glandular nodules lie just cephalad of the parotid duct terminal. They are separated by a short interval from a more extensive series of superior alveobuccal glands ( 8 ), to which group I believe they belong genetically.

Figure 12 shows this same preparation from in front and below, opening up a view into the deep entomasseteric fossa and emphasizing the divergent course of the orbital series $(7)$ and the parotid duct in reference to the two surfaces of the masseter muscle. The latter has been divided at the cephalic border of the parotid and the cephalic segment, together, with mandible and internal pterygoid, have been removed, in order to expose the orbital glandular row. In the intact condition of the masseter the orbital glands lie on the mesal surface of the muscle, separated by the same from the parotid duct.

Figure 7 shows the same group of separate and distinct glandular masses of the orbital series (7) caudomesal to the main parotid duct terminal, extending from the latter's buccal orifice mesal to the masseter muscle. 
II. GLANDS OF THE ALVEOLINGUAL AREA, ARCUS PALATINUS, AND SOFT PALATE

I. Submaxillary Gland. - The adult human submaxillary gland is composed of two segments:-

a. The main submaxillary gland $(I)$ is placed dorsocaudal to the free border of the mylohyoid around which the duct turns to reach the oral floor. The exposure of the medial surface given in Fig. Io shows this portion in the interval between the temperomaxillary (35) and facial veins, which groove its caudal border and ectal surface, and the caudal margin of the mylohyoid (20). The facial artery (33) lies between the cephalic border of the gland and the internal pterygoid muscle $(15)$, while its mesal surface and caudal margin are grooved by the posterior belly and intermediate tendon of the digastric muscle. This main portion of the submaxillary gland is usually divided into three or four large lobes by incisures penetrating to the hilus.

$b$. The second portion of the submaxillary gland is composed of a group of smaller gland masses, for the most part placed above the mylohyoid, which empty by small separate ducts into the main submaxillary canal. These are the accessory $\left(I^{\prime \prime}\right)$ and secondary $\left(I^{\prime}\right)$ submaxillary glands and ducts. They vary greatly in number, position, and in the arrangement of their ducts. This topographical relation of the two portions of the gland to the mylohyoid muscle (20) is well shown in the preparation hardened in situ exhibited in Fig. 19.

The general relation of the submaxillary gland as a whole to the mandible and mylohyoid muscle (20) is given in the lateral and median views of the preparation shown in Figs. $I_{3}$ and $\mathrm{I}_{4}$. The structures here were hardened in situ before exposure, and hence the general contour and modeling of the gland is well preserved.

The lateral view (Fig. I3) shows the deep groove on the ectal surface of the main glandular body which lodges the facial vein and its confluence with the temperomaxillary vein. A deficiency in the mylohyoid sheet also allows the cephalic extremity of the supramylohyoid accessory portion of the gland $\left(I^{\prime \prime}\right)$ to be seen in this riew. The medial aspect (Fig. I \&) shows the forward extension of the acces- 
sory portion on the cephalic surface of the mylohyoid beyond the point of emergence of the duct from the main gland. The duct $(I)$ has been divided and the free end turned cephalad to expose the mesal surface of the lesser sublingual glands (3).

Figure ro, also taken from an adult human body hardened before dissection, gives another medial view of the submaxillary gland in a case in which the greater sublingual or Bartholinian gland was present. The accessory submaxillary element $\left(I^{\prime \prime}\right)$ forms a long narrow glandular band which extends forward nearly to the symphysis, closely interlocked with both the greater (2) and lesser (3) sublingual glands, all three elements entering into the composition of a macroscopic "massa sublingualis," whose constituents only become clear when the individual distinct submaxillary and greater sublingual glands are defined by differential injection through their ducts.

Figure I 5 gives a lateral view of the submaxillary complex, fully exposed by the removal of the mandible, in another adult human subject in which the greater sublingual or Bartholinian gland (2) was present.

The main submaxillary gland $(I)$ is ovoid in shape. The cephalic pole, from which the duct emerges, turns slightly ventrad around the mylohyoid border. The first portion of the duct receives the smaller ducts of one dorsal and three ventral accessory submaxillary glands $\left(I^{\prime \prime}\right)$. The most cephatic of the ventral accessory elements is the largest, forming a bilobed mass resting on the geniohyoglossus and entering the ventral circumference of the main submaxillary canal by a short duct at the cephalic border of the lyyoglossus. In the natural position of the parts its cephalic pole rested against the medial surface of the greater sublingual gland (2). The lesser sublingual glands (3) form in this individual a relatively small mass, displaced caudad in the figure in order to expose the underlying structures covered by its medial surface in the natural position.

Figure 16 shows the opposite side of the same subject in a similar exposure. The greater sublingual gland is not developed. On the other hand the lesser sublingual group (3) is more extensive, forming two divisions, of which the larger extends dorsocaudad along the lingual nerve into the faucial region.

A group of five accessory submaxillary glands $\left(I^{\prime \prime}\right)$, three dorsal and 
two ventral, drain by short ducts into the main submaxillary duct on the hyoglossus muscle.

The first ventral accessory gland is a long tongue-shaped mass which extends cephalad into the angle between the geniohyoid and the geniohyoglossus muscles. This seems to be a fairly constant, or at least very frequent, component of the accessory submaxillary group. It is seen $\left(I^{\prime \prime}\right)$ in a typical instance, in Fig. 17 , with its cephalic prolongation abutting against the mesal surface of the lesser sublingual mass (3). In this individual there is also a single large dorsal accessory submaxillary gland which lies on the hyo- and stylo-glossus between the cephalic pole of the main gland $(I)$ and the lingual nerve $\left(3^{8}\right)$, separated by the latter structure from the dorsocaudal extension of the lesser sublingual mass (3) towards the arcus palatinus.

A still more highly developed instance of the ventral accessory submaxillary gland is shown in Fig. 8. In this individual, again with absence of the greater sublingual or Bartholinian gland, the submaxillary duct receives the drainage of two smaller dorsal accessory glands $\left(I^{\prime \prime}\right)$ above the mylohyoid. The rentral accessory gland $\left(I^{\prime \prime}\right)$ opens by a short canal into the main duct nearer the hilus. Its body forms an elongated voluminous mass which extends forward, with the cephalic extremity under cover of the lesser sublingual glands, nearly to the symplyysis.

In all these forms the ventral accessory submaxillary gland is characterized by its forward extension along the floor of the mouth in intimate relation with the medial surface of the lesser sublingual mass, and of the Bartholinian gland, when the same is present. The secretion drains in a cephalocaudal direction back into the main submaxillary duct near the hilus. In a few adult human subjects the site of the usual ventral accessory gland is occupied by a submaxillary component whose duct is directed cephalad, accompanying the ventral border of the main submaxillary duct, into which it opens after a longer or shorter independent course. This gland resembles very closely the element which is found in the submaxillary complex of some of the lower primates and which I have termed the secondary submaxillary gland and duct to distinguish it from the more commonly cncountered accessory submaxillary glands and ducts.

The greater individual character and independence of this gland, as 
well as the direction and length of its duct, entitle it. I think, to recognition when it appears in the human subject, and I have hence designated it under the term sccondary submaxillary gland and duct. Functionally it is, of course, the equivalent of the more commonly encountered ventral accessory gland above described and illustrated, and its elements are derived from the same portion of the common primitive alveolingual glandular field which gives origin to the latter structure. But its distinct adult morphological characters imply a different genetic use of the available primitive glandular anlages to produce the final result, and hence, at least tentatively, the suggested differentiation of the two elements appears justified.

In its simplest form the adult human secondary submaxillary gland $\left(I^{\prime}\right)$ is shown on the left side in Fig. 9. It forms a rounded body, situated above the mylohyoid, in contact with the cephalic margin of the main submaxillary gland $(I)$ and partly covered by the latter's mesal surface. The duct ascends, crossing the medial side of the lingual nerve $(3 \delta)$ and enters the ventral border of the main submaxillary duct under cover of the caudal extremity of the lesser sublingual mass. There are no accessory submaxillary glands in this individual.

A ligher degree of independence is achieved on the right side of the example shown in Fig. 7. Here the main inframylohyoid portion of the submaxillary gland $(I)$ is composed of two lobes, separated by a vertical cleft. The dorsal pole of this mass is capped by an extensive accessory submaxillary gland $\left(I^{\prime \prime}\right)$ whose cluct runs forwards, above the mylohyoid, is joined by the duct of a similar smaller gland $\left(I^{\prime \prime}\right)$, and then empties almost immediately into the dorsal aspect of the main submaxillary canal just caudal to the intersection of the same with the lingual nerve $(3 \delta)$.

The ventral portion of the supramylohyoid submaxillary area is occupied by a large pyramidal secondary submaxillary gland $\left(I^{\prime}\right)$. The duct runs cephalad along the ventral border of the main submaxillary duct, crosses the medial aspect of the lingual nerve in its company, and then extends under cover of the lesser sublingual mass to a point nearly midway between lingual nerve and plica sublingualis, where it joins the main submaxillary duct.

2. The Greater Sublingual or Bartholinian Gland. - This is not a constant component of the adult human alveolingual complex, but 
develops occasionally on one or both sides in individual cases. When present, the gland is usually small, confined to the cephalic portion of the alveolingual field, intermediate in position between the mass of the lesser sublingual glands laterally and the main submaxillary duct mesally.

Figure 10 shows the type in which the duct of the greater sublingual gland joins the submaxillary duct and opens in common with the same by a single orifice on the parafremular papilla.

Figure $I_{5}$ shows an instance in which the greater sublingual gland is present on the left side in an adult human subject, the duct emptying by a separate and independent orifice caudolateral to the submaxillary duct. On the opposite side of the same subject (Fig. I6) the greater sublingual has not developed. I have received the distinct impression that the presence of a greater sublingual or Bartholinian gland, with separate duct, either opening independently, or joining the terminal of the main submaxillary duct, involves a reduction in the size and extent of the group of lesser sublingual glands. On the other hand the human adults which do not possess a greater sublingual gland show a more extenșive development of the lesser sublingual group.

I have also encountered instances in which the injection of a very minute orifice, caudolateral to the opening of the main submaxillary duct, filled one or two small lobules firmly embedded in the mass of the lesser sublingual glands. I consequently believe that the description of the older writers is substantially correct when they define the Bartholinian gland as an occasional alveolingual component, derived from the general group of the lesser or Rivinian sublingual glands, by union of certain glandular components of the latter with the production of a short common duct draining the separate elements thus combined within the framework of a special gland.

Conditions encountered in some of the lower mammalia (e.g. Hydrocherus capyabura, Part VII, page 320 ) lead me to believe that a further splitting off of a third distinct individual gland, with separate duct, from the general mass of the diffuse lesser sublingual or Rivinian group, may represent an advanced stage in the phylogenetic progress of the lateral alveolingual field, which, as yet, has been attained by only a few types; but which, if carried further, would develop, in addition to the greater sublingual or Bartholinian gland, a second 
specialized gland of the intermediate alveolingual area, between the medial line of the submaxillary duct and the lateral alveolingual group of separate individual lesser sublingual glands, at the expense of the volume and extent of the latter.

In this case the median of the two intermediate glands might either join the submaxillary duct or open independently on the parafrenular papilla, conforming to the two known types of the greater sublingual or Bartholinian gland, while the lateral gland would appear as an entirely new component of the alveolingual complex, evolved by combining certain of the medial anlages of the lesser sublingual group into a separate and distinct gland with its own conducting canal. This condition is purely hypothetical and has not yet been observed in the mammalian forms examined. The nearest approach to it is offered, as above stated, by the apparent reduplication of the greater sublingual gland seen in Hydrocherus.

3. Tle Lesser Sublingual, Isthmian, and Palatine Glands. - The lateral component of the adult human alveolingual field is formed by a mass of separate individual glands, each with its own ductule, opening upon the lateral alveolingual ridge of the oral mucosa. The cephalic elements of this chain of separate individual glands are always more numerous and better developed than the caudial nembers of the series, and they constitute the mass of the lesser sublingual or Rivinian glands proper. In general they lie lateral to the submaxillary duct and to its accessory or secondary tributaries, and also lateral to the greater sublingual or Bartholinian gland and duct, when this member of the alveolingual complex develops. Occasionally a few scattered glandular masses extend mesad beneath the greater sublingual and submaxillary ducts to the lateral border of the tongue. These elements may be responsible for the derelopment of the Blandin-Nuhn gland in the apical portion of the tongue (Fig. I 8 ) and for the occasional glandular masses which, under the name of Weber's gland, are lescribed as occupying portions of the interval between the submaxillary duct and the lateral surface of the tongue proper.

The caudal end of the group of the lesser sublingual glands usually tails off into a narrow dorsilly deflected process which extends nearly to the lingual nerve. In some cases the ribbon of the lesser sublingual glands is prolonged mesad of the nerve into the anterior faucial pillar. 
In other cases, the lesser sublingual group of glands stops cephalad of the lingual nerse, and the series is resumed caudad of this point as a scattered collection of separate glands which ascend in the mucosa covering the arcus palatinus. These constitute the isthmian or faucial glands.

They may be confined to the limits of the anterior faucial pillar, or they may extend without interruption caudodorsad to become continuous with the field of separate glands located in the mucosa of the velum palati and forming the group of the palatine glands.

Owing to the close relation of the lingual nerve of the primates to the alveolingual oral mucosa (cf. Part III, page 78 , Figs. $A, B$ ), the line of the nerve may, in this mammalian order, represent the division between a lesser sublingual group of glands sensu stricto, and a caudal group of the same derivation which ascends, as the isthmian glands, into the faucial pillar. In the same way the palatoglossal muscle may interrupt the continuity of the isthmian group of separate glands with the glands of the soft palate. But morphologically all three sections of greater sublingual, isthmian, and palatine glands represent a single glandiferous lateral line which, in proceeding cephalocaudad along the lateral limit of the narrowing oral floor, escapes from the confines of this area by turning first caudodorsad, and then mesad, into the anterior faucial arch and then into the palatine area. The close apposition of the lingual nerve to the oral mucosa may or may not interrupt the continuity of the lesser sublingual and isthmian elements. In the same sense there may or may not be a break in the glandular line as the same turns from the palatine arch into the soft palate.

Genetically all the elements of the lesser sublingual, isthmian, and palatine groups must be regarded as derivatives from an originally continuous lateral border line which has conformed to the secondary conditions imposed by the mechanical adaptations of the mammalian vestibule and oral cavity. The widely different conditions which obtain in manmalia in general, other than the primates, in reference to the topographical position of the lingual nerve in relation to the lateral alveolingual glandular field, are discussed in detail in other portions of this volume (cf. Part III, page 78 . Part VIII, page 328).

One point deserves especial notice, namely, the tendency exhibited 
in the lesser sublingual group of the adult human subject to divide into more or less separate and distinct glandular masses. The clefts separating these individual aggregations are irregular, at times coronal, at times sagital, or in many instances oblique. They seem to imply a very primitive impulse toward the collection of the individual glandular anlages into more definite aggregations, such as must have preceled the more perfect development of the same principle in the medial alveolingual district which led to the establishment of the separate major submaxillary and greater sublingual glands and ducts.

DETAILED DESCRIPTION OF THE ADULT HUMAN GROUPS OF THE LESSER.

SUBLINGUAL, ISTHMIAN, AND PALATINE GLANDS IN THE INDIVIDUAL

1NSTANCES HERE RECORDED AND FIGURED

Figure 6 exposes the lateral aspect of the right lesser sublingual mass (3) by fenestration of the body of the mandible in an adult human subject, hardened by the intra-arterial injection of a 5 per cent formalin solution. The aveolar border and greater portion of the right mandibular body, together with the cephalic portion of the ramus and overlying masseter muscle, has been removed.

The lesser sublingual glands (3) form a dense mass extending caudal to the lingual nerve and thence turning, on the cephalomesal aspect of the latter, dorsad into the faucial pillar, as the isthmian glandular group.

The submaxillary duct, on the mesal aspect of the lesser sublingual mass, is entirely hidden by the same. A small portion of the supramylohyoid division of the submaxillary gland is visible behind and below the knee of the lingual nerve.

The preparation also shows the relation of the facial vein (36) and of the accompanying lymphnodes (37) to the ectal surface of the inframylohyoid division of the submaxillary gland.

In Fig. 8 the mass of the lesser sublingual glands (3), exposed by resection of the left mandible, appears as a sharply circumscribed triangular body, occupying the area between the plica sublingualis and the lingual nerve. Narrowing at each extremity, with a wider intervening body, the cephalic end of the mass covers laterally the termination of the submaxillary duct (and of the greater sublingual 
duct, when present). The caudal pointed end ascends for a short distance along the lingual nerve on the lateral aspect of the styloglossus muscle. It does not, in this individual, extend dorsomesad of the nerve into the palatine arch.

This is the simplest type encountered in the adult human subject in which the development of the lateral separate alveolingual gland field is confined to the production of a circumscribed group of lesser sublingual glands proper, cephalad of the lingual nerve line. In general extent and relations this human type closely conforms to the conditions commonly encountered in the lower Old World primates, notably the Macaques and Baboons (cf. Part III, page $8_{3}$, Figs. 3 to 7 incl.).

Figure if shows another example of this type on the right side of an adult human subject, in which the caudal prolongation of the lesser sublingual mass is in contact, at the lingual nerve intersection, with a large dorsal accessory submaxillary gland $\left(I^{\prime \prime}\right)$, but does not extend beyond this point into the palatine arch.

In contrast with the preceding preparation, the individual shown in Fig. 7 , in a similar exposure from the right side, illustrates a much greater degree of development in the field of the separate lateral alveolingual elements. The lesser sublingual group proper (3) maintains the typical triangular form. The caudal angle is, however, prolonged along the lingual nerve dorsomesad into a distinct isthmian group of glands $\left(3^{\prime}\right)$ occupying the anterior faucial pillar and disappearing under the cut edge of ramus and internal pterygoid muscle on its way toward the palate.

In addlition a distinct group of fuur glandular lobules (f) rest on the lateral surface of the tongue, mesad to the main submaxillary duct. These are the medial lesser sublingual detached elements which form the so-called "Gland of Weber."

Figure I 6 exhibits one of the frequently encountered types in which the lesser sublingual mass (3) is divided by a sagittal cleft into two distinct segments $\left(3^{a}\right.$ and $\left.3^{b}\right)$. (Cf, supra, page 18.) The caudal extremity of the gland, prolonged along the dorsal border of the lingual nerve, is separated by a short gland-free interval from a detached collection of istlmian glands $\left(3^{\prime}\right)$.

Figure ro, showing the lesser sublingual group hardened in situ in an exposure from the medial side, affords another example of the 
THE ANATOMY OE THE ADULT HUMAN SALIVARY GLANDS 2 I

cleavage of the entire mass into several distinct districts. The preparation also demonstrates well the topographical relations of the lesser sublingual glands (3) to the submaxillary $(I)$ and greater sublingual glands (2) and to their ducts.

In Fig. 9, the lesser sublingual glands (3) form a trapezoid mass covering the lateral aspect of the submaxillary duct which receives a short duct draining a ventral secondary submaxillary gland $\left(I^{\prime}\right)$. Mesal to the submaxillary duct, between it and the lateral border of the tongue, a small aggregation of glandular nodules (4) represents "Weber's gland." A well-marked group of isthmian glands $\left(3^{\prime}\right)$ lie along the dorsal border of the lingual nerve, separated by a short gland-free interval from the caudal prolongation of the lesser sublingual gland proper.

Comparison of Figs. 9 and $\mathrm{i} 7$ shows an interesting conformity to the same type in the organization of the adult alveolingual glandular field.

Coincident with the development of an independent intermediate or greater sublingual gland (2), and the unfolding of the submaxillary line into four accessory submaxillary glands in the supramylohyoid region, the individual shown in Fig. 15 exhibits a relative reduction of the lesser sublingual group to a short and narrow band of individual glands, deflected ventrolaterad in the figure, to expose the underlying more medial structures.

Finally Fig. ig shows a preparation of the tongue and adjacent soft parts removed after preliminary fixation through formalin injection.

This individual offers an unusual degree of development of the lesser sublingual (3) and isthmian $\left(3^{\prime}\right)$ glandular groups. The former, separated into two main divisions by a coronal cleavage line, extends as a compact mass along the lateral border of the alveolingual field.

The point of closest approximation of its caudal extremity to the lingual nerve $(3 S)$ is marked by the development of two small isolated glandular collections beyond which the glandular line ascends along the faucial pillar as an unusually well-developed series of closely packed isthmian glands $\left(3^{\prime}\right)$. 
III. SEPARATE SMALL GLANDS OF THE LINGUAL, LATERAL, AND PHARYNGEAL REGIONS

The relations of the isthmian group $\left(3^{\prime}\right)$ to the oral cavity, to the palatine $\left(3^{\prime \prime}\right)$, and pharyngeal ( 10 ) glands, and to the tonsil ( 42$)$ and peritonsillar adenoid follicles (I2), are shown in Fig. 20. This is a view of the left side of a dissection in which the oral and pharyngeal cavities were distended by a preliminary injection. The parotid duct (5) is shown in its passage through the buccal mucosa, with a small separate gland immediately caudomesal to the duct. This is the first of the above-described orbital series. (Cf. page 7.)

The ventral view of the same preparation is given in Fig. 2I, showing the group of lymphoid follicles at the base of the tongue $(I I)$ and the inferior labial glands $(9)$.

Figure 22 shows both inferior and superior labial glands in an instance of unusual development (Negro).

The inferior group forms a continuous glandular band along the entire transverse width of the lower lip.

The superior set is divided symmetrically into left and right portions, by a gland-free interval descending from the nasal septum.

PART I

I. Glands.

ANNOTATION OF LEADERS IN ALI FIGURES

$I$. Main submaxillary gland and duct.

$I^{\prime}$. Secondary submaxillary gland and duct.

$I^{\prime \prime}$. Accessory submaxillary glands and ducts.

2. Greater sublingual gland and duct.

3. Lesser sublingual glands.

3. Isthmian or faucial glands.

$3^{\prime \prime}$. Palatine glands.

4. Weber's gland.

5. Parotid gland and duct.

6. Accessory parotid glands.

7. Orbital glands.

8. Superior alveobuccal glands.

9. Labial glands.

Io. Pharyngeal glands.

II. Lymphoid tissue at root of tongue.

I2. Peritonsillar Jymphoid tissue. 
II. Muscles.

13. Temporal.

If. External pterygoid.

I5. Internal pterygoid.

I6. Masseter.

17. Buccinator.

I8. Stylohyoid and posterior belly of digastric.

19. Anterior belly of digastric.

20. Mylohyoid.

21. Geniohyoid.

22. Geniohyoglossus.

23. Hyoglossus.

24. Styloglossus.

25. Stylopharyngeus.

26. Palatoglossus.

27. Sternonastoid.

28. Infrahyoid muscles.

III. Vessels and nerves.

29. External carotid artery.

3o. Internal maxillary artery.

3I. Superficial temporal artery.

32. Lingual artery.

33. Facial artery.

34. Internal jugular vein.

35. Temperomaxillary vein.

36. Facial vein.

37. Lymphatic nodes.

39. Lingual nerve.

39. Spinal accessory nerve.

IV. Miscellaneous structures.

4o. Pharynx.

41. Pharyngeal tubercle.

42. Tonsil.

43. External auditory canal.

41. Arcus palatinus.

45. Mandible, divided.

46. Cheek pouch. 




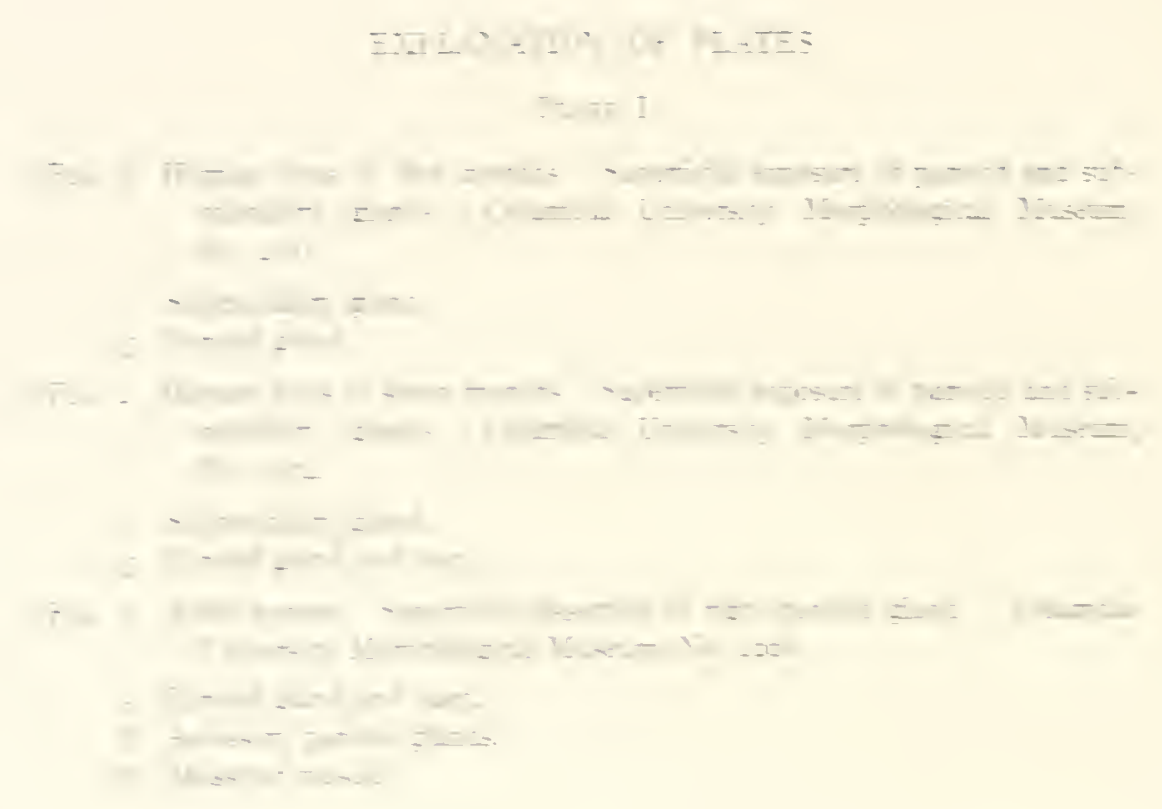




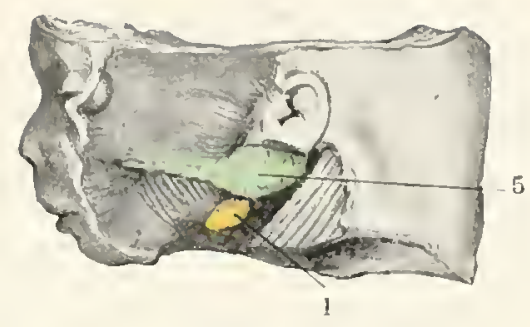

Plate 1.

FIC. I.

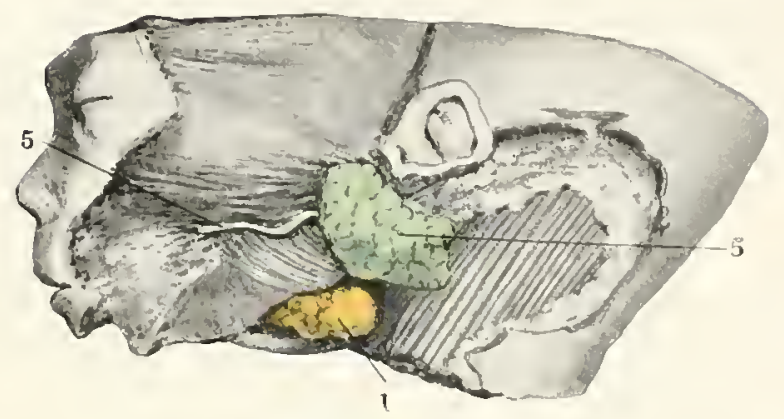

FIG. 2.

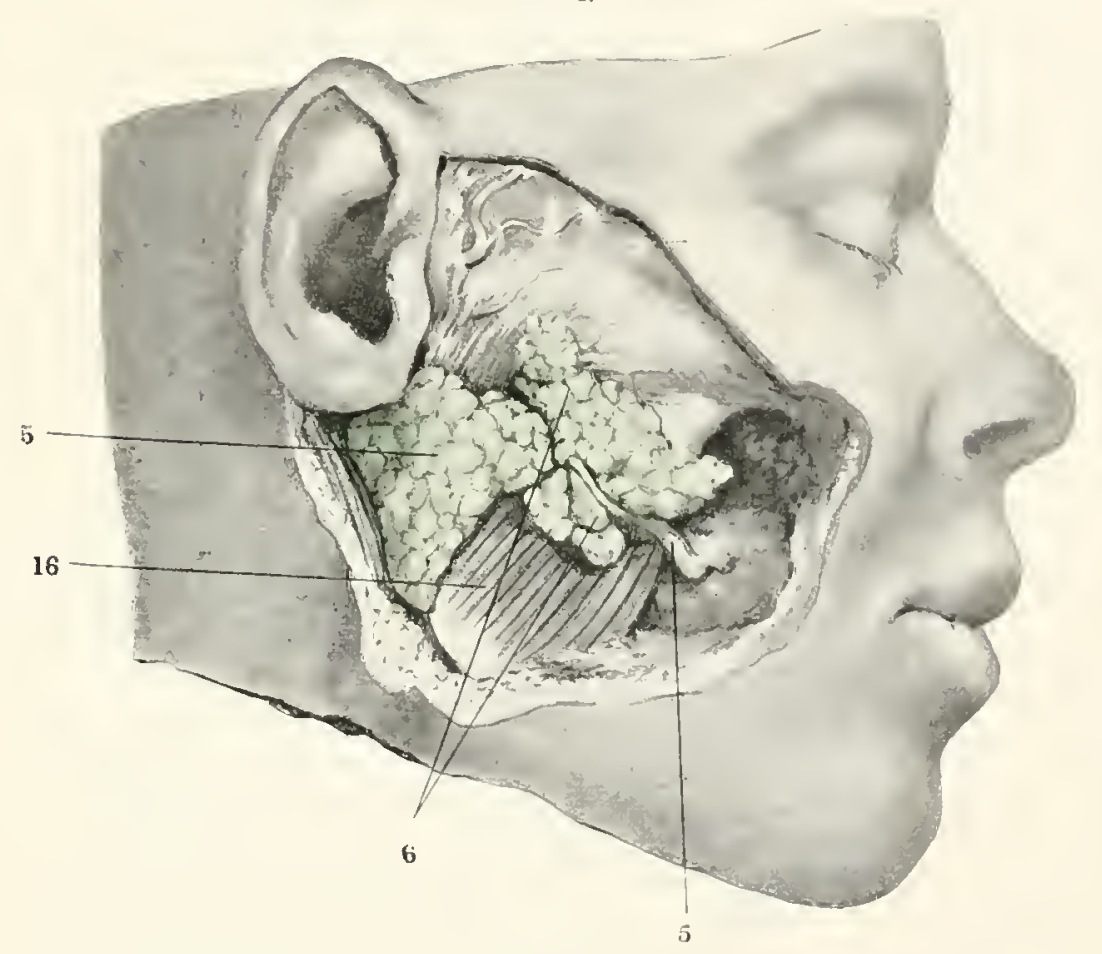

FIG. 3. 


\section{Plate II}

FIG. +. Cynocephalus porcarius. Superficial dissection of left parotid gland. Columbia University Morpholgical Museum, No. Igio.

5. Parotil gland.

27. Sternocleidumastoid.

43. External auditory canal.

FIU. 5. Macacus rhesus. Dissection of salivary glands. Princeton University Morphological Museum, No. 906.

I, $I$. Submaxillary gland and duct.

3. Lesser sublingual glands.

5. 5. Parotid gland and duct.

76. Cheek pouch. 
PLATE II.
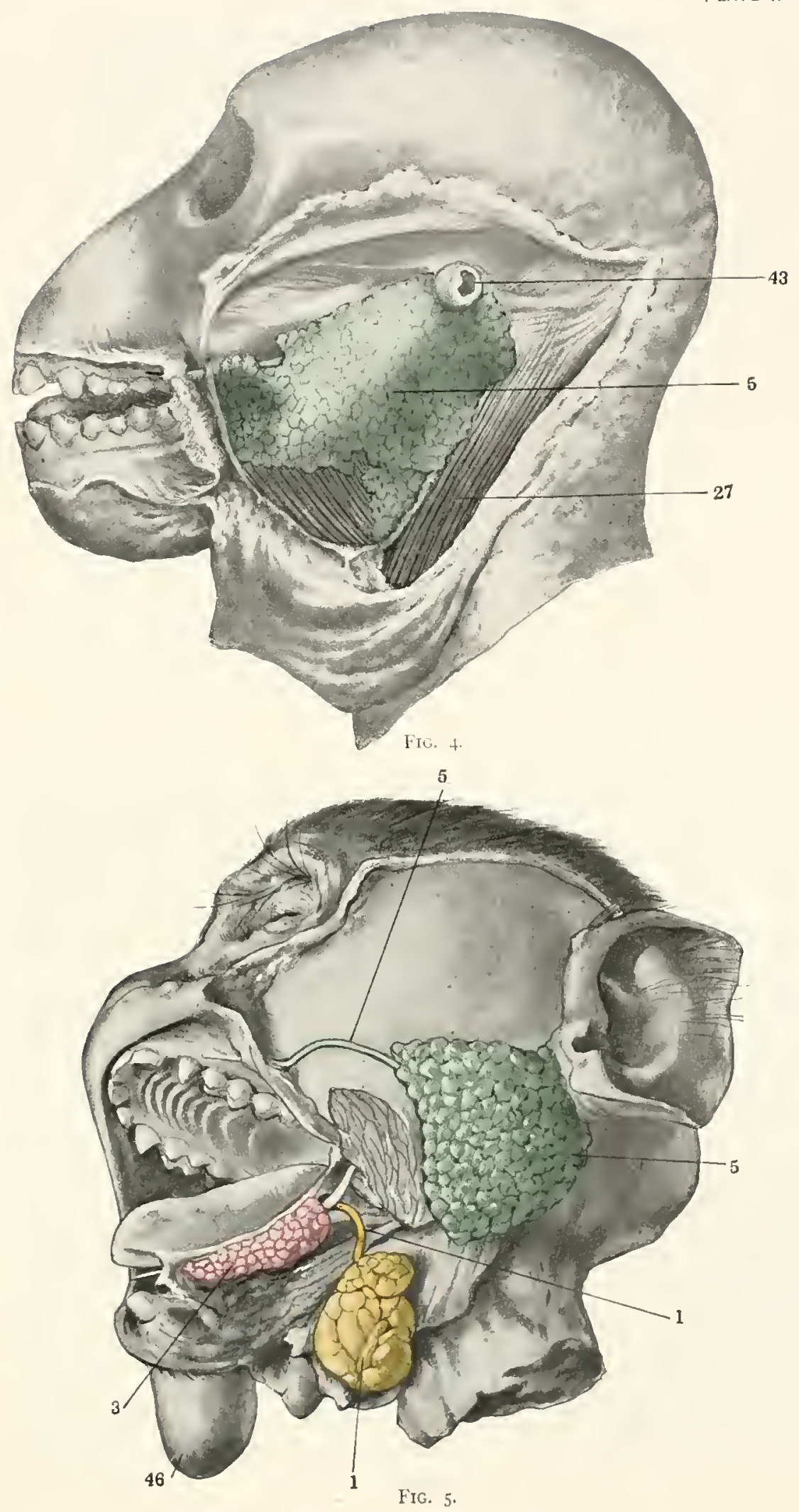


\section{Plate III}

FIG. 6. Dissection of adult human salivary glands of the right side, with resection of portion of mandible. Columbia University Morphological Museum, No. $19+9$.

1. Submaxillary gland.

3. Lesser sublingual and isthmian glants.

5. Parotid gland.

6. P'arotid duct carrying dorsal accessory parotid lobules.

3h. Facial vein.

37. Lymphatic nodes.

Fig. 7. Deep dissection of adult human salivary glands of the right side exposed by resection of mandible. Columbia Iniversity Morphological Museum, No. 1973 .

I. Main submaxillary gland.

$I^{\prime}$. Secondary submaxillary gland.

$I^{\prime \prime}$. Accessory submaxillary gland.

3. Lesser sublingual glands.

$3^{\prime}$. Isthmian glinds.

7. Weber's grlanul

5 5. Parutid gland and duct opening.

6. Associalte parotid gland.

7. Orbital glands.

I6. Masscter.

I7. Buccinator.

rS. Posterior belly of rligastric.

20. Mylohyoid.

21. Geniohyoil.

22. Geniohyouglossus.

27. Sternocleidomástoid.

29. Infrahyoid muscles.

37. Lympthatic nodes.

3९. Linguil nervet

t5. Mandible, livided. 
PLATE III.
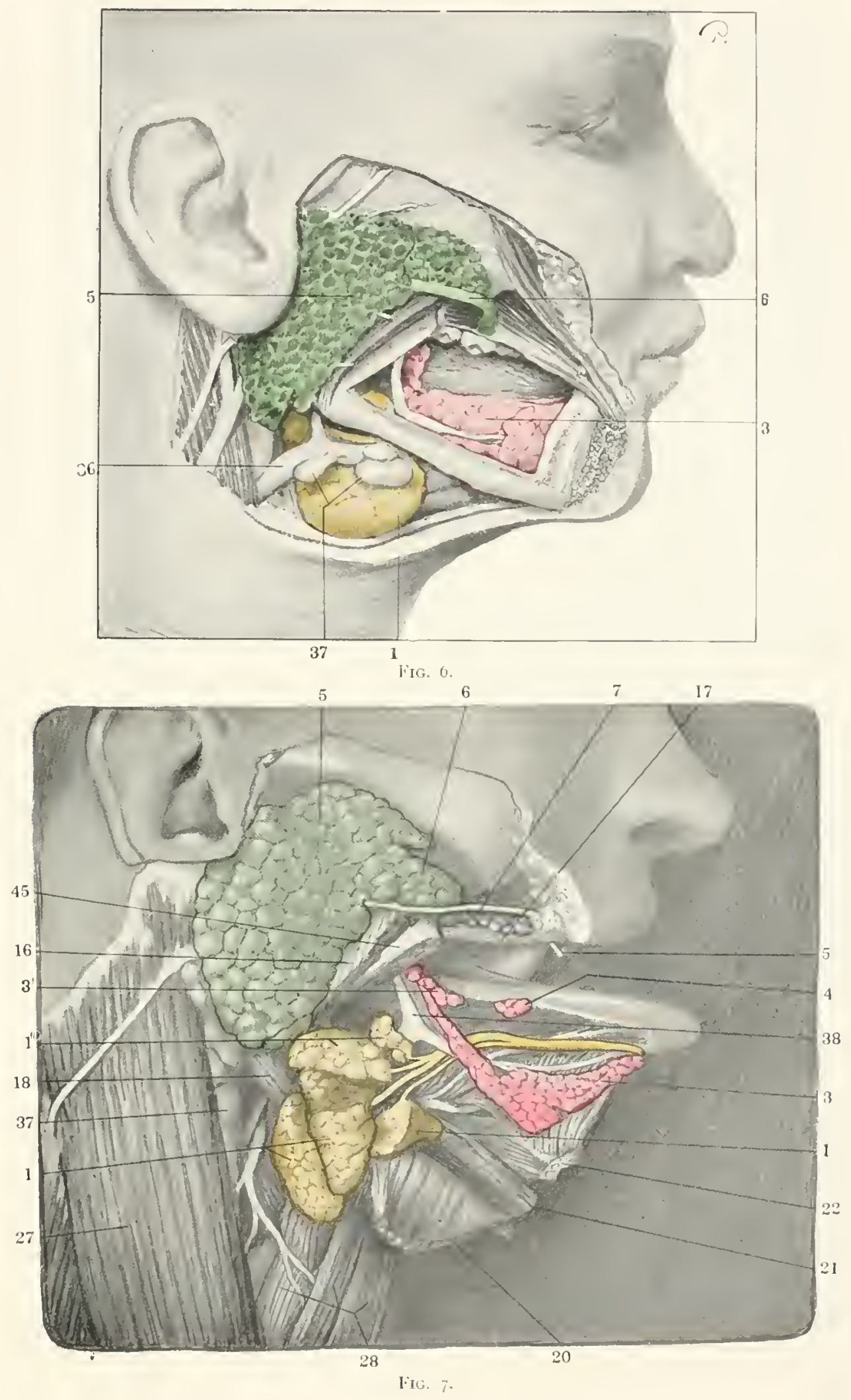


\section{Plate IV}

Fig. 8. Deep dissection of adult human salivary glands of the left side, exposed by resection of the mandible. Columbia University MIorphological Museum, No, 2160.

I. Main submaxillary gland.

$I^{\prime \prime}$. Accessory submaxillary gland.

3. Lesser sublingual glands.

5. Parotid gland.

I6. Masseter.

17. Buccinator

IS. Stylohyoid and posterior belly of digastric.

20. Mylohyoid.

2I. Geniohyoid.

2?. Geniohyoglossus.

27. Styloglossus.

27. Sternocleidomastoid.

3\$. Lingual nerve.

45. Mandible, divided.

FIG. 9. Deep dissection of adult human salivary glands of the left side, exposed by resection of the mandible. Columbia Lniversity Morphological Museum, No. 2305.

I. Main submaxillary gland.

$I^{\prime}$. Secondary submaxillary gland.

3. Lesser sublingual gland.

$3^{\prime}$. Isthmian glands.

4. Neber's gland.

5. Parotid gland.

6. Accessory parotid gland.

7. Orbital glands

8. 8. Superior alveobuccal glands.

I6. Masseter.

17. Buccinator.

I8. Stylohyoid and posterior belly of digastric

19. Anterior belly of digastric.

20. Mylohyoid.

21. Geniohyoid.

23. Geniohyoglossus.

27. Sternocleidomastoid.

38. Lingual nerve.

45. Mandible, disided 
PLATE IV.
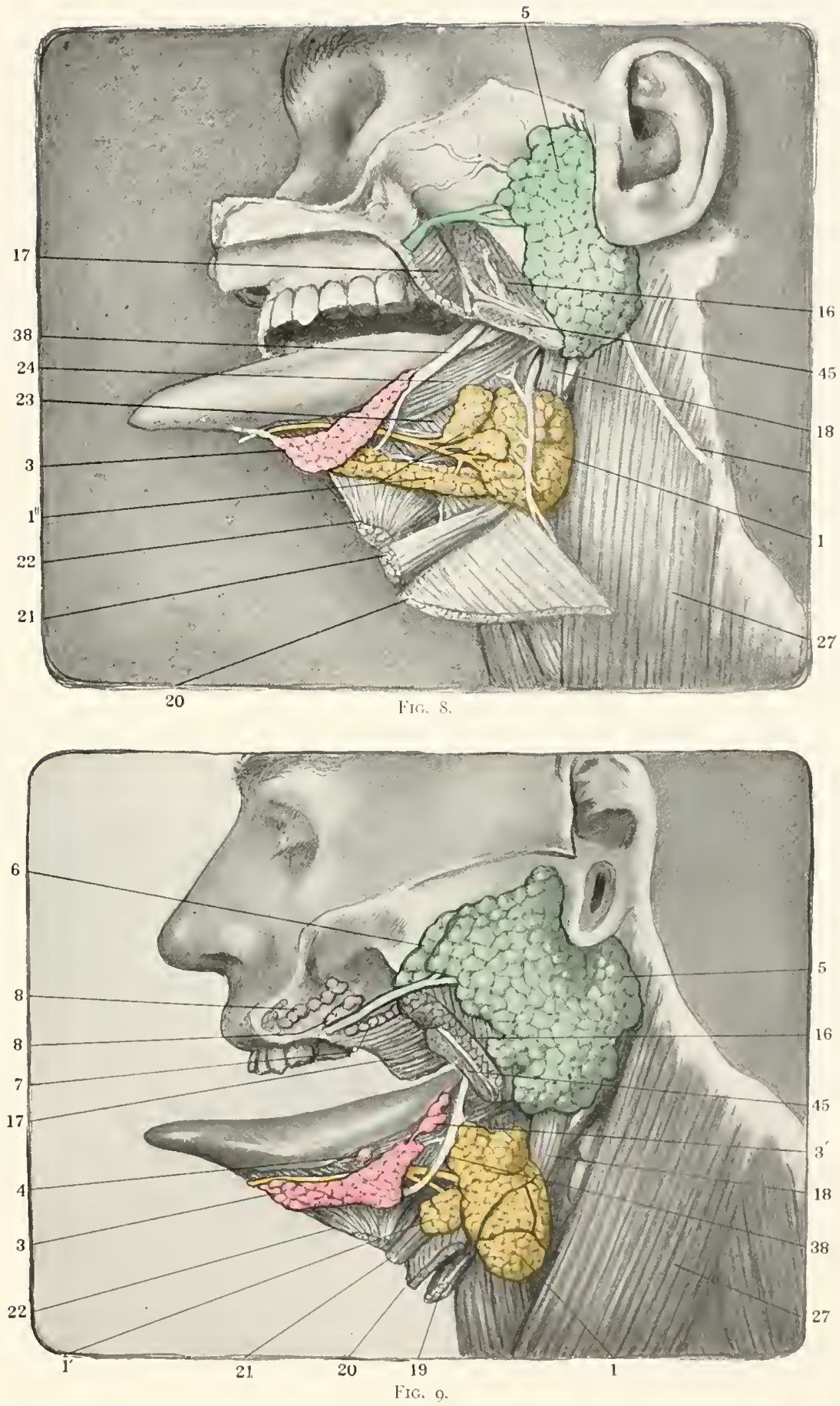


\section{I'LATE V}

FIG. Io. Adult human salivary glands of the right sirle, exposed, after hardening in situ, from the medial aspect. Columbia University Morphological Museum, No, 2I 40.

I. Main submaxillary glamel and duct.

$I^{\prime \prime}$. Accessory submaxillary gland and duct.

2, 2. Greater sublingual gland and duct.

3. Lesser sublingual glands.

5. 5. Parotid gland and duct opening.

13. Temporal muscle.

1. Lxternal pterygoid.

15. Internal pterygoid.

I9. Interior belly of digastric.

20. Mylohyoid.

29. External carotid artery.

30. Internal maxillary artery.

33. Facial artery:

35. Temperomaxillary vein.

Fis. 1 1. Mrult human subject, showing ventral view of the two parotid glands. The divided pharynx appears between them. Columbia University Morphological Museum, No. 2.310.

5. Parotid gland.

24. Styloglossus.

25. Stylopharyingeus.

3n. Internal maxillary artery.

31 . Superficial temporal artery.

32. Lingual artery.

33. Facial artery. 
PLATE V.

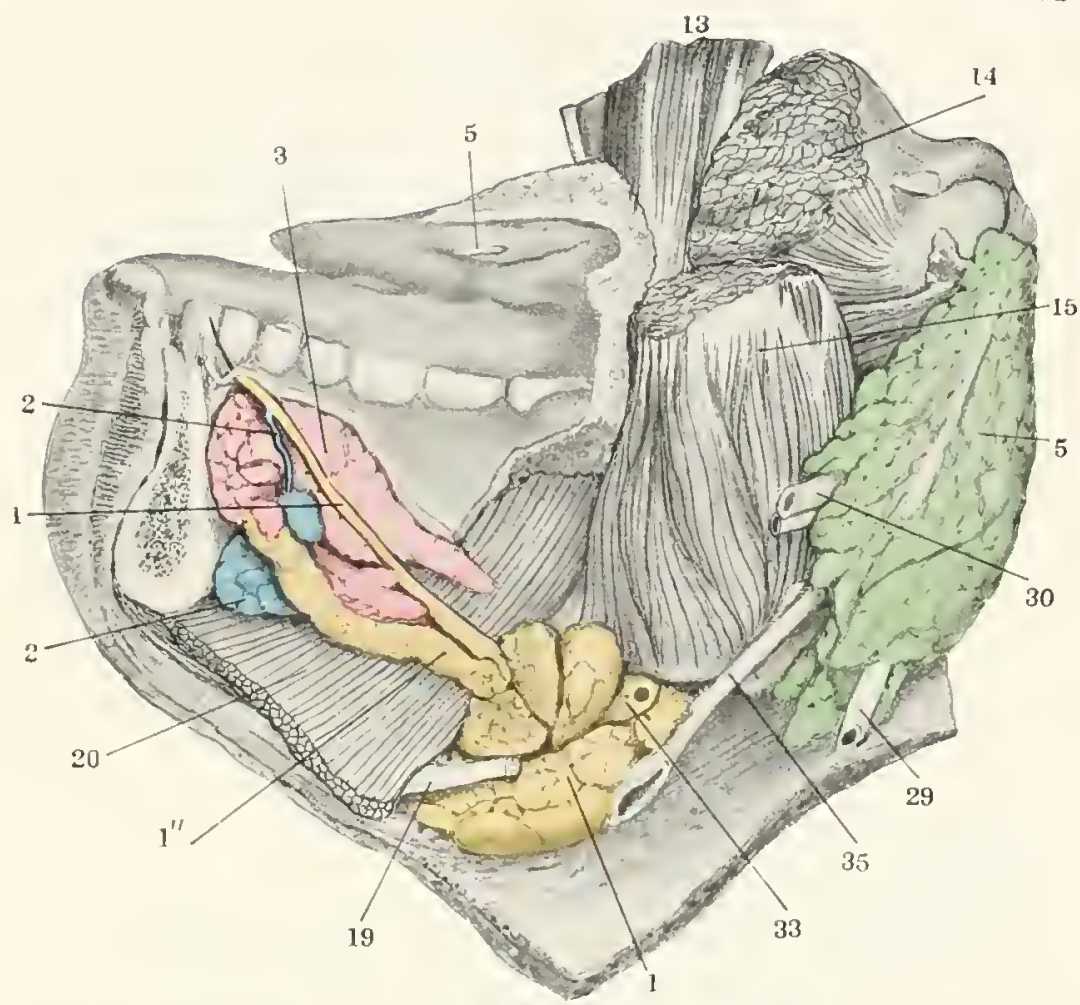

Fig. IO.

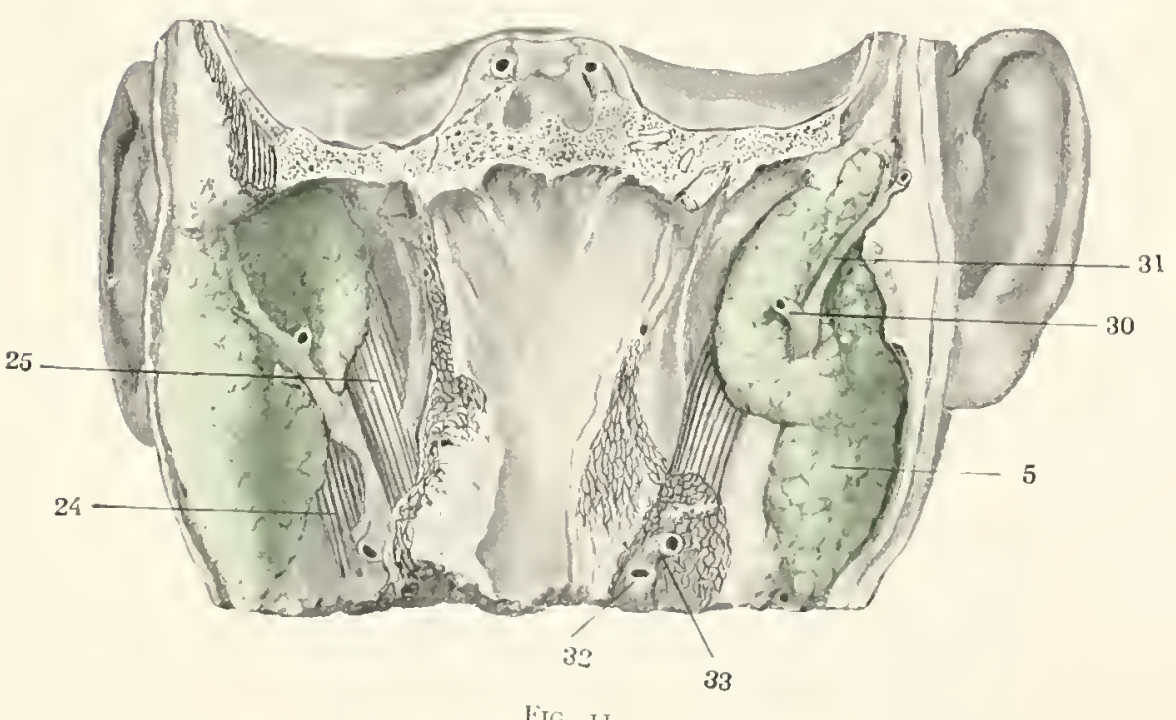


Plate IT

FIG. 12. View of upper portion of preparation shown in Fig. o, from below with head tilted to expose the entomasseteric recess lodging the orbital glands.

5. Parotid gland.

7. Orbital glands.

8. Superior alveobuccal glands.

I6. Masseter.

I7. Buccinator.

IS. Stylohyoid and posterior belly of digastric.

38. Linguat nerve.

45. Mandible, divided.

FIG. I3. Ifuman adult. Mandible and mylohyoid with submaxillary and lesser sublingual glands hardened in situ. Columbia University Morphological Museum, No. 2150 . Lateral view.

I. Nain sulmaxillary gland.

$I^{\prime \prime}$. Accessory submaxillary gland.

20. Nylohyoid.

Fig. It. The same preparation, medial view:

I, I. Main submaxillary gland and duct, the latter divided and turned cephalolaterarl.

3. Lesser sublingual glands.

20. Nylohyoid. 

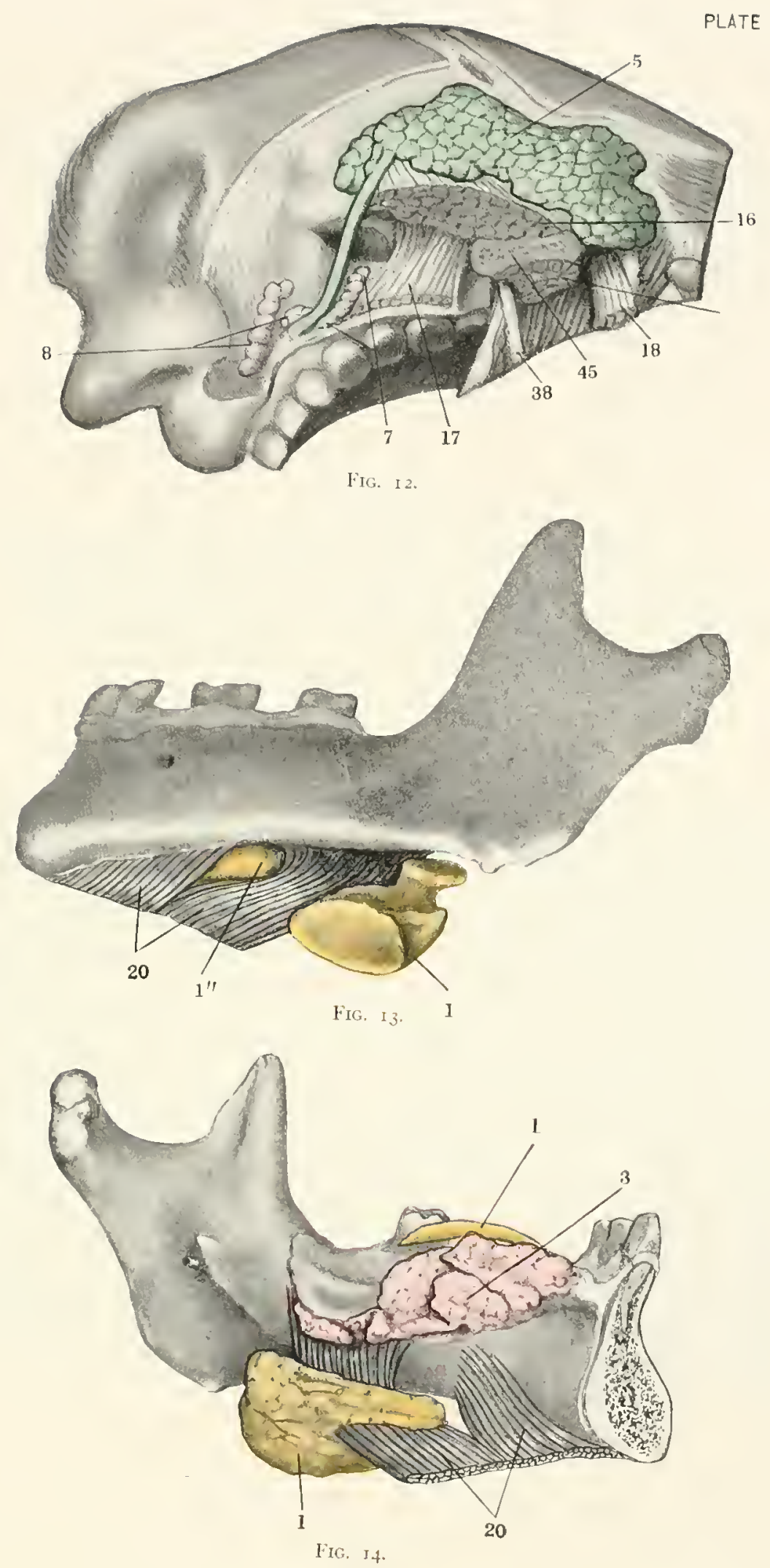
FIG, 15. Adult human subject. Left half of tongue and adjacent structures showing salivary glands of the alvenlingual region. Columbia Lniversity Morphological Museum, No. IoSo.

I. Mlain submaxillary gland.

$t^{\prime \prime}$. Accessory submaxillary glands.

2. Greater sublingual gland.

3. Lesser sublingual glands.

IS. Stylohyoid and posterior belly of digastric.

20. Nylohyoid.

21. Creniohyoid.

22. (reniohyogrossus.

23. IIyoglossus.

24. Styloghossus.

2S. Infrahyoid muscles.

33. Facial artery

Fig. 16. Right half of tongue and surrounding parts of the same subject as the preceding Fig. 15. Columbia University Morphological Museum, No. 19\$I.

I. Nain submaxillary gland.

$I^{\prime \prime}, I^{\prime \prime}$. Accessory submaxilliry glands.

3. 3. Lesser sublingual glands.

3 . Isthmian glands.

18. Stylohyoid.

20. Mylohyrid.

21. Geniohyoid.

22. Geniohyoglossus.

2.3. Hyoglositus.

24. Styloglossus

2.8. Infrahyoid muscles.

3.3. Facial artery:

39. 3९. Linguil nerve.

Fí. I $_{7}$. Arluit human subject. Deep dissection of right alveolingual glandular area after resettion of mandible. Columbia Luiversity Morphological Museum, No. 2133 .

I, I. Main submaxillary glind.

$I^{\prime \prime}, I^{\prime \prime}$. Access ry submaxillary glamis.

3. Lesser sublingual glands.

18. Stylohyoid and posterior belly of digastric.

19. Interior belly of digastric.

20. Mylohyouid.

21. Geniohyoicl

22. Geniohyoglossus

23. Hyoglossus.

27. Styloglossus.

2.S. Infrithyoid muscles.

is. lingual nerve.

41. Ircus palatimus. 

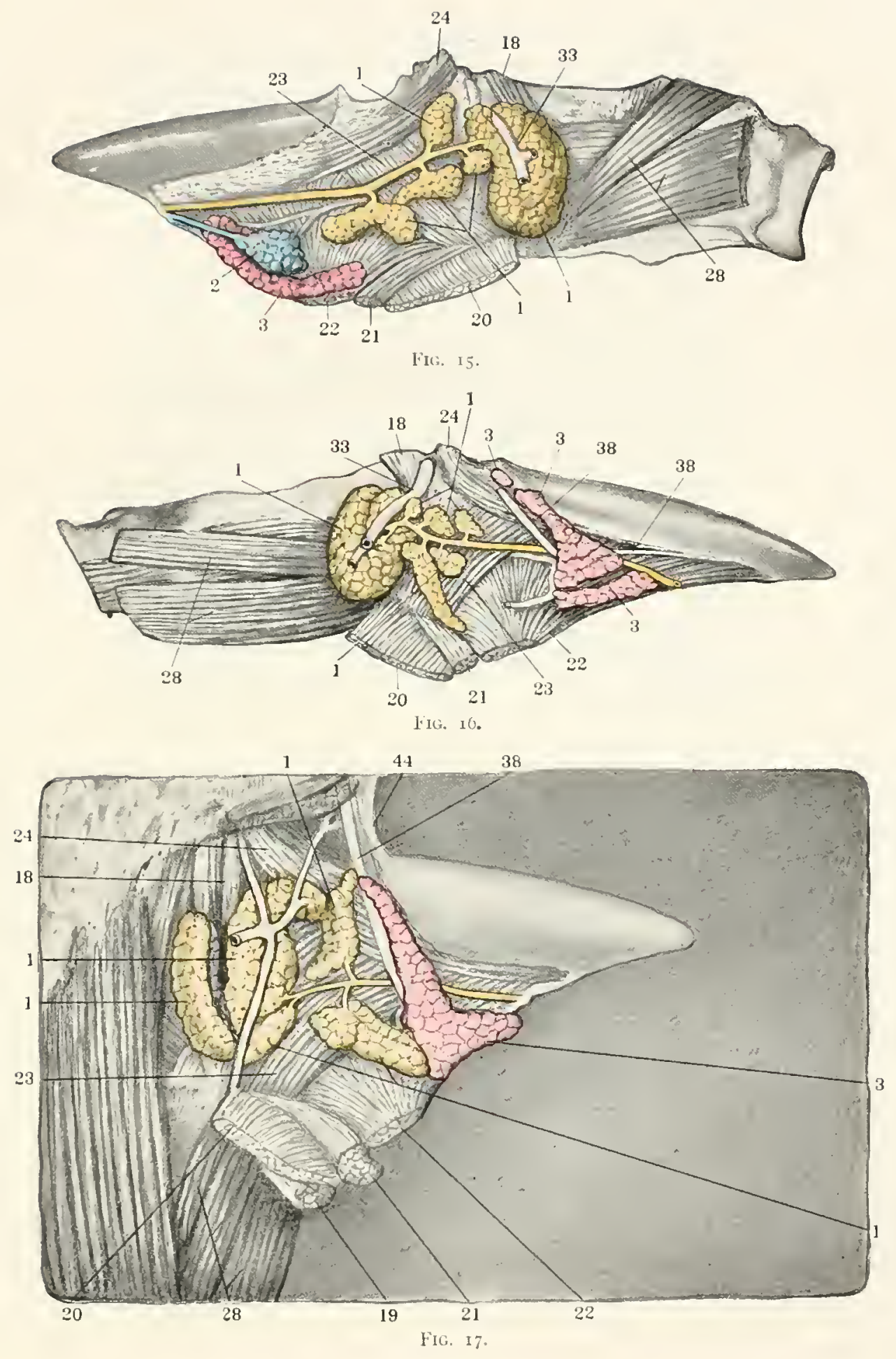


\section{Plate VTI}

FIG. IS. Adult human subject. Dissection of apical gland of tongue (BlandinNuhn gland). Columbia University Morphological Museum. No. 1955.

Fig. I0. Adult human subject. Tongue and surrounding parts removed after preliminary formalin fixation. Columbia University Morphological Museum, No. roor.

1. Main submaxillary gland.

3. Lesser sublingual glands.

3 . Isthmian glands.

I8. Stylohyoid and posterior belly of digastric

I9. Anterior belly of digastric.

20. Mylohyoid.

21. Ceniohyoid.

27. Styloglosius.

25. Stylopharyngeus.

26. Palatoglossus.

28, 2.8. Infrahyoid muscles.

3. Internal jugular vein.

38. Lingual nerve. 
PLATE VIII.

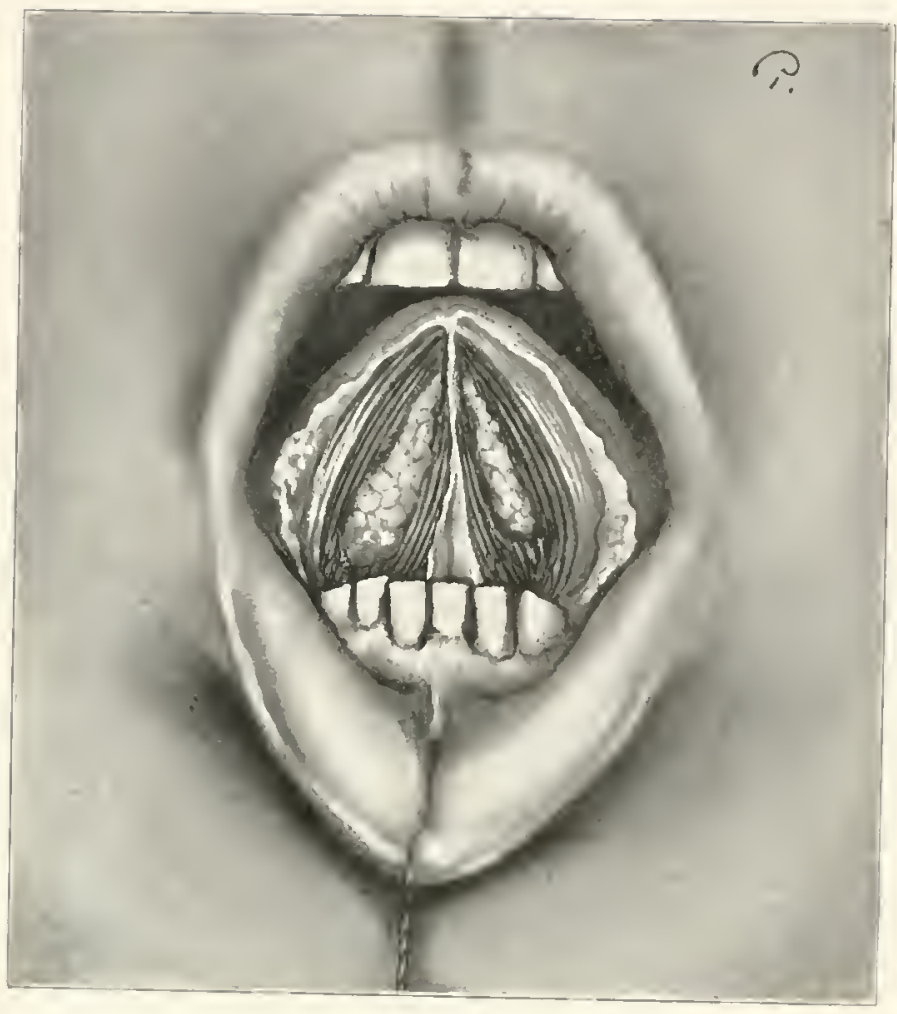

FIG. IS.

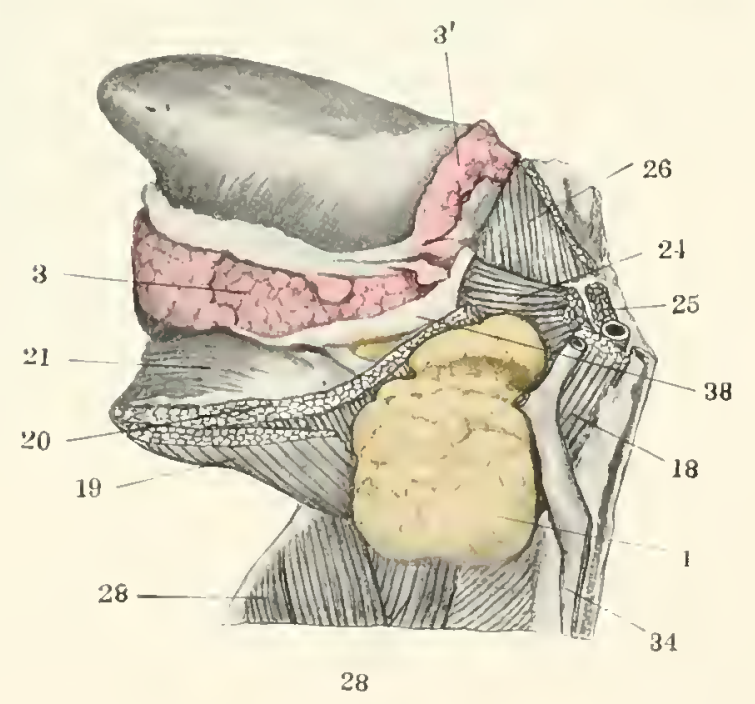

Fie, 19. 


\section{PIATE IX}

FIG. 20. Human adult. Dorsolateral view of tonsil, peritonsillar, isthmian, palatine, and pharyngeal glands. The mouth and pharynx are distended by a preliminary hardening injection. Columbia University Morphological Museum, No. 21 to.

3'. Istlumian glanls.

$3^{\prime \prime}$. P'alatine glands.

5. I'arotid iluct.

9. Labial glands.

10. Plaryngeal glands.

12. Peritunsillar lymphoil follicles.

fiv. Pharynx.

fI. Pharyongeal tulsercle.

t. Tonsil. 
PLATE IX.

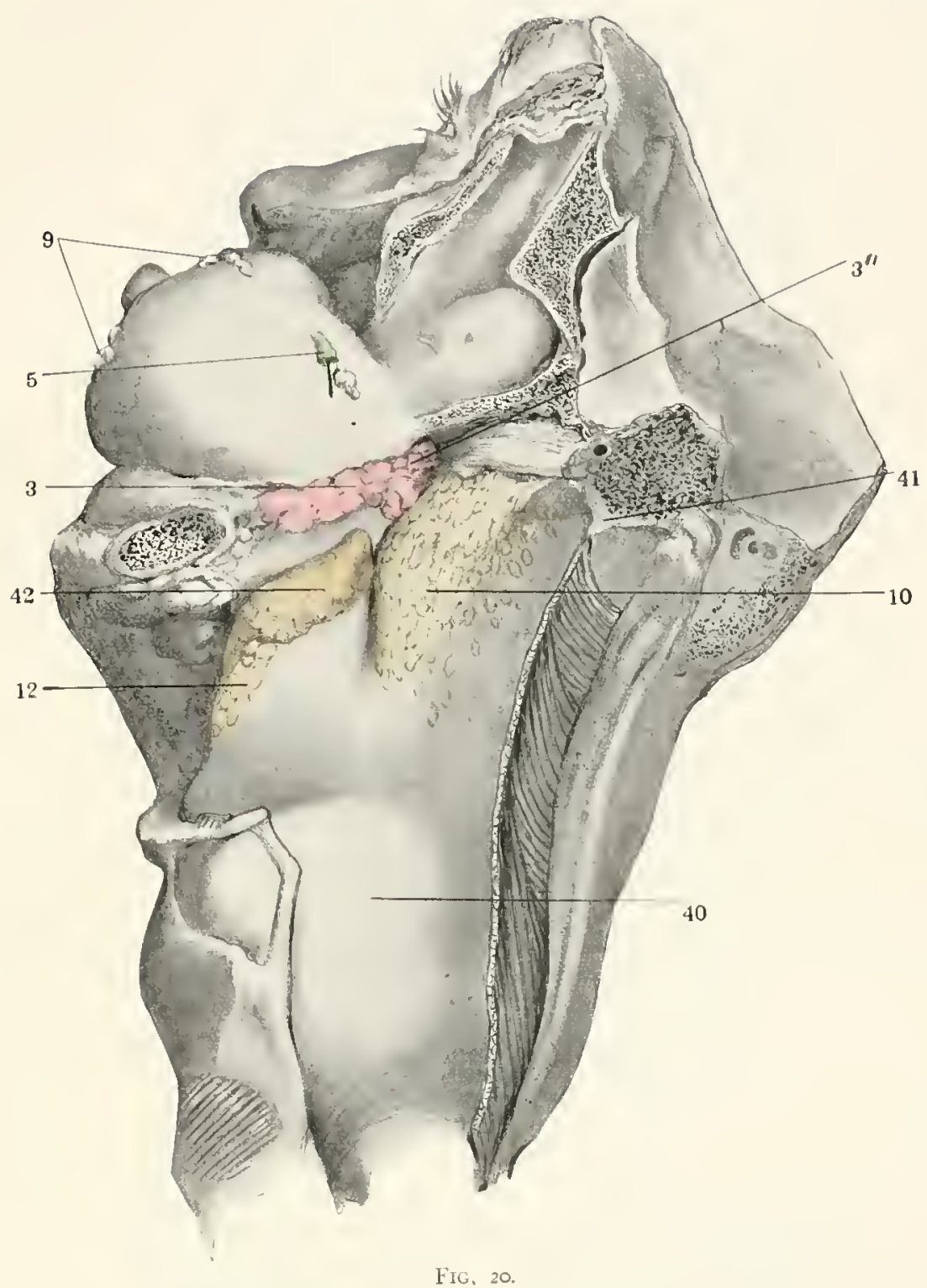


Plate $\mathrm{X}$

FIG. 21. Ventral view of same preparation.

9. Labial glands.

11. Lymphoirl tissue at root of tongue.

FIg 22. Adult human subject. Superior and inferior labial glands. Columbia Lniversity Morphological Museum, No. 2 I 53. 

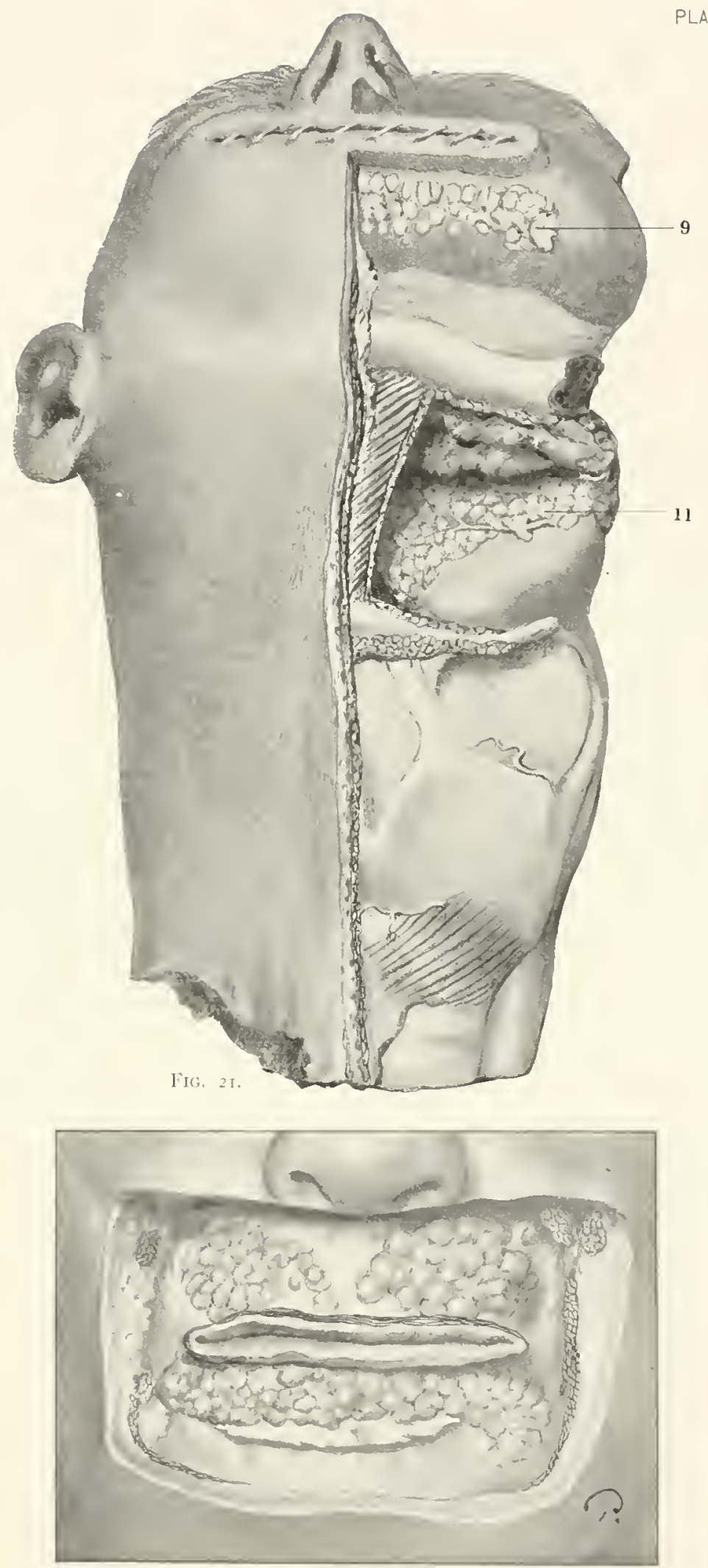

Fig. 22. 


\section{PART II}

\section{THE DEVELOPMENT OF THE SALIVARY GLANDS IN MAN}

\section{BY H. Von IV. Schulte}

As a result of investigations in the comparative anatomy of the salivary glands begun by Carmalt, and since his untimely death continued by Professor Huntington, a large series of observations have been made upon the conditions that obtain in primates, which are published elsewhere in the work of which this paper forms a part. The wide range of variation found in these forms, and in particular anong the lower primates, has made it desirable to collect for purposes of comparison all available embryologic data, limited though they are to observations upon human embryos. The comparison, as might have been expected, shows a remarkable correspondence between the conditions in the various adult primates and the possibilities offered in the more generalized embryo. While the embryos rary among themselves, they yet constantly exhibit a potentially more complex organization than is often realized by an individual adult. So that here, as elsewhere, notably in the vascular system, the adult type is attained not alone by progressive development of the anlage, but also by suppression of elements, by simplification of the embryonic plan. Thus a single embryo may present a composite of a large series of adult variations, while on the other hand owing to their minuteness and apparent insignificance, many of the details of the embryonic formations are apt to escape observation that is not guided by a knowledge of adult variants.

The list of embryos on which is based our present knowledge of the salivary glands is not a formidable one. Chievitz ('85) and Bujard ('т) alone have published detailed descriptions of individual embryos. The interesting and important notices of His ('\$5). Hammar ('O2), and Paulet ('II), with the brief memoranda of Sudter ('O2), taken together comprise a bare half-dozen pages. That our knowl- 
edge is as complete as it is, in major matters, is owing to the accurate work of the several writers, above all to the fine objectivity of the admirable Chievitz.

At the outset the hopelessly confused and confusing nomenclature of the glandiferous sulci is hampering. The sulcus between the mandibular and maxillary processes, which gives origin to the parotid gland and the orbital inclusion, received a name first from Moldenhauer, sulcus lingualis. This term Hammar ('oz) replaced with the more suitable sulcus buccalis. The wide gutter intervening between the tongue and the inferior alveolar process, which receives the projection of the palate process, Chievitz terms sulcus alveololingualis. The bottom of this gutter presents at certain stages of its development three small furrows (Fig. I): one $(\delta)$ bounding it against the tongue and giving origin to the submaxillary gland has no specific name in the literature; a second $(I f)$ defining the gutter from the alveolar process, in association with which develop some of the early sprouts of the lesser sublingual glands, is termed the sulcus sublingualis by His, who conjectured that it gave origin to the sublingual gland. Between the two a much shallower furrow $\left({ }^{2} 6\right)$ is found in embryos of about $5^{-22}$ millimeters in length. It may be seen in the figures of His (' 85 , Fig. 65 , right side) and Chievitz (' 85 , Fig. 7$)$ as a very slight concavity indenting the ridge that separates the other two furrows. In our 20 millimeter embryo it is more distinct and the epithelium along its fundus is thickened to form a slight keel (Fig. 14, 16). In man it has not been found to give rise to sprouts. As it is necessary to consider these sulci in some detail, the following terminology is suggested : for the wide gutter between the tongue and the alveolar process, regio alicolingualis, alveolingual region or gutter; for its median limiting furrow, sulcus lingualis, lingual sulcus; for the lateral furrow, sulcus alvcolaris, alveolar sulcus; the fainter furrow between may conveniently be called the intermediate sulcus, sulcus intermedius. For the lateral border of the oral cavity, the appropriate designation of Hammar is retained, sulcus buccalis.

In reference to the situation of gland sprouts it is often necessary to define accurately their position. When they are attached to the exact fundus of the sulcus, occupying the middle of its crown and projecting as the keystone of an arch often projects beyond the other 
voussoirs, the position will be termed fundal. When the plug is attached to the wall of the sulcus, or if to the fundus, not at its crown, it will be said to be parietal in position. The large salivary glands are peculiar in that a process of folding affects the region of the sulcus where their sprouts are about to appear. The result is a blind fold, or flange as we have termed the structure, in order to distinguish as sharply as may be between it and simple crests of proliferation which play an important rôle in the formation of the ducts. The flange involves the whole thickness of the epithelium, both basal and periderm layers, while the crest is composed of basal cells alone.

The sublingual gland of the human adult has occasioned anatomists considerable difficulty from a failure at first to recognize, and later to express in accurate terms, the fact that it is a complex resulting from the enclosure in a single capsule of primitively distinct elements. The discovery of the glandular mass having long anterlated the recognition of its several ducts, the sublingual has come to

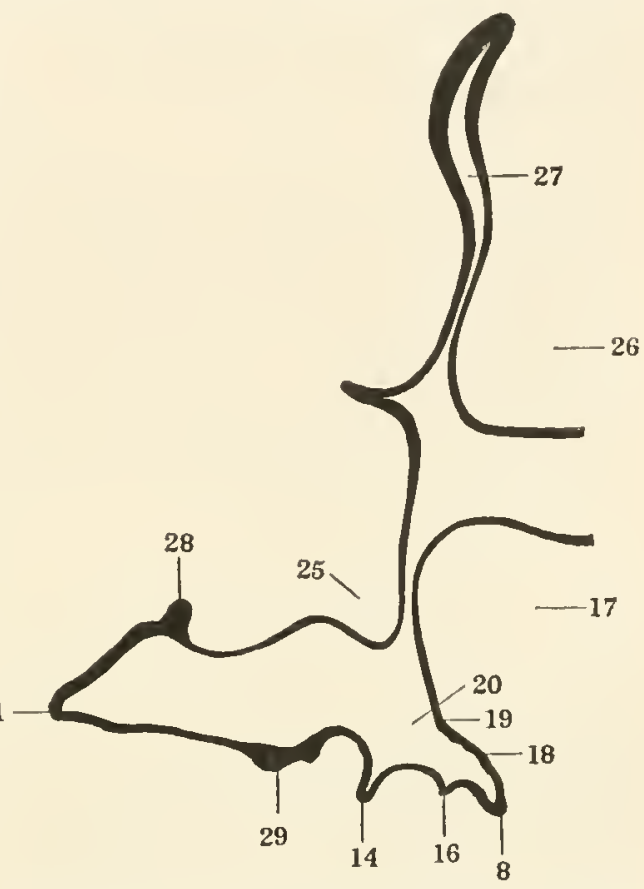

FIG. 1. Camera lucida outline of the oral epithelium of a 20 millimeter embryo in frontal section. Columbia Collection, No. 325 .
I. Buccal sulcus.
8. Lingual sulcus.
14. Alveolar sulcus.
16. Intermediate sulcus.
I7. Tongue.
I8. Sublingua,
10. Plica fimbriata.
20. Alveolingual region.
25. Palate process.
26. Septum nasi
27. Nasal fossa.
28. Superior dental anlage.
29. Inferior dental anlage. 
be looked upon as a gland having multiple outlets, a point of view evidently determining the usage of the B.N.A. (gl. sublingualis, ductus sublingualis major, ductus sublinguales minores). Whaterer may be the value of such a concept to the surgeon or the topographical anatomist, it is not admissible for the embryologist and is futile from the standpoint of the morphologist. The matter is not greatly helped by the adoption of Illing's terms, glandula sublingualis polystomatica and glandula sublingualis monostomatica; for here again the fundamental error is repeated of confusing in terminology a single gland with a group of glands, although some progress is made in supplying a distinctive name for the territory that is drained by the ductus sublingualis major. It would seem desirable, therefore, to limit the term gland to the system of ducts and acini or tubules derived from a single epithelial sprout, except in cases where fusion of sprouts is known to occur and a more or less reticulated gland results. To glands of this type that retain more than one duct, the term polystomatic might find a useful application. A series of small glands derived from independent sprouts is better denoted by a plural noun. In the "sublingual" of man three distinct lines of drainage have long been recognized: the ducts of Rivinus (sublinguales minores), the duct of Bartholin (sublingualis major), and a small branch or branches of the submaxillary duct. Concerning the last, embryological data are as yet lacking, but the variants of the adult would indicate that they are merely outlying lobules of the supramylohyoid portion of the submaxillary. His ( 85 ), and independently Chievitz ('85), showed the derivation of the submaxillary gland from the lingual sulcus, and Chievitz also establisherl the origin of the Bartholinian element as an inconstant branch from the proximal portion of the submaxillary duct, terming it glandula sublingualis. Chievitz further found the early sprouts of the ducts of Rivinus springing from the alveololingual sulcus, and designated them accordingly, the alveololingrual glands. As these facts were available, it seems unfortunate that they were not utilized at Basel, instead of confirming in slightly modified terms a mistaken usage, the continuation of which is fertile in misconceptions.

What, therefore, passes as the sublingual gland is evidently a complex of heterogeneous elements in a common connective tissue investment 
and mily accordingly be designated, massa sublingualis, sublingual mass. Its components are the constant Rivinian elements, glundulce sublinguales minores, lesser sublingual glands; the inconstant Bartholinian gland, glandula sublingualis major, greater sublingual gland; and finally variant lobules of the submaxillary draining into the venter of the duct. which on comparative grounds Huntington has designated ventral accessory submaxillaries.

It is convenient to divide the salivary glands for purposes of description in to those of the vestibule and those of the cavum oris proprius. In order to secure as continuous an account of the development of the several elements as the material permits, the embryos liave been arranged solely with reference to the degree of development of the glands under consideration, and as this is subject to some variation of rate, there are a few departures from chronological order in the series. Descriptions of three embryos of the Columbia Collection have been inserted.

THE GLANDS OF THE VESTIBULE

It may facilitate the interpretation of this discontinuous and scanty series of human embryos if a brief summary of the findings in the domestic cat be prefixed. In a large, and for the early stages, complete series of these embryos it was possible to follow step by step the formation of the derivatives of the buccal sulcus. The sulcus in embryos of $9^{-10}$ millimeters presented a continuous thickening of its epithelium along the fundus, thinning mesad along its ventral and dorsal walls. Out of this continuous anlage a cylinder of cells was formed by a process of folding and constriction. Ultimately it is widely displaced from the oral epithelium and comes into close contact with the ental surface of the muscles of mastication, where it persists until the stage of 70 millimeters, the oldest embryo as yet examined. This element has been termerl the orbital inclusion because of its derivation from a segment of the buccal sulcus which subsequently in the cat gives rise to the orbital glands. and because of its ultimate complete separation from the oral epithelium and inclusion in the mesenchyme. The folding begins caudad at the level of the mandibular nerve and spreads craniad from that point involving an increasing 
extent of the buccal sulcus. The sulcus increases in length, apparently by the addition of successive increments from in front, as the maxillary and mandibular processes increase in size and their area of coalescence enlarges. In this new segment the fold of origin of the parotid appears close to the angulus oris. It therefore appears that the buccal sulcus is subject to two distinct processes of folding; one advances caudocraniad (the orbital fold), while the other, later in time and of less extent, affects the cranial segment of the sulcus (paroticl fold). There regularly intervenes between the folds a segment of the sulcus which escapes compression, the orbitoparotid interval. This, like the rest of the furrow, is lined with thickened epithelium. It is subject to a wide range of variation, in length, in becoming encroached upon secondarily by the orbital fold, and in the development of independent sprouts from its epithelium. Rarely the whole segment becomes involved in the process of folding and a flange is formed connecting the cranial extremity of the orbital inclusion with the parotid, the orbitoparotid bridge. A constriction and separation of this in toto from the oril epithelium has not been observed in the cat. Alway's the process is interrupted; the interruption, however, varies considerably in site and extent. Any portion of the flange may give rise to a sprout; this variant is common. The sprout may arise from the cranial extremity of the flange in continuity with the parotid anlage; in its later stages this condition presents itself as a small branch arising at the junction of the parotid duct with the oral epithelium. Less frequently a branch is attached to the parotid duct, between its orifice and the cranial border of the masseter. If however, the sprout takes origin from an intermediate portion of the bridge, it will in its later stages appear as a plug arising directly from the oral epithelium, the direction of which may be parallel to the parotid duct or parallel to the buccal sulcus. These elements are termed orbitoparotids. Occasionally they become entirely separated from the mouth and form orbitoparotid inclusions.

The buccal sulcus in the first phase of its activity in the cat is thus seen to produce from a common epithelial anlage two constant elements, the parotid and the orbital inclusion, separated by a variable orbitoparotid interval, over which the anlages may be continuous by a flange, the orbitoparotid bridge. The interval is capable of giving 
rise to variant sprouts, orbitoparotids, which in turn mily give rise to inclusions.

The following series of human embryos covers the period from the latter part of the first to the end of the third month of gestation. It permits us to observe the changes in the buecal sulcus from the first appearance of the orbital inclusion to the establishment of the paroticl in its definitive position. There are, however, gaps in the series, the most inconvenient of which is perhaps that between Hammar's embryo of 11.7 millimeters and that of Paulet of 14.7 millimeters. This appears to be the critical period in the formation of the paroticl fold of Hammar, the evidence for which, I believe, is still incomplete so far as the human embryo is concerned.

I. Hammar. Embryo of 8 millimeters, N.L., end of first month. Near the angulus oris is a slight pouting (Ausbuchtung) of limited extent.

2. Columbia Collection, No. 229. 7.5 millimeters, N.B., measured after fixation in formalin. Obtained by Dr. A. J. Brown. The epidermis and oral epithelium are in many places separated from the basement membrane. The left side of the head is damaged; on the right the general outlines of the oral epithelium are well preserved. The sections are very obliquely frontal in the head region. The buccal sulcus draws rapidly away from the surface in the first portion of its course as it sweeps mesad across the area of union of the maxillary and mandibular processes, becomes more nearly sagittally directed in its caudal half, and finally disappears as the first entodermal pouch is approached. From the angulus oris for five sections of $13.3 \mu \mathrm{a}$ marked thickening of the epithelium is found at the fundus and extending into the dorsal wall of the buccal sulcus (Fig. 2, 7). The sulcus itself is widely open to the oral cavity, but presents a perceptible narrowing opposite the mesal limit of the epithelial thickening. From the angulus oris caudad the thickening diminishes and comes to occupy mainly the dorsal wall of the sulcus; coincidently the constriction becomes more pronounced. In the six sections caudal to the thickening (the 6-IIth behind the angulus oris) a fold is clearly defined. In the 8th and gth sections it is closed (Fig. 3, 3); a nearly circular mass of cells with a small central lumen appears in the sections, connected to the oral epithelium by a rather narrow pedicle, through the 
middle of which a line of less deeply staining periderm cells extends between the lumen of the mass and the oral cavity. The whole formation extends about I $_{4} 6 \mu$ from the angulus oris, though owing to the obliquity of the sections and the curve of the sulcus the measurement cannot be considered exact. In the sections immediately cranial to those showing the closed fold, an indefinite mass of cells situated in the mesenchyme lateral to the sulcus is thought to be the mandibular nerve. The nerve tissue throughout is in very bad condition. but this object resembles areas elsewhere that from their situation can be recognized as parts of peripheral nerves.

3. Hammar. Embryo of I I.7 millimeters, N.L. The middle third of the sulcus buccalis presents a small shallow furrow, the "sulcus paroticleus."

These three embryos present successive stages of the transformation of a fold into a cylinder of cells by a process of constriction reducing the lumen to a fissure or line at the point of constriction. Hammar does not state explicitly that his anlage contains a lumen, but that it does so may be inferred from his note upon his next older embryo. The situation of the fold with reference to the angulus oris requires a word of explanation. It occupies at the outset a small bit of the cranial end of the sulcus; it then involves the whole of its cranial segment; in the third embryo, only its middle third. Two explanations offer: the fold at its cranial extremity may have opened again into continuity with the oral carity; or, on the other hand, the sulcus buccalis may have lengthened by increment from in front. In no case unfortunately has the relation of the fold to the mandibular nerve been clearly established. Hammar interprets the fold as the anlage of the parotid. He has not proved this to be the case, as his next embryo is of 17 millimeters length and presents an advanced stage of the parotid, too wide a gap in the series safely to be spanned by an inference. It is by no means clear that the fold and sulcus parotideus of Hammar are not incident to the formation of the orbital inclusion in whole or in part. The general mode of formation of the anlages of the salivary glands in the forms as yet studied corresponds so closely, that conditions known in one species should not be without weight in the interpretation of a fragmentary series of another. In the cat the orbital inclusion is formed in a manner so similar, and 
changes its position in a manner so analogous, to the fold here in question, that it can hardly be duubted that this is its homologue. In the cat the orbital fold first appears in the plane of the mandibular nerves, and from this point spreads craniad nearly to the angulus oris, later to be displaced caudad as the sulcus lengthens. From the new postangular segment of the sulcus the parotid takes origin as a short fold, to which is soon added a sprout. There is, as a rule, an increasing but variable interval between the anlages, but exceptionally the fold of the orbital inclusion involves the whole interval and becomes continuous with that of the parotid. The continuity of the parotid with an entomasseteric duct (orbital inclusion) in one of Chievitz's human embryos is inferential evidence of an early confluence of their folds of origin. It is therefore possible that Hammar's fold may refer to this condition and represent continuous anlages of the parotid in its cranial, and of the orbital inclusion, in its caudal segment.

4. Paulet. Embryo of 14.7 millimeters, V.B.; I 3.8 millimeters, N.B. The length of the anlage is $300 \mu$, its distance from the angulus oris $650 \mu$.

Im Grunde der Wangenfurche lässt sich eine Crista beobachten, welche vorn in der Nähe der Lippenkommissur endet, hinten in eine rundliche Sprosse iibergeht die in der Tiefe des Wangenblindsacks gelegen ist: dies ist die Parotisanlage. Wie bei den Submaxillardrüsen, kann man auch hier zwei Abschnitte unterscheiden: einen epithelialen Strang, die Anlage des Ausführungsganges und den rundlichen Sprossen, die Anlage der Drüse selbst. Diese Bildungen entstehen in der am meisten zurückgelegenen Partie der Vestibularfurche; die knospenförmige Anlage des Parotiskörpers wendet sich zur äusseren Oberfläche, von der sie .05 millimeters entfernt ist.

As compared with the parotid of corresponding development in the cat $\left(13 \cdot 5^{-1} 4\right.$ millimeters $)$ this anlage is very long, but above all is peculiar in its origin from the caudal portion of the buccal sulcus, which in that form, as also in the pig, mole, tree-shrew, and chevrotain, gives rise to the orbital inclusion, the parotid a rising from a more cranial portion of the sulcus as in the following embryo of His. The anlage of Paulet is not dissimilar to that of the orbital inclusion in the cat of 13.5 millimeters, presenting the broad and narrow portions which are characteristic of the structure in this stage. This raises a question of the orientation of Paulet's reconstruction, for the broad portion of the inclusion is cranial, the narrow, caudal. In his twelfth and thir- 
teenth figures, the submaxillary and the anlage in question are shown, and their narrow portions point in opposite directions. The legends do not inform us of the orientation of the models, or of the side of the embryo from which they are taken. Of course the ducts of both parotid and submaxillary must point craniad from their inception. while the narrow portion of the orbital inclusion has an opposite direction, so that it seems not impossible that here again there has been confusion between the two derivatives of the buccal sulcus.

5. His. Embryo Zw. listed as between I5-22 millimeters. The series contains 730 sections, 0.02 millineter in thickness. The parotid, which is established later than the submaxillary, earlier than the sublingual, is represented by a solid sprout (Zellenknospe). It arises from the buccal sulcus at a point where the sulcus appears to alter its direction suddenly. In the accompanying cut it is represented as a retort-shaped solid object, directed ventrad with a slight inclination laterad. The attachment is fundal.

The buccal sulcus changes its direction rather abruptly a short distance caudal to the angulus oris, and again more gradually in the entomasseteric portion of its course. (Cf. Fig. 4.) His's illustration (Anat. mensch. Emb. III, Fig. 65) leaves no doubt that the reference is to the former bend.

6. Hammar. Embryo of i 7 millimeters length. The fold previously described (embryos $\mathrm{I}$ and 3 ) is constricted off from the oral cavity in the greater part of its extent, "so dass sie als ein Länge des Bodens der Wangenrinne (sulcus buccalis) verlaufendes Rohr, Ductus Stenonianus, hervortrit."

Again the description fits the orbital inclusion at a period in development prior to its complete separation.

7. Columbia Collection, No. 325. Length 20 millimeters, N.B., measured after fixation in formalin. Obtained by Professor W. J. MacCallum. Preservation good. This embryo presents a small parotid, though its submaxillary is of a size equal to that described in other human embryos of about its length. In the lateral view of the reconstruction of this embryo (Fig. 5) the sulcus buccalis ascends gently from the angulus oris for the greater part of its extent, to terminate by a rather abrupt descent a short distance in front of the first entodermal pouch. where it approaches the sulcus lingualis. It is confluent with a sulcus 
which defines the ectal border of the palate process from the roof of the lateral extension of the oral cavity. This cctopalatine sulcus is shown in Figs. $7^{-19}$. 3f. Behind the termination of the superior dental ridge it deepens and receives the buccal sulcus laterally. A second smaller sulcus, parallel to the ectopalatine and placed lateral to it, extends from the parotid plane to the region of the orbital angle (Figs. I6-IS, 35). In the 22 millimeter embryo this sulcus has disappeared; the ectopalatine is conspicuous in this embryo also, and the line of the buccal sulcus is prolonged upon its lateral wall as a low crest (Fig. 24, I). Viewed from below (Fig. 4) the greater part of the buccal sulcus is seen to pursue a general sagittal direction with, however, a moderate convexity laterad. In front and behind this segment two shorter portions of nearly transverse direction complete its trajectory; the cranial, extending mesad from the angulus oris (24), forms the cranial border of the area of union of the maxillary and mandibular processes; the caudal, which corresponds to the abrupt descent of the sulcus, meets the main segment at a rounded angle. Here, then, the sulcus undergoes a change of direction both in the sagittal and in the horizontal planes, describing a curve which may be designated the orbital angle. It marks the commencement of the narrowing of the oral cavity towards the fauces, and in forms in which the material has allowed the observation, corresponds to a primitively broader portion of the orbital inclusion. In this region also the inclusion is crossed by the buccal nerve. In the sections the buceal sulcus is $\mathrm{V}$-shaped, with the angle most acute in its caudal segment and in the parotid region, while in the interval the fundus becomes slightly rounded. Craniad to the parotid the floor of the mouth presents a small convexity immediately mesad of the buccal sulcus. This convexity is defined at its mesal border by a faint furrow. The formation extends from the parotid to the angulus oris, being best developed in the middle of its extent and diminishing towards its extremities. A similar proparotid convexity occurs in other forms, suggesting a tendency to form a fold in this segment also of the buccal sulcus, a tendency soon repressed, however, for in the 22 millimeter embryo there is no sign of the convexity.

The parotid is attached to the buccal sulcus at about the middle of its sagittal segment, with which it forms nearly a right angle. It is 
of a pyriform shape, slightly flattened on its ental surface, and has a rather broad pedicle connecting it with the oral epithelium. The enlarged dependent fundus bulges forward as well as backward of its pedicle, coming thus to exceed it considerably in sagittal extent. In the sections (Figs. 12-14) passing through the pedicle, it is seen that the attachment is sulcal, and that the pedicle, projecting nearly horizontally laterad, makes an approximately right angle with the ventrolaterally directed fundus. The latter is a solid mass of cells, staining rather faintly at its center, where, however, the nuclei are perfectly distinguishable and no trace of a cleft or lumen is seen. Evidently at this stage of development there is no question of an open duct.

The sections immediately craniad of the pedicle require a rather minute consideration, for upon such evidence as they afford must be based our opinion of the mode of formation of the proximal portion of the parotid duct. This question necessarily involves the further question of the displacement of the parotid orifice secondarily from its point of origin, by the formation of a duct or duct segment anterior in position to the primitive anlage. To anticipate, it may here be stated that subsequently, for a time, the parotid has a point of attachment nearer the angulus oris than in this embryo. A secondary displacement must therefore be accepted as occurring. As this displacement is absolute and not relative, it must be inferred that it is due to an actual carrying forward of the pedicle along the buccal sulcus. Two possibilities offer: the advance of the duct may be due either to the proliferation of a crest or to the formation of a fold, which in turn might, or might not, have a lumen. In either case a process of constriction must supervene to free the duct from the oral epithelium.

On the right side of this embryo of 20 millimeters the five sections immediately in front of the parotid pedicle are represented in Figs. 8-12. The first of these shows the buccal sulcus without indication of any process of duct formation. The ventral convexity is here very slight, and the inferior alveobuccal sulcus is ill-defined. The next four show a flange projecting from the buccal sulcus and increasing in breadth as the paroticl is approached. In the last the flange has attained an extent corresponding to the horizontal portion and angle of the pedicle in the next section (Fig. I2). In its first sections (Figs. 9 and 10) it 
presents itself as a slight projection from the ectal surface of the epithelium, its cells having the same staining properties as the basal cells. The periderm in these sections presents no disturbance of its curve in the buccal sulcus, and there is no suggestion of a fissure or fold to account for the crest, which in these sections appears to be no more than a localized thickening of the oral epithelium. In the next sections, however (Figs. IO, II), and especially in the second, the crest presents a pale center, which, with higher magnification, is found to comprise an area of cells in which the cytoplasm stains little, while the nuclei are pyknotic. Similar areas are noted in succeeding sections at the attachment of the pedicle and have been already described in the center of the parotid anlage. These cells placed far from the basement membrane appear to undergo a cytomorphosis analogous to that of the periderm cells of the oral cavity. As similar pale centers appear in the secondary and tertiary sprouts of the submaxillary, they need not be directly referred to the obliteration of the lumen of a hypothetical fold, in which periderm had appeared before the lumen was lost, but can as well be explained as preparatory to the acquisition of a lumen in a solid epithelial plug. It is further to be noted that these pale areas are separated from the periderm lining of the buccal sulcus by deeply staining cells (Fig. II), which would hardly be the case were they extensions of that layer in a blind fold. The appearances of the left side are similar, with the pale areas well marked. The evidence here given seems to point to an interpretation of the proparotid crest as a proliferation keel, an extension forward of the proliferation of the parotid sprout so that one continuous process appears in the formation of the duct as well as of the gland. This point will be again referred to in the consideration of the submaxillary and sublingual glands, where it appears that an essentially similar process is at work.

The foregoing is not intended to deny the existence of a parotic fold, but greatly to limit its rôle in the development of the gland. In the cat a minute fold is formed, in connection with which the parotid sprout makes its appearance. The subsequent history of the parotid is the history of the sprout, from which the duct and the branches of the gland are derived by proliferation. While I am not convinced that such a fold of inception has as yet been observed in man, the 
general analogy of development here with that in the cat seems to confer a high degree of probability upon the assumption of its temporary existence.

The sections through the posterior portion of the pedicle of the parotid throw some light on the method of its separation. Here the horizontal portion of the pedicle appears destined to reduction. In Fig. I 4,38 , it presents two incisures ventrally. In the next section (Fig. 15,38 ) a very small mass of cells is interposed between the parotid and the buccal sulcus. This occupies the position not infrequently assumed by the orbitoparotid in the cat, which, in some cases, springs from the angle between the parotid duct and the oral epithelium. On the left side there is no trace of this element.

The orbital inclusion (Figs. 4, 5, 17-19.3) is separated from the oral epithelium by a small amount of mesenchyme. It corresponds to almost the whole postparotid segment of the buccal sulcus, the course of which it follows on a slightly ventral plane. Its two extremities are slightly enlarged, the intervening portion being extremely tenuous. The center in section is pale at the enlargements, but a lumen cannot definitely be made out, though some sections suggest it strongly. No notable difference obtains between the two sides. The buccal nerve, which is lateral to the inclusion posteriorly, crosses it ventrally near the orbital angle and continues forward mesad of the cranial portion of the inclusion and of the parotid. At the point of crossing the inclusion is closely applied to the nerve.

The following measurements obtained by section counts may serve for comparison with other embryos.

\begin{tabular}{|c|c|c|c|c|c|c|c|c|c|c|c|}
\hline Angulus oris to parotid & . & & & . & . & • & • & & & $\begin{array}{c}\text { RIGHT } \\
425.6 \mu\end{array}$ & $\begin{array}{l}\text { LEFT } \\
+25.6 \mu\end{array}$ \\
\hline Sagitsal length of parotid & . & . & . & . & . & . & . & . & . & I $50.6 \mu$ & I $86.2 \mu$ \\
\hline Attachment of parotid & . & . & . & . & . & . & . & . & . & $53.2 \mu$ & $66.5 \mu$ \\
\hline Orbitoparotid interval & & . & . & . & . & . & . & . & . & $53.2 \mu$ & $66.5 \mu$ \\
\hline verage length of orbital i & nclus: & ons & & . & . & . & . & . & . & & \\
\hline
\end{tabular}

8. Chievitz. Embryo of 8 weeks. The attachment of the parotid is fundal, practically in the same plane as that of the submaxillary. Thence the duct extends caudad 0.26 millimeter. The fundus lies on the lateral surface of the masseter. In the seventh figure of his paper an interesting outline is given of this parotid at its attachment. 
It has the outline of the handle and one ball of a dumb-bell. The ball represents the parotid duct, the handle an intermediate region which must be reduced to free the duct. The intermediate element has convex borders, and is set off against both buccal sulcus and parotid duct by slight constrictions. Were these conceived as broken through, a mass of cells corresponding to the handle of the dumb-bell would be interposed between the duct and the oral epithelium, resembling in general the condition found on the right side of the 20 millimeter embryo. In the cat such sections as this occur only in the presence of an orbitoparotid. The appearances in this and the preceding embryo suggest that a search for this element in man with more abundant material might not be without results.

9. Hammar. Embryo of 18.5 millimeters. The presence of connective tissue is noted between the duct and the buccal sulcus.

Io. Columbia Collection, No. 3, length 22 millimeters. Obtained by Professor J. A. Blake. The epidermis and oral epithelium have in some places separated from the basement membrane; the staining property of the tissue is somewhat impaired; the pallium is in folds, but the oral cavity and adjacent structures are fairly preserved. The right side of the embryo was cut into sagittal sections, not however quite to the median line. The remainder was sectioned in the frontal plane. The transverse sections are almost perfectly oriented, $30 \mu$ in thickness. The parotid on the left side springs from the buccal sulcus $240 \mu$ from the angulus oris. Its attachment which is parietal, being displaced dorsad of the fundus of the sulcus, has a sagittal extent of $60 \mu$. Its duct lies in the submasseteric position, the enlarged but unbranched fundus resting against the side of the masseter near its lower border, in a slight thickening of the mesenchyme. Owing to poor preservation, no histological details can be observed. The orbital inclusion lies nearer the pterygoids than to the oral cavity. Its length is $240 \mu$; its anterior extremity, slightly enlarged, lies $300 \mu$ behind the attachment of the parotid. On the right side, which was cut sagittally, the parotid and the orbital inclusion present the same general characters.

II. Hammar. Embryo of 24.4 millimeters length. The duct opens into the buccal sulcus at an acute angle. The fundus is scantily branched. 
12. Chievitz. Embryo of ro weeks. The left side was dissected. The massive fundus of the parotid was found in the retromandibular position. It shows the beginning of sprouts, five of which are present. At about the junction of the middle and cranial thirds, a short solid ascending branch was found, the socia parotidis.

The right side was sectioned. The parotid arises 0.76 millimeter caudad of the plane of the frenulum. The duct crosses the craniodorsal angle of the masseter, where, as on the left, it gives off a solid ascending branch. Arrived at the caudal border of the muscle, the duct divides into two primary branches, each of which has a few secondary buds. After a careful description of the topography, Chievitz concludes as follows:-

Ich muss noch ein räthselhaftes Gebilde erwähnen, welches sich an der rechten (mikrotomirten) Seite dieses Embry'o fand. Fünfzehn Schnitte [Schnittdicke $=\mathrm{I}$ ' 50 millimeter] hinter der Parotismündung tritt nämlich der Querschnitt eines mit Epithel ausgekleideten Ganges auf, welcher längs der Aussenseite der Nundhöhle in einer aussıreckung von 0.68 millimeter horizontal nach hinten veräuft. Während die nach aussen von diesem Gange liegende Parotis sich in ihre seitlichere Lage an der Aussenseite der Masseter hinaus begiebt, folgt unser Gang der Aussenseite der MIundhöhle und geht an seinem hinteren Ende medial rom Unterkiefer, wo er am vorderen Rande des M. pterygoid. int. ein wenig verdickt endet. Ich habe rom diesem Gange keine V'erbindung weder mit der IIundhöhle noch mit der Parotis finden können; ein ähnliches Gebilde sah ich aber bei einem zwölf wöchentlichen Embryo von dem Ductus parotideus ausgehen.

13. Bujard. Embryo of 5 centimeters total length; Tete-siege 3.5 centimeters. The parotid has developed branches of the third order and contains a lumen except in the distal ends of the buds, and in a few sections close to its orifice. A socia parotidis is represented on the left side by two branches set close together, of which the first is a simple. short sprout. the second, forming the bulk of the socia, presents branches of the third order. A considerable interval separates this element from the next branch of the duct. All of the branches are directed dorsad and caudad, and are surrounded by a mesenchyme rich in cells. Ental to the masseter, midway between the muscle and the oral epithelium, is found a cord of cells which Bujard recognizes as the entomasseteric duct of Chievitz's descriptions.

Ce cordon suit un trajet parallèle au canal parotidien; il se renfle à son extrémité rlorsale avant de s'effacer au niveau du bord ventral du . 1 . ptérygoïdien interne; il disparait brusquement à son extrémité ventrale. en s'effilant un peu; il ne présente ainsi aucune connexion visible avec les épithéliums voisins. buccal ou parotidien. 
14. Chievitz. Embryo of 12 weeks. The parotid has attained essentially its definitive form and position.

I5. Chievitz. Second embryo of I2 weeks. A furrow running entad from the angulus oris terminates without reaching the parotid orifice, which has ceased to be sulcal in position. It is situated I.ro millimeters behind the angulus oris. With regard to the duct Chievitz writes : - -

Es fand sich an demselben Embryo ein merkwiirdiger Seitenast des Ductus Stenon., welcher einen ähnlichen Verlauf hat, wie der beim zehnwöchentlichen Embryo erwähnte Gang. Kurz vor dem vorderen Rande des Masseter geht von der medialen Seite des Ductus parotideus ein nach hinten gerichteter Gang ab, welcher medial vom Masseter sich bis zum Pterygoideus int. fortsetzt und nach einem Verlauf von I millimeter blind endet. Der auf dem Querschnitte runde Gang sieht aus ganz wie die iibrigen Drüsengänge; er besitzt in seinem grösseren Theile ein Lumen, umgeben von Epithelzellen, deren Längliche Kerne in zwei Reihen geordnet sind. Der N. buccinatorius kommt von hinten her zwischen dem M. temporalis und M. pterygoid. int. auf den Gang herab und schlägt sich um die laterale Seite desselben, um ihn weitherhin an der unteren Seite zu begleiten. Ein Blutegefäss liegt lateral vom Nerven.

Recently Elizabeth Weishaupt has published a study of the orbital inclusion which she interprets as a rudimentary branch of the parotid (ramus mandibularis ductus parotidei). She notes the condition of the parotid anlage in four embryos, one of 13.5 , two of 18 , and one of 25 millimeters. It is at first a slight thickening in the course of the buccal sulcus. Later it is displaced to a dorsal parietal position. The solid duct is freed by constriction and secondarily acquires a lumen. In all of these embryos she failed to find the orbital inclusion, or, to be precise, found no branch associated with the parotid anlage. In seventeen other embryos ranging from iz millimeters to 40 millimeters in length an epithelial cord or duct was uniformly present between the buccal sulcus mesad and the masseter and internal pterygoid muscles laterad, and in close relation to the buccal nerve. In three fetuses of 7.5. I0, and I centimeters the structure was also found, and while reduced in length, yet showed a tendency to further development in the formation of sprouts, a most important observation, which goes far to place the orbital inclusion in the class of ductless glands. In none of these embryos was the inclusion connected with the parotid duct.

The foregoing data suffice to show that the buccal sulcus in 
man gives rise to two constant structures, the orbital inclusion and the parotid, and in ardition suggest the possibility of the occasional presence of a third element, the orbitoparotid. The orbital inclusion has a wide distribution in the mammalian series, having been found in embryos of the cat. pig, mole, tree-shrew (Tupaia), cherrotain, and opossum, in all of which it appears to be constant. The orbitoparotid appears as a frequent variant in the cat, and indications of its presence are found in Tupaia and Didelphys embryos, while the two ducts of the parotid of Hyrax appear most easily explained on the assumption that one of them is a highly developed orbitoparotid. If the "ductus Stenonianus" of Hammar and Paulet is interpreted as referring to the orbital inclusion, an outline of the history of this elenent may be constructed for the human embryo, agreeing in essentials with the more detailed findings in the mammalian embryos above referred to. In appearance it antedates the salivary anlages, being present in embryos of 7.5 and 8 millimeters, while the earliest undoubted parotid that has been described is that of His's embryo Zw., which is already somewhat advanced in development. The inclusion owes its origin to a process of folding and constriction resulting in separation from the oral epithelium, a process which may be conceived as advancing caudo-craniad if Hammar's description of conditions in his 17 millimeter embryo may be taken as applying to the orbital inclusion. Here a duct with a lumen lies parallel to the oral epithelium, to which, it may be inferred, it is attached by its cranial extremity, in view of the fact that it was interpreted as the parotid. If this be the explanation of the somewhat perplexing findings in this embryo, the separation of the orbital inclusion in man is progressive caudo-craniad, as in the pig, and not initiated at an intermediate point, as in the cat. The difficulty in thus interpreting Hammar's account lies in the fact that a younger embryo (His's Zw.) has a well-marked parotid of a retort shape, affording ample evidence of active proliferation in the anlage. To assign Hammar's description to the orbital inclusion is to imply either that he has overlooked the presence of a well-developed parotid anlage, or that his embryo was abnormal in the suppression of that element. In this connection it should be borne in mind that except in the older embryos of Chievitz and in that of Bujard the orbital inclusion as a matter of fact has been overlooked. The finding of the orbital inclusion in the 
later stages, and the failure to find it in earlier ones, appears due to the fact that with the extension of the parotid caudad along the surface of the masseter, the two structures come into the same sections, one ectad and one entad of the muscle. In younger embryos when the parotid has not begun its caudal growth, but projects ventrolaterad from the buccal sulcus, it disappears from the sections in the orbitoparotid interval, before the anterior extremity of the inclusion is reached. An observer intent upon the parotid would have no occasion to follow his sections farther than that anlage extended, and unless he did so would not come upon the inclusion. The possibility of confusing the two derivatives of the buccal sulcus is easily accounted for, if only one was sought and the whole length of the sulcus was not examined. Finally, Hammar's description of the anlage in his 17 millimeter embryo as a slender duct cannot be made to harmonize with conditions in the 20 millimeter embryo of the Columbia Collection, where a solid retort-shaped mass is present with no free duct, but with signs of beginning separation at the caudal margin of its attachment. The order of events is then, first, the establishment of a sprout, and second, the formation of a proximal portion of the duct by constriction.

The orbital inclusion once separated from the oral epithelium is gradually displaced laterad, until it comes to lie close to the muscles of mastication. Its caudal extremity, slightly enlarged, rests against the internal pterygoid. Its cranial extremity, which also tends to be enlarged, may run out into a tapering process (Bujard) or may even be continuous with the parotid duct (Chievitz). The simplest explanation of these variants is to suppose the fold of origin to extend farther craniad, encroaching upon the orbitoparotid interval, which in Chievitz's case has evidently given rise to an orbitoparotid bridge, which, separated in its entirety, connects the parotid with the orbital inclusion. On this supposition it is possible that Hammar's embryo of II.7 millimeters actually presents this continuity, though more information upon this stage and those but little older is greatly to be desired. A like connection has as yet been found only in three embryos of the pig (Weishaupt 2, Columbia Collection I) and one of a chevrotain. The cat, however, presents many variations in the length of the interval and extension craniad of the orbital inclusion. 
The orbitoparotid interval increases greatly in later stages. Measuring in the 20 millimeter embryo $53-66.5 \mu$, it has attained a length of $300 \mu$ in that of 22 millimeters and in Chievitz's embryo of so weeks. That this is not due to reduction of the inclusion is seen by a comparison of its length in the 20 millimeter embryo and Chievitz's of 10 weeks, $432 \mu$ against $680 \mu$. The displacement appears, then, to be due to growth of the interval itself. The inclusion, however, varies within wide limits in these older embryos, from $249 \mu$ in the 22 millimeters to I millimeter in that of Chievitz of 12 weeks. Its later stages and ultimate fate have not as yet been investigated.

The question of the origin of the parotid, whether by a simple sprout, or by the formation of a fold with subsequent budding, must still await a definitive solution as far as the human embryo is concerned. The problem is one of considerable delicacy, being complicated by the site of the anlage at the line of union of two sloping epithelial planes, the roof and floor of the mouth and further, by the early appearance of the periderm, the bulging nuclei and pale cell bodies of which disturb the ental contour of the epithelium and in a fold obscure the line of the obliterated lumen. Further, in gland sprouts we find the central cells possessed of the staining properties of periderm, so that in a given case it may well be impossible to decide, whether a paler axial line represents layers of periderm in contact, or the central cells of a solicl sprout undergoing an analogous cytomorphosis. Finally, active proliferation of cells along a linear area may produce a slight fissure-like indentation of the ental surface of an epithelium in a region where no furrow has previously been observed (e.g. the greater sublingual anlage of the cat). The final settlement of these questions can only be expected when a study of this anlage is undertaken on the basis of a complete series of embryos at the requisite stages. But when the proof of the inception of the parotid by a fold is finally brought, which on grounds of analogy with conditions in the cat may be expected, we shall again be met with difficulties in assigning to the fold its quantitative value as against the claims of the sprout, from which undoubtedly the whole periphery of the gland and a part of the duct are derived, and this in large measure because of the almost insuperable difficulty of distinguishing in a fundal anlage between a crestlike proliferation and a blind fold. The point in this instance is really a minor one, for both 
must here be due to proliferation of the oral epithelium, the question being, whether we are to conceive this as chiefly localized in the roof and floor of the oral cavity, or at the fundus of the buccal sulcus. In the former case the simple proliferation of cells would enlarge the buccal cavity transversely and displace its border, the buccal suleus, laterad in the direction of the resultant of the planes of growth. But the advancing edge is subjected to the pressure of the enlarging maxillary and mandibular processes, which tend to compress the advancing angle, reducing its lumen to a fissure and finally obliterating it. The solid flange so formed would undergo displacement downward, were the rate of growth in the maxillary process greater than in the mandibular process. That this is indeed the case craniad seems indicated by the overhanging of the maxillary process, and by the ectal position of the superior dental ridge in reference to the inferior. But when the parotid has assumed a retort shape, as in His's embryo Zw., the rôle of the simple fold is at an end or at least complicated by the acceleration of cell proliferation at its free edge, as instanced by its increased thickness laterad, so that the anlage can no longer be conceived simply as a blind fold. The appearance leads us to attribute the further development of the anlage to the free growth of the bud. In the 20 millimeter embryo the bud has already a pale center which is not continuous with the periderm of the mouth, and therefore appears to have developed in situ, as in the sprouts of the submaxillary in this embryo.

The formation of a proximal portion of the parotid duct craniad of the sprout is another and a later question. That the attachment is for a time carried forward towards the angulus oris can be determined by measurements. In the 20 millimeter embryo the anguloparotid interval is $425.6 \mu$; in that of 22 millimeters the distance has been reduced to $240 \mu$. The sagittal length of the attachment in the former case is $53-66.5 \mu$, in the latter $60 \mu$. The absolute diminution of the anguloparotid interval can only be accounted for by an absolute addition to the duct craniad of the sprout. As is shown by the measurements of the attachment, this formation must be accompanied by a freeing of the new-formed element from the oral epithelium in a caudocranial direction. This is accomplished by a process of constriction which is initiated in the 20 millimeter embryo and of which 
all trace has disappeared in the 22 millimeter, where the attachment is already parietal. In older embryos the distance between the parotid and angulus oris again increases, and in Chievitz's 12 weeks embryo is 1.26 millimeters. This second displacement appears due to growth in the proparotid segment of the cheek, and is associated with obliteration of a portion of the buccal sulcus, and extensive changes in topography.

Further evidence of the addition to the parotid of a proximal segment is afforded by the site of its junction with the orbital inclusion in Chievitz's embryo of 12 weeks. Here the two elements are joined at the cranial border of the masseter. Their continuity must have been achieved before separation from the oral epithelium, by extension of the constriction of the orbital inclusion orer the whole orbitoparotid interval, into continuity with the usually distinct process which frees the parotid. The parotid duct of this embryo distal of the union with the inclusion would then be referable to the sprout. The segment intervening between the junction with the inclusion and the oral epithelium, that is, the whole promasseteric segment of the duct. is of secondary formation. More information is desirable as to the mode of this process, and especially as to whether it may continue after the parotid has lost its sulcal position. The evidence obtainable from the 20 millimeter embryo has been stated, and seems to give preference to the proliferation of a crest, rather than to the formation of a blind fold as the source of this material. The primitive position of the parotid duct is submasseteric in man as in other mammals (Chievitz), a position which is retained in ungulates. Subsequently it attains a horizontal higher position, by a dorsal displacement over the surface of the masseter and a straightening of its curve.

THE ALIEOLINGUAL REgION; ITS SLLCI AND THEIR DERIYATIVES

In human embryos from about $\mathrm{I}_{5}$ to 22 millimeters in length, the alveolingual region (Fig. I, 20) is a broad gutter into which projects the palate process (25). Here the epithelium forms a fold, as it passes from the tongue laterad to a prominent convexity, produced by an accumulation of mesenchyme between Meckel's cartilage and the floor of the mouth. This convexity is limited laterad by a shallow 
wide sulcus, where the epithelium shows a slight increase of thickness (29), the anlage of the inferior dental ridge; its mesal limit is sharply defined by a deep open furrow (14), which at the same time forms the lateral border of the alveolingual region (I2). The convexity corresponds to the ental portion of the alveolar process, for which reason the furrow is conveniently termed sulcus alveolaris. It corresponds to the sulcus sublingualis of His, and to the lateral furrow of the sulcus alveololingualis of ('hievitz. The mesal limit of the alveolingual gutter is given by the sulcus lingualis ( 8 ), to which are attached the anlages of the submaxillary and greater sublingual glands, and a mesal derivative which appears to be the apical gland of the tongue (Fig. I2). The mesal wall of this furrow is formed by the tongue, which in the sections presents a well-defined angle (Fig. r, I9) at its side, separating from its general surface a narrow ventral strip sloping ventromesad. This region $(I \&)$ Chievitz has identified with the sublingua, the angle or ridge (19) above it with the plica fimbriata. Between the lingual and alveolar sulci, a less extensive and more ephemeral furrow (I6) grooves the floor of the gutter, in places showing a slight thickening of the epithelium along its fundus. It is distinguishable in His's cut of Zw. (Anat. mensch. Emb. III, Fig. 65, left side) and in Chievitz's figure of his 8 weeks embryo (' 85 , Fig. 7). In the 20 millimeter embryo of the Columbia Collection it is well marked (Figs. 4, 7, 12-19, I6), while in the 22 millimeter embryo it has almost disappeared (Fig. 23, I6): From its position it may be termed the intermediate furrow; in man it apparently supplies no derivatives.

Ventral to the alveolingual region is an area of mesenchyme well defined topographically. It is linited entad by the hyoglossus muscle and hypoglossal nerve, ectad by Meckel's cartilage, and ventrad by the mylohyoid muscle. While presenting no especial structural characters of its own, it becomes continuous at the posterior border of the muscle with the conspicuous circumscribed mass of condensed mesenchyme, described by Kölliker, Chievitz, and others, which forms a sort of scrotun into which the sprout of the submaxillary descends (Fig. 17,39).

The lingual nerve (30) passes craniad in the suboral mesenchyme. crossing the alveolingual region obliquely in its course to the tongue. Here it presents a bulky ganglionic enlargement (Fig. 17, 3I) which 
involves its trunk and extends along its branches into the tongue. The lingual crossing is a classic landmark in this region, which can be rendered more precise by limiting its application to the fibers of the nerve and to the lingual sulcus, in which sense it is used in the descriptions of the Columbia embryos. In passing it may be noted that the relation of a gland to the lingual nerve in the adult is of no deeper morphological significance than any other topographical relation, though it has imprinted itself upon the nomenclature of this region in comparative anatomy. Glands, like other structures, are more profitably compared upon the basis of their origin, and should be referred to the sulcus from which their anlages are derived. irrespective of their ultimate size and the length of duct they-may attain, on which factors of growth their topographical situation will secondarily depend.

The findings in the individual embryos may now be considered. Here. again, the series is arranged on the basis of the development of the glands: chronology is not strictly adhered to.

I. Sudler. Embryo CLA, N.B. 10.5. V.B. I I. Probable age 5 weeks. In his serenth figure there is a small, almost senucircular, projection from the oral epithelium ventrad from a point below the anterior extremity of the first pouch. The ridge from which it projects is continued caudad into the lateral border of the pharyns. The figure suggests the early anlage of the submaxillary as it occurs in the cat and the pig. It is not referred to in the text.

2. Hammar. Embryo of $\mathrm{I}_{3.2}$ millimeters length. The floor of the alveolingual region shows a ridgelike thickening of the epithelium, which increases in height as it is followed caudad, and terminates abruptly at about the middle of the sagittal length of the gutter. The anlage is thickened in its caudal sections.

This description would lead us to conceive the anlage as having the outline of a right triangle in lateral view, the hypothenuse and shorter leg free, the base attached to the lingual sulcus. The thickening in the caudal sections would indicate the beginning of active proliferation preparatory to the establishment of a free-growing sprout.

3. His. Embrro Sch. 2, of I 3.8 millineters length. The caudal end of the lingual sulcus runs out into a blind epithelial tube, the anlage of the submaxillary gland (Anat. mensch. Emb. III, Fig. 64). 
The formation of this tube is attributed to a bridging over of the lingual sulcus by coalescence of its walls.

4. Sudler. Embryo CLIIV, N.B. I2, V.B. I4. Probable age $5 \frac{1}{2}$ weeks. The anlage of the submaxillary is "simply a rounded rod of cells staining deeper than the surrounding tissues." It is represented ('o2, Fig. 8) as projecting at an acute angle from the lingual sulcus, with a blunt, but not enlarged, extremity.

5. Chievitz. Embryo of I $_{4}$ millineters length, after preservation in spirits. Age 6 weeks. The tongue is bounded by a sulcus which deepens caudad. From this the pluglike submaxillary extends Io4 $\mu$ ventrad. The anlage is a little larger on the left side. The plug is cranial to the plane of the angulus oris, $560 \mu$ from the frenulum; immediately craniad of it the lingual nerve crosses the lingual sulcus. In Fig. $6 \mathrm{~B}$, which is taken from a graphic reconstruction, the sulcus lingualis is given a peculiar slope, owing to his assumption that the roof of the mouth formed a straight horizontal line in median section. The rodlike submaxillary projects from the sulcus, forming with it in front an obtuse angle, which justifies the assumption that an acute angle would have been made behind the anlage, had he kept his sulcus straight. The oral epithelium was lost in this embryo except for a plug (Epithelpfropf) in the anlage.

6. Paulet. Embryo of $\mathrm{I}_{4.7}$ millimeters length, V.B. The anlage of the submaxillary is solid and comprises a ridge corresponding to the duct, and a round bud which represents the body of the gland. The anlage of the duct is about twice as long as that of the body; together they have a length of $800 \mu$. The central cells of the bud are more voluminous and stain less intensely in carmine than the peripheral cells. The body is still attached to the oral epithelium.

The agrecment of Chievitz, Hammar, Sudler, and Paulet, taken together with the perfect objectivity of their descriptions, must be held to establish the solidity of the anlage and outweigh His's statement that it is a tube. As has been said, the anlages of the salivary glands quite uniformly present sections in which the centers of the ducts and sprouts are more faintly stained than the basal cells. In rumning over thick sections with il low magnification, it is easy to mistake the pale center for a lumen.

A comparison of the triangular anlages of Hammar and Paulet 
with the inclined plugs of Chievitz and Sudler suggests that the position of the plugs corresponds to the hypothenuse of the flange, and that the plug acquires its freedom by a solution of continuity in the primitive anlage. Sudler's reconstruction and statement show no enlargement of the fundus, so that active proliferation on the part of the free-growing duct cannot have been initiated in his embryo at the time the separation took place, while in Hammar's and Paulet's embryos, on the other hand, the anlage shows a distal enlargement when it is still attached in its whole length.

7. Sudler. Embryo XLIII, N.B. I4, V.B. i6. Probable age 6 weeks. The submaxillary is "a straight cylindrical shaft with a knob turned directly away from the middle line.... It is a solid object throughout."

8. His. Embryo Zw., I4.6 millimeters. In the illustration of this embryo (Anat. mensch. Emb. III, Fig. 65) the submaxillary has a long duct, which, after crossing the lingual nerve, is enlarged and studled with numerous small knobs. No sublingualis major was present. It is suggested that it may arise from the lateral sulcus near the alveolar process, which is therefore termed sulcus sublingualis by His.

9 and 10. Hammar. Embryos of 17 millimeters and 18.5 millimeters. The submaxillary duct is formed caudo-craniad by a constriction which frees the epithelial flange from the sulcus, while the thickening of the earlier stages, at the caudal end of the flange, enlarges to form a retort-shaped gland body.

II. Sudler. Embryo XXII, N.B. I8, V.B. 20. Probable age 7 weeks. The submaxillary has grown into an "oval-shaped body covered with rounded enlargements marking the future lobes of the gland." Around it the connective tissue shows slight condensation. No other saliviry gland was observed in this embryo.

I2. Chievitz. Enlbryo of 8 weeks. After noting the presence of an early condition of the plica fimbriata and sublingua, Chievitz describes the origin of the submaxillary from a median sulcus bordering the tongue (sulcus lingualis). The point of attachment is $240 \mu$ caudal to the plane of the angulus oris, and to $\mu$ nearer the frenulum than in his embryo of 14 millimeters ( 6 weeks). The anlage is prolonged craniad to the lingual crossing by an epithelial keel or crest, such as appears in the pig. This crest has a sagittal length of $200 \mu$. A lumen is present 
in parts of the duct, which passes the lingual nerve and its ganglion, turning ventrad and laterad beyond the mylohyoid muscle into a welldefined roundish area of richly nucleated connective tissue. The duct here divides into two primary branches: one directed candarl bears two rounded terminal buds; the other continues the direction of the duct and has three similar enlargements. From the lateral surfice of the epithelial crest of the submaxillary arises a short rounded process, the sublingual gland.

13. Columbia Collection, No. 325, length 20 millimeters, V.B. (Figs. +20 ). The alveolingual regions are deep gutters beside the tongue, almost horizontal in course, converging craniad and becoming confluent in frout of the frenulum. The bounding sulci, the lingual (S) mesad and the alveolar (1f) laterad, are well defined. The latter is almost sagittally directed, and near its cranial extremity crosses Neckel's cartilage $(2 I)$ dorsally (Fig. 6), and approaches the dental ridge (29), which is interrupted near the point at which the furrow terminates (Fig. 4). No glindular anlages are attached to the sulcus in this embryo. The lingual sulcus $(S)$ forms the boundary between the tongue and the alveolingual gutter. It begins a short distance behind the frenulum (Fig. 6), and diverging from its fellow caudad, is continued into the lateral border of the pharynx, which it joins almost at right angles (Figs. 5 and 19). Defined by these boundaries the alveolingual region as a whole narrows caudad, so that at the level of the lingual nerve it is not more than half as wide as at the frenulum (Fig. 4). The increase in width craniad is in part due to the extension of the region mesad at the expense of the tongue, which it undermines increasingly as the frenulum is approached (Figs. 6, 7, ז2-17). The lateral surface of the tongue falls into two areas, separated by a blunt angle (Ig); the upper, nearly vertical, looks to the palate process, the lower, narrow and uneven $\left({ }_{I} S\right)$, corresponds to the extension of the alveolingual region just mentioned. Following Chievitz, we may term this the sublingua; the angle between it and the vertical surface of the tongue, the plica fimbriata. Both begin a short distance behind the frenulum and diminish caudal (Figs. 7, I2-17).

Three solid anlages are attached to the lingual sulcus; all have a triangular shape and increase in size caudad, where they terminate in free sprouts. The larger of these is sulcal in position and is continued 
into the free duct of the submaxillary (9), while the other two are parictal, one lateral to the submaxillary, the greater sublingual ( $I O)$, the other mesal, the apical gland $(I I)$.

The submaxillary anlage in its cranial scctions appears as a small keel attached to the fundus of the still open sulcus (Fig. 7, 9). As the lingual crossing is approached, it forms a massive flange, increasing both in height and thickness, while the lingual sulcus is reduccd to a shallow furrow indenting its base (Fig. I2), and the other two flanges appear attached to its sides. At the lingual crossing it separates from the sulcus and is continuous with the solid submaxillary duct (Figs. 13-I7); yet the nature of its separation is such that caudad of the duct a low flange remains attached to the sulcus. which from this circumstance has been termed the postglandular flange (Figs. I $4^{-I} 7$. 13). This I take to be a persistence of the attached border of the triangular submaxillary anlage of younger embryos (Nos. 2 and 6), which has escaped destruction in the solution of continuity incident to the freeing of the submaxillary duct. It is itself constricted at its base, and has in some of its sections a second similar narrowing near its middle, so that it is almost divided into two small circular areas. There are no sprouts arising from the flange, which has itself entirely disappeared in the 22 millimeter embryo. The constrictions may therefore be instrumental in its reduction; yet they resemble closely the furrows, which in the cat are the means of freeing such structures as the orbital inclusion and the duct of the greater sublingual gland. The postglandular flange is present in that form also and is reduced without constriction. It is probable, therefore, that as the anlage in man is of somewhat greater development than in the cat, some other primate may retain this element in the adult as one of the components of its submaxillary complex (vide Part III).

Of the two parietal anlages the lateral has the greater breadth. Its free angle presents a small spherical enlargement (Fig. I2) which, in the next section (Fig. I3), is free in the mesenchyme. The cranial portion of this crest is attached to the lingual sulcus immediately latcral to that of the submaxillary; in the lingual region it is attached directly to the flange of the larger gland. At the point of separation of the submaxillary the conditions differ on the two sides; on the right it retains the connection with the submaxillary, on the left it is attached 
to the postglandular flange (Fig. I 3). This lateral crest is identical with Chievitz's sublingual anlage, and the difference in its behavior on the two sides of this embryo nay be related to the two conditions of the Bartholinian duct in the adult, whether tributary to the submaxillary or with an independent orifice of its own. These lateral or sublingual crests have each an interruption in their cranial portion; on the right of $93 \mu$, on the left of $40 \mu$, in a total length for each of $240 \mu$ from end to end. A similar interruption occurred in the left submaxillary crest.

The interruptions in the crests reckoned by section counts may be tabulated as follows:-

Fundal (submaxillary) crest.
Length of interruption . . . . . . . . . . .

An ental crest, rather short and bulky, but of the same general character as the others, projects mesad into the substance of the tongue, with a slight inclination dorsad. The free angle is slightly thickened (Fig. 12), but no free sprout has as yet appeared. From its position in this embryo the anlage might be equally well assigned to the gland of Nuhn-Blandin or of Weber. In older embryos (vide infra) an ectal plug is attached to the lingual sulcus close to the frenulum, which suggests that this anlage, like the others, advances craniad. It is therefore, on the whole, more probable that this sprout belongs to the apical gland (Nuhn-Blandin) than to that of Weber. The crest in this embryo (20 millimeters) is in the region of the lingual crossing (Fig. I2), where the combined anlages present a triradiate cross-section.

The minor differences in the flanges of the two sides appear in the following table:-

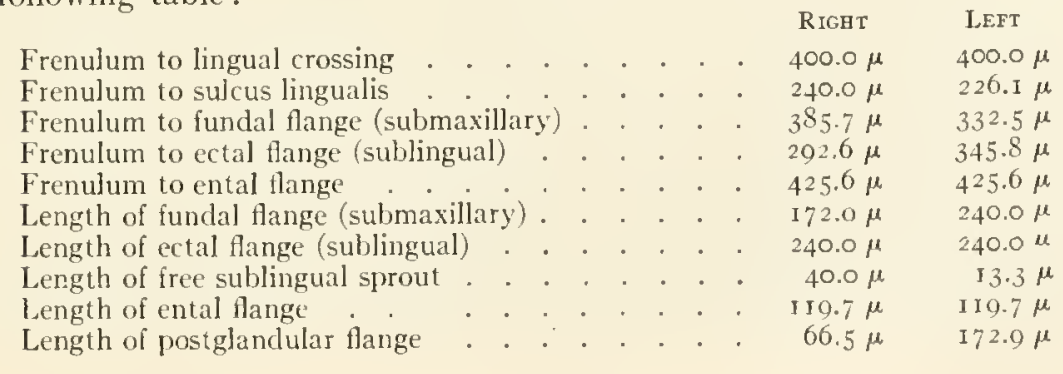


The free duct of the submaxillary descends with a caudal and slightly lateral inclination, and escaping from the embrace of the lingual nerve and its ganglion, plunges into a sharply circumscribed retort-shaped mass of dense mesenchyme (Figs. I6-I8), which incloses all the branches of the gland. An important though inconspicuous element occurs in the course of the duct, while it is still in intimate relation with the submaxillary ganglion. Vertically beneath the postglandular flange, on the dorsolateral aspect of the convex curve of the duct for a section or two on each side is found a slight enlargement partially constricted from the rest of the duct, but showing no evidence of sprouting (Fig. I6, 12). Like the postglandular flange this appears to be a remnant of the original flange of the submaxillary left adherent to the duct when it became free. The branches of the gland fall into three sets. each composed of several buds irregularly arranged upon a short common stem. The one in continuation of the line of the duct is the largest. Of intermediate size is al dorsal, caudally directed complex. These two groups eridently correspond to the two primary branches of Chievitz's 8 weeks embryo. A third smaller group arises from the concavity of the duct, ventral to the lingual crossing and the mylohyoid muscle; these sprouts are directed craniad.

With respect to the presence of a lumen in the submaxillary duct, the appearances in this embryo raise some questions of interpretation. The gland sprout together with its branches is solid, as is also the prelingual keel which continues the anlage craniad along the fundus of the lingual sulcus. The intermediate region alone offers difficulties. Here a high flange is prolonged ventrad trom the sulcus, which is reduced to a shallow indentation of the base of the flange, a portion of which in consequence appears to be formed by the apposition of the walls of the sulcus. Since in this embryo a periderm layer is everywhere present in the mouth, the contact of the walls must be in detail that of their periderm layers, the bulging nuclei of which interlock along the line of the obliterated lumen, and destroying sharp surface contours make it impossible to be sure that actual fusion of the layers has taken place. In some sections a pale streak may be seen in the axis of the flange; in a few, the pale area widens irregularly and suggests the presence of a space between the periderm cells. The distal or aboral cdge of the flange, and the prelingual kecl and duct with which it is 
continuous, appear as solid, deeply staining cell masses; only in some of the terminal buds are pale centers conspicuous. In embryo i4 of this series the lumen of the submaxillary duct is lined with a well-marked simple squamous epithelium, from which it might be inferred that a potential lumen is retained in the flange by reason of the non-adhesion of the periderm cells derived from the opposite sides of the sulcus, although it seems more reasonable to suppose them derived from a secondary differentiation in situ from the cells of the anlage. In either event, we may certainly reject His's description of the constriction and separation of an open fold, such as occurs in the case of the orbital inclusion according to Hammar.

The intermediate sulcus (Figs. I, 4, 7, I 2-I 8,16 ) is a distinct though shallow furrow with a slight irregular thickening of the epithelium along its fundus. It is directed caudad and laterad, crossing the alveolingual region obliquely, without however becoming continuous with either the lingual or alveolar sulcus (Fig. 4). Its cranial extremity is at the level of the sublingual anlage. Caudad it terminates on the right side, a little beyond the lingual crossing; on the left, it extends considerably farther, lying close to, but not joining, the alveolar sulcus (Figs. $4^{-1} 8$ ). Between it and the lingual sulcus the floor of the alveolingual gutter presents small irregular thickenings near the interruption of the sublingual flange, where on each side they form two short ridges (Fig. 7, 40). Between the intermediate sulcus and the alveolar sulcus, at the level of the lingual crossing, a faint furrow is seen in some sections (Fig. I 2).

I4. Columbia Collection, Embryo No. 3. Length 22 millimeters (Figs. 2I-24). The lingual sulcus $(8)$ extends from the frenulum to a point opposite the caudal border of the lingual ganglion, where it terminates abruptly without any conspicuous preliminary reduction in size. It is throughout its course a simple furrow, angulate except in its most cranial sections, where it is rounded at the fundus. Nowhere is there at tached to it an epithelial keel or flange. From its cranial extremity, opposite the orifice of the submaxillary duct, a sprout arises directed mesad and caudad into the substance of the tongue (Fig. 22, II). This appears in three sections (of $3 \circ \mu$ ). In the last only is the anlage free; in the other sections it is attached accurately to the fundus of the sulcus. On the right side a like condition obtains. The 
identity of this sprout with the mesal flange of the 20 millimeter embryo is suggested by its direction, but it springs from a point elose to the frenulum, and terminates craniad of the level at which the flange showed signs of proliferation. Either it has been carried bodily forward by unequal growth along the sulcus, which is improbable, or its advance along the line of its keel has been accompanied by a loss of its caudal portion.

The lateral limit of the alveolingual gutter is given by the alveolar sulcus (Fig. 23, I4), which, while preserving the general topography of the 20 millimeter embryo, has altered in extent and relative size. It extends caudad only to the region of the lingual crossing, where it teminates sonewhat abruptly. Craniad it loses depth by the gradual reduction of its mesal wall, and comes to form a mere angle at the lateral border of the alveolingual gutter. Here it is continued in a direction that causes it to pass at first dorsal, and finally lateral, to Meckel's eartilage, becoming indistinguishable a little in advance of the plane of the symphysis. Before it has left its position ental to the cartilage, it is connected by a shallow circumflex furrow with the lingual sulcus, the two sulci defining a slight convexity of the floor of the alveolingual region, the anlage of the plica sublingualis. Over this and the adjacent segments of the bordering sulci, the epithelium is thickened. Along the mesal portion of the circumflex sulcus (39) it forms a keel projecting ventrad and entad into the subjacent mesenchyme, from which arise two small solid epithelial plugs, the mesal of which is the larger, the anlages of the lesser sublingual glands. Owing to the rapid inward sweep of the sulcus, the lateral plug appears in section intermerliate between the two sulci; its attachment to the keel is clear in reconstruction (Fig. 21, I6). Conditions on the two sides are elosely similar. The eireumflex sulcus, to which these sprouts of the lesser sublingual glands are attached, appears in the 22 millimeter embryo as a new element. In the descriptions of older embryos which follow it is not recognized as distinct from the alveolar sulcus, while the prolongation of the latter ectal to Meckel's cartilage is not mentioned. Apparently the alveolar sulcus loses a primitive cranial extremity, which is replaced by the circumflex sulcus. It is in connection with this neomorph that the anlages of the lesser sublingual glands appear. A keel prolongs its fundus into 
the mesenchyme, and from this spring the sprouts of the glands, which are established successively in a craniocaudal direction until five are present (Bujard). To some extent the furrow appears to be complementary to the elevation of the plica sublingualis. With regard to the epithelial keel, whether antecedent to and conditioning the gland formation, or merely the expression of their active proliferation and the crowding of their anlages, sufficient data are not available to determine.

The submaxillary duct ( $(9)$ opens upon the plica sublingualis towards its mesal side, but separate from, and lateral to, the sulcus lingualis (Figs. 21, 22). The orifice is about I $20 \mu$ behind the frenulum on the left; on the right side the distance is $90 \mu$. The duct bends dorsad to its orifice almost at a right angle. It is then directed caudad, with a slight inclination away from the oral epithelium as far as the lingual crossing, where it sweeps in a wide curve ventrolaterad. Immediately ventrad of the nerve the branches appear, surrounded by a capsular thickening of the mesenchyme. As the mesal branches are smaller and fewer than the lateral, the duct lies to the mesal side of the bulk of the gland. It is situated also on its cranial aspect, as is seen from the dominantly caudal direction of its branching. One hundred and twenty micra distad of its attachment a lateral solid branch is attached to the duct (Figs. 2I, 23, Io), the greater sublingual anlage, which, diverging laterad, terminates after a free course of r $20 \mu$. It is solid throughout. Just opposite the lingual crossing the submaxillary duct is dorsoventrally flattened, gaining considerably in width, and presenting a reniform section (Figs. $21,24,12$ ). This configuration obtains in four sections $(\mathrm{I} 20 \mu)$. They are situated at the point where the duct is about to pass ventrad and laterad from the embrace of the mylohyoid muscle and the lingual ganglion - a point vertically below the end of the lingual sulcus, which at this stage is devoid of a postglandular flange. Of the two convex ends of the reniform cross-section, the mesal continues into the descending portion of the duct. The lateral in its last section appears dorsally, as well as ventrally defined against the duct by a very slight incisure. It is highly probable that this element represents the dorsal accessory submaxillary of Huntington. The submaxillary duct of the left side contains a lumen as far as the origin of the greater sublingual, where it is 
obliterated, to appear again in the lingual region for a distance of г $20 \mu$, extending into the cranial half of the reniform segment of the duct.

At the orifice the lumen is reduced to a slit with its walls in contact. The wall of the duct is composed of two or three rows of cuboidal elements. Next the lumen there is a well-defined single layer of squamous cells. On the right side the greater sublingual is absent. The lumen extends from the orifice for a distance of $\mathrm{I}_{50} \mu$. The duct shows the same arrangement of its cells as that of the opposite side. A reniform segment was not observed.

I5. Chicvitz. Embryo of ro weeks. Right side dissected. Left side cut into serial sections. On the left the orifice of the submaxillary is situated $360 \mu$ caudal to the frcnulum, in a parietal position. The orifice is continued craniad by a very faint sulcus, the fundus of which shows no epithelial thickening. The alveolar sulcus (laterale Rinne) is widely separated from the lingual sulcus. From its fundus a crest projects rentrad and mesad. A few short rounded sprouts are attached to this crest. Farther craniad a small plug is attached to the floor of the alveolingual gutter between, and without relation to, its sulci. A similar sprout is attached to the lateral wall of the lingual sulcus (also present on the right). The lumen of the submaxillary duct extends into some of its penultimate divisions.

16. Hammar. Embryo of 2.4 millimeters length. Near the orifice of the submaxillary duct are five small sprouts, which arise from the lateral wall of the alveolingual region somewhat assymetrically. For these elements there is no special epithelial ridge.

I7. Bujard. Embryo of about ro weeks. Total length 5 centimeters. The submaxillary has attained an advanced stage of development. Its duct opens craniad of the frenulum close to the median line; its proximal portion is vertical to the epithelium of the mouth for a short distance, then, turning abruptly, it is directed horizontally caudad parallel to the floor of the alveolingual gutter, eventually bending ventrolaterad to join the body of the gland. Here it divides into three principal trunks. Just before undergoing this division the duct gives off a ventral branch, which supplies an accessory submaxillary lobule, the relation of which to the mylohyoid is not given. A lumen is present as far as the terminal sprouts. In the submaxillary 
duct and its larger branches it is well defined; the walls are composed of two layers of low epithelial cells.

The greater sublingual gland arises from the submaxillary duct near the angle which it makes as it approaches its orifice. The duct extends caudad in close relation to that of the submaxillary to terminate in two buds, one of which shows evidence of secondary sprouting. The wall of the duct is composed of two layers of epithelial cells; the lumen extends to the terminal bucls.

The lesser sublingual glands, five in number, are attached to a deep epithelial crest directed ventromesad. They diminish in size craniocaudad. All of these anlages are solid and appear as continuations of the basal cells of the epithelium, which is indented by a sulcus along the attachment of the epithelial keel. A few isolated sprouts are found farther caudad, springing from the surface of the epithelium, unattached to any crest; these Bujard designates, rather infelicitously, diffuse buccal glands.

IS. Chievitz. Embryo of 12 weeks. A well-developed plica sublingualis extends from the palatine arch to a point craniad of the frenulum. The orifice of the submaxillary is situated on the mesal surface of this fold 0.12 millimeter cranial to the frenulum. In point of outward form and topography the gland has attained essentially the adult condition. A typical greater sublingual gland occurs on the left side. From the submaxillary duct, immediately caudal to its orifice and from its lateral side, a smaller duct arises, which after a course of I millimeter forms a small gland with sprouts of the second order, in the unaltered mesenchyme ventral and lateral to the duct of the submaxillary. On the right there was no trace of this element. On each side are found $11-I_{3}$ lesser sublingual glands, solicl plugs, for the most part unbranched, set in a row at intervals of about 1.5 millimeters, the first of the series lying immediately craniad of the submaxillary. They are attached to the apex and lateral surface of the plica sublingualis and no longer are related to any sulcus; their sprouts are lateral to the submaxillary and greater sublingual glands, and not in contact with the latter.

I9, 20, 21. Zumstein. Fetuses of 6, 8, and 9 months. The alveolingual region was studied in serial sections. In all the greater sublingual is lacking. The lesser sublinguals extend caudad in to the arcus 
palatinus and are continuous with the isthmian glands. Craniad, isolated lobules were found in front of the caruncle. The submaxillary duct is ventral to the lesser sublinguals caudad, then mesal, and finally at its orifice dorsal to them. In the supramylohyoid portion of its course it is often accompanied by portions of the gland, which may be in contact with the lesser sublinguals; in other cases the two glands are widely separated:

An attempt may now be made to reconstruct the history of the derivatives of the alveolingual region. Of these the development of the submaxillary has been followed in most detail. The anlage arises from the lingual sulcus at, and just caudal to, the lingual crossing (His, Chievitz) ; its development consists in the formation of a postlingual sprout which invades the mesenchyme distad, and of a prelingual duct prolonged proximad along the lingual sulcus. The time of its appearance cannot be stated definitely. In Hammar's embryo of I 3.2 millimeters the anlage has attained a certain degree of development; if my interpretation of Sudler's figure is correct, it is present in an embryo of i i millimeters, where it forms a nearly semicircular projection from the sulcus. In Hammar's youngest embryo it has a triangular outline and the structure of an epithelial flange. Hammar interprets this as the result of a process of folding affecting the walls of the lingual sulcus. This view is supported by the findings in the 20 millimeter embryo, where the sulcus gradually diminishes as the flange increases in depth, until where the latter has attained a maximum, the sulcus becomes a shallow furrow indenting its base. The first indication of the sprout is a thickening of the free angle of the flange which is present in the 13.2 millimeter embryo (Hammar). At about the same period, or even antedating the appearance of the sprout, the duct begins to separate from the lingual sulcus. This may be accomplished by a destruction of the intermediate portion of the flange, progressing craniad from its caudal border, for in the embryos of $\mathrm{i}+$ millineters (Chievitz, Sudler) the anlage is a plug inclined at an acute angle to the sulcus, in the position of the hypothenuse of the primitive flange. In neither of these embryos is a thickened free extremity noted. The flange is placed vertically above the lingual nerve as it crosses the sulcus of the same name. In subsequent stages the bud gives origin to the body of the gland and the duct system dis- 
tal of the lingual crossing, while the lingual and prelingual portions of the duct correspond to the thickened border of the flange. In Fig. 25 these conditions are indicated schematically. The triangular anlage is represented as giving rise to the duct along its hypothenuse and to the bud at its free angle. The area between the dotted lines is lost in freeing the duct. Along the lingual sulcus and along the duct the

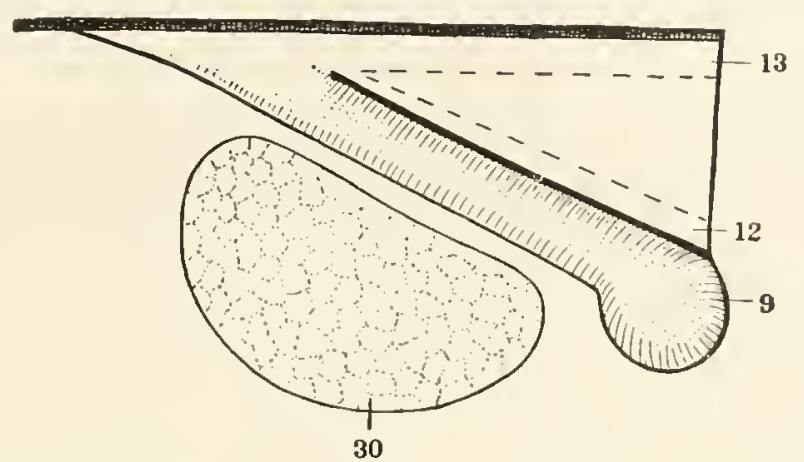

FIG. 25. Schema of anlage of submaxillary. Stage of $\mathrm{I}_{3}-\mathrm{I}_{4}$ millimeters. Embryos $2,4,6$, and 7 .

9. Submaxillary sprout.

12. Dorsal accessory submaxillary.

13. Postglandular flange.

30. Lingual nerve.

areas defined by the dotted lines escape reduction at this period, and represent respectively the postglandular flange $\left(1_{3}\right)$ and the dorsal accessory submaxillary (12).

From the angle of the flange, proliferation advances along its free margin and eventually reaches the unfolded fundus of the lingual sulcus, where it forms a solid epithelial crest. At the same time the sprout at the angle enlarges and begins to invade the mesenclyyme. This condition is attained in the $\mathbf{I} 3.8$ millimeter embryo of Paulet, and carried further in Hammar's embryos of 17 millimeters and 18.5 millimeters. In Chievitz's embryo of 8 weeks the attachment is described as a crest. In the 20 millimeter embryo of the Columbia Collection both crest and flange are present. In the region of the lingual crossing the lingual sulcus is reduced to a shallow furrow, a character which it retains in the whole length of the postglandular flange, caudal to which it regains its lumen. Craniad the flange becomes smaller and very 
gradually the sulcus regains its lumen. But to its fundus are now attached the keels of the submaxillary and greater sublingual glands. The whole of the duct appears therefore to owe its formation to proliferation localized at the fundus of the lingual sulcus, and proceeding in a caudocranial direction; only in its caudal portion the sulcus has first been reduced to a flange, the free border of which represents its primitive fundus. The flange, as such, does not directly give rise to the duct, being lost in the process of its separation, but serves rather to support the marginal proliferation and to determine the direction of the growth of the sprout away from the alveolingual region. The formation of the fold is explained by His as incident to the enlargement of the tongue, and the resistance offered its dorsal expansion by the roof of the mouth. In this process the bulky submaxillary ganglion would seem from its situation to be also a factor. The view here taken of the mode of formation of the submaxillary duct is supported by the findings in the cat, where the lingual sulcus appears in two segments, which in a minority of cases fail to become continuous; yet over the gap the submaxillary advances by an epithelial keel, which is precisely similar to those more usual ones where the sulcus is present. Other glands in the cat, for example the orbitals, have ducts formed later than their sprouts and prolonged along the oral epithelium in the form of keels, without the intervention of any sulcus. The same is true of the human greater sublingual in so far as it is attached to the submaxillary, and probably also of the apical gland of the tongue. It would appear therefore that while the relation of a gland to a sulcus may in some way favor and accelerate the formation of its anlage, yet the actual material for its duct is formed by the proliferation of new cells and not the working over of materials that have once formed the walls of the sulcus.

The separation of the duct is accompanied by a solution of continuity and probably also by a loss of substance in the flange. The 20 millimeter embryo affords evidence of its incomplete reduction, in the postglandular flange ( 13 ) extending along the lingual sulcus caudad to the submaxillary. The flange is constantly present in the cat, where it is reduced caudocrainad, puri pussu with the advance of the duct. In this human embryo it presents evidence of constriction which may be preliminary to its reduction, as in the 22 millimeter embryo it has en- 
tirely disappeared. Vertically beneath it a similar element is attached to the submaxillary duct, rather on its lateral aspect, as though the duct had rotated slightly, and in the 22 millimeter embryo also this element persists on one side.

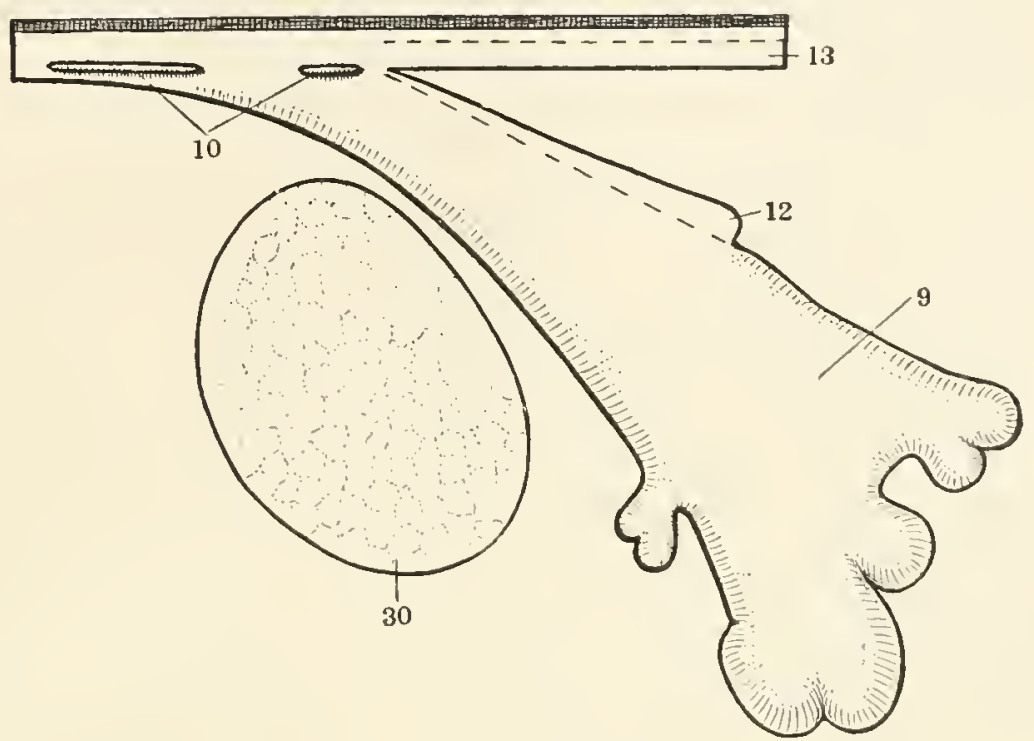

FIG. 26. Schema of anlages of submaxillary and greater sublingual glands Stage of 20 millimeters. Embryo, No. I3.
9. Submaxillary anlage.
I 2. Dorsal accesșory•submaxillary.
ı. Greater sublingual anlage.
I2. Postglandular flange.

30. Lingual nerve.

In the schema (Fig. 26) is shown the correspondence in position of these elements $\left(I 2, I_{3}\right)$ with the marginal zones of the earlier flange (Fig. 25). With regard to the postglandular lange there is no evidence as yet in the human embryo that it becomes the seat of proliferation or sprouting. The element attached to the duct, however, in the 22 millimeter embryo, seems to be on the point of initiating this process. In the submaxillary complex of the lower primates both of the elements are represented, the postglandular flange as the secondary submaxil- 
lary, the rudiment attached to the duct as the dorsal accessory submaxillary (Huntington).

Distad the duct invades a peculiar circumscribed thickening in the mesenchyme (Kölliker, Chievitz), where it divides into branches. In the I4 millimeter embryo there are two primary divisions, a dors? I and a ventral, the latter continuing the line of the duct (Chievitz). In the 20 millimeter embryo a new group appears from the concavity of the duct (Fig. 5). These three primary divisions are present in the 5 centimeter embryo of Bujard, together with an additional ventral duct, which supplies a small lobule, the accessory submaxillary of Bujard, which is probably the equivalent of the ventral accessory element in primates, and at least serially homologous with the recurrent ducts of the supramylohyoid portion of the gland in man, concerning the development of which nothing further is known.

The definitive orifice of the submaxillary is cranial to the frenulum upon the surface of the plica sublingualis, that is, lateral to the lingual sulcus. In the 22 millimeter embryo (Fig. 22,9), although it is still a short distance caudal to the frenulum, its position has become parietal. The abandonment of the fundus of the sulcus of origin is a feature common to the ducts of the larger salivary glands. It is most easily accounted for, by the assumption of unequal growth in the walls of the sulcus. The wall in which growth is relatively" rapid tends constantly to form a new fundus displacing the original one, with the anlages attached to it, towards the opposite wall, along which they travel upwards as the sulcus deepens. In this case it is the ental wall which appears accelerated, and the argument for an actual rolling outward at the fundus is strengthened by the displacement of the ental parietal flange of the 20 millimeter embryo to an accurately fundal attachment in that of 22 millimeters (Fig. 22,II). With regard to the shift craniad of the submaxillary orifice to a prefrenular position, after the abandonment of the sulcus, the acquisition of a lumen, and the disappearance of the epithelial crest, our knowledge is very incomplete. Chievitz mentions a small fissure leading craniad from the oritice of the duct in his 10 weeks embryo, and states that there is no thickening of the epithelium along it. A short proximal segment of the duct in the adult is lined with stratified squamous epithelium. It is possible that this may have a different formation from the rest of the duct, as by the folding 
of the walls of Chievitz's fissure; there are, however, no clata to decirle the point, and the prefrenular position may be acquired merely by unequal growth in the parts about the frenulum.

The development of the lumen is preceded by changes in the central cells of the duct, the cytoplasm of which stains faintly, while the nuclei become pyknotic. The lumen in its first appearance is discontinuous (Chievitz, 8 weeks), a condition retained on one side in the 22 millimeter embryo, where it is lined by a single layer of squamous cells, the remainder of the wall being composed of two rows of polyhedral elements. In older embryos to the stage of 5 centimeters the duct epithelium is composed of two rows of low columnar cells (Chievitz, Bujard).

The greater sublingual gland makes its appearance at 8 weeks as a rounded process, attached to the lateral surface of the submaxillary flange (Chievitz). In the 20 millimeter embryo it is represented by a triangular keel resembling in form the early anlage of the submaxillary, but directed laterad and in the horizontal plane. At its free angle the proliferation of a sprout has just begun. It is prolonged craniad by a keel along the submaxillary flange and then independently along the lingual sulcus. Its attachment is in line with the advancing gap in the submaxillary flange (Fig. 26), which may pass either dorsal or ventral to it, leaving it attached in the one case to the postglandular flange, in the other to the submaxillary duct, as on the left and right sides respectively of this embryo. In the older embryos, the greater sublingual, when present, is attached to the submaxillary duct, so that it would appear, in the light of our present knowledge, that the solution of continuity in the flange of the latter is usually dorsal to the attachment of the greater sublingual anlage. Here there can be no question but that this advance of the duct is due to the proliferation, and subsequent constriction of a crest, for in its inception, apparently, the anlage is attached to the submaxillary flange and not to a sulcus. In the 20 millimeter embryo it has acquired an independent keel along the lingual sulcus, lateral to that of the submaxillary, while in embryos of 22 millimeters and over it is attached to the proximal portion of the submaxillary duct. Here the union of the two crests is plainly secondary, and not primary as appears to be the case with the caudal portions of the anlages in man. It is easy to suppose that the two crests 
advancing side by side may eventually fuse, and then separating from the sulcus, give rise to the united ducts, or failing to fuse, permit the greater sublingual to attain an independent orifice. An alternative supposition is possible. It may be that the fold continues to advance after the stage of 20 millimeters, forming a flange in the region to which the crests are attached, as previously in the region of the submaxillary ganglion, and that the inrolling incident to the formation of this portion of the flange is the means of uniting the two ducts. In this case it must further be supposed that the proximal portion of the sublingual crest is suppressed in those cases in which the two glands have a common orifice, to which suppression the interruption of the sublingual crest in the 20 millimeter embryo may be preliminary. While there is no evidence to decide, the latter supposition is interesting in that it calls in question the primitiveness of the attachment of the sublingual bud in Chievitz's ro weeks embryo. Here also the anlage may have been established prior to the completion of the flange. and subsequently annexed as the flange drew into itself more of the adjacent epithelium.

It is evident that the anlages of the submaxillary and greater sublingual glands afford abundant material for variation, in irregular separation of their flanges, in the possible active development of such rudiments as the postglandular flange and the dorsal accessory submaxillary, and in the mutual relations of the keels of the ductș. In Figs. 26 and 27 these factors are schematically indicated; the first based largely upon conditions in the 20 millimeter embryo presents conditions actually observed; in the second a schema of possibilities is drawn, which might be realized by the full development of these rudiments. In both the ventral accessory element has been omitted. It is attached to the concavity of the submaxillary duct craniad to its division in to three major branches (Bujard). While the human adult fails to utilize this abundant material at all fully, it is interesting to note that its possibilities are realized in other primates (Huntington), and that individual and specific types of this complex present themselves as more or less complete realizations of the human embryonic plan.

Of the mesal derivatives of the lingual sulcus our knowledge is meager. In the 20 millimeter embryo a flange of the same form as the sublingual is directed mesal into the substance of the tongue. In 
the 22 millimeter embryo a plug is attached to the lingual sulcus a short distance caudad of the frenulum. In his ro weeks embryo Chievitz describes a small plug arising from the lingual sulcus, but in this

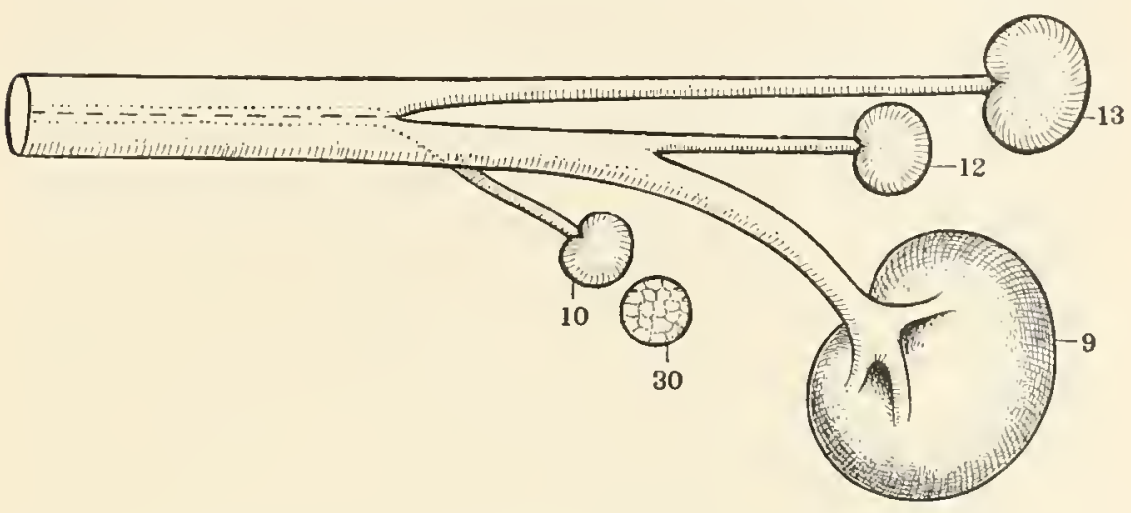

FIG. 27. Hypothetical schema of the derivations of the submaxillary and greater sublingual anlages. The ventral accessory submaxillary sprouts are omitted.

9. Submaxillary gland. I2. Dorsal accessory submaxillary gland.

I0. Greater sublingual gland. I3. Secondary submaxillary gland. 30. Lingual nerve.

The dotted lines in the course of the ducts of 9, I0, and I 3 indicate possible variations in the drainage of 10 and 13 , whose ducts may be tributary to that of the submaxillary or acquire independent orifices.

case from the lateral wall. Its direction is not stated, and it is mentioned in connection with the lesser sublingual glands; its identity with the mesally directed plugs is more than questionable. Of the subsequent history of this element nothing is known. Its presence is not recorded in Bujard's careful study of his 5 centimeter embryo. That these sprouts represent the apical gland is only a conjecture, and even the identity of the postfrenular plug with the mesal gland of the lingual region lacks proof, although the resemblance of this to the other flanges at 20 millimeters, is so striking as to suggest with much probability the cranial shifting of its attachment in an analogous manner.

The lesser sublingual glands appear first in association with an epithelial crest (Chievitz), which is indented by a sulcus (circumflex) at 
its attachment and is continuous distad with the alveolar sulcus, the cranial segment of which it seems to replace. The glands sprout from this crest at intervals, the most cranial being first established. At a later period they lose their association with the crest, and additional ones are formed diffusely from the epithelium of the plica sublingualis and the floor of the alveolingual gutter (Chievitz, Hammar, Bujard). These glands then appear rather as diffuse products of the alveolingual gutter, than as peculiar derivatives of the alveolar sulcus which forms its lateral limit. The early appearance of some of the glands in association with a crest and furrow merely indicates that in some way a sulcal position favors the development of glands, and that those elements of the series which abut upon the furrow are accelerated and antedate their fellows. The late appearance in ontogeny of these simple and phylogenetically ancient elements is noteworthy:

In the embryo of 20 millimeters between the intermediate sulcus and the lingual sulcus are a few small thickenings of the epithelium which have disappeared in the embryo of 22 millimeters. These like the lesser sublingual glands seem referable to very primitive conditions. If the diffuse glandular formation obtaining in this region in some amphibians and in some reptiles be had in mind, these simple glands of the mammal will appear as their direct equivalents, while the larger elements may be interpreted as hypertrophied individuals of the same series (Reichel), or, in view of the interruptions observed in their formative crests, it may be preferable to regard them as row's of primitively distinct elements condensed and fused to form the ducts, while their individual tendencies to proliferate are retarded. That they may at times become active in this direction is shown by the late incrustation of some of the ducts with small lobules, for example, the greater sublingual in the cat. At the mesal border of the primitive gland field, perhaps in consequence of the presence of the lingual sulcus, the process of condensation attains its maximum, and the line of the submaxillary is established. In the cat, at least, a second line is established lateral to this, which in direction corresponds to the intermediate sulcus of man; from it is derived the greater sublingual gland. With the establishment of these dominant lines the intervening area appears exhausted and produces no glands (cat) or merely abortive rudiments $(\operatorname{man})$. 
The primitive gland field of the alveolingual gutter thus divided by an oblique line falls into a craniolateral and a caudomesal triangle, in which markedly different principles of development are at work. In the lateral area small independent glands develop relatively late in ontogeny, and no higher organization is attained than the temporary association of the earlier sprouts with an epithelial keel. In the mesal triangle the borders become the site of increased and coöperative activity. At their caudal extremities relatively huge sprouts are formed, the submaxillary and greater sublingual (cat). Anlages appear early, grow with great rapidity, and produce relatively enormous secretory surfaces. In the cranial portion kecls are formed which supply the ducts, and only late, if at all, give rise to gland sprouts. The ducts are, in the view outlined above, provided by the suppression of individual glands, the price of organization. But it is noteworthy that here, as in the vascular system, the direction of specialization has been to manufacture a smaller number of highly efficient organs, by the selection of few and the suppression of many similar elements.

\section{SUMMARY}

I. The buccal sulcus in man gives rise to two constant derivatives, the orbital inclusion and the parotid. There is some evidence to show that an intermediate elenent may at times be formed, the orbitoparotid.

2. The orbital inclusion is a column of epithelium derived from the caudal portion of the sulcus by a process of folding and constriction, and comes thereafter to lie in the mesenchyme on the ental surface of the masseter and internal pterygoid muscles. Exceptionally it is continuous with the parotid at the border of the masseter (Chievitz).

3. From the lingual sulcus and a flange derived from its compression arise the submaxillary and the greater sublingual (Bartholinian) glands, and a mesal element which may prove to be the apical gland (Nuhn-Blandin).

4. The lesser sublingual glands (Rivinian) are diffuse glands of the alveolingual region, some of which are at their first appearance associated with the sulcus at the lateral margin of the plica sublingualis 
(Chievitz, Bujard), but later they arise from the surface of this fold and the floor of the alveolingual region (Chievitz, Hammar, Bujard).

5. The massa sublingualis is a topographical aggregate of a number of distinct glands in a common connective tissue investment as is clearly shown by the plurality of its ducts as well as by its developmental history. Three components participate in its formation: the greater sublingual (Bartholinian) gland, the lesser sublingual (Rivinian) glands, and supramylohyoid lobules of the submaxillary. Of these the lesser sublinguals alone are constant.

6. The parotid and submaxillary agree in mode of formation (Hammar). In both a flange is formed; in both proliferation occurs at its free angle and margin; in both the duct is carried craniad beyond the limits of the fold, by an advance of the proliferation along the oral epithelium; in both the duct is freed by a solution of continuity in the flange. In this process remnants of the flange may remain attached to the cluct or to the oral epithelium; these may serve as starting-points for sprouts, the dorsal submaxillary and secondary submaxillary respectively in the one case, the orbitoparotid in the other.

7. The greater sublingual gland arises from the flange of the submaxillary. It forms a crest of proliferation, its orifice is shifted craniad by the advance of the crest, and the duct is freed by constriction. The apical gland has probably a like history.

\section{BIBLIOGRAPHY}

BUJARD, EUg. IgIr. Réconstruction plastique des glandes salivaires d'un fœetus humaine de ro semaines environ. Inat. Anzeiger, Bd. $38,4,5$.

Chinevitz, J. H. I885. Beiträge zur Entwickelungsgeschichte der Speicheldruisen. Arkh. f. Anat. u. Physiol., A mat. Abt.

Goeppert, E. 1902. Die Entwickelung des Mlundes unrl der Mundhöhle mit Drüsen und Zunge. Hertwig's Handbuch der Enhwickehngsgesch., Bd. 2, Th. I.

Hamis, J. August. roor. Notiz über der Entwickelung der Zunge und der Mundspeicheldrüsen beim Menschen. Anat. Anzeiger, Bd. I9.

His, IV. I 885 . Anatomie menschlicher Embryonen. 'Th. 3. Leipzig.

Illing, G. I004. Vergleichende Makroskopische und Mikroskopische Untersuchungen über die Submaxillaren Speicheldrüsen der Haussäugetiere. Inatomische IIeftc. Bd. 26, Heft 2, 3 . 
Kölliker, A. I88ł. Grundriss der Entwickelungsgeschichte des Menschen und der höheren Thiere. Leipzig.

Paulet, J. L. igir. Kopf und Bucconasale Bildungen eines Menschlichen Embryo von 14.7 Scheitelsteisslänge. Arch. für Mikroskop. Anat. u. Entwickd, Bd. LXXVI, Heft 3 .

Sudler, Miervin T. I902. The development of the nose and of the pharynx and its derivatives in man. Am. Jour. Anat., Vol. I.

Weisiaupt, Eliz. igri. Ein rudimentärer Seitengang des Ductus Parotideus (Ramus mandibularis ductus parotidei) Beitrag zur vergleichenden Entwickelungsgeschichte der Mundspeicheldrüsen. Arch. f. Anat. und Physiol. Anat. Ibt., Heft I and 2.

Zunstein, J. J. I89I. Ueber die Unterkieferdrüsen einiger Säuger. Habilitationschrift. Marburg.

\section{PART II}

ANNOTATION OF LEADERS IN ALL FIGURES

I. Buccal sulcus.

2. Parotid anlage.

3. Orbital inclusion.

4. Orbitoparotid interval.

5. P'roparotid crest.

6. Proparotid ridge.

7. Thickening of the epithelium of the buccal sulcus near the angulus oris.

S. Lingual sulcus.

g. Submaxillary anlage.

Io. Greater sublingual anlage.

11. Anlage of apical gland.

12. Dorsal accessory submaxillary.

I3. Postglandular flange.

14. Alveolar sulcus.

15. Anlages of lesser sublingual glands.

16. Intermediate sulcus.

I7. Tongue.

$I S$. Sublingua.

I9. Plica fimbriata.

20. Alveolingual region.

21. Meckel's cartilage.

22. Frenulum.

23. Aveolingual region.

27. Ingulus oris.

25. Palate process. 
26. Septum nasi.

27. Nasal fossa.

28. Superior dental anlage.

20. Inferior dental anlage.

30. Lingual nerve.

31. Submaxillary ganglion.

32. Hypoglossal nerve.

33. Buccal nerve.

31. Ectopalatine sulcus.

35. Accessory ectopalatine sulcus.

36. First entodermal pouch.

37. Hypophysis (stalk).

38. Orbitoparotid.

39. Circumflex sulcus.

40. Epithelial thickening between the intermediate and lingual sulci. $4 I$. Submaxillary mesenchymal condensation. 


\section{PLATE XI}

FIG. 2. Transverse frontal section of the buccal sulcus in a 7.5 millimeter human embryo near the angulus oris. Columbia Collection, No. 220, slide 4 , row 4 . section $S, \times 18_{7}$, reduced $\frac{1}{2}$

Fig. 3. Same embryo, slide 4, row 4 section 2. More caudal section of buccal sulcus.

Fig. +. Reconstruction of the oral epithelium of it 20 millimeter human embryo. Columbia Collection, No. $325, \times 60$, reduced $\frac{1}{2}$. Vintral view.

I. Buccal sulcus.

2. Parotid anlage.

3. Orbital inclusion.

4. Orloiforarotid interval.

6. Proparoticl riclge.

7. Thickening of the epithelium of the buccal sulcus near the angulus oris.

8. Lingual sulcus.

9. Suhmaxillary anlage

10. Greater sublingual anlage.

11. Anlige of apical gland.

If. Mreolar sulcus

I6. Intermediate sulcus.

22. Frenulum.

24. Angulus oris.

20. Inferior dental anlage. 
PLATE XI.

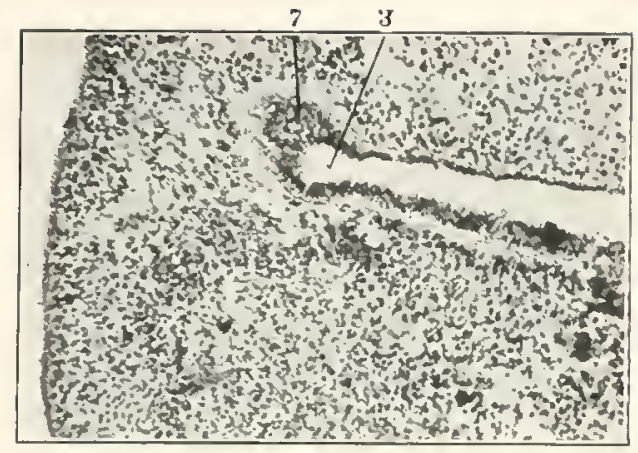

Fili. 2.

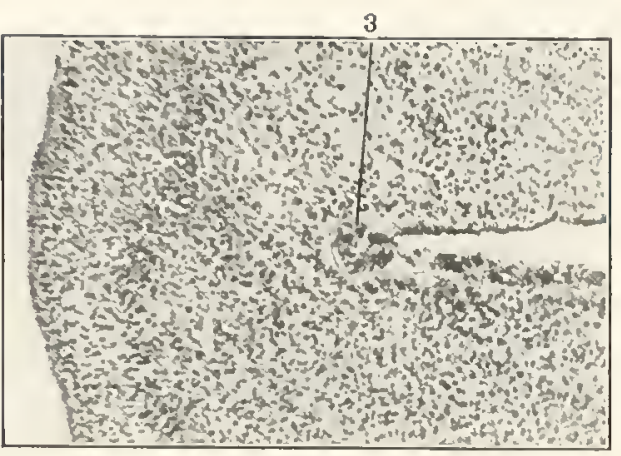

FIG. 3.

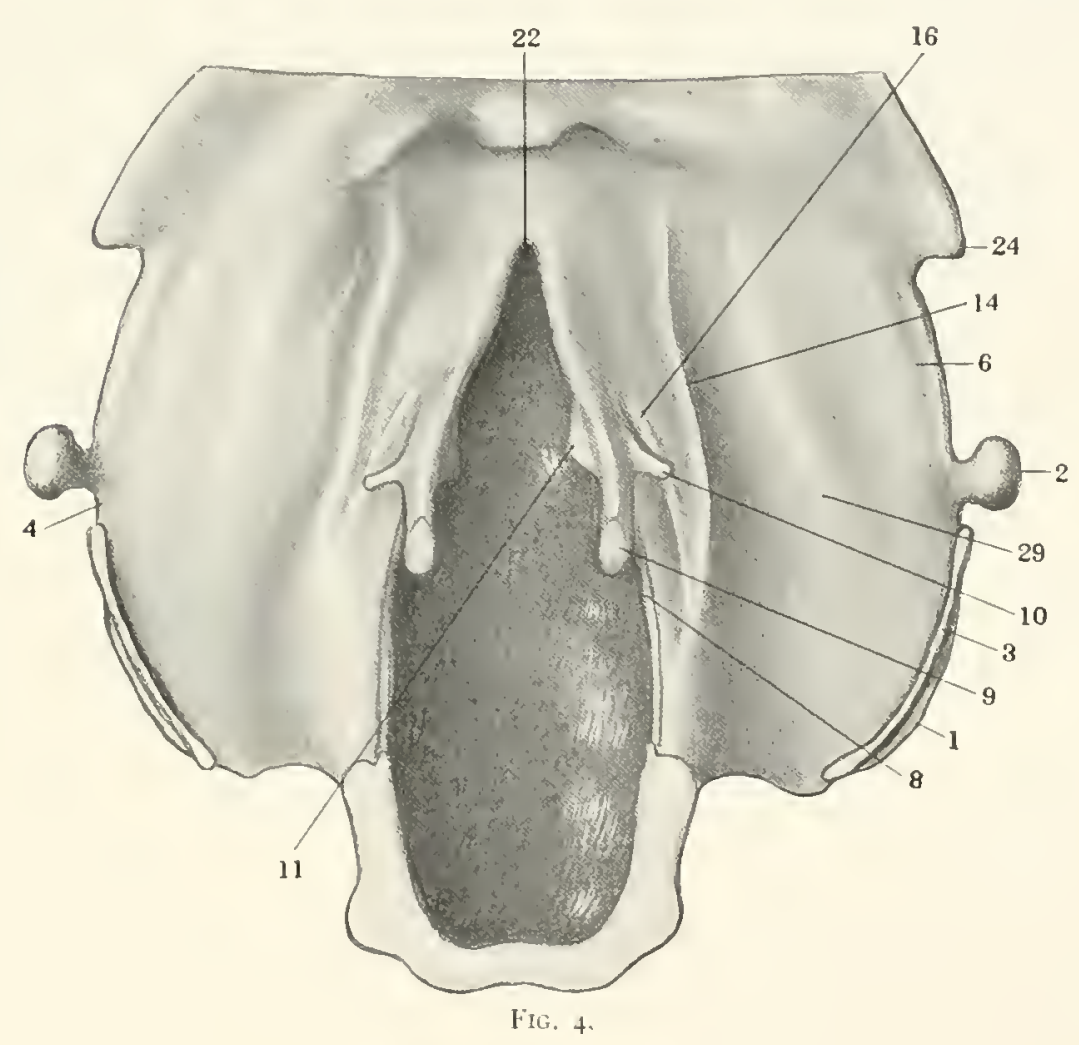


Plate XII

FIG. 5. Reconstruction of oral epithelium of a 20 nillimeter embryo. Columbia Collection, No. $325, \times 60$, reduced $\frac{1}{2}$. Lateral view.

r. Buccal sulcus.

2. Farotid anlage.

3. Orbital inclusion.

9. Submaxillary anlage.

If. Alveolar sulcus.

27. Angulus oris.

27. Nasal fossa.

28. Superior dental anlage.

36. First entodermal pouch.

37. Hypophysis (stalk). 
PLATE XII.

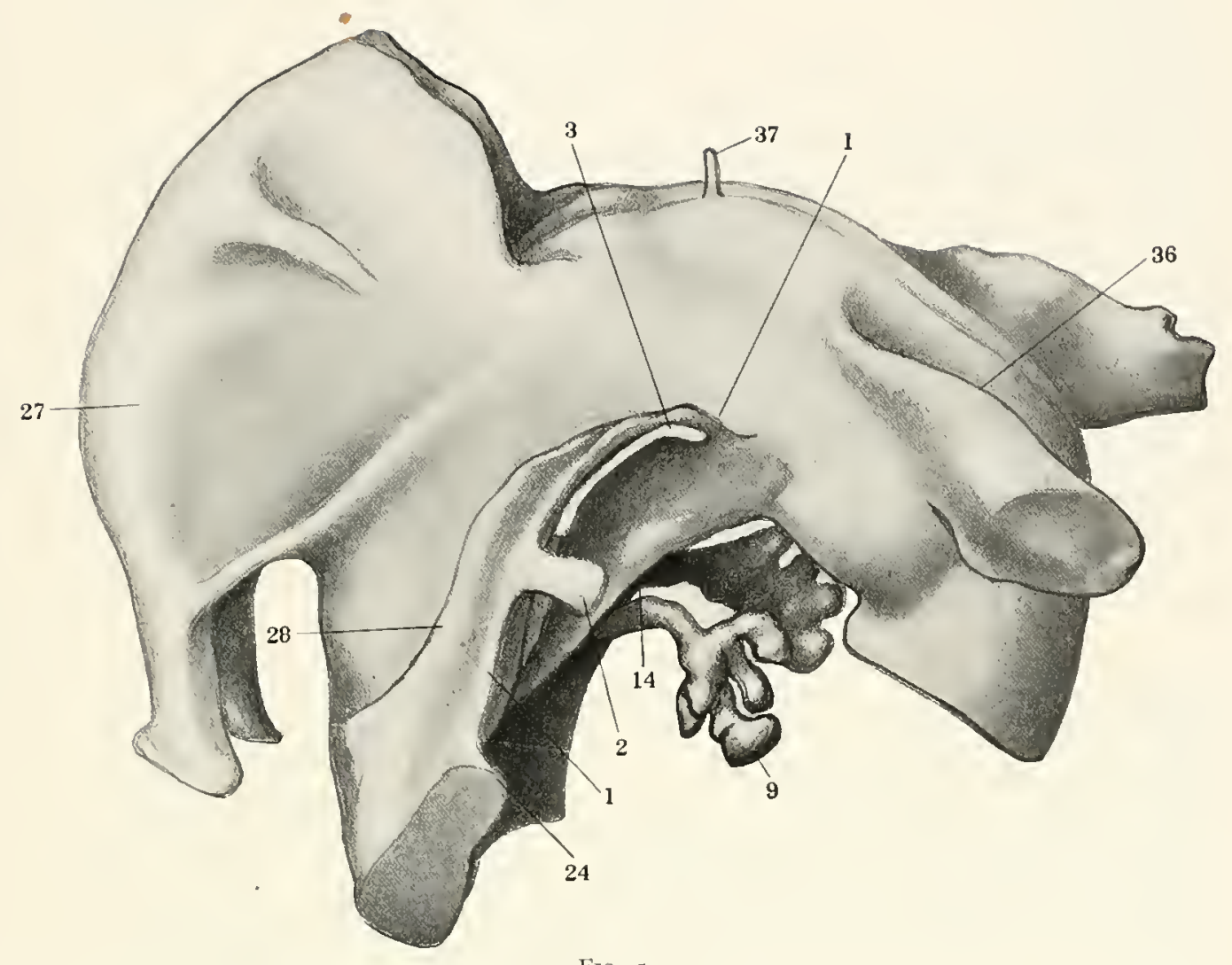

FIG. 5. 
FIGS. 6 to Io. Transverse frontal sections of a 20 millimeter embryo. Columbia Collection, No. 325, X So, reduced $\frac{1}{2}$. For levels of sections see Fig. 20.

Fig. 6. Series No. 325, slicte 17, row, 3, section S.

FIG. 7 . Series No. 325 , slide 17 , row 2 , section 2.

I. Buccal sulcus.

6. Proparotiel riclge.

8. Lingual sulcus.

g. Submaxillary anlage.

10. Greater sublingual anlage.

1f. Nveular sulcus.

16. Intermediate sulcus.

17. Tongue.

18. Sublingua

19. I'lica fimbriata.

2L. Meckel's cortiliage.

25. Superior dental anlage.

20. Inferior dental anlage.

fo. Epithelial thickening between the intermediate and lingual sulci. 


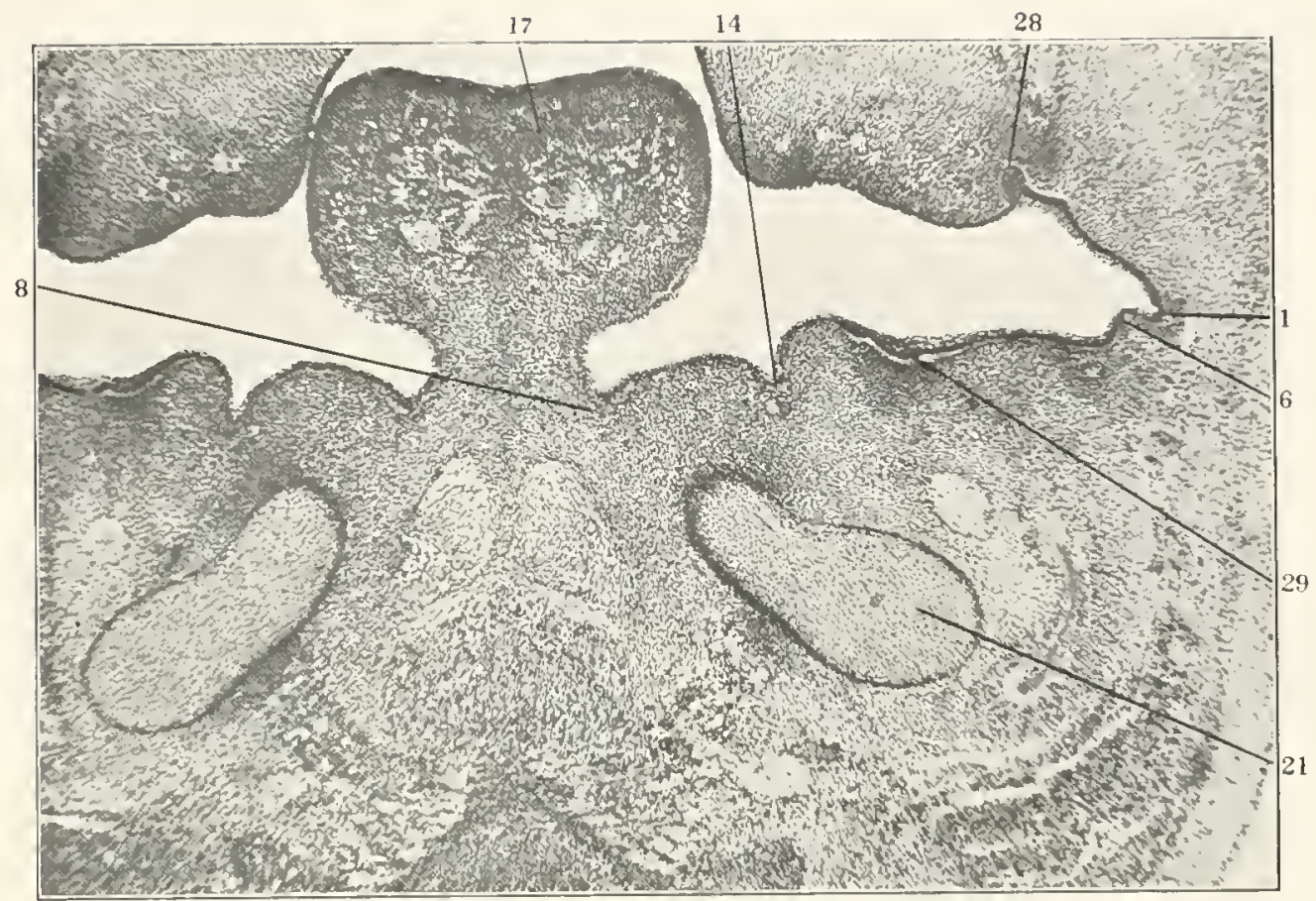

[ifc. 0

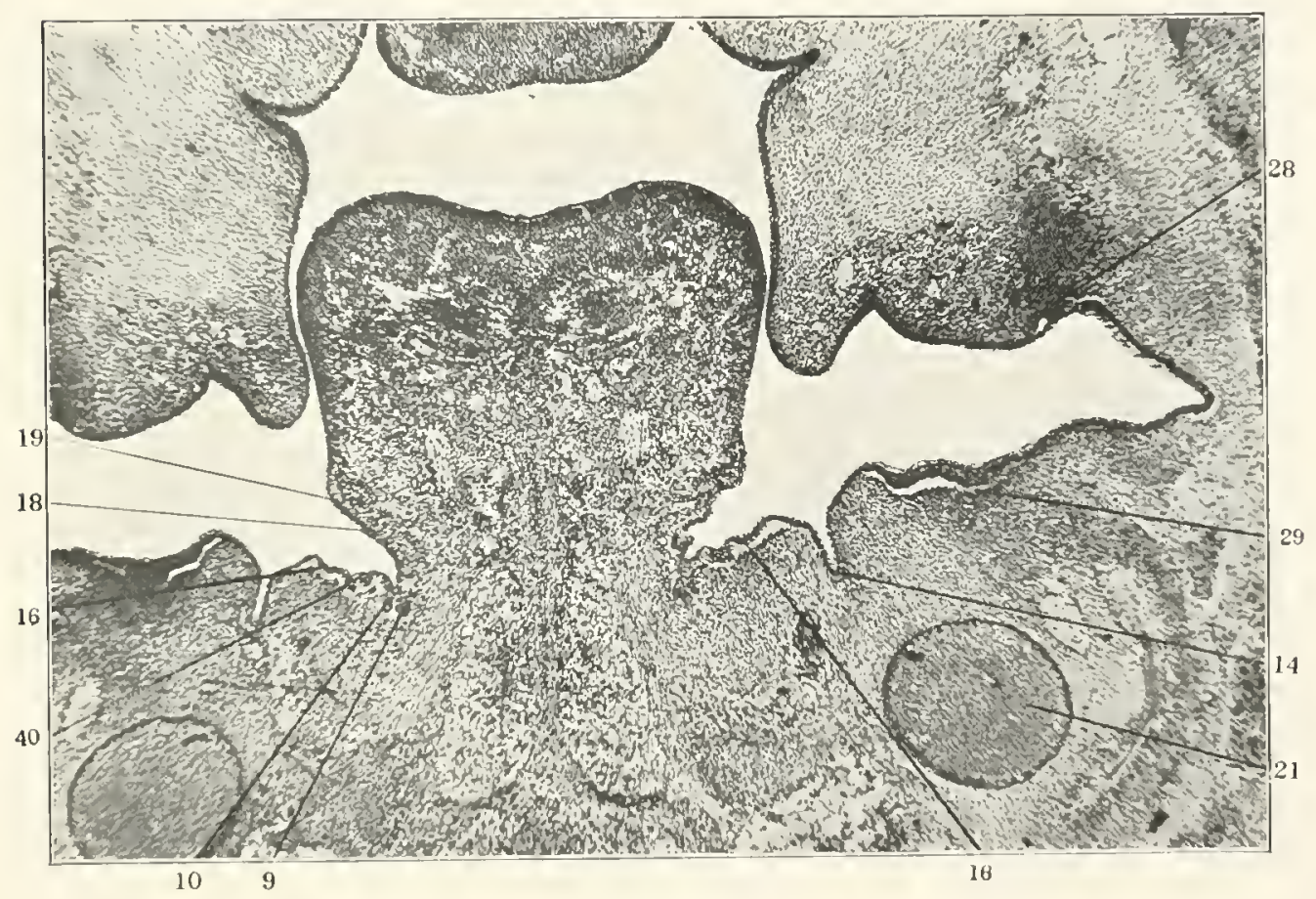

Hig. 7 . 


\section{Plate MIV}

FIG. S. Series 325 , slide 17 , row 1 , section $6, \times$ So, reduced $\frac{1}{2}$.

Fig. 9. Series 325 . slide 17 , row 1 , section $5, \times$ So, reduced $\frac{1}{2}$.

FIG. I0. Series 325 , slide 17 , row 1 , section $4, \times$ So, reduced $\frac{1}{2}$.

Fig. I I. Series 325 , slide 17 , row 1 , section $3, \times$ So, reduced $\frac{1}{2}$. 
PLATE XIV.

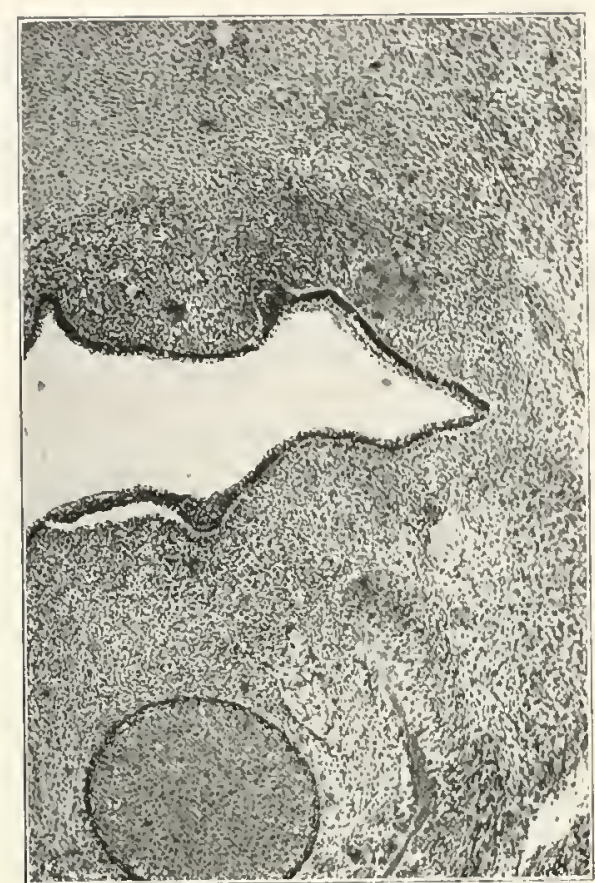

FIG. 8.

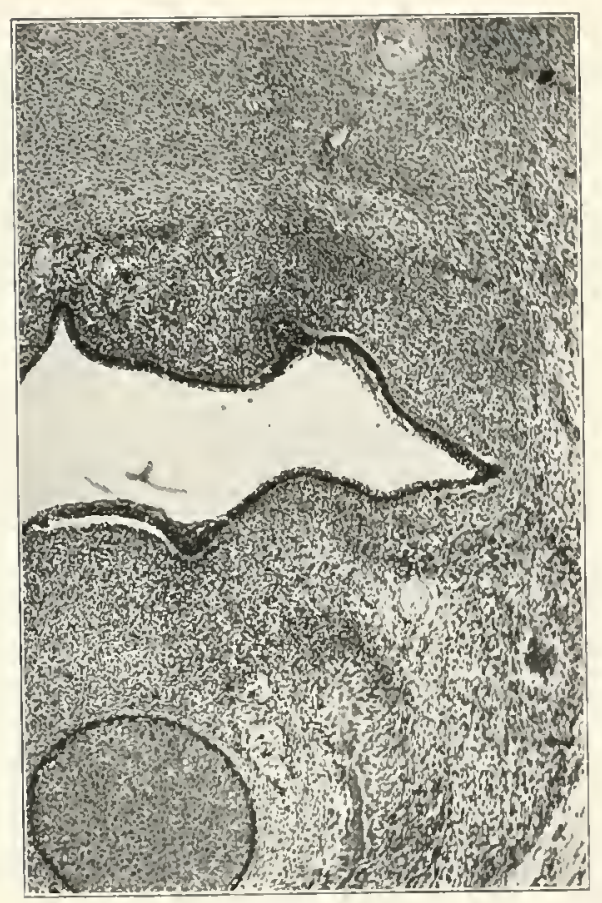

FIG. IO.

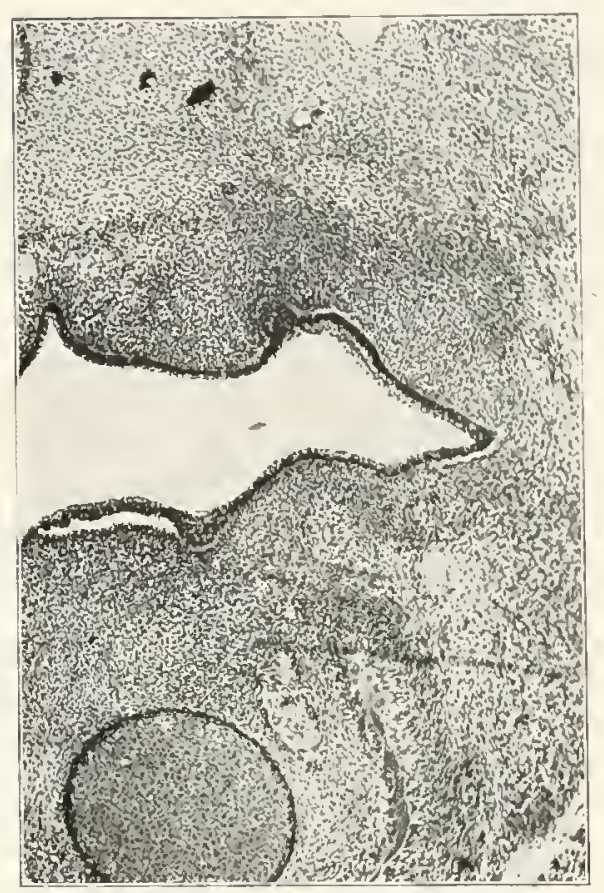

FIG. 9.

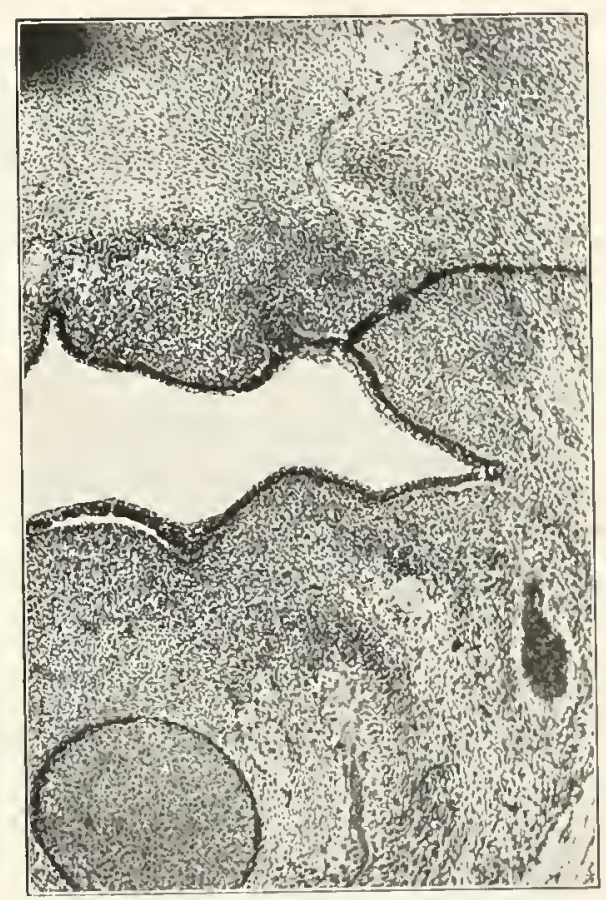

FIG. II. 


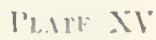

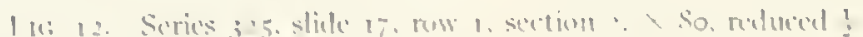

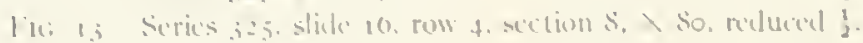

$\therefore$ Parotiel amlige

; l'ropirotial crest.

0. Submuxill.ury . mblikre.

(1). tirester sublingual anlage.

11. Intage at apicil glamel.

1.3. Pontglumblatar Hange.

$\therefore$. Mrithel's cirtiluge

-). Suprerer atental anlige

su. Inlerier dental anlage.

iv. Lingual merve

$\therefore$ Ilypughesul nerse.

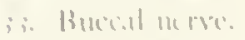

if linkpolation sulius. 

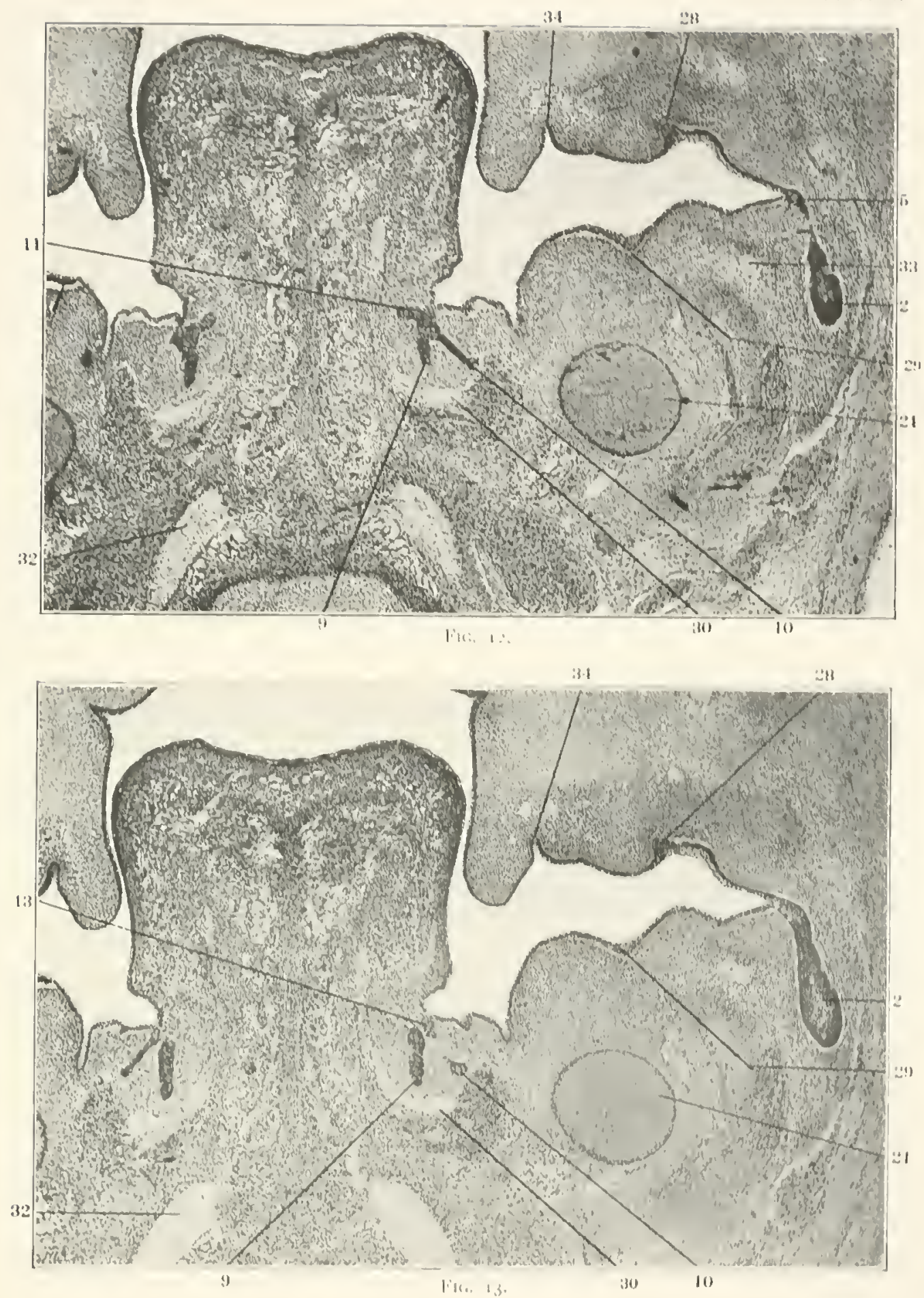


\section{Plate Xit}

FIG. I4. Series 325 , slide I6. row + , section $7, \times$ So, reduced $\frac{1}{2}$.

Fig. 15. Series 325 , slide 16 , rum 4 , section 0 , $x$ so, reduced $\frac{1}{2}$.

2. Parotil anlage.

10. Greater sublingual anlage.

I 3. Postglan Iular flange.

14. Niveular sulcus.

I6. Intermediate sulcus.

21. Meckel's cartilage.

2.S. Superior dental anlage.

31. Lingual nerve.

32. Ilypoglossal nerve.

37. Ectopalatine sulcus.

3R. Orbitoparotid 
PLATE XVI.
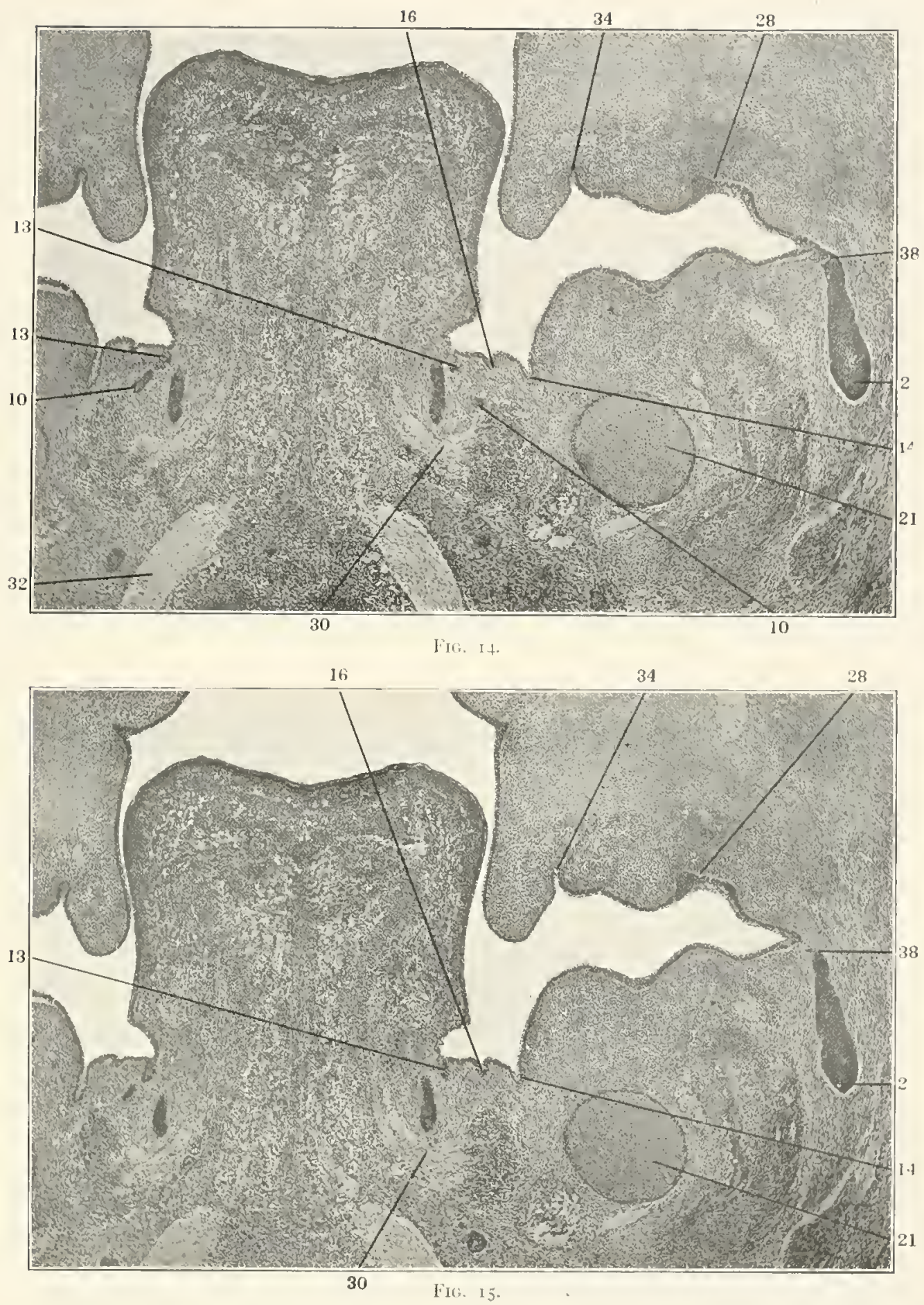
FIG, I6. Series 325 , slide 16 , row 4 , section $3, \times$ so, reduced $\frac{1}{2}$.

FIG. 17 . Series 325 , slide 16 , row 3 , section $6, \times$ So, reduced $\frac{1}{2}$.

I. Buccal sulcus.

3. Orbital inclusion.

I2. Dorsal accessory submaxillary.

53. Postglandular flange.

17 Alveolar sulctis.

I0. Intermediate sulcus.

21. Neckel's cartilage.

28. Superior dental anlage.

3i). Lingual nerve.

3I. Submaxillary ganglion.

32. Hypoglossal nerve.

33. Buccal nerve.

37. Ectopalatine sulcus.

35. Accessory ectopalatine sulcus.

7I. Submaxillary mesenchymal condensation. 

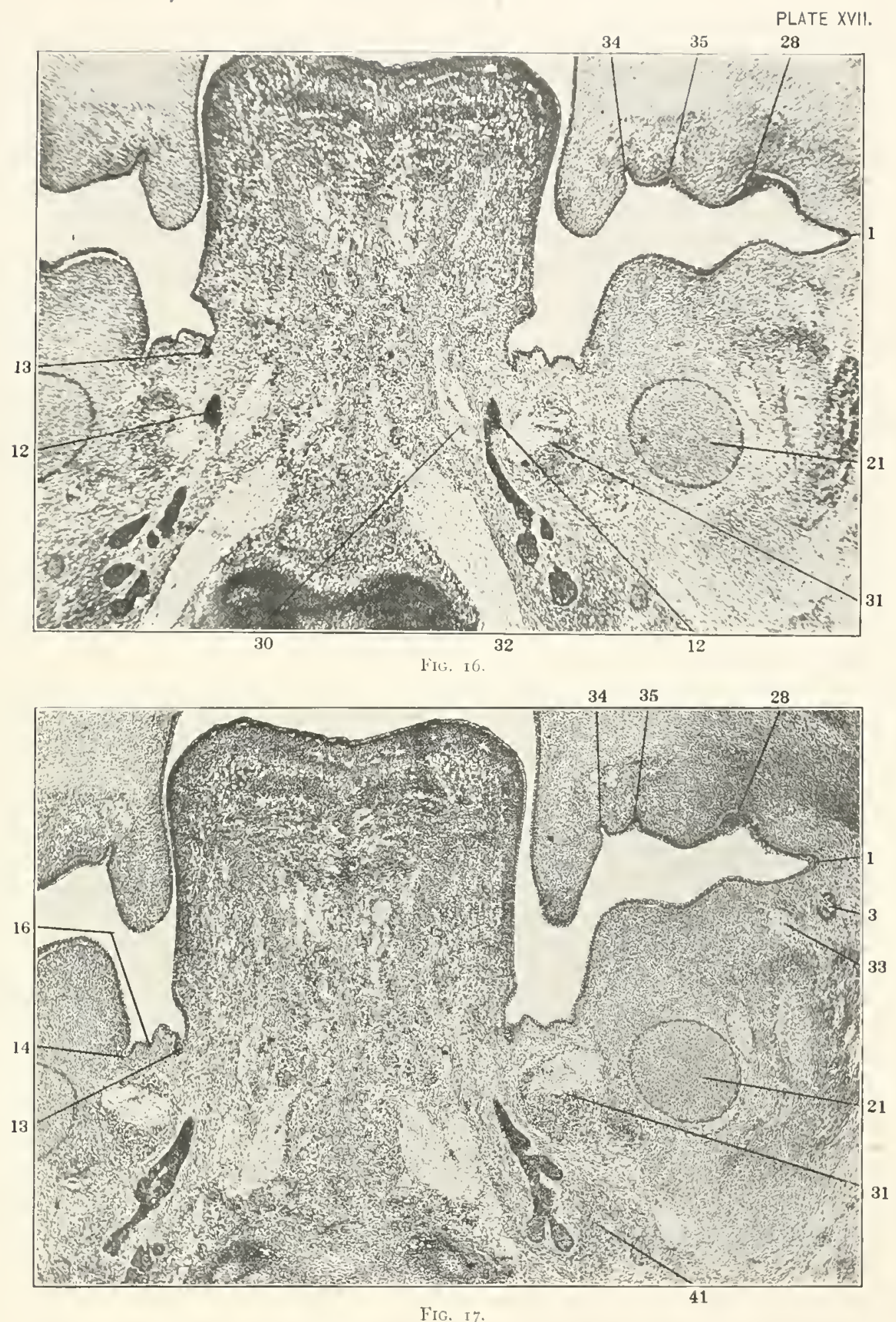
Plate XIIII

FIg. IS. Series 325 , slide I6, row 2 , section $8, \times$ So, reduced $\frac{1}{2}$.

FIg. 19. Series 325, slide I 5, row 3 , section $8, \times$ So, reduced $\frac{1}{2}$.

I. Buccal sulcus.

3. Orbital inclusion

8. Lingual sulcus.

It. Nveolar sulcus.

I6. Intermediate sulcus

21. Meckel's cirtilage.

3.9. Simerior dental anlage.

30. Lingual nerve.

32. Hypoglossal nerve

33. Buccal nerve.

37. Hetomalatine sulcus

35. Iccessury ectopralatine sulcus. 
PLATE XVIII.

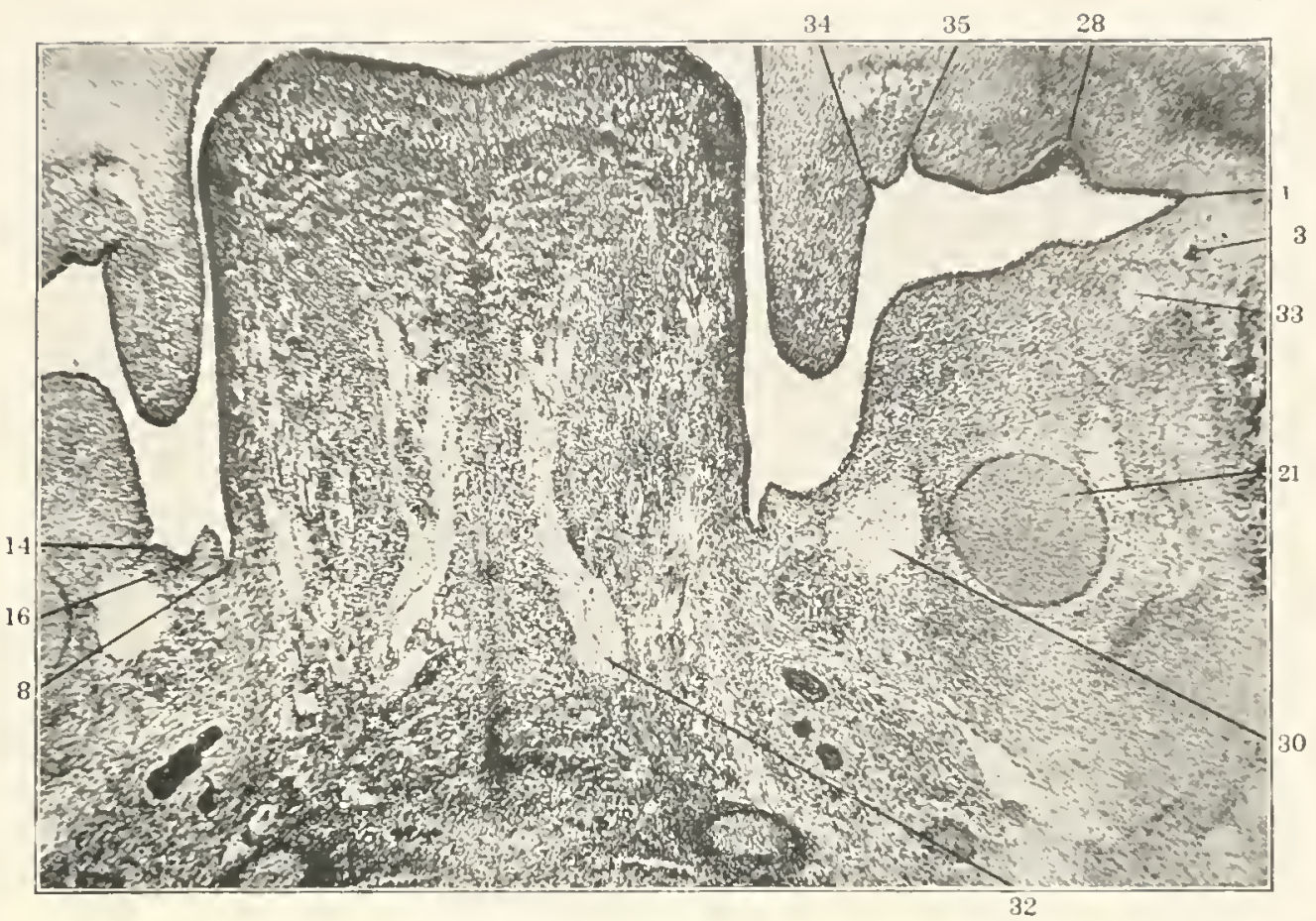

Fig. IS.

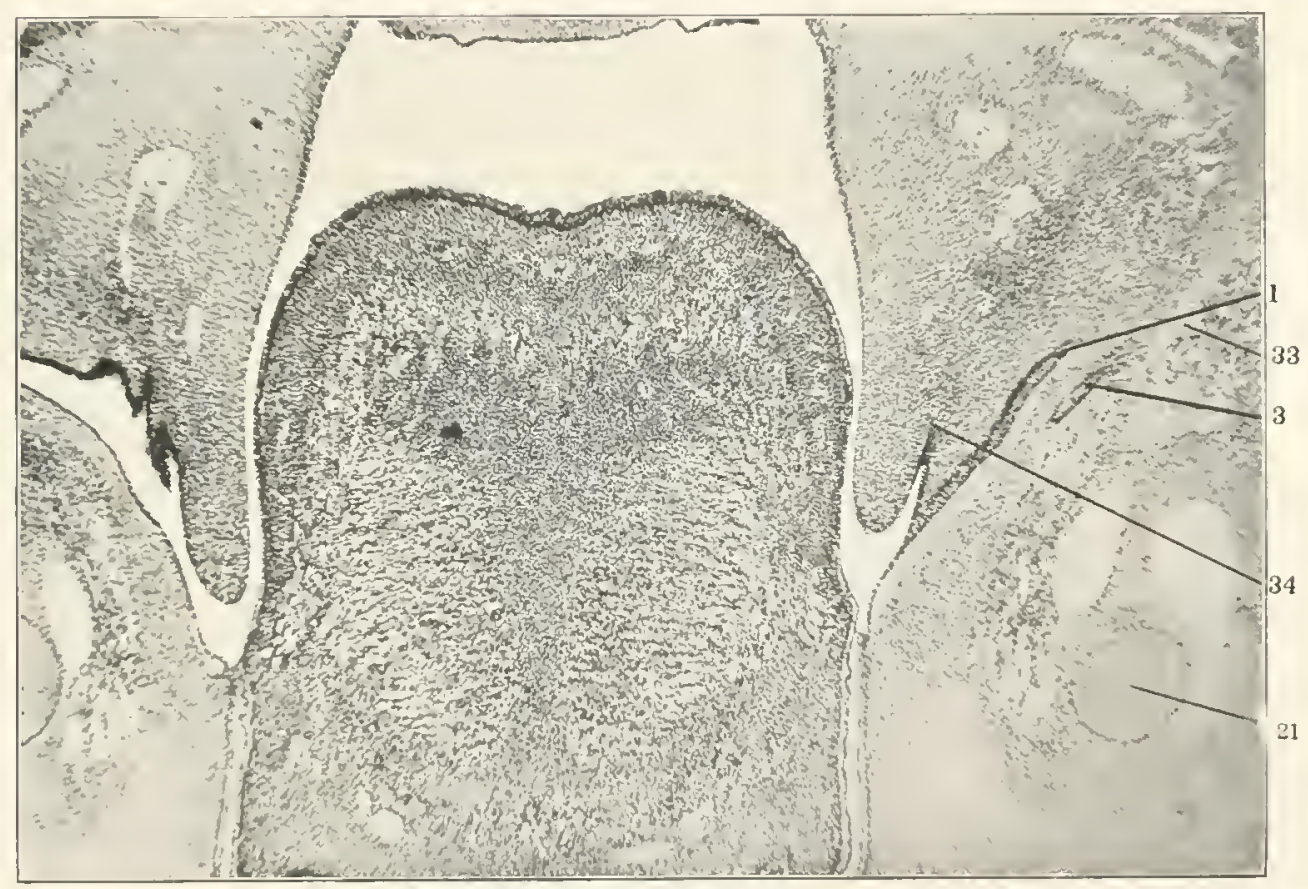

Fig. 19. 


\section{Plate XIS}

FIG. 20. Schematic outline of reconstruction of 20 millimeter embryo. Columbia Collection, No. 325 , to show levels of foregoing sections.

Fig. 2I. Reconstruction of the alveolingual region of a human embryo of 22 millimeters. Columbia Collection, No, $3, x_{5} \circ$, reduced $\frac{1}{2}$. Left side, rentral view.

S. Lingual sulcus.

g. Sulmaxillary anlage.

IO. Cireater sublingual anlage.

II. Inlage of apical gland.

12. Dorsal accessory submaxillary.

15. Anlages of lesser sublingual glands.

39. Circumtlex sulcus. 
PLATE XIX.

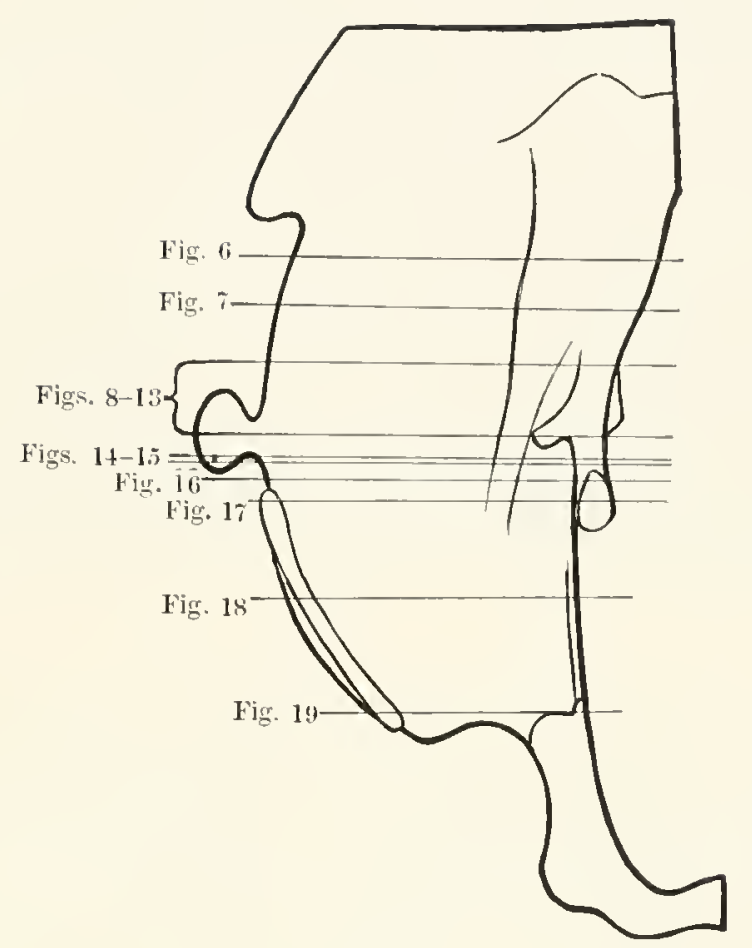

FIG. 20.

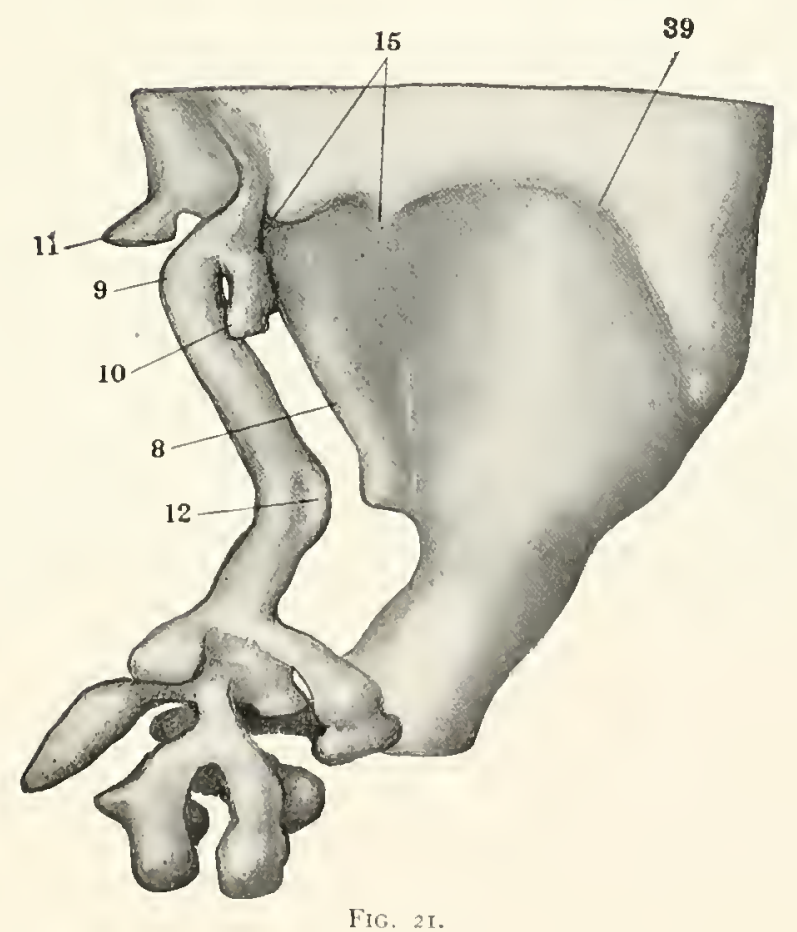




\section{P'LATE XX}

Fic. 22. Transverse frontal section of a human embrro of 22 millimeters, Columbia Collection, No. 3, near the frenulum lingure, $X$ i 57 , reduced $\frac{1}{2}$. Slide 3, row 2, section 15 .

Fig. 23. The same embryo, slide 3 , row 2 , section $12, \times 157$, reduced $\frac{1}{2}$. Section passes through the junction of the greater sublingual anlage and the submaxillary duct.

Fig. 24. The same embryo, slide 3, row I, section 10, X I57, reduced $\frac{1}{2}$. Section passes through the clorsal accessory submaxillary.

I. Buccal sulcus.

8. Lingual sulcus.

9. Submaxillary duct.

10. Greater sublingual anlage.

11. Inlage of apical glimel.

14. . Iveolar sulcus

16. Intermediate sulcus.

19. Plica fimbriata.

2.3. Aveolingual region.

25. Palate process.

3.). Lingual nerve,

37. Submaxillary ganglion.

3\%. Ectopalatine sulcus. 
PLATE XX.

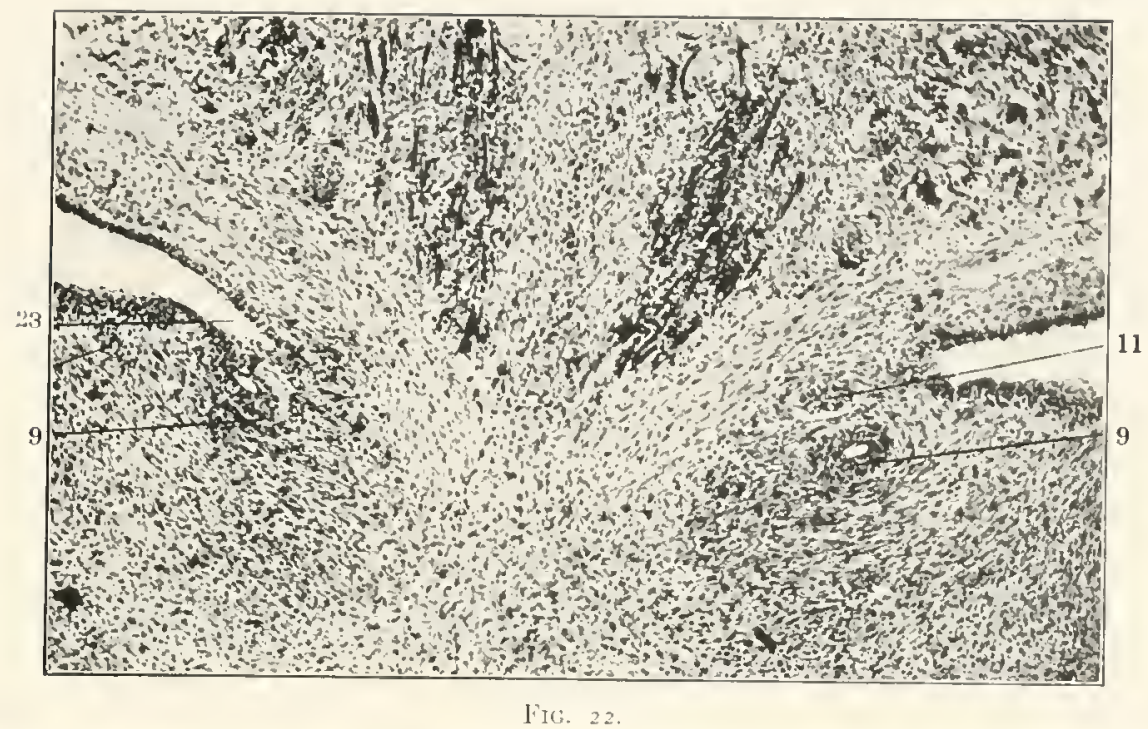

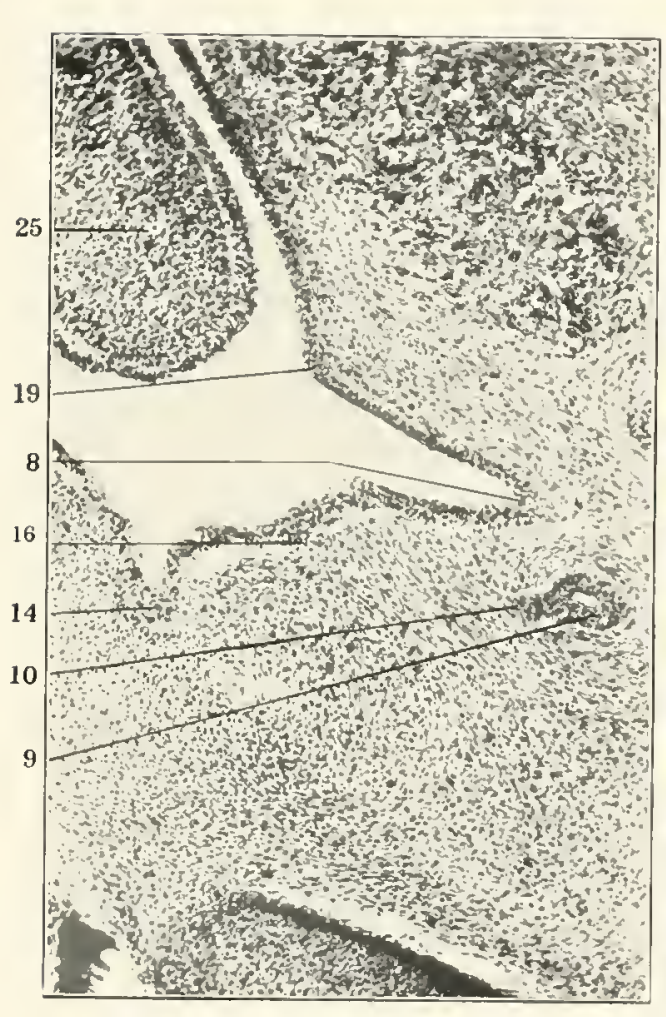

FIG. 23.

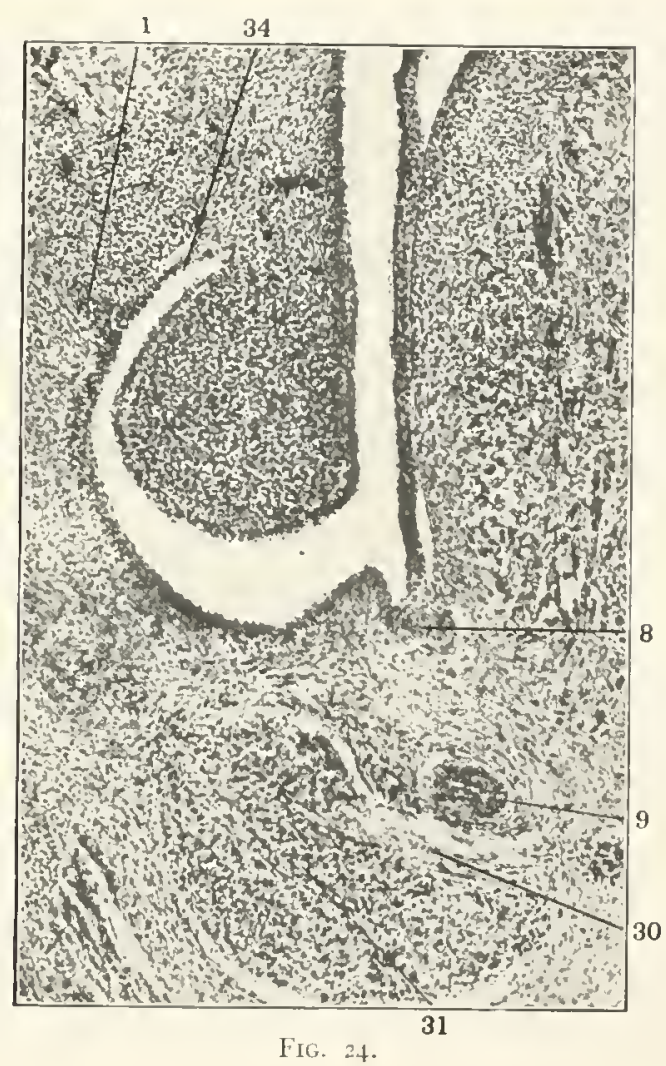

FIG. 24. 



\title{
PART III
}

\section{THE MACROSCOPIC ANATOMY OF THE SALIVARY GLANDS IN THE LOWER PRIMATES}

\author{
By Geo. S. Huntington
}

\section{List of Material}

THE following genera and species were examined, in the majority of cases several specimens of each being used:

Troglodytes niger

Simia satyrus

Cynocephalus hamadryas

Cynocephalus sphinx

Cynocephalus babouin

Cynocephalus papio

Cynocephalus mormon

Macacus rhesus

Macacus nemestrinus

Macacus pileatus

Macacus speciosus

Macacus cynomolgus

Cercopithecus callithrix

Cercopithecus niger

Cynopithecus niger

Semnopithecus entellus
Cercocebus fuliginosus

Cercocebus collaris

Chlorocebus rufo-viridis

Nyctipithecus trivirgatus

Cebus capucinus

Cebus hypoleucus

Ateles ater

Ateles hybridus

Ateles sp. ?

Lagothrix humboldtii

Mycetes seniculus

Mycetes rufus

Hapale jacchus

Hapale pencillata

Lemur varius

Lemur mongoz

Nycticebus tardigradus

The glands, with the exception of the alveolingual mass, were injected through the duct orifices with a 20 per cent solution of glycerine gelatine, colored with moist water-colors in tubes, and filtered before using, with the addition of $\frac{1}{10}$ per cent saturated solution of iodide of potash to delay the hardening of the gelatine. 
The alveolingual region was exposed by resection of one-half of the mandible on one side, the other side being used for the topographical demonstration with intact mandible. The following preparations have been selected from this material for description and illustration in the present communication. They are all contained in the Morphological Museum of Columbia University, with the exception of the preparation of Lemur mongez (Fig. I3), which is No. I48z of the Princeton Morphological Museum.

I have, naturally, in common with previous investigators, encountered the difficulty of adjusting results to the current nomenclature which the submandibular group of the salivary glands has inherited from anthropotomy. Ranvier, Maximow, and Illing complain justly of the insufficiency of existing definitions of mammalian salivary components in this region, and of the inaccuracies of the attempted homologies. This question will again be discussed after dealing with the comparative anatomical data here recorded. In the preliminary descriptive portion of this communication we deal with the unmistakable parotid gland of the lower primates, and with the glandular complex of the sub- and intermandibular regions. For descriptive purposes, and on grounds to be subsequently defined in detail, the following terminology has been adopted:

\section{PAROTID Group}

\section{MAIN PAROTID GLAND AND DUCT (STENSON'S DUCT) 2. ACCESSORY PAROTID GLAYD (SOCIA PAROTIDIS)}

A glandular mass, distinct from the main parotid and opening by a separate duct, or by several ducts, into the parotid canal.

This component may be situated at any point between the frce ceplalic border of the main gland and the engagement of the duct in the buccinator muscle. In the latter case close topographical relations are established between it and the members of the next succeeding group of the orbital glands, or elements developing as distinct glands in the orbitoparoticl interval (cf. infra, Parts II and VI, in Schulte's description of this area in embryos of man and cat). In some instances several accessory parotid glands occur, and the cases in which 
the entire masseteric segment of the parotid duct is glandiferous point to a still higher degree of development of accessory parotid structure.

3. ORBITAL GLANDS AND GLATDS DEVELOPED IN THE ORBITOPAROTID INTERI AL

The obscrvations of these structures are confined to the adult human instances figured and described in Part I (cf. page Io, and Figs. 7,9 and 12 ).

They form a series of discrete small glandular masses, beginning mesal to the termination of the parotid duct and extending thence caudad between the ental aspect of the masseter muscle and the oral mucosa, on whose surface they empty by separate orifices, occupying the area of the carnivore stomal ridge described below by Schulte (cf. Part V).

\section{Sub- and Intermandibular Groups}

I. SUBMAYILLARY GLAND AND DUCT (WIIARTON'S DUCT) AND ASSOCIATED STRUCTURES

(a) Main submaxillary gland. - The large gland situated mesocaudal to the mandibular angle, whose duct reaches the floor of the mouth by turning cephalad around the caudal margin of the mylohyoid muscle.

(b) Accessory submaxillary gland or glands. - The term is here applied to single or multiple smaller glands, distinct from the chief submaxillary gland, developed along the course of Wharton's duct and emptying into the same by small separate canals.

These elements may be situated above or below the main submaxillary duct and are hence capable of being further distinguished as either dorsal or ventral accessory submaxillary glands. The so-called "supramylohyoid portion" of the adult human submaxillary complex belongs to this group.

(c) Secondary submarillary gland. - This element is tentatively distinguished from the remaining submaxillary components as a gland located in the interval between the lingual nerve and the supra-mylohyoid accessory submaxillary elements, and possessing a separate duct 
which advances along the dorsmedial aspect of the main submaxillary duct and, after a longer or shorter independent course, unites with the same before the plica sublingualis is reached.

This gland and duct is of considerable importance on account of the close topographical resemblance to the retrolingual gland described by Ranvier in the lower mammalia, in those forms in which the retrolingual and submaxillary ducts unite prior to reaching a common orifice on the plica sublingualis (cf. infra, page 9r).

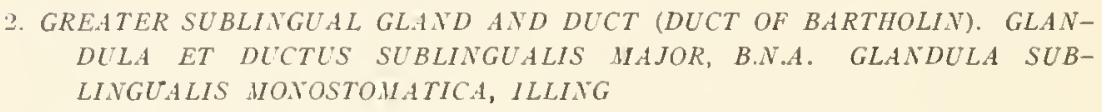

These terms denote the inconstant component of the intermandibular complex which appears in certain forms as a distinct gland, intermediate between the submaxillary duct with its adnexa and the lateral group of the lesser sublingual glands, and whose duct either unites with the terminal of the submaxillary duct or else opens on the plica sublingualis by a separate orifice caudolateral to the submaxillary opening.

\section{LESSER SUBLINGUAL GROUP}

(a) Lesser sublingual glands and ducts proper (ducts of Rivini) situated in the lateral clivision of the alveolingual field:

(Glandula et) ductus sublinguales minores, B.N.A.

Glandula sublingualis polystomatica, Illing.

Glandulce alveololinguales, Chievitz.

The term alveololingual glands, first applied by Chievitz to the group of separate salivary glands oecupying the lateral district of the entire area betwcen border of tongue and nandibular alveolus, appears in the modern literature of the salivary glands as the most generally accepted designation of these structures, the somewhat awkward term of "alveololingual" being replaced by the concentration "alveolingual." It has the theoretical disadvantage of selecting one of the three components of the entire alveolingual salivary area and of distinguishing the same by a name properly belonging to the whole region of the oral floor, bounded mesally by the suicus lingualis and laterally by the sulcus alveolaris. This region contains in the adult 
along its medial boundary the submaxillary duct and its occasional associate, the duct of the secondary submaxillary gland; further laterad, as an inconstant intermediate component of the entire intermandibular salivary complex, the greater sublingual (Bartholinian) gland and duct, with either an independent parafrenular orifice, or joined to the terminal of the greater submaxillary duct; lastly, on the lateral border of the entire area, and extending thence in some forms dorsocaudad into the arcus palatinus and the soft palate, the group of the smaller sublingual (Rivinian, or, in Chievitz's sense, "alveololingual") glands with numerous separate orifices along the lateral line of the oral floor.

Logically, perhaps, the collection of lateral separate glands could be defined, within the limits of the alveolingual area, as the "alveolar" group, or, more correctly, as the "median alveolar" group, in contradistinction both to the "lateral alveolar," or so-called "inferior molar" glands of the inferior alvobuccal sulcus, and to the two remaining components of the entire alveolingual field above mentioned. In this case the constant median element would, with its occasional further accessory and secondary derivatives, be genetically referred to the median or lingual sulcus, as the generalized submaxillary line, while the inconstant greater sublingual or Bartholinian gland and duct would appear as an additional development, intermediate between the lateral and medial boundaries of the entire field.

In view, however, of the adoption by the B.N.A. of the term "Ductus sublinguales minores" for the Rivinian series of the lateral glandular orifices, it seems wise to extend the scope of this term to include the glands of these ducts and to define them consequently as the Glandula sublinguales minores or Lesser sublingual glands. This terminology is therefore used in the following, as defining the lateral group of individual isolated glands of the alveolingual area, frequently described as the Rivinian series.

(b) Isthmian glands. - A group of discrete separate glands with individual duct orifices which lie beneath the oral mucosa as the latter turns cephalodorsad into the palatine arch.

In many cases these glands appear in the lower primates in the direct line of the caudal prolongation of the lesser sublingual series, only separated from the latter by the lingual nerve. It often appears as if 
the presence of the nerve in this situation had produced an interruption of an originally continuous glandiferous line, dividing the same into the lesser sublingual group proper (3) and the isthmian elements $\left(3^{\prime}\right)$. This impression is strengthened by the few instances in which the two groups were actually continuous with each other and only somewhat thinned and reduced in number at their point of intersection with the lingual nerve. There seems little doubt that the human structure described

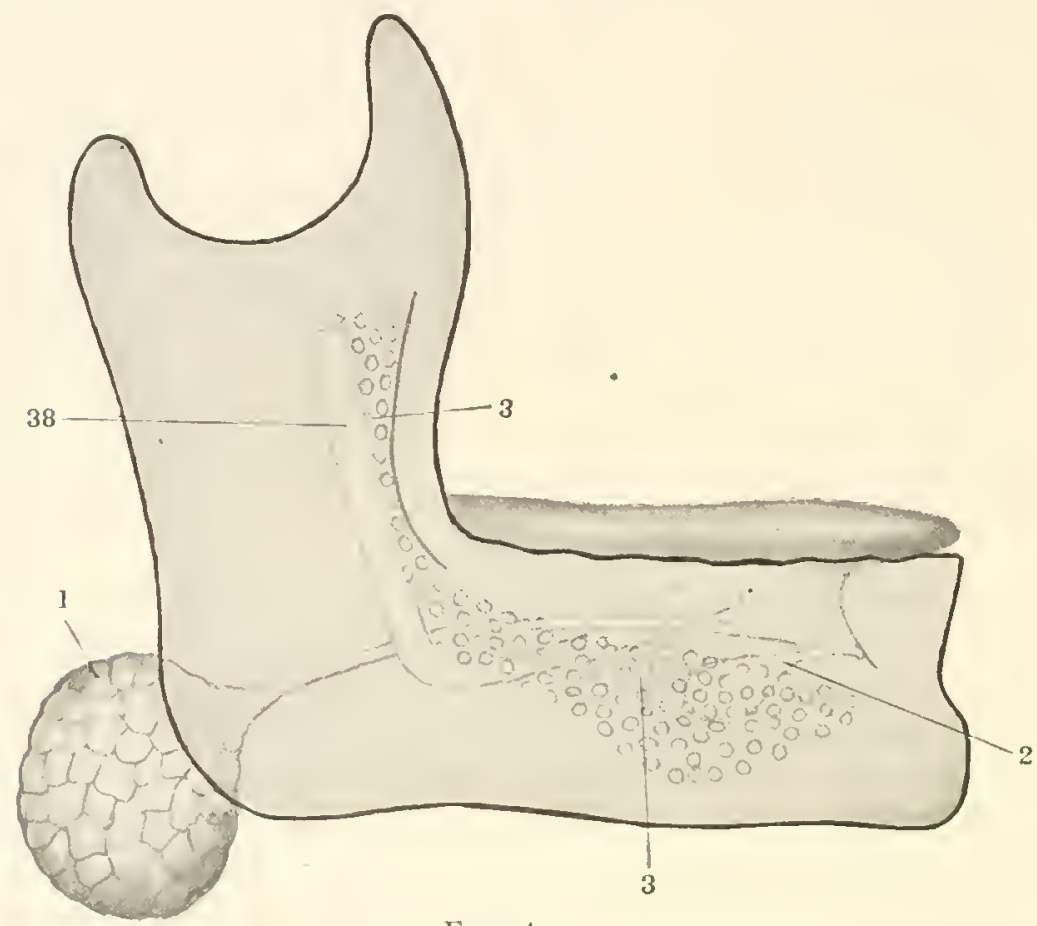

Fig. A.

as the gland of Weber is nothing more than one of the first isthmian elements, encountered just caudal to the lingual nerve and separated by the same from the lesser sublingual group proper.

At the other extremity the isthmian series approaches, and in some instances (Lemurs) merges with, the gland mass of the soft palate.

It is necessary to state clearly in this connection that the above outlined relation of the lingual nerve to the lesser sublingual group of glands is a condition peculiar to primates, which does not obtain in the 
lower mammalian orders. In describing this portion of the primate oral cavity the topographical relation of the lingual nerve to the lateral alveolingual gland field is not used in the sense in which Ranvier, and later Zumstein, employed it in defining a so-called "retrolingual" gland (cf. Schulte, Part VIII).

The close apposition of the primate lingual nerve $(38)$ to the oral mucosa, and its consequent relation to the lateral gland field, appears to depend upon the high vertical index of the primate mandibular ramus.

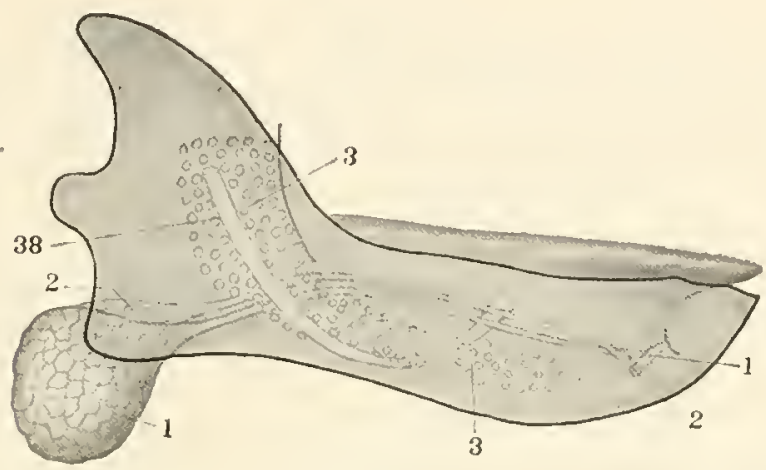

Fig. $B$.

This forces the proximal portion of the lingual nerve into a parallel vertical position and brings the terminal scgment, in approaching the tongue, into close contact with lateral oral mucosa. The difference in the topographical relations of the lingual nerve and of the glands of the atveolingual area may be indicated in the following schema, Fig. $A$ represcnting the primate condition, Fig. $B$ that obtaining in a generalized mammal of the lower orders.

The above is a provisional and tentative terminology, adopted merely for sake of consistency in the description of the adult morphological and topographical conditions encountered in the primate series investigated. A discussion of its bearing on the human sub- and intermandibular complex, and its relation to the genetic problems of the salivary complex of this region, is reserved for a summary based on the individual findings here recorded and on Schulte's ontogenetic analysis of the human, ungulate, and carnivore salivary apparatus. 


\section{A. DESCRIPTION OF THE INDIVIDUAL SPECIES HERE REPORTED}

\section{ANTHROPOIDEA}

I. SMIA SATYRUS, $\delta$

Columbia University Morphological Museum, No. 2I29, Fig. I

\section{A. PAROTID}

The main portion of the gland, nearly quadrangular in shape (5), is composed of small, closely packed lobules, and occupies a submeatal position, covering the masseter, and extending into the retromandibular region over the sternomastoid. In addition to this main gland, and only separated from the same by the masseteric branch of the facial vein, an extensive socia parotidis (6), composed of larger and more loosely connected lobules, envelops Stenson's duct between the point of its emergence from the ventral margin of the main gland and its engagement in the buccinator, so that only the short intramural segment of the duct is free from glandular investment. The associated parotid lobules enter the main parotid canal by a smaller dorsal and larger ventral duct, directed forward towards the intramural segment. There is no retroauricular extension of the main gland.

\section{B. ITTERILAYDIBULAR COMPLEX}

The three typical glands of this region are present and well developed.

(a) Submaxillary gland ( $I$ ). - The gland is simple, consisting of a single oval mass situated entirely below the mylohyoid in the submandibular fossa, deeply grooved on its ental surface by the submaxillary vascular trunks. The hilus occupies nearly the center of the ventromedial surface. Wharton's duct passes as a single canal without lateral derivatives in the classical course to its separate terminal orifice $(I)$ on the plica sublingualis, mesal and cephalal to the remaining glands in the floor of the mouth (Fig. I, $I$ ).

(b) The greater sublingual gland (2). - This gland appears as a welldefined almond-shaped body, lying below and behind the main portion 
of the lesser sublingual mass (3), above the mylohyoid, between it and the musculature of the tongue. The duct ascends obliquely forward, crossing the mesal surface of the lesser sublinguals, and terminates in a separate caruncular orifice (2), lateral and a little caudal to the opening of the main submaxillary duct $(I)$.

(c) The lesser sublingual glands (3) form an elongated mass, beginning with a pointed ventral extremity opposite the genial tubercle and extending caudad nearly to the lingual nerve. This group of scparate individual glands lies on the lateral aspect of the two preceding ducts and intersects their course in a cephalodorsal dircetion at an acute angle. The caudal margin of the lesser sublingual group (3) is slightly notched to accommodate the greater sublingual gland (2) which lies below and belind the main part of the lesser sublingual mass.

\section{TROGLODYTES NIGER, $\delta$}

Columbia University Morphological Museum, No. 729 , Fig. 2

\section{A. PAROTID}

The parotid appears as a firm, clearly defined egg-shaped mass, placed ventrocaudal to the external auditory meatus, with its long diameter nearly vertical and the cephalic pole impinging against the vertical border of the lobule. The gland is surrounded by a welldefined and exceedingly firm fibrous capsule. There is no socia, and the duct runs clear of lateral derivatives to its buccal orifice (5).

\section{B. INTERMANDIBULAR COMPLEX}

(a) The submaxillary gland $(I)$ is a large loosely lobulated mass, situated mainly below the mylohyoid level, but extending with a partially separate cephalic accessory portion under cover of the ramus behind and above the caudal margin of the mylohyoid muscle (IO). This portion is closely related to the deep surface of the parotid, and is incompletely separated from the main caudal inframylohyoid part of the gland by grooving branches of the submaxillary artery. The duct emerges from the ventral margin of this portion of the entire gland as a canal with very wide lumen and thin walls, and is crossed on its lateral aspect almost immediately by the lingual nerve (I 3 ). It 
then continues forward under cover of the lesser sublingual glands (3), and finally appears above the cephalic margin of the latter. In this part of its course the duct of the greater sublingual gland (2), turning cephalomesad, reaches and accompanies the submaxillary duct along its submucous border for a short distance. Submaxillary and greater sublingual ducts then unite, forming a short common terminal segment (4) which opens by a single orifice on the parafrenular papilla.

(b) The greater sublingual gland (2) forms a small pear-shaped structure lying superficially on the lateral surface of the lesser sublingual mass. It and its duct, whose course and termination have just been described, are filled by the injection from the single papillary orifice in common with the submaxillary (4). For the sake of consistency, and in order to facilitate the subsequent general comparative analysis, the gland and its duct have been colored in Fig. 2 in accordance with the scheme (blue) adopted throughout. The terminal segment common to submaxillary and sublingual ducts ( $t$ ) has been distinguished by the complementary green color.

The topographical position of the greater sublingual gland, on the lateral, instead of the medial surface of the alveolingual mass, in the specimen here figured and described, is aberrant, and depends evidently on individual and very unusual variation. In four other examples of the same species, the greater sublingual gland occupied the typical position under cover of the lesser sublingual mass and on the latter's medial surface. In all of these specimens the short sublingual duct joined the main submaxillary duct, the two terminating by a single common orifice.

I have figured and described this aberrant chimpanzee here, rather than one of the normal individuals, because the topographical displacement of the greater sublingual gland to the loteral, instead of to the medial side of the lesser sublingual mass is one of the supports of the genetic theory of the intermandibular salivary development which will be advanced after the actual conditions in the individual types examined have been recorded (cf. Part IV).

(c) The lesser sublingual group of glands (3) extends, in this individual chimpanzee, along the lateral aspect of the submaxillary duct, between it and the greater sublingual gland, dorsocephalarl to the lingual nerve intersection. A little beyond the caudal pointed ter- 
mination of the lesser sublingual line, and not connected with the same, a group of similar glands (not colored in Fig. 2) begins and extends thence from a subramal position into the soft palate. These are the above-defined isthmian glands.

\section{CERCOPITHECID\&}

\section{A. CYNOCEPHALUS}

I. CYNOCEPHALUS SPHINX, $\delta$

Columbia University Morphological Museum, No. 1905,

Fig, 3

\section{A. PAROTID (5)}

A firm, closely lobulated gland, of hammer shape, extending from the sub- and pre-auricular region to the buccal angle. The broad handle of the hammer envelops the parotid duct entirely and is directly continuous with the main para-auricular portion of the gland.

This condition evidently represents the full and complete development of that portion of the paroticl complex which in other forms appears as the associate parotid glands connected, as isolated glandular masses, with the otherwise free parotid duct. In this respect the parotid of Cynoccphalus is in strong contrast with the preceding example of Troglodytcs (Fig. 2), while the intermediate condition is shown in Simia (Fig. I).

\section{B. INTER MANDIBULAR COMPLEX}

(a) Submaxillary gland (I). - A relatively small gland, composed of three loosely lobulated divisions, situated mainly behind the caudal margin of the mylohyoil ( $I O$ ), a cephalic segment projecting slightly above this margin, and two caudal portions extending below the same. In front of the caudal mylohyoid border a collection of accessory submaxillary glands $\left(I^{\prime \prime}\right)$ connect by short ducts with the ventral circumference of the main submaxillary duct under cover of the caudal extension of the greater sublingual gland (2). The latter opens by a separate orifice on the plica sublingualis.

(b) Lesser sublingual glands (3). - This complex is relatively reduced in extent, and confined to the cephalic sublingual area. It 
forms a small, alnond-shaped mass which lies lateral to and below the greater sublingual and submaxillary ducts and extends from the frenulum to the ventral margin of the greater sublingual gland, whose lateral surface is slightly overlapped by the caudal extremity of the lesser sublingual group.

This individual presents a remarkable instance in which the glandiferous field usually assigned to the lesser sublingual group is in large part transferred to the intermediate or grater sublingual area. The portion of this gland ( 2 (blue), in Fig. 3) which extends caudodorsad across the line of the lingual nerve is, in the majority of the primates, represented by the caudal prolongation of the lateral field of the separate glandular integers forming the lesser sublingual series ( 3 (red), in Fig. 3).

\section{CYNOCEPHALUS BABOUIN}

Columbia University Morphological Museum, No. 2130, Fig. 4

\section{A. PAROTID (5)}

The gland is especially developed in the vertical diameter. The caudal extremity extends well below and behind the mandibular angle, and receives the cephalic pole of the submaxillary in al concavity of its ventral margin and medial surface. On the other land, the sagittal diameter is reduced, and the greater part of the masseter muscle is uncovered.

\section{B. INTERMINDIBULAR COMPLEX'}

All three components of this complex are present and well developed.

(a) Submaxillary gland (I). - A round, globular mass situated below and behind the mylohyoid (10) and digastric (9), largely under cover of the mandibular angle and of the adjacent ventral margin and median surface of the parotid. In front of the lingual nerve crossing the ventral circumference of the duct receives a distinctly developed ventral duct from an accessory submaxillary gland $\left(l^{\prime \prime}\right)$. The latter lies between the main duct and the oral border of the sublingual gland.

(b) Greater sublingual gland (2). This gland opens on the papilla Jy a short duct, close to the submaxillary orifice, lateral to and a little caudal to the same. The gland forms an elongated tongue-shaped 
structure which lies caudolateral to the main submaxillary duct $(I)$ and its accessory gland $\left(I^{\prime \prime}\right)$. Its terminal portion is crossed on its lateral aspect by the ascending tail of the lesser sublingual mass, and extends to a point beyond and below the intersection of lingual nerve and main submaxillary duct.

(c) Lesser sublingual glands (3).- An elongated mass, beginning anteriorly at the level of the papilia, and extending thence caudad, below and lateral to the submaxillary and greater sublingual glands. The terminal extrenity, ascending obliquely to the border of the tongue, crosses the greater sublingual gland and submaxillary duct and extends beyond the lingual nerve into the palatine arch. This specimen is an exceedingly good example of uniform and full development of ail three components of the submandibular salivary group. The free unfolding of the greater and lesser sublingual elements is especially marked.

\section{CYNOCEPHALUS HAMADRYAS}

Columbia University Morphological Museum, No. 215I, Fig. 5

\section{A. PAROTID (5)}

The extensive parotid development, characteristic of the Cynocephalidx in general, is in this species modified by the separation of the mass into two distinct segments:

(a) Accessory parotid. - A bilobed glandular mass (6), opening into Stenson's duct, occupies the angle of the mouth, at the ventral border of the masseter, overlying the facial vein and nerve. The gland, which was filted by injection through the buccal orifice of the parotid duct. surrounds the terminal portion of the latter, just prior to its engagement in the buccinator. It corresponds topographically to the so-called "facial" or "angle" gland found in some mammals at the oral angle overlying the labial commissure, but in hamadryas it is clearly a parotid derivative and not an independent product of glandular development from the peripitrotid oral epithelium. Its position and independence suggests that it represents Schulte's "orbito-parotid," combined with the duct of the main gland into a short common terminal duct segment with single buccal orifice. 
(b) The main gland (5) occupies the sub-and pre-auricular regions, overlying the masseter and sternomastoid. It is of irregular quadrangular shape, with a prolongation from the ventrocephalic angle along the main duct, and is somewhat more loosely lobulated than in the majority of the species belonging to this group.

\section{B. INTERMANDIBULAR COMPLEX}

(a) The submaxillary gland ( $I$ ), of moderate size, occupies the usual position, partly under cover of the mandibular angle, lying behind the mylohyoid (IO), and above the digastric (9), crossed by the facial vein $\left(I_{4}\right)$. The main duct, in front of its intersection with the lingual nerve, receives six short accessory ducts from three accessory submaxillary glands $\left(I^{\prime \prime}\right)$, two of which are located on the dorsal aspect of the main duct, while one larger conglomerate mass, with three ductules, is placed ventral to the same.

(b) Grater sublingual gland (2). - The duct is separate from the submaxillary duct, and opens by an independent orifice on the parafrenular papilla. The gland lies under cover of the lesser sublingual mass. Its caudal extremity is partly overlapped on the literal aspect by the larger ventral accessory submaxillary gland.

(c) Lesser sublingual glands (3). - These form a narrow, relatively short mass, lateral to the preceding. In Fig. 5 this mass is shown rotated into a vertical position to expose the underlying deeper and more medial ducts and glands.

\section{B. MACACUS}

\section{MACACUS CYNOMOLGUS}

Columbia University Morphological Museum, No. 2004, Fig. 6

\section{A. PAROTID}

The parotid forms an oval mass, occupying the interval between the masseter and sternomastoid. The cephalic pole of the gland is fitted around the caudal circumference of the external auditory meatus. The caudal pole presents on its medial surface a concavity into which the adjacent cephalic portion of the submaxillary gland fits in the natural conditions. In Fig. 6 the latter has been depressed. 
The parotid duct is simple, without lateral derivatives, and with a relatively long buccal submucous terminal segment (5).

\section{B. INTERMANDIBULAR COMPLEY}

\section{a. Submaxillary Gland}

The submaxillary gland $(I)$ is a globular mass, situated entirely ventrocaudal to the digastric (g) and mylohyoid (Io). The duct is simple and opens by a separate orifice on the medial aspect of the caruncle.

\section{b. Greater Sublingual Gland}

The greater sublingual gland (2) forms a triangular body occupying the anterior paralingual field, covered partially on its lateral aspect by the lesser sublingual glands, but exposed by a deep incisure in the latter's caudal margin, which incompletely divides the lesser sublingual mass into a cephalic and a caudal segment, connected along their oral border by a narrower bridge of gland tissue. The greater sublingual duct follows the oral margin of the cephalic lesser sublingual segment, between it and the submaxillary duct, and opens on the parafrenular papilla by a separate orifice.

\section{c. The Lesser Sublingual Glands}

The distribution of the gland mass (3) is above described, and is typical of the genus, presenting two triangular segments, connected along their oral margins by an intermediate narrower portion, thus allowing the lateral surface of the greater sublingual gland to be seen in the resulting interval from the lateral aspect. The caudal end of the lesser sublingual mass ascends on the lateral aspect of the lingual nerve into the arcus palatinus, and can be traced through the same into continuity with the glands of the soft palate.

\section{MACACUS NEMESTRINUS}

Columbia University Morphological Museum, No. 97r,

Fig. 7

A. PAROTID (5)

The gland forms an elongated cleanly lobulated mass, extending from the caudal and ventral circumference of the external auditory 
meatus to the labial commissure, and entirely enveloping the masseteric segment of Stenson's duct, which presents a short intramural segment.

No preparation could more clearly illustrate the potential character of the primate parotil duct in the sense of giving origin to extensive secondary or accessory parotid derivatives.

Usually the potential capacity of the gland duct is limited in its actual results to the production of so-called "sucie" or "accessory" parotid elements, such as are illustrated in Part I by Figs. 3, 6, 7, 9. But in the present instance the entire masseteric course of the typical duct of Stenson is covered by a paraductular glandular efflorescence which carries the physiological activity of the parotid gland up to the premasseteric engagement of the duct in the buccinator muscle. It would be very easy to deduce from this adult parotid complex, by exaggeration of certain components, and elimination of the remaining accessory parotid elements surrounding the main duct, conditions which explain the formation of the parotid complex of IIyrax, of Gulo, and, to a lesser degree, of Procyon. Considering, however, our present lack of correct and detailed information concerning the ontogeny of these forms, it seems more fitting to accept these adult types as individual morphological conditions which may eventually be brought, by proper ontogenetic evidence, into line with the adult salivary organization of forms very far removed in the generally accepted zoölogical scale.

\section{B. SUBMAVDIBULAR COMPLEX (:)}

(a) Submaxillary gland. - I. The main submaxillary gland $(I)$ is located entirely in the submandibular recess below and behind the mylohyoid $(\mathrm{IO})$.

2. Above the mylohyoid is lodged a large secondary submaxillary glund $\left(I^{\prime}\right)$, whose separate duct follows along the dorsal border of the main submaxillary duct and unites with the same about midway between the intersection with the lingual nerve and the plica sublingualis. The large resulting common canal $(\phi)$ is joined near its termination by the greater sublingual duct (2) and opens on the plica by a single orifice common to all three glands (main submaxillary, secondary submaxillary, and sublingual glands). 
(b) Greater sublingual gland (2). - This gland, largely under cover of the lesser sublingual mass, is situated far back, its caudal margin projecting beyond the lingual nerve. The duct follows the main submaxillary duct and the common canal $(4)$ formed by its union with the secondary submaxillary duct $\left(I^{\prime}\right)$, and joins the same, as above stated, on the plica sublingualis.

(c) The lesser sublingual glands are disposed in the irregular trapezoid mass characteristic of the Macaques. The greater sublingual gland is placed relatively ligh, under cover of the caudal part of the lesser sublingual group, and the latter presents only a slight indication of the usual incisure along the ventral margin.

\section{CEBID $\mathrm{E}$}

\section{NYCTIPITHECUS TRIVIRGATUS}

Columbia University Morphological Museum, No. 1945,

Fig. 8

The salivary apparatus in this species is characterized by enormous development of both parotid and main submaxillary glands.

\section{A. PAROTID (5)}

The parotid gland (5) is a large multilobular structure which extends from the subauricular region dorsocaudad into the neck and rests on the submaxillary gland. There are no lateral derivatives from the main duct.

B. INTERMANDIBULAR COMPLEX

(a) Submaxillary gland ( $I$ ). - The gland is very large and occupies the hyoid and infrahyoid regions, the organs of the two sides meeting in the ventral midline of the neck for a considerable distance. The submaxillary duct is simple and opens on the caruncle.

(b) Greater sublingual gland entirely absent.

(c) The lesser sublingzal glands (3) form a narrow band, whose caudal extremity, intersecting the lateral aspect of the submaxillary duct at an acute angle, ascends towards the faucial region, and abuts against a well-developed group of isthmian glands $(\delta)$, which in turn extend into the soft palate. 


\section{ATELES HYBRIDUS, \&}

Columbia University Morphological Museum, No. I96I, Fig. 9

A. PAROTID (5)

The gland corers the entire area between angle of mandible and external auditory meatus, whose caudal circumference it closely embraces, sending a small retroauricular process behind the concha.

\section{B. LNTERMAYDIBULAR COMPLEX}

(a) The submaxillary gland is divided into a main portion ( $I$ ), situated below the mylohyoid, partially under cover of the mandibular angle, and an adjacent supramylohyoid complex of two accessory glands $\left(I^{\prime \prime}\right)$, one lateral, the other mesal to the main duct.

(b) The lesser sublingual complex (3) forms an ellipsoid mass, whose caudal end abuts against the mesal accessory submaxillary element $\left(I^{\prime \prime}\right)$.

\section{LAGOTHRLX HUMBOLDTII}

Columbia University Morphological Museum, No. I9I I

Fig. Io

\section{A. PAROTID (5)}

The gland forms a nearly quadrangular subauricular mass, extending below and behind the mandibular angle, and abutting against the main submaxillary gland. The parotid duct is simple without derivatives.

\section{B. INTERMANDIBLLAR COUPLEX}

(a) Submaxillary. - The submaxillary group is divided into three elements :-

r. Iain submaxillary gland (I), globular in shape, below the mylohyoid ( $I O$ ), occupying the interval between digastric (9) and the caudal extremity of the parotid.

2. Accessory submaxillary glands $\left(I^{\prime \prime}\right)$. - A large dorsal mass, and two smaller ventral lobes, surround and empty into the main submaxillary duct in the interval between the dorsal margin of the mylohyoid (Io) and the digastric (9).

3. Sccondary submaxillary gland $\left(I^{\prime}\right)$. - A small but well-defined gland lying directly behind the lingual nerve $\left(I_{3}\right)$, between it and the larger dorsal accessory submaxillary, and dorsal to the main sub- 
maxillary duct. The duct of the gland $\left(I^{\prime}\right)$ runs forward along the dorsal border of the main submaxillary duct and unites with it shortly before the papilla is reached in a common terminal segment (4) with single opening of the caruncle.

(b) The lesser sublingual group (3) cxtends from the papilla caudad to just beyond the lingual intersection, along the ventral and lateral border of the submaxillary duct.

$$
\text { 4. ATEles SP. ? (probably A. niger) }
$$

Columbia University Morphological Museum, No. 2006, Fig. I I

$$
\text { A. PAROTID (5) }
$$

The cephalic border of the trapezoidal-shaped gland is concave and fitted around the caudal circumference of the external auditory meatus. The ventrocephalic angle and adjacent portion of the ventral margin is prolonged forward on the duct.

Two small accessory glandular nodules (6) connect with the main duct about midway between the point of its emergence from the gland and the buccal papilla (5).

\section{B. INTERUANDIBULAR COMPLEX}

This is more complicated than in any of the preceding forms, but of grcat interest because it comprises, in the single individual, representatives of all components which have been encountered in the species previously described.

\section{(a) Submaxillary Gland}

I. Main gland ( $I$ ). Below and behind the mylohyoid (IO) composed of one larger and three smaller lobes.

2. Accessory submaxillary gland $\left(I^{\prime \prime}\right)$. A small gland belonging to this group enters the main submaxillary duct by a short canal just after the latter has crossed the caudal margin of the mylohyoid (Io).

3. Sccondary submaxillary gland and duct $\left(I^{\prime}\right)$. - The small globular gland is situated in the identical position which the corresponding structure occupies in Lagothrix (Fig. IO), viz. caudal to the lingual nerve $\left(I_{3}\right)$, between it and the accessory submaxillary gland $\left(I^{\prime \prime}\right)$, and dorsal to the main submaxillary duct $(I)$. Its duct passes on the mesal aspect of the lingual nerve $\left(I_{3}\right)$ and of the caudal cnd of the lesser 
sublingual gland (3), in company with the main submaxillary duct, and then follows the dorsal border of the latter to near its termination. where it joins the short common canal $(4)$ produced by union of the main submaxillary $(I)$ and the greater sublingual ducts (2).

(b) Greater sublingual gland. - A small oval mass, situated between the lesser sublingual glands (3) and the submaxillary duct ( 1 ). Its short duct joins the latter a little prior to its union with the secondary submaxillary duct. Main $(I)$ and secondary $\left(I^{\prime}\right)$ submaxillary glands and the greater sublingual gland (3) thus open by a single orifice $(t)$ on the plica sublingualis.

(c) Lesser sublingual group (3) extends from near the papilia to the lingual nerve and then ascends along the latter's ventromedial border, intersecting both main and secondary submaxillary ducts at an acute angle.

\section{LEMIURIDE}

I. LEHUR VARIUS

Columbia Unirersity Morphological Museum, No. 2I 5o, Fig. I2

A. PAROTID (5)

The parotid is a relatively small sub- and preauricular gland, whose duct is simple, without associated elements. It runs a relatively long submucous course, after penetrating the buccinator, to its buccal orifice (5). In this segment it is in relation laterally with a narrow elongated glandular band (7), whose components open independently on the buccal mucosa, without connecting with the parotid duct. The relation of these separate glands, appearing near the termination of the parotid duct, but not connected with the same, to the derivatives of the orbital series and of the orbitoparoticl interval is discussed by Schulte in another chapter of this volume (cf. Part V).

\section{B. IYTERMANDIBULAR COMPLEX}

(a) Submaxillary gland $(I)$ is globular in shape and occupies the usual submandibular recess. The duct is long and simple.

(b) The greater sublingual gland (2) forms a narrow mass whose duct unites with the main submaxillary duct just prior to the latter's termination on the papilla $(4)$. 
(c) The lesser sublingual group (3) extends from near the frenulum to the lingual nerve, as a flat and relatively narrow ribbon of gland tissue. Its caudal end does not meet the isthmian $(S)$ and palatine mass, which is highly developed and continuous.

\section{LEMUR MONGOZ}

Princeton University Morphological Museum, No. I482,

Fig. I3

\section{A. PAROTID}

The quadrangular gland fits by a concave dorsal margin around the external auditory canal, and by a similar concavity of the ventral border adapts itself to the rounded submaxillary mass. The parotid duct is simple, without accessory derivatives. A distinct crescentic mass of separate glands ( 7 ) belonging to the alveobuccal or "molar" series occupies the angle of the lips and repcats conditions encountered in some carnivores (cf. infra, Part V)

\section{B. INTERMANDIBULAR COMPLEX}

(a) The submaxillary gland $(I)$ is a rounded mass fitted into the concavity of the ventral parotid margin and divided into three main lobes.

The submaxillary duct is simple ( $I$ ).

(b) The greater sublingual gland is absent.

(c) The lesser sublingual group extends as a clearly defined glandular mass with distinct oral openings from the sublingual plica to a point caudal of the lingual nerve, covering the lateral aspect of the submaxillary duct.

B. ANALYSIS OF THE FOREGOING INDIVIDUAL DISSECTIONS, AND GENERAL CONCLUSIONS REGARDING THE ADULT SALIVARY ORGANIZATION OF THE LOWER PRIMATES

The facts just adduced seem to warrant the following conclusions in respect to the adult organization of the salivary glands in the lower primates. 


\section{PAROTID}

The parotid gland is uniformly present and the duct invariably takes the transmasseteric course. The intramural segment of the duct appears to be longer in the Lcmurs and Cebida, thus carrying the buccal orifice further forward than in the Cercopithecidæ. The gland is relatively highly dereloped in the South American forms, chiefly sub- and retro-auricular in position.

Myctipithccus (Fig. 8) presents the greatest individual development of the gland as a lobulated mass extending from the auricular and submandibular regions into the neck.

The South American types are generally characterized by condensation of the parotid elements into the single main gland, leaving the parotid duct free without derivatives. In only one form, the specimen of Alcles shown in Fig. I I, two small accessory parotid lobules occur along the course of the main duct. The same character of single parotid with clean duct is found in the Lemurs.

On the other hand the Old-World forms tend to glandular proliferation along the course of the parotid duct. Simia salyrus (Fig. 1) and Cynocephalus hamadryas (Fig. 5) afford good examples of extensive associate parotid gland development (6) along Stenson's duct. In Cynocephalus sphinx (Fig. 3) and Macacus nemestrinus (Fig. 7) the entire masseteric segment of the duct is enveloped by a glandular mass continuous with the main gland.

\section{Intermandibular Complex}

The floor of the mouth, in the gutter between the tongue and the alveolar border of mandible, presents three lines of salivary glandular development, of which two, the submaxillary and lesser sublingual, are constantly present and appear developed independently of each other in varying degrees in the individual lower primate species here described. The third, intermediate in position between the other two, is the inconstant greater sublingual gland and duct encountered in certain forms. In them it appears either as an independent salivary: gland, with separate duct and orifice, or its duct unites in its terminal segment with that of the medial submaxillary gland, both opening by a common parafrenular orifice. The three lines of potential 
salivary glandular development in the alveolingual region of the lower primates behave as follows:-

I. The submaxillary line. - The submaxillary gland complex is the largest and most highly developed of the entire series in the lower primates. The main gland occupics the typical position below the mylohyoid muscle in the submandibular recess. The duct extends thence around the caudal border of the mylohyoil forward along the floor of the mouth, occupying the innermost of the three alveolingual lines above described. The supra-mylohyoid portion of the main duct $(I)$ receives, in certain species, the ducts of secondary and accessory glands $\left(I^{\prime}\right.$ and $\left.I^{\prime \prime}\right)$, which present the following general arrangement :-

$\left(I^{\prime}\right)$ Secondary submaxillary gland. - This is a separate and distinct supramylohyoid gland, situated above the main gland between the caudal margin of the mylohyoid muscle and the point of intersection of the main submaxillary duct with the lingual nerve. The duct of this secondary gland follows the course of the main duct, dorsal to and closely connected to it. The two ducts unite at a variable point caudal to the plica sublingualis, upon which they open through a common shorter or longer terminal segment by a single parafrenular orifice. While such a condition is quite conceivable and may exist in certain forms or in variant individuals, I have encountered among the lower primates heretofore examined no instance in which the duct of this gland attained a separate paraplical orifice. In every case in which the secondary submaxillary gland and duct were present the latter joined the main submaxillary canal. The length of the terminal duct segment common to the secondary and main submaxillary ducts varies in the different species possessing the secondary gland. The same appears as an occasional component of the adult human intermandibular salivary complex (cf. supra, Part I, page I4, Figs. 7 and 9).

$\left.{ }^{\prime \prime}{ }^{\prime \prime}\right)$ Accessory submaxillary glands. - By this term we define small glandular masses studding the course of the main submaxillary duct and opening into the same by short single or multiple ducts. These accessory glands may be either pre- or post-lingual, i.e. either in front or behind the point of intersection of the main submaxillary duct and the lingual nerve. They may be single, or double, or multiple. The highest number of separate ductules leading from these glands into 
the main duct encountered in this series is six, occurring in the specimen of Cynoceplatus hamadryas shown in Fig. 5.

The submaxillary is a single gland without additional elements derived from the duct in both Lemurs here described (Figs. I 2 and I3).

Nyctipithecus (Fig. 8) also possesses a long simple submaxillary duct, but the gland is very large, occupying an infrahyoid position in the ventral cervical region.

The remaining three South American forms (Figs. 9, IO, II) all possess additional submaxillary elements. All three show accessory submaxillary glands $\left(I^{\prime \prime}\right)$ and both Lagothrix (Fig. Io) and Ateles sp. (Fig. II) carry also a clearly defined secondary gland $\left(I^{\prime}\right)$. As far as can be therefore determined from the small number of individuals examined, the secondary submaxillary gland is more prevalent in the Cebille, although it is also encountered, slightly modified, in OldWorld forms (1/acacus nemestrinus Fig. 7), and as a human variant (Part I. Figs. 7 and 9). With exception of the specimens of Simic salyrus (Fig. I) and Macucus cynomolgus (Fig. 6), all the lower primates of the Old World here reported show an increase in the development of the submaxillary line by the acquisition of accessory supramylohyoid glands. In connection with the frequent occurrence of corresponding elements in the human subject this extension of the submaxilliary anlage may be accepted as a very widely distributed and typical general primate salivary character.

2. The greater sublingual line.

\section{Gl. Bartholini. \\ Gl. sublingualis monostomatica, Illing. \\ Gl. sublingualis major, B.N.A.}

The greater sublingual gland is a frequent, but not constant, component of the alveolingual salivary complex of the lower primates. In this regard there appears a marked difference in comparing the Old- and New-World monkeys. Thus in the series here illustrated the gland is only found in one South American species, the specimen of Aleles shown in Fig. II, whereas it is lacking in the remaining three Cebidæ, Nyctipithecus trizirgahus (Fig. 8), Ateles hybridus (Fig. 9), and Lagothrix humboldtii (Fig. 10).

On the other hand, the greater sublingual gland is present in all the 
(old-IVorld forms here reported with the single exception of the specimen of Lemur mongos from the Princeton University Collection (Fig. I3).

The greater sublingual gland of the lower primates is not to be confounded with the secondary submaxillary gland, since, as shown in the instance of Ateles (Figs. I I and 25), both of these components may develop side by side in the same individual. Neither can the greater sublingual element be regarded as forming part of the lesser sublingual or Rivinian complex, except in the sense that a number of separate glands of the latter unite and develop a separate duct. In spite of its close topographical relationship to the lesser sublingual row it is structurally independent of the same and appears as a distinct element interposed between submaxillary and lesser sublinguals. Considering the junction of the duct with that of the main submaxillary encountered in many forms, it appears more closely associatted with the submaxillary system than with the lesser sublingual.

The greater sublingual gland of the lower primates appears in two forms :-

A. With independent duct, opening on the parafrenular papilla lateral and usually a little caudal to the orifice of the submaxillary duct:- Simia satyrus, Fig. I.

Cynocephalus sphinx, Fig. 3 .

Cynoceplualus babouin. Fig. 4 .

Cynoce platus hamadryas, Fig. 5 .

Macucus cynomolgus, Fig. 6.

Macacus nemestrinus, Fig. 7.

$B$. The duct of the greater sublingual gland opens into the submaxillary duct a short distance before the latter's termination:

Troglodytes niger, Fig. 2.

Ateles sp., Fig. I I.

Lemur varius, Fig. 12.

3. The lesser sublingual line.

Gl. Rivini.

Gl. sublingualis polystomatica, Illing.

Duclus sublinguales minores, B.I.A.

The multiple alveolingual complex (Chievitz), composed of a varying number of discrete glands with separate orifices along the alveo- 
lingual ridge, is present, in varying degrees of development, in all the primates examined, constituting the most lateral component of the entire group. It may be confined to the anterior part of the area, lying altogether in front of the lingualis intersection, or extend backwards towards the isthmian region, crossing the lateral aspect of both submaxillary duct and lingual nerve. In certain forms ( $\mathrm{Yycli}$ pithecus and some Lemurs) its caudal extremity becomes continuous with the isthmian series and thus reaches or actually joins the dense mass of glandular tissue lodged in the soft palate. The greater sublingual gland, when present, is closely associated with the alveolingual mass, usually more or less imbedded in the same, but without parencyhmatous continuity. Injection of the greater sublingual gand through its own duct, or through the common terminal duct belonging to it and the submaxillary gland, will always demonstrate its complete structural independence of the lesser sublingual mass, no matter how closely interlocked the two may be topographically. Usually the greater sublingual gland lies embedded in the mesal surface of the lesser sublingual mass, extending obliquely from the submucous ventral border of the latter to the dorsal margin, beyond which its terminal portion frequently projects. The presence of a well-cleveloped greater sublingual gland seems to reduce, over the area of their mutual contact, the development of the lesser sublingual acini, so that the latter mass appears divided into a cephalic and caudal segment comnected by a narrow intermediate portion, covering the lateral surface of the greater sublingual. This condition is especially well marked in the Macaques. On superficial examination in these forms greater and lesser sublinguals appear to form a single and uniform glandular mass. Differentiation of the latter by injection will, however, clearly reveal their mutual extent and relations. Occasionally (e.g. Simia) the greater sublingual duct is so long that it alone lies in relation to the medial surface of the lesser sublingual mass, the greater sublingual gland proper being lodged below the latter's dorsal border, directly on the mylohyoid. In only one instance (the specimen of Troglodyles shown in Fig. 2) was the usual relation of greater and lesser sublingual glands reversed, the former occupying a position on the lateral aspect of the latter mass. This is, however, evidently an individual variation, because in four other examples of the same ape, the 
greater sublingual occupied the usual site, embedded on the medial surface of the lesser sublingual.

\section{SLMMARY}

A comparative study of the salivary structures in the ilveolingual area of the individual species above described reveals some interesting facts. For the purpose of such comparison the individual conditions, reduced to schema and, where necessary, transposed for sake of uniformity to the left side, are shown in the series of outline drawings, Figs. If to 25 .

The material here reported divides itself into the following natural groups and subdivisions:

I. Forms in which the greater sublingual gland (2) is not developed and in which the group is represented by only two distinct glands, viz. :-

Submaxillary gland $(I)$.

Lesser sublingual glandular complex (3).

These are consequently characterized by a single parafrenular duct orifice, and by the series of separate Rivinian duct openings along the alveolingual ridge.

(a) Nyctipithecus trivirgatus (Figs. S and $\mathbf{1}_{4}$ ). Lemur mongoz (Figs. I 3 and I4). Submaxillary (I) a single large gland with simple duct, without derivatives $(t)$.

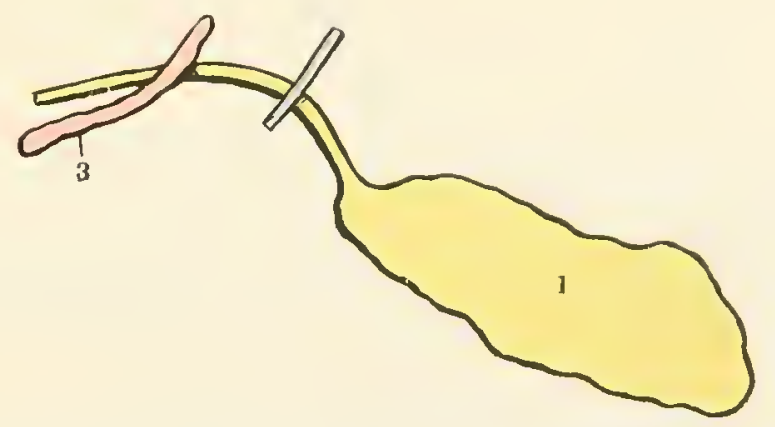

Fig. I4. Schema of alveolingual salivary complex in Nyclipilhecus trizirgatus (Fig. 8) and Lemur mongoz (Fig. 13). 
(b) Aleles hybridus (Figs. 9 and ${ }^{5}$ ). Main submaxillary duct $(I)$ with lateral derivatives $\left(t^{\prime \prime}\right)$, forming the accessory submaxillary glands above described.

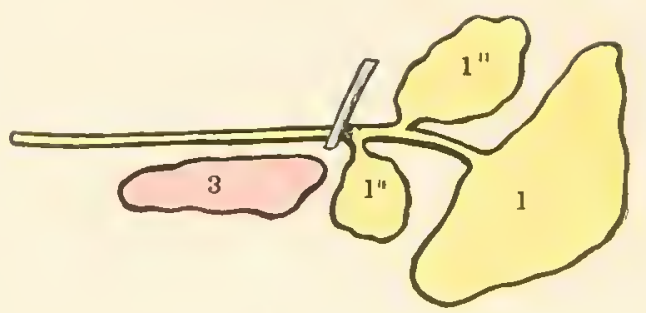

F1G. I5. Schema of alveolingual salivary complex in . thles hybrilus (Fig. 9).

(c) Lagothrix humboldlii (Figs. Io and 16). In addition to the accessory submaxillary glands and ducts $\left(I^{\prime \prime}\right)$, developed as above $(b)$, the main submaxillary duct carries a secondary submaxillary gland $\left(I^{\prime}\right)$.

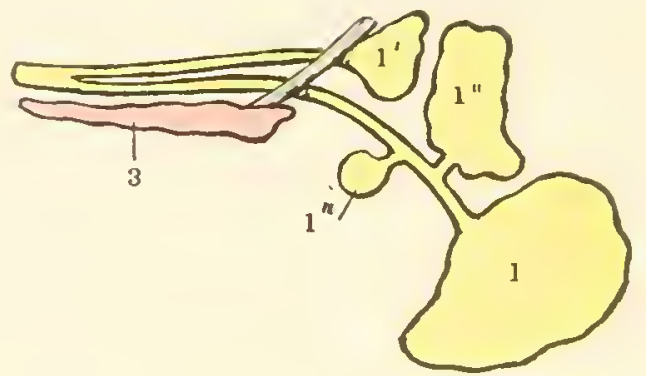

FIG. 16. Schema of alveolingual salivary complex in Lagothrix humboldtii (Fig. IO).

II. Forms in which, with the development of the greater sublingual gland, three distinct glands are encountered, the submaxillary $(I)$, greater sublingual (2), and lesser sublingual mass (3).

Two subdivisions of this group must be distinguished, according to the arrangement of the duct terminals of the two medial glands:

$I$. Submaxillary $(I)$ and sublingual (2) ducts remain distinct and separate throughout their entire extent. Two separate duct orifices appear on each side of the parafrenular papilla. 
(a) Submaxillary duct $(I)$ is simple, without accessory derivatives :-

Macacus cynomolgus (Figs. 6 and I 7 ).

Simia satyrus (Figs. I and I8).

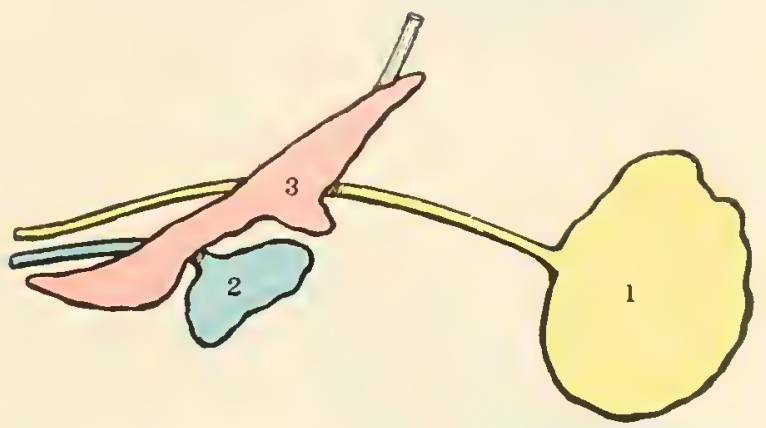

FIG. I7. Schema of alveolingual salivary complex in Macacus cynomolgus (Fig. 6).

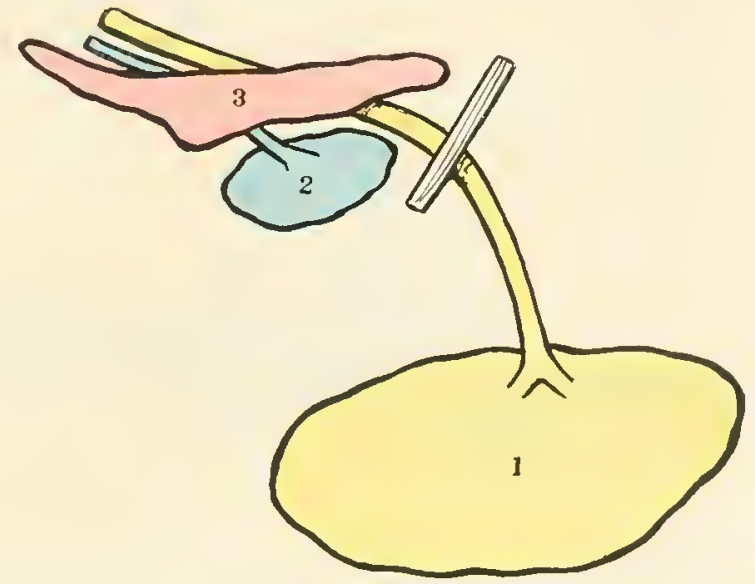

FIG. IS. Schema of alveolingual salivary complex in Simia satyrus (Fig. r).

(b) Submaxillary duct is compound, carrying accessory prelingual associated gland masses $\left(I^{\prime \prime}\right)$ : -

Cynocephalus sphinx (Figs. 3 and 19).

Cynocephalus babouin (Figs. 3 and 20).

Cynocephalus hamadryas (Figs. 5 and 21). 


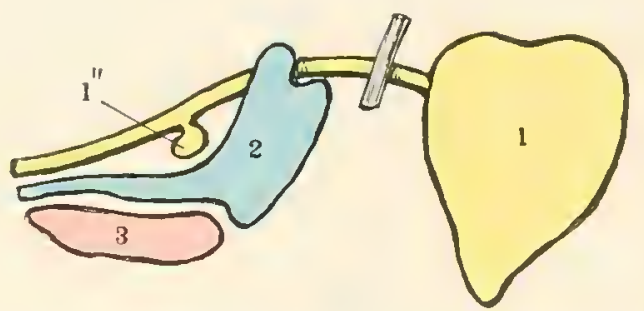

FIG. Iq. Schema of alveolingual salivary complex in Cynocephalus sphinx (Fig. 3).

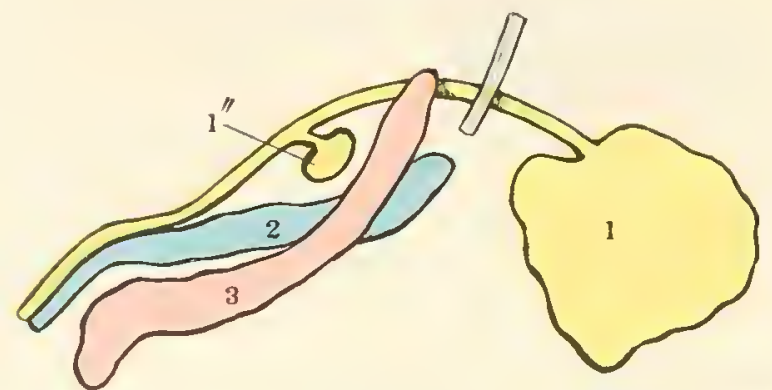

FIG. 20. Schema of alveolingual salivary complex in Cynocephalus babouin (Fig. 4).

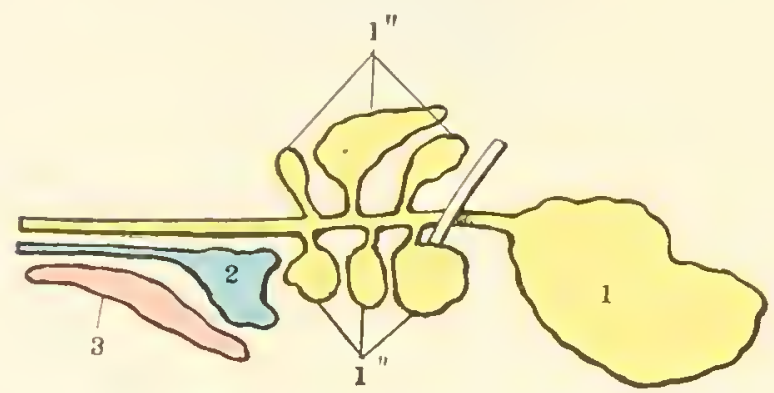

FIG. 2I. Schema of alvcolingual salivary complex in Cynocephalus hamadryas (Fig. 5).

(c) Submaxillary duct $(I)$ is joined midway between the plica sublingualis and the caudal margin of the mylohyoid by the duct of a well-defined secondary submaxillary gland $\left(I^{\prime}\right)$. The greater sublingual gland extends further caudad than usual beyond the line of the lingual nerve: -

Macacus nemeslrimus (Figs. 7 and 22) 


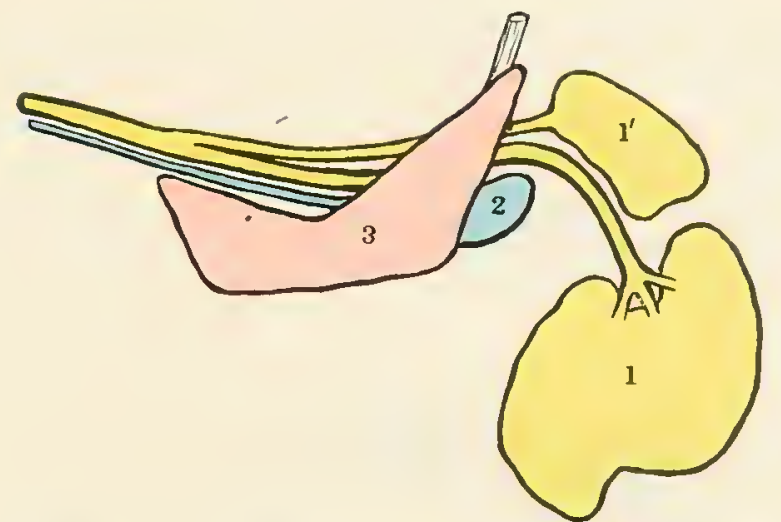

FIG. 22. Schema of alveolingual salivary complex in Macacus nemestrinus (Fig. 7).

$I I$. Submaxillary $(I)$ and the greater sublingual (2) ducts unite in their terminal segments into a single canal and open on the parafrenular papilla by a common orifice.

(a) Submaxillary duct $(I)$ simple:Troglodyles niger (Figs. 2 and 23)

Lemur varius (Figs. 12 and 24 )

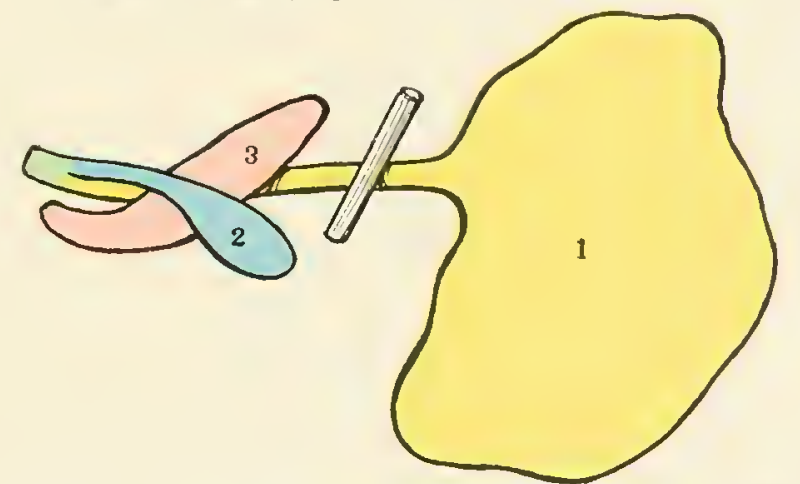

Fig. 23. Schema of alveolingual salivary complex in Troglodytes niger (Fig. 2).

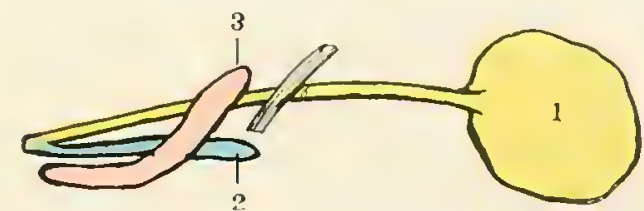

FIG. 24. Schema of alveolingual salivary complex in Lmur arrius (Fig. I2). 
(b) Submaxillary duct ( $I$ ) compound, carrying accessory postlingual gland $\left(I^{\prime \prime}\right)$. In addition the secondary submaxillary gland and duct $\left(I^{\prime}\right)$ is present, so that the terminal common papillary segment of the parafrenular duct system is the result of the union of three distinct and separate canals, viz: the main submaxillary rluct $(I)$, the secondary submaxillary duct $\left(I^{\prime}\right)$, and the sublingual duct (2).

Atcles sp? (ater?) (Figs. I and 25).

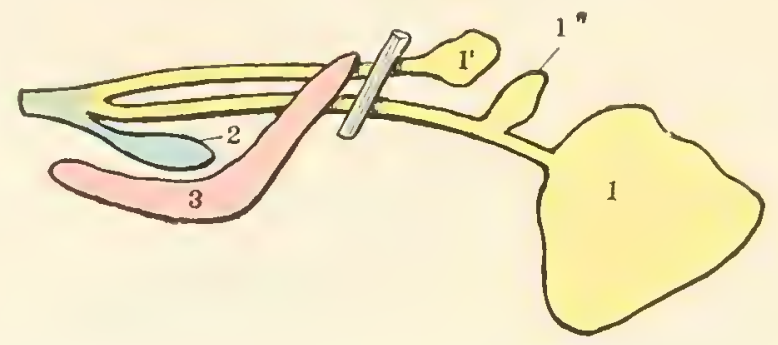

FiG. 25. Schema of alveolingual salivary complex in Ates sp.? (Fig. II).

III. All the genetic possibilities of primate salivary development in this region appear combined in the preparation of Ateles above describer (Figs. 11 and 25), viz. :-

1. Main submaxillary gland.

$I^{\prime}$. Secondary submaxillary.

I". Accessory submaxillary gland.

2. Greater sublingual or Bartholinian gland.

(Glandula sublingualis monostomatica, Illing.)

3. Lesser sublingual glands.

(Alveolingual or Rivinian glands.)

(Glanduli sublingualis polystomatica, Illing.)

In the absence of definite data in regard to the ontogenesis of the salivary apparatus in the lower primates, it is of course impossible to trace the developmental history of these structures except by inference and through comparison with known stages in the human embryo. and with embryos of the lower mammalia.

We know, as will be shown in detail in Schulte's ontogenetic studies of the salivary apparatus of man and cat, forming part of this volume (Parts II and VI), that in general the individual component glands are 
laid down as primitive anlages in definite and constant situations and grow thence by further extension and proliferation of the glandular epithelium.

In regard to the components of the general alveolingual field, the multiple individual glandular elements composing the lesser sublingual group proper practically represent a primitive embryonic type of glindular aggregation carried into the adult organization. As a matter of observation these simple and phylogenetically more ancient elements appear relatively late in the ontogeny. The earlier lesser sublingual sprouts have a temporary association with an epithelial keel, which fact is of very pregnant significance in regard to the genetic interpretation of salivary structures (cf. Part IV). The first lesser sublingual anlages develop as sprouts derived at intervals from a continuous lateral epithelial crest of the alveolingual area, the most cranial buds being the carliest in appearance. Later on in development they lose the primitive connection with the crest, and multiple additional members of the group are formed as separate and distinct derivatives from the epithelium of the sublingual plica and lateral area of the alveolingual floor.

On the other hand, the earliest anlages of the two remaining members of the entire alveolingual group, the submaxillary and greater sublingual components, arise in man in connection with the lingual sulcus and the flange derived therefrom. In the human embryo of 20 millimeters a few epithelial thickenings appear as an intermediate anlage between the lingual and alveolar sulci. Possibly these structures represent in the human embryo an extremely evanescent intermediate salivary genetic line (primitive greater sublingual) which normally merges into the median submaxillary line, since the sprouts are no longer found in the human embryo of 22 millimeters, whereas in some of the lower mammalia (cf. Schulte on ontogeny of Cat and Pig, Parts VI and VIII) this intermediate or greater sublingual line appears more definitely organized and plays a greater part in the developmental evolution of the median alveolingual field. The early individual embryonic anlages may unite into integers of two kinds, differing in their final form both functionally and structurally from each other :-

I. The submaxillary and greater sublingual anlages give rise at their caudal ends to large epithelial sprouts, and the secretory portions of 
the adult organs grow from the initial anlage caudad by further extension and proliferation of the glandular epithelium, the intraglandular duct system developing by subsequent canalization of primarily solid branching epithelial cylinders.

2. On the other hand, the extraglandular excretory ducts of the submaxillary and greater sublingual components are developed as proliferating epithelial keels which extend cephalad fron the primitive anlage and subsequently acquire a lumen. These may in later stages give rise to accessory glandular sprouts.

In comparing the lower primate species here described it becomes apparent that the individual conditions can be interpreted with the aid of our available ontogenetic data on the plan of the composite scheme shown in Fig. 26.

The entire floor of the mouth, between tongue and alveolar border of mandible, can be divided into three potential glandular districts in the broad sense, including in the term both the development of gland tissue and the formation of duct canals.

The most lateral of these districts (3) is purely glandular in its results, and yields the constant primate component of the entire group which, since Chievitz's investigations, has bein known as the alveolingual complex. consisting of a rarying number of individual glands, opening by separate orifices along the crest of the alveolingual ridge. This component is here described as the collection of the lesser sublingual glands.

The most medial district $(I)$ is also constantly responsible for primate glandular development, and forms the largest, and, in its details of structure, the most variable, component of the entire group.

It can be divided into three secondary areas, $I, I^{\prime}$, and $I^{\prime \prime}$.

I represents the line of development of the main submaxillary gland and duct. Both gland and duct may be simple and single. as above clescribed.

This medial alveolingual district, forming thus the site of development of the main submaxillary gland and duct, exhibits additional potential genetic characters.

Thus the epithelial crest which forms the anlage of the main cluct is capable of yielding, by more or less complete subdivision, a secon- 


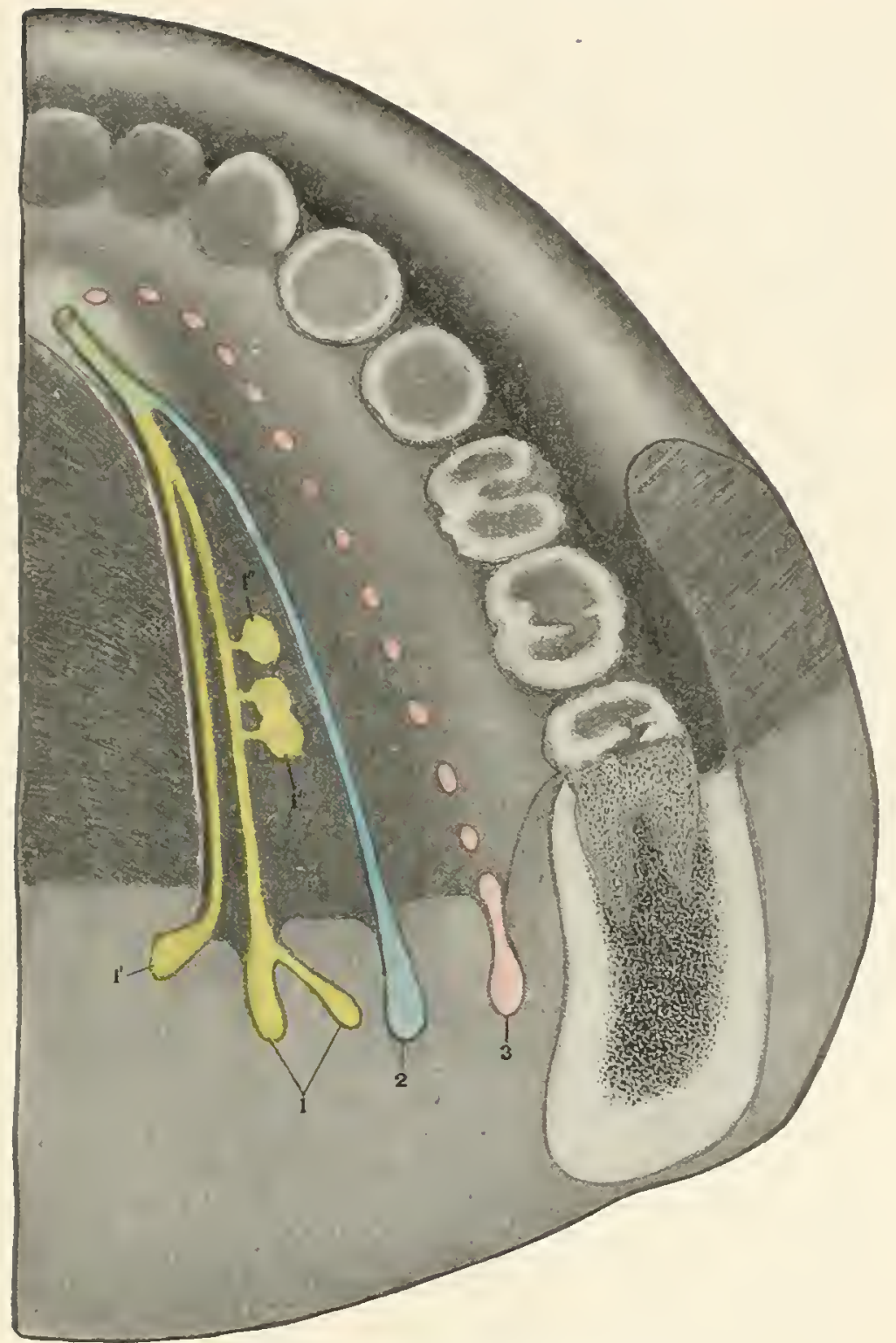

FIG. 26. Schema of primate alveolingual area.

I. Submaxillary gland.

2. Greater sublingual gland.

$I^{\prime}$. Secondary submaxillary gland. 3. Lesser sublingual glands. $I^{\prime \prime}, I^{\prime \prime}$. Accessory submaxillary glands. 
dary parallel channel $\left(I^{\prime}\right)$, the duct of the sccondary submaxillary gland. Moreover, the main submaxillary line is capable of furnishing by subsequent sprouting additional glandular components, the accessory submaxillary glands $\left(I^{\prime \prime}\right)$, the latter opening by short ducts directly into the main channel.

Both of these additional components may develop side by side (Lagothrix, Figs. 10 and I3; Ateles. Figs. is and 25), or only one of them may appear (Aleles, Figs. 9 and 15; Macacus, Figs. 7 and 22; Cynocephalus, Figs. 2, 4, 3, and 5 ; Figs. 19, 20, and 21).

The intermediate district (2) does not always develop glandular elements in the lower primates. It is the site of origin of the inconstant component here described as the greater sublingual gland. A glance at the series of schemata of the individual types selected will show its distribution in the order and its general relations.

In the anterior region the terminations of the individual ducts on the parafrenular papilla deserve special notice.

Three conditions may be encountered:-

A. The main and secondary submaxillary ducts join into a shorter or longer common terminal piece, which opens by a single orifice on the sublingual papilla. This, according to our observations, is invariably the arrangement found in instances in which the secondary submaxillary gland develops (c.g. Lagothrix. Figs. 10 and 16; Ateles, Figs. II and 25; Macacus, Figs. 7 and 24). Genetically it must be assumed that the subdivision of the submaxillary crest, responsible for the production of the secondary parallel duct, ceases anteriorly behind a common area still included in the forward extension of the duct and destined to form the terminal segment common to both. The greater sublingual gland, if present, has a separate papillary orifice, lateral and a little caudal to the main submaxillary opening. It is to be noted that we have encountered no instance in our series of lower primates in which, with the development of both secondary submaxillary and greater sublingual glands, the orifice of the terminal rluct segment, common to the former and to the main submaxillary duct, opened side by side with that of the sublingual duct.

$B$. This condition has been, therefore, only found by us in forms in which the secondary submaxillary duct does not develop, and in which the main submaxillary duct is either simple (Macacus cynomol- 
gus, Figs. 6 and 17 ; Simin salyrus, Figs. I and 18 ), or compound in the sense of carrying ouly the accessory glands (all three type's of Cynocephalus, Figs. 3, 4, 5, 19, 20, 21).

C. Finally in certain forms the sublingual papilla has a single orifice which represents the terminal of both the submaxillary complex and of the greater sublingual duct. The submaxillary duct in these instances may be simple (Lemur, Figs. I 2 and 23; Troglodyles, Figs. 2 and 22), or compound, with both secondary submaxillary gland and duct, and accessory glands (Ateles, Figs. 11 and 25).

Genetically this condition must be derived from the preceding forms, by extension of the keel formation forward in the papillary zone beyond the level of the separate openings of submaxillary and sublingual ducts, so that, by further canalization of the crest, both ducts obtain a single common terminal segment, indicated in Fig. 26 by the green area $C$.

As far as generic characters are concerned, the three Cynocephalus species here reported (Figs. 3, 4, 5, 19, 20, and 2I) are absolutely congruent. They possess all three alveolingual components. The greater sublingual duct has a separate papillary orifice. The secondary submaxillary duct and gland has not developed, and the main submaxillary duct receives the short ductules of accessory prelingual glands. This arrangement seems, therefore, characteristic for the Baboons.

The two Macaques here figured (Figs. 6, 7, 17, and 22) also show a consistent type common to the entire genus, characterized by the separate orifice of the greater sublingual duct. The main submaxillary duct of Macacus cynomolgus (Figs. 6 and 17 ) is simple, as it is also in several additional species examined (Macucus pilealus, rhesus, ochrealus). This arrangement appears to be typical for the genus as a whole. Macacus nemestrinus (Figs. 7 and 22) shows in addition a secondary submaxillary duct, approaching in this respect closely to one of the adult human variants recorded in Part I (cf. supra, Part I, page 14, Figs. 7 and 9).

A marked character of the Macaques is the partial subdivision of the lesser sublingual mass, the resulting interval being occupied by the greater sublingual gland:

The South American forms are in general characterized by great 
development of the submaxillary complex and absence of the greater sublingual gland.

The submaxillary duct may be simple (Nyctipithecus trivirgatus, Figs. 8 and $\mathrm{I}_{4}$ ), with relatively enormous unfolding of the main gland, or compound, with accessory submaxillary glands empyting into it (Ateles hybridus, Figs. 9 and 15 ). or both accessory and secondary submaxillary elements may be fully developed (Lagothrix humboldtii, Figs. 10 and 16 ).

In only one instance (Atcles sp.? (ater!) Figs. I I and 25) a greater sublingual gland was present in addition to all the submaxillary derivatives.

The two anthropoid apes here reported present in main congruent conditions, corresponding accurately to two of the types encountered in the human adult. In the specimen of Simia shown in Figs. I and is the greater sublingual duct opens by a separate oritice on the papilla, distinct from the submaxillary duct. In the individual of Troglodytes (Figs. 2 and 22) greater sublingual and submaxillary ducts are united into a short common terminal segment with a single papillary orifice. The portion of the submaxillary gland corresponding to the human accessory supramylohyoid segment is well developed in Troglodytes, absent in Simia, where the entire gland is inframylohyoid in position. In neither ape is there a secondary submaxillary duct.

The nomenclature here employed is a makeshift, necessitated by the traditional designations of anthropotamy and by the terms employed in the comparative investigations of previous observers.

The common genetic bed. from which all these glands take their origin. suggests the propriety of designating them all as alveolingual derivatives, and of further distinguishing three main components of the group, which, mesolaterad, might le indicated as follows:--

I. Derivatives of the medial alveolingual field:-

I. The main submaxillary gland and duct $(I)$. Glandula submaxillaris; Ductus submaxillaris

(Whartoni) B.N.A.

I'. Secondary submaxillary gland and duct.

I". Accessory submaxillary glands and ducts. 
II. Derivatives from the intermediate alveolingual field:-

Greater sublingual gland and duct.

Glandula sublingualis, s. Bartholini.

Ductus Bartholini.

Glandula sublingualis monostomatica (Illing).

Glandula retrolingualis (Ranvier).

III. Derivatives from the lateral alveolingual field:-

Lesser sublingual glands and ducts.

(Glandulæ et) ductus sublinguales minores, B.N.A.

Glandulæe et ductus Rivini.

Glandula sublingualis polystomatica (Illing).

We have, of course, encountered the difficulty met by all previous investigators of the mammalian salivary apparatus, which is based on the complexity of the nomenclature, and the unsatisfactory character of the homologies which have been drawn between different groups, and especially between the human glands and those of other mammalia. We have no desire or intention of further complicating the terminology of these structures, and the foregoing table is introduced solely for the purpose of calling attention to what we consider the chief cause of the difficulty. This we believe consists in the tendency to confound glands of genetically different origin and significance with each other. This tendency is augmented by failure to recognize the instable and inconstant character of certain of the secondary components which may enter into the alveolingual group in certain forms, while they default in others. The most important of these variable structures are those that we have above designated as the secondary or lesser submaxillary gland and duct and the greater sublingual or Bartholinian gland. Most of the confusion appears to have arisen through confounding these two genetically separate and different derivatives, and lience regarding them as mutually interchangeable and equivalent components. That they do not possess this significance is proved by their simultaneous occurrence in the species of Ateles shown above in Figs. I and 25. One or the other, or both, may, however, default entirely in certain forms. The Bartholinian gland is in most species altogether prelingual, although in a few its caudal extremity may reach and extend beyond the intersection of 
the main submaxillary duct with the lingual nerve. The secondary submaxillary gland is always retrolingual in position, and usually closely associated topographically with the cephalic part of the main submaxillary gland, although there is no glandular continuity between their respective acimi. Provisionally, it appears useful to us to adopt a genetic classification, even for those types whose ontogenesis is at present not accessible, and to group the individual components of the alveolingual complex in any given form on the necessarily broad and elastic lines furnished by the developmental history of those species which offer sufficient accessible embryonic material for a close and consecutive study.

The chief purpose of the account here given of the salivary organization in the lower primates is to establish, in them, the following points:--

I. The range of variation and of additional development along the main submaxillary line.

2. The occurrence of a distinct and typical "secondary submaxillary gland and duct," as a derivative of the median alveolingual area.

3. The possibility of confounding this structure topographically with Ranvier's so-called "retrolingual" gland.

4. The impropriety of longer retaining this term of "retrolingual" gland in the salivary nomenclature of the alveolingual region because:-

a. The line of intersection of the lingual nerve with the alveolingual glandular field is an entirely arbitrary and purely topographical standard, of no value in determining glandular homologies.

$b$. The greater sublingual gland may be either pre- or retrolingual in position, or extend both cephalad and caudad of the line of the lingual nerve.

c. Hence the retention of the term "retrolingual," in contradistinction to a "sublingual" gland, separates elements which genetically belong together as derivatives of the intermediate alveolingual district.

d. The secondary submaxillary gland, as above stated, resembles in some cases, in topographical position, a greater sublingual gland carricd caudad of the lingual nerve, and hence simulating Ranvier's "retrolingual" element. Opportunity for further unnecessary confusion in a field already laboring under excessive multiplicity of terms woukd be offered by the retention of a "retrolingual" gland. 
5. The individual and distinct character of the greater sublingual or Bartholinian gland, as an independent, although not constant, component of the entire alveolingual glandular complex.

6. The relation of this gland to the lesser sublingual group (atreolingual series of Chievitz, Rivinian glands).

ANNOTATION OF LEADERS IN ALI, FIGURES

I. Submaxillary gland, duct, and duct opening.

$I^{\prime}$. Secondary submaxillary gland and duct.

$I^{\prime \prime}$. Accessory submaxillary glands and ducts.

2. Greater sublingual gland, duct, and duct opening.

3. Lesser sublingual glands.

4. Common terminal segment of main and secondlary submaxillary ducts, or of main submaxillary and greater sublingual ducts, or of main and secondary submaxillary ducts combined with greater sublingual duct.

5. Parutid gland, duct, and duct opening.

6. Accessory parotid gland.

7. Superior alveobuccal or molar glands.

8. I'alatine glands.

9. Digastric.

Io. Mylohyoid.

II. Geniohyoid.

12. Geniohyoglossus.

I3. Lingual nerve.

If. Facial artery.

I5. Facial nerve.

16. Masseter.

I7. Sternomastoid.

IS. Panniculus.

ro. External jugular vein.

20. Lymphatic norles. 


\section{PLATE XXI}

FIG. I. Simia satyrus. Orang. Columbia University Morphological Museum, No. 2120.

$I, I$. Submaxillary gland and duct

2. 2. Greater sublingual gland and duct,

3. Lesser sublingual glands.

5. 5. Parotid gland and luct.

6. Acressory parotid gland.

Io. Mylohyoicl.

14. Facial artery.

15. Facial nerve.

I6. Masseter.

17. Sternomastoid. 
PLATE XXI.

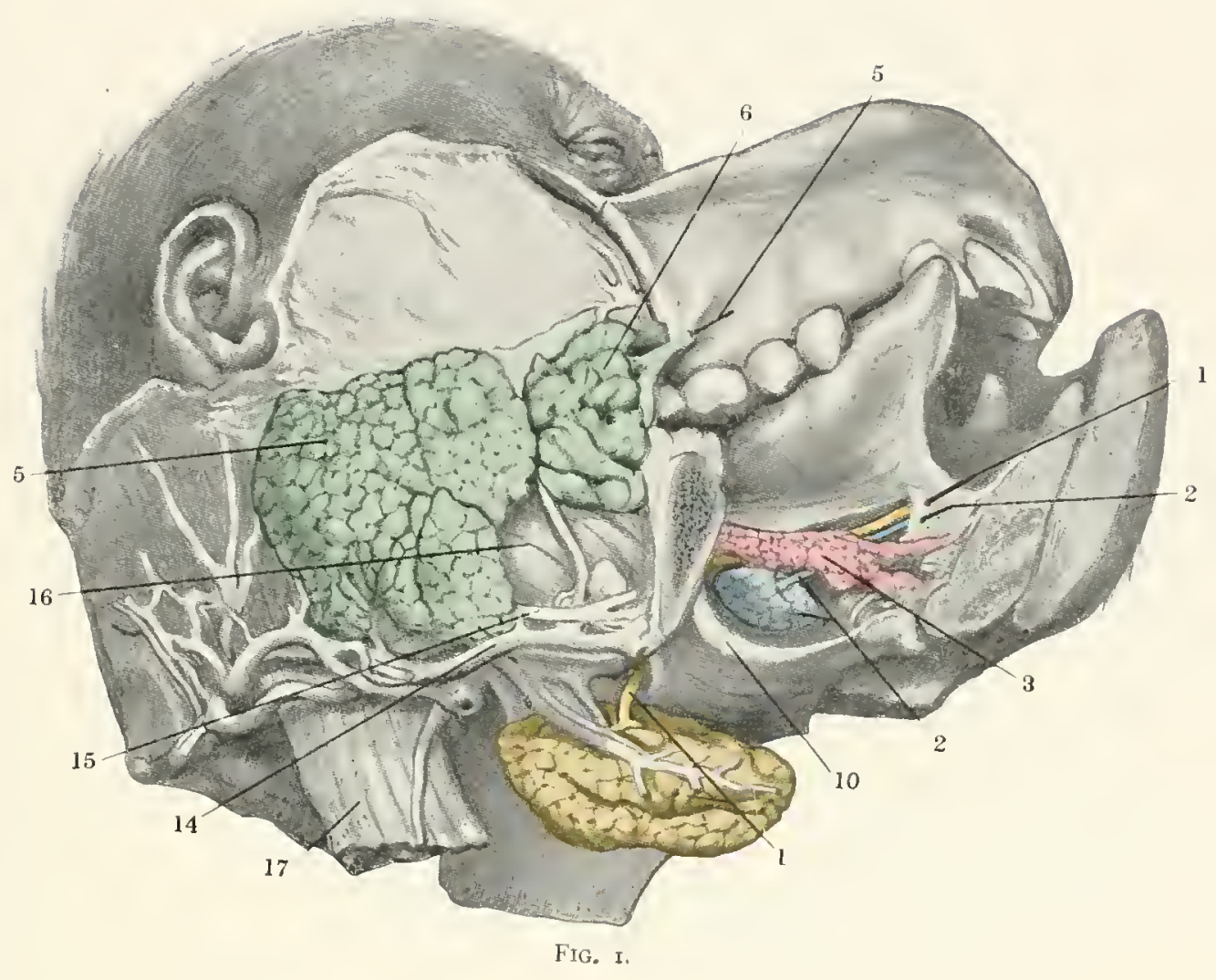




\section{PLATE XXII}

FIG. 2. Troglodytes niger. Chimpanzee. Columbia University Morphological Museum, No. I004.

I. Submaxillary gland,

2. Greater sublingual gland.

3. Lesser sublingual glands.

4. Common terminal of submaxillary and greater sublingual ducts.

5. 5. Parotid gland and duct.

9. Digastric.

I0. Mylohyoid.

II. Geniohyoid.

I3. Lingual nerve. 


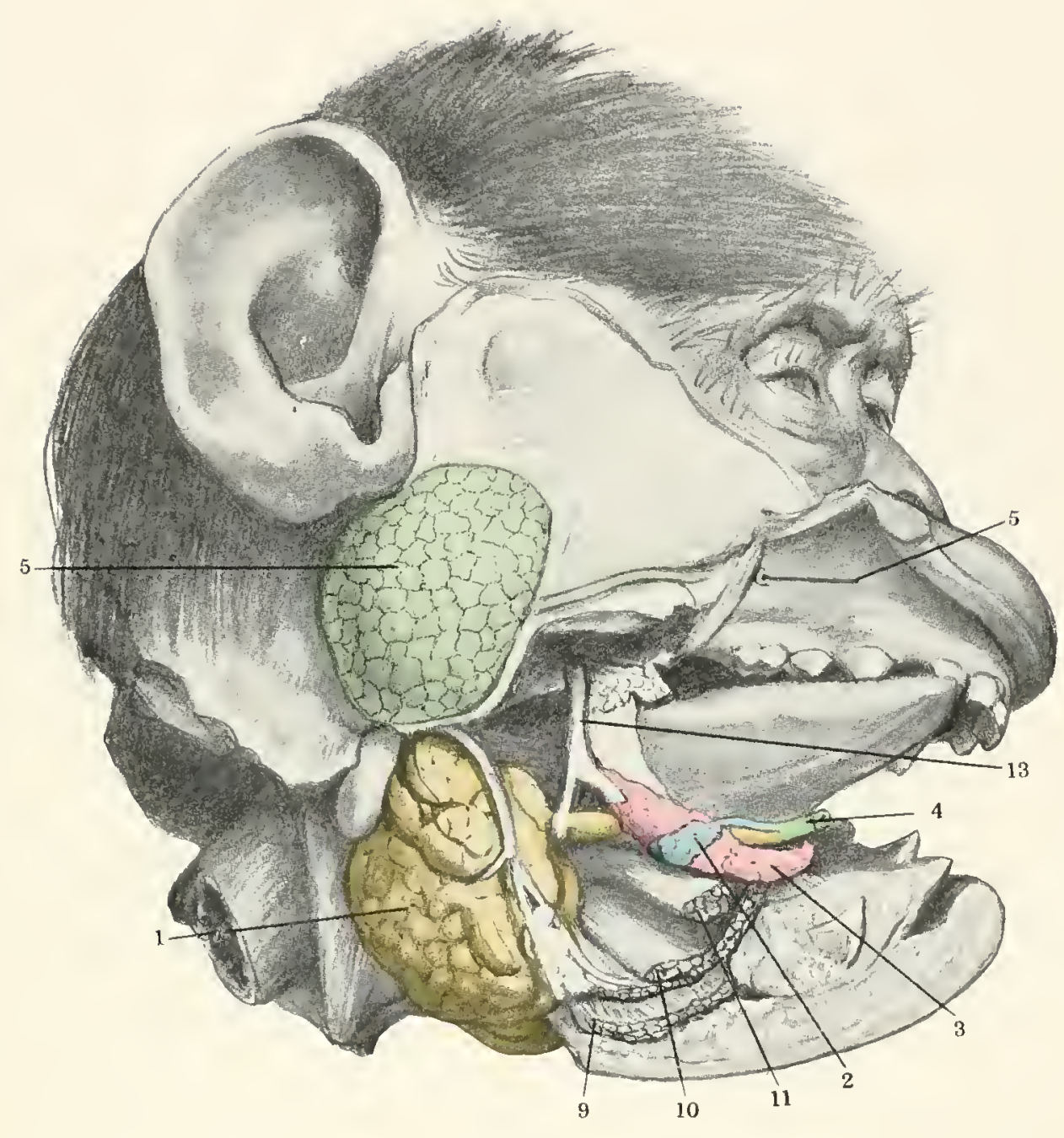

FIG. 2. 


\section{PLATE XXIIII}

FIg. 3. Cynocephalus sphinx. Papion baboon. Columbia Lniversity Morphological Nluseum, No. I005.

$I, I$. Submaxillary gland and duct.

$I^{\prime \prime}$. Accessory submaxillary gland.

2. Greater sublingual gland.

3. Lesser sublingual glands.

5. 5. Parotid gland and duct opening.

Io. Mylohyonid.

11. Digastric.

17. Sternomastoirl.

IS. I'anniculus.

19. External jugular vein. 


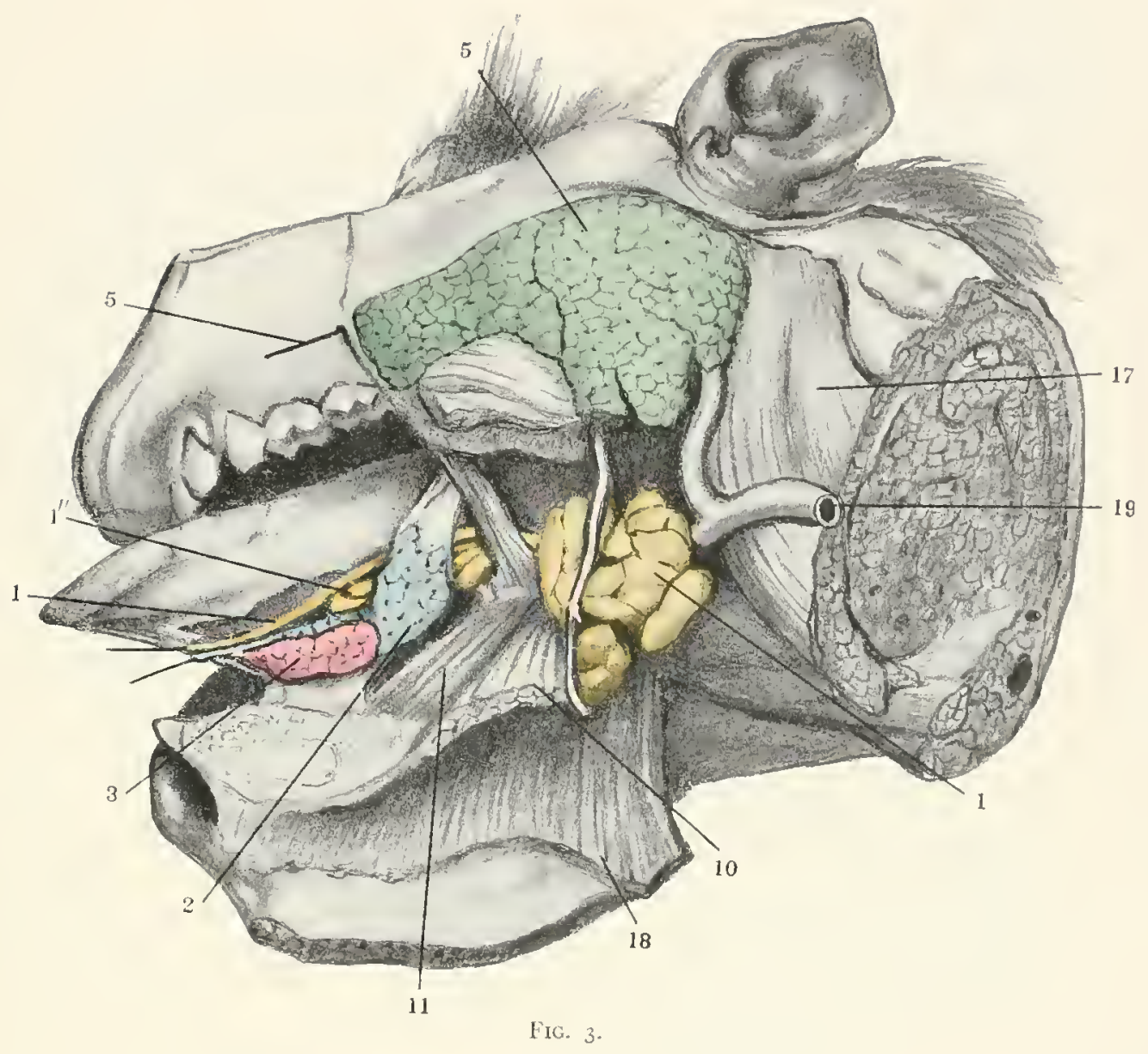




\section{Plate MXIV}

FIG. 4. Cynocephalus babouin. Baboon. Columbia University Morphological Museun, No. 2130.

$I, I$. Sulmaxillary gland and duct.

$I^{\prime \prime}$. Accessory submaxillary gland.

2, 2. Greater sublingual gland and duct.

3. Lesser sublingual glands.

5, 5. Parotid gland and duct opening.

o. Digastric

10. Mylohyoir.

II. Geniohyoid, 


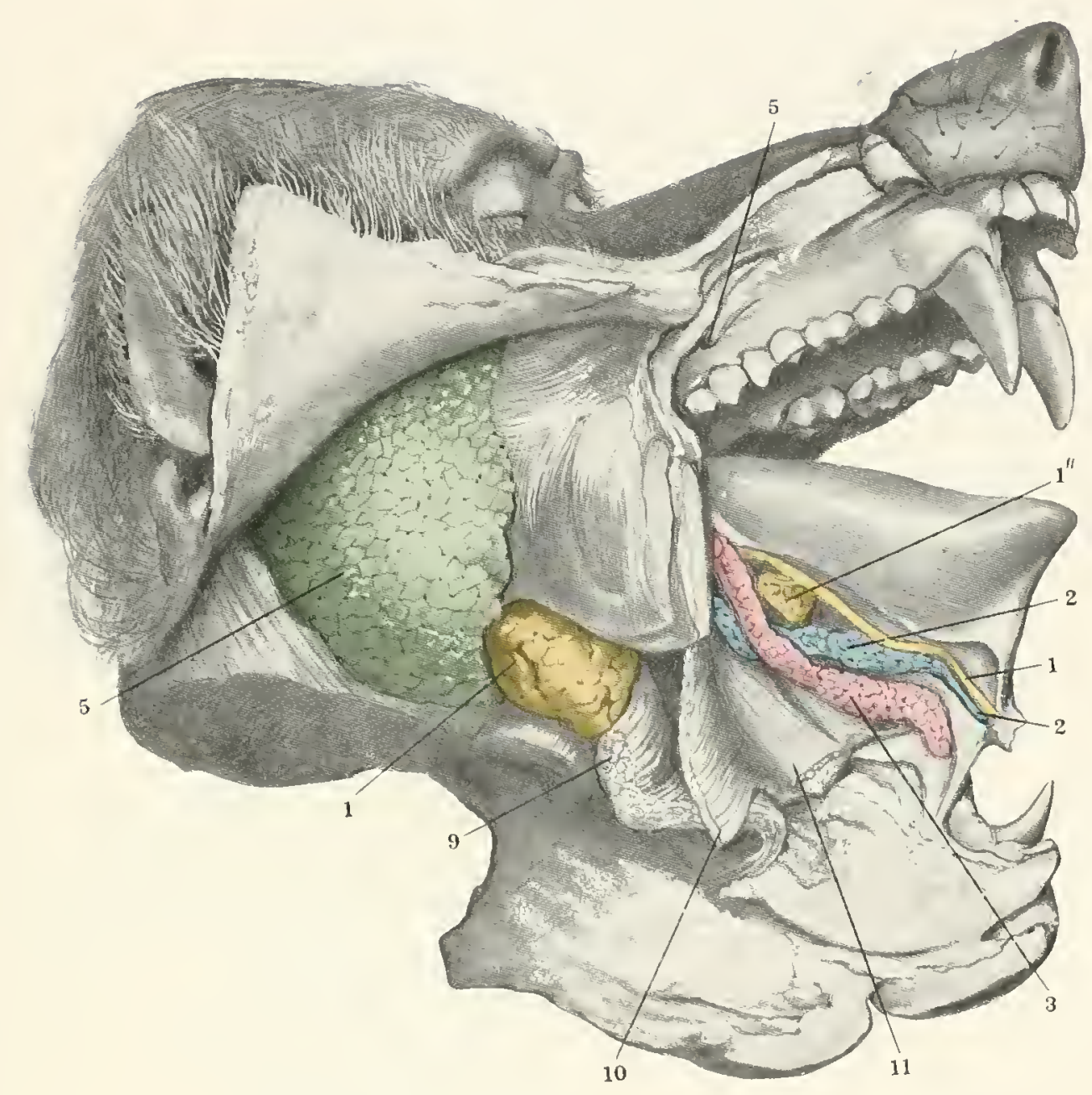

FIG. 4. 


\section{PLATE STI}

FIG. 5. Cynocephalus hamadryas. Arabian baboon. Columbia University Morphological Museum, No. 2I 5 I.

$I, I$. Submaxillary gland and duct opening.

2. 2. Greater sublingual gland and duct opening.

3. Lesser sublingual glands.

5. 5. Parotiu gland and duct opening

6. Accessory parotid gland.

o. Digastric.

I0. Mylohyoid.

I3. Lingual nerve.

If. Facial rein.

15. Facial nerve.

I9. External jugular vein. 


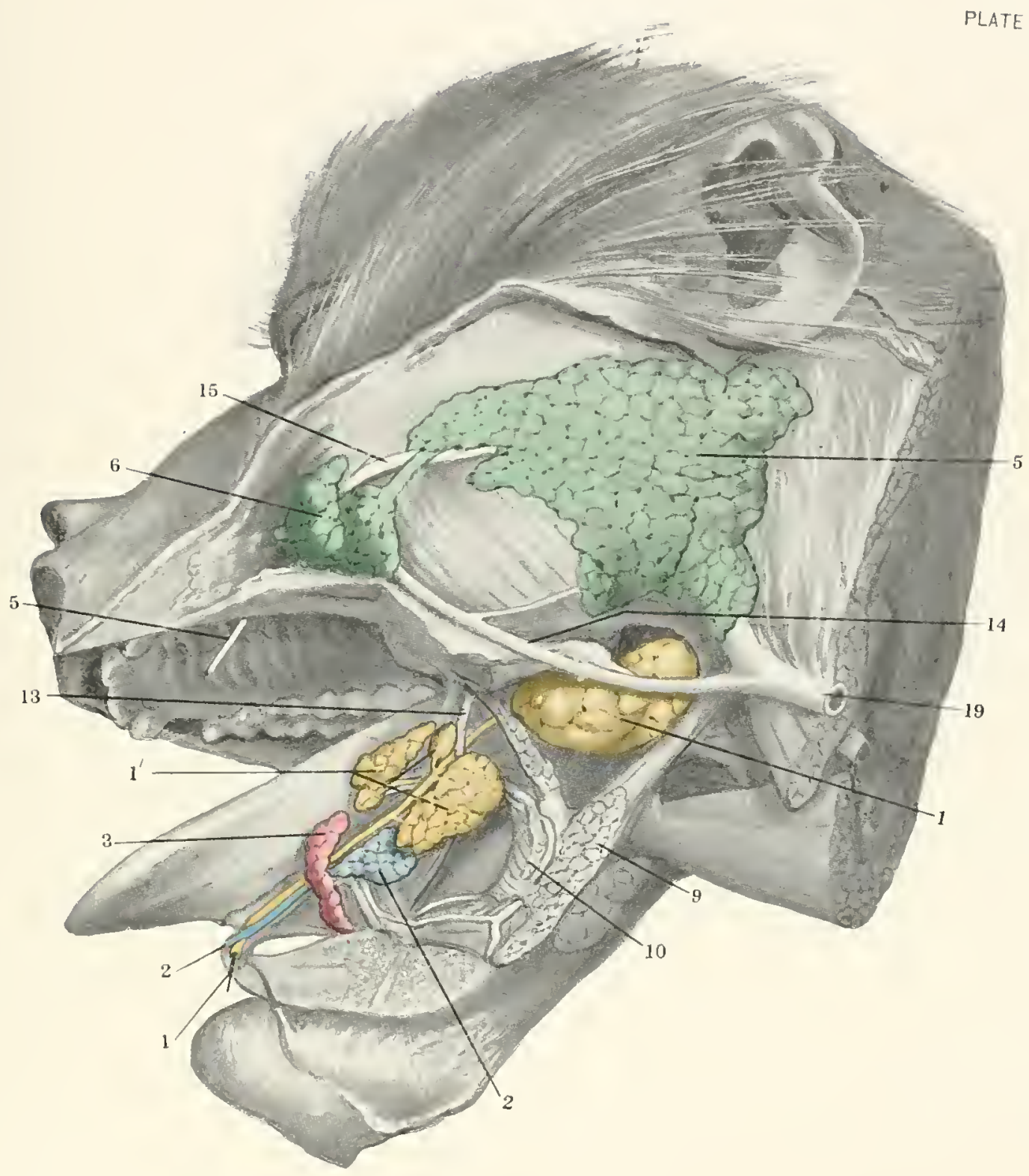

PLATE XXY.

FIG. 5 . 


\section{PLATE X.TVT}

FIG. 6. Macacus cynomolgus. Kra monkey. Columbia University Morphological Museum, No. 2004 .

$1, I$. Submaxillary gland and duct opening.

2,2 . Greater sublingual gland and duct opening.

3. Lesser sublingual glands.

5. 5. Parotid gland and duct opening.

9. Digastric.

10. Mylohyoid. 
PLATE XXVI.

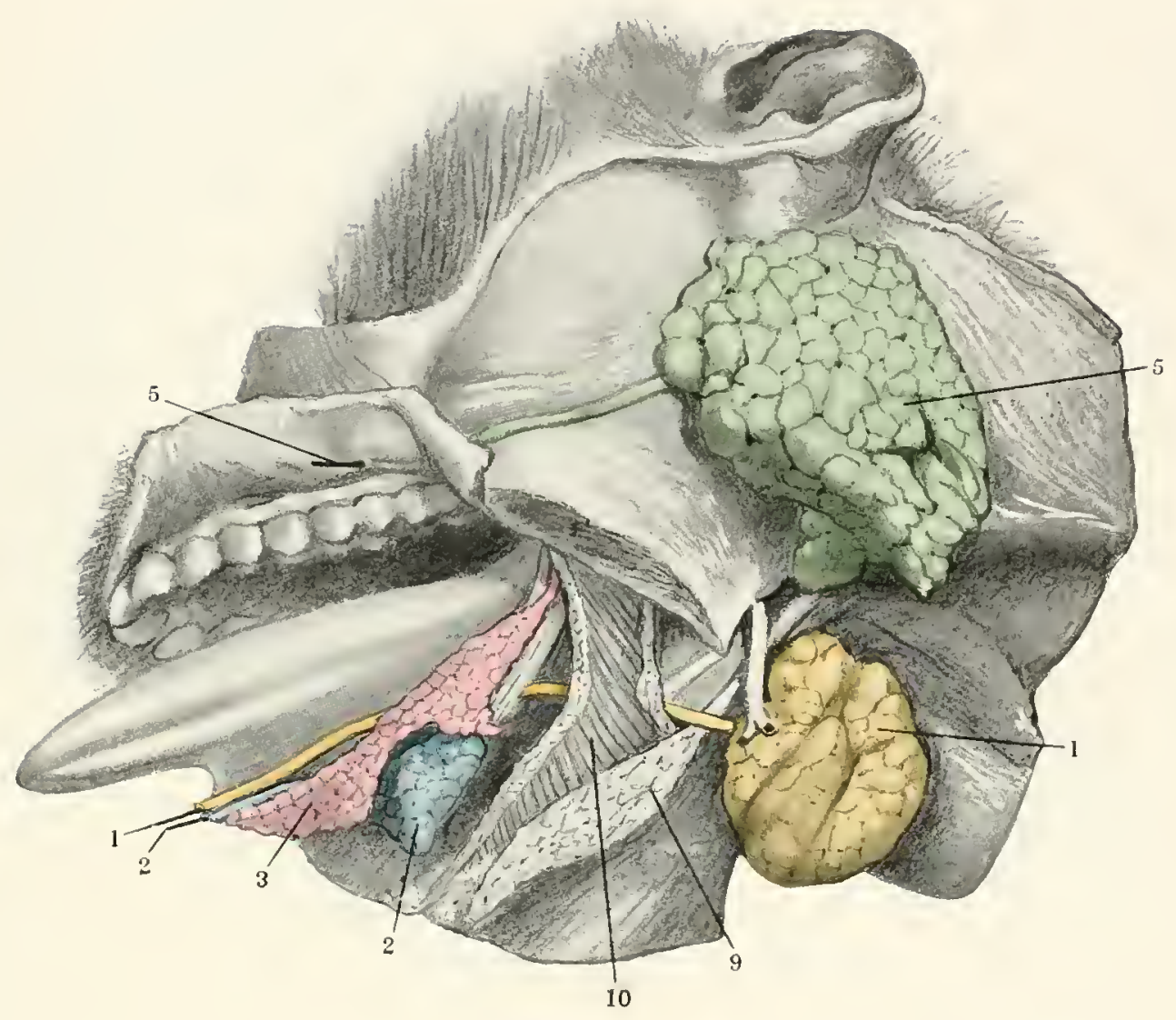

FIG. 0. 


\section{Plate xylit}

FIG. 7. Macacus nemestrinus. Pig-tailed Macaque, or Bruh. Columbia University Morphological Museum, No. 971.

I. Submaxillary gland.

$I^{\prime}$. Secondary submaxillary gland.

2. Greater sublingual gland.

3. Lesser sublingual glands.

7. Duct common to main and secondary submaxillary glands.

5, 5. Parotid gland and duct opening.

10. Mylohyoil.

II. Geniohyoid. 


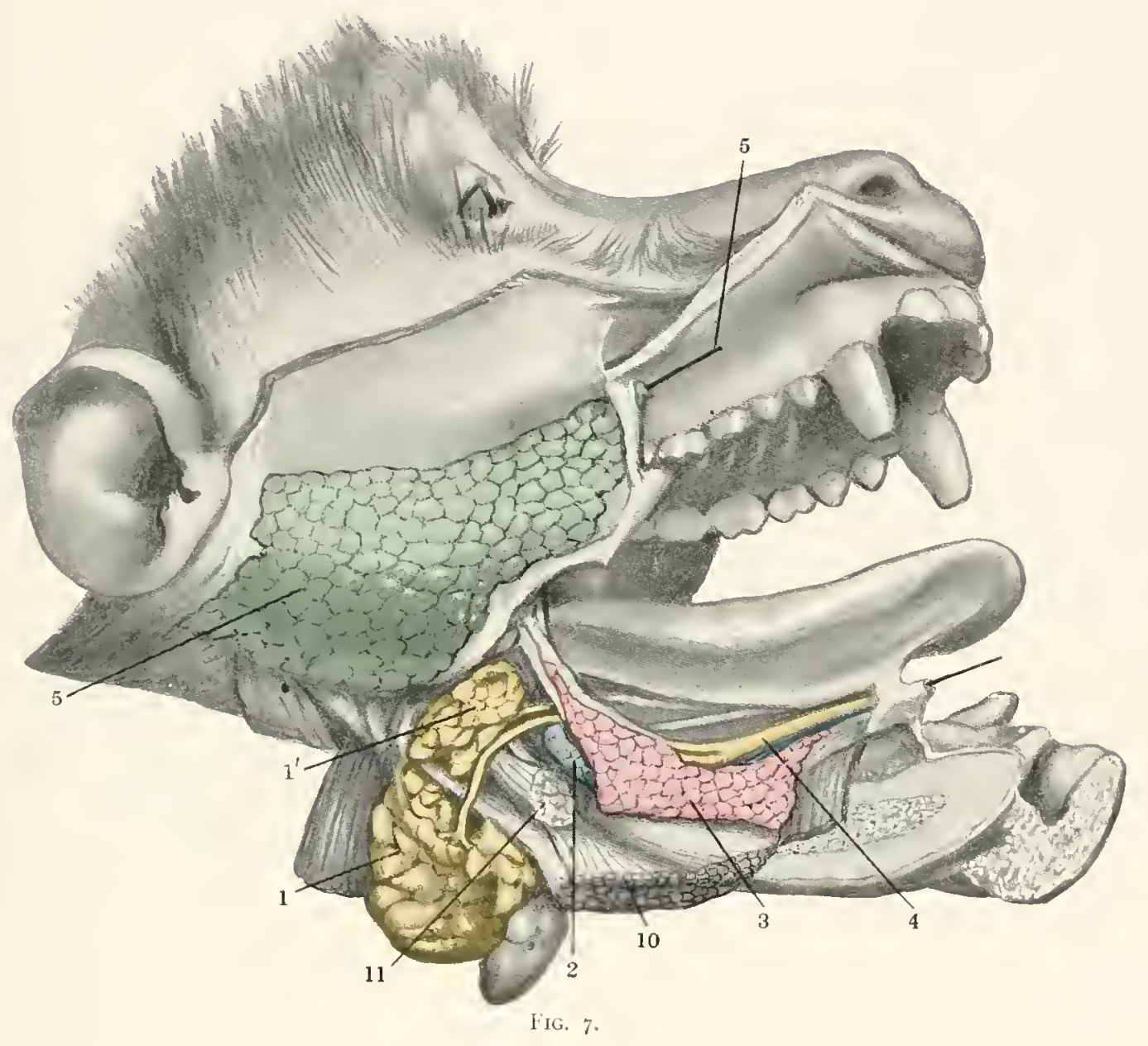




\section{PLATE XXITII}

FIG. 8. Nyctipithecus trivirgatus. Douroucouli. Columbia University Morphological Museum, No. 805.

$I, I$. Submaxillary gland and duct.

3. Lesser sublingual glands.

5. 5. Parotid gland and duct opening.

8. Palatine glinds.

ro. My'lohyoid. 
PLATE XXVII.

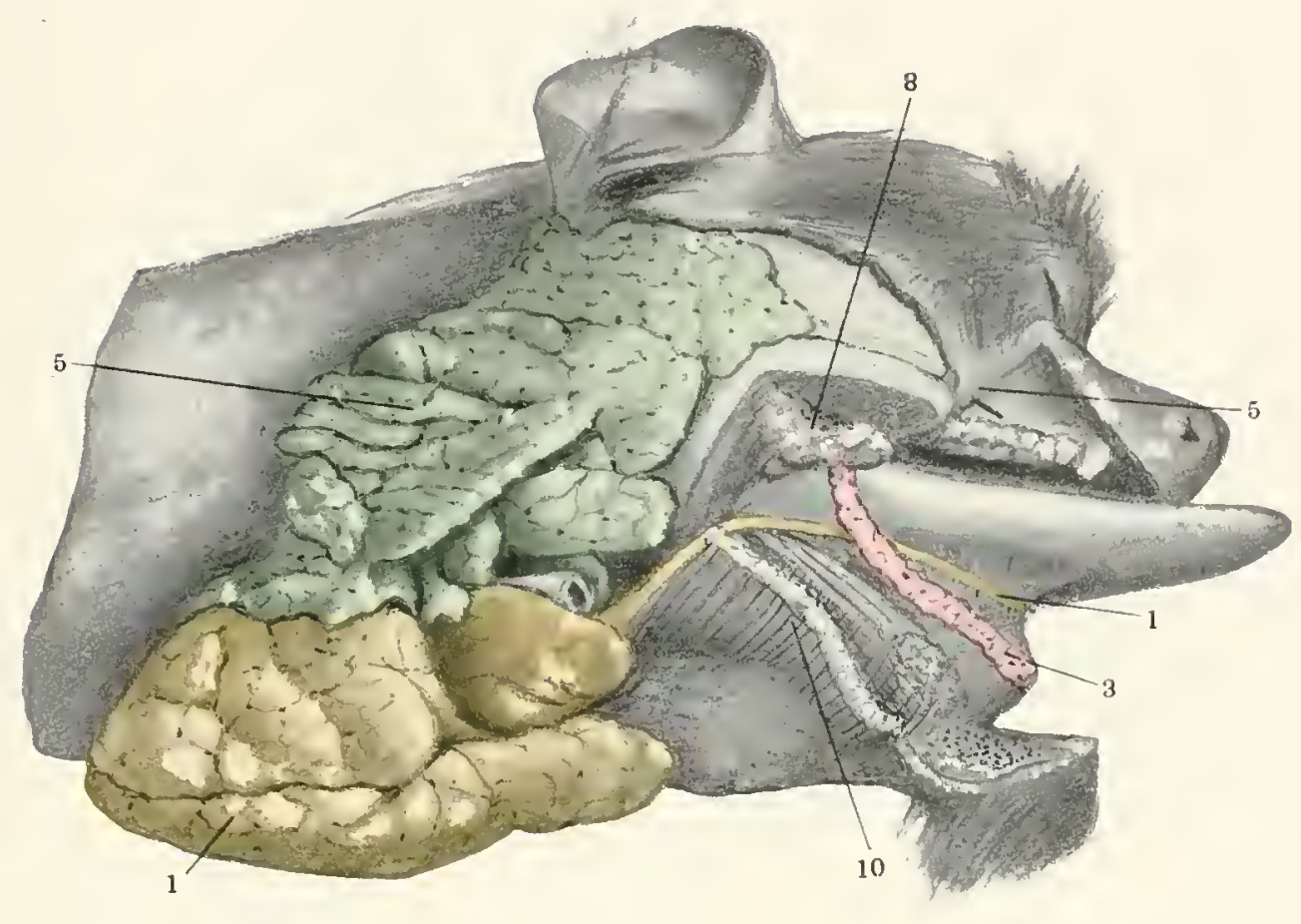

FIG. 8. 


\section{P'Late: XXIX}

FIg. 9. Ateles hybridus. Brown spider monkey. Columbia University Morphological Museum, No. I gor.

$I, I$. Submaxillary gland and duct opening.

$I^{\prime \prime}$. Accessory submaxillary glands.

3. Lesser sublingual glands.

5. 5. Parotid gland and duct opening. 
PLATE XXIX

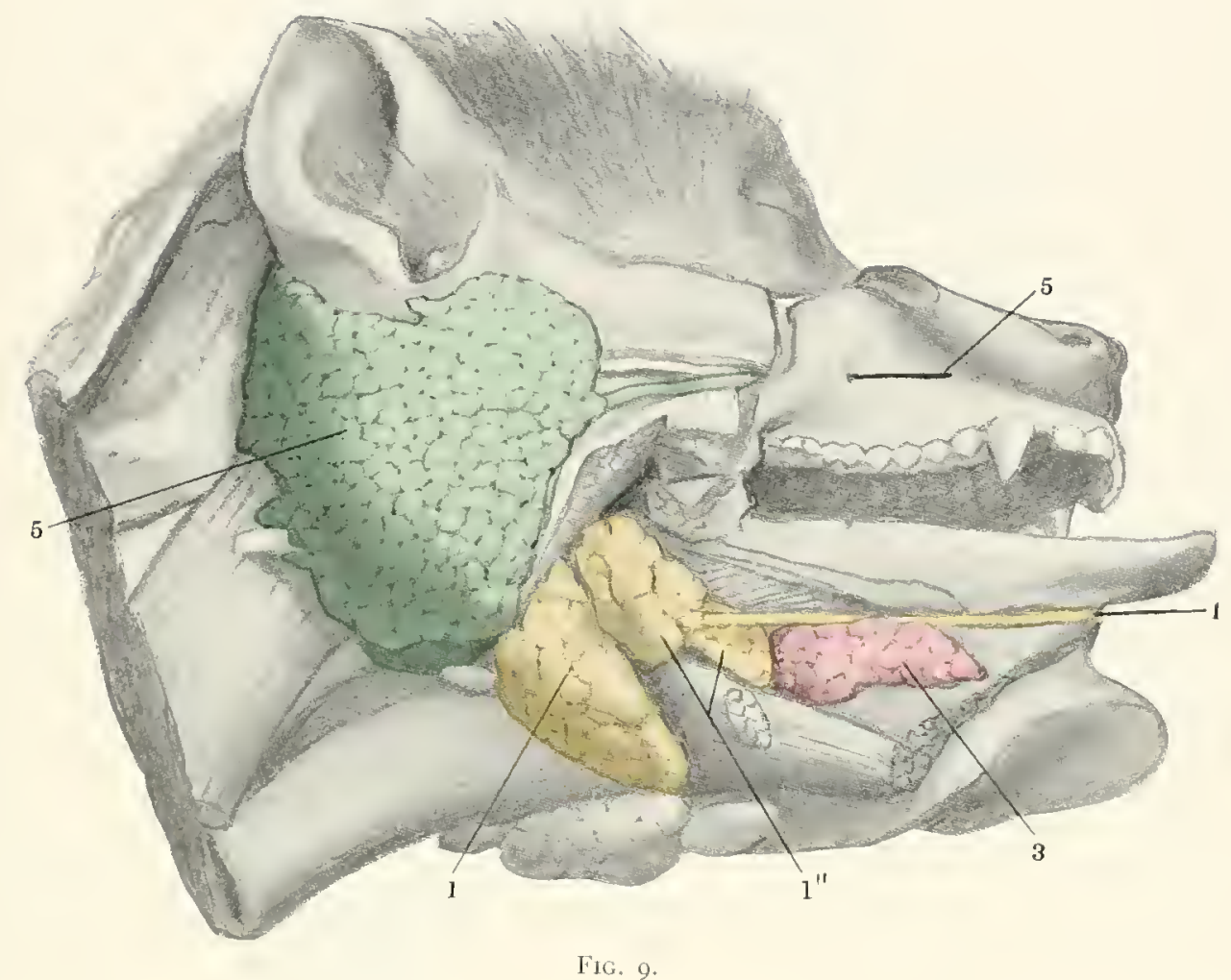




\section{PLATF, MYY}

FIG. Io. Lagothrix humboldtii. Humboldt's lagothrix. Columbia University Morphological Museum, No. Igr.

$I, I$. Submaxillary gland and duct.

$I^{\prime}, I^{\prime}$. Secondary submaxillary gland and duct.

$I^{\prime \prime}$. Accessory submaxillary glancls.

3. Lesser sublingual glands.

4. Duct common to main submaxillary and secondary submaxillary glands.

5 . 5. Parotil gland and duct opeuing.

9. Digastric.

10. Mylohyoid.

I1. Geniohyoid.

12. Geniohyoglossus.

13. Lingual nerve. 



\section{Plate XXXI}

Fig. II. Ateles sp.? Spider monkey. Columbia University Morphological MIuseum, No. 2006.

I. Submaxillary gland.

$I^{\prime}$. Secondary submaxillary gland.

$I^{\prime \prime}$. Accessory submaxillary gland.

2. Greater sublingual gland.

3. L.esser sublingual glands.

7. Common terminal segment of main and secondary submaxillary ducts combinerl with greater sublingual duct.

5. 5. Parotid gland and duct opening.

6. Accessory paroti] glinds.

10. Mylohyoid.

I 3. Lingual nerve. 
PLATE XXXI.

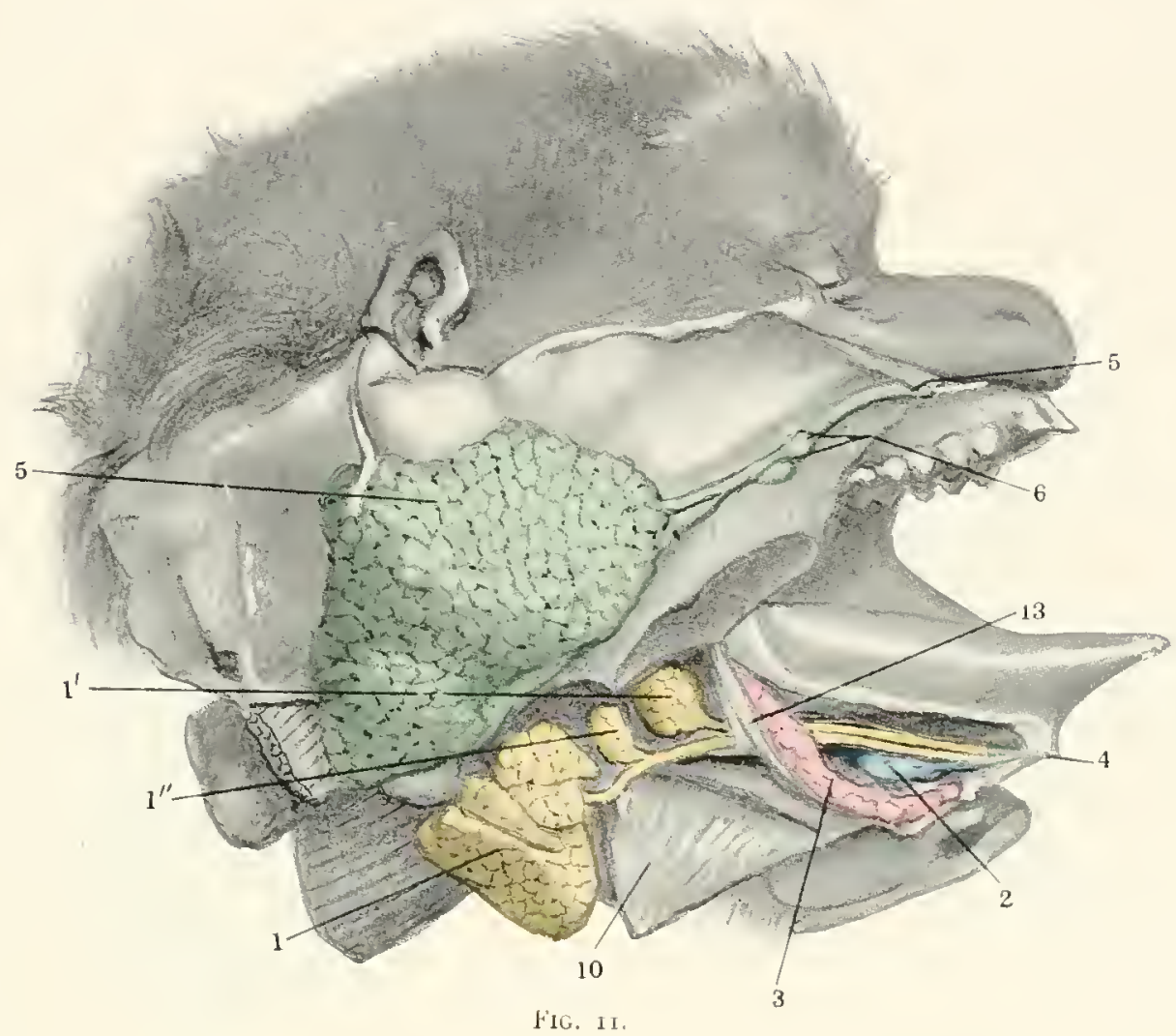


PLATE XXXII

Fici.12. Lemur varius. Ruffed Lemur. Columbia University Mlorphological Museum, No. 2I 50.

I. Submaxillary gland.

2. Greatter sublingual gland.

3. Lesser sublingual glands.

4. Common terminal segments of submaxillary and greater sublingual ducts.

5. 5. Parotid gland and duct opening.

7. Superior alveobuccal or molar glands.

8. Palatine glands. 


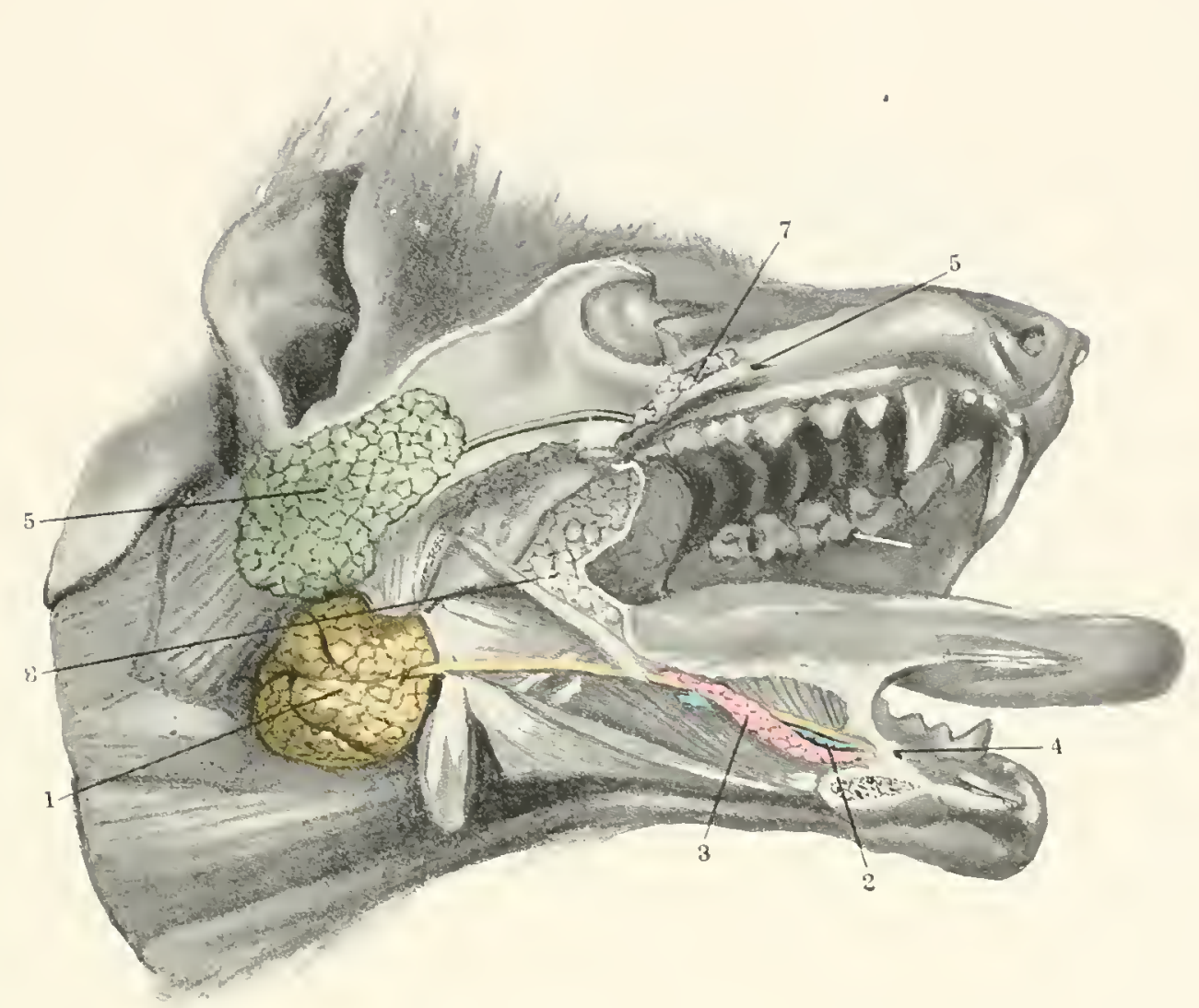

IIIG. I2 
PLATI: XXXIII

FIG, 13. Lemur mongoz. Wholy Lemur. I'rinceton University Morphological Museum, No. If8z.

$I, I$. Submaxillary glanel anel duct.

3. 3. Lesser sublingual glands and duct openings.

5.5. Parotid gland and duct.

7. Superiur alveobuccal or melar glands.

20. Lymphatic nodes. 


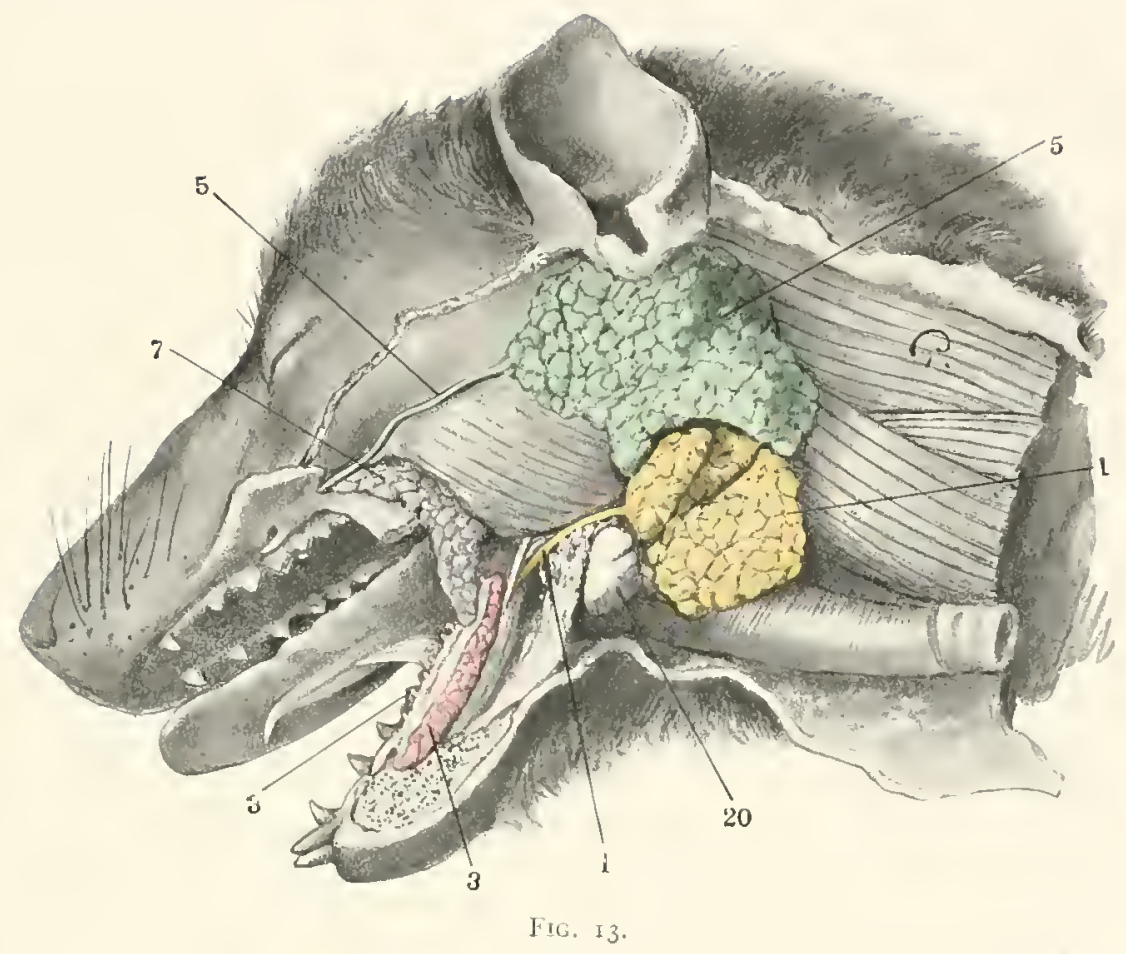



PART IV

\section{GENETIC INTERPRETATION OF THE PRIMATE ALVEO- LINGUAL SALIVARY AREA}

\section{By Geo. S. Huntington}

THE attempt to furnish a morphogenetic interpretation of primate salivary organization in the sub- and inter-mandibular area, based on observations in adult man and in the lower genera of the primate order is necessarily restricted by the limits which our relatively scant knowledge of primate salivary ontogenesis imposes. The present state of our information on the development of the salivary glands in the human embryo is summed up in a separate chapter of this volume by Schulte (cf. Part II), who has been able to supplement the small and incomplete series of previous records by new observations based on additional material. We lack, on the other hand, as yet all knowledge whatsoever regarding salivary development in the lower primates.

In attempting, therefore, at this time a definition of the morphological significance of the entire primate salivary apparatus of the intermandibular area, as well as of the relative value of its individual components, we are forced to draw our conclusions from the following available sources:-

I. The structure of the adult human salivary glands of the alveolingual region, including variants.

These olsservations are valuable because the large number of available individuals enables us to determine both the average normal and the occasional variant conditions. A more comprehensive and definite comparison of the human structures with those of lower primates thus becomes possible.

2. The development of the aveolingual salivary glands in the human embryo, as far as the same is at present ascertained. 
3. The adult inter- and sub-mandibular salivary structures in the lower primates.

4. In riew of the unavoidable limitations of these sources of information it seems not only permissible but desirable to enlarge the riewpoint by a critical comparison of primate conditions with those found both in the adult and embryo of other mammalian orders.

It will, however. be obvious that a generalized morphological analysis of the primate salivary field here concerned can, in the absence of definite ontogenetic information on miny important and critical points, possess at best only a tentative value, and must remain subject to further revision, as the material for its completion and correction may become available.

In seeking for a satisfactory interpretation of the widely diversified glandular organization encountered in adult primates, and, secondarily, in adults of other mammalian orders, the observer becomes convinced that in spite of the multiplicity of the types, often differing materially on the two sides of the same individual, some inherent genetic ground plan is common to all grades of variation and combination, and that the establishment of adult sub- and inter-mandibular salivary homologies in mammals must be based on the definition of a comprehensive potential genetic field in which ontogenetic and phylogenetic selection becomes responsible for the development of the individual types of the adult animal. In other words, the same genetic method, which has made the interpretation of the closely interlocked axial vascular channels of adult mammalia possible, may prove of equal service in clarifying the involved problem of the mutual relations of mammalian salivary glands.

This result might be achieved by adopting the following procedure:

r. The establishment of a general theoretical dogmal of salivary - development within a plastic and uniform ontogenetic and phylogenetic framework, which would include all individual types and allow such individual types to erolve from the common comprehensive ground plan by embryonic selection and further development of typical districts, with suppression of the intervening areas.

2. The alignment of actually recorded adult conditions within the appropriate sections of the common framework. thus permitting close analysis of divergent types. 
3. The collection and interpretation of all arailable ontogenetic data in support and definition of this theoretical morphogenetic field and of its specialized lines of higher development.

In pursuing this plan for determining the mutual relations of adult salivary components of the sub- and inter-mandibular regions in primates, and. secondarily, in other mammalian orders, it is desirable at the very outset to assemble briefly the facts offered by mimmalian salivary ontogenesis in this region in support of the far more extensive theoretical assumptions upon which the generalized interpretation is based. Schulte's investigations of the development of the salivary glands in the luman embryo and in other mammals, notably the cat and pig, are given in full in other parts of this work (Parts II, VI, VIII).

For the purposes of the present consideration it is only necessary to briefly define some of his results bearing directly upon the problems here involved.

He has established the following facts:-

I. The primary anlage of a future gland or of a circumscribed glandular area develops in a definite and constant situation and grows thence in both directions, cephalad and caudad, by further extension and proliferation of the glandular epithelium.

2. In the components which appear in the adult as larger definite glands with main ducts (submaxillary and greater sublingual) the caudal extension is a continuous and uninterrupted ontogenetic process. and unfolds, by epithelial proliferation, the secreting elements of the gland proper, and the intraglandular system of ducts. The cephalic extension, from the site of the primary embryonic anlage, forms the extraglandular duct of the gland along the line of a primitive epithelial keel, which subsequently becomes canalized.

3. This cephalic prolongation of the glandular anlage may appear as the continuous and uninterrupted derelopment of the epithelial keel. On the other hand the process may be discontinuous. In the latter case the sagittal line subsequently occupied by the completed canal presents in the earlier stages segments of the epithelial keel separated by-barren intervals in which as yet no anlages of the future duct exist. The latter is finally laid down by elongation of the primitive separate anlages and their subsequent fusion with each other, 
thus bridging the intervals to form a continuous epithelial keel whose canalization will establish the definite duct.

'This observation is of very great significance because it establishes the morphogenetic principle of ultimately continuous glandular ducts by union of originally separate and distinct salivary anlages. This process is extremely reduced and evanescent in the mammalian embryo, but its occurrence, even to the limited degree observed, establishes its validity as a developmental character in earlier phylogenetic conditions.

4. The separate and distinct glands which, as the lesser sublingual group, occupy the lateral alveolingual district in all adult primates. appear in the human embryo relatively late ontogenetically. The elements which first develop sprout at intervals from a continuous lateral epithelial keel of the alveolingual area, the most cranial buds appearing first. In the later stages these lose the early association with the keel, while multiple additional elements (Chievitz, Hammar) develop as direct individual derivatives from the epithelium of the lesser sublingual field.

It seems proper to interpret these ontogenetic findings in the following sense in their bearing on the phylogenetic history of the alveolingual field:

a. The separate and individual glands forming the lateral lesser sublingual group represent the more primitive archeal type of glandular development of the oral floor.

b. In the median districts of the submaxillary, and of the more inconstant greater sublingual, they have very largely abandoned this primitive type by combining to form definite major glands with common ducts. The discontinuous development of the latter, by fusion of originally separate anlages of the epithelial keel, is the last reminiscence of phylogenetically older conditions.

c. The lateral group of the lesser sublingual glands, on the other hand, very largely maintains the primitive type of separate individual glands each with its own short duct.

d. The lateral anlages, which are the first to appear ontogenetically, seem inclined to follow the phylogenetic advance which already completely dominates the submaxillary, and, to a lesser degree, the greater sublingual line. This is manifested by the fact that the earlier lesser sublingual elements are associated with an epithelial crest or keel. 
If they had followed this first impulse toward a higher type of compound glandular development the temporary keel would have evolved into the common duct draining a group of lesser sublingual elements now united within the frame of a separate major gland. The tendency toward the formation of such a gland evidently exists in the lesser sublingual field, but is, in the evolutionary sense, not yet sufficiently developed to produce typical and constant adult results. On the contrary, the attempt on the part of the first lesser sublingual elements toward a definite association into a separate gland with common duct is temporary and soon abandoned. The components implicated in this attempt then revert to the common primitive type and are included in the group of the more numerous buds which appear at a later ontogenetic period and remain from the beginning as separate individual structures. It is interesting to note that the more highly advaneed and special components of the alveolingual complex, as the submaxillary, predominant in the adult, are also the first and most fixed to appear ontogenetically, whereas the phylogenetically more ancient and primitive form, as the lesser sublingual group, develops at a much later embryonic period. Further, that this chronologically: earlier and more adranced condition is manifested even within the confines, of the more primitive lateral lesser sublingual area by those components which, through association with a temporary epithelial crest, aspire toward the assumption of the more highly differentiated medial type of separate major gland development, even although they do not ultimately attain this status. It suggests that the line of greater structural and functional evolution has traveled mesolaterad from the lingual to the alveolar border of a common primitive uniform glandiferous intermandibular area.

5. If the above suggested interpretation of the ontogenetic conditions is eorrect, the primate alveolingual salivary field illustrates two important embryonic conditions:-

a. In selective development, with the greater structural and functional advance of individual districts of a common field, the anlages of the portions so selected and differentiated appear earlier in the ontogeny than the components of the more primitive areas. The potential greater functional value of the preferred elements to the organism as a whole may account for this preference. 
b. The details of embryonic organization follow not only the biogenetic law of revealing rudiments of phylogenetically abandoned stages, but they also offer evidence of progressive changes toward a higher evolutionary type. Thus, in case of the early lesser sublingual anlages, sprouting from a common epithelial keel, this attempted morphogenetic advance of selected components of the entire group to a higher and more specialized glandular type, is not a reversional reminder of past phylogenetic conditions, but a temporary and evanescent indication of a progressize tendency toward the acquisition of a structurally more complex and, probably, functionally more efficient organization.

6. The inference lies at hand that the genetic cause of the inconstant and variable occurrence of the greater sublingual (Bartholinian) gland may be sought in this relation of the medial and lateral alveolingual areas. The former represents the earliest and oldest line along which specialization of the component elements led to the establishment of the constant and largest major gland, the submaxillary, with all its range of accessory and secondary glandular development. The latter is still largely in the primitive condition, developing numerous individual separate glands. Between the two is the debatable intermediate field, occupied occasionally by the greater sublingual gland and its duct. In the most thoroughly known primate, man, this gland, when present, varies much in size and in the termination of its duct. The latter may open independently on the plica sublingualis, or join the termination of the main submaxillary duct. In many other human adults the gland does not develop. Individual instances of its occurrence on one side and default on the other side of the same subject are not uncommon. Its variable development in the lower primates has already been described (Part III). In the lower primate types, in which it is recorded as absent in the individuals examined, and in the corresponding human variation, the lesser sublingual group is usually large and extensive. The distinct impression is given, by the examination of a series of primate forms, that the more medial elements of the lesser sublingual complex tend, in the primate order, to become associated into a separate gland with a common duct, the greater sublingual or Bartholinian component of the entire alveolingual group. That this tendency has not yet 
developed to the phylogenetic point of yielding constant results, is shown by the inconstant and variable occurrence of the greater sublingual gland in the different primate genera and by the human adult variants. When present, it is normally situated on the mesal aspect of the remainder of the lesser sublingual mass of separate glands, reducing over the area of its own extent, the bulk of the latter. In only a single individual of all the primates examined (the variant specimen of Troglodytes shown in Fig. 2 of Part III) does it lie lateral to the lesser sublingual group. Normally, therefore, it is intermediate in position between the submaxillary and the lesser sublingual districts. If, as above suggested, the evolutionary tendency toward the production of major and functionally more effective glands manifests itself in a mesolateral direction from the lingual toward the alveolar sulcus, the medial elements of the lesser sublingual group would be the first to respond to this impulse, which may have attained the point of establishing in a large number of primates the intermediate greater sublingual gland and duct. In this case the evanescent appearance in rudiment of the same process in the remaining lesser sublingual field may portend the gradual future acquisition of a distinct third sublingual gland out of primitive component elements at present still included in the general mass of the lesser sublingual group.

7. While Schulte's researches clearly prove that mammalian intermandibular salivary development in general proceeds along typical and definite lines, selected from the entire available alveolingual field and separated from each other by barren and non-productive intervals, yet he notes the occurrence, in these intervals, during the ontogeny, of occasional rudimentary glandular anlages which do not develop into permanent functional salivary components. This observation offers strong presumptive evidence in favor of the concept of a primitive and uniform glandiferous oral floor, which potentially, by phylogenetic selection, becomes subdivided into specialized and independent districts. These ontogenetic observations, in themselves scanty, are confirmed by the adult conditions in man and the lower primates already recorded, such as the extension of individual elements of the lesser sublingual type mesad of the line of the submaxillary duct.

8. Lastly, his analysis of the ontogenetic stages in this mammalian salivary area proves the influence which the mechanical conditions 
and the topographical relations of the oral cavity and its environment exert during development on the ultimate disposition and arrangement of the individual salivary components. His results suggest that this influence may be one of the strongest factors responsible for the initial selection of special areas of a common primitive glandiferous field for more individual and higher development as distinct and independent major glands. (Cf. Schulte, Parts VI and VIII.)

\section{Genetic Theory of Primate Alveolingual Salivary Development}

The ontogenetic conditions just outlined, and the additional evidence supplied by the adult salivary structures of this area in some of the lower vertebrates, make it possible to conceive the entire alveolingual gutter of the oral floor as the site of a group of primitive equivalent individual glandular anlages distributed uniformly over its entire extent. This common potential field may be assumed to be capable of specific differentiation into distinct separate districts of ontogenetic salivary activity. This tendency to rearrange the individual components of the glandiferous area into specialized groups may manifest itself along, -

I Coronal lines of segmentation.

II Sagittal lines of segmentation.

III Lines which are formed by combinations between sagittal and coronal segmentation.

Thus if the left side (I) of Fig. I represents the uniform diffuse development of separate glands in the alveolingual gutter, these elements can be arranged into the three cephalocaudad groups, $A, B, C$, shown on the right side of the same figure (II) by the coronal lines of segmentation indicated at $a$ and $b$, along which suppression of glandular formation occurs. The left side of Fig. 2 (III) shows the rearrangement of the same elements into the lateromesal divisions, . I, $B, C$, separated by sagittal lines of segmentation $a$ and $b$.

On the right side of the same Fig. 2 (IV) a combination of sagittal and coronal division has selected certain of the elements into a compound gland whose cephalic elements unite in to a common duct, while 
the lateral border of the field is occupied by a number of separate small glands surviving from the primitive sagittal line $A$ of the left side.

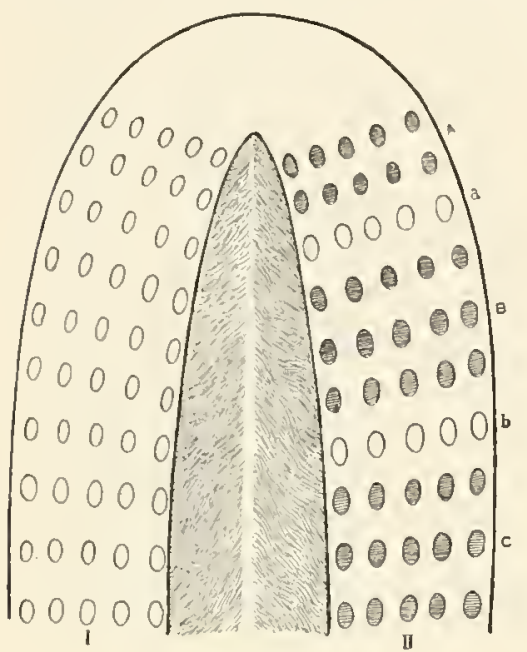

FIG. I.

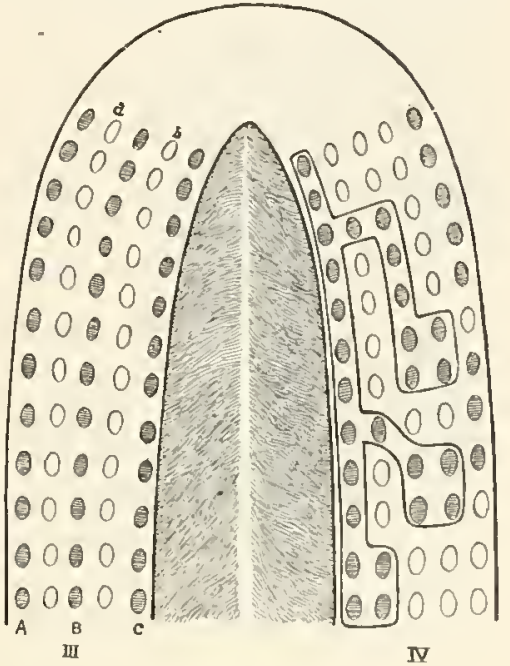

FIG. 2.

If the entire genetically available field of the alveolingual glandular anlages were imagined spread out in the form of a square containing ten individual anlages each in ten sagittal and coronal lines, it would be theoretically possible to deduce from the one hundred separate glinds, through continued development of certain groups and suppression of intervening elements, the definite patterns characterizing the various types of adult glandular arrangement in this region, provided the fact were recognized that some of the primitive anlages are destined to develop into conducting canals, while others group together to form the secreting glands. Thus if the series of separate glands shown on the left side of Fig. 3 have genetically resulted from selective development and differentiation of the corresponding portions of a primitive uniform alveolingual field shown on the right side, this process might be analyzed in the schema given in Fig. 4. Here the chief line of cleavage is at the coronal level $F$, and it divides the entire complex into main cephalic and caudal groups. The coronal cleavage line $F$ may not be absolutely retained throughout, in which case, for example, the four primitive glandular anlages forming the 


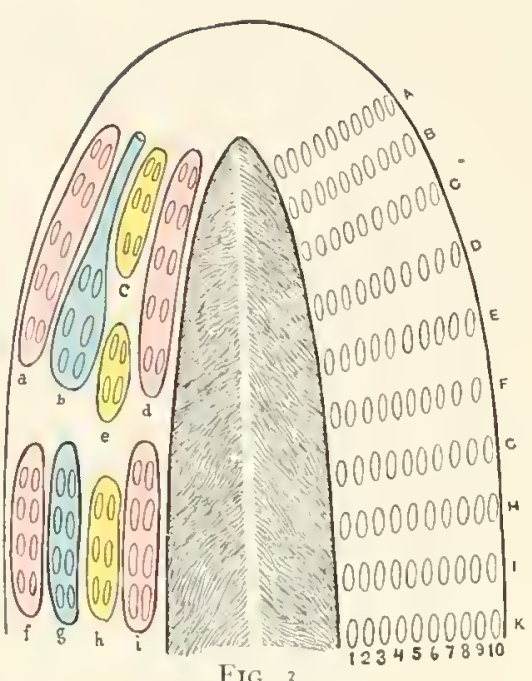

Fig. 3 .

group $e$ may bridge the interval. There are further subdivisions of the main cephalic and caudal groups by secondary lines of sagittal segmentation. The resulting individual glandular collections, $a, b, c$, and $d$. belong wholly to the cephalic group, the corresponding caudal masses, $f, g, h$, and $i$, form the individual components of the main caudal group, while the separate element $\varepsilon$ bridges the principal coronal interval $F$ and occupies an intermediate position between the two chief divisions of the entire area. The majority of the thus individualized districts selected from the primi-

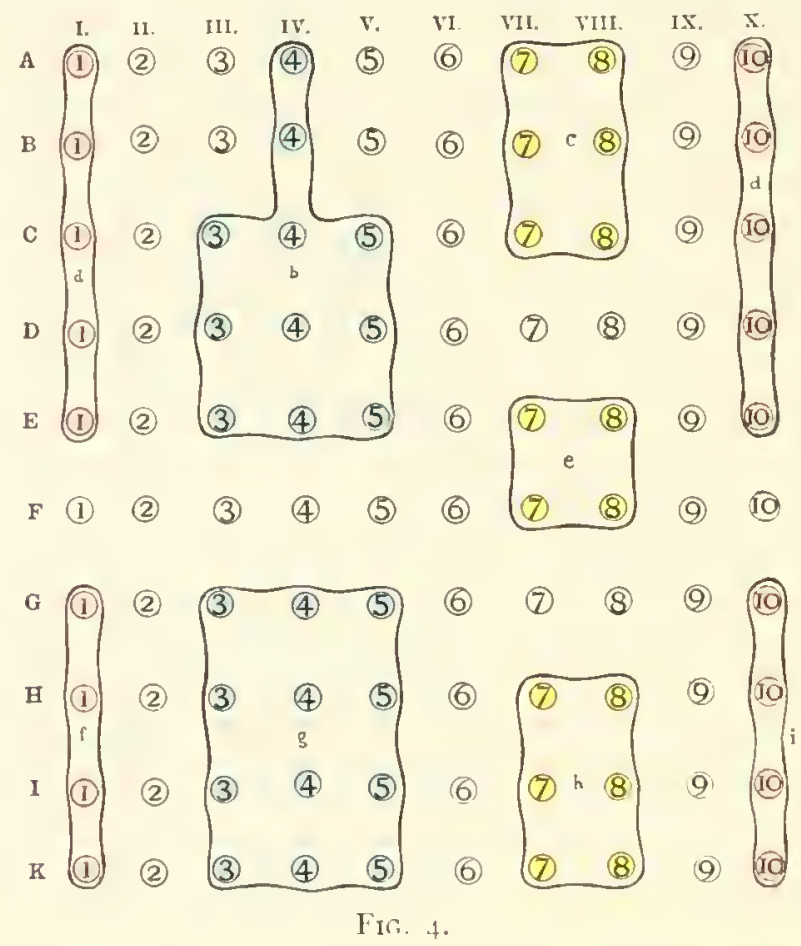


tive uniform anlage for further development may retain the earlier character as collections of separate indiviclual glands, each possessing a distinct opening upon the oral mucosa. The border fields along the sagittal lines $I$ and $X$ are especially so characterized, forming cephalocaudal series of simple glands, only interrupted at the coronal cleavage level $F$.

It is, however, possible that in certain areas portions of the available anlages of a definite district unite to form a conducting canal, while the remainder develop the secreting glandular mass draining into the same.

Thus, in the cephalic division in Fig. 4 , the two elements $A^{4}$ and $B^{4}$ of sagittal line $I V$ may unite and acquire a lumen forming a duct for the secreting gland produced by continued development of the nine primitive anlages, $C^{3.450}, D^{3.45}$ and $E^{3.4 .5}$. The whole intermandibular salivary apparatus in such a case will then differentiate in to a complete compound gland $(b)$ whose body and duct are embedded among the adjacent masses of individual simple glands, which in turn are separated from each other by the lines along which glandular development was suppressed.

This general type of intermandibular glandular distribution finds representation among adult vertebrates in a few forms (reptilian) in which "anterior" and "posterior" "sublingual glands" are distinguished.

Among the mammalia the chicf lines, along which segmentation of the primitive uniform glandiferous field of the oral floor takes place, are sagittal, resulting in the formation of a series of cephalocaudally directed glandular integers, separated from each other by the intervening sagittal strips of mucosa in which gland development is suppressed. This prevailing mammalian type may be carried through consistently, or may be varied by combinations in which the main sagittal segmentation lines of glandular suppression are interrupted by the partial preservation of coronal lines of glandular retention and further levelopment, thus joining elements of adjacent sagittal gland areas to each other in a great variety of types.

Further, the mammalian alveolingual gland field is characterized by the retention along its lateral boundary (alveolar border) of the primi- 


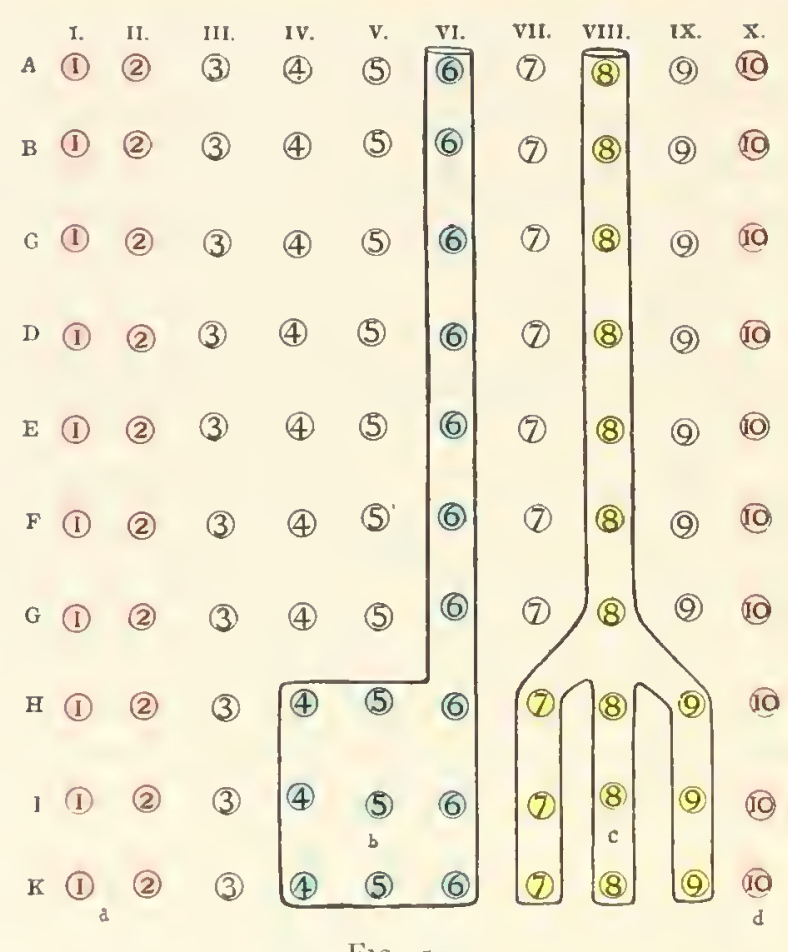

Fig. $5 u$.

tive type of numerous separate glands, each with its own distinct

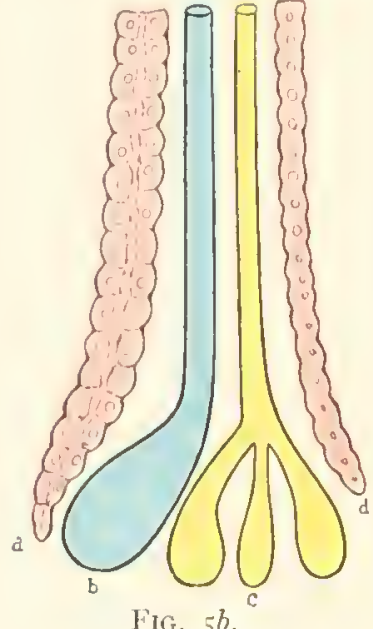
orifice, while further mesad, and especially along the medial (lingual) border the more cephalic elements of each sagittal set tend to unite into a conducting canal, while the more caudally situated anlages develop into the secreting gland proper draining into the duct.

At the extreme median limit of the alveolingual area, and extending partially along the side of the tongue, a much less complete development of separate small gland formation may occur. These scattered separate glands then lie on the mesal side of the main salivary duct or ducts. 
Thus one of the simplest, and at the same time most complete, patterns of mammalian intermandibular salivary development can be schematically represented in Figs. $5^{a}$ and $5^{b}$.

In the genetic analysis of this type, (Fig. $5^{a}$ ) development occurs by cleavage of the uniform field in sagittal lines into four parallel cephatocaudal districts, $a, b, c$ and $d$. In the lateral $(a)$ and medial $(d)$ districts the single glandular anlages of the sagittal rows I, II and X retain their primitive individual character and open by separate orifices along the mesal and lateral ridges. In the intervening region the cephalic components of the two sagittal rows VI and VIII unite to form two parallel and separate ducts draining the two compound glands $b$ and $c$.

In the pattern shown in Fig. 6 the number of distinct glands is reduced to two (Fig. $6 b$ ). Of these the lateral element, $a$, cxtending along the alveolar border, is composed of a double sagittal row of separate glands, each with its own orifice opening on the alveolingual ridge. The rest of the potential oral field yields by selection a complex gland, $b$, with a single main excretory duct along sagittal line I'III (Fig. 6a) which opens by a single orifice. Coronal and oblique lines of duct development extend the drainage area of the main canal into adjacent glandular districts, chiefly laterad of its own course.

This plan of development results in the formation of a main caudal trilobed gland $\left(b, b^{\prime}, b^{\prime \prime}\right.$, Fig. $\left.6 a\right)$, whose duct (IIII) further cephalad receives two additional lateral canals draining the accessory glands $X$ and $Y$.

It will be noted that four of the individual anlages entering into the formation of these accessory glands $\left(B^{6}, C^{6}, E^{6}, F^{6}\right)$ are in the sagittal gland line $V I$, which in the preceding pattern (Fig. $5^{a}$ ) served for the development of the duct of the intermediate gland (b). Also that the body of this latter gland (Fig. $5^{a}$ ) contains four components ( $I^{4}$, $I^{5}, K^{4}, K^{5}$ ) which in Fig. 6a form the lateral element in the trilobed main gland and drain along the oblique duct $I^{6} G^{7}$ into the principal duct formed along line VIII. Individual adult types offer, therefore, two conditions which must be considered in determining homologies:

I. Secretory glandular fields of identical derivation may drain cephalad by separate parallel ducts along sagittal lines to separate orifices, or they may empty by shorter coronal or oblique ducts into an arl- 


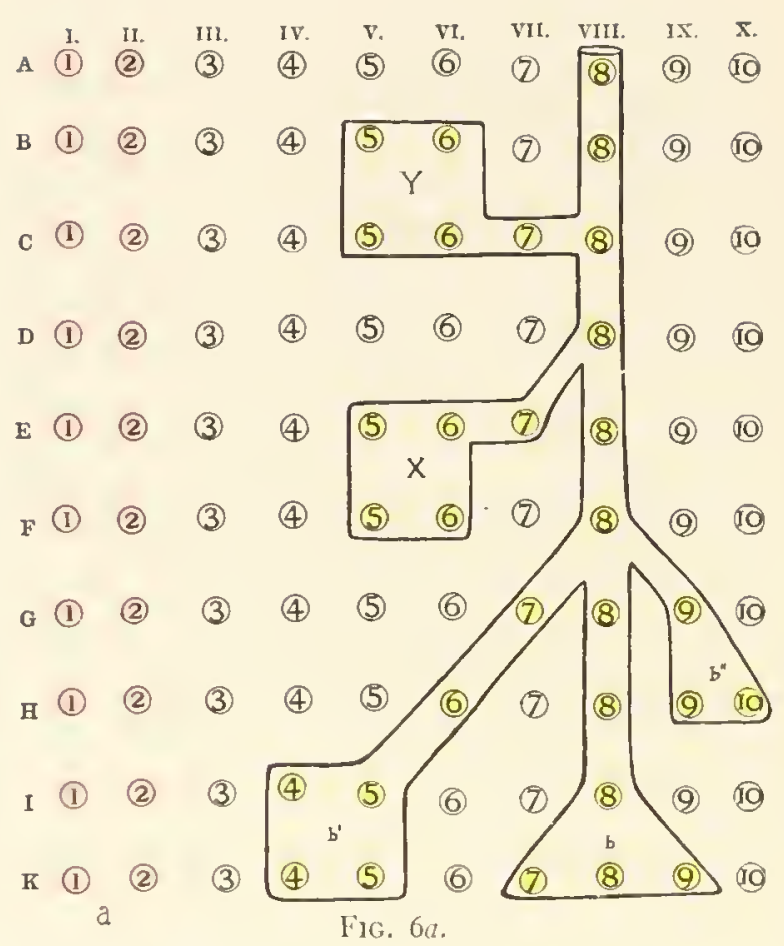

jacent canal as accessory elements added to the glandular complex of the

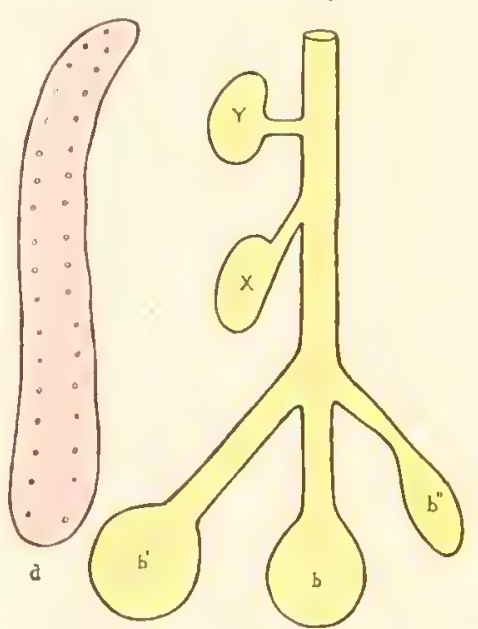

Fig. $6 b$ latter. In this case the number of independent ducts and, consequently, the number of separate duct orifices is reduced, while in the former type of development they are increased.

2. Glandular components of the primitive alveolingual area, which are in some forms used in the development of conducting canals, may, in others, by selective rearrangement, be assigned to the secretory division of the entire apparatus, and thus form part of the actual gland body, instead of entering into the composition of the ducts. 


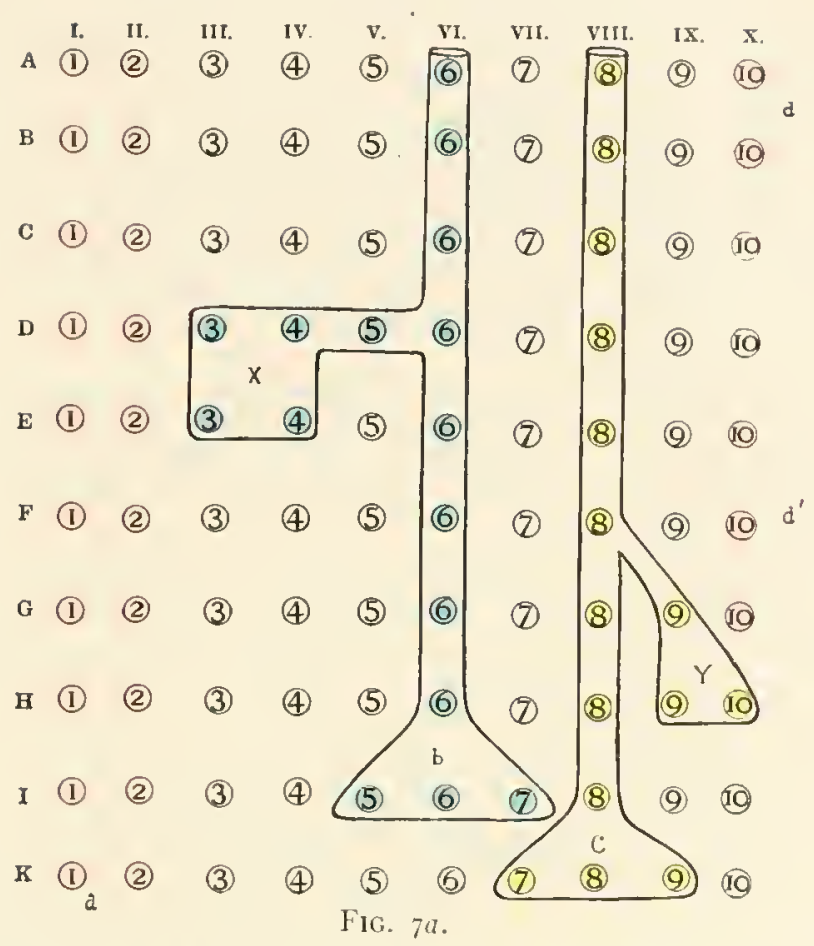

It will be seen that this principle leads to final adult conditions which at first sight appear to differ radically from each other in type, number and extent of the definite permanent glands, while the actual difference in organization depends upon relatively slight changes in the selcction and adaplation of the individual components within the same available framework. This phylogenetic factor is of such importance in the analysis of individual types and of variants that it warrants some further detailed illustration.

In Figs. $7 a$ and $7 b$ the glands are arranged in four latero-mesal districts, $a, b, c$, and $d$.

I. A lateral group of single glands $(a)$ with separate individual orifices, derived by uniform

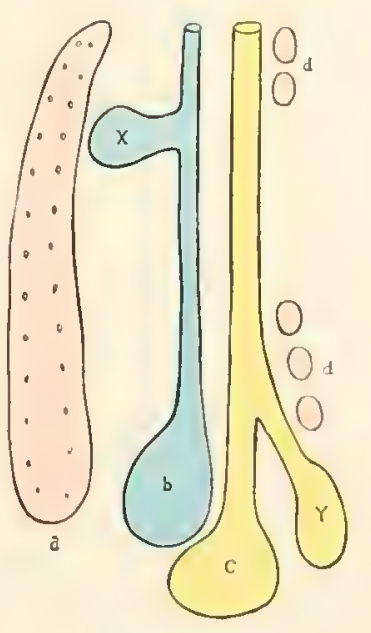

FIG. 7 h. 
development of the primitive anlages forming the genetic lines $I$ and $I I$ (Fig. $7 a$ ).

2. An intermediate gland $(b)$ whose separate duct develops by concrescence of the sagittal anlages of line $V I$ cephalad of the coronal level $H$, behind which point the secreting epithelium of the gland proper arises from anlages $I^{5}, I^{6}, I^{\overline{ }}$. The duct of the gland receives at level $D$ a lateral duct draining a small accessory gland $(x)$ formed by anlages $D^{3}, D^{4}, E^{3}$ and $E^{4}$.

3. A mesal gland (c) formed in its chief part by anlages $I^{8}, K^{7}, K^{8}$ and $K^{9}$, and draining by a duct developed cephalad along line $\boldsymbol{V} I I I$. At coronal level $F$ this duct receives the outlet of a small accessory gland $(r)$ formed by anlages $G^{9}, I^{9}, H^{10}$.

4. Along the mesal border of the field a broken series of single separate glands containing two cephalic $(d)$ and three caudal $\left(d^{\prime}\right)$ components. These represent the partial development of some of the anlages of sagittal line $X$.

Figs. $S a$ and $S b$ show respectively the genetic ground plan and the resulting adult type of a form in which, compared with the preceding Figs. $7 a$ and $7 b$, without altering the total number of the component anlages involved, a different result is obtained. Only a single major duct (c) exists, which, shortly prior to its termination, is joined laterally by the duct of gland $b$. This, from the gross anatomical standpoint, important difference in the organization of the chief intermandibular glands and their ducts, may be assumed to have occurred by the single exchange of a coronal for a sagittal anlage, as shown in the schemata $7 a$ and $8 a$. If $V I A^{6}$ of the former pattern had not developed into the terminal of the independent duct $b$, but if in its place $V I I B^{7}$ had been employed as a coronal link between the conducting lines $V I$ and IIII, then the conditions shown in Figs. $8 a$ and $8 b$ would have resulted.

The two conditions just discussed find their concrete illustration in the two relations exhibited in the adult human subject between the ducts of the submaxillary and greater sublingual (Bartholinian) glands when the latter structure develops as one of the major glinds of the intermandibular complex.

It is thus not difficult to see how by slight shifting in the selection of the available genetic anlages and a small increase in the number of 
PRIMATE ALVEOLINGUAL SALIVARY AREA
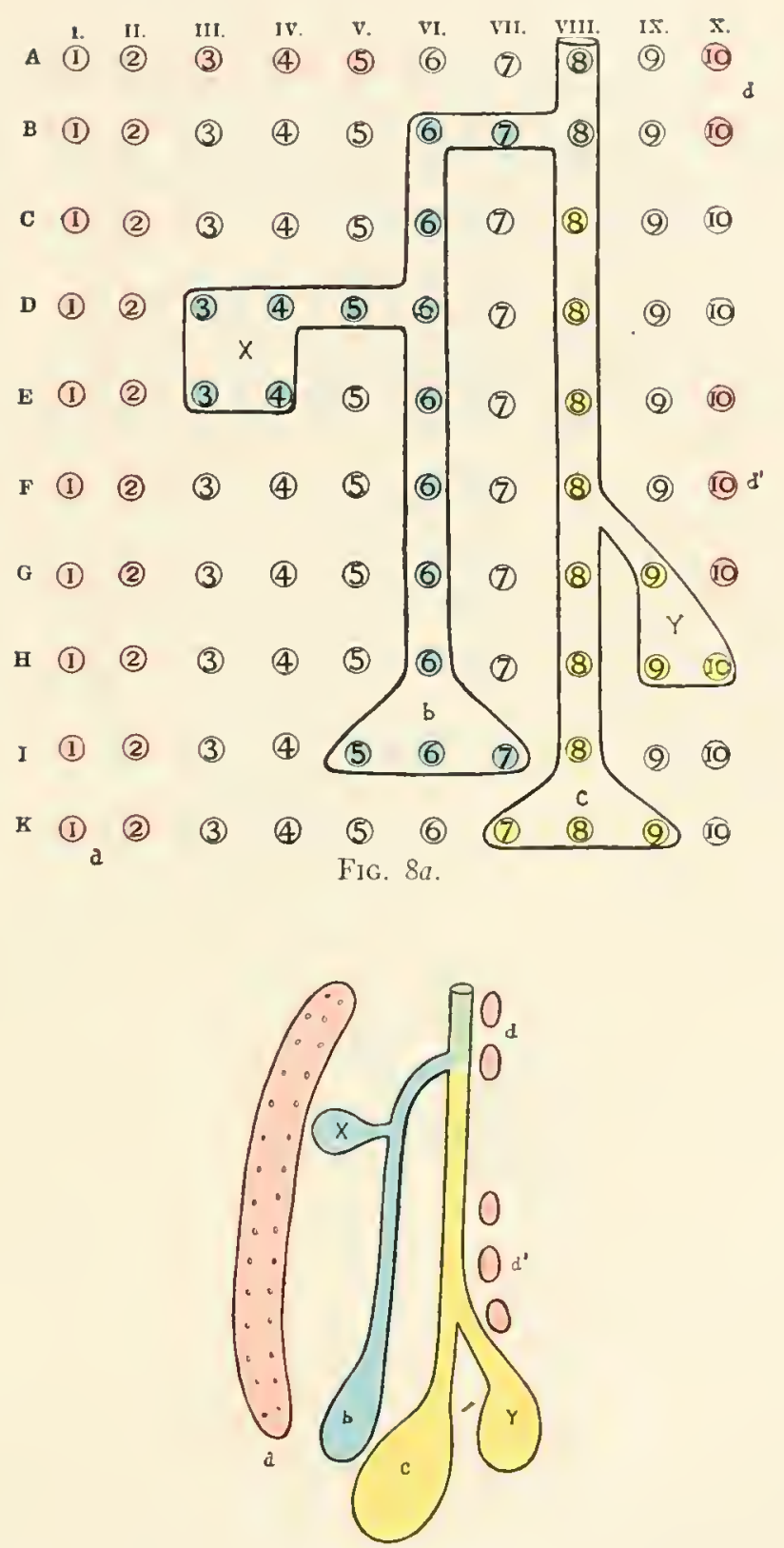

Fig. $S b$. 

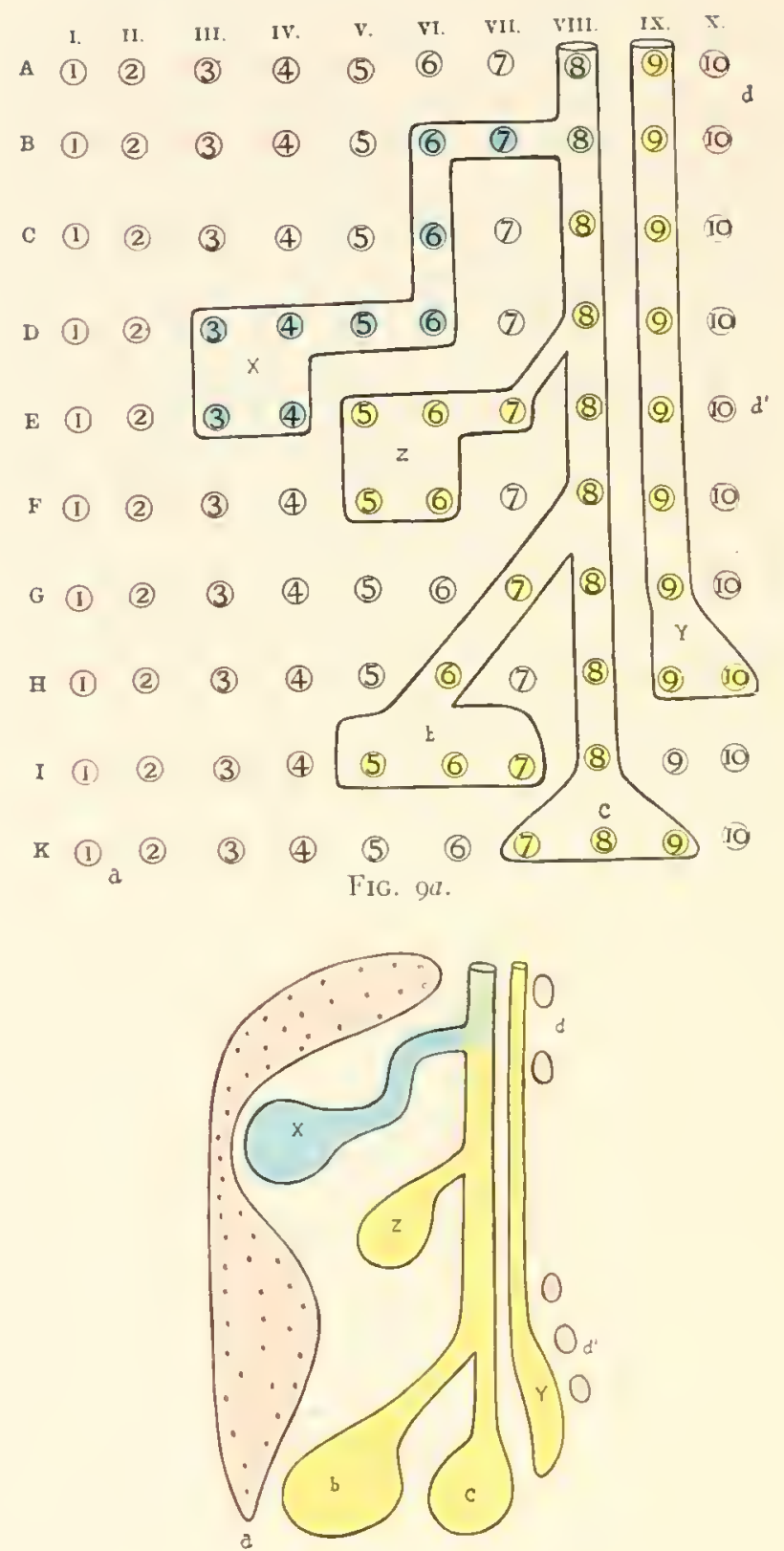

FIG. $9 b$. 
elements employed, the patterns of Figs. 7 and 8 might have been changed to those shown in Figs. $9 a$ and $9 b$, which represent one of the most complex and highly developed types encountered in the entire adult mammalian series. The preceding examples may suffice to suggest the inherent possibilities in glandular combinations.

\section{Mechanical Factors in the Formation and Relations of . the Oral Floor influencing Alveolingual Glandular De- VELOPMENT}

In applying the preceding strictly hypothetical genetic considerations to the interpretation of the adult mammalian types, it becomes evident that development is greatly influenced by the mechanical conditions imposed on a uniform potential glandiferous ficld in the alveolingual region and its immediate environment. The area of the oral floor bounded mesad by the elevation of the tongue, creating the lingual sulcus, and laterad by the vertical projection of the mandible along the alveolar sulcus, suffers in the first place a reduction of its available coronal diameter in proceeding cephalocaudad. This is primarily due to three factors:-

(a) The space occupied by the tongue proper on the oral floor in the interval between the alveolingual gland areas steadily increases in transverse measure in the cephalocaudal direction.

(b) The caudal portion of the alveolingual area is further narrowed from the sides by the prominence of the ramus and the internal pterygoid muscle, and from above by the anterior faucial fold and the contained palatoglossus muscle.

(c) The lingual nerve, in acceding to the lateral border of the tongue, comes, in primates, into close and intimate relations with the oral mucosa and the lateral alveolingual glandular field, and exerts a definite influence on its development.

As previously pointed out (Part III), this topographical relation of the lingual nerve is a peculiar primate character, due to the brachiocephaly and the high development of the mandibular ramus obtaining in the order. These primate characters are not shared by the more generalized mammalian orders, and hence in them the lingual 
nerve does not bear the same relation to the lateral alveolingual field. The details in the carnivore type are further considered by Schulte (Part VI).

Consequently, in the primates, the individual glandular anlages of the entire available alveolingual field, considered as originating at equidistant intervals from each other, will encounter secondary modifying influences in the cephalic, intermediate, and caudal divisions of the entire area.

Cephalad of the intersection with the lingual nerve the topographical and mechanical relations of the alveolingual gutter will permit of a relatively free unfolding of the primitive anlages. At the level of the lingual intersection the entire available alveolingual area will experience a transverse constriction of the potential glandular field, and tend to tilt its individual lateral components dorsomesad toward the faucial and palatine areas, while its medial components will already tend to escape from a strictly intermandibular position, above the mylohyoid, in a caudolateral direction, beyond the confines of the caudal margin of the mylohyoid into the far more available submaxillary interval between this muscle and the digastric. This reconstruction of a possible phylogenetic path of intermandibular glandular development is, perhaps, of value in explaining the intersection of the drainage lines presented by the adult mammalian types of separate and distinct ducts, with indifferent separate glandular development along the lateral border of the primitive available field.

It seems reasonable to assume, without direct reference to the ontogeny of the individual glands presently to be considered in detail, that the escape from the narrowly limited confines enables the primitive glandular anlage to develop more fully into the secretory apparatus of the adult, while the mechanically more limited and restricted area of the primitive generalized field will, under these conditions, suffice for the establishment of a duct, a structure necessarily less exacting in its demand on the available space, compared with the bulk of the secreting gland, and capable of utilizing in addition any remaining portions of the adjacent primitive field for the development of accessory and secondary secreting glandular collections.

The impression which a comparative study of the adult mammalian intermandibular salivary complex gives is that the relation between 
secreting gland and conducting canal is largely governed by the mechanical limits of the supramylohyoid oral floor.

Cephalad of the lingual nerve intersection the available developmental field is ample, affording the opportunity for multiple separate glandular development, as well as for the production of the ducts of the more specialized individual glands. Caudad of the lingual nerve intersection the genetically available space diminishes as the fauciolingual isthmus is approached. This potentially reduced area between the lingual nerve and the anterior faucial pillar is apparently bridged in two ways:-

1. The line of the lateral alveolingual separate glands escapes the constric-

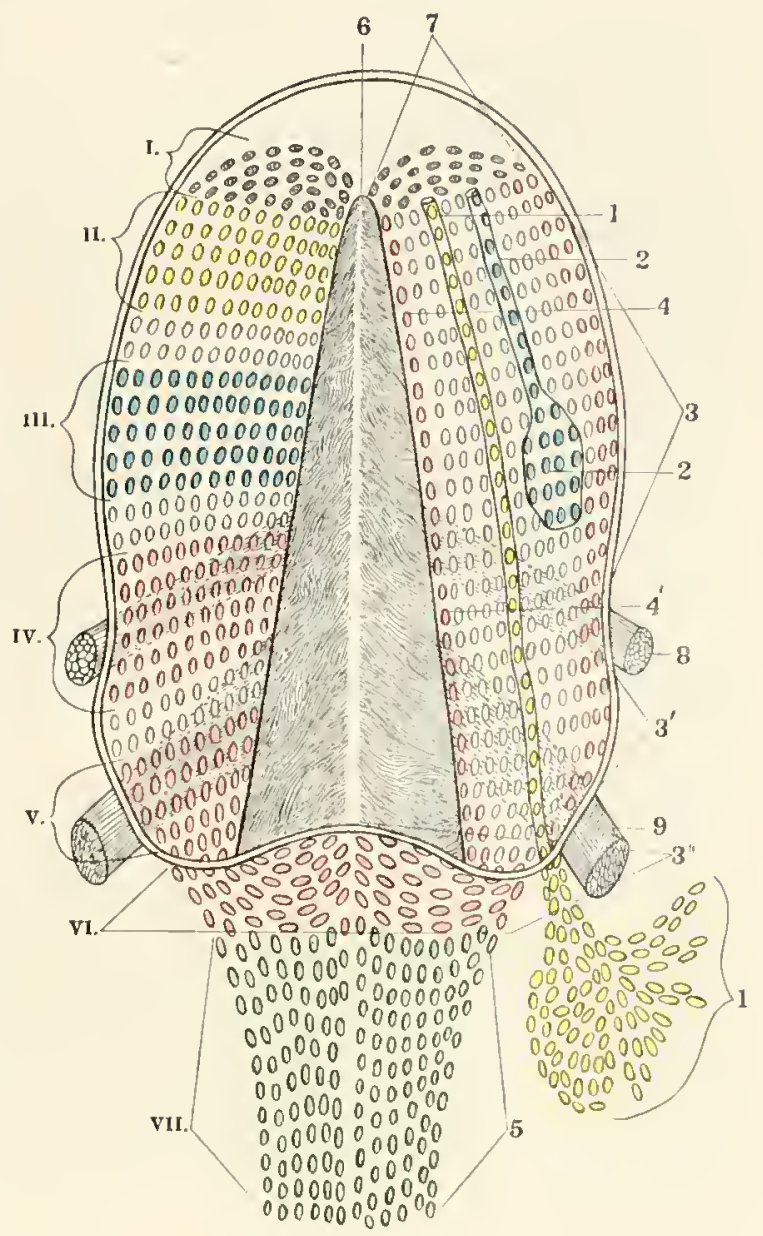

FIG. IO.

$I, I$. Submaxillary gland and duct.

2,2. Greater sublingual gland and duct.

3. Lesser sublingual or lateral alveolingual glands.

$3^{\prime}$. Isthmian glands.

$3^{\prime \prime}$. Palatine glands.

t. Medial alveolingual glands.

$t^{\prime}$. Gland of Weber. 7. Parafrenular glands.

5. Pharyngeal glands. $\delta$. Lingual nerve.

6. Frenulum. 9. Arcus palatinus. 
tion by turning dorsomesad into the anterior faucial pillar and beyond into the soft palate.

2. The medial glandular line, on the other hand, swings caudolaterad, intersecting the preceding alveo-isthmian-palatine line at an acute angle and escapes from the confines of the oral cavity proper, by extending beyond the caudal margin of the mylohyoid into the digastric interval of the submaxillary fossa which permits of the freer unfolding of the main secretory salivary glands.

Figure ro shows in schena the topographical divisions of the alveolingual area.

On the left side the prelingual area cephalad of the lingualis nerve is shown divided into three glandular groups, I, II, III, by coronal cleavage lines. The lingual area (IV) corresponds to the lateral constriction effected by the lingual nerve. Caudad of this point the glandular elements of the postlingual or isthmian area (V) turn dorsomesad into the anterior faucial field and soft palate to become continuous with the glands of the palatine (VI) and pharyngeal areas (VII).

The right side of the same figure shows the developmental plan usually followed in mammals, characterized by retention of separate single glands along the lateral (3) and to a much less degree along the medial $\left(f, f^{\prime}\right)$ border of the field, while the intervening area gives rise to the ducts of the submaxillary $(I)$ and greater sublingual (2) glands, whose bodies, extending beyond the mylohyoid border into the digastric interval of the submaxillary fossa, find here greater opportunity for developing the secretory portion of the salivary apparatus. 
III. Detalled Analysis of the Adult Primate Sub- and INTER-MANDIBULAR SAlivary COMPLEx ON tIE Basis OF the Preceding Genetic Theory

A study of the individual primate adult forms previously describerl, on the basis of the genetic interpretation just outlined, is, perhaps, best undertaken without reference to the zoölogical position of the species considered. This procedure has the double advantage of allowing variants (chiefly human) to be grouper with other primate types along morphogenetic lines, and of accentuating the plasticity of the alveolingual area in a developmental sense by direct comparison of adult types derived from individual examples of widely separated zoölogical primate genera.

It may, however, be appropriate at this point to clearly define the meaning of the analytical study of primate alveolingual salivary organization.

From what has already been said the inference might be drawn that the arrangement of the glands in any given adult individual is a matter of pure chance in selection of one developmental route out of the many offered, and that in consequence the actual individual type of glandular organization is of no morphological and phylogenetic significance. This is by no means the case. We are dealing here with conditions which, for example, are repeated in the development of the postrenal segment of the postcaval vein in the cat. In this latter instance a uniform and comprehensive groundplan of available periaortal axial venous channels is actually provided in every embryo. In the course of what we regard as normal and typical development, the majority of individuals select one of these numerous available hydrostatic lines, the right supracardinal, for further development into the adult ressel. This particular vascular area of the cat is, however, signalized by a very extensive range of primary adult variations. Each of the variants recorded in a large series of adult animals fits accurately into the framework of genetic possibilities offered by every embryo in the earlier stages. Consequently, we are in this case absolved from the necessity of going beyond an ontogenetic explanation of recorded adult variants. They all show clearly the embryonic selection of an available venous pathway, which is not so used by the 
majority of the individuals composing the genus, but which, at one time in the course of normal derelopment, was equally available to all. It would not be difficult to reason from these findings far forward along the line of future specialization to a point in the cat's vascular development where the at present unlimited choice of axial venous pathways becomes reduced ontogenetically to a degree permitting only limited selection of vascular lines for further development into adult conditions. With the attainment of this stage the cat would, in this department of its venous system, possess far greater "fixity of type" than it at present enjoys.

If we translate these findings to the entirely different field of alveolingual glandular development, then it becomes apparent, from our knowledge of the development of these structures in man and in some of the lower mammalia, that the mammalian embryo, if it ever phylogenetically retained an unlimited choice for the selection of special lines of glandular derelopment, no longer enjoys the liberty.

There is some ontogenetic evidence, as previously stated, that a more liberal and comprehensive groundplan formed the basis for the evolution of the present embryonal and adult types of alveolingual salivary organization. But in general the mammalian salivary glands of this region develop in each inclividual along ontogenetic lines which are definite and limited from the period of their first appearance up to the accomplishment of the final result.

Notwithstanding these facts, we are confronted in the adult with a very considerable range of individual variation.

Man is, at present, the only primate available for the purpose of determining this variant range in the adult. In him we encounter three perfectly distinct adult types in the relation of the submaxillary line to a possible intermediate element, the greater sublingual gland and its duct, and to the lateral group of separate and distinct glandular elements which form the division of the "alveolingual glands" or of the lesser sublingual glands. This analysis is entirely" independent of the complications introduced into the interpretation of the adult human "massa sublingualis" by the incorporation into the same of elements derived from the submaxillary line by the development of "accessory" or "secondary" submaxillary components. 
We are hence confronted with a series of adult human variants which practically include, within their own scope, the entire range of the various types established by the detailed examination of adult individuals belonging to the various genera and species of the primate order of mammals.

It follows that observed types of salivary organization in imlividuals have the gambler's value of a concrete instance of the number of points shown by the cast dice. Still the culbe of the dice must show on each face all of the available points, and if, in a long-continued succession of throws, the same results appear, then it is fair to assume that they are weighted. In other words, the organization of the alveolingual salivary area obtaining in a majority of individuals of any particular group represents the product of all possible combinations plus a determining factor. This establishes an average phylogenetic type for the group as a whole accuired during its period of definite differentiation. This view does not limit individuals of such a group to a constant and necessary conformity with the prevalent and standard type of salivary organization. It does, on the other hand, imply that departures from this standard, common to the group as a whole, have attained the value of phylogenetic, in contradistinction to ontogenetic, variants.

In analyzing the adult primate salivary glands of the alveolingual area including those of man, in the light of the preceding genetic considerations, all the conditions above reported may be grouped under the following main headings:-

I. Primate forms in which all three of the typical sagittal alveolingual lines of potential salivary development are utilized and in which the adult individual consequently possesses the lateral or lesser sublingual group of individual glands, the intermediate or greater sublingual gland and duct, and the medial or submaxillary gland and duct (with or without accessory and secondary glandular elements).

This general group is divided naturally into the following subsections :

A. Forms in which the submaxillary and greater sublingual glands carry their respective ducts to separate and distinct parafrenular orifices without producing accessory or secondary derivatives of the 
ducts. The simplest type of this salivary complex is found in Simia satyrus (Fig. 1, Part III) and Macacus cynomolgus (Fig. 6, Part III).

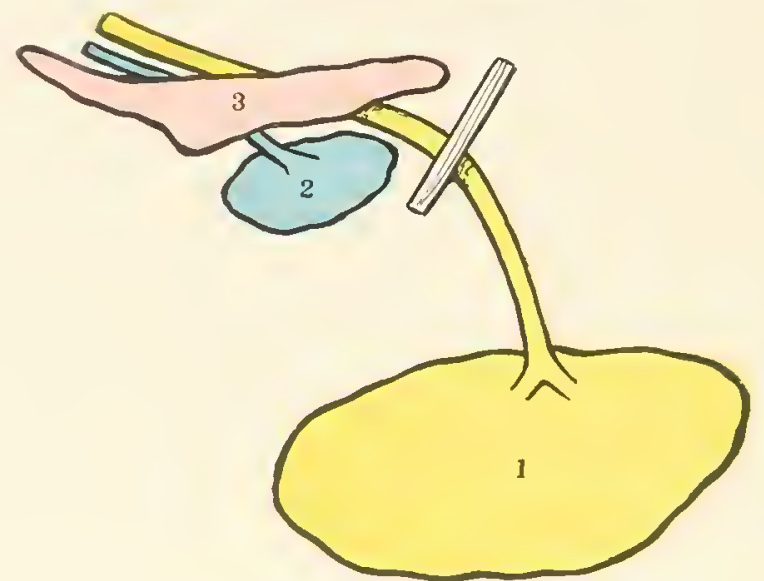

Fig. I1. Schema of alveolingual salivary complex of Simiz satyrus (Part III, Fig. I).

In outline these conditions are here reproduced schematically in Figs. I I and I2, and their genetic interpretation is shown in schema on the

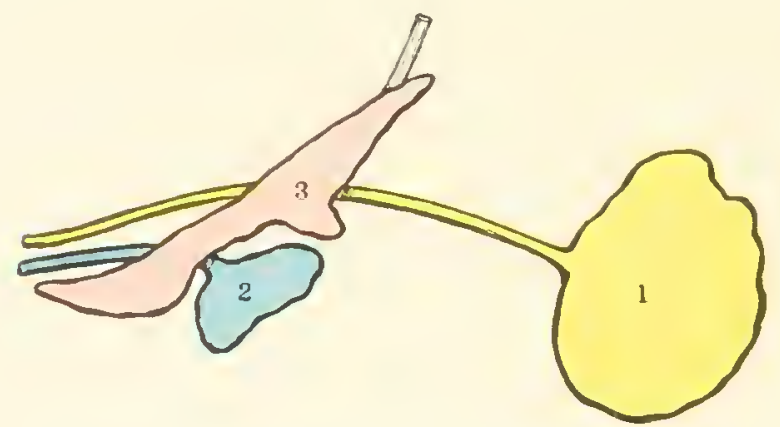

FIG. I2. Schema of alveolingual salivary complex of .Iucicus cynomolgus (l'art III, Fig. 6).

right side of Fig. I3. These primate examples are characterized by the following features:

(I) The submaxillary gland $(I)$ is relatively large.

(2) The submaxillary duct, from its emergence at the glandular 
hilum, continues as a clean-cut canal, without efllorescence or lateral derivatives, to its own individual parafrenular orifice.

(3) The glandula sublingualis major, s. Bartholini, the greater sublingual gland (2) of the terminology adopted in this paper, repeats the characters of the submaxillary gland and duct, but remains confined to the cephalic portion of the alveolingual field, forward of the lingual nerve intersection, in close topographical association with the main submaxillary duct and with the mass of the individual lesser sublingual glands.

(4) The lesser sublingual (Rivinian) glands (3) form the lateral component of the entire complex, and extend as a group of separate and individual glands in Macacus cynomolgus (Figs. 6, Part III, and I 2, Part IV) caudad of the lingual nerve intersection toward the arcus palatinus and the glandiferous area of the soft palate (Fig. I3, $\left.3^{\prime}\right)$, while in Simia satyrus (Figs. I, Part III,

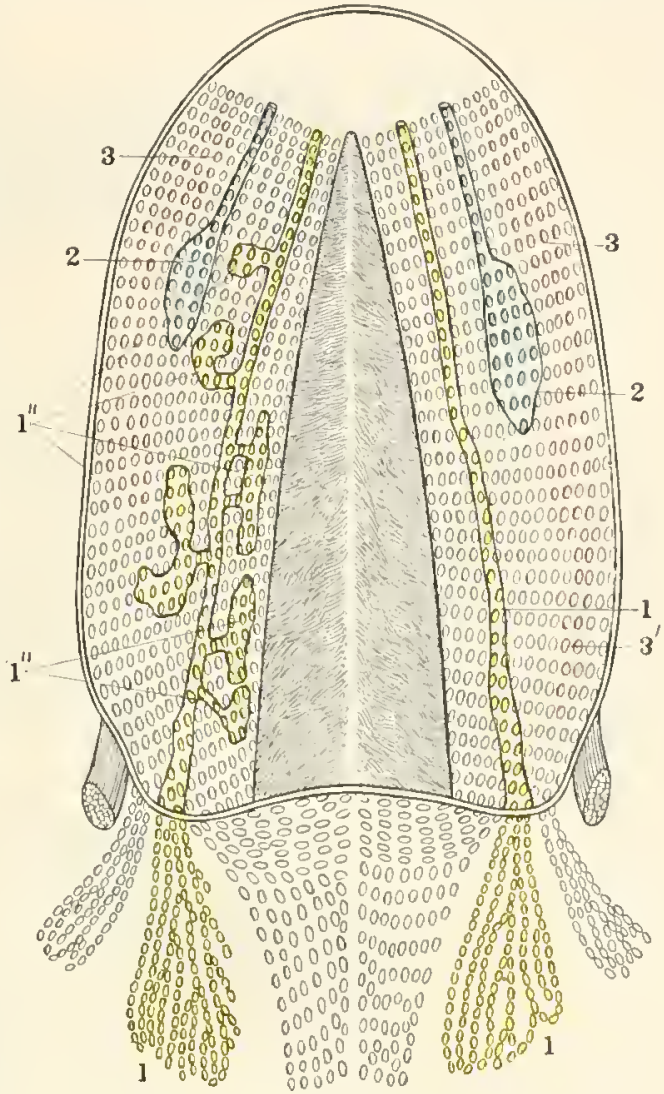

FIG. I3. and 1 i, Part IV) the caudal limit of the group (loes not extend as far as the lingual nerve.

$B$. Included in this general first primate division are instances of adult salivary organization in which, while all three potential sagittal genetic lines are utilized, the conditions become more complicated because the median or main submaxillary line develops the additional 
accessory submaxillary glands ( $\left.I^{\prime \prime}\right)$ above detined as emptying into the submaxillary duct.

This is a rery prevalent primate type and is illustrated in the present series by the adult human form shomn in Figs. Io and I5. Part I. and by

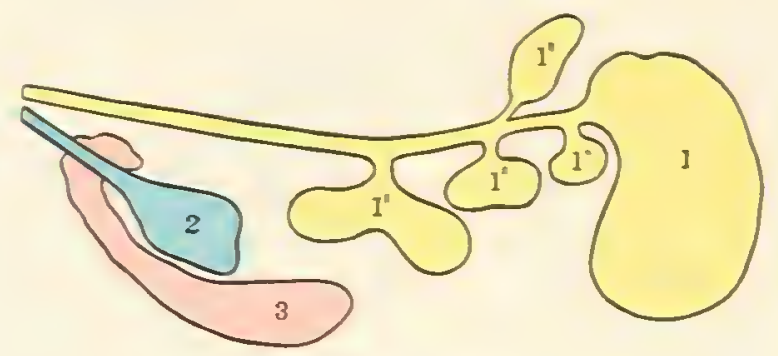

FIG. If. Schema of adult human alveolingual salivary complex Part I. Figs. 10 and 15 ).

the glands of all three species of Cymoccphulus sphinx. buboum and hamadrus. Figs. 3. 4. and 5. Part III.

The conditions found in these instances are shomn in schematic outline in Figs. If to 1 , and their derivation from the theoretical common genetic groundplan is indicated on the left side of Fig. I3.

The extent of the glandular territory covered by the accessory submaxillary glands may vary from the small ventral mass (I") draining

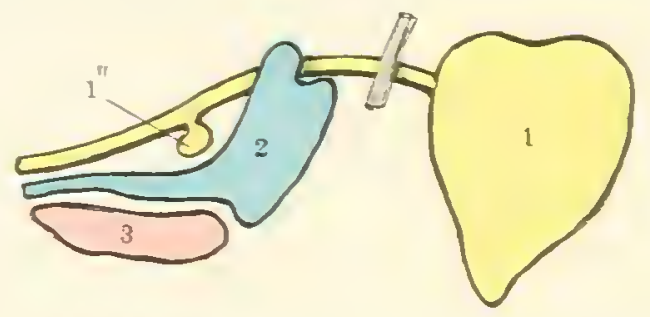

Fig. I5. Schema oi alveolingual salivary complex of (ynoccphalus sphin Part III. Fig. 3).

into the submarillary duct in Cymocephulus sphinx and bubouin Figs. 3 and 1 . Part III. schemata Is and IO. Part IT. I" to the multiple small glanda which in C ynocephulus hamadrys Fig. s. Part III. schema I7. Part IY. I"l empty by six short canals into both the rentral and dorsal circumference of the submaxillary duct just cephalad of the lingualis intersection. 
In the human variant belonging to this group (Figs. 10 and 15 . Part I, schema I\&, Part IV, $I^{\prime \prime}$ ) both rentral and dorsal accessory submaxilaries are present. The former extend forwards in the supramylohyoid space, and their relation to the greater sublingual

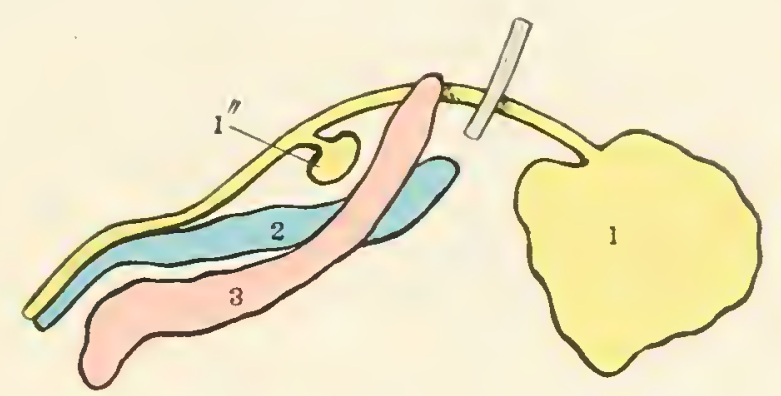

FIG. I6. Schema of alveolingual salivary complex of Cynocephalus bubouin (Part III, Fig. 4).

gland (2) and the group of the lesser sublinguals (3) shows their participation in the building up of the adult "massa sublingualis" by all three glandular components $\left(I^{\prime \prime}, 2\right.$, and 3$)$. In addition the human subject may develop a few separate glandular elements, belonging to the primitive diffuse oral floor, mesad of the main sub-

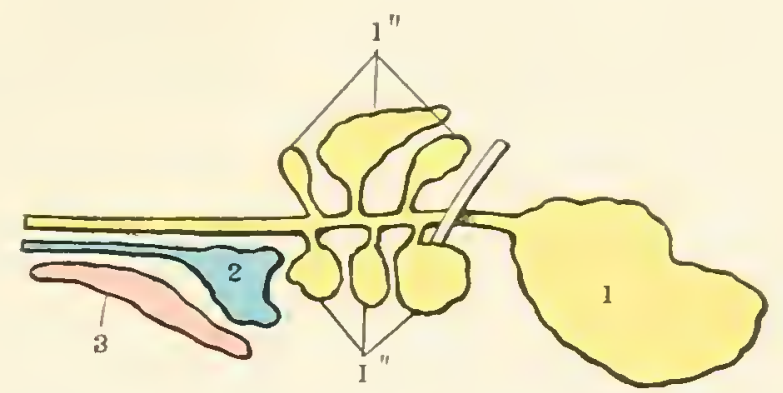

FIG. 17. Schema of alveolingual salivary complex of Cynocephalus hamadryas (Part III, Fig. 5).

maxillary duct. These small glandular elements, inconspicuous in the majority of individual instances, may in others reach a greater degree of development and even become confluent with the lateral diffuse field of the lesser sublinguals, in which case the submaxillary. 
duct lies in al glandular furrow connecting the marginal lateral and median strips of primitive oral glands.

As has been previously pointed out (page i26), the caudal members of the median series, placed between the submaxillary duct and the side of the tongue, form, when more than commonly distinct, the structures to which the name of the "gland of Weber" has been somewhat unnecessarily applied. It may further be noted that the ventral accessory submaxillary gland $\left(I^{\prime \prime}\right)$ present in the human sulject shown in Fig. Io of Part I is an extensive, long-drawn-out element which drains cephalocaudad into the beginning of the main submaxillary duct and evidently occupies

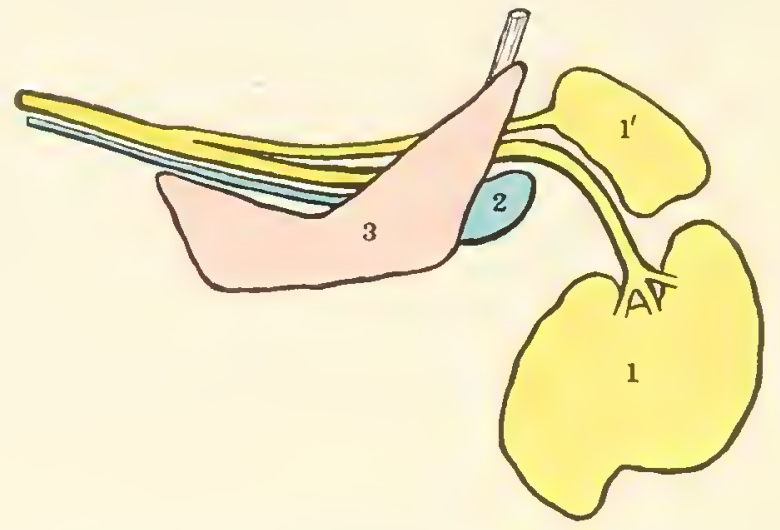

FIG. I8. Schema of alveolingual salivary complex of Macucus nemestrinus (Part III, Fig. 7).

glandiferous territory assigned in other types, as, for example, in the specimen of Cynoceplutus babouin (Fig. 4, Part III, and schema Fig. 16, Part $\left.\mathrm{IV}^{\prime}\right)$, to the glandula sublingualis major (2). This reciprocal relation of mutually interchangeable potential glandular fields distributed among available adult glands is again illustrated loy the varying proportions exhibited in the above primate series $B$ by the relative development of the lesser and greater sublingual glands in Hacacus cynomolgus (Fig. 6, Part III, schema Fig. I2, Part IV) and Cynocephalus sphinx (Fig. 3, Part III, schema Fig. I5, Part IV). Also by the replacement in Cynocephalus hamadrys (Fig. 5 . Part III, schema Fig. 17. Part IV) of the caudal elements of both the 
greater and lesser sublingual areas $(2,3)$ of the other forms by increased development in the district of the accessory submaxillary glands $\left(I^{\prime \prime}\right)$.

C. Finally, there is a relatively small group of adult intermandibular salivary glands, characterized by the lesser sublingual group (3) and by separate ducts and distinct parafrenulat orifices of both main submaxillary (1) and greater sublingual (2) glands, in which the main submaxillary duct $(I)$ is joined, at some point caudal to the terminal opening, by a parallel duct, which apparently drains, through a separate and distinct canal, a secondary submaxilliry gland $\left(I^{\prime}\right)$ situitted above the mylohyoid ind caudal to the lingual nerve intersection. These conditions are illustrated by the specimen of Macacus nemestrinus shown in Fig. 7 , Part III (schema Fig. 18, Part IV'). Their genetic derivation is indicated on the right side of schema Fig. I9, Part IV. The individual character of this gland, the distinct and the specialized position of its

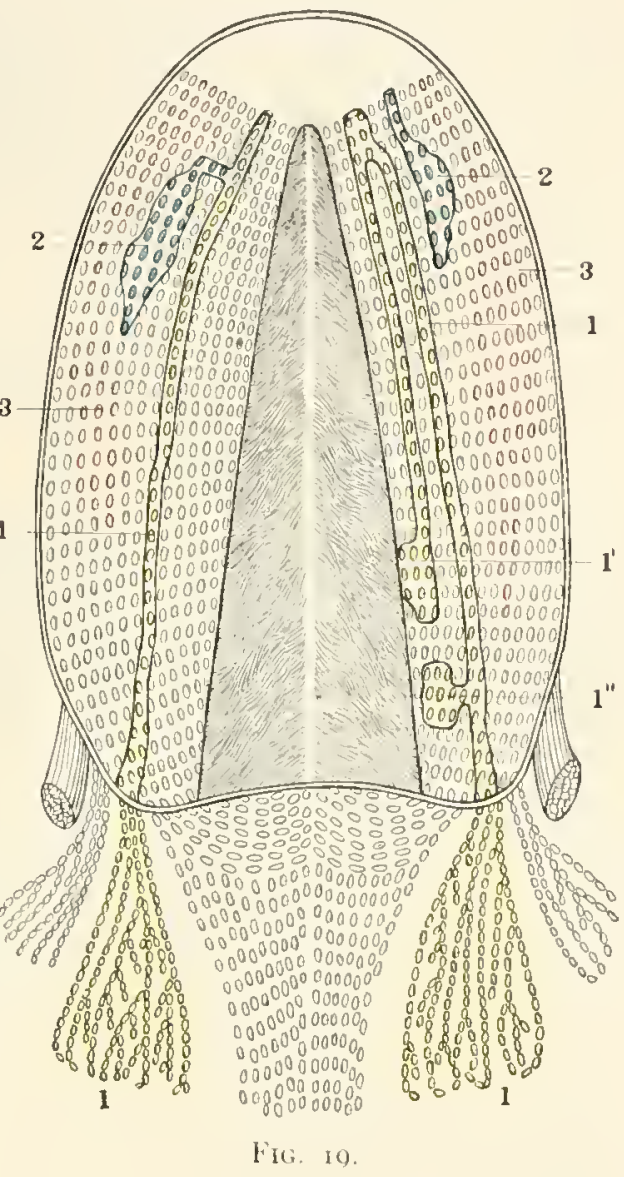
luct, above the main submaxillary duct, have led me to define it as a "secondary submaxillary gland," in contradistinction to a prolongation of the glandula sublingualis major caudad of the line of intersection of the salivary ducts with the lingual nerve, so as to produce what Ranvier, without mor- 
phological or ontogenetic justification, called a "retrolingual" gland. It is possible to define in certain mammals a "retrolingual" gland which extends far caudad of the lingual nerve into the neck ur upon the ventrolateral wall of the thorax. This is seen in many of the myrmecophagous Edentates in its fullest development. It is quite evichent that this specialized development of the intermandibular glandular field should be interpreted as an extension of the intermediate tield, ordinarily yielding in the more individualized primate only the supramylohyoid glandula sublingualis major, s. Bartholini, in other typical more generalized forms capable of extension caudad of the lingual nerve, thus forming a "retrolingual" gland in the perverted sense in which Ranvier employed this term.

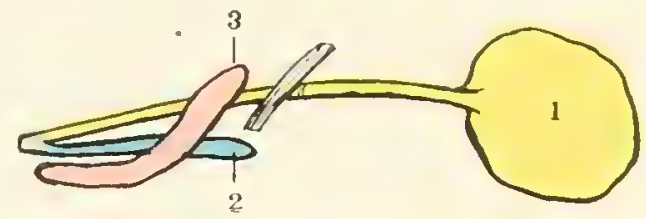

FIG. 20. Schema of alveolingual salivary complex of Lemur vurius (Part III, Fig. I2).

1. Submaxillary gland and duct.

2. Greater sublingual gland and duct.

3. Lesser sublingual glands.

11. A second general group of primate intermandibular salivary organization is characterized by the union of the submaxillary and greater sublingual (Bartholinian) ducts shortly prior to their opening through a single parafrenular common orifice. In its simplest form this type is found in the specimen of Lemur varius (Fig. I2, Pilrt III, and schema Fig. 20, Part IV). It is also seen in the adult human subject of Fig. 9, Part I (schema Fig. 21, Part IV), although in this case the main submaxillary duct also drains an accessory submaxillary glandular mass $\left(r^{\prime \prime}\right)$.

The derelopment of this type is schematically indicated on the left side of Fig. 19. Part IV. In addition, two important variants in the primate series here recorded belong to this general group.

(a) The first is the aberrant arrangement noted in the specimen of Troglodytes niger (Fig. 2, Part III, and schema Fig. 22, Part IV). 
In this individual the greater sublingual gland (2) drains into the terminal of the main submaxillary duct $(I)$ but lies on the lateral aspect of the lesser sublingual miss (3), instead of occupying the

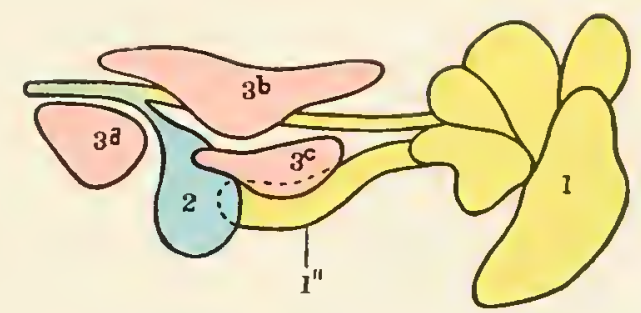

Fig. 2I. Schema of adult human alveolingual salivary complex (Part I, Fig. 9).

I. Submaxillary gland and duct.

$I^{\prime \prime}$. Accessory submaxillary gland and duct.

2. Greater sublingual gland and duct.

$3^{a}, 3^{b}, 3^{c}$. Lesser sublingual glands.

typical intermediate position, as is the case in the three other individual Chimpanzees examined.

The greater sublingual gland, as appears clearly in many of the types here figured, often deeply indents the median surface of the lesser sublingual mass and projects beyond the latter's caudal border, some-

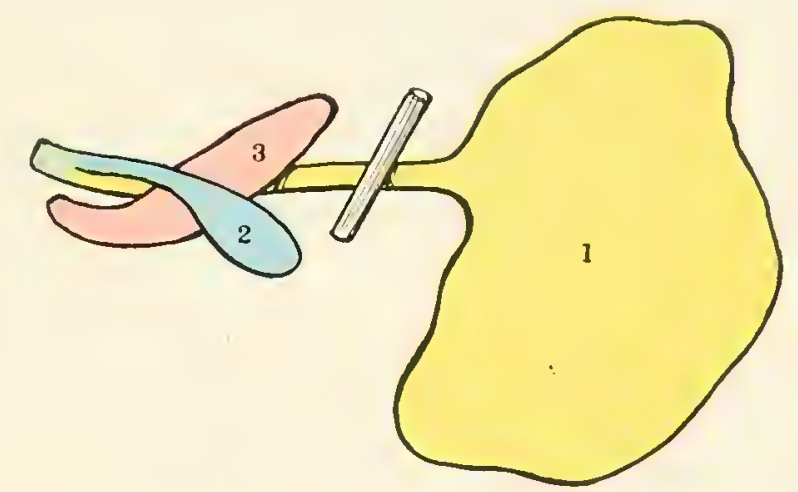

FIG. 22. Schema of variant alveolingual salivary complex of Troglodytes niger (Part III, Fig. 2).

I. Submaxillary gland and duct.

2. Greater sublingual gland and duct.

3. Lesser sublingual glands. 
times filling a triangular notch of the same. In all these forms, however, the greater sublingual duct is intermediate between the submaxillary duct and the lesser sublingual glands. The rariant Chimpanzee

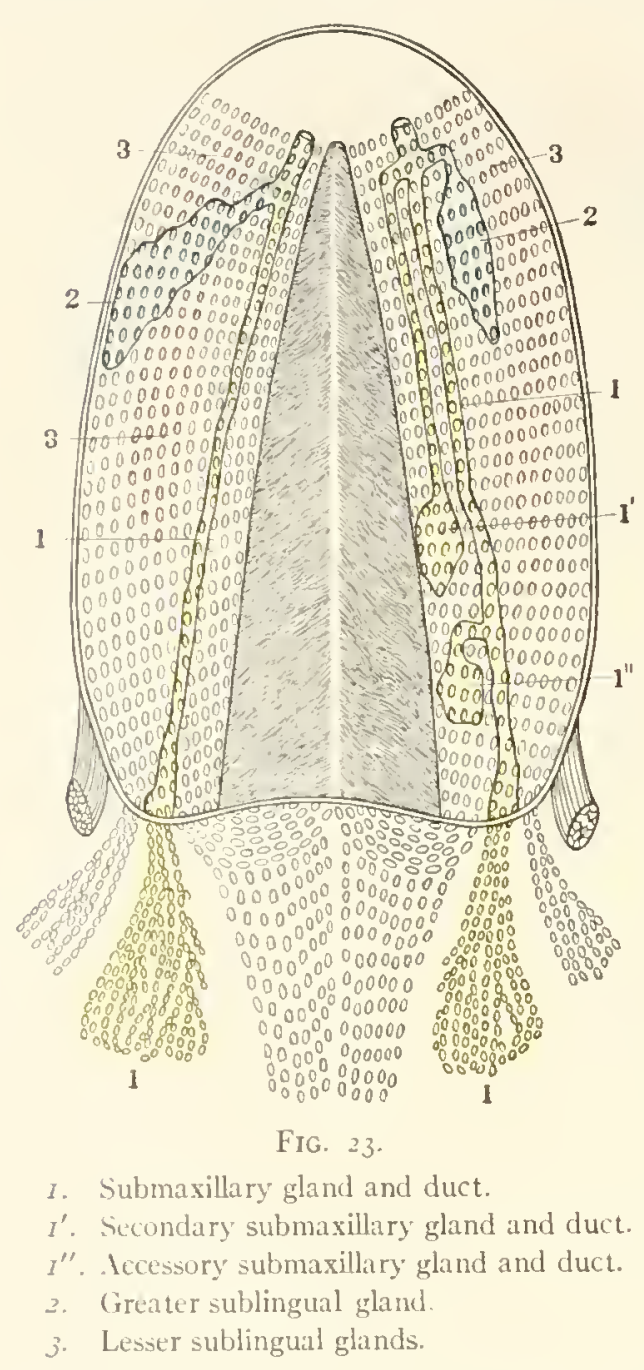
above figured and described presents the only instance in the primate series examined in which the regular topographical order of the three intermandibular glandular components appears changed and in which the greater sublingual gland occupies the lateral position. its duct crossing lateromesad $r^{\prime}$ the cephalic margin of the intermediate lesser sublingual group to its point of union with the main submaxillary duct.

The plan of development of this variation may be schematically indicated on the left side of Fig. 23, Part IV. The occurrence in an individual of a primate genus normally conforming to the usual primate type is a strong argument in favor of the hypothetical genetic interpretation of intermandibular salivary structures here adopted.

(b) The second observation within this general primate group which deserves special consideration concerns the specimen of 1teles shown in Fig. 11, Part III and schematically in Fig. 24, Part IV. This animal is an extremely valuable link in the entire 
primate series because it exhibits in the same individual all five potential components of the primate intermandibular salivary field carried to full development in the adult. The observation is of especial importance because it proves, since both structures exist side by side in the same individual, that the gland here described as the "secondary submaxillary" is not an exaggerated "greater sublingual," whose duct joins the submaxillary duct, and whose body extends caudad of the lingual nerve intersection, simulating the s.c. "retrolingual" gland of Ranvier.

In this form the main submaxillary gland $(I)$ occupics the typical position. The duct receives, above the mylohyoid, the drainage of a

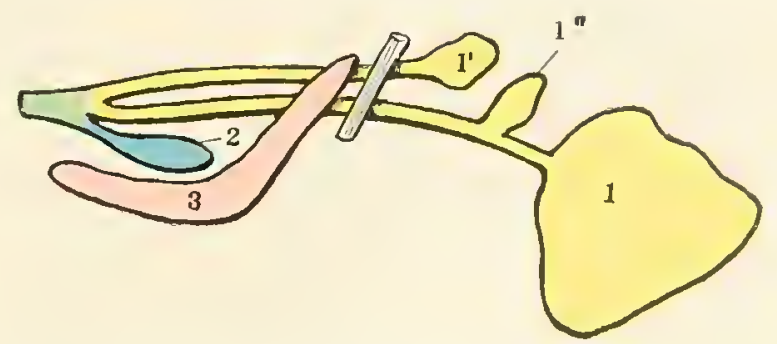

Fig. 24. Schema of alveolingual salivary complex of Ateles sp.?

(Part III, Fig. II.)

I. Submaxillary gland and duct.

$I^{\prime}$. Secondary submaxillary gland and duct.

$I^{\prime \prime}$. Accessory submaxillary gland and duct.

2. Greater sublingual gland and duct.

3. Lesser sublingual glands.

dorsal accessory submaxillary gland $\left(I^{\prime \prime}\right)$. It is paralleled, nearly throughout its entire course, along the floor of the mouth along its dorsal margin, by the duct of a secondary submaxillary gland $\left(I^{\prime}\right)$ which joins it near the termination.

In the same situation, on its lateral aspect, the main submaxillary duct receives the duct of the greater sublingual gland (2), in conformity to the type of the primate group II, to which it belongs. The single caruncular orifice of this animal drains, therefore, the following inclividual glandular components:

1. Main submaxillary gland $(I)$.

2. Through the latter's duct, an accessory submaxillary gland $\left(I^{\prime \prime}\right)$. 
3. The secondary submaxillary gland $\left(I^{\prime}\right)$.

4. The greater sublingual gland (2).

The fifth component of the alveolingual field, the lesser sublingual group (3) is well developed, extending, as the most lateral slement, from the plica sublingualis caudad nearly to the lingual nerve. The plan of development of these conditions is schematically indicated on the right side of Fing. 23, Part IV.

III. The third general group of primate intermandibular glands comprises those forms in which the intermediate glandula sublingualis major (Bartholini) defaults, so that the complex contains only two

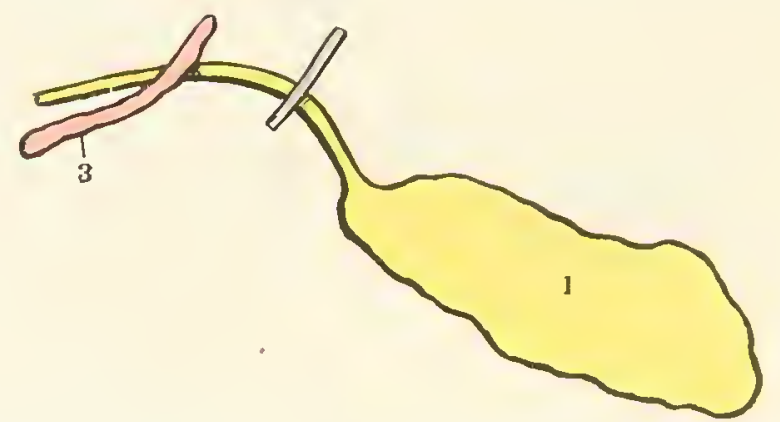

FIG. 25. Schema of alveolingual salivary complex of Vyctipithecus trivirgatus (Part III, Fig. 8) and Lemur mongoz (Part III, Fig. I3).

I. Submaxillary gland and duct.

3. Lesser sublingual glands.

distinct components, viz. the medial submaxillary gland and duct, with or without accessory and secondary submaxillary elements, and the lateral series of the separate lesser (Rivinian) sublingual glands.

Three ninor subdivisions of this general group may be recognized:

A. Forms in which the submaxillary duct is simple, without either accessory or secondary submaxillary additions.

In the present series the type is illustrated by Nyclipithecus trivirgatus (Fig. 8, Part III, and schema Fig. 25, Part IV') and Lemur mongoz (Fig. I3, Part III), and its genetic derivation is slown in the left side of schematic Fig. 26, Part IV.

In Myctipithecus (Fig. 8, Part III) both parotid and main submaxillary gland appear enlarged far beyond the limits usually observed in primates. The two multilobar submaxillary glands are in touch with 
each other in the ventral mid-cervical line and interlock with the caudal prolongations of their respective parotids.

In Lemur mongoz (Fig. I3, Part III) the glandular development is less pronounced, but the submaxillary gland, composed of three lobes, fits closely into the concave caudal border of the overlapping parotil.

Accessory salivary glands are present and well developed in both of these animals.

In Nyctipithecus the caudal end of the lesser sublingual group, after crossing obliquely cephalodorsad on the lateral aspect of the submaxillary duct, abuts directly against a dense glandular mass (Fig. 8, Part III, \&) which occupies the arcus palatinus (isthmian glands) and becomes continuous with the glands of the soft palate.

In Lemur mongoz the lesser sublingual glands extend caudad beyond the lingualis-submaxillary duct intersection, while the oral angle is occupied by an alveobuceal series of glands (Fig. I3, Part III, 7) which fills as a crescentic mass the inter-

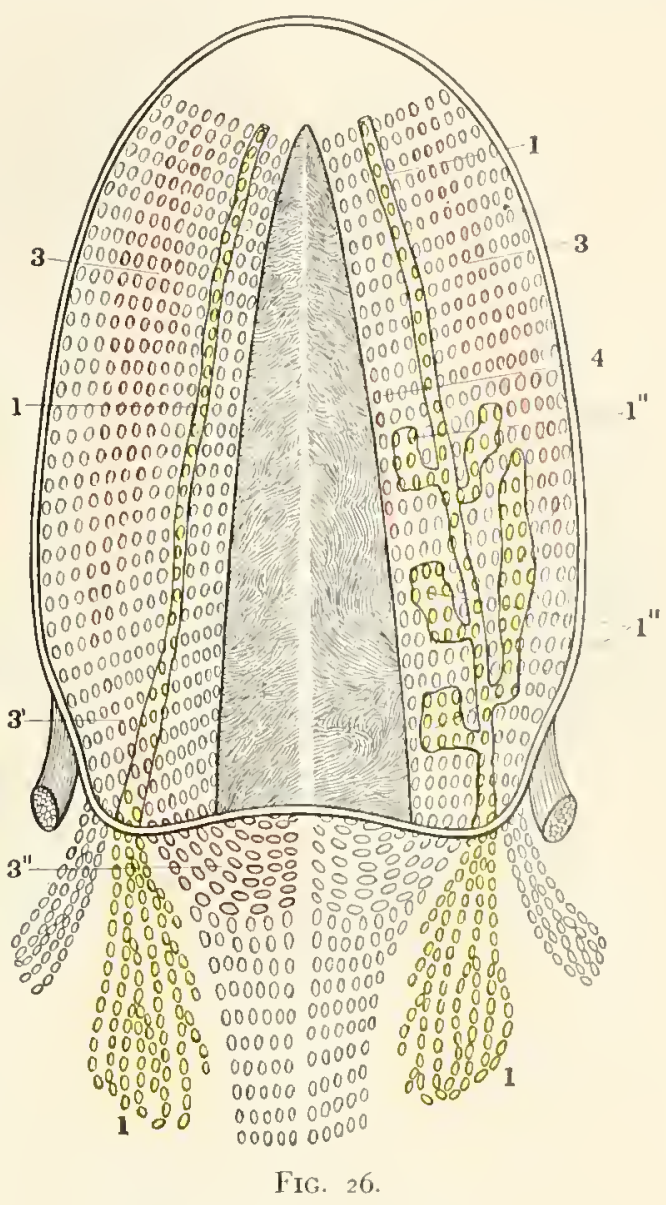

I. Submaxillary gland and duct.

$I^{\prime \prime}$. Accessory submaxillary glands and ducts.

3. Lesser sublingual glands.

$3^{\prime}$. Ithmian glands.

$3^{\prime \prime}$. Palatine glands.

4. Weber's gland. 
val between the parotid duct and the cephalic border of the lesser sublingual group.

$B$. The second subdivision of the third primate intermandibular group consists of forms in which the duct of the main submaxillary

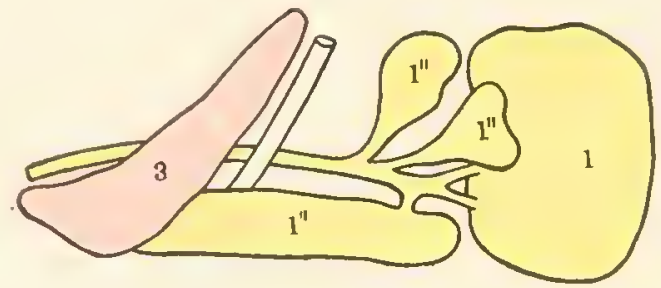

FIG. 27. Schema of adult human alveolingual salivary complex (Part I, Fig. 8).

$I$. Submaxillary gland and duct.

$I^{\prime \prime}$. Accessory submaxillary glands and ducts.

3. Lesser sublingual glands.

gland receives the ductules of the accessory supramylohyoid submaxillary glands.

The human variations shown in Figs. 8,16 , and 17 , Part $I$, and the glands of the specimen of Atcles hybridus, Fig. 9, Part III, illustrate this condition.

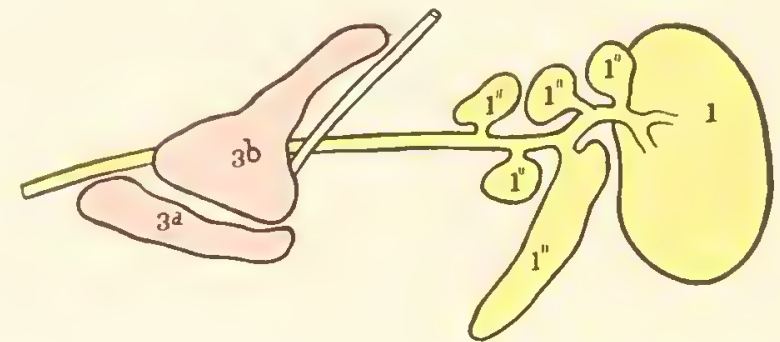

FIG. 28. Schema of adult human alveolingual salivary complex (Part I, Fig. 16).

I. Submaxillary gland and duct.

$I^{\prime \prime}$. Accessory submaxillary glands and ducts.

$3^{6} \cdot 3^{b}$. Lesser sublingual glancls.

In these instances the main submaxillary duct $(I)$ receives both dorsal and rentral accessory submaxillary ducts $\left(I^{\prime \prime}\right)$ draining isolaterl supramylohyoid accessory submaxillary glands.

The corresponding schemata are given in Figs. 27, 28, 29, and 30, 
Part IV, and the lines followed in the genetic evolution of this type are indicated on the right side of Fig. 26, Part IV.

$C$. Finally, in the third subdivision of this group, the main submaxillary duct $(I)$ carries both ventral and dorsal accessory submax-

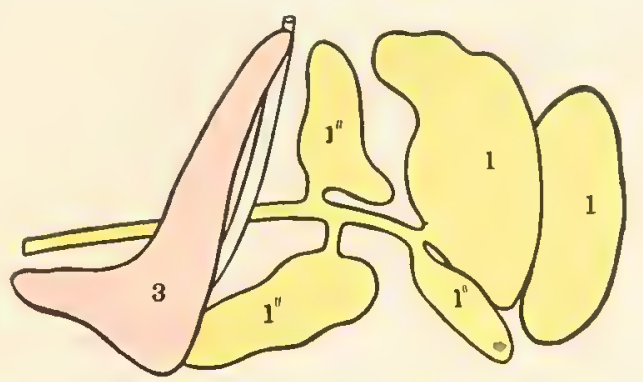

FIG. 29. Schema of adult human alveolingual salivary complex (Part I, Fig. 17).

I. Submaxillary gland and duct.

$I^{\prime \prime}$. Accessory submaxillary glands and ducts.

3. Lesser sublingual glands.

illary components $\left(I^{\prime \prime}\right)$ and is joined near its termination by the duct of a well-dilferentiated secondary submaxillary gland $\left(I^{\prime}\right)$.

The specimen of Lagothrix humboldtii, shown in Fig. IO, Part III, and in schematic outline in Fig. 3I, Part IV, illustrates this type. It

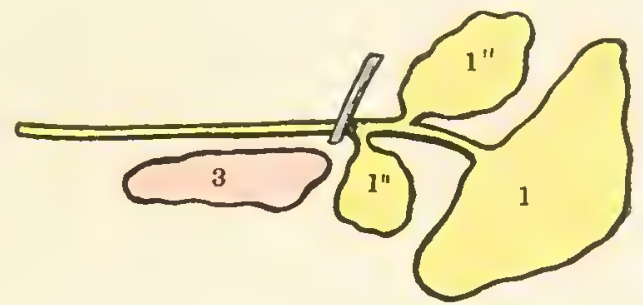

FIG. 30. Schema of alveolingual salivary complex of Atcles hybridus

(Part III, Fig. 9).

I. Submaxillary gland and duct.

$I^{\prime \prime}$. Accessory submaxillary glands and ducts.

3. Lesser sublingual glands.

will be noticed that the conditions in this animal correspond closely to those found in another South American monkey, Ateles, shown in Fig. II, Part III (schemata Figs. 23, 24, Part IV), except that in the 
latter, in addition to secondary and accessory submaxillary elements, a distinct greater sublingual (Bartholinian) gland and duct (2) is present. Both forms correspond, however, closely in the high degree

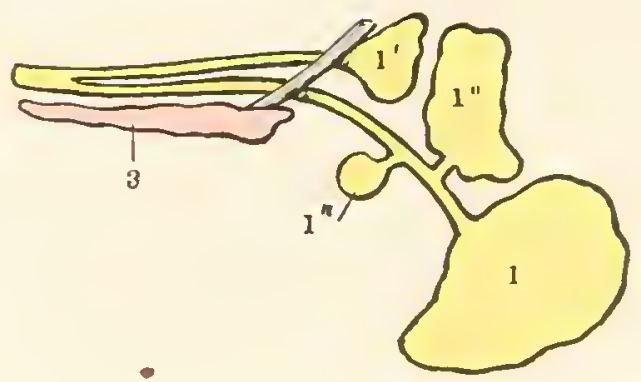

FIG. 3r. Schema of alveolingual salivary complex of Lagothrix humboldtii (Part III, Fig. Io).

$I$. Submaxillary gland and duct.

I.' Secondary submaxillary gland and duct.

$I^{\prime \prime}$. Accessory submaxillary glands and ducts.

3. Lesser sublingual glands.

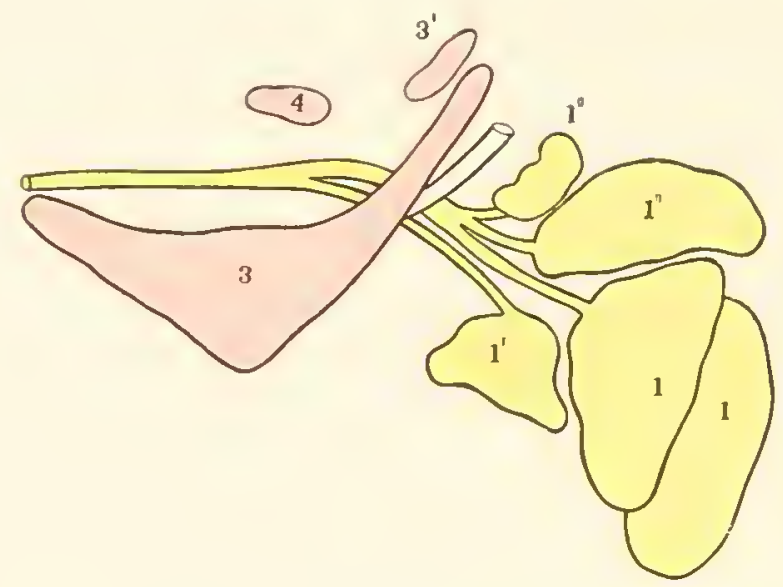

FIG. 32. Schema of adult human alveolingual salivary complex (Part I, Fig. 7)

I. Submaxillary gland and duct.

$I^{\prime}$. Secondary submaxillary gland and duct.

$I^{\prime \prime}$. Accessory submaxillary gland and duct.

3. Lesser sublingual glands.

$3^{\prime}$. Isthmian glands.

7. Weber's gland. 
of development and differentiation to which the submaxillary genetic line has been carried.

The human variants which may be classed under this group are represented by the individuals shown in Figs. 7 and 9, Part $I$, and in schemata 32 and 33, Part IV. They are characterized by the ventral

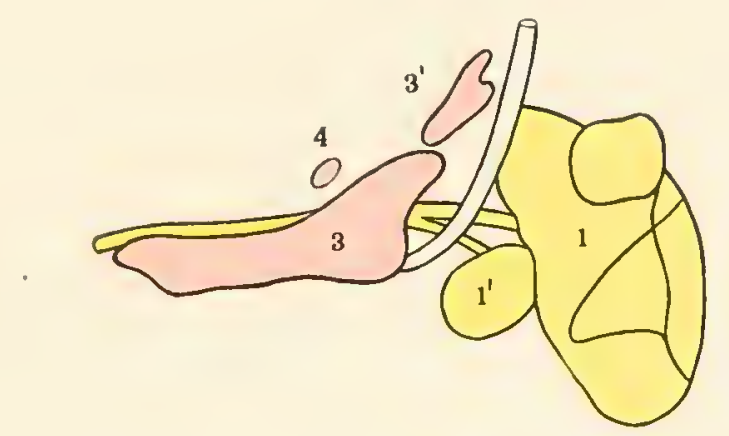

FIG. 33. Schema of adult human alveolingual salivary complex (Part I, Fig. 9).

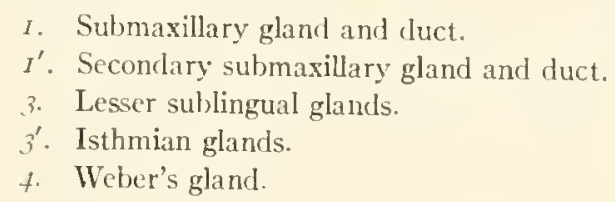

position of the secondary submaxillary gland $\left(I^{\prime}\right)$ and the relatively short course of its duct.

It is also noteworthy that the human variants representing this primate group (Figs. 7 and 9, Part I, schemata Figs. 32, 33, Part IV) present, in addition to the secondary and accessory submaxillary glands, an extensive development of the lesser sublingual field, which extends beneath the terminal portion of the submaxillary duct along the mesal margin of the latter. The dropping out of the complex of the separate greater sublingual gland and duct seems, therefore, as would be expected, to be met by selective greater development both in the lesser sublingual group and along the submaxillary genetic line. 
. 


\section{PART $V$}

\section{THE ANATOMI OF THE SALIVARY GLANDS IN THE CARNIVORA}

\section{By Cinurchill Carmalt}

THE salivary glands of the domesticated carnivores, the dog and cat, have naturally been the subject of much study, and the larger elements are described in some detail and with moderate accuracy, in the numerous works which deal with the anatomy of the domesticated animals collectively, or solely with that of the cat. Apart from such general studies, the glands of the alveolingual region have been the objects of more critical investigation in recent years. Ranvier ('86) and Zumstein ( $9 \mathrm{I}$ ) have recorded their condition in a large number of mammals, and Illing ('O4) has made careful and detailed studies of their anatomy and minute structure in the domesticated animals, giving in addition a copious bibliography and review of the literature. Elsewhere (Part V'III) the general results of the study of these glands and their bearing upon questions of terminology have been considered; accordingly we shall limit ourselves here to the definitions of the several glands in question and the statement of the names by which we shall designate them.

I. The glands of the alveolingual region.

I. Glandula submaxillaris. - The body is below the angle of the mandible and lateral to the digastric muscle. The duct passes between this muscle and the lower jaw, to gain the oral surface of the mylohyoid muscle, where it passes forward horizontally to open upon a minute caruncle, common to it and the ductus sublingualis major, attached to the frenulum lingux close to the symphysis. The submaxillary duct is ventral to that of the glandula sublingualis major, its orifice mesal.

2. Glandula sublingualis major, greater sublingual, or Bartholinian, gland. - The body regularly extends caudad of the free border of the 


\section{50 ANATOMY OF THE SALIVARY GLANDS IN TIE CARNIVORA}

mylohyoid muscle, and is usually in contact with the digastric, upon which it may be molded. The duct is frequently surrounded by encrusting lobules which prolong the gland forward and constitute a supramylohyoid process. The duct is ventral to that of the submaxillary gland; the orifice is laterally placed upon the common caruncle.

3. Glandula sublinguales minores, lesser sublingual, or Rivinian glands. - These elements were uniformly present in all the specimens examined. In this our results are in agreement with those of Zumstein and Illing and in disagreement with those of Ranvier, whose illustrations and descriptions of these glands in the carnivora and other mammals are grossly inaccurate, notwithstanding the careful technique of his preparations (masceration in 30 per cent alcohol, dissection under a lens). In degree of development the series varies within wide limits. It may extend from near the caruncle to the arcus palatinus, and then be continuous with the isthmian glands. On the other hand it may be represented only by a few scattered elements in the vicinity of the lingual nerve. With reference to the submaxillary and sublingual ducts the bodies are in general lateral, but as the arcus palatinus is approached, they gradually assume a dorsal position.

II. Glandula isthmianx, isthmian glands. An inconstant group which occupies the arcus palatinus, continuous dorsad with the palatine glands; ventrad they may or may not be continuous with the lesser sublinguals.

III. The glands of the vestibule. The literature of the glands of the vestibule still lacks such a compilation as that of Illing for the glands of the alveolingual region. In addition to standard works upon comparative anatomy, the sunrces for these structures are the descriptions of the older writers and numerous scattered references in recent zoölogical literature. Both are so often merely perfunctory statements of the occurrence of the several glands, with, perhaps, a reference to the relative size of parotid and submaxillary, that they yield but a small return for the labor of collating them. We shall note a few points in connection with our list of these elements which follows.

I. Glandula purotis. - The body is sulmeatal, thence tending to extend over the surface of the masseter and cephalohumeralis muscles, and to embrace the meatus with pre- and post-meatal processes. The 
duct is ectomasseteric, crossing the muscle obliquely or horizontally (transmuscular) and, so far as known, never, except in the embryo of the cat, following its border (inframuscular), as in ungulates. The orifice is usually opposite the upper carnassial tooth. Accessory lobules are sometimes attached to the transmuscular portion of the duct (Mivart, Wilder, Reighard and Jennings). They represent isolated portions of an efflorescence of the duct, which may extend from the body of the gland to the border of the masseter muscle (Fig. 13).

2. Glandule orbilales. - These elements, six to eight in number, are embedded in the infraorbital fat, where they form a mass diminishing in size caudad. Their ducts are entomasseteric; they pierce the buccinator and open in series with that of the parotid, upon a low stomal ridge opposite the upper molars and behind them. The ridge terminates in the interval between the internal pterygoid and masseter muscles, where some of the caudal elements open. The first orbital gland was discovered by Nuck and has occasionally borne his name. It is variously styled orbital, infraorbital, zygomatic, and subzygomatic in the literature. The plurality of elements is usually overlooked. Three ducts were observed in the dog by Ellenberger and Baum. Ward records the presence of several such glands in man, in line with the parotid duct and interposed between the masseter and buccinator muscles, which he terms molar glands. Recently Liadze ('10) has given a detailed account of these elements in the cat and dog.

3. Glandula orbitoparotis. - A constant clement, which, when of small size, occupies the space bounded by the border of the masseter, the paroticl duct, and the oral mucous membrane, i.e. has a promasseteric position and is intermediate between the parotid and orbital elements. When larger, it may assume an inframuscular or even ectomasseteric position. The duct opens either into the proximal portion of the parotid duct, or independently upon the stomal ridge between the parotid orifice and that of the first orbital gland.

4. Glandule alveobuccales inferiores (molar gland or inferior iabial glands of authors). - The term designates a series of glands associated with the sulcus of the same name, and does not inclucle scattered glands of the cheek, which, in none of our specimens, attained macroscopic size. They extend when well developed from the diastemal fold to the deep facial vein and the border of the masseter, 
along which they occasionally ascend a short distance towards the parotid duct, which, so far as our observations go, they never reach, far less surround its orifice or come into relation with the orbital glands. They are then both labial and buccal or vestibular in position, a fact which makes it inconvenient to term them simply buccal or labial glands, and has led us to propose to designate them from the sulcus with which they are associated developmentally.

In addition to my own dissection I have made use of several of the beautiful preparations of Mr. C. F. Silvester in the Morphological Museum of Princeton University, in order to gain a broader basis for generalization and to supply gaps in my material. For the opportunity to use and publish descriptions of these specimens, which are acknowledged individually below, I owe my most grateful thanks both to Mr. Silvester and to Professor C. F. IT. McClure, for whose helpful assistance and generous interest in the progress of these studies. I desire to record my sincere appreciation.

The ducts of the larger salivary glands were injected with gelatine. The introduction of the canula is facilitated by the previous insertion of a bristle or horsehair into the orifice. This procecture greatly diminishes the difficulty of the proceeding, which in many cases is almost impossible otherwise. In this way the parotid, submaxillary, greater sublingual, and first orbital glands were injected. The smaller clements were simply dissected. Their orifices easily observable with a lens will usually admit a fine bristle, but very little is gained by this procedure. In the cat the region of the stomal ridge, together with the orbitoparotid and orbital glands were studied in serial sections.

The following species were examined :-

Felis domestica

Felis leo

Canis familiaris

Ursus thibetanus

Procyon lotor

Mephitis putila

Taxidea americana (2 specimens)

Gulo luscus

Zalophus californianus (3 specimens)

Macrorhinus angustirostris 
Of the cat and dog about fifty individuals of each were examined. Of these only five in each species were studied statistically, and that solely with reference to the occurrence of accessory parotid lobules.

\section{FELIS DOMESTICA}

The vestibule and cavum oris proprius communicate caudad to the teeth by a triangular orifice, bounded dorsad by fibers of the masseter, which arise from the maxillary tuberosity, caudoventrad by the border of the mandibular ramus, and cranial by the last premolars. The masseter further overlies the vestibular end of this passage, which it assists in closing when contracted. The closure depends in addition upon temporary. folds of the adjacent mucosa, which appear when the jaws are approximated, and a small permanent plica attached to the mandible (Figs. I and 2, 43). This is sagittally directed and extends from the border of the ramus, increasing in height to the mesal side of the last premolar. When the mouth is shut its cranial end fits into and fills the space between the last upper premolar and the rudimentary molar, while farther caudad its crest enters a groove (Fig. 2, 45) at the mesal border of the masseter. This furrow, corresponding to the functional separation of vestibule and cavum oris, it is convenient to take as a formal boundary between the two cavities. It extends from the border of the mandibular ramus to the maxilla near the molar tooth (42). Ventrad it intervenes between the masseter and internal pterygoid $(30,32)$. Dorsad the muscles separate, exposing a triangular area $\left(4^{6}\right)$ where the bodies of the orbital glands and infraorbital fat are in contact with the mucous membrane, which appears paler in consequence, unless the cat happens to be either pure white or black. On account of its relation to the orbital glands, it may be termed the glandulur trigone. Along its lateral border open the ducts of the caudal members of this series $(13)$, and close to the maxilla the deep facial vein $(3 t)$ is seen at its lateral angle. The division here proposed between restibule and cavum oris proprius in the postdental segment of the mouth, looks merely to precision and convenience of description. In reality we are dealing with a region in which this differentiation, which depends on the presence of the teeth, has not occurred. Its small morphologic significance is shown by the fact 
that the boundary passes between the orifices of the third and fourth orbital glands, while the whole series develop from sprouts in the course of the secondary buccal sulcus.

The vestibule, thus limited entad, comprises a buccal portion and labial portions, the latter divided into alveobuccal and alveolabial sulci. The angulus oris corresponds to the last cusp of the upper carnassial. Caudal to this the check is formed by the buccinator, which has a sagittal direction, and the masseter, the ental surface of which slopes mesad and caudad. The border of the masseter is visible as a slight ridge extending obliquely from the tuberosity of the maxilla to the mandible at the level of the last lower tooth (Figs. I and 2, 3o). The superficial facial vein (35) can be seen through the mucosa following this border, while the deep facial vein (37) crosses it obliquely to disappear at the border of the maxilla as it ascends to the orbit.

The glands of this portion of the vestibule open upon a low stomal ridge $(15)$ which begins opposite the third cusp of the carnassial, crosses the border of the masseter in a sagittal direction, and then turns mesocaudad across the deep facial vein to terminate in the trigonum glandulare. From the deep facial vein caudad it is indistinct, and can be easily obliterated by traction. It is separated from the alveolus and border of the hard palate by a shallow sulcus continuouswith that between the upper lip and akveolar process, the equivalents respectively of the secondary buccal and superior alveobuccal sulci of the embryo. The orifice of the parotid (3) is at the cranial extremity of the fold opposite the interval between the mid and third cusps of the carnassial. The next constant orifice is that of the first orbital (10) opposite the caudal extremity of the carnassiat. At an interval of about 2 millimeters follows the orifice of the second orbital (II). That of the third is at the point where the stomal ridge crosses the deep facial vein (I2). Cáudal to this again in the region of the glandular trigone are several minute orifices set in an irregular row at the end of the ridge and just beyond its termination. A minute osculum $(\delta)$ was once seen between the orifice of the parotid and that of the first orbital gland. It was situated on the summit of the ridge and accurately in line with the other orifices. It corresponds in site with one of the positions of the orbitoparotid of the embryo. In the serial sections of this region in the adult a few minute glands are found scattered along the stomal ridge. Their 
orifices are ratrely visible to the naked eye. The small opening (I 4 ) lateral to the parotid was taken to belong to an element of this series. It was found but once in five cats which were examined particularly in regard to the orifices upon the stomal ridge.

At the angulus oris the vestibule is continuous with the atveobuccal sulci. This term is applied to the space between the lip and alveolar process as far forward as the canine teeth. The shallower sulci between the incisor teeth and the lips are the alveolabial sulci. Typically the furrows are separated at the diastema by transverse folds which extend from the sockets of the canine teeth to the margin of the lips (diastemal folds). The upper tends to be reduced in the carnivora; in the cat it is suppressed. In the embryo its presence is indicated only by the primitive discontinuity of the superior alveobuccal and alveolabial furrows. Caudad the alveobuccal furrows extend into the vestibule as its dorsal and ventral boundaries; the superior is continuous with the furrow dorsal to the stomal ridge; the inferior terminates near the border of the masseter.

The superior alveolibial sulcus is a deep sinus, corresponding in its region of greatest depth to the canine tooth, caudal to which it becomes shallow abruptly and is continuous with the superior alveobuccal sulcus. Opprosite the incisors, also, it is shallow; in the median line it is separated from its fellow by a narrow fold extending from the premaxillitries to the margin of the lip.

The inferior alveolabial furrow is small; limited in the midline by a minute fold between the symphysis and lip, it deepens beside the canine tooth and ends abruptly at the diastemal fold. This arises broadly from the lip and narrows to a pointed attachment to the back of the socket of the canine. Its dorsum rises above the general level of the lip in a fleshy pad, against which the upper canine rests when the jaws are approximated.

The distinction between alveolabial and alveobuccal sulci is based upon their frequent separation by diastemal folds, their primitive discontinuity in the embryo, and certain differences in their mode of development which are described in Part VI of this work.

Of the sulci the inferior alveobuccal alone is the site of macroscopic glands. These to the number of $20-30$ form a mass which extends from the diastemal fold to the border of the masseter. Its summit produces 
a ridge in the ectal wall of the alveobuccal sulcus upon which the orifices of the glands, often slightly pigmented, open in two irregular rows.

The cavum oris proprius presents on either side of the tongue, between it and the alveolar processes, the alveolingual regions or gutters. Caudad they are widely separated and terminate against the internal pterygoid muscle and the arcus palatinus (Fig. 2, 32. 49). Craniad they are separated very imperfectly by the frenulum. This has a crescentic form, its deeply concave free border is opposite the diastema. a dorsal cornu is prolonged along the venter of the tongue, a ventral cornu along the floor of the mouth to the symphysis. This portion does not appear when the parts are relaxed, but a faint median furrow separates the plicæ sublinguales. These are minute triangular folds which rest against the shelving surface of the symphysis. Their shortest border is nearly transverse and presents the orifices of the submaxillary gland mesad, of the sublingualis major laterad. The border of intermediate length is attached to the frenulum, traction on which lifts the plicæ from the symphysis to the distance of about I millimeter.

The ducts of these glands which are in close contact, appear through the mucosa as a white line parallel to the mandible as far caudad as the lingual nerve. Here they are obscured by the bodies of the lesser sublinguals, the orifices of which are visible both in front and behind the nerve and in the ventral portion of the arcus palatinus. The dorsal portion of the arcus, together with the hard palate, is studied with minute orifices, easily recognized by their pigmentation, which belong to the isthmian and palatine glands.

The parotid gland (Fig. 3, I), irregularly triangular in shape, occupies the angle between the posterior auricular $(38)$ and superficial temporal reins (37). Its dorsal border, which is concave, corresponds to the cartilage of the external auditory meatus. Not infrequently there is a deep notch in this border. The angles are prolonged in front and behind the meatus into a premeatal and a rudimentary postmeatal process. which are variable within moderate limits. The ventral angle is regularly prolonged beyond the superficial temporal vein. It is of looser structure than the rest of the gland and often manifests a tendency to resolve itself into more or less independent lobules. 
Occasionally there is a ventrally directed tongue-like process, which crosses the posterior auricular vein and overlies the submaxillary gland. An elongated lymphnode is placed at the caudal border of the gland (26), and a sccond smaller one at its cranial border (25), usually dorsal to the duct. These nodes were considered to be portions of the parotid by Mivart (The Cat, Fig. Ss).

The deep surface of the gland presents a vertical ridge between two concavities. Of these the narrow cranial one corresponds to the masseter and temporal muscles, the caudal to the external auditory meatus.

The duct emerges from the ventral angle of the gland, usually in two or several divisions, which unite in the caudal half of its course; rarely it is single at its emergence. Its course, which is horizontal, may be designated as transmuscular in contrast to the inframuscular position which it has in the early stages of development. At the border of the masseter the duct enters the angle between the deep and superficial facial veins; under cover of the latter it pierces the buccinator obliquely and reaches its orifice at the cranial end of the stomal ridge, opposite the last cusp of the carnassial. The promasseteric segment of the duct is short, in correlation to the brachycephalism of the cat.

In the transmuscular portion of the duct accessory lobules are frequently present, (a) ventral to the midthird of the duct and closely applied to it. $(b)$ near the ventral border of the masseter opening by a slender ascending cluct into the parotid duct close to its bifurcation. The former of these (Fig. 5,6) corresponds to the facial gland of Mivart. It is horizontally placed immediately ventral to the parotid duct, into which its single duct opens directly. It is oroid in shape, its horizontal diameter about double its vertical. It was present three times in five adult cats. Its size varied between $2 \times$ I millimeter, and $10 \times 5$ millimeters. The second element (Fig. 5, 7) is minute in size, a flattened disk about 2 millimeters in cliameter. It is situated on the surface of the masseter near its lower border. The minute duct ascends nearly vertically, in some cases inclined slightly caudad, to join the parotid duct close to the ventral angle of the gland. It was present five times in five specimens examined. Its position suggests that it may be a branch of the parotid duct which retains the inframuscular position in some degree when the main duct is shifted dorsad. Two similar 
branches have been found in embryos of the cat (Schulte) one of 25 millimeters, one of 31 millimeters. Both ascended from the border of the muscle, with a moderate caudal inclination, and joined the main duct close to its bifurcation (Part VI, page 246).

The orbitoparotid (Fig. 5. $\delta$ ) is a minute element, not exceeding 2 millimeters in diameter and $3^{-}+$millimeters in length in any of our

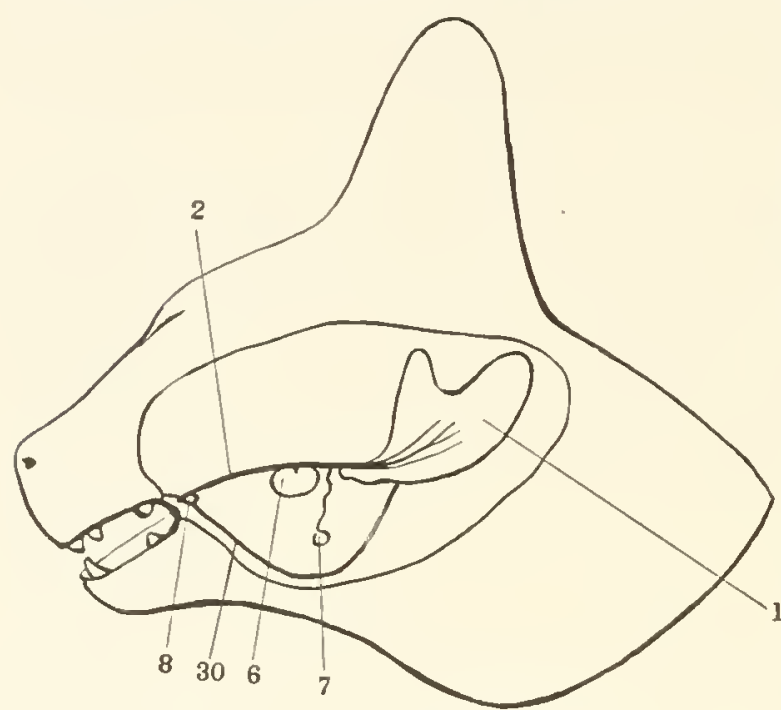
specimens. It is interposed between the parotid duct and the oral epithelium, in the space between the deep and superficial facial veins mesad and laterad, and the border of the masseter caudad, to which its fundus is applied. Its possibilities of growth are thus confined within narrow

FIG. 5. Schema of the orbitoparotid and accessory parotid limits. On the elements. mesal surface of

r. Parotid gland.

2. Parotid duct.

6. Accessory parotid lobule.

7. Accessory parotid lobule with recurrent duct.

S. Orbitoparotid.

30. Masseter muscle. the muscle the deep facial vein offers a further obstruction which effectually bars the path to the orbit. Only laterad and ventrad along the sloping border of the masseter is there space for expansion, and this is somewhat infringed upon by the superficial facial vein. The duct opens either into that of the parotid close to its orifice, or upon the stomal ridge midway between that of the parotid and that of the first orbital gland (Fig. 2, 8). This clement was present six times in our five cats.

The orbital series is composed of six or eight glands diminishing 
in size caudad; their ducts open upon the stomal ridge (Fig. 2, IO-13), their bodies united by a common connective tissue investment form a small mass, which is cmbedded in the delicate fat between the periorbita and the oral mucous membrane. Pyramidal in shape, its axis obliquely mesocaudal in direction, it presents its ventral side to the oral mucosa in the lateral area of the triangle bounded by the maxilla, the masseter, and the internal pterygoid muscles (Fig. 2, 46). Its lateral surface is applied to the masseter, a little fat intervening, while dorsally and mesally it is in contact only with the suborbital fat. Its base, turned craniad and slightly laterad, is crossed by the deep facial vein. It has a length of about $\mathrm{I} .4$ centimeters and at its base a vertical diameter of I centimeter, and a transverse of about one-third as much. The three cranial members of the series are distinguished by their larger size and longer ducts. These pierce the buccinator, and, turning nearly at right angles craniad and latcrad, are continued in the mucosa of the stomal ridge to their respective orifices, the first behind the last cusp of the upper carnassial, the third close to the deep facial vein, the second midway between (Fig. 2, IO, II, I2). In this course the duct of the first is ectal, of the second intermediate, of the third ental in position. The duct of the first bifurcates before entering its gland, in which two lobes are casily recognized. The disparity in size between the first and second orbitals is not extreme in the cat, the whole series gradually diminishing from first to last. The caudal members are small, and their ducts pass directly or at most with moderate obliquity through the scattered fibers of the buccinator to open along the margin of the trigone close to the masscter.

This muscle then forms the boundary between the orbital and parotid glands, in reference to which the orbitoparotid occupies an intermediate position at the cranial border of the muscle. The conditions obtaining in the adult, as well as in the embryo, point to the interpretation of these several glands as members of a series interrupted by the masseter, the approximation of which to the oral mucosa tends to retard, though not always to suppress, the formation of sprouts at the point of contact and determines an ectomasseteric path for the cranial, an entomasseteric for the caudal members of the series.

The glands of the stomal ridge are hardly of macroscopic size; their orifices may be seen with a lens irregularly scattered along 
the ridge. A rather large one was found once close to that of the parotid, to its lateral side (Fig. 2, I4). In one specimen examined in serial sections, about half a dozen were found, the majority in the caudal portion of the ridge, ental to the buccinator. One opened into the duct of the first orbital close to its orifice.

The inferior alveobuccal glands have a common connective tissue investment which unites them into a gland mass of considerable density, in which the individual elements are not easily distinguished. The series extends from the disastenal fold to the masseter muscle and facial vessels, here ascending dorsad, but not to such a degree that it can be said to approach the parotid, from which it is separated by a wide interval in all of our specimens; in none of them was the termination of the parotid duct cmbedded in small glands as Mivart shows it. The mass increases in size caudad; at the diastemal fold it is narrow, thin, and of looser structure. The lucts, 20-30 in number, open in two somewhat irregular rows upon a ridge midway between the margin of the lip and the fundus of the alveobuccal sulcus. The bodies are covered ectally by the facial platysma.

Illing has given a detailed description of the glands of the alveolingual region of the cat, with which in the main our results are in agreement.

The body of the submaxillary (Figs. 3 and 4,20 ), ellipsoidal in shape, and of firm texture, is placed ventrad of the parotid with which it is in contact, and by which it may be partially overlapped. In our figure the body of the submaxillary has been slightly depressed, to expose the sublingualis major. In front of the parotid it is in contact with the masscter muscle. Superficially it is crossed by the temporo-maxillary (36) and common facial veins (33), which unite near its ventral border to form the external jugular (39). Two lymphnodes are regularly found at the sides of the common facial rein (27); they were taken for accessory submaxillary glands by Mivart. By its deep surface the submaxillary is in contact with the digastric muscle and the greater sublingual gland, which separate it from the muscles of the tongue and pharynx. At the hilus there may be a deep horizontal incisure (Fig. 4). The duct (2I), single at its emergence, passes between the mandible and the digastric muscle, crossing the borly of the sublingualis major ventrally, as it ascends to the caudal border of the mylohyoid. It is 
then continued horizontally, nearly parallel to the mandible, to its orifice close to the symphysis. Dorsally it is in relation with the body and duct of the sublingualis major $(24)$. Close to its termination the duct of the sublingualis major deviates to its lateral side. Near the arcus palatinus it is crossed by the lingual nerve (29). In mone of our specimens were there any lobules whatever attached to the duct, after its emergence from the hilus of the gland.

The sublingualis major (Fig. 4, 23) regularly has an elongated body, extending from the lingual nerve to the submaxillary gland. Two portions may be distinguished, a caudal, of denser structure in which the duct bifurcates, and a cranial extension in the form of small lobules incrusting the duct. While no sharp demarcation can be made between these portions by dissection, yet in general the body proper is in relation to the digastric muscle, while the circumductular lobules are supramylohyoid in position. Rarely, as in the individual of Fig. 4, this latter portion is suppressed and the duct is entirely free of accessory lobules. The sprouts of these incrusting lobules are formed at a late period in development, and their anlages are still minute when the body of the gland has attained a considerable size and contains branches of the third and fourth order (Schulte). We may then recognize in the sublingualis major, as in the submaxillary of many forms, a body sensu stricto and an efflorescence of incrusting lobules along the duct.

The body is molded upon the digastric muscle ventrally (Fig. 4). Laterally it is covered by the submaxillary gland, and the internal pterygoid muscle; mesally it rests against the styloglossus and superior constrictor muscles. The duct surrounded by incrusting lobules passes forward between the internal pterygoid and the muscles of the tongue, here lying immediately ventral to the oral epithelium, in contact with, and dorsal to, the submaxillary duct, and separated from the mylohyoid muscle only by this duct and a small quantity of connective tissue. I have not found these lobules extending farther forward than the lingual nerve. At this point they conre into relation with the lesser sublinguals, which are mainly dorsal to them, though a few of the more ventral members of the group are lateral to the submaxillary duct. With the exception of the single individual referred to, where the suppression of the collateral lobules was complete and bilateral, I have not observed any considerable variation in the degree of 
their development. The duct is continued horizontally forward from the lingual nerve, dorsal to, and in immediate contact with, the submaxillary duct, from which position it deviates laterad close to its orifice on the caruncula salivaris.

The lesser sublingual glands (Fig. 4, I8) are represented by a number of small elements in the vicinity of the lingual nerve, for the most part dorsal to the ducts of the larger glands. They occupy an area measuring about I.5 centimeters sagittally, crossed near its middle by the lingual nerve (29). They are placed near the ventral extremity of the arcus palatinus, with the glands of which (the isthmian glands) they are continuous, and from which they cannot be distinguished in the adult eat. This condition no doubt accounts for the frequency with which they are reported absent in descriptions of the cat. Their presence is recognized by Zumstein and Illing, but I fail to see why these investigators have restricted them by definition to a prelingual position, for they are in perfect continuity with postlingual glands of the same character, and it is obvious that such a topographical landmark as the lingual nerve can have no great morphological importance. They are for the most part dorsal rather than lateral to the ducts, as Illing states, and certainly not ventral as he represents them in his Fig. I.

The propriety of separating the lesser sublinguals morphologically from the isthmian glands may be questioned because of the continuity of the two groups in the adult. In an embryo of 70 millimeters three undoubted anlages of the lesser sublinguals were present, prelingual in position, and separated by a wide interval from the glandular anlages of the faucial region, with which they agreed in being simple sprouts. The arcus palatinus was not defined (Schulte). This seems a sufficient reason for recognizing two foci of gland formation which extend and ultimately meet in the arcus palatinus, but as yet there is nothing to show which focus plays the major rôle in the process. The condition of these elements in the glutton (Fig. I3) is important in this connection. In it the arcus palatinus is free of glands except for its extreme ventral end. Here, in the position of the lesser sublinguals of the cat, both behind and in front of the lingual nerve is a group of small seattered elements. This condition, taken in connection with that of the embryo cat referred to, justifies the recognition of a lesser sublingual series in the carnivora, distinct, though rarely separate 
in the adult, from the isthmian series, which I take to be the cranial extension of the faucial focus of the embryo.

The isthmian glands are a numerous group in the arcus palatinus, filling the interval between the lesser sublinguals and the palatine glands, with both of which they are continuous in the adult. The palatine group, the orifices of which are scattered over the soft palate and the surface of the internal pterygoid muscle, are separated from the orbital series only by the inner gland-free area of the trigonum glandulare. In the embryo cat of 70 millimeters (vide Part VI, Fig. I I 4 ) there is a sagittal interval between the anlages of the orbital and faucial elements; the latter are attached to the roof (palatine glands) and sides (isthmian glands) of the fauces and are perfectly continuous at this stage, the earliest in which their presence has been observed. The recognition of isthmian and palatine groups, both evolved from the faucial focus of the embryo, is purely for convenience of reference and implies rather a topographical than an important morphological distinction.

\section{FELIS LEO}

In a lioness (Morphological Museum of Princeton University, No. I47I) conditions very similar to those of the cat obtain (Fig. 6). The parotid orifice (3) is at the extremity of a stomal ridge (15), opposite the midcusp of the upper carnassial. The duct (2) is horizontal, transmuscular, devoid of accessory lobules, single at its emergence from the body of the gland $(I)$, which lacks a ventral angle. Premeatal and postmeatal processes are moderately developed. The first orbital (g) is large, bilobed; its duct opens on the stomal ridge behind the parotid, opposite the third cusp of the carnassial. The inferior alveobuccal glands are well developer; caudad they ascend rather nearer to the parotid than in the cat. The submaxillary (2o) closely resembles that of the cat. The sublingualis major (23) is elongated, molded upon the digastric $(3 I)$, its funclus applied to the cranial and a portion of the mesal surface of the submaxillary. The prolongation along the duct is well developed and not externally clistinguishable from the body proper. Its cranial extremity is placed ventrad to its own duct (24), and is crossed by the duct of the submaxillary gland $(2 I)$ on its lateral surface. The orifices of these ducts are 
close to the symphysis, the submaxillary mesal, the greater sublingual lateral. The lesser sublinguals are present $(I S)$ in the ventral part of the arcus palatinus and the adjacent portion of the alveolingual gutter, and lie dorsal to the large ducts. They are continuous with the isthmian glands.

\section{CANIS FAMIILLARIS}

The stomal ridge is well developed, extending from the second cusp of the upper carnassial sagittally to a point just caudad of the maxillary tuberosity, then turning obliquely caudad and mesad to be lost in the trigonum glandulare. The orifices of the parotid and seven or eight orbital glands are conspicuous, and give the crest of the fold a serrated appearance. The parotid opens opposite the second cusp of the carnassial at the cranial extremity of the fold. Its duct passes laterad through the buccinator and turns almost at right angles caudad, a conformation that renders the introduction of a canula a little troublesome. The duct has a longer promasseteric course than in the cat; close to the border of the muscle it passes between the deep and superficial facial reins. Its transmuscular portion is slightly oblique, ascending from the ventral angle of the gland to its orifice. The borly is triangular, of the same general shape as in the cat, but of less compact structure and with more produced angles. The inferior is prolonged ventrad and overlies the body of the submaxillary. It is especially loose in structure, and manifests a tendency to resolve itself into lobules more or less independent of the rest of the gland (Fig. 7.5). The duct may be single at its energence, or in two or several branches. Accessory lobules are frequent in the middle third of its course. I have not seen them exceed 2 centimeters in length nor I centimeter in breadth. In five dogs examined with reference to these lobules, their presence was noted seven times; five were dorsal, two ventral to the duct; in one case both a ventral and a dorsal lobule were present on the same side. All were dense in structure, with smooth surfaces; their very short single ducts opened into that of the parotid almost at right angles. An orbitoparotid was not found.

The orbital mass is relatively much larger than in the cat, and owes its size in the main to the hypertrophy of the first member of the series $(g)$. This is a bulky lobulated gland, the duct of which emerging vent rally 
pierces the buccinator and turns forward along the stomal ridge to open opposite the cranial cusp of the first molar. This is the gland described by Nuck, whose obscrvation was made upon the dog. Seven or eight elements are present. Their bodies form a series diminishing in size caludad; the second orbital is not more than a twentieth of the size of the first. Their ducts pierce the buccinator obliquely and open at almost equal intervals upon the stomal ridge. The ducts of the second and third are somewhat larger than the others, but have not so long a course in the mucosa as their homologness in the cat.

The inferior alveobuccal glands are well developed, as a rule about 20 in number, extending from the diastemal fold to the border of the masseter, there ascending slightly. In these respects they resemble closely those of the cat; the individual elements are somewhat larger and more easily distinguished through their connective tissue investment. In a pregnant bitch (Columbia Morphological Museum, No. 2040, Fig. 7, I6) they are especially well developed, and the caudal members of the series ascend along the border of the masseter at an angle with the rest of the mass, towards, but not reaching, the parotid duct.

The submaxillary, sublingualis major, the lesser sublinguals, and the isthmian glands conform closely to the type of the cat. The submaxillary is proportionately larger and of very dense structure. In the bitch above referred to, there is a small accessory lobule dorsal to the duct and in contact with the upper pole of the gland, which is ir is ad in the narrow interval between the digastric muscle and the manumble.

\section{URSUS THIBETANUS}

The preparation (Morphological Museum of Prinçeton University, No. 1380 ) is from a young specimen. The parotid (Fig. 8, I) is large; it extends caudad upon the cephalohumeralis muscle and partially overlies the submaxillary gland ventrad; the three angles are less marked than in the preceding forms, but are easily recognized. The dorsal border is no longer concave, but forms a blunt angular projection where it rests against the cartilage of the external auditory meatus. The duct (2) emerges near the ventral angle and ascends slightly in its course across the masseter. The orifice is at the extremity of a stomal 
ridge opposite the second molar tooth. Inferior alveobuccal glands are present; the caudal end of the series ( $I \sigma)$ ascends at the border of the masseter above the level of the angulus oris, and approaches the parotid duct, which, however, is not embedded in the mass. The submaxillary gland (20) also is large, its structure firm, its lobules sharply defined inside the dense capsule. It is reniform in shape, with its long axis nearly vertical. The duct $(2 I)$ emerges from the concavity of the cranial border, turns over the digastric muscle to reach the dorsal surface of the mylohyoid, and continues horizontally to its orifice upon the caruncula salivaris close to the symphysis. The greater sublingual gland (23) closely resembles that of the cat, but is somewhat smaller relatively and for the most part mesal to the digastric muscle; the lateral margin is in contact with the submaxillary only at its upper pole. The lesser sublinguals $(I S)$ are well developed and form an elongated mass dorsal to the ducts of the submaxillary and greater sublingual glands. They extend into the arcus palatinus and are continuous with the isthmian glands.

\section{PROCYON LOTOR}

(Morphological Museum of Princeton University, No. 22I.) In the raccoon the parotid is quadrangular and very large (Fig. 9), extending forward on the masseter, and behind over the trapezius abecia?phalohumeralis muscles. Its lower margin is prolonged to cover and almost conceal the submaxillary. In our illustration it has been reflected slightly to expose this gland. The duct (2) emerges from its cranial border, nearer the ventral than the dorsal angle. It ascends stightly on the surface of the masseter, crosses its sloping border and opens at the end of the stomal ridge, opposite the second cusp of the first upper molar tooth. Into the promasseteric portion of the duct opens an orbitoparotid $(\delta)$, the borly of which has an inframuscular position, following the sloping border of the masseter as far as the mandibular ramus. The orifice of its duct corresponds to one of the sites of orbitoparotid sprouts in embryos of the cat, and the body to the direction of its growth, which often follows the parotid rluct along the border of the muscle. For these reasons I have no hestitation in interpreting this element as an orbitoparotid, and hold 
it to be homologous with the small inconstant gland of the cat at the border of the masseter, which opens either into the parotid duct or independently upon the stomal ridge.

The submaxillary gland (2o) is small, pyriform, and largely under cover of the parotid and of a large lymphnode (27) at its lower border; only caudad is its surface uncovered in the natural position of the parts. A small ventral accessory lobule is present (22) close to the emergence of the submaxillary duct. The sublingualis major $(23)$ is also small and retort-shaped, its supramylohyoid extension reduced, its body mesal to the accessory submaxillary. The ducts $(2 I, 2,4)$ have the same disposition as in the cat. The lesser sublinguals ( 18 ) are well developed. Their situation and extent are shown in the figure.

\section{MEPHITIS PUTIDA}

(Morphological Museum of Princeton University, No. I688.) The parotid is of moderate size, resembling that of the lioness in the suppression of its ventral angle (Fig. 10, I). The duct (2) emerges in two branches which immediately unite. Its transmuscular portion ascends obliquely. The orifice is opposite the cranial cusp of the carnassial. The submaxillary is ovoid, its long axis oblique, paralle! to the margin of the cephalohumeralis muscle. The duct emerges from its dorsal pole; near the lingual nerve there is a minute accessory lobule (22) of lateral position. The sublingualis major $(23)$ is remarkable for its deep position mesal to the stylohyoid. Its duct is devoid of incrusting lobules. In other respects the ducts have the same disposition as in the cat. The lesser sublinguals ( $I 8)$ are very rudimentary.

\section{TAXIDEA AMERICANA}

(Morphological Museum of Princeton University, No. 1756.) The parotid is of moderate size, quadrangular (Fig. II, I); the premeatal process is rudimentary, the postmeatal absent. The duct emerging from the cranial border ascends to its orifice opposite the second cusp of the carnassial. The stomal ridge is well marked, and shows the orifices of several orbital glands, two of which are shown in the figure behind the bristle which marks the parotid orifice. The 
inferior alveobuccal glands (I6) are of mocierate development. The caudal end of the series is near the angulus oris; the cranial does not quite reach the diastemal fold.

The submaxillary (20) resembles that of Mephitis in its ovoid form and vertical axis. The duct $(21)$ emerges a little below the dorsal pole, ascends over the digastric muscle, and thence extends horizontally to its orifice behind the symphysis. A small dorsal accessory lobule is present, draining into the distal segment of the duct, and closely applied to the dorsal pole of the gland. There are two submaxillary lymphnodes. The greater sublingual gland (23) is smaller than in any of the forms we have been considering, wholly ental to the digastric and supramylohyoid in position. The body is oroid ; the duct emerges from its cranial pole; small incrusting lobules about the duct are wholly lacking. The lesser sublinguals $\left({ }_{I} \delta\right)$ are of moderate development, extending from the arcus palatinus to within a short distance of the frenulum.

A second specimen of this animal (Columbia Morphological Museum. No. 2I53) presented important departures from the foregoing, especially in the conditions of the glands of the alveolingual region. The submaxillary (Fig. I2, 20) was peculiar in the development of dorsal accessory lobules, three of which were present. The largest occupied the angle between the duct and the dorsal pole of the gland body; ectal to the digastric, it eridently corresponds to the smaller lobule noted at this point in the preceding specimen. It drains by several ductules into the main submaxillary duct. The second lobule is placed at the cranial border of the digastric, separated by a small interval from the one just described. It is ovoid and drained by a single duct. The third and smallest rests against the hyoglossus muscle. Its ductule, which is long and slender, is directed craniad and ventrad to join the submaxillary duct near its point of intersection with the lingual nerve. This is the greatest development of the submaxillary complex I have met with in the carnivora, as regards the size and number of accessory lobules. The lesser sublinguals (I 8 ) are also a larger mass than in the other specimen, and extend from the frenulum into the arcus palatinus, where they are continuous with isthmian glands. They are best developed craniad, where they surround the submaxillary duct on its dorsal and lateral aspects. The caudal members of the series are smaller, forming a thin sheet from the 
lingual nerve to the arcus palatinus, where they are reduced to scattered elements, as are also the isthmian glands. On the other hand, the sublingualis major is absent; its orifice could not be found, nor did a careful search reveal any trace of its duct or body. Taken in connection with the large development of the submaxillary and lesser sublinguals, this absence of the gland of Bartholin is important as pointing to the possibility of vicarious or compensatory growth on the part of the several gland elements of the alveolingual region, in the sense that size and complexity of one of them, in a region so circumscribed topographically, is not without influence upon the others, as tending to limit the space available for their expansion by its growth, or by its reduction to afford opportunity for the appearance of accessory elements, which in ordinary circumstances are latent. It is not meant to imply, however, that spatial opportunity is the sole factor in determining the development of variant elements, or the degree of development of the salivary complex as a whole, the explanation of which must be sought in far more intricate conditions than those of topography, but merely that in a given region there may be something of the nature of a struggle for existence among the several elements which are potentially capable of occupying the available space.

The vestibular glands of this specimen differ in a few particulars from those of the other barlger. A minute dorsal accessory lobule is attached to the parotid duct a few millimeters from its emergence. The inferior alveobuccal glands form a larger mass, extending from the diastemal fold to the facial vein, which separates them from the masseter. The caudal extremity of the mass ascends to the level of the angulus oris, and forms with the remainder of the mass an acute angle, in which a slip of the facialis muscle passes to its insertion into the oral mucosa. The condition is similar, though less in degree, to that of the bitch of Fig. 7. As the diastemal fold is approached these elements diminish in size, and the mass terminates by a pointed extremity.

The orbital glands of the badger are seven or eight in number, opening upon the summit of a stomal ridge by a series of minute papillæ. The first orbital is relatively a little smaller than in the cat; the series diminishes in size caudad.

A superior diastemal fold is present. It resembles the inferior, 
but is of less development. Arising by a broad base from the lip, it rises in a low ridge separating the superior alveolabial and alveobuccal sulci, and narrowing, is attached to the gum on the caudal aspect of the upper canine tooth.

\section{GLLO LUSCUS}

(Columbia Morphological Museum, No. 2152.) Left side (Fig. I3). The parotid $(I)$, which is of looser structure than usual, is almost divided at the meatus auditorius into two lobes, a larger submeatal, a smaller premeatal in position. The latter, occupying the groove between the masseter and the auricular cartilage, evidently corresponds to the cranial border and premeatal process of the gland in the cat. The submeatal lobe is of denser structure, and thicker; caudad it overlies the trapezius and cephalohumeralis. A very rudimentary projection of the dorsal border corresponds to the postmeatal process of the cat, in comparison with which this gland of Gulo is peculiar chiefly in the great development caudad of the body. The duct (2) emerges from the cranial border near the rentral angle. A tongue of gland tissue accompanies it on its dorsal aspect as far as the sloping border of the masseter; this is composed of small lobules which are drained by short direct ducts. The orifice of the parotid is at the extremity of a stomal ridge, opposite the interval between the labial cusps of the upper carnassial. On the stomal ridge open an orbitoparotid and seren orbital glands. The former is minute. about 2 millimeters in diameter, placed at the cranial border of the masseter between the deep and superficial facial veins. Its duct passes directly through the buccinator to its orifice opposite the second cusp of the carnassial. In the undisturbed condition of the parts this small gland lies at a level dorsal to that of the parotid duct. where it crosses the border of the masseter, a relation which is important in riew of the conditions observed on the opposite side (aide infru). The orbital glands open in series upon the stomal ridge. Their ducts pierce the buccinator; their bodies are embedded in the infraorbital fat. That of the first gland is relatively smaller than in the cat.

The inferior alveobuccal glands $(I \sigma)$ are reduced to a small mass in 
the vicinity of the angulus oris, almost wholly confined to the buccal region of the vestibule. The condition is evidently to be interpreted as the persistence of the caudal, and the suppression of the cranial, members of such a series as is found in the cat.

The submaxillary gland is large and of firm structure. The ovoid body lies upon the cephalohumeralis muscle; its axis is nearly horizontal. A tongue-like extension of its cranial pole accompanies the duct as it passes over the digastric muscle, and comes in contact with the fundus of the sublingualis major. This portion is extremely loose in texture and reduced to a series of easily separated lobules. The largest of these, from which the main duct emerges, is placed at, and molded upon, the cranial surface of the digastric, to the mesal side of which it is in part situated. From this a branch of the duct passes to the lateral surface of the muscle and drains two lobules; the first of them is still in the main in front of the muscle, the second distinctly to its lateral side and in contact with the extension of the submaxillary. This specimen shows in a high degree the effect of the digastric in determining the configuration of the sublingualis major, the duct of which divides at its border to drain the portions of the gland on its ental and ectal surfaces. The tendency of the gland to revolve itself into ecto- and ento-digastric lobes is especially clear in this form, where a remarkably great development of the muscle coexists with a reduced sublingualis major. In the supramylohyoid portion of their course the ducts have the usual disposition; both are devoid of incrusting lobules.

The lesser sublinguals $(I S)$ are reduced to half a dozen minute scattered elements at the junction of the arcus palatinus and the alveolingual gutter, dorsal to the large ducts, and on both sides of the lingual nerve.

Right side (Fig. 14). The parotid of the same general configuration as on the left lacks the efflorescence of small lobules along the duct. Below its ventral angle there is a small compact ovoid lobule which is drained by a slender duct. This ascends on the lateral surface of the massseter, crosses the parotid duct at the border of the muscle, and opens into its proximal segment on its mesal aspect. In point of debouchment it therefore corresponds to one of the conditions of the orbitoparotid in the cat; in the situation of its body and the long 
course of its duct it seems to be equivalent to the ventral parotid of Hyrax (Carmalt, Huntington). The one difficulty in interpreting it as an orbitoparotid, the dorsal crossing of the duct, seems to be met by the position of the orbitoparotid of the opposite side before referred to. Should such an element attain a larger growth, its sprout would cross the parotid duct dorsally, and this is the more probable in view of the primitive inframuscular position of the parotid duct in the only carnirure in which its development is known. So far as our knowledge of these variants at present extends, I can see no objection, nor, indeed, any alternative, to the interpretation of this element as an orbitoparotid gland.

The other glands closely resemble those of the left side. There is, however, a difference in the relations and relative development of the extradigastric lobules of the greater sublingual and the accessory portion of the submaxillary. The latter is reduced, and resolved into a small portion retaining its relation to the body of the gland, and an outlying small lobule which rests against, and is to some extent embedded in, the sublingualis major. This is of greater development than on the opposite side and, passing mesal to the accessory submaxillary, abuts upon the extension of that gland along its duct. In the comparison of the conditions here upon the two sides we have a striking example of the manner in which these elements substitute for one another within the limits of a confined space.

Meckel notes the large size of the parotid in several of the Procyonidie (Mustela, Lutra, Nama, Taxus) and its enormous development in Procyon. He scems to consider the orbital glands as belonging to the inferior alveobuccal group, as he occasionally refers to both as Backendrisen, though quite as frequently he terms the former Augenhoblendriisen, the latter Lippendriisen. He notes the large size of the orbitals in Mustela and Lutra. Zumstein describes in detail the glands of the alveolingual region in Putorius. The sublingualis major is ental to the cligastric muscle, which separates it from the submaxillay, while its borly extends forward to near the lingual nerve. Its duct opens at the caruncle lateral to that of the submaxillary in $P$. vulgaris and $P$. erminea ; in P. europea its orifice is situated I centimeter cauclal to this point. The lesser sublinguals are chorsal to the larger ducts; in P. europea they have an extent of about 1.5 centi- 
meters; in P. vulgaris and $\mathrm{P}$. erminea they join the isthmian glands. So far as these elements are concerned, Putorius seems closely to resemble Taxidea.

ZALOPHUTS CALIFORNIANUS

(Morphological Museum of Princeton University, No. 824.) In the sea-lion (Fig. 15) the salivary glands, with the exception of the lesser sublinguals, are of relatively small development. The parotid $(I)$ is submeatal in position and shows no tendency to extend over the cephalohumeralis muscle. It is of an elongated pyriform shape, its cranial extremity extending forwarl along the duct (2). This has at distinctly ascending course upon the masseter, at the cranial border of which it passes between the deep and superficial facial veins, pierces the buccinator obliquely, and opens opposite the first upper molar. In the shape of its body and the course of the duct it resembles conditions attained in the cat embryos of 35 and 51 millimeters.

The submaxillary $(20)$ is smaller than the parotid, ovoid with its long axis oblique. Like the parotid, the submaxillary resembles more closely than in the other carnivores the developmental conditions in the cat. In the embryos referred to, it has an elongated form and an axis nearer the horizontal than the vertical plane. The duct $\left(2_{I}\right)$ emerging from its dorsal pole has the usual course and relations. There is a small dorsal accessory lobule, ental to the digastric, draining by a short ductule into the beginning of the supramylohyoid segment of the submaxillary duct. It is immediately caudal to the sublingualis major. This gland is elongated; its fundus corresponds to the lingual nerve, and is, therefore, entirely of supramylohyoid position and terminates without reaching the digastric muscle. The gland is prolonged forward by small incrusting lobules about the duct, which is free only in a short terminal segment. The lesser sublinguals (I8) are well developed, and correspond in sagittal extent to the body of the sublinguilis major. The isthmian glands are absent. The typical reciprocal relations of the glinds of the alveolingual region are well shown in the figure, the submaxillary duct ventrad, the alveolinguals dorsad, the sublingualis major intermediate.

In two other specimens in the Columbia Collection similar conditions 
were found. The orbital series and the inferior alveobuccal glands were present and of moderate development.

In a recently acquired specimen of Macrorhinus angustirostris (Columbia Morphological Museum, No. 2154) the parotid gland is absent, as are also the orbitals. The submaxillary is large and lies immediatcly below the auditory meatus, overlying the masseter, and dorsal rather than lateral to the digastric muscle, so that topographically it has usurped the position of the parotid. Its duct has the usual course, but opens at the side of the tongue caudal to the frenulum. The greater sublingual is absent; the lesser sublinguals are present in the form of very small scattered glands in the arcus palatinus and the caudal portion of the alveolingual region.

The divergent findings in the pinmpedia illustrate the difficulties of this suborder and the need of more extended obscrvations. Nor are the reports in the literature more concordant: Cuvier is responsible for the statement that the parotid, sublingual, and orbitals are absent in the seals (Sechunde); Meckel also reports the absence of the sublingual, and notes the small size of the parotid and submaxillary, while Owen states of the seal tribe in general that the parotid is small or wanting and that there are no orbital glands. - ED1TORs' NoTE.]

It is apparent from the foregoing data that in each of the larger salivary glands, the parotid, the submaxillary, and the greater sublingual, we may distinguish between a body proper and a highly variable extension along the duct, which may have the character of a massive prolongation, or, when less developed, appear in the form of isolated lobules usually termed accessory.

The sublingualis major among the carnivora has this extension more highly and more uniformly developed than the other glands. The anlage is in the cat a thickening of the epithelium of the alveolingual region just caudad of the lingual nerve. Here a distally growing sprout is formed, which soon branches, and gives rise to all the epithelium of the gland beyond the point of division of the duct. The proliferation which gives rise to the sprout advances craniad along the oral epithelium as a keel, which, becoming free, forms the duct. Secondarily and at a later period the duct becomes incrusted with small sprouts from the region of bifurcation as far proximad as the lingual nerse. There are then grounds for regarding the earlier formed portion, with forking ducts, as the primary gland, to which is added a prolongation by the secondary development of small circumductular lobules. This portion is highly variable. Regularly 
present and well developed in the dog and cat, it was in one instance totally suppressed. Rudimentary in Procyon and in Ursus thibetanus, it is suppressed in the Mustelidæ that we have examined, while in Zalophus it constitutes the bulk of the gland and extends far forward towards the frenulum.

The submaxillary gland resembles the sublingualis major in the formation of its duct by an advancing proliferation, with this difference, that the segment in the vicinity of the lingual nerve appears as the thickening of the border of a blind fold or flange associated with the lingual sulcus. When the duct becomes free, the intermediate portion of the flange remains attached to its dorsum. While this gives rise to no sprouts in the cat, the preponderating dorsal position of accessory submaxillary lobules points to it as favoring the development of sprouts. Only in one instance (Procyon) was a ventral lobule found. In comparison with other orders, the carnivora present but a small range of variation as regards these elements; possibly this stands in relation to the uniformly large size of the digastric muscle. In the cat and $\log$, where the material was sufficiently abundant to give some weight to general statements, but one was found. They occurred, in contact and intimately united to the body of the gland, in Taxidea and on one side in Gulo. As isolated lobules they were found along the postlingual segment of the duct in Mephitis, Taxidea, and Zalophus, and one on the left side of Gulo.

The parotid resembles the submaxillary in the presence of a flange in connection with its anlage, which likewise gives rise to a distal sprout and a proximal keel. The latter forms the oral segment of the duct, at least as far as the border of the masseter. At an early period a variable sprout is formed arising from the flange, in the angle between the parotid sprout and the oral epithelium. This evidently corresponds in position to the intermediate portion of the submaxillary flange. As the duct is freed by constriction, it is clear that this sprout cannot long retain its attachment at the angle between the duct and the mouth, but must become separated from one or the other. In later stages it is found arising sometimes from the duct, more frequently from the oral epithelium between the parotid and the first orbital gland. On account of its intermediate character it has been termed the orbitoparotid element. There is evidence that 
in late stages of development orbitoparotid sprouts may be formed directly from the oral epithelium, for their frequency increases in the larger embryos, and to judge from the conditions in the adult they may arise in later periods from the promasseteric portion of the parotid duct. On the other hand. in two embryos only. on one side in each, were sprouts found in the transmuscular segment of the duct. They were ventrally directed and close to the point where the duct divided, a small proximal bud, and a slencler recurrent branch, corresponding in general disposition to the lobules 6 and 7 of Fig. 5. No other derivatives of the duct have been recorded in embryos of the cat.

The extension of the parotid along its duct attains its highest derelopment in Gulo, where it extends to the border of the masseter and is dorsal in position. Accessory lobules representing a less degree of this process have been found in Canis (dorsal and ventral), in Felis (ventral only), and in Taxidea (a minute dorsal lobule). The ventral angle of the gland is frequently of loose structure and manifests a tendency to resolve itself into independent lobules. The duct also varies in its emergence, being sometimes single, sometimes in two or several branches, and these variations occur in individuals of the same species and often on the two sides of the same individual (dog and cat). The ventral angle may be suppressed (lioness) and the duct emerge abruptly from the body of the gland, or the duct may continue undivided in the gland substance for a considerable distance (scalion). In consequence of these frequent variants the transition between circumductular portion and body (sensu stricto) is far less definite in the parotid than in the submaxillary, while in the sublingualis major, on the other hand, the two prortions are often not recognizable externally.

Apart from these conditions at the hilus, and in contrast to the extensions along the ducts, the bodies of the glands seem to be subject to little variation in the species where sufficient material hats been available for comparison. Their shape bears a direct relation to their size, in that this determines the degree of their contact with, and consequent adaptation to, their topographical environment. As this is different for each gland, each has a characteristic form impressed upon it, which can be referred to definite factors. We may take as the primitive form of all these glands an elongated ovoid, rounded distad, 
pointed proximad, with a horizontal or nearly horizontal long axis, the duct emerging from the apex. This shape is characteristic of the intermediate stages of development in the cat, and is retained in the adults of other genera where the gland is small, e.g. the parotid of Zalophus.

The sublingualis major (Fig. I6) retains its developmental form in Mephitis and Taxidea. A rudimentary circumductular portion is added in Procyon and Ursus thibetanus. In all these the body is of small size. Its larger growth brings it into intimate contact with the mylohyoid against which it is molded, presenting a gutter to
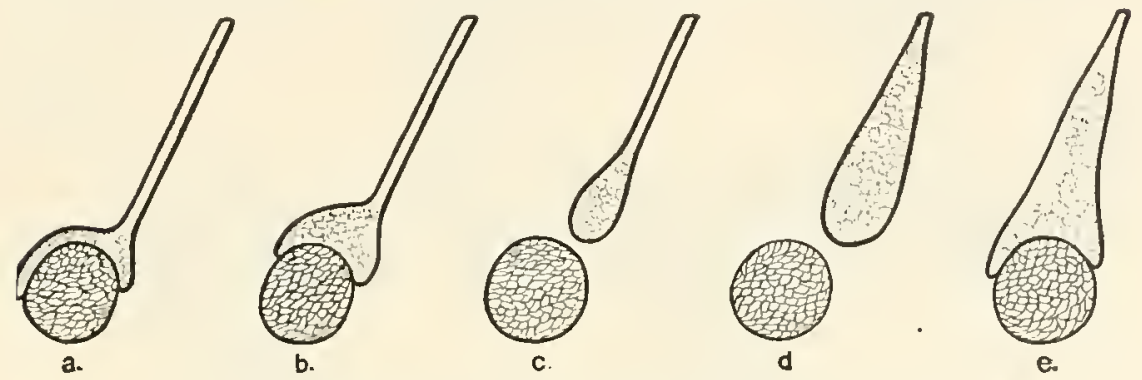

FIG. I6. Schemata of the greater sublingual gland in relation to the digastric muscle. The gland is represented in horizontal section.

a. Glutton.

c. Cat, embryo.

b. Cat, variant.

d. Sea-lion.

c. Cat, usual type.

the muscle and tending to extend itself on its ental and ectal aspects. This condition obtains in Felis and Canis. In Gulo, where the muscle is of great size, the gland is almost divided into two portions.

In the case of the submaxillary (Fig. I 7) we may distinguish forms of small, of moderate, and of great development. In the first class the gland is of the embryonic type except that its axis is more distinctly oblique; the body rests against the cephalohumeralis muscle (Procyon). As the gland enlarges, the influence of the muscle becomes more pronounced and the axis becomes vertical (Mephitis). The duct loses its apical emerge and is displaced ventrad; a dorsal pole begins to rise above the hilus (Taxidea, Gulo). These forms have also an extension along the duct. The large glands, retaining the vertical axis, develop a larger dorsal pole, while the duct emerges from, or near 
the middle of, the cranial surface. Finally they become reniform and may even present a transverse fissure at the hilus. These changes are present in increasing degree in Canis, Felis leo, Felis Domestica, and Ursus thibetanus. In these forms there is evidently dorsoventral compression between the mandible, the masseter and internal pterygoid muscles and the parotid gland dorsally, and the infra-hyoid muscles ventrally. In Zalophus alone the submaxillary does not reach the cephalohumeralis, but is in apposition with an enormous
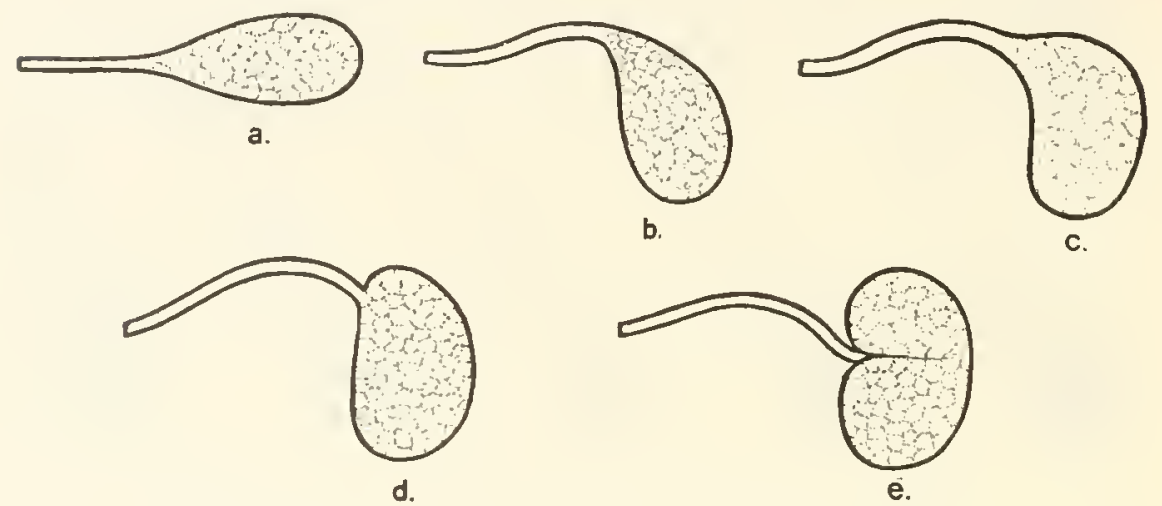

Frg. I 7. Schemata of the submaxillary gland in carnivores.
a. Cat, embryo.
c. Raccoon.
b. Sea-lion.
d. Badger.

e. Thibetan bear.

lymphnode at the ventral border of the digastric. Its axis makes an angle of about $45^{\circ}$ with the horizontal.

The partoid (Fig. I8) tends to be confined by the auditory meatus and the cephalohumeralis muscle. In Zalophus $(a)$ the gland is hardly large enough to be affected by these structures; at most a rudimentary postmeatal process is distinguishable. In Felis leo (b) the gland is molded upon the meatus; the premeatal and postmeatal process are still small; the border between them is concave. The processes are more marked in Felis domestica (c) and Canis, and these forms have also a loosely constructed ventral angle which reaches forward along the duct and tends to develop a ventral process descending upon the submaxillary. With further enlargement the gland tends to extend over the cephalohumeralis and to fill up the 
concavity between its meatal processes. The duct emerges from the cranial border a short distance from the ventral angle in Mephitis $(d)$ and Ursus thibetanus (e). The enormous gland of Procyon $(f)$ has become quadrilateral by developing from the convex caudoventral border a caudal angle extending upon the cephalohumeralis. The parotid thus passes from an ovoid, through the stage of crescent and triangle, to a quadrangular shape as its size increases. In Taxidea

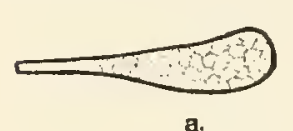

a.
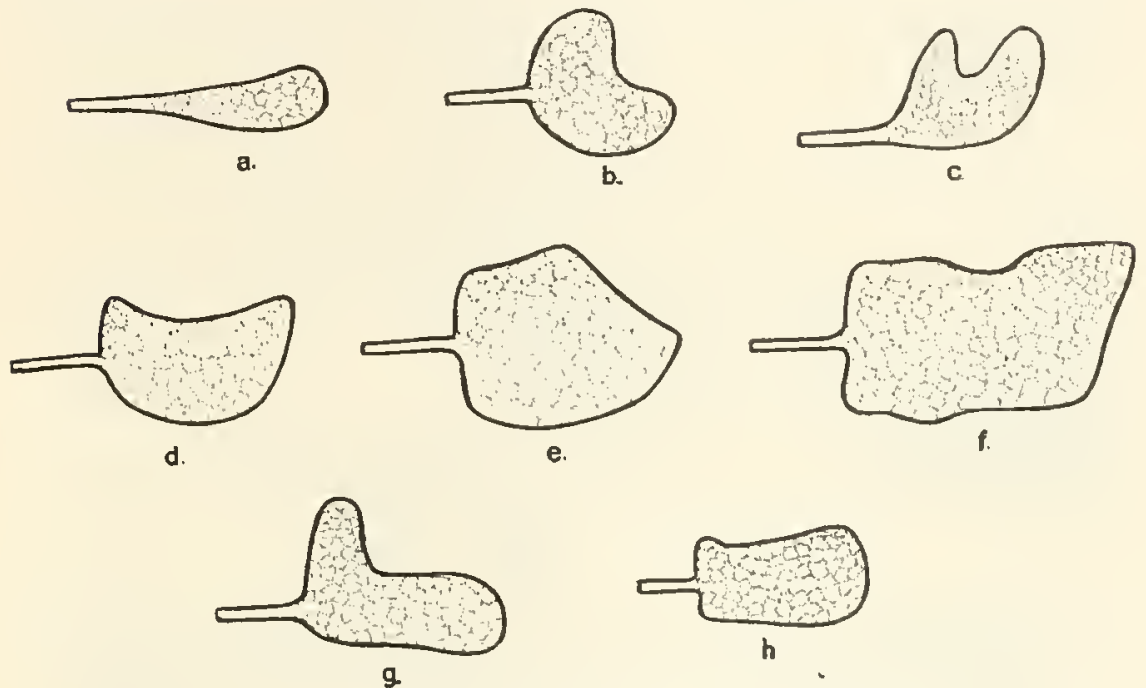

FIG. IS. Schemata of the parotid gland in carnivores.
a. Sea-lion.
c. Thibetan bear.
b. Lioness.
f. Raccoon.
c. Cat.
g. Glutton
d. Skunk.
h. Badger.

(h) the parotid is not large, but has the quadrangular shape and extends upon the cephalohumeralis. This depends upon the flatness of the head and the large size of the external auditory cartilage, so that relative to the space available for expansion the gland is of large size, and has the corresponding habitus. The same is true of Gulo (g), but there is here, in addition, a large though thin premeatal process.

The molar glands usually extend from the diastemal fold to the superficial facial vein. The series tends to enlargement at its caudal end, where it may ascend along the border of the masseter (bitch, 
Ursus thibetanus). The cranial members are always smaller and are reduced in Taxidea; they may be suppressed and the mass reduced to a small body near the angulus oris (Gulo). In none of our specimens do they reach the parotid duct or surround its proximal segment.

The lesser sublingual glands tend to reduction in the carnivora, especially at the cranial end of the series. In none of our specimens were they found in the vicinity of the caruncle or near the orifices of the submaxillary and sublingual glands. Caudad they extend to the beginning of the arcus palatinus and here seem to be always present, while the isthmian glands may be suppressed (Gulo, Zalophus). The lesser sublinguals were most extensively developed in an individual of Taxidea in which the sublingualis major was suppressed (Fig. 12). They here extend from the frenulum to the arcus palatinus and are placed lateral to the larger ducts in the cranial portion of their course, becoming dorsal as the lingual nerve is approached; a similar condition is found in Ursus thibetanus (Fig. 8). In a second badger they are of less extent (Fig. II) and resemble those of Procyon (Fig. 9). In Zalophus they are well developed. but the isthmian glands are suppressed (Fig. I5). In the other forms examined they are confined to the ricinity of the lingual nerve, caudal to which they are continuous with the isthmian glands if the latter are present (Canis. Felis, Mephitis). The isthmian glands are suppressed in Gulo, where the lesser sublinguals also are extremely rudimentary.

The orbital glands form a series of six to eight elements diminishing in size caudad. In the cat the first three have a development similar to that of the sublingualis major; the remainder seem to be simple sprouts. In the cat the diminution of the series is gradual, in the dog abrupt, the first orbital being here of great relative size.

The orbitoparoticl gland is an inconstant and usually small element. In the cat it is always confined to the region in front of the border of the masseter between the parotid duct and the oral epithelium. It opens either into the mouth or into the parotid duct. An element of this description was found in Gulo on one side, opening upon the stomal ridge. In the same specimen on the right side a larger orbitoparotid was present (Fig. 14) with a slender duct opening into that of the parotid and a body near the ventral angle of the larger gland. In Procyon. also, a large orbitoparotid was found (Fig. 9), inframus- 
cular in position, draining into the parotid duct. The grounds for regarding this element as intermediate between the parotid and the orbital series have already been stated, from which it follows that the glands opening upon the stomal ridge are to be regarded phyletically as a single series, secondarily divided in mammals by the suppression of its intermediate portion. of which the variable orbitoparotid is representative. The modifying factor is the masseter, in relation to which the series resolves itself into an ectomasseteric element, the

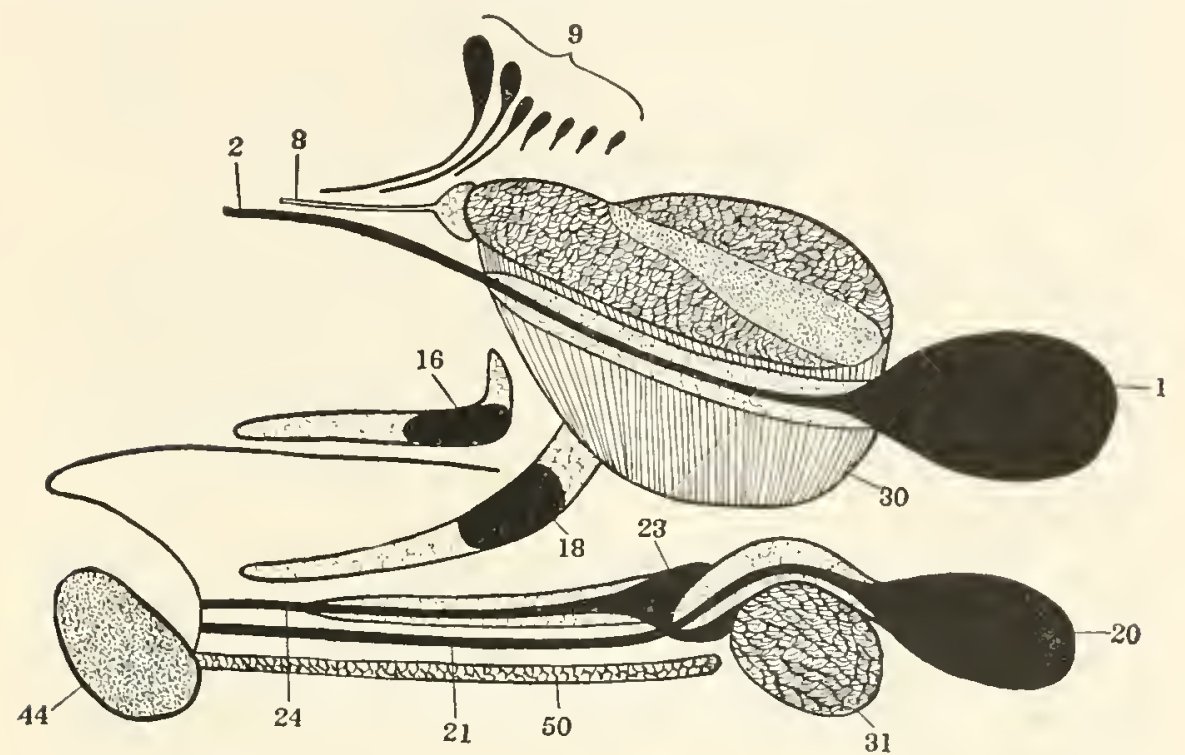

FIg. 19. Schema of the salivary glands in fissipede carnivores. The constant elements are shown solid, the variants in outline.

parotid, entomasseteric elements, the orbital series, and promasseteric elements, orbitoparotids. The last, when well developed, tend to escape from their confinement along the border of the masseter, following the line taken by the parotid sprout; they may retain the inframuscular position (Procyon) or acquire a position on the lateral surface of the muscle near its ventral border (Gulo).

The diagram (Fig. I9) is intended to express graphically these conclusions as to the composition of the fissipede carmivore salivary complex. The constant elements are represented in solid black, 
the variants are shaded. The lesser sublinguals $(18)$ are considered constant in the vicinity of the lingual nerve with a disposition to spread forward along the alveolingual gutter towards the caruncula salivaris. Similarly the inferior alveobuccal elements ( $I 6)$ are always present from the border of the masseter to a point beyrond the angulus oris, thence extending themselves towards the inferior diastemal fold, their cranial limit. They also extend inconstantly dorsad a short distance along the border of the masseter. The orbitoparotid $(S)$ abuts upon this muscle much in the same way as the sublingualis major upon the digastric, and has like the latter gland a tendency to develop a lateral process and so escape the obstruction. The duct opens either upon the stomal ridge or into that of the parotid.

\section{SUMMARY}

I. In the fissipede carnivora the full complement of salivary glands are present; opening into the vestibule, the parotid, the orlijtals, the inconstant orbitoparotid, and the inferior alveobuccal (molar) glands; opening into the carum oris proprius, the submaxillary, sublingualis major, sublinguales minores, isthmian, and palatine glands.

2. The parotid, orbitoparotid, and orbitals constitute a single series which is divided by the masseter into cranial ectomasseteric and caudal entomasseteric elements, the parotid and orbital glands respectively. The orbitoparotid is an inconstant intermediate gland, corresponding to the border of the masseter, and in consequence tending to suppression.

3. The lesser sublinguals, greater sublinguals, and submaxillary glands are, respectively, dorsal, intermediate, and ventral in position. With regard to the lesser sublinguals, this statement applies strictly to their orifices alone; their bodies, when well developed, are lateral to the larger ducts from the region of the lingual nerve craniad.

4. The parotid, submaxillary, and sublingualis major glands have bodies in which their ducts divide and ranify, and circunductular extensions which are composed of small lobules draining by short ductules into the main duct. These extensions are inconstant and highly variable; isolated portions of them are usually described as accessory parotids or submaxillaries. In the case of the sublingualis major, the circumductular extension seems either to be present as a 
whole or absent; its occurrence in the form of isolated accessory lobules has not been observed.

5. Of the finnipede carnivores Zalophus has the full complement of salivary glands. In Macrorhinus those of the vestibule, the parotid, orbitals, and inferior alveobuccals are suppressed, together with the greater sublingual. The lesser sublinguals are rudimentary; the duct of the submaxillary fails to reach the frenulum lingux.

\section{BIBLIOGRAPHY AND SOURCES}

Chauteau and Arloing. i8go. Traité d'anatomie comp. des animaux domestiques. Paris.

Cuvier. ISto. Vorlesungen über vergleichende Anatomie. Leipzig.

Elienberger and Baum. I89i. Systematische und topographische Anatomie des Hundes. Berlin.

ILling, G. I904. Vergleichende Makroskopische und Mikroskopische Untersuchungen über die Submaxillaren Speicheldrüsen der Haussäugetiere. Anatomische IIcfle. Bd. 26 , Hefte 2, 3 .

Liadze, IV. I910. Die Backen und Lippendrüsen des Hundes und der Katze. Intug. Dissert. Basel.

Merkel, J. F. i 829 . System der vergleichenden Anatomie. Halle.

Mivart, St. G. 1881. The Cat. New York.

Nuck, A. 1723. Sialographia. Edito tertia. Leyden.

Owen, R. I 868 . The Anatomy of Vertebrates. London.

RANVter, L. I886. Étude anatomique des glandes connues sous le nom de sousmaxillaire et sublinguales chez les mammiferes. Arch. de Phys. Norm. et Path.

Reighard and Jennings. igor. Anatomy of the Cat. New York.

IVARD, N. I $8+7-18+9$. The Salivary Glands. Todd's Cyclopediu of Anutomy and Physiology, Vol. IV, Part 1. London.

WEBEr, Max. Igof. Die Saugetiere. Jena.

Wilder, Burt G., and GAge, S. H. Anatomical Technology as applied to the Domestic Cat. New York.

Zumstein, J. J. т $\$ 9$. Ueber die Unterkieferdrüsen einiger Säuger. Habilitationschrift. Marburg.

Silvester, C. F. Dissections of the Salivary Glands in the Morphological Museum of Princeton University.

\section{ANNOTATION OF LEADERS IN ALL FIGURES}

I. Parotid gland.

2. Parotid duct.

3. Parotid orifice.

5. Outlying lobules of the ventral angle of the parotid.

6. Accessory parotid lobule. 
7. Accessory parotid lobule with recurrent duct.

8. Orbitofarotid gland.

$\mathcal{S}^{\prime}$. Orbitoparotid duct.

9. Orbital glands.

10. First orbital gland.

II. Second orbital gland.

12. Third orbital gland.

13. Caudal orbital glands.

1.t. Gland of stomal ridge.

15. Stomal ridge.

16. Inferior alveobuccal glands (molar gland, buccal glands).

17. Isthmian glands.

1S. Lesser sublingual glands.

20. Submaxillary gland.

21. Duct of submaxillary gland.

22. Accessory submaxillary gland.

23. Greater sublingual gland.

24. Duct of greater sublingual gland (Bartholinian duc1)

25. Preparotid lymphnode.

26. Postparotid lymphnode.

27. Submaxillary lymphnodes.

28. Lymphnode.

29. Lingual nerve.

30. Masseter muscle.

3I. Digastric muscle.

32. Internal pterygoid muscle.

33. Common facial vein.

34. Deep facial vein.

35. Superficial facial vein.

36. Temporo-maxillary vein.

37. Superficial temp ral vein.

38. Posterior auricular vein.

39. External jugular vein.

7o. Transverse jugular vein.

f1. Upper carnassial tooth.

42. Upper molar tooth.

43. Fold beside lower molar tooth.

H. Nandibular symphysis.

45. Sulcus between internal pterygoid and masseter muscles.

46. Triangle of orbital glands.

47. Greater cornu of hyoid bone.

48. Thyroid gland.

49. Arcus palatinus.

50. Mylohyoid muscle. 



\section{l'LATE XXXIV}

FIG. r. Felis domestica. Oral cavity.

FIG. 2. Detail of the same, schematized, to show the stomal ridge and the orifices of the parotir, orbitoparotid, and orbital glands.

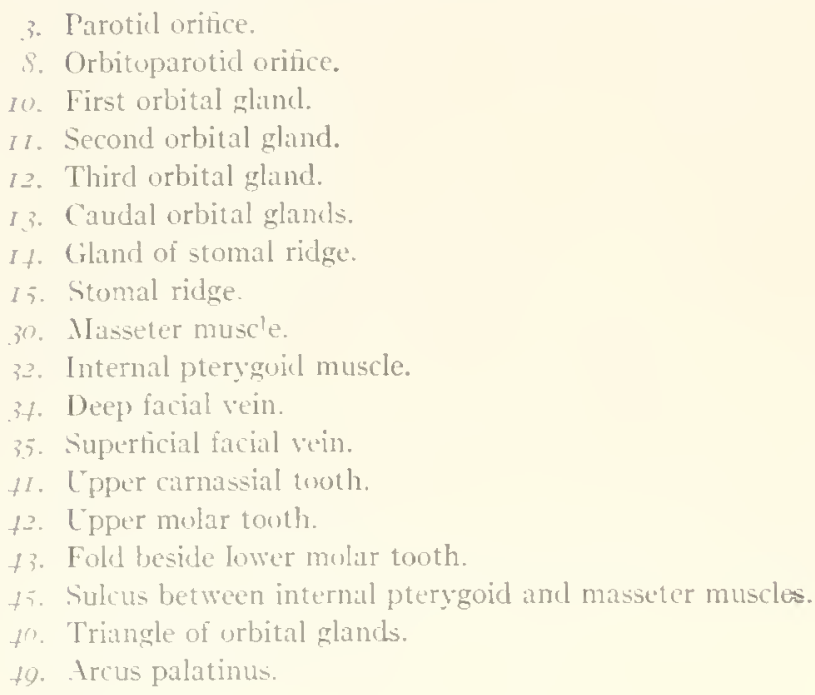


PLATE XXXIV.
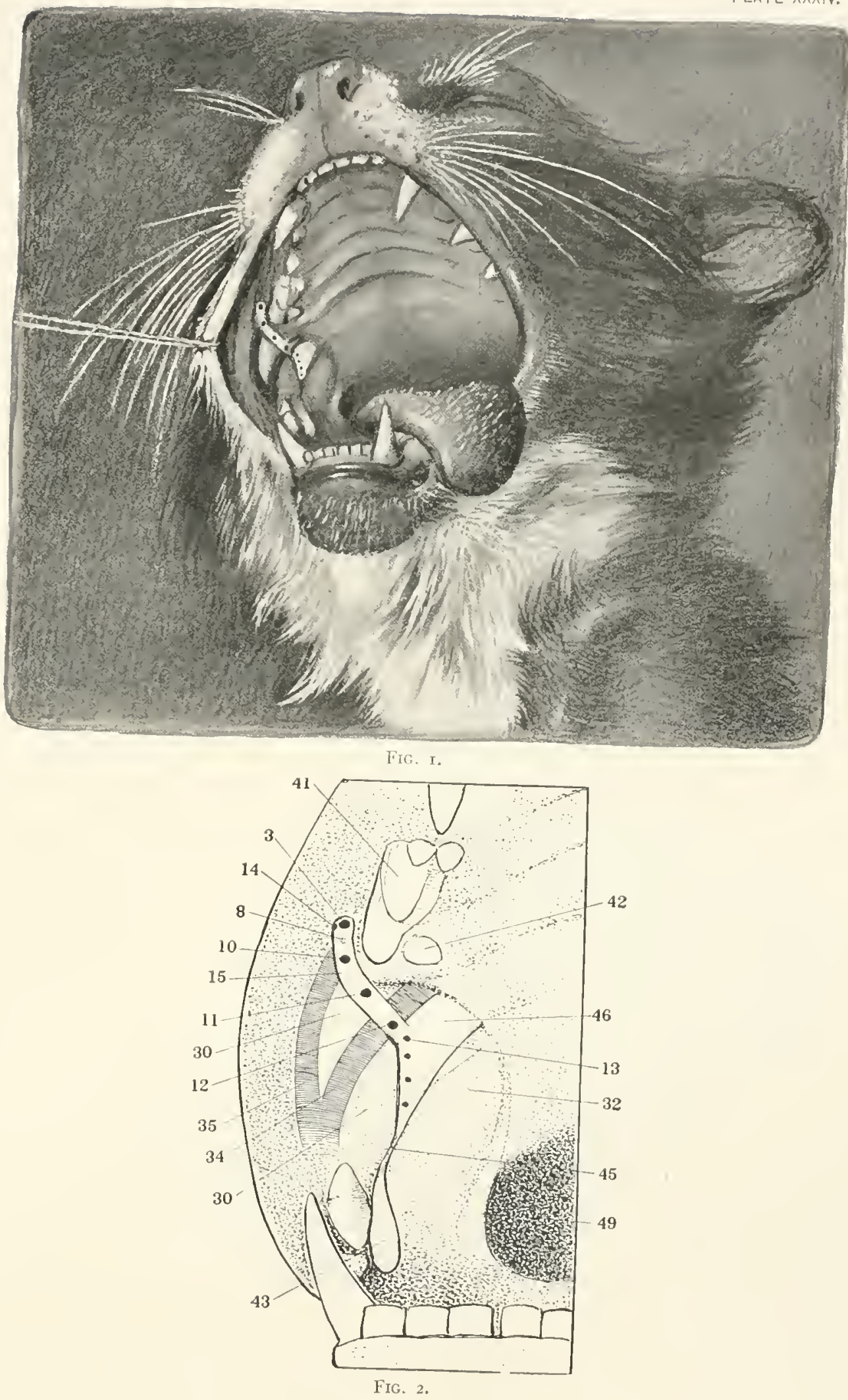


\section{PLATE XXYY}

FIG. 3. Felis domestica. From a fresh dissection. The body of the mandible, the mylohyoid, and a portion of the digastric muscle have been removed.

FIG. 4. Same specimen, with the additional removal of the angle of the mandible and portions of the masseter and temporal muscles.

I. Parotid gland.

2. Parotid duct.

15. Stomal ridge.

I8. Lesser sublingual glands.

20. Submaxillary glancl.

21. Submaxillary duct.

23. Greater sublingual gland.

24. Greater sublingual duct.

25. Preparotid lymph node.

26. Pustparotid lymph node.

27. Submaxillary lymplı nodes.

20. Lingual nerve.

30. Masseter muscle.

3I. Digastric muscle.

33. Common facial vein

3t. Deep facial vein

35. Supxerficial factial vein.

30. Temporo-maxillary vein

37. Superficial temporal vein

39. Posterior auricular voin

39. External jugular vein

40. Jugular arch 
PLATE XXXV.
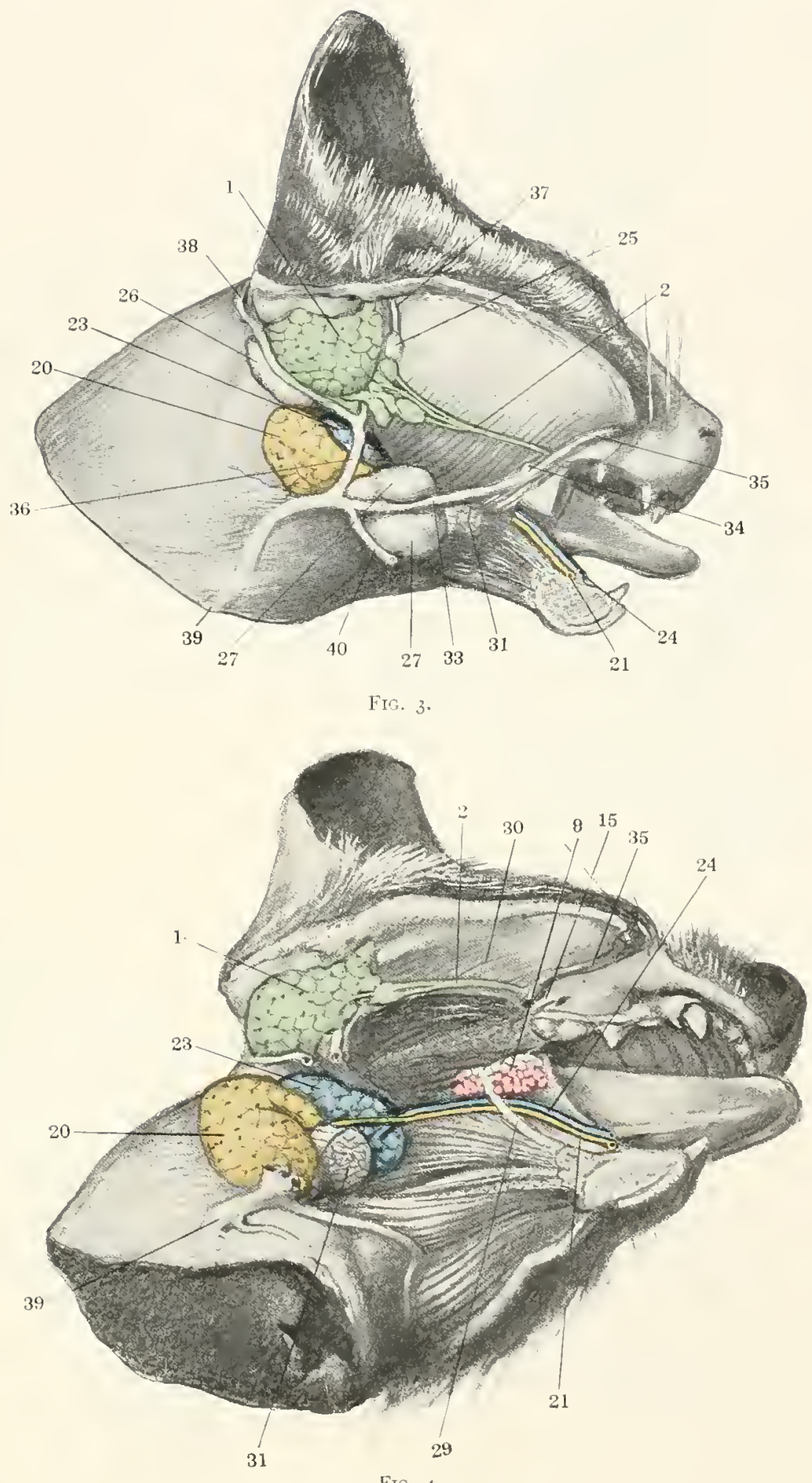

FIG. 4 . 


\section{PLate TXXII}

FIG. 6. Felis leo, $x$. Morphological Museum of I'rinceton University. No. 147 T.

IIG. 7. Canis familiaris. Morphological Museum of Columbia University, No. 4060.

I. Iarotid gland.

2. Parotid duct.

3. Parotid orifice.

5. Outlying lobules of the ventral angle of the parotid gland.

g. Orbital glands.

I0. Orifice of first orbital gland.

I5. Stomal ridge.

If. Inferior alveobuccal glankls.

IS. Lesser sublingual glands.

20. Submaxillary glank1.

2I. Submaxillary duct.

2.3. Cireater sublingual gland.

2\%. I) uct of greater sublingual gland.

27. Submaxillary lymph nodes.

31. Digastric muscle.

48. Thyroid gland. 
PLATE XXXVI.

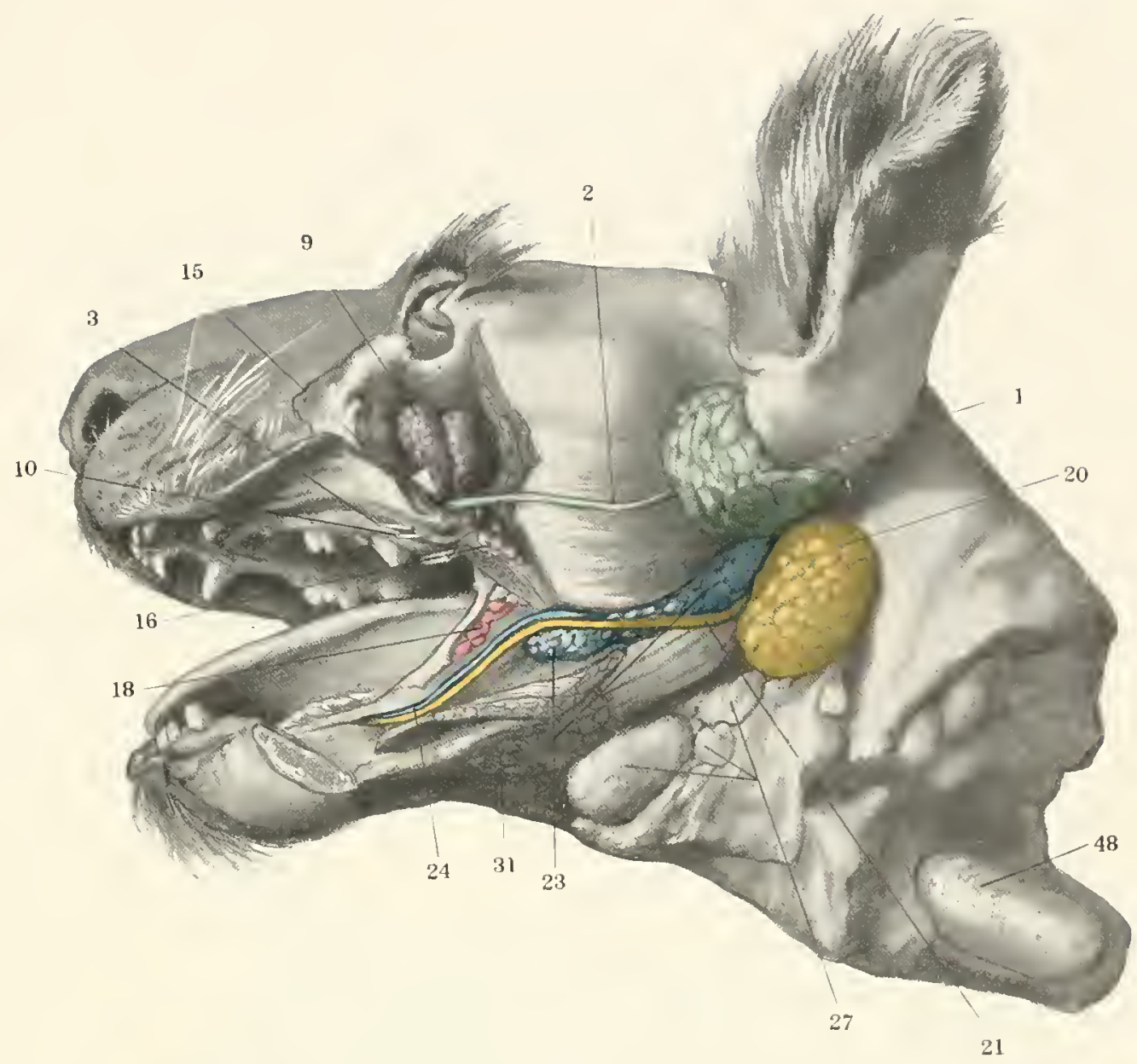

FIG. 6.

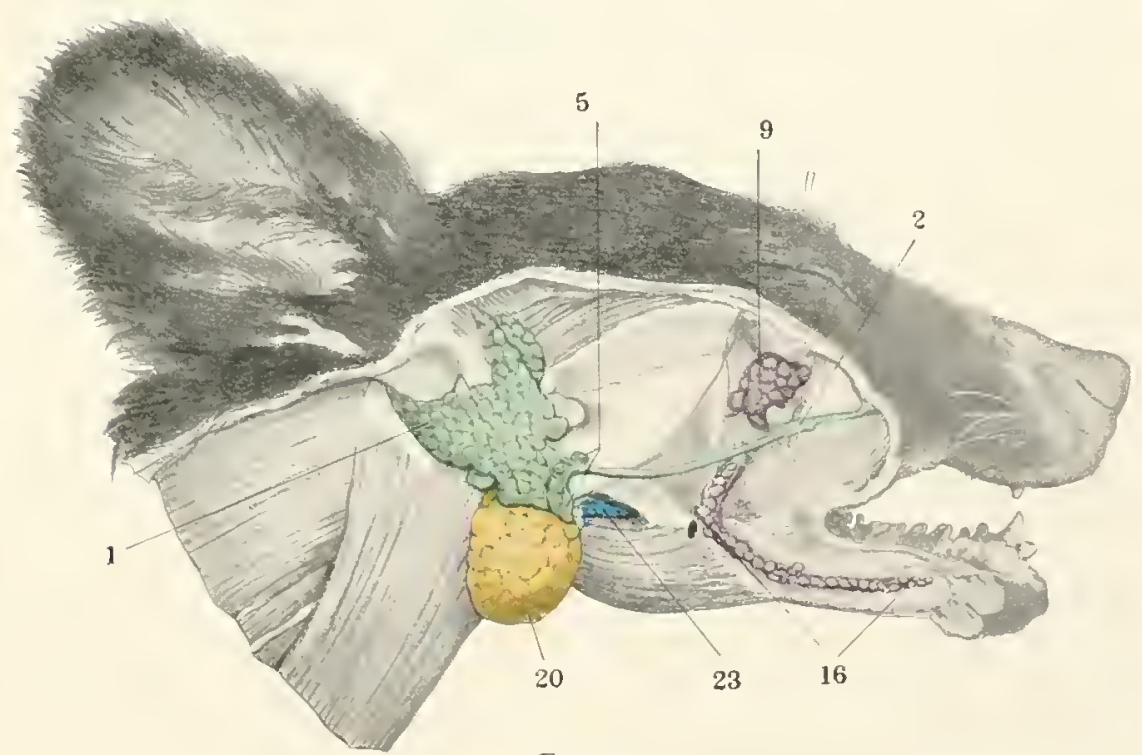

FIG. 7 . 


\section{PLATE XXXlI}

Fig. 8. Ursus thibetanus. Morphological Museum of Princeton University, No. I 3 So.

Fig. 9. Procyon lotor. Morphological Museum of Princeton University, No. 22 I.

1. Parotid gland.

2. Parotid duct.

S. Orbitoparotirl gland.

I6. Inferior alveobuccal glands.

IS. Lesser sublingual glands.

20. Submaxillary glanı.

2I. Duct of submaxillary gland.

22. Accessory submaxillary gland.

23. Greater sublingual gland.

24. Duct of greater sublingual gland.

27 . Submaxillary lymph nodes.

28. Lymph node.

50. Mylohyoid muscle. 

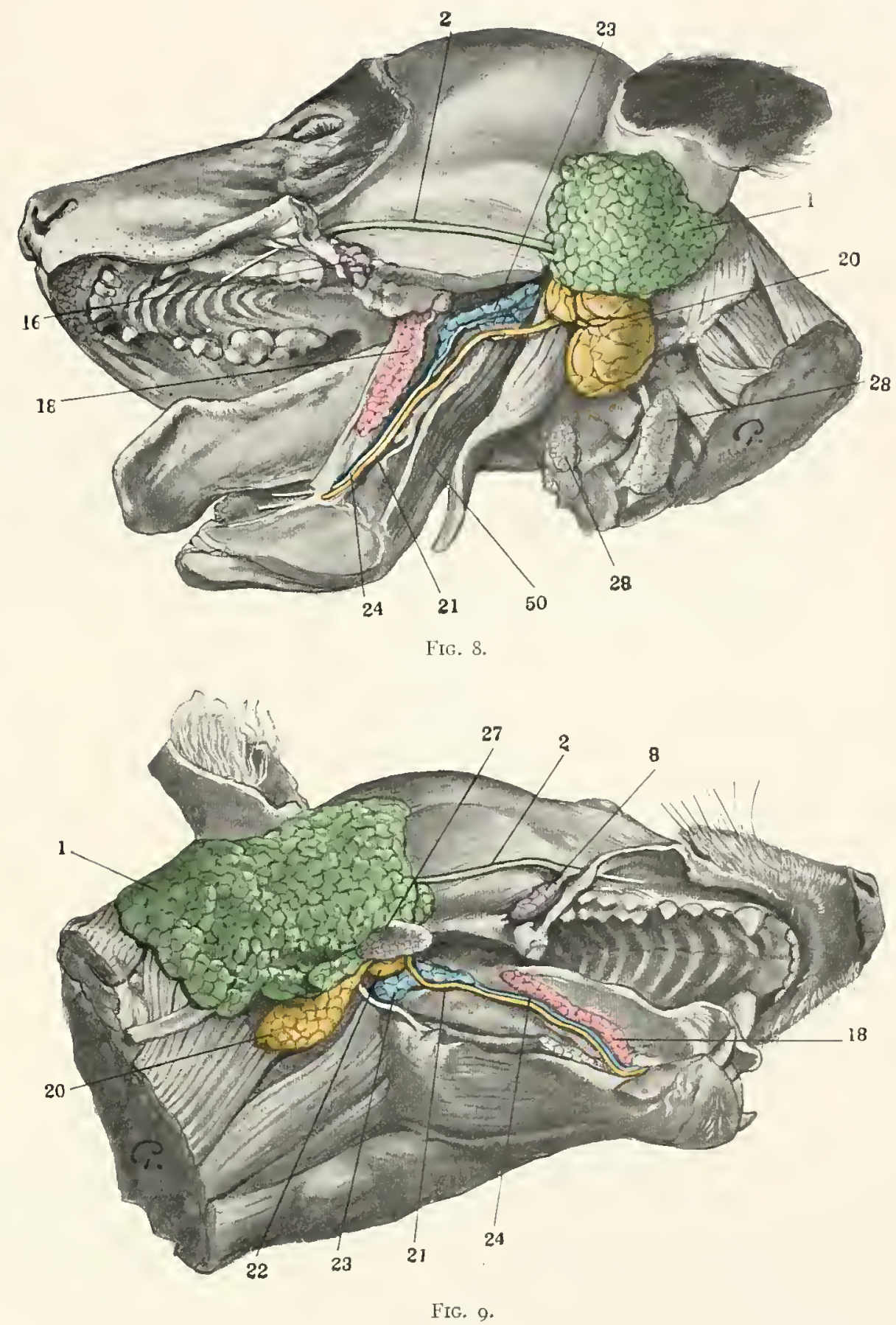


\section{PLATE XXXYIII}

Fig. ro. Mephitis putida. Morphological Museum of Princeton University. No. 1686.

FIG. II. Taxidea americana. Morphological Museum of Princeton University, No. 1756 .

I. Parotid gland.

2. Parotid duct.

In. Inferior alveobuccal glands.

18. Lesser sublingual glandls.

20. Submaxillary gland.

21 . Duct of submaxillary gland.

22. Accessory submaxillary gland.

23. Greater sublingual glind.

24. Duct of greater sublingual gland.

27. Submaxillary lymph nodes.

2.S. Lymph node.

3I. Digastric muscle.

47. Greater cornu of hyoid bone. 


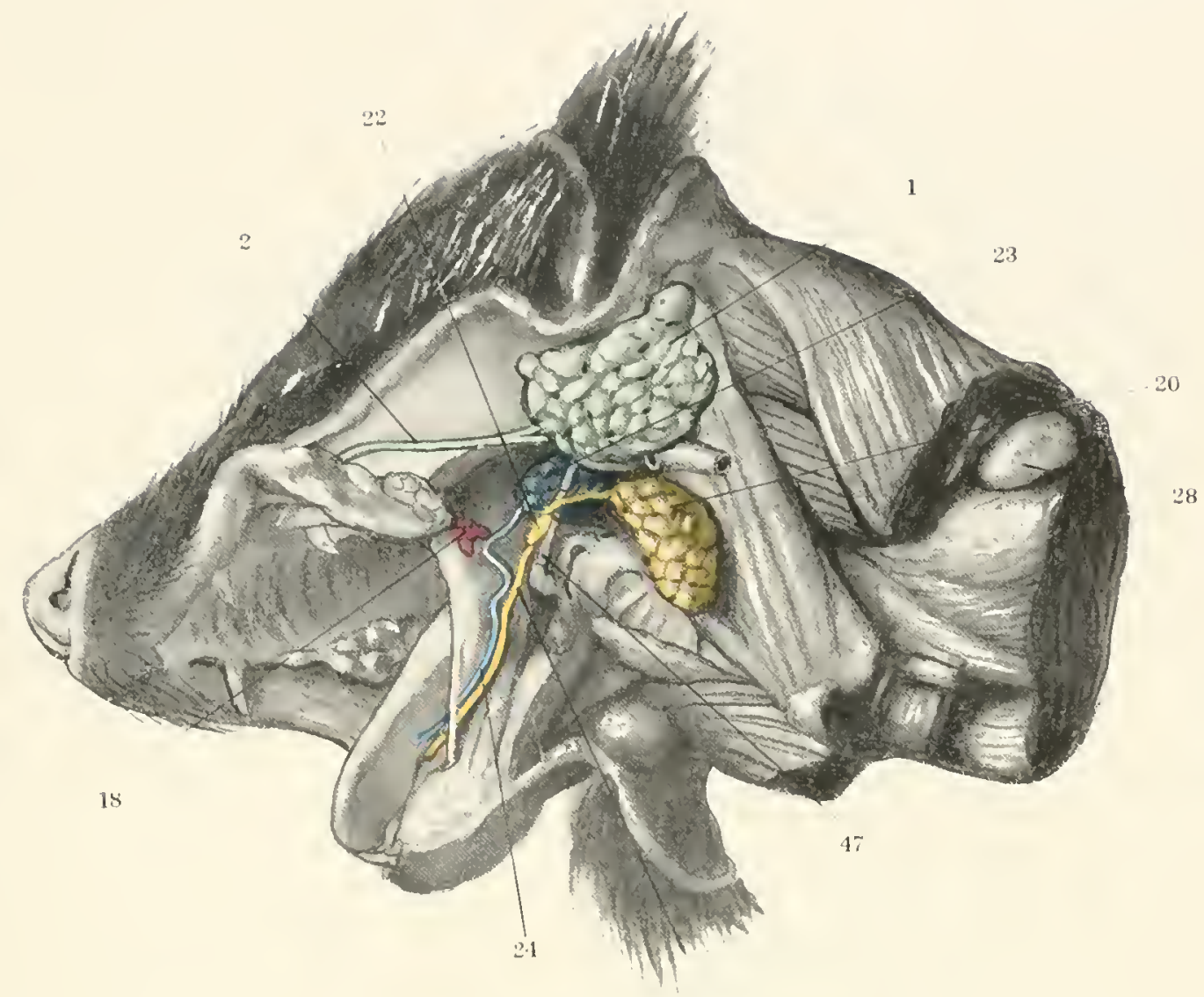

FIIG. 10. 21

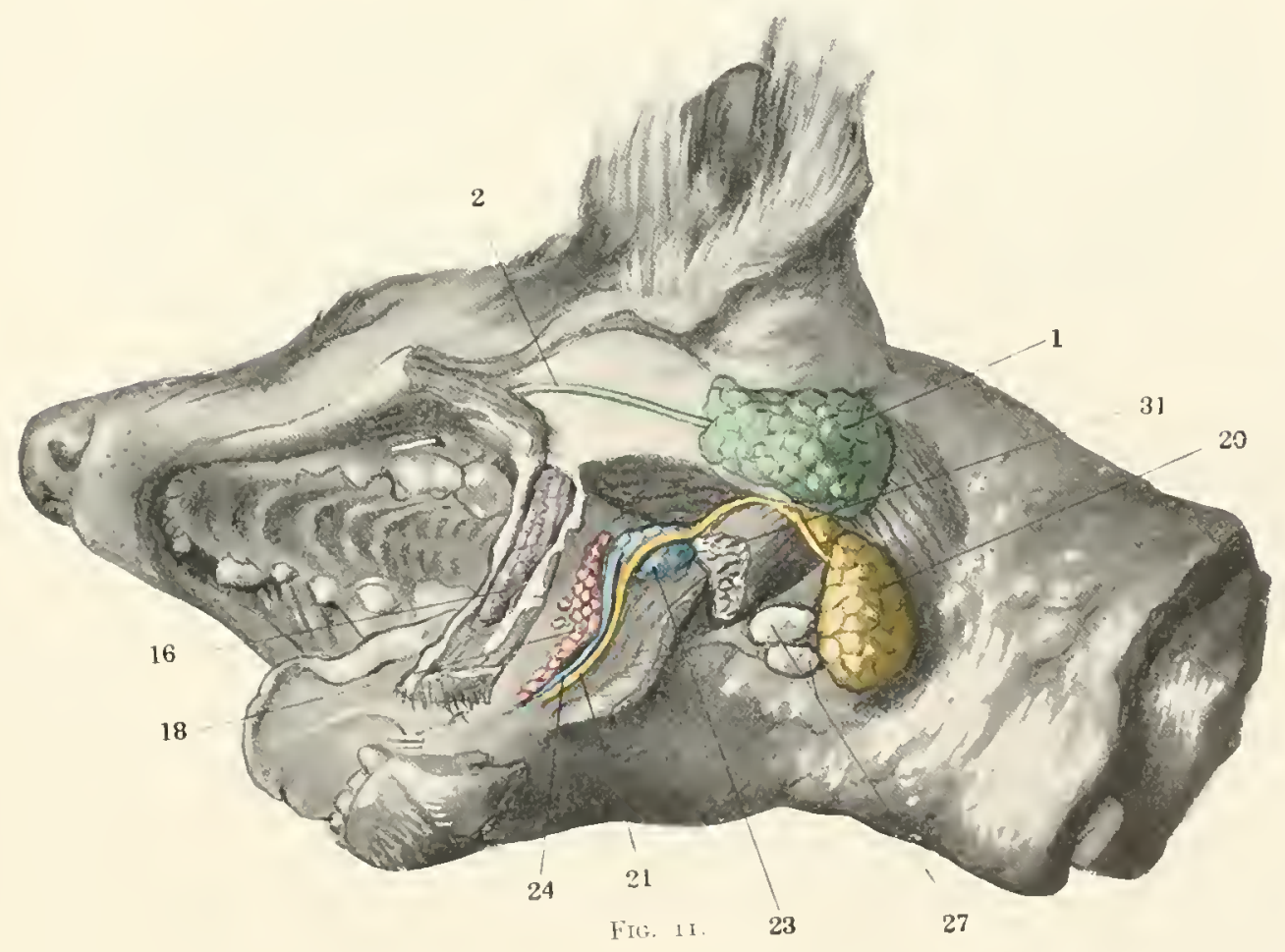




\section{Plate Xixis}

Fig. I2. Taxidea americana. Morphological Museum of Columbia University, No. 2 I 5.3 .

Fig. I3. Gulo luscus. Morphological Museum of Columbia L'niversity, No. 2152.

I. Parotid gland.

2. Parotid duct.

3. Parotid orifice.

15. Stomal ridge.

16. Inferior alveobuccal glands.

18. Lesser sublingual glands.

20. Submaxillary gland.

21. Submaxillary duct.

23. Greater sublingual gland.

24. Greater sublingual duct.

28. Lymph norle.

29. Lingual nerve.

3I. Digastric muscle.

50. Mytohyoid muscle 


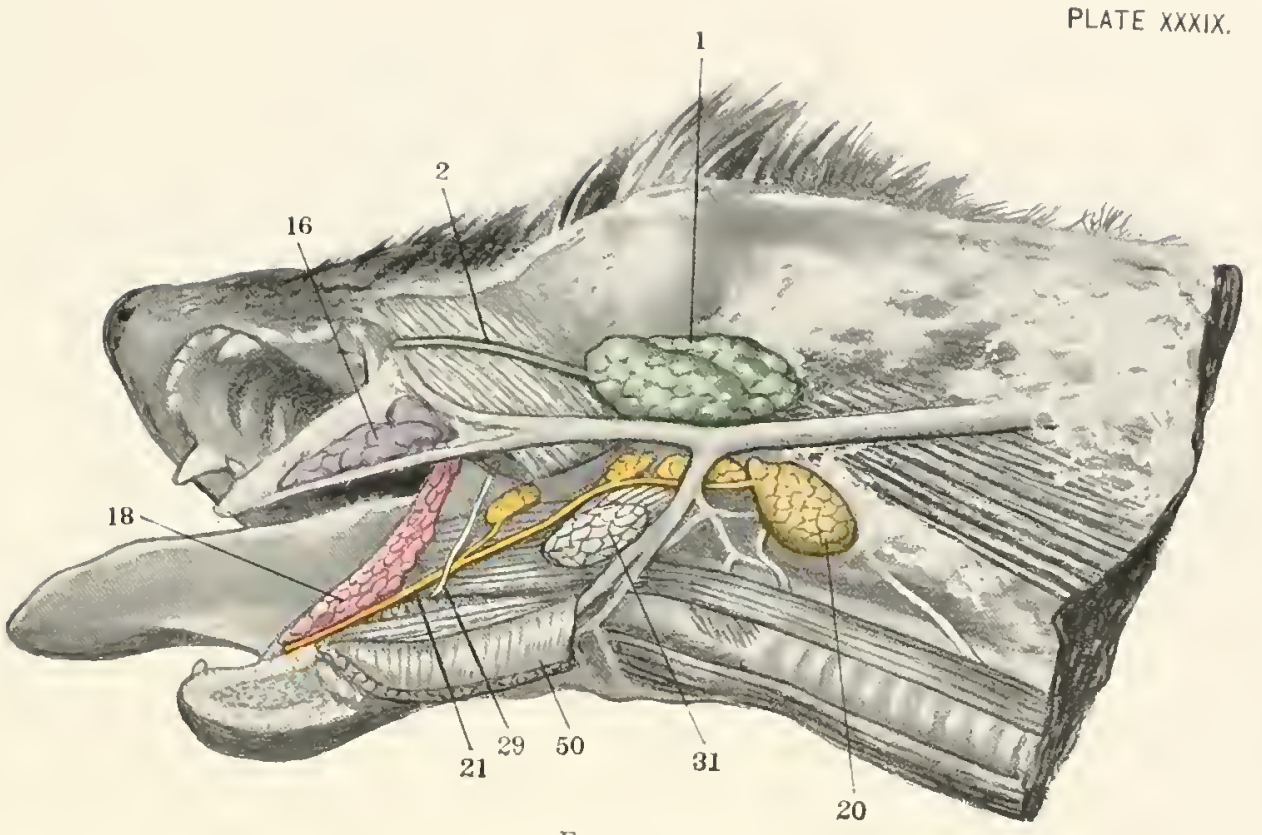

FIG. I 2.

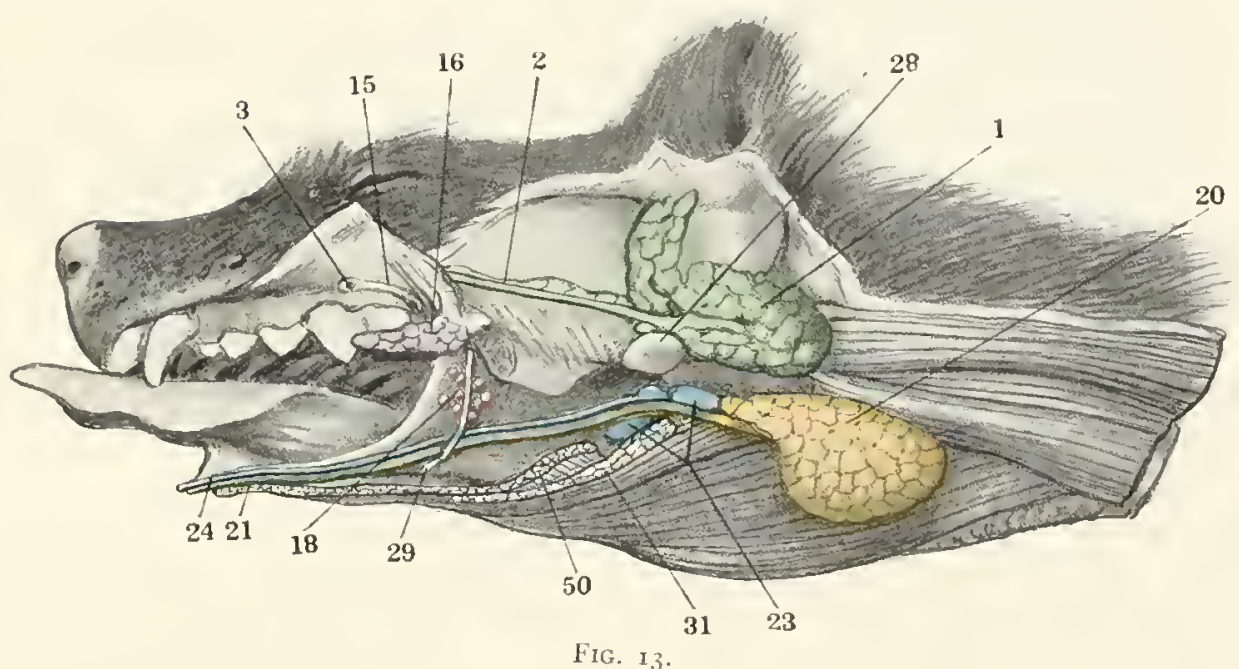


PLATE XL

Frg. It. Gulo luscus. Same specimen as Fig. 1.3. Right side.

FIG. 15. Zalophus californianus. Morphological Museum of Princeton University. No. S24.

I. Parotirl gland.

2. Parotiıl duct.

8. Orbitoparotid gland.

8'. Orbitoparotid duct.

T6. Inlerior alveobuccal glands.

18. Lesser sublingual glands.

20. Submixillary glani.

2r. Submaxillary duct.

23. Greater sublingual grland.

24. Greater sublingual duct.

27. Submaxillary lym'n nodes.

28. Lymph node.

31. Masseter muscle.

3I. Digatstric muscle.

5). Mylohyoid muscle. 

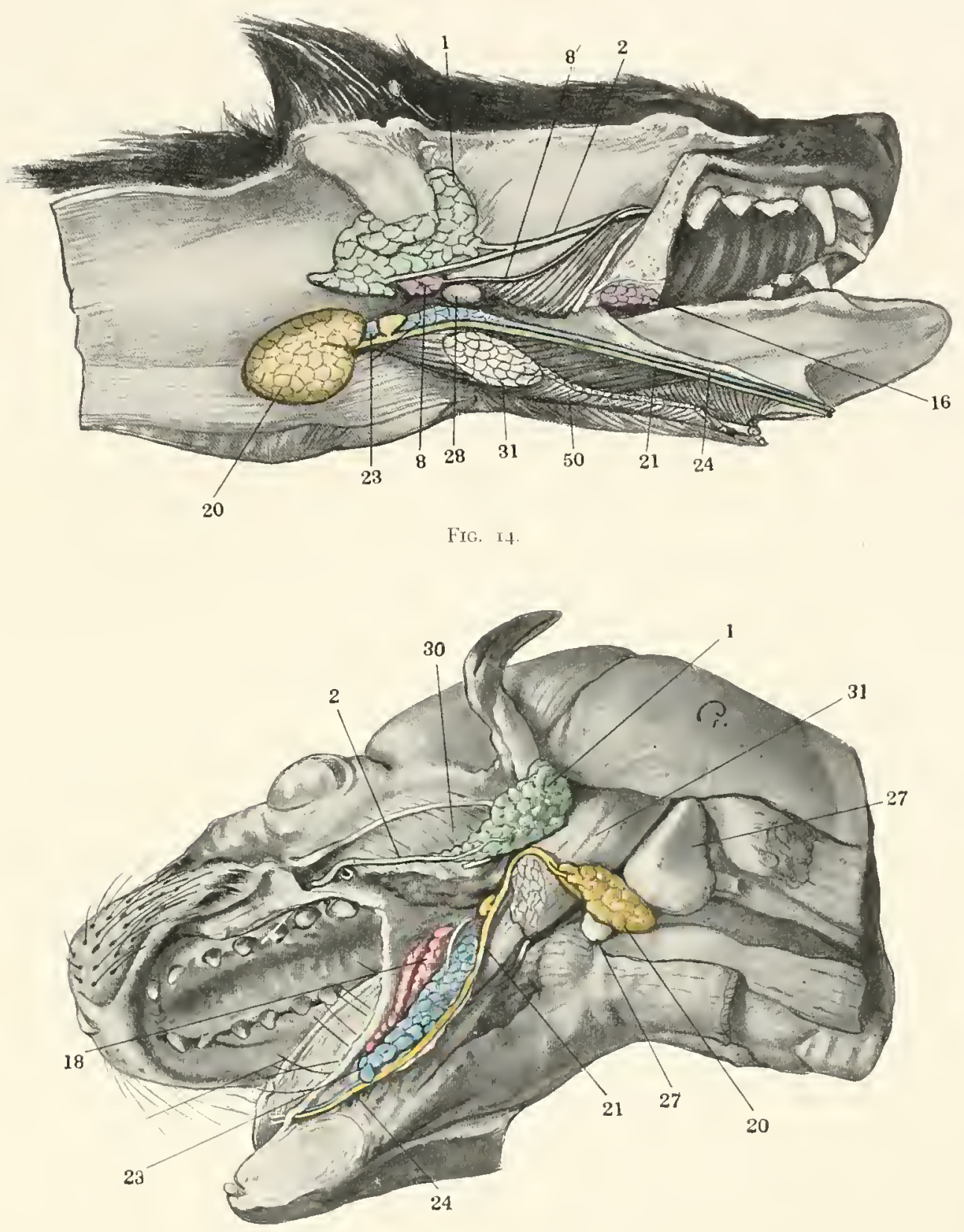

FIG. I5. 



\section{PART VI}

\section{THE DEVELOPMENT OF THE SALIVARY GLANDS IN THE DOMESTIC CAT}

\section{By H. von W. Schulte}

THE aim of the present paper is to follow, in as much detail as our material permits, the development of the salivary glands of the domestic cat, with a view, first, of ascertaining, if possible, the morphologic status of the several glands and their reciprocal relationships, and second, of determining the nature of the developmental process, especially in reference to the rôle played by folds in the inception of the anlages and the formation of the ducts of the larger glands. Chievitz's discovery of an entomasseteric duct in the human embryo, in one case connected with the parotid, indicated the at least occasional production of oral derivatives postparotid in situation and very likely of the same source as the parotid itself. The occurrence in the cat of a small gland at the border of the masseter, the zygomatic gland of Mivart. which Carmalt, and later Professor Huntington, found of occasional occurrence in a wide series of mammals, and finally the discovery of the two parotids in Hyrax (Carmalt, Huntington) gave ground to the hope that further study of the development of this region might throw some light upon the morphology of these structures. It seemed, also, desirable to examine the submaxillary complex in a form where adult conditions were simple, which it was thought might aid in elucidating the involved problems of its interpretation in the mammalian series at large.

In the development of the larger glands there is again the question of the mode of the process. Chievitz ascribes the formation of the lucts to the constriction and separation from the oral epithelium of solid crests. His had already expressed the opinion that in the case of the submaxillary the duct was formed by the bridging over of a sul- 
cus and the cutting off of a tube of epithelium. Hammar modified this view, describing a blind fold or flange, which, losing its continuity with the oral epithelium, becomes a solid rod of cells, only secondarily acquiring a lumen. In this Sudler concurs. Hammar described a similar process for the parotid, but in this case he held the result of the constriction to be hollow, as in His's view of the submaxillary. Sudler pointed out that here, also, the anlage was solid. In this Sudler and Chievitz are undoubtedly correct. Yet Hammar's assumption that the processes of formation of these ducts should be of the same nature is more than plausible. It seemed, therefore, desirable to utilize the series of cat embryos in the Columbia Collection for the reinvestigation of this point in particular.

The material comprises the following embryos cut transversely in serial sections :-

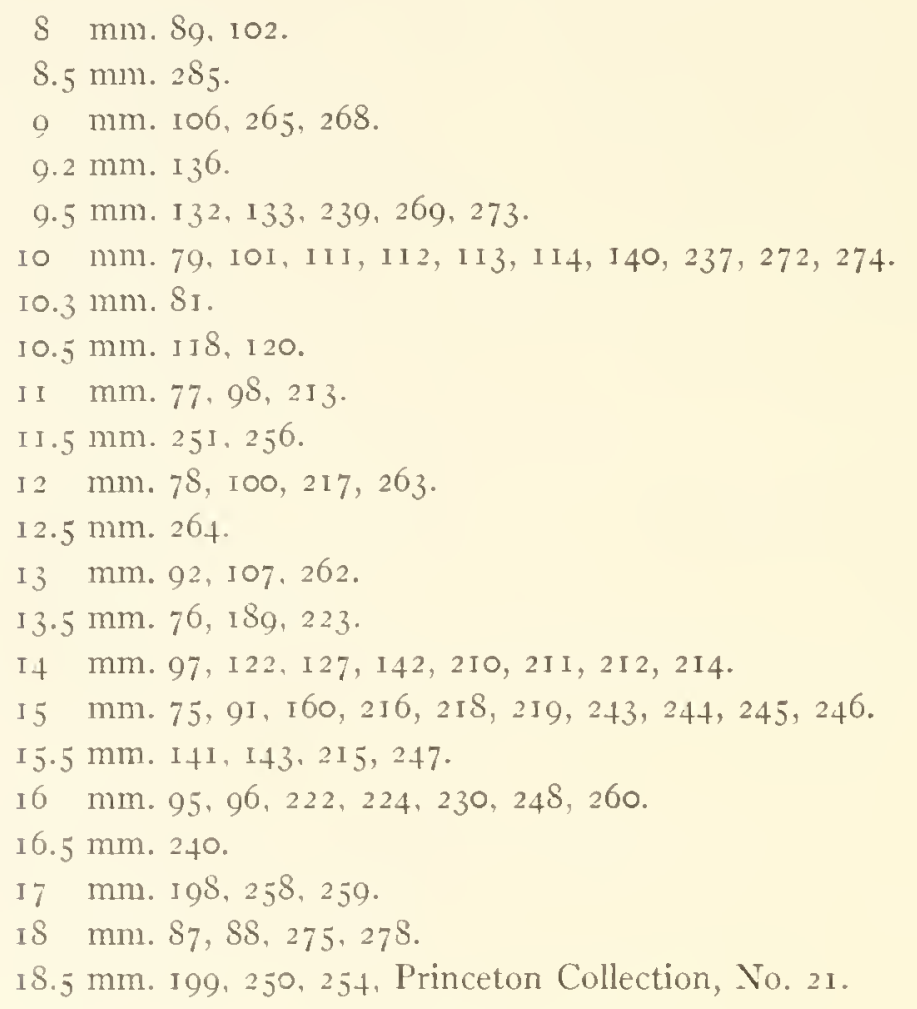


DEVELOPAENT OF SALIVARY GLANDS IN THE DOMESTIC CAT I93

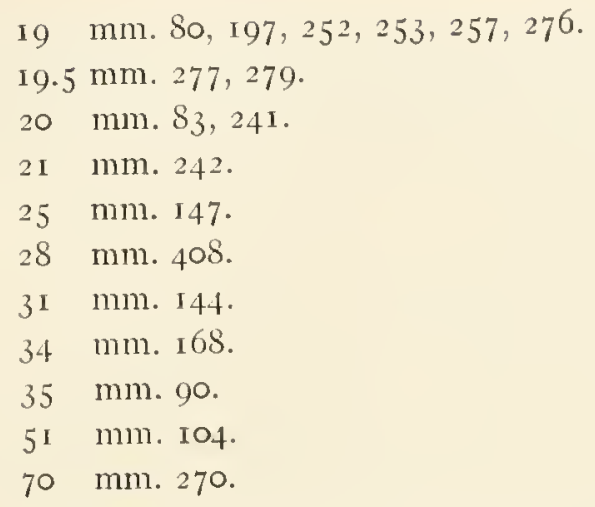

The measurements are vertex-breech, taken after fixation, for which in almost all cases ${ }^{-}$Zenker's solution was used. In certain stages, where the embryos are numerous, a considerable range of development is presented. The embryos of 12 millimeters, for example, form a small series in which the inception of the parotid fold can be followed in minute detail. Such small discrepancies are in part due to the variations in the degree of flexure of the head, which causes embryos of the same general development, or even litter mates, to differ slightly in length. In the second place, the embryos are rated in millimeters and half millimeters only, and consequently are entitled to show differences in the same rating. This renders a precise chronology of details rather difficult; in general I have based my statements upon the average of a group, or have simply noted the earliest and latest period at which a condition was observed. That the processes are themselves variable in rate to an appreciable though not large degree, is shown not only by differences between litter mates, but also by discrepancies in the relative size of the several glands, even on opposite sides of the same embryo.

For the purpose of demonstrating the relation of the anlages to the oral cavity, wax reconstructions were made by the usual method. As the anlages are solid, the ectal surface of the epithelium was followed. Relative to the mouth the anlages are very minute in their early stages. Consequently, a model of moderate magnification (40-100 diameters) shows little more than their position. In order to demonstrate their details, it was nccessary to reproduce them on a scale of 600 diameters. 
Here the field drawn was too small to afford orientation marks, and in piling the plates the smaller models were used as guides. Naturally these reconstructions have no claim to more than approximate accuracy of line. The graphic method was used in a few cases.

In the description of the anlages several terms have been coined and are used in a precise sense. It will be convenient to cite the more important here. The larger salivary glands, such as the parotid and submaxillary, develop in the cuurse of sulci and undergo a modified development in consequence. These glands have been termed sulcal in contradistinction to those which appear as simple sprouts from the basal cells of the epithelium, which are called diffuse. The anlages of the sulcal glands are at their first appearance attached accurately to the fundus of the sulcus; this position is termed fundal. Later they undergo a displacement to one of the walls of the sulcus, to a parictal position. It is important to distinguish between a solid epithelial ridge, formed by proliferation of the basal cells, and a blind fold of the epithelium involving all its layers and produced by the obliteration of a sulcus. The former is here designated $k c c l$ or crest, the latter flunge.

In the terms of direction applied to the developing mouth the flexure of the head is disregarded, and the parts are conceived to be in the adult position.

The situation of the anlages with reference to the oral cavity is a matter of fundamental importance in questions concerning the lomologies of the definitive glands. It is, therefore, necessary to follow the more conspicuous changes in the mouth during a considerable period of its development, with the view of correlating the derelopment of the salivary glands more intimately with that of the entire oral cavity. In order to shorten this necessary but long digression, I have held myself excused from any but the most scanty references to the literature. and this the more readily because few of the investigators have concerned themselves with the rather minute details that are gemane to our topic, and of them only $\mathrm{A}$. Pohlman, ${ }^{1}$ among recent writers, has chosen for his material embryos of the cat. His interesting paper, however, deals with major problems of interpretation. which are not, for the most part, of immediate importance to the study of the salivary

tPohlmann, A. H. I010. Die embryonale Metamorphose der Physiognomie und der Mundhöhle des Katzenkojfes. Morph. Jahrb. XLI. Leipzig. 
glands. The development of the oral cavity is here followed, as a whole, to the stage of I 3.5 millimeters. From that period the individual glands are discussed separately, first those of the vestibule, then those of the carum oris proprius.

THE ORAL CAVITY IN EMBRYOS OF 8.5 MILLIMETERS TO I 3.5 MILLIMETERS

In the embryo of 8.5 millimeters the oral cavity forms a wide, shallow, dorsoventrally flattened vestibule to the pharynx. Craniad its roof passes by a gradual curve in to the surface of the head. The widely open diverticulum of the hypophysis extends from a point slightly craniad of the mandibular symphysis to end just caudad of the plane of the anguli oris. From this it appears that we are dealing with a stage where as yet the nasal fossie and the material for the formation of the palate lie beyond the arch of the mandibles, which in this cavity correspond to the hypophysial and methypophysial segments of the roof, i.c. in general to the nasopharynx. The general features of the region are shown in camera lucida outlines in Figs. $\mathbf{I}-8$.

The mouth in section has the shape of an elongated lozenge laid on its side; both roof and floor show a slight but independent modeling. The roof in the middle presents a deep $\mathrm{V}$-shaped gutter continued from the hypophysis into the pharynx, where it attains a maximum in the plane of the first entodermal pouch, and thence diminishing is lost between the pouches of the fourth pair. From this gutter the roof slopes almost uniformly to its union with the floor at the buccal sulcus (Figs. 5 and 6). Two pairs of sulci diverging from the hypophysial region, craniad and caudad respectively, interrupt this descent. The cranial pair, the nasal sulci, are continued into the nasal pits, intervening between the frontal process mesad and the maxillary and faintly indicated outer nasal process laterad (Figs. I-5, 82 ). The caudal pair of furrows are the tubotympanic sulci of Moldenhauer. They begin caudad to the hypophysis and are continued into the dorsal borders of the first pouches (Figs. 6, 7, 86). The nasal and tubotympanic sulci are not at this period continuous.

The floor of the oral cavity is formed by the mandibular processes and the tuberculum impar. The mesal region is depressed relative to the lateral portions, which extend in a generally horizontal direction 
to the buccal sulci. The midline is marked by the depression between the mandibular processes at their cranial extremity. At the planc of the anguli oris the tuberculum impar appears in this depressed area (Fig. 5). and farther caudad forms a prominent triangular elevation, separated from the maxillary processes by well-marked concavities (Figs. $6,7,8, f I$ ). Caudad it is continuous with the radix lingue without demarcation, the foramen cocum and thyreoglossal duct having completely disappcared. The mandibular processes form prominent convexities in the oral cavity by their mesal borders, diverging and diminishing in prominence from the symphysis towarls the first entodermal pouch. Their oral surface in its more lateral portion is nearly horizontal at the angulus oris (Figs. 5-8, 40). Caudad it presents a slight concarity.

As a whole the mouth narrows from the anguli oris to the first entodermal pouch. Its lateral limits, the buccal sulci, are of especial importance in the study of the salivary glands. At this stage they are short, extending from the angulus oris to the origin of the first. pouch. In the greater part of their extent they are deep and well defined; caudad they become broad and shallow and are lost as the pouch begins to define itself. The buccal sulci acquire during development a rather complex system of curves. At this period they ascend slightly as they are followed caudad. In the horizontal plane they converge throughout their whole extent but most rapidly in the cranial third of their course, describing a gentle curve with the concavity turned laterad and caudad. At the anguli oris (Fig. 5,2) they pass transversely laterad into continuity with faint surface furrows which run but a short distance caudad. These furrows afford the onty boundary between the maxillary and mandibular processes caudad of the angulus oris.

Along the buccal sulcus the epithelium is thickened, the cclls are higher, and two or three irregular rows of nuclei are present. The thickening dininishes very gradually mesad, extending along the floor of the mouth to the summit of the maxillary convexity, and on the roof a somewhat shorter distance, not quite to the nasal and tubotympanic sulci (Figs. 5 and 6). The portion of the oral cavity lined by this thickened epithelium presents, as the pharynx is approached, a degree of conformity of its roof and floor (Fig. 6). At the angulus 
each has an independent relief, the roof sloping to the buccal sulcus, the floor approaching it horizontally (Fig. 5).

The mandibular nerve descends laterad to the sulcus near its caudal end, a small quantity of mesenchyme intervening (Fig. 6, 67). Here the buccal sulcus and adjoining portions of the oral cavity are tilted dorsad, as though the presence of the merve were felt through the intervening mesenchyme as an obstacle to further lateral cxtension. Further effects that may be attributed to such resistance are the mcreasing conformity between the floor and roof, and a beginning apposition of the walls of the buccal sulcus, with conconitant reduction of its lumen to a minute fissure. In this embryo the process has barcly been initiated and is expressed only by an increased acuteness of the angle formed on the ental surface of the epithelium.

These effects become more pronouncel in older embryos. Unfortunately, owing to the spiral twist which is marked at this stage, the scctions through the head are usually oblique, and that to a varying degree, which renders a direct comparison of dimensions as a rule impracticable. An embryo of 10 millimeters, No. 237 of our scries, is oriented almost perfectly in the transverse plane, and though the sections are considerably inclined dorsoventrally, permits a comparison of its transverse dimensions with those of the 8.5 millimeter cmbryo. The camera lucida outlines of Figs. 9 and Io are reproduced upon the same scale as Figs. I-8. It will be seen that at the angulus oris the diameter has increased about one-fifth, while it has remained stationary between the mandibular nerves. The interval between the nerves has not increased, although the head as a whole is broader. The oral cavity adapts itself to the space thus determined for it by a dorsal tilting of its lateral portion. As a result the buccal sulci become arched, ascending slowly from the anguli oris to their crowns opposite the mandibular nerves, and thence making an abrupt descent to their terminations caudal to the nerves. Their horizontal curvature is also increased, the caudolateral concavity more pronounced. Meanwhile the fold along the buccal sulcus in the vicinity of the mandibular nerve las increased in degree and extent (Fig. Io, 6). It surmounts the buccal sulcus as a solid flange, the base of which is indented by a small fissure, the remnant of the lumen of the sulcus. Craniad the fissure widens and all trace of the fold is quickly lost. In this fold we meet 
the earliest of the derivatives of the buccal sulcus. It has been termed the orbital inclusion, because it is derived from a segment of the sulcus which later gives origin to the orbital glands, and because in its subsequent development it separates from the oral epithelium and becomes embedded in the mesenchyme along the ental surface of the masseter and internal pterygoid muscles.

The roof of the mouth ental to the buccal sulcus presents a welldefined convexity, the rudiment of the palate process, which diminished craniad attains its maximum in the mandibular plane, and may, therefore, in part at least, owe its inception to the confining influence of the mandibular nerves. These do not retain their primitive relation to the buccal sulcus. Gradually they undergo a relative displacement caudad toward the fauces. Their place is taken by the anlages of the muscles of mastication, which occupy the region between the buccal sulcus and the first pouch, and continue to present an obstacle to the expansion of the caudal portion of the oral cavity.

The floor of the mouth still presents distinctly three sagittal ridges, the tuberculum impar and the maxillary convexities, or the lateral tongue swellings (seitliche Züngenwülste) of Kallius. The latter have increased and seem to be displacing dorsad the tuberculum impar, which has remained approximately of the same size (Fig. 10). From this time the tuberculum impar begins to lose its identity and become more and more blended with convexities of the mandibular processes. In an embryo of 10.5 millimeters it forms a slight crest along the midline of the elevation produced by their fusion (Fig. I I). The time of its ultimate disappearance varies. It is lost in the II.5 millimeter embryos of our series; on the other hand, in the I 3.5 millimeter embryo, No. r89, it is still recognizable (Fïgs. $36-39$ ).

The formation of the cranial segment of the tongue here conforms to the description given of it by Kallius for reptiles, and by Hammar for man, and contains both the lateral anlages of Born and the tuberculum impar of Jis. The caudal and cranial segments of the tongue thus agree in composition, having the same components, the ventral ends of visceral bars and median copular elements. That the tuberculum impar is a copulit element seems given by its position, interposed as it is between the extremities of the mandibular and hyoid 
arches. Gegenbauer ${ }^{1}$ has argued from the occurrence of an isolated cartilage in this situation in Heptanchus that here an element of the visceral skeleton has been suppressed in the interest of freer movement of the jaws. The proportional contribution of the tuberculum impar is insignificant, merely a median strip along the dorsum of the tongue.

The embryos of II.5 millimeters to I3.5 millimeters show a progressive enlargenent and increasing intimacy of contact on the part of the tongue and palate processes, which in the older embryos of this period have come to interlock like a mortise and tenon, while the roof and floor of the mouth become accurately coapted to one another and the cavity is gradually reduced to a slit. Only craniad as the plane of the anguli oris is approached do the dorsal and ventral walls retain any independence of relief. The $1 \mathrm{I} .5$ millimeter embryo (Figs. 12-14) and that of 12.5 millimeters (Figs. 15-17) show intermediate stages; in the 13.5 millimeter embryo the process has attained completion (Figs. 36-39).

The mouth is now divided into threc portions, a medial circumlingual cavity and two lateral or marginal regions (Mittelraum oder Gaumenrinne and Kaunishe of Aulmann). ${ }^{2}$ These regions are contimuous at the ventral border of the palate process, the region of junction forming a trough or gutter concave ventrally (Figs. 36-39), which evidently corresponds to the shallow concavity beside the lateral tongue swellings of earlier embryos (Figs. 10, 20). This portion of the mouth subsequently furnishes from its ventral epithelium the material for the anlages of the submaxillary, greater sublingual, and lesser sublingual glands. On account of its importance from this standpoint, it is convenient to recognize it as a region of the oral cavity distinct from, and intercalated between, the circumlingual and marginal cavities. It may be termed the alvelingual region; its floor the alveolingual fold or gutter. Here a departure is made from the terminology of Chievitz, which, to avoid confusion, had better be stated explicitly. Chievitz terms the whole region the

${ }^{1}$ Gegenbauer, Carl. I 898 . Vergleichende Anatomie der Wirbelthiere mit Beriucksichtigung der Wirbellosen. Leipzig.

${ }^{2}$ Aulmann, G. 1009. Die Mundrachenwand der Vögel und Säuger. Morph. Jahrb. XXXIX. Leipzig. 
alveololingual sulcus. As it is by no' means a furrow comparable to the others in the oral cavity; but a broad gutter, it seems justifiable to alter the term.

The circumlingual region has the shape of an inverted $\mathrm{U}$, and presents three planes or segments, which, named by their boundaries, are the craniolingual, and the paired palatolingual planes. The craniolingual plane is horizontal in the sections (Figs. 19-20) or nearly so (Fig. 22); in reconstruction it has a gentle sagittal curve with dorsal convexity. It is bounded by the dorsum of the tongue and the basis cranii with the adjacent mesenchyme. Laterad its roof joins the palate process at an angle (the entopalatine angle) which is continued craniad into the nasal sulcus (Fig. 23), and caudad, beconing rounded, is continuous with the tubotympanic sulcus. At the attachment of the hypophysis the craniolingual plane joins the pharynx almost at right angles. The palatolingual planes have a ventrolateral inchination in embryos of I1.5 millimeters (Figs. I3, I4). Gradually they become vertical (Figs. 16,3638 ), and in the embryo of 13.5 millimeters the primitive direction is retained only in their caudal portion (Fig. 39). Later they acquire a ventromedian slope and the palate processes come to embrace the tongue more closely. (Fig. I00).

The alvelingual regions have the shape of broad horizontal gutters diverging from the frenulum, where they are confluent, to the region of the first entodermal pouch, where, becoming narrow, they are continuous with the lateral borders of the pharynx. Against the tongue the region is definerl by an angle (Fig. If) which gradually deepens to form a furrow, (29) the sulcus lingualis. In the cat the sulcus appears in separate segments, one beside the tip of the tongue (Fig. I5), a second later portion caudad in the neighborhood of the lingual nerve and its large ganglion (Fig. I6). The two segments are usually continuous in embryos of 13.5 millimeters and over. Occasionally union fails to occur; quite regularly this intermediate portion is shallower than the earlier formed segments of the sulcus.

In the cat the alveolingual region passes laterad into direct continuity with the marginal cavity; the alveolar sulcus, which forms a conspicuous boundary in man (cf. Part II, Figs. I $2-17$ ), is here indefinite or lacking altogether. 
Ventrad of the alveolingual region is situated the lingual nerve and the submaxillary ganglion. The nerve passes obliquely ventrad of the lingual sulcus, approximately at the junction of its intermediate and caudal segments, thence ascending into the tongue accompanied by a prolongation of the ganglion (Fig. I6, 49). The point where the fibers of the nerve lie vertically beneath the sulcus is a convenient and classic landmark in this region and is termed the lingual crossing; in later stages, where the nerve crosses in two branches, having divided lateral to the sulcus, the larger caudal branch is referred to. Owing to the large size of the ganglion and its prolongations, only the nerve fibers are had in view in measurements reckoned from this point.

The marginal cavity forms a winglike extension of the mouth laterad from the alveolingual region to the buccal sulcus. The mesal limit corresponds to the crest of the palate process which is sagittal for the greater part of its length, turning towards the median line only at its cranial extremity, and that to a very slight degree (Figs. I5, I6, I7). Owing to the divergence of the buccal sulci, the cavity has the shape of an irregular triangle with its base craniad, truncated at its caudal extremity where it joins the pharynx. The roof is formed by the palate and maxillary processes, the floor in its whole extent by the mandibular process. The composition of the roof permits a division of the cavity into a median zone, the palatomandibular plane, and a lateral, the maxillomandibular. The lateral border of the palate process is marked by a concavity, subject to some variation in its definition, but becoming more distinct and sulcuslike as development proceeds and attaining its maximum just prior to the closure of the palate in embryos of 19 to 20 millimeters. This is the ectopalatine sulcus (Figs. 97, 100-103, 62). It is nearly parallel to the crest of the palate process, having a course in general sagittal with a slight mesal deviation of its cranial extremity. Caudad it approaches the buccal sulcus, but becomes very shallow and ill defined. At no stage in the cat does it distinctly reach the buccal sulcus, as it does in the human embryo (cf. Part II, Figs. I9, 24. 34). In embryos of ro- I millimeters the ectopalatine furrow can be followed to the plane of the mandibular nerves. Here the orbital fold is forming at the expense of the extreme border of the marginal carity (Figs. 10-II). In embryos of II.5 and I 2.5 millimeters the fold has 
begun to undergo constriction at the line of its union with the oral epithelium (Figs. If and $I_{7}$ ). In these sections the roof of the marginal carity presents a small convexity just mesal to the orbital fold. With this the ectopalatine sulcus is continuous. After the separation of the orbital inclusion, this convexity forms the fundus of the secondary buccal sulcus, which now constitutes the lateral border of the mouth (ride infra, page 217). UP to the stage of 13.5 millimeters (Fig. 35) the ectopalatine sulcus retains its continuity with the secondary buccal sulcus, near the end of the orbital inclusion. Later the continuity is lost by the obliteration of the caudal extremity of the furrow (Fig. 97).

The palatomandibular plane thus bounded extends as a sagittal strip of nearly uniform breadth from the pharynx to the plane of the anguli oris, there to turn mesad, narrow, and rapidly lose its relief. Throughout it has a dorsolateral inclination, which is progressively diminished craniad as the rertical extent of the palate process is reduced (Figs. 9, I5). The epithelium of its floor gives rise to the inferior dental anlage. Apart from this, the plane retains the character of a dorsolaterally inclined and almost featureless space, until the closure of the pilate, when its dorsomedian wall becomes the roof of the carum oris and its ventrolateral is added to the alveolingual region. The caudal portion of the marginal cavity where it is composed of this plane alone has an equally uneventful history. It corresponds to the postclental region of the adult mouth, where the restibule communicates with the cavum oris and the whole cavity narrows to the fauces. Here the masseter and internal pterygoid abut upon the mucous membrane, a condition established for the latter muscle in the embryo of 53.5 millimeters (Fig. 37. 73), a contact which no doubt operates to impede the growth of the maxillomandibular plane in this region.

The maxillomandibular plane, bounded by the buccal and ectopalatine sulci, is triangular, diminishing caudad as the sulci converge. Here it enters into relations with the orbital inclusion, which must subsequently be considered in some detail. The ro.5 millimeter embryo (Figs. 9, ro) maly serve to illustrate this condition. In the plane of the mandibular nerves the marginal cavity lateral to the palate process is reduced to a blind fold or flange, the orbital inclusion 
(Fig. 10, 6). In this section the ectopalatine sulcus is present as at minute indentation of the oral epitheliun dorsally near the base of the fold, which, thus occupying the region between the ectopalatine and the buccal sulcus, is seen to be the reduced equivalent of the maxillomandibular plane. Craniad the fold disappears and is replaced by a considerable cleftlike space of horizontal direction, extending in the sections (Fig. 9) from the faintly indicated palatomandibular plane to the angulus oris. At this period, therefore, the orbital inclusion would appear to correspond to the caudal portion of the plane in its entirety. This holds true in later stages of the caudal portion of the inclusion only, as is shown by the termination of the ectopalatine sulcus at the tip of the inclusion, or in line with it, as has already been stated (Figs. 35, 97). As the maxillomandibular cavity enlarges, the orbital fold is formed at the expense of only its lateral portion, the triangular caudal portion of which is inserted between the orbital fold and the ectopalatine sulcus (Fig. 35). With reference, therefore, to the orbital inclusion, the maxillomandibular plane fills into two segments, a cranial and a caudal, the latter characterized by a reduction of its lateral portion to form the fold. In situation this segment is entomasseteric; the cranial, unfolded region, which escapes the embrace of the muscle, is promasseteric (compare Fig. 36 with Figs. 37 and ${ }_{3} 8$ ). The junction of these regions coincides with a change in direetion of the buccal sulcus (Fig. 35, 7), which here passes by a gradual curve from a more transverse to a more sagittal course. The curve has been termed the orbital angle. It lies ental to the masseter, where the buccomasseteric nerve crosses the buccal sulcus (Fig. 35, 69).

It has already been stated that the lateral portion of the mouth in the 8.5 millimeter embryo is lined with thickened epithelium, extending mesad to regions corresponding to the ectopalatine and lingual sulci. This area corresponds to the whole of the maxillomandibular and the ventral epthelium of the pala tomandibular plane and alveolingual region. Out of this epithelium the several anlages of the dental ridges and salivary glands emerge as local retentions and increases of the thickening, which in intervening regions undergoes relative attenuation. A thinning first appears in the alveolingual fold, while mesad along the lingual sulcus, a very narrow strip of thicker epithelium persists. The inferior dental anlage is distinguishable at $\mathbf{1} \mathbf{1 . 5}$ millimeters as a wide 
but slight groove with thickened epithelium. Lateral to it the epithelium of the floor becomes thinner and an interval gradually forms and widens between it and the thicker epithelium of the buccal sulcus, which gives rise to the orbital fold, the parotid and orbitoparotid elements. The superior dental ridge is the last to emerge. At $\mathrm{I}_{3.5}$ millimeters its epithelial thickening is still continuous with that of the buccal sulcus (Fig. 49, 64). These anlages are first defined in the plane of the angulus oris; caudad they diminish and are soon lost. This circumstance would seem to indicate that their separation from the prinitive thickening depends upon the broadening of the marginal carity, the epithelium thinning in places as the area to be covered increases in width; the continuous thickening persisting longest caudad, where the transverse increment is least.

The lateral border of the mouth, or more particularly of the maxillomandibular plane, is the buccal sulcus. This does not long retain the simple curvature present in the 8.5 millimeter embryo. As the mouth lengthens, the sulcus develops a marked sagittal arch ascending from the angulus oris to the orbital angle and thence making a rather abrupt descent to the root of the first entodermal pouch (Figs. 96, 97). This curvature is gradually acquired in embryos of 10-18 millimeters and persists as long as the furrow retains its continuity. In horizontal projection the sulcus is a concaroconvex. Its region of maximum convexity is the orbital angle (Figs. 35, 97, 5). Here it comes into close relation with the buccomasseteric nerve (Fig. 35, 69), and gives rise to a broader segment of the orbital inclusion (Figs. 35, 7, and 97). The orbital angle coincides with the crown of the sagittal arch. The sulcus is thence continued craniad in a nearly sagittal direction to within a short distance of the angulus oris, where it turns rather abruptly laterad. In early stages this postangular segment is short and distinctly oblique, becoming more nearly transverse as development proceeds and actually so in embryos of 20 millimeters and over. The sagittal segment is the largest portion of the sulcus; its junction with the postangular portion may conveniently be termed the postangular bend (Figs. 35, 97, 4). It evidently corresponds to that change in direction of the buccal sulcus at which His found the parotid anlage in the embryo $Z w$.

The manner in which the buccal sulcus acquires this course is a 
question not altogether simple of explanation and the data at present available hardly suffice for more than a suggestion of the probable nature of the process. The mandibular nerves first, and later the anlages of the muscles of mastication, must be looked upon as tending to confine the caudal portion of the mouth, the edge of which undergoes a dorsal deflection in consequence. This entails changes in the buccal sulcus, which becomes arched and at the same time acquires an obliquity in the horizontal plane, on account of the lessened rate of transverse growth in the caudal, as contrasted with the cranial, segment of the oral cavity. When we endeavor to ascertain the nature of the longitudinal growth of the mouth, and to estimate its effects upon the curvature of the buccal sulcus, we enter upon more debatable matter. At the outset we are confronted by the question of the rôle played by fusion between the maxillary and mandibular processes in the lengthening of the mouth. A. Pohlman has recently criticized the generally accepted doctrine in an able and careful paper, which is additionally important to our problems from the fact of its dealing with the embryos of the cat. Pohlman points out the low relief of the various processes, the extreme shallowness of the separating sulci, and the absence of evidence of fusion in the form of epitheliat plates or remnants along the lines of the sulci, and argues that the processes have too little independence or individuality to be considered as more than mere surface elevations, and lays stress upon their perfect internal continuity with the general mesenchyme of the head. The formation of the face he regards as the result of a subtle remodeling of the embryonic material, not to be attributed to the fusion of previously distinct processes nor accomplished by the obliteration of sulci. Pohlman's paper is concerned mainly with the nasal field and the mesal portion of the mouth; the marginal cavity and the buccal sulcus fall outside the limits of his immediate problem. While admitting the accuracy of his observations and the cogency of his general reasoning, there are some facts in the development of the marginal cavity which point to a different conclusion. Here the processes in question are separated entally by a deep cleft, the whole maxillomandibular plane of the mouth, and here also we have direct evidence of fusion between the opposed processes, admittedly small in degree, in the separation of the orbital inclusion (vide infru). The question naturally arises as 
to the lengthening of the buccal sulcus, whether at the angulus also there may not be a progressive fusion. If so, the advance of the angulus produces the buccal sulcus as a moving point describes a curve; if on the contrary no fusion occurs, then the angulus must be looked upon as a definitive structure, bodily displaced craniad by growth in the mesenchyme caudal to it.

A striking feature of the development of the orbital inclusion and of the parotid is the caudal displacement which these structures undergo relative to the angulus oris (Figs. 34, 4I, 45). The interval between the angulus oris and the orbital inclusion, after a prelininary stage to be discussed hereafter, steadily increases. The same holds true of the parotid in the cat throughout its development. This, of course, must be explained by a more rapid growth of the interval. But when we consider that the orbital inclusion practically reaches the anguhus in the Ir.5 millimeter embryos, and the parotid at I 2 millimeters is within a few micra of it at the preangular bend, we have reduced the elongating interval practically to a growing point, the angulus oris.

Again in embryos between 8.5 millimeters and Io millimeters in length the marginal cavity and the postangular sulcus are horizontal (Fig. 5). If in these embryos preangular sections are examined, the maxillomandibular plane is found to be inclined ventrolaterad (Fig. 4). Here the palate process has almost disappeared and the maxillary has begun to overlap the mandibular process laterad. Farther craniad the overlapping is even more markel. This condition is retained in the adult as a wide, hairless area of the lower lip, which is covered by the upper when the mouth is tightly shut. Could we imagine the angulus to advance along the cleft between the maxillary and mandibular processes keeping close to the surface, in later stages the maxillomandibular plane at the angulus wouk not be horizontal but ventrolaterally inclined. This condition is achieved at II.5 millimeters (Fig. 12) and marked at I 2.5 millimeters (Fig. 15).

In these and older embryos the overlapping of the mandible by the maxillary process increases craniad, and usually attains such a degree that towards the tip the mandible is covered completely and concealed from lateral view. From the side the cleft hetween the processes alppears to curve ventrad from the angulus. The angulus advancing 
along this line would describe an arch with its convexity clorsad, the buccal sulcus; the maxiliomandibular plane would gain a lengthening cranial segment of ventrolateral inclination, the degree of which would also increase craniad; and the regions of horizontality, marking the site of the angulus of the Io milimeter embryo, would become relatively more and more caudal in situation. The sections of the I3.5 millimeter embryo indicate the fulfilment of these conditions. In Fig. 36 the section passes through the parotids; its plane is given by the position of these ankages in the model (Fig. 35). Here the maxillomandibular plane has a slight ventrolateral inclination. Only so far caudad as the region of the masseter (Figs. 37,38 ) is the horizontal region of the plane encountered, here undergoing compression in its lateral portion to form the orbital fold. The arch of the buccal sulcus is shown by its successively higher positions in Figs. 3638. In Fig. 39 its descent is begun. All of these conditions, in this and the preceding embryos, are satisfactorily explained by the assumption of an active advance of the angulus by progressive fusion of the opposing epithelia of the maxillary and mandibular processes, thus incorporating into the oral cavity preangular portions of the interval between the processes, these retaining the inclination ventrolaterad that was impressed upon them while yet preangular in position.

When we turn from such considerations as these to look for direct evidences of fusion at the angulus, it must be admitted that they are inconspicuous. The postangular portion of the buccal sulcus frequently has a minute keel projecting from its fundus (Fig. 24), rarely the surface furrow has the like. Platelike formations, as in Figs. 3 and 9, while constant, have never a considerable extent. Neager as they are, these appearances are more readily explained as the result of fusion than otherwise, nor can we argue from their minuteness that the degree of fusion is itself inconsiderable. Fusion between processes must mean not only blending of their surface epithelia, but also reduction of the plates so formed. The degree of plate formation observable at any time is not an index of the fusion per se, but of the degree by which the reduction lags behind it. If the two processes, fusion of epithelium and destruction of epithelium, advance by equal steps, no gross evidences of the process could be expected. From what has been sairl of the direction of the postangular sulcus 
and the surface sitnation of the angulus, it is seen that we are dealing with little more than a point of fusion, and here if anywhere the formation of keels or plates should be minimal.

In the I 3.5 millimeter embryo (Fig. 35) the buccal sulcus has attained a form which it retains until the transformation of the maxillomandibular plane into the vestibule. It comprises a short postangular segment, a postangular bend (4), a longer more sagittal section extending to the orbital angle, where the direction again becomes more nearly transverse. This oblique terminal segment carries the sulcus close to the first entodermal pouch $\left(\delta_{4}\right)$. From the orbital angle caudad the maxillomandibular plane is reduced to a fold, the orbital inclusion $(7,8)$. This it may be recalled is horizontal at the orbital angle (Fig. 38). At romillimeters the plane is horizontal at the angulus, at II only the extremity of the postangular sulcus is ventrally inclined. In embryos of this length the orbital inclusion extends beyond the postangular bend, within a very few micra of the angulus. It would seem possible, therefore, that the orbital angle corresponds to the postangular bend of these embryos, which, becoming involved in the orbital fold, retains the primitive curvature of the stage at which the fold is formed, while in more cranial portions of the sulcus the successive positions of the postangular bend leave no permanent record of their position, the latter increments falling in line with the sagittal segment of the sulcus by a slight degree of remodeling; or it may prove to be the case that the whole postangular segment is a line where fusion occurs, and that it is the postangular bend and not the angulus oris which traces out the buccal sulcus as it advances. The solution of this point requires a more careful study of the distribution of rudimentary keels about the angulus than has yet been made.

To recapitulate, the oral cavity is lengthened by additions at its cranial end. The angulus oris advances along a line determined by the relation of the maxillary and mandibular processes. As the maxillary overhangs the mandibular process laterad, and increasingly towards its tip, the maxillomandibular plane acquires a torsion about a sagittal axis passing from horizontal at the orbital angle to a marked ventrolaterall slope craniad. Changes in the internal conformation of the cavity are initiated candad, and appear due, first, to the confining influence of the mandibular nerves, and second, to that of the 
muscles of mastication; the palate process appears in the roof and the buccal sulcus begins to be arched. The enlargement of the palate process divides the mouth into a circumlingual and a marginal cavity, meeting at the crest of the palate process in the alveolingual gutter. Is the tongue emerges by the fusion of its three anlages it becomes defined against the alveolingual region by the lingual sulcus, which appears first at its tip, then in the region of the sulmaxillary ganglion, and last in the intermediate region. The lateral limit of the palate process is defined by an ectopalatine sulcus, which serves to divide the marginal cavity into an ental zone, the palatomandibular plane, and an ectal, the maxillomandibular. Owing to the confinement of the caudal portion of the mouth, the maxillomandibular plane is here reduced to a solid fold, the orbital inclusion. This extends to the orbital angle. The orbital angle marks the division of the marginal cavity into a caudal postclental region, and a cranial dental portion, which is characterized by the presence of the maxillomandibular plane and the dental ridges. Caudad of the dental ridges the marginal cavity narrows rapidly to the fauces, with which the circumlingual space is broadly continuous. In subsequent development the circumlingual space, the alveolingual region, the palatomandibular plane, and the maxillomandibular plane as far as the dental ridges are allotted to the cavum oris proprius and the nasal fossa, only the lateral portion of the maxillomandibular plane forms the vestibule. Caudal of the dental ridges, which stop at the orbital angle, the terminal portion of the palatomandibular plane forms the small postdental vestibule, communicating behind the teeth with the carum oris and rapidly narrowing to the fauces.

The development of the salivary apparatus begins caudad, in the ontogenetically older portion of the carity and proceeds craniad. The glands of the cavum oris and vestibule form two distinct groups, developing in the alveolingual region and maxillomandibular plane. It will be convenient to follow their history in separate accourts.

\section{THE GLANDS OF THE VESTIBULE}

The glandiferous sulci are the buccal, the secondary buccal, and the inferior alveobuccal, the last forming the rentral limit of the definitive vestibule, and in front of the angulus oris intervening between the 
alveolar process and the lower lip as far as the diastemal fold. The derivatives of the buccal sulcus are, in order of their appearance, the orbital inclusion, the parotid, and the inconstant orbitoparotid sprouts. which arise from the furrow in the interval between the parotid and the inclusion. The anlages of the orbital glands are associated with the secondary buccal sulcus and are formed after the inclusion has separated. The inferior alveobuccal glands are a series of simple sprouts in the course of the sulcus of the same name, and constitute the "molar gland" of authors. At a late period when the orifices of the parotid and orbital glands have come to open upon a sagittal ridge (stomal ridge), a few small elements appear in its course and along its ventral limit. These are termed the glands of the stomal ridge. I shall proceed to describe the derivatives of the buccal and secondary buccal sulci in the following order: orbital inclusion, parotid, orbitoparotid, and orbital glands. The inferior alveobuccal and the glands of the stomal ridge will be described under the heading of diffuse glands.

\section{THE ORBITAL INCLUSION}

In the 8.5 millimeter embryo the oral cavity presents appearances in the region of the mandibular nerves which can be attributed to resistance to its lateral expansion. These are a dorsal tilt of the marginal cavity carrying the buccal sulcus to a higher level; some degree of conformity in the curvature of the roof and floor. the convexity of the roof representing the palate process; and, finally, the formation of a rather acute angle at the ental surface of the epithelium of the buccal furrow. This gives the fundus of the sulcus a slightly pinched look (Fig. 6). It was apparent in two sections only on each side. The sections have a thickness of $13.3 \mu$.

In embryos of 9 millimeters a small but distinct fold is found, not only opposite the mandibular nerve, but extending slightly craniad of its crossing. In embryo No. 268 it is still minute, having a sagittal length of only $40 \mu$. In the sections (Fig. I8) it is characterized by a rather abrupt narrowing of the oral cavity to a fissure at the buccal sulcus, and by a slight indentation of the ectal outline of the epithelium dorsad, as though kinked at this point. In embryo No. 106, also of 9 millimeters, the process has advanced somewhat; the fold has a length 
DEVELOPHENT OF SALIVARY GLANDS IN THE DOMESTIC CAT 2 II

of $60 \mu$ reckoned by sections. In section (Fig. 19) the fissure is obliterated by approximation of its walls and a minute flange is formed, the pale center of which is continuous with the remnant of the fissure that indents its base. The palc area in the flange therefore represents an obliterated portion of the fissure; its pallor is due to the presence of cells with faintly staining cytoplasm. Similar pale areas occur in the flanges, ducts, and buds of all the salivary glands. In the case of a flange they undoubtedly are included periderm cells, which in this 9 millimeter embryo are present upon the surface of considerable areas of the oral epithelium. In buds their presence must receive another explanation. Here they are not flattened, but polygonal in shape; in their faintly staining clear cytoplasm, and in their pyknotic nuclei they resemble periderm cells, and are probably the result of an analogous cytomorphosis, possibly dependent on their distance from the basement membrane and their, in consequence, less advantageous nutrition. Their presence causes the centers of the salivary anlages to appear pale, and with low magnification suggests a lumen long before one is actually present.

The embryos of 9.2 to 10.5 millimeters form a close series showing the gradual advance of the fold from the mandibular crossing to the angulus oris; a process of constriction is begun by which the fold is ultimately separated from the oral epithelium, and the fold itself is differentiated into two areas, a caudal narrow, and a cranial broad portion. Figure 21 is from a reconstruction of the ectal surface of the epithelium of the marginal cavity in an embryo of 10 millimeters. The orbital fold involves the greater part of the buccal sulcus. The constriction is indicated by a small furrow on the dorsal surface of the epithelium parallel to the buccal sulcus. This is shown in the section (Fig. 20), where also a very faint ventral furrow can be distinguished. These furrows gradually deepen until they meet and free the orbital inclusion. As they must frequently be referred to, they will be termed the separating sulci; it is seen that the dorsal slightly precedes the ventral in development, being present incleed in the 9 millimeter embryo. In the model only the constricted portion of the fold can be seen. This forms a solid cylinder of uniform diameter and circular cross-section, the pars cylindrica of the orbital inclusion. Further craniad the fold loses its external relief, while in the sections 
(Fig. 22) all its dimensions increase, especially its breadth. In the region of the mandibular nerve a remnant of the fissure still indents the base of the pars cylindrica; in more cranial sections the fold is laid open in its entire breadth by a narrow cleft, which, becoming wider. causes the fold to disappear a short distance from the angulus oris. This broad cranial addition to the fold is the pars lata.

In the embryo of 10.5 millimeters the orbital fold attains its maximum relative to the buccal sulcus. Caudad for a section or two the sulcus is uninvolved; craniad the fold extends beyond the postangular bend into the postangular segment, failing, but only just failing, to reach the angulus itself. In running over the sections in a craniocaudal direction, we meet in the same plane as the angulus the pars lata, with a narrow fissure extending through its whole breadth; the walls of the fissure then come into contact, and a solicl flange with a pale axial line of periderm is seen, its base indented by a remnant of the fissure; the flange then narrows, and a constriction. appearing at its base, becomes circular in section. The process being progressive caudocraniad, the evidences of folding and constriction are most marked in the plane of the mandibular nerves. Of the orbital fold itself, about half corresponds to the pars cylindrica, about half to the pars lata. Their junction is effected by gradual transition near the point where the small buccomasseteric nerve comes into close contact with the oral epithelium. The orbital inclusion retains its relation to the buccomasseteric nerve as late as in the 70 millimeter embryo. In embryos of 20 millimeters and less the contact is intimate, apparently no mesenchyme intervening.

In immediately succeeding stages the orbital inclusion becomes separated from the angulus oris by an increasing length of unfolcled buccal sulcus. This segment of the sulcus appears to be an addition from in front. It meets the older region of the sulcus at an appreciable though rounded angle, which I have called the orbital angle. This, it will be remembered, is characterized not only by a change of direction in the horizontal, but in the vertical plane as well. It forms the crown of the sagittal arch of the sulcus and corresponds to the junction of the pars lata and cylindrica of the orbital inclusion and to the crossing of the buccomasseteric nerve. This nerve is now the most available landmark in this region, for already the mandibular 
nerve is becoming separated from the mouth in a caudolateral dircction, and has no longer the value of a relatively fixed point in the changing topography of the buccal sulcus.

We may make use of the buccomasseteric crossing and the orbital inclusion to investigate the nature of the formation of the preorbital segment of the buccal sulcus. The following measurements, all of the right side, are section counts reduced to micra. On account of the obliquity of the buccal sulcus they have no absolute value, but since the obliquity does not vary greatly in the several embryos, and the planes of the sections correspond fairly well, they suffice for a rough comparison and throw some light on the complex conditions of growth in this portion of the oral cavity. The position of the second and third embryos in this small series requires a word of explanation. They are litter mates corresponding closely in general development. One, howerer, measured 9.5 millimeters, the other ro millimeters. Both are intermediate in development between a ro.5 millimeter embryo, No. I 20, and that of I m millimeters. No. 2 I3, all of which were measured under identical conditions. Some variations in the degree of currature of the embryos is probably the explanation of the disorder of the series. As similar discrepancies occur in several of our litters, one is disposed to wonder whether an estimation of volume might not form a more accurate criterion of development than linear measurement. Thus qualified the dimensions in question follow:-

\begin{tabular}{|c|c|c|c|c|c|}
\hline Evbryo No. & Rating & $\begin{array}{l}\text { ANGULUS ORIS } \\
\text { TO ORBITAL } \\
\text { INCLUSION }\end{array}$ & $\begin{array}{l}\text { LENGTH OF } \\
\text { PARS LATA }\end{array}$ & $\begin{array}{l}\text { ANGULUS ORIS } \\
\text { TO BUCCOMAS- } \\
\text { SETERIC NERVE }\end{array}$ & $\begin{array}{c}\text { LENGTH OF } \\
\text { PARS CYLIN- } \\
\text { DRICA }\end{array}$ \\
\hline I 20 & $\begin{array}{l}\mathrm{mm} . \\
10.5\end{array}$ & $\underset{\text { Minimal }}{\mu}$ & $\begin{array}{l}\mu \\
80\end{array}$ & $\begin{array}{l}\mu \\
\text { So }\end{array}$ & $\begin{array}{l}\mu \\
80\end{array}$ \\
\hline 272 & 10 & 40 & 9.3 & I 33 & 93 \\
\hline 273 & 0.5 & So & 80 & 160 & So \\
\hline 213 & II & 146 & So & 226 & So \\
\hline 251 & I I. 5 & 226 & 146 & 372 & I 20 \\
\hline
\end{tabular}

The first four embryos show a progressive increase of the distance between the buccomasseteric nerve and the angulus oris, while the orbital inclusion remains of approximately the same size. The pre- 
orbital segment of the buccal sulcus, in view of its non-existence in embryo No. I20, appears rather to represent a cranial addition to the suicus than the result of locally accelerated growth. In the I I millimeter embryo the orbital inclusion is still quiescent, while the sulcus craniad of it has continued to lengthen. From this period the orbital fold, which in embryos of 8.5 millimeters to 10.5 millimeters advanced at a rate far exceeding that of the lengthening of the buccal sulcus, and for a moment approximately reached the angulus, is no longer able to maintain the balance of growth in its favor and henceforth undergoes a relative caudal displacement. Further, it is to be noted that in the four younger embryos of this series the pars lata does not increase in size and that, therefore, the advance of the fold for the time being has come to a standstill. In comparing the 11 and 11.5 millimeter embryos one or two points require comment. In this period the pars cylindrica has lengthened one-half. On account of the obliquity of the pars cylindrica which is attached to the terminal entomasseteric segment of the buccal sulcus, this element is considerably underestimated in section counts. while the pars lata involving the beginning of the sagittal segment receives nearly its full value. In reconstructions made of 11.5 and 12 millimeter embryos it was found to be no longer than the pars cylindrica. From this period the pars cylindrica lengthens more rapidly and in later stages many times exceeds the length of the pars lata (Fig. 45). The rate of growth in the pars cylindrica is such as to maintain its parity with the sulcus to which it is attacherl, except at its extreme caurlal end. Here it gradually lags a little behind the sulcus, which acquires a short terminal segment that never becomes folded.

The general features of the buccal sulcus at 1 r. 5 millineters are shown in Figs. 23-30, a series of sections from embryo No. 256 which corresponds closely with No. 25I. Its trajectory comprises a rather abrupt sweep mesad from the angulus (Fig. 23, 2), a gradual ascent in nearly a sagittal direction to the orbital angle (Fig. 27), and there a second change of direction to its oblique terminal segment. The maxillomandibular plane is ventrolaterally inclined at the angulus oris (Fig. 23), nearly horizontal near the orbital angle (Fig. 26). while caudad it is almost wholly reduced to form the pars cylindrica (Fig. 27). The epithelium is thickened at the fundus of the sulcus. On the floor it thins 
rapidly mesad and the inferior dental anlage is already separate. On the roof the thickening gradually diminishes towards the palate process; as yet the superior dental anlage is but faintly indicated. Close to the angulus oris a small epithelial crest is attached to the buccal sulcus for a few sections (Fig. 24). Its presence suggests the occurrence of some degree of fusion at the angulus, the crest being a remnant of the epithelium destroyed in the process. It is present constantly in embryos of about this stage, being most marked immediately behind the angulus and thence rapidly diminishing caudad. A similar crest is sometimes attached to the furrow on the surface which intervenes between the maxillary and mandibular processes. Their bearing upon the question of fusion at the angulus has already been discussed. Near the orbital angle the lumen of the buccal sulcus is reduced to a narrow fissure (Fig. 26), which in the next section is obliterated (Fig. 27) and the pars lata is formed. The union of the layers so as to cut off a portion of the fissure from the oral cavity in Fig. 26 is unusual and may be due to obliquity in the section. The pars lata is broad at its cranial extremity and though it becomes somewhat broader in the following sections (Fig. 27) shows as yet no tendency to taper into a point craniad. It narrows abruptly where the buccomasseteric nerve comes into contact (Fig. 29,69) here sending a short process caudad on the lateral aspect of the nerve (9). In its inception this lateral process appears as a mere bulge beyond the nerve. In later stages its variable length suggests some independent growth. The pars cylindrica (Figs. 29, 30, 8) is circular in section, the center somewhat pale, the separating sulci well defined. Caudad it accurately surmounts the buccal sulcus (Fig. 30); its position is fundal. Near its junction with the pars lata the inclusion has begun to undergo a dislocation ventrad. The epithelium of the mouth mesad to the dorsal separating sulcus is convex, suggesting here a more active growth and consequent tendency to fold, as contrasted with the ventral wall of the sulcus. The sulcus is, in fact, in process of forming a new fundus on a higher level. In later stages the ventral displacement of the inclusion becomes marked and affects its whole extent. This is a good illustration of the tendency of the oral anlages to shift from a fundal to a parietal position. In all cases it appears to be the sulcus which is active and produces a new fundus to one side of the flange, as though its presence 
formed an obstacle to the deepening of the sulcus which is avoided in this way.

It will be noted that, while the processes of folding and constriction are progressive in a caudocranial direction, and this obtains of later stages as well, that of dislocation begins at an intermediate point. It has not yet affected the pars lata, and the caudal extremity of the inclusion retains its fundal position. This raises the question of a possible caudal growth of the pars cylindrica, which could be accomplished either by the extension of the fold or by proliferation. The first alternative may, I think, be rejected. The caudal segments of the inclusion are uniformly well constricted and never show the presence of a fissure, as in the stages of the inception of the fold. That occasionally some proliferation occurs here is highly probable. In a minority of cases the caudal section or two of the inclusion are free, before the separation of the pars cylindrica has progressed to its caudal end. These cases are not numerous and the length of the free tip is always inconsiderable. In such forms as the pig and cherrotain, a considerable caudal process of horizontal direction can be distinguished from the pars cylindrica, and is apparently due to proliferation. It would appear, therefore, that in the cat this tendency is only exceptionally manifester to a very slight degree; its suppression possibly is correlated to the brachycephalism of the Felida.

The orbital inclusion is now composed of a pars cylindrica and a oars lata, and manifests a slight tendency to growth lateral to the buccomasseteric nerve, the processus lateralis. In the $\mathrm{I} 2$ millimeter embryos it completes its form by the acquisition of a tapering cranial extremity, the processus cranialis. Hitherto its cranial end has been blunt in the form of a broad flange which was suddenly effaced by the opening of a fissure throughout its breadth. From this period the cranial end shows a number of sections of diminishing width, the fissure indenting their bases more and more as they are followed craniad, until finally the inclusion is lost in the thick epithelium of the buccal sulcus. As the pars lata does not diminish in sagittal length during this process, the pointed extremity must be regarded as an addition to the inclusion, which becomes an harpoon-shaped object, with dorsoventrally flattened blade and rounded shaft, while the barb is represented by the lateral process. It is still attached to the buccal 
sulcus in its whole length; the extremities are fundal in position, the intermediate portion parietal.

The I3 millimeter embryo (Fig. 3T) is scarcely arlvanced beyond these conditions, as far as the orbital inclusion is concerned. The dorsal separating sulcus is well defined; craniad it broadens and turns laterad, towards but not reaching the buccal sulcus, defining the pars latia and the as yet insignificant cranial process. Mesal to the separating sulcus the oral epithelium presents a convexity which is more apparent in section (Fig. 33, Ia). This is the forming fundus of the secondary buccal sulcus, which after the separation of the orbital inclusion, replaces the buccal sulcus as the lateral border of the mouth. The pars cylindrica $(\delta)$ is well constricted at its junction with the oral epithelium and is beginning to undergo a displacement ventrad. This is more clearly to be seen in the sections (Fig. 33). The ventral separating sulcus becomes deeper as the displacement increases. Craniad it also widens into a shallow concavity in the region of the pars lata (Fig. 32). These sections are disturbed by a tear along the axis of the fold, an artefact which occurs with wearisome iteration in embryos otherwise satisfactorily sectioned, and causes the orbital inclusion to resemble an open fold. It seems to depend upon an as yet imperfect adhesion of the opposed periderm layers. An undamaged section of a slightly older embryo is given for comparison in Fig. 42.

In the 13.5 millimeter embryo (Fig. 34 ) the changes are slight. The constriction is complete along the greater part of the pars cylindrica; the separating sulci have met, but the inclusion remains in contact with the oral epithelium and no mesenchyme has entered the cleft. The dorsal separating sulcus, after broadening beside the pars lata, turns laterad and now extends to the buccal sulcus. In consequence, the narrowing fold of the cranial process is depressed ventrad in reference to the buccal sulcus, causing the border of the model in this region to present some resemblance to a knife blacle with the edge turned. In the sections from a second embryo of 13.5 millimeters (Fig. 57) the fold of the cranial process is seen to be fundal in position but deflected rather sharply ventrad. The buccal sulcus has now a well-defined arch; the pars lata occupies its crown, the pars cylindrica its decline; the cranial process extends a short distance 
along its sagittal segment. Both in this and in the preceding embryo the lateral process is rudimentary. The buccomasseteric nerve lies close to the caudal border of the pars lata (Fig. 35).

In the 14 millimeter embryos the separation of the inclusion from the oral epithelium is begun. The region affected is the cranial portion of the pars cylindrica; here mesenchyme enters the cleft formed by the separating sulci and the inclusion begins to undergo a lateral as well as a ventral displacement. In embryo No. 211 (Fig. 4I) the process is initiated at a point rather farther caudad than usual; as a rule, it is first seen at the cranial end of the pars cylindrica close to the pars lata (Fig. 43). For the rest, embryo No. 2 I I requires little comment ; the lateral process is rudimentary; the pars lata shows no ventral displacement; the dorsal separating sulcus does not extend as far craniad as in the 13.5 millimeter embryo nor does it form a broad concavity in the region of the pars lata. The cranial process, which is distinct in the sections, though ill defined on the surface, is separated by a definite, though small interval (15) from the parotid (I2). In embryo No. 127 (Fig. 43) the ventral displacement of the inclusion is marked throughout its whole extent. The cramial process runs out into a low ventrally directed flange ( 16$)$, which prolongs it almost to the paroticl (12), from which it is separated only by a small incisure. This embryo illustrates the occasional tendency to continuity of the parotid and orbital folds, a tendency but rarely realized (zide infra). In this embryo, also, the pars cylindrica is narrowed at its junction with the pars lata. This condition is of rare occurrence; a solution of continuity at this point has not been observed.

The 15 millimeter embryos (Figs. 44.45) show an advance of the process of separation; only the tip of the cranial process and the caudal half of the pars cylindrica are now attached. The interval between the inclusion and the secondary buccal sulcus has increased in width; the ventral displacement is also marked. The pars lata on separation loses its dorsoventral flattening and soon becomes circular in the sections, where it is distinguished from the pars cylindrica only by its larger size. Craniad it tapers to the cranial process, which is prolonged along the buccal sulcus, as in the earlier embryos, by a low ventrally directed flange. In embryo No. 219 (Fig. H4), on the right side this extends into continuity with the parotid, forming a complete 
orbitoparotid bridge. The usual condition is shown in Fig. 45 from embryo No. 2r6. Here the cranial process is continued by a short flange, fundal in position, but deflected ventrad, between which and the parotid is a well-marked interval. The cranial process shows a slight constriction at its union with the flange. With reference to alljacent structures, the site of this junction is entomasseteric and opposite the point where the deep facial vein crosses the sulcus on its way to the orbit. This point may be taken as the usual cranial limit of the process, the length of which is subject to wide variations. The caudal half of the pars cylindrica is attached in a ventral parietal position and is well constricted throughout (Fig. 45). In embryo No. 219, however, its caudal extremity is still fundal and unconstricted. The late persistence of these primitive conditions suggests again the possibility of a caudal extension of the inclusion at least as a variant, but hardly warrants a positive conclusion. In the same embryo the lateral process is remarkable for its bulk as well as for its lengtl. The angle between it and the pars cylindrica lodges the buccomasseteric nerve.

The separation of the inclusion is completed first at its cranial extremity. It occurs by a subterminal constriction, as in Fig. 45, leaving attached to the buccal sulcus a short ventrally directed remmant of the flange, which soon disappears. The time of separation is subject to some variation. The tip was free in one embryo of 15 millimeters. The latest period at which it was found attached was 19.5 millimeters; in two embryos of this length it was attached on one side in each. In fifteen embryos ranging in length from 16.5 to 19 millimeters the tip of the cranial process was found free seventeen times, attached thirteen times. In some of these embryos the tip wis close to the buccal sulcus, which retained a rudimentary flange for a section or two craniad of it, indicating that separation had just occurred. In the older embryos in which attachment persists the cranial process is exceedingly long and tenuous, extending craniad of the deep facial vein. In the I5 millimeter embryo in which the inclusion was free, the cranial process was short and blunt, not reaching the vein. It would seem, therefore, that the length of the cranial process depends upon the time of separation, and this in turn is dependent upon the degree of flange formation in the orbitoparotid interval. Inclusions of the type of embryo 219 (Fig. 44) separate late and have long tenuous cranial processes, those 
of the type of embryo 216 (Fig. 45) are relatively blunt and separate early.

The time of separation of the caudal extremity of the inclusion varies within wider limits. The earliest separation observed was in an embryo of 18.5 millimeters; the latest retention of the caudal attachment in one of 35 millimeters, on one side only. In the embryos of 19-2I millimeters it is free rather oftener than not. In those of this period in which the attachment persists, it is situated considerably ventrad of the secondary buccal sulcus on the ventrolateral wall of the palatomandibular plane. Here the oral epithelium bulges in a small conical process to meet the tip of the inclusion. A thick stratum corneum is present, the ental contour of which is a little concave opposite the attachment of the inclusion. There is a well-marked constriction at the junction of the inclusion and the oral epithelium. The appearances are suggestive of traction on the oral epithelium, resulting from the displacement laterad of the inclusion, as mesenchyme accumulates between it and the oral epithelium. In a few cases the caudal attachment persists to a late period. It is present in the 25 millimeter and the 35 millimeter embryos, in each on one side. In the 5I millimeter embryo on the left side the constriction is complete, but contact is still retained. In all these cases the extent of the attachment is minimal, rarely of greater length than one section. The possibility of extension caudad by proliferation has already been alluded to. If it occurs to a degree adequate to explain the differences in the time of separation, it must be correlated in rate to the process of separation with great nicety, for the length of the attachment is remarkibly constant in the embryos studied. Of the free growth of a caudal process, the only evidence is the occasional finding of a free ultimate section or two of the inchusion, while the penultimate portion is still attached.

The orbital inclusion, as soon as separation is completed in any segment, begins to be displaced laterad towards the internal pterygoid muscle, with the ental surface of which it comes ultimately into juxtaposition. Its topography at 18.5 millimeters, the earliest example of its complete separation, is shown in Fig. 103. The pars lata $(7)$ lies farthest laterad, resting in a small concavity of the surface of the pterygoid $(7.4)$ vertically above the mandible $(5-1)$. From this point the 
pars cylindrica $(\delta)$ slopes ventrad, caudad, and mesad towards the oral epithelium, which it approaches ventrad of the secondary buccal sulcus ( $I$ a ) near its termination. 'This relation to the sulcus is due merely to in increase of the early dislocation of the inclusion from its fundal position. The sulcus has been carried dorsad as the palatomandibular plane has continued to enlarge. forming a new fundus at a higher level, the secondary buccal sulcus; while the orbital inclusion repre-, sents the earlier and more ventrally placed fundus of the buccal sulcus. In this embryo the cranial process is short and does not reach the deep facial vein. In others of about the same stage, where the cranial process is longer, the tip lies close to the oral epithelium. The displacement of the inclusion is greatest at the junction of the pars lata and pars cylindrica, where it was initiated, and thence diminishes craniad and caudad. In later stages the whole inclusion is gradually approximated to the internal pterygoid. Inclusions with longer cranial processes may extend beyond the pterygoid under cover of the masseter and the deep facial vein. Such are not uncommon in embryos of is 20 millimeters. In many of these, however, and regularly in later stages, the cranial process is short and blunt.

On separation the pars lata rather quickly assumes a circular section. There is no loss of substance in this clange, nor evident deforming force, for the inclusion is everywhere surrounded by mesenchyme and in contact only with the buccomasseteric nerve. It would seem, therefore, an effect of something akin to surface tension at the junction of the inclusion with the mesenchyme. The growth of the inclusion after separation continues at about the same rate as the lengthening of the sulcus that has given rise to it. The pars lata, distinguishable by its larger section and its contact with the buccomasseteric nerve, still is found opposite the orbital angle. The pars cylindrica extends along the greater part of the secondary buccal sulcus. From an early stage ( 12 millimeters) there has been a small segment of the sulcus caudal to the end of the inclusion. This lengthens progressively both before and after separation of the pars cylindrica. There is no way of telling after separation whether any of the relative gain of this segment is due to a diminished rate of growth in the inclusion. The disparity in size between the pars lata and the pars cylindrica is gradually effaced. After assuming a cylindrical shape, the 
pars lata seems rather to dininish in section and eventually cannot be distinguished from the pars cylindrica. In one of the 18 millimeters embryos (Fig. 97) it can scarcely be recognized. However, it usually is clearly marked up to 28 millimeters. In the later stages (Figs. I07, 109, 114) the whole inclusion appears of about the same diameter.

The cranial process may be very long and tapering after separation, in embryos of $18-20$ millimeters extending not rarely to the deep facial vein and occasionally craniad of it. Its position is such cases is indicated in Fig. 102 (dotted circle below 20, not leadered). In embryos of more than 20 millimeters this tapering form is rare and the inclusion ends caudad of the rein, at an interval increasing in later stiges. The cranial process is exceedingly variable in length, so that it cammot positively be asserted of these short forms that they were longer at an earlier period, vet it seems probable that atrophy has here occurred, and that the pressure of the facial rein may play a rôle in its causation.

The lateral process never attains a large size. The one in the I 5 millimeter embryo (Fig. +4 ) is a fair example of its maximum. It is a blunt or conical projection from the pars lata, lateral to the buccomasseteric nerve, varying in length from $13 \mu$ to $36 \mu$. It is not always present (Figs. 45, 97). It never attains the retortlike shape of an active sprout, and in many cases it is hard to satisfy one's self that it is more than the bulging of the pars lata, which is pressed against the bucconasseteric nerve. This contact is absolute in embryos of 13.5 to I5 millimeters, no mesenchyme intervening. After the separation of the inclusion, the lateral process soon disippears and is not present in any embryo of greater length than 22 millimeters. Here, as in the processus caudalis, the tendency to sprouting is rery feeble in the cat.

It has been said that the displacement of the inclusion with reference to the secondary buccal sulcus is at first ventral and lateral. The latter direction is retained throughout the period covered by our series. The direction of the vertical displacement is reversed in later stages when. with the enlargement of the jaw and the muscles of mastication, the inclusion comes to occupy a more dorsal position. In the embryos of 28 millimeters and 35 millimeters it lies at about the level of the secondary buccal sulcus. In those of $5 \mathrm{I}$ millimeters and 70 millimeters (Figs. ro9, I14) it is placed dorsal to the sulcus, except for its caudal extremity, which turns ventrad, in the case of the $5^{\text {I }}$ 
millimeter embryo, as far as the horizontal plane of the furrow (Fig. I09, 6).

In the 70 millimeter embryo and in this alone sprouts occur in the course of the inclusion. These are shown in Fig. IIf. One projects ventrad in the cranial fourth of its extent, one dorsad near its termination. Both are caudad of the buccomasseteric nerve and are, therefore, to be assigned to the pars cylindrica. They are small, in section circular, and their cells stain very deeply, is is usual in active sprouts. The orbital inclusion thus manifests a tendency to proliferation in the course of the pars cylindrica, as well as in the processus lateralis and perhaps also at its caudal extremity. The reasons for considering the inclusion as the representative of the caudal portion of the maxillomandibular plane have already been given. If this view is the correct one, there is no difficulty in interpreting these sprouts as rudimentary glands of the buccal sulcus series.

The structure of the orbital inclusion resembles closely that of the oral epithelium. At the time of the closure of its fold a single layer of flattened periderm cells with bulging nuclei have appeared. As the fold closes, the periderm layers are brought into apposition. No cleft can be distinguished, as their interlocking nuclei completely conceal the fissure. A firm agglutination of the layers probably does not occur before the separation of the fold, as is shown by the frequency before alluded to of small tears through the axial periderm of the fold in embryos otherwise successfully prepared.

The sections of the separated inclusion show a pale center, which, with sufficient magnification, is found to be composed of clear, faintly stained cells with pyknotic nuclei. The surrounding polygonal elements are arranged in one or two rows, stain deeply, and are precisely like the basal cells of the oral epithelium. The inclusion retains this structure in the $5 \mathrm{I}$ millimeter embryo, where it shows no appreciable increase in diameter, although it has greatly lengthened. In the embryo of 70 millimeters the inclusion as a whole is less deeply stained than the oral epithelium, in a considerable part of its length its cells have a turbid look and the nuclei are pale. The central cells in places cannot be made out, and a minute lumen seems to be present. Here for the first time signs of degeneration appear; the buds, however, stain deeply. 
THE PAROTID

The formation of the parotid is foreshadowed in the embryos of II.5 millimeters by minute changes in the buccal sulcus affecting the segment that intertenes between the orbital inclusion and the angulus oris. I small fairly circumscribed area where the nuclei are crowded appears in the mesenchyme below the floor of the maxillomandibular plane close to the buccal sulcus (Fig. 24.13). It extends from the angulus oris to the orbital fold. In the epithelium opposite a change in the position of the nuclei accompanies its appearance. Over a narrow strip bordering upon the buccal sulcus they withdraw towards the oral ends of their cells, leaving a clear zone of cytoplasm ectad. At first sight there seems to be a concavity of the ectal surface of the epithelium, but on closer examination the basement membrane may be seen to pass in an even curve to the fundus of the sulcus. The ental surface is convex. This is due to the abrupt thinning of the epithelium of the sulcus at a point just mesad of the mesenchyme condensation, where a very faint furrow can be observed.

The embryos of $\mathrm{r} 2$ millimeters form a small series in which the development of the parotid may be followed from the stage we have just described to the formation of its sprout. In the least advanced, No. 1oo, conditions differ little from those found in the i . 5 nillimeter embryo. The convexity of the floor is somewhat more pronounced. encroaches more upon the lumen, which laterad close to the buccal sulcus is undergoing obliteration (Fig. 46). Here the domed periderm cells of the roof and floor interlock, and a small less deeply staining area forms the axis of a minute flange. The region thus altered is a short segment, about $40-50 \mu$, of the buccal sulcus, midway between the angulus oris and the orbital inclusion. at the region of the postangular bend. The flange diminishes in both directions; its lumen is gradually restored and widens into a buccal sulcus of the same general charater as in the embryos of 11.5 millimeters.

In embryo No. 217 (Fig. 47) the convexity entad is larger, but there is as yet but little concavity of the ectal surface of the epithelium. The fundus of the buccal sulcus is slightly deflected ventrad. The faint furrow which forms the mesal limit of the thickened epithelium is deeper. The flange has the same general appearance as in embryo 
No. Ioo. It has a slightly greater sagittal length, extending from the postangular bend somewhat nearer to the orbital fold. The mesenchyme condensation terminates ventrad of the pars lata of the orbital inclusion.

In embryo No. 78 a definite flange is formed. It has a sagittal length of $r 00 \mu$ in the sections, increasing in width to its middle and thence as gradually diminishing. At its maximum the lumen is obliterated from the buccal sulcus to the small furrow before mentioned; a pale line of interlocking periderm cells replaces the fissure. In the other sections the flange extends a less distance mesad, where its base is more or less indented by the remnant of the fissure. The flange as a whole is concave ventrad, the concavity being occupied by the mesenchyme condensation. Dorsad its convexity is evenly continuous with that of the ectal surface of the roof of the mouth. In reconstruction the parotid anlage forms a semicircular projection beyond the general line of the buccal sulcus, which while in part the result of compression, may also depend, even at its inception. upon an increased rate of proliferation in the walls of the sulcus, the effects of which soon become evident in the increased width of the flange. The fold is reduced to a flange by an elevation of the floor meeting the roof and obliterating its lumen from the buccal sutcus mesad. The order of events is, first, a thickening of the mesenchyme and a displacement of some of the nuclei of the epithelium, and second, the gradual elevation of the floor of the mouth. The mesenchyme thickening would appear to be the active agent in the process.

Between the parotid flange and the orbital inclusion the sulcus recovers its lumen, but retains the primitive thickening of the epithelium. The condensation in the mesenchyme persists, but the little furrow in the epithelium along its mesal border becomes indistinguishable in the caudal sections of the flange. In this embryo a definite, though short, segment $(60 \mu)$ of unfolded sulcus intervenes between the parotid and the cranial process of the orbital inclusion, which we may term the orbitoparotid interval. It is, therefore, evident that two distinct folds are formed in the course of the buccal sulcus, the orbital advancing craniad from the caudal segment, and the parotid appearing at the postangular bend. In the thickened epithelium connecting them and in the mesenchyme condensation we 
have indications of a possible continuity of the folds, a condition occasionally realized in the cat, as appears in the next embryo.

In this, No. 263, likewise of 12 millimeters, the fold of the parotid has much resemblance to that just described. 'It gradually broadens to a maximum and then diminishes somewhat, but is, nevertheless, continued as a perfectly definite though narrow flange to the cranial process of the orbital inclusion. An orbitoparotid interval, therefore, does not exist; the intermediate flange which has replaced it may be called the orbitoparotid bridge. Apart from its continuity with the parotid, the inclusion is of the usual conformation. In this embryo (Fig. 48) the parotid bud makes its appearance as a slight enlargement of the lateral border of the flange at its point of maximum breadth. The axial tine of periderm cells, the gradual opening of the fissure mesad, the uniform curve of the dorsal surface of the anlage, and the dense area of mesenchyme ventrad, are well shown in this section.

In all of these embryos the parotid fold is situated near the postangular bend of the buccal sulcus. On account of this change in the curvature of the sulcus, section counts are of little or no value in determining the relation of the anlage to the angulus oris; all that can be said is, that the more developed folds appear to be situated farther caudad, undergoing from the time of their appearance a relative displacement in this direction. This becomes perfectly clear in older embryos (Figrs. 4I, 43-45).

The anlage of the masseter is represented at the stage of 12 millimeters by a dense area in the mesenchyme, which craniad diminishes and becomes indistinguishable from the thickening destined to form the zygoma. The ventral border of the anlage slopes ventrad and caudad and passes the buccal sulcus in the orbitoparotid interval, here coming closer than elsewhere to the oral epithelium. The parotid Alange lies rentrad to the cranial prolongation of this anlage: but with reference to its intersection with the buccal sulcus it is promasseteric. On account of this relation a line of least resistance is determined for the sprout in a ventrocaudal direction along the sloping border of the masseter, which in this respect serves to divide the buccal sulcus into a promasseteric segment, the derivatives of which grow along the ventral border and lateral surface of the muscle, and an entomasse- 
DEVELOPMENT OF SALIVARY GLANDS IN THE DOMESTIC CAT 227

teric segment, the derivatives of which are in relation with the ental surface of the muscle. Between these two segments, the orbitoparotid interval forms a region of transition and its derivatives show a tendency now to ecto-, now to ento-masseteric, growth.

In the embryo of 12.5 millimeters the whole buccal sulcus has lengthened, but especially the preorbital portion. The mesenchyme condensation and the accompanying convexity of the floor of the sulcus no longer extend to the angulus oris, though still near it. As the sections are followed caudarl, the convexity increases; the lumen is obliterated at first laterad, then throughout the width of the convexity. The flange slowly attains a maximum breadth to dwindle more rapidly caudad; it increases in width for $6_{5} \mu$, diminishing for $27 \mu$. It is, then, in the way of assuming a triangular shape. Its absolute width has increased; the enlargement of the free border is more marked and extends from the section of maximum breaclth cranial for $40 \mu$. The proliferation results first in broadening the flange and in modeling a portion of the duct along the oblique edge of the flange, while the invasion of the mesenchyme by the free growth of a bud follows later. The anlage is solicl. The orbitoparotid interval has a length of $80 \mu$; here the epithelium of the sulcus is thick, but there is no sign of folding. The anlage of the masseter appears immediately lateral to it in the sections. The anterior process of the orbital inclusion is well defined; its sections show it to be a flange with an axial periderm line opening mesad into a fissure.

In the embryo of $\mathrm{I}_{3}$ millimeters the parotid has advanced but little upon the conditions just described. Its site (Fig. 3I), however, and the proportions of the mouth have altered somewhat. The buccal sulcus craniad of the orbital angle has lengthened relatively to a considerable degree. The parotid (I2) no longer is attached at the postangular bend, but at a considerably more caudal point. There is a long orbitoparotid interval $(15)$, which is, in part, due to the shortness of the cranial process of the inclusion in this embryo. From the inception of the proliferation, the flange of the parotid has been growing broader in the region of the bud, while its caudal border has gradually become transverse, until now the anlage has the form of a nearly equilateral triangle with an enlargement at the free angle and along the lateral border, which is somewhat greater than in the I 2.5 milli- 
meter embryo, but as it projects ventrad it is not seen in the view of the model here shown.

Conditions in an embryo of $\mathrm{I} 3.5$ millimeters are shown in Fig. 35 from a model of the ectal surface of the entire oral epithelium; in Fig. 3t the left buccal sulcus and its anlages are represented on a larger scale. The buccal sulcus has a distinct sagittal arch, the crown of which the pars lata $(7)$ of the orbital inclusion now occupies. The flexures, the postangular bend, and the orbital angle are well defned; about midway between them is the triangular flange of the parotid (12). A section of the head passing through this anlage is shown in Fig. 36, which gives an indication of the relative size and topography of the structure in a stage which it is necessary to study in some detail. On the right the triangular anlage of the zygoma is seen a short distance dorsal to the parotid, while the facial vein is shown as a commashaped dark object lying lateral and ventral to the anlage. On the left the small subparotid mesenchyme condensation shows clearly. A complete series of sections of the anlage of the right side is given on a larger scale in Figs. 49 57. The flange, which is sulcal in attachment, extends through six sections $(8 \circ \mu)$; in five it increases in width (Figs. 50-54). In the next section it is narrow and its outlines are obscured by a greater density of the mesenchyme (Fig. 55), a usual feature of the caudal section of the flange. In Figs. 56 and 57 we enter upon the orbitoparotid interval, where, apart from the angularity of the buccal sulcus, there is no evidence of compression. Here the anlages of the zygoma and as yet scarcely differentiated masseter are somewhat nearer the sulcus than in the more cranial sections. The lateral border is thickened in its section of greatest breadth (Fig. 54) and in the one preceding it (Fig. 53). In these sections the intermediate portion of the flange, between the thickened border and the buccal sulcus, appears compressed, and here, also, the subparotid area in the mesenchyme is most clearly defined. Turning now to the conditions obtaining in the epithelium of the flange itself and in the adjacent portion of the oral cavity, a periderm layer is seen to be everywhere present. This is composed of il single layer of domed cells except at the buccal sulcus, where it accumulates and partially fills the funclus (Fig. 49). In this section a small tearlike fissurc invades the mass of periderm. In Fig. 50 the fissure is larger and 
occupies the axis of an incipient fold, while in the following sections (Figs. 51, 52) the fold is reduced to a flange with a pale axial streak and indented at its base by a minimal fissure. Such appearances are characteristic of the cranial end of the anlage up to the stage shown in the 20 millimeter embryo. If the sections are read in a craniocaudal direction, they show a fold gradually compressed to a flange and gradually increasing in width, to which, finally, a sprout is added at the free margin. An anlage like this repeats the stages of the ontogenetic process in its several segments. The inference is, therefore, that the earlier phases of the process are still active and are progressive along the buccal sulcus craniad, that the fold of the parotid continues to extend after the establishment of the bud, and that, consequently, the definitive duct will be attached to the mouth at a point craniad of its origin. On the left side there is a departure from this type of anlage, which may be mentioned in passing as it forms the inception of a frequent and important variant. As far as the bud the flange resembles that of the right side. In this section, however, the intermediate portion of the flange is not flat, but thickened and circular in outline (Figs. 34, I7, 36, 40). An additional center of proliferation has appeared and is separated partially, both from the parotid and the buccal sulcus, by minute furrows. The sprout does not in this enbryo project freely into the mesenchyme. This is the earliest example of the orbitoparotid element in our series. Caudal to it the flange subsides abruptly.

In embryos of I4 millimeters the sprout of the parotid begins to grow distad into the mesenchyme. In embryo No. 2II (Fig. 4I) this growth is but barely initiated; only in two sections $(27 \mu)$ is the sprout free from the oral epithelium. In embryo No. I 27 (Fig. 43) the sprout is longer and slightly enlarged at its extremity. It is directed from the free angle of the flange rentrad, slightly caudad and laterad, a direction determined for it, first, by the ventrolateral inclination of the flange itself and, second, by the relation of the masseter before alluded to. In this anlage, again, the orbitoparotid variant makes its appearance (I7). A model of a parotid, in which the free growth of a sprout is on the point of beginning, is shown in Fig. 95. The flange is triangular; its intermediate portion is much compressed both on its dorsal and on its ventral aspect; at the free 
angle is a spherical enlargement, the parotid sprout. This tapers along the margin of the flange, but ceases to be distinguishable from the intermediate portion craniad, and so does not reach the fundus of the buccal sulcus. This marginal extension of the proliferation foreshadows the parotid duct. A distinction is now possible between the area of the flange destined to reduction, the intermediate portion,

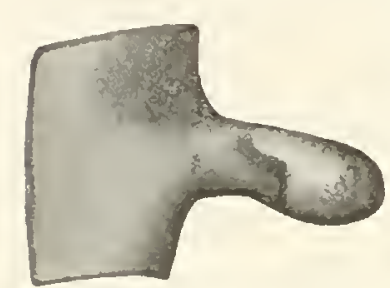

FIG. 95. Reconstruction of the right parotid anlage of a 14 millimeter embryo. Columbia Collection, No. 97. Dorsal view, $\times 200$, reduced to $\frac{1}{2}$. and the proliferation which forms the definitive gland. In this also a distinction may be drawn between the marginal thickening which forms the proximal segment of the duct. and the bud at the angle which will give rise to the distal duct system and the secretory epithelium of the gland.

A parotid intermediate in size between that of embryo No. 127 and those of the 15 millimeter embryos is shown in a series of alternate sections in Figs. 58-65. In its cranial sections it closely resembles the anlage in embryo No. I89 (compare Figs. 58,59 with Figs. 49, 50). Caudad its flange is more compressed (Figs. 60, 53) and its last sections distinetly broader (Figs. 6I, 54). The lateral border is slightly thickened (Figs. 60, 6I), but the thickening does not extend to the cranial end of the flange. The sagittal length of the attachment, as reckonerl by section counts, has slightly increased, Iо $\mu$ in this embryo as against $S \circ \mu$ in embryo No. 189 . This fact, taken in connection with the greater development of its caudal segment and the retention of primitive conditions craniad, supports the inference that the fold of origin is still advancing toward the angulus oris.

The bud springs from the lateral angle of the flange (Figs. 6I, $62)$; it is directed ventrad, slightly laterad and caudad, and is received in a concavity of the dorsum of the facial vein (Figs. 6r-63), the tributaries of which encircle it. The lateral elements of the plexus at this time are the larger and communicate dorsad with the ophthalmic vein (Figs. 63, 64). The sprout enlarges distad to a bulky fundus; the sections are circular and deeply staining throughout. Caudad of the parotid, the buccal sulcus runs out into a small ventrally 
deflected flange, a continuation of that of the parotid (Figs. 63, 64); in the last section it appears to be forming a sprout. In this region the anlage of the masseter, which is as yet hardly distinct from that of the zygoma, comes closer than elsewhere to the buccal sulcus, and is now absolutely nearer than in embryo No. 189 (Figs 55-57), the deep facial vein and a small quantity of mesenchyme intervening. The appearances in Fig. 62 require comment. This is the first section in which the parotid is free. It will be seen that the mesenchyme in the interval between the sprout and the buccal sulcus is more dense than in the succeeding sections (F gs. $\left.6_{3}, 6_{4}\right)$, and that where the epithelium of the mouth and of the anlage impinge upon this area, their outlines become indefinite. This may be due to their being covered in the thick section by the mesenchyme at these points. On the other hand, it is likely that epithelium is here being destroyed; the intermediate portion of the flange actually does disappear subsequently, and quite regularly at its caudal border appears a simitar thickening of the mesenchyme and obscuration of the ectal outline of the epithelium. In other cases where epithelial structures are undergoing reduction like conditions are seen, as, for example, in the orbitoparotid flange in Fig. 65.

From this period the sprout grows activety into the mesenchyme and the anlage comes to extend through considerable series of sections. It will be convenient to follow the changes in the flange first in detail, and deal subsequently with distal conditions in a more summary manner. With regard to the attachment of the anlage we have to consider, first, the transformation of the flangelike attachment into the circular orifice of the adult and, second, the mode in which the position of the attachment is shifted away from the buccal sulcus. For the satisfactory analysis of this latter process it will be necessary to enter somewhat upon the changes in the vestibule, by which it is transformed from a horizontal to a vertical space.

In the 15 millimeter embryo, No. 219 , the parotid anlage is a solid retort-shaped object, attached to the buccal sulcus in a fundal position, a little caudal of the midpoint between the angulus oris and the buecomasseteric nerve (Fig. 44). The latter, which is not represented in the cut, occupies the angle between the pars cylindrica $(8)$ and the lateral process $(9)$ of the orbital inclusion. The parotid flange and 
the cranial process are contimuous by means of a low flange, the orbitoparotid bridge ( $I 6)$. The sprout is directed rentrad, slightly caudad, and laterad from its attachment, which lies dorsal to the facial vein, intervening between its mesal and ventral tributaries. A series of sections through the flange is given in Figs. 66-73. The cranial sections resemble those of the embryos already described, save for the absence of the parotid fissure. This appears in the caudal sections as a minute indentation of the base of the flange. The sagittal length of the attachment is reduced to $67 \mu$. In Fig. 72 the outlines of the intermediate portion are obscured, the adjacent mesenchyme is thickened. If this section is compared with the caudal section of the flange in embryo No. 213 (Fig. 61), the distance from the enlargement of the duct to the oral epithelium will be found to be the same. The difference is in the obscuration of the intermediate portion of the flange, so that it is difficult in Fig. 72 to determine whether the duct is free or not. In the next section the duct is free, but a minute flange projects from the fundus of the buccal sulcus. Its outline is indistinct, it is constricted at its base, and the adjacent mesenchyme is thickened. Caudad it is more strongly deflected ventrad, but can be followed into continuity with the orbital inclusion -.. it is the orbitoparotid bridge.

In embryo No. 2I6 (Fig. 45) the sprout has lengthened; its enlarged fundus is more distinctly defined against the slender duct; its position with reference to the angulus oris and the buccomasseteric nerve is not materially different from that in embryo No. 219. The orbitoparoticl interval is well defined (15); an orbitoparotid element is present on the left side at the junction of the parotid with the oral epithelium. Except in this point the anlage of the right side is identical. A serics of sections through it are given in Figs. $74^{-8}$ I. The cranial sections resemble those of the earlier stages. The sagittal length of the anlage is reduced to $54 \mu$. The intermediate portion of the flange is lacking. In its caudal section (Fig. 78) the flange projects ventrad and laterad from the buccal sulcus, thickened at its lateral border, constricted at its attachment. In the next section (Fig. 79) the duct is free and separated from the buccal sulcus by rather dense mesenchyme. In the following section the duct lies at a distance from the buccal sulcus, and in a position corresponding to the thickened margin of the flange in carlier cmbryos. A comparison with cmbryo No. 219 makes it 
evident that the intermediate portion of the flange has been reduced, a concomitant thickening occurring in the mesenchyme, and that only the thickened border of the flange gives rise to the parotict duct. The retention of primitive conditions in the cranial sections of the anlage gives ground to infer that meanwhile the fold continues to advance. The proliferation of the duct advances very slowly along the margin of the fold and has not yet reached its cranial extremity (Figs. $75^{-78}$ ).

The character of the flange alters little in succeeding stages, until the embryo has attained a length of 20 millimeters. An example near the upper limit of this period is shown in Figs. $82-87$, a series of alternate sections from the ig millimeter embryo, No. 277. The flange has a sagittal length of $54 \mu$. Its bulk is somewhat greater, but in other respects it closely resembles the anlages of earlier stages. In Fig. 83 there is a very slight thickening of the basal cells at the fundus of the buccal sulcus.

Thus far the history of the parotid may be summarized as, first, the formation of a flange by the compression of an open fold, and second, a process of proliferation along the frec border of the fold artvancing towards the fundus of the buccal sulcus. The duct thus formed is freed by the destruction of the intermediate portion of the fold. This has now disappeared, and the proliferation is on the point of extending craniad along the oral epithelium proper; coincidently the anlage abandons its sulcal position.

In the 20 millimeter embryo, No. 24I (Figs. 88-94), the attachment of the parotid is formed by a kcel, $50 \mu$ in length, composed of cells resembling the basal cells of the oral epithelium, deeply staining throughout. It diminishes craniad so gradually that it is difficult to determine the precise point at which it stops. Caudad it is constricted at its junction with the oral epithelium. Its attachment is fundal except for its cranial extremity, which deviates dorsad from the funclus of the buccal sulcus, which is here curving ventrad toward the angulus oris.

In the $2 \mathrm{I}$, millimeter embryo, No. 242 , the attachment is parietal in its whole extent. It has a length of $67 \mu$. It is composed of basal cells alone, staining deeply throughout and containing no axial line of periderm. The stratum corneum, which is thick in the fundus of the buccal sulcus, does not enter the keel. In its caudal section it is slightly 
constricted at its base. It projects horizontally from the sloping dorsal wall of the buccal sulcus, a short distance from its fundus.

The attachment retains the form of a short longitudinal keel, composed of cells resembling the basal celts of the oral epithelium, until the embryo has attained a length of 31 mittimeters. In all these embryos it closely resembles that just described in the embryo of 21 millimeters, craniad minute, of semicircular cross-section, gradually broadening caudad; the terminal sections regularly show a constriction at the base, which deepens as the free duct is approached. This has an increasingly long horizontal segment, and shows for a time a slight bend, where its direction becomes pronouncedty ventrolateral, which appears to corresponsl to the junction of the sprout with the primitive flange. This gradually is effaced as development proceeds. As long as the caudal segments of the keel are constricted, we may infer that portions of it are being added to the free duct. In the 34 millimeter embryo the character of the attachment has assumed its definitive form. It is now circular and a lumen is present. The duct has come to rest, except in so far as the position of its orifice may be altered by changes in the oral cavity itself.

The character of the parotid attachment in the embryos of 20 millimeters to $3 \mathrm{I}$ millimeters is plainly that of a keel formed by the proliferation of the basal cells, without the intervention of a fold or fissure. This fact supports the riew we have taken of the formation of the duct at the border of the flange, viz. that from the first we have been clealing with a process of proliferation advancing along the edge of a solid fold. Taking origin at the widest part of the flange, in successive stages it extends craniad, involving ever narrower portions of the flange. Eventually it reaches the end of the fold and thence continues its arlvance along the oral epithelium. Pari passu the flange undergoes destruction in a cauclocranial direction until in the embryo of 21 millimeters it has wholly disappeared. That the flange itself is prolonged craniad during this process seems highly probable; as long as the fissure existed the possibility was given; yet the presence of the fissure rloes not of itself prove the reality of the advance, for in the transition from flange to open sulcus, the presence of an intermediate region with a fissure is a physical necessity. The point loses importance in view of the fact that the whole process of the formation 
of the paroticl appears to be one of proliferation, not only as regards the free sprout in the mesenchyme, but also in the formation of the proximal segment of the duct. From this standpoint the flange becomes merely auxiliary to the process of proliferation, which it serves as a guide in determining the direction of its growth and perhaps also, arguing from the early appearance and rapid enlargement of this and other sulcal glands, in some way contributes to accelerate its derelopment.

While the evidence derived from the structure of the anlage seems adequate to establish the fact of the advance of the parotid duct, the attempt to estimate the degree of the process is encumbered with difficulties. The buccal sulcus lengthens by cranial increment, and the rate of this process being greater than that of the advance of the parotid, the distance between it and the angulus oris is progressively increased. Measurements from this point, therefore, are of no assistance. Nor are the measurements from the buccomasseteric crossing more satisfactory. They show merely an increase in the distance from the nerve to the parotid, without enabling us to determine how much of the increment is to be assigned to the sagittal lengthening of the oral cavity, and how much to the displacement of the anlage. We are, therefore, forced to rely upon indirect evidence. In the 13.5 millimeter enbryo (Fig. 34, I7) a variant sprout was formed at the junction of the parotid with the oral epithelium, the orbitoparotid element. Subsequently this may retain its connection with the oral epithelium or with the parotid duct. In cases of the latter type we have a means of estimating the amount of duct formed by constriction. In two cases this element was found attached to the parotid as far caudad as the border of the masseter. This condition will be described more fully in the sequel. It indicates that the whole promasseteric portion of the duct is to be ascribed to the process of constriction and not to the free distal growth of the sprout. The promasseteric segment of the parotid duct has a length of about one centimeter in the adult.

Thus far we have been considering the sigittal advance of the parotid. Coincidently it undergoes a displacement in the transverse plane, which carries it away from the buccal sulcus along its dorsal wall mesad towards the dental ridge. The degree of the shift is not 


\section{DEVELOPMENT OF SALIVARY GLANDS IN THE DOMESTIC CAT}

large; its nature can better be appreciated after a brief consideration of the changes in the vestibule with which it is associated.

The marginal portion of the oral cavity in its early stages is a narrow space extending almost horizontally to the buccal sulcus. With the appearance of the dental anlages the limits of the future vestibule are defined. In the embryo of 13.5 millimeters the superior anlage (64) appears as a shallow furrow lined with thickened epithelium, which is continuous laterad with that lining the buccal sulcus (Figs. 49-57). Caudad the furrow becomes very faint, but can be followed into the orbitoparotid interval, where it is finally lost a short distance craniad of, and in line with, the orbital angle. The epithelial thickening also diminishes in width caudad, and at the orbital angle becomes confined to the forming fundus of the secondary buccal sulcus. These structures are too minute to appear in a model of the scale on which the oral epithelium of this embryo was reproduced (Fig. 35), where, incleed, the larger ectopalatine sulcus $(62)$ can barely be indicated. In the seetions (Figs. 49-53) the furrow of the dental anlage is parallel to the larger sulcus and lateral to it, extending from the orbitoparotid interval craniad a short distance beyond the plane of the angulus oris. The mesal limit of the thickened epithelium is a sagittal line about midway between these furrows, which caudad reaches the secondary buccal sulcus near the buccomasseteric crossing. While the epithelial thickening of the roof thus retains its primitive continuity, that of the floor has separated into three areas: a minimal residuum of its mesal border can be recognized along the fundus of the lingual sulcus; its lateral portion extends from the buccal sulcus to the minute furrow before referred to in connection with the parotid fold, which is the inception of a new fundus of the buccal sulcus; finally, an intermediate thickened region comprises the inferior dental anlage and the inferior alveobuccal sulcus (Figs. 36, 49-54). The former is of the same structure as the superior dental anlage, but larger and ental in position. Both furrow and thickening disappear caudad before the orbital angle is reached. Craniad the formation extends beyond the plane of the angulus oris, there converging towards its fellow of the opposite side. The earlier emergence of the ventral anlages would seem to stand in relation to the more rapid expansion of the epithelium of the floor, depending in turn upon the greater enlargement of the mandibu- 
lar process as a whole in comparison with the maxillary; for in the roof of the mouth at this period the transverse increment is greatest in the region of the palate process and the craniolingual plane, while the increase of the maxillary process is small. In this embryo the vertical extent of the vestibule is greatest in the plane of the parotid. Caudad and craniad it lessens, and the roof and floor conform more closely in relief. The changes which supervene and eventually transform the vestibule from a nearly horizontal to a vertical cleft are initiated in this intermediate region of the cavity, and thence extend caudad and craniad without, however, affecting the terminal portions of the buccal sulcus. The secondary buccal sulcus from the orbital angle caudad escapes obliteration, as does also the cranial segment in the vicinity of the postangular bend and the angulus oris.

In the embryos of 15 millimeters (Figs. 66-8I) the buccal sulcus is wide with a rounded fundus in the parotid region and immediately craniad, gradually narrowing thence in both directions to a more acutely angular furrow. Between the fundus and the superior dental ridge a faint angle is observable, at which the inclination of the ventrally sloping roof is slightly increased; this is the superior alveobuccal sulcus. In the floor the concavity of the inferior alveobuccal sulcus has increased; the thickening of its epithelium is, however, scarcely perceptible. From the buccal sulcus mesad to the dental ridges the cavity increases in height and, has now a <-shaped section. The sagittal length of the region affected is as yet small. In embryo No. 216 (Figs. $74^{-79}$ ) the furrow at the mesal border of the parotid convexity is better marked. Caudad and craniad of the parotid flange it merges with the buccal sulcus. With reference to this forming furrow the parotid is already parietal; the fundus of the buccal sulcus having been utilized to form its flange, a new fundus is formed to one side, as in the case of the orbital inclusion, with the difference that it is here produced on the ventral aspect of the obstructing fold.

A series of changes are thus initiated by which new sulci are substituted for the buccal sulcus in almost its whole length. Caudad the process has been followed in detail in connection with the orbital inclusion. The changes at the cranial end of the sulcus may here be briefly dismissed. It has been said that the small furrow, which appears first mesal to the parotid fold as the limit of its epithelial 
thickening and, subsequently deepening, forms a new border for the vestibule ventrad of the parotid, merges farther craniad with the fundus of the buccal sulcus. On account of the minute size of the new element it seems more natural to regard the resulting furrow as the representative of the buccal sulcus, which continues to lengthen as formerly, by the advance of the angulus, there being no evidence to show that in this region a secondary fundus is formed.

The intermediate region, extending from the parotid flange to the orbital angle, must be considered in more detail.

Here the buccal sulcus becomes reluced and is finally obliterated. The changes are, however, very gradual, and extend over a long period of development; the embryo of $5^{1}$ millimeters is the first in which actual interruption of the sulcus is found.

The embryo of I9.5 millimeters (Figs. $82-87$ ), apart from increase of size, has not advanced greatly beyond the stage attained by the 5 millimeter embryos. The superior alveobuccal sulcus (25) is confined to the immediate vicinity of the parotid. It can be recognized in Figs. $S_{4}$ and $S_{5} ;$ in Fig. 86 it has completely disappeared. Craniad of the parotid the buccal sulcus is very broad, and while presenting a generally rounded outline, yet shows in the ectal contour of its epithelium two faint angles, of which the dorsal is continuous with the superior alveobuccal sulcus. The ventral soon becomes deep and is continued to the angulus oris. The inferior alveobuccal sulcus is broad and shallow; towards the middle of its concavity the thickness of its epithelium increases slightly. The vertical extent of the vestibule has markedly increased and its roof and floor meet at a wider angle.

In the 20 millimeter embryo (Figs. 88-94) the changes are clear and definite. Dorsad of the parotid the angle of the superior alveobuccal sulcus is distinct. It is still confined to the region of the parotid and is separated by a long interval from the secondary buccal sulcus. The inferior alveobuccal sulcus is deeper and more angular at its fundus, and in its lateral wall the sprouts of two rows of glands have appeared. The superior and inferior alveolabial sulci have also appeared. The former is represented by an angle in the epithelium of the roof of the mouth at some distance laterad to the dental anlages. It lies wholly craniad of the plane of the anguli oris, but otherwise it closely resembles the superior alveobuccal sulcus at this stage. 
Dorsal to the line of the buccal sulcus, three discontinuous furrows have now appeared: the secondary buccal sulcus, in the postdental segment of the marginal cavity ; the superior alveobuccal, in the region of the parotid; and the superior alveolabial, which is preangular in position, and corresponds to the anlages of the canine and incisor teeth. Ventrad in addition to the inferior alveobuccal sulcus, the inferior alveolabial is now present. This, like its fellow of the upper jaw, is situated far craniad. It is a shallow furrow closely associated with the inferior dental anlage, and has attached to its fundus a keel of epithelium which projects into the adjacent mesenchyme.

In subsequent stages the superior aheolabial, akeobuccal, and secondary buccal sulci become confluent (Figs. 164, I65), mainly by the extension of the intermediate clement in both directions. In the embryo of 25 millimeters the superior alveobuccal sulcus has extended caudad into continuity with the secondary buccal sulcus; craniad as the angulus oris is approached it loses its angularity and becomes a rounded curve where the horizontal epithelium of the roof passes into the nearly vertical layer of the lateral wall. In the plane of the anguli oris and craniach it again becomes well defined. Here the roof makes a rectangular junction with the vertical lateral wall which descends to the buccal sulcus. Still farther craniad a distinct furrow appears, the superior alveolabial sulcus, which rapidly deepens in to a cleft opposite the canine tooth and again abruptly diminishes opposite the incisors. The fundus of the sulcus is prolonged into the mesenchyme by an epithelial crest, which, splitting, serves to deepen the cleft and to assist in freeing the lip. In the presence of this keel the alveolabial sulci differ from the alveobuccal, which are formed by simple bending in the oral epithelium, and subsequently deepen as the alveolar processes enlarge and the cheeks become vertical. Similar conditions obtain in the region of the lower jaw and ventral limit of the vestibule, with the difference that the inferior alveolabial and alveolsuccal sulci never become confluent, but are permanently separated by a diastemal fold which extends transwersely from the margin of the lip to the socket of the canine tooth (Figs. Io9, I I 4 ). Caudad the inferior alveobuccal sulcus approaches the buccal sulcus, but becomes shallow and disappears near the border of the masseter, not inuprobably in consequence of the presence of the muscle. 
The canine teeth thus serve to define in the adult the boundary between two segments of the lip, the development of which differs. Caudal of the canine, the space between the lips and jaw represents an extension of the restibule, with which it agrees wholly in mode of formation, and into which during development its caudal portions are progressively absorbed as long as the angulus oris continues to arlvance. The fundus of the clefts are the alveobuccal sulci, both of which are continued into the restibule. The alveolabial sulci, the development of which is associated with the presence of epithelial keels, are confined to the region of the incisor and canine teeth. In the cat the superior sulcus becomes confluent with the alveobuccal by the suppression of the upper diastemal fold, which, however, is present in other mammals, as, for example, the Suidæ and some marsupials and edentates. One of the latter, Tamandua bivittata, affords an interesting confirmation of the view just stated of the ahveobuccal sulci, that they represent a region of the mouth which is potentially vestibule. In this form the angulus oris is placed far craniad, the restibule greatly lengthened, and the gape of the mouth correspondingly reduced. Both upper and lower diastemal folds are well developed and attached to the margin of the maxillaries caudal to the small canine teeth. Their lateral extremities are attached to the angulus oris. Thus the whole of the alveobuccal sulci are here included in the vestibule, and the angulus has realized to the full its possibilities of cranial advance.

The superior alveobuccal and the secondary buccal sulci agree in being formed dorsal to the buccal sulcus after its fundus has been obliterated to form a flange, in the case of the former the parotid, of the latter the orbital inchusion. They appear, therefore, to define equivalent areas of the maxillomandibular plane, of which a portion is sacrificed during development to the space requirements of the muscles of mastication, viz. the orbital inclusion, the urbitoparotid bridge, and the parotid flange. As in the flanges, so in the sulci, there is a discontinuity in the process, which is incident at two points in the course of the buccal sulcus, caudad in the region of the mandibular nerve and its musculature, and craniad of the point at which the border of the masseter intersects the line of the sulcus. Secondarily, the new sulci become confluent and the dorsal limit of the vestibule is established. The flanges as a rule fail to become continuous. From this 
standpoint the border of the masseter appears as a disturbing factor in the development of the maxillomandibular plane. The same changes occur in the oral epithelium cranial and caudal to it, and at a later period, regularly as regards the sulcus, rarely as regards the fold, involve the segment opposite the muscle, and become continuous. It is difficult to escape the impression that a separation in primitively continuous structures has here been occasioned by developmental exigencies, which nevertheless the momentum of heredity from remote non-mammalian ancestors is sufficient to overcome, at a later period in the case of the sulcus, as a rare variant in that of the flange. If this be the explanation of the temporary disjoining of the superior alveobuccal and secondary buccal sulci, it follows that united they constitute a valid morphologic line and that the derivatives of its respective segments form a single series; the superior alveobuccal and the orbital glands are, therefore, homodynamous.

Once established the alveobuccal sulci form the dorsal and ventral limits of the vestibule. Between them as they deepen the wall of the cavity gradually becomes vertical by the opening out of the lateral portion of the maxillomandibular plane and the obliteration of its lateral border, the buccal sulcus. This becomes broad and rounded and in the $5^{\mathrm{I}}$ millimeter embryo (Fig. 110 ) is represented only by a moderate convexity of the lateral wall, while in the 70 millimeter embryo it has disappeared in the orbitoparotid interval (Fig. 115), though persisting near the angulus (Fig. II4). The process is illustrated in Figs. 157-160 from embryos of 12 millimeters to 70 millimeters in length. These sections are preparotid in position and show, accordingly, a region of the restibule where the dorsal component of the cheek tends to equal or exceed that derived from the floor. It is evident that the lateral wall of the vestibule is formed by the elevation to a vertical position of the regions lying between the alveobuccal and the buccal sulci, and that in consequence of the unequal extent of these regions in the roof and floor of the mouth, their contributions to the cheek must be unequal. In fact, the greater part of the latter is formed at the expense of the floor, as Chievitz was the first to demonstrate. This is true, however, of the caudal portion of the vestibule only. Craniad, in consequence of the ventral inclination of the buccal sulcus, the roof forms an increasing proportion of the 
cheek, until near the angulus its share exceeds that of the floor. Our concern is with the caudal and intermediate regions, and here the cause of the greater contribution of the floor is apparent in the greater distance between the buccal sulcus and the inferior alveobuccal sulcus as compared with the superior. This is but an expression of the

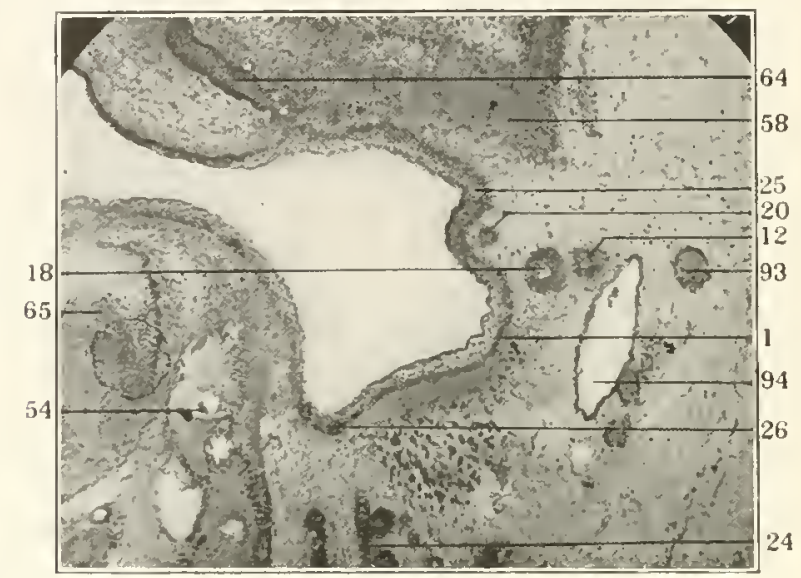

Fig, iro. Frontal section through the orbitoparotid inclusion (18) in its region of greatest diameter in the 5 I millimeter embryo. Columbia Collection, No. 10.4, $\times 1$ I 5 , reduced to $\frac{1}{2}$.

I. Buccal sulcus.

12. Parotid duct.

18. Orbitoparoticl inclusion.

20. Duct of first orbital gland.

2.7. Inferior alveobuccal glands.

25. Superior alveobuccal sulcus.

26. tnferior alveobuccal sulcus.

54. Inferior maxillit.

58. Zygoma.

64. Supcrior dental anlage.

65. Inferior dental anlage.

9.3. Facial nerve.

94. Facial vein.

greater general expansion of the floor as contrasted with the roof of the marginal cavity, as is shown also by the earlicr disruption of its epithelial thickening, and the earlier appearance of its dental anlage 
and alveobuccal sulcus. In the roof growth in the maxillary process is accelerated mesad and results in the palate process. The corresponding region of the mandibular process gives rise to the lateral tongue swellings, and these gain a mesal position with reference to the palate processes, which thus become fixed and offer resistance to the expansion of the roof of the maxillomandibular planes. An equal obstacle to its lateral extension is afforded by the presence of the mandibular nerve and quintus musculature. In these circumstances the trinsverse growth of this region is impeded in the roof; its epithelial thickening long retains its continuity, and the several anlages on their appearance are erowded together; further, the periphery of the plane is sacrificed as the orbital inclusion. Craniad of the masseter space is gained, and near the plane of the anguli, the palate process deviating mesad and becoming small, more farorable conditions obtain. Here the separate anlages first appear and are widest apart, converging and blending as they are followed caudad. An idea may be formed of the relatively enormous and rapid expansion of the floor, when we reflect that the palate processes and lateral tongue swellings, being mesal portions respectively of the maxillary and mandibular processes, are in this sense equivalent regions, and that their lateral borders, the lingual and ectopalatine sulci, are to this extent equivalent lines. From both a primitive epithelial thickening extends to the buccal sulcus. Its earlier resolution into separate anlages ventrally and their greater size appear correlated to the rapid expansion of the region, while the more lateral position of the dorsal elements and their nearness to the buccal sulcus depend upon the lateral position taken by the palate process with reference to the tongue swelling. With the closure of the palate a readjustment is permitted, and then the dorsal elements come to lie more nearly opposite their ventral equivalents, though retaining even in the adult a slightly ectal position, most clearly seen in the relation of the teeth.

As a consequence of the greater expansion of the ventral region and its greater proportional contribution to the vertical wall of the vestibule, the parotid is shifted dorsad, and this would be the case even were its fundal position retained. While no doubt this is the main cause of the displacement of the parotid two minor factors require consider- 
ation: first, the assumption by the anlage of a parietal position and, second, the direction of its keel of proliferation.

In the 15 millimeter embryo (Figs $75^{-78}$ ) the parotid still retains in its flange a remnant of the buccal sulcus in the form of a minute fissure. Ventral to the flange there is a minute bulging of the oral epithelium. This increases slowly and, deepening laterad in the embryo of 20 millimeters (Figs. $89^{-} 93$ ), has come to form the lateral border of the marginal cavity. Attention has already been called to the similarity of the process to that at work in the displacement of the orbital inclusion. The formation of the new fundus is the result of unequal growth in the walls of the sulcus, and as a consequence funclal structures are displaced to a parietal position. For convenience we may term the new sulcus subparotid. In the 20 millimeter embryo it has deepened to such a degree, that the parotid attachment has come to lie midway between it and the superior alveobuccal furrow, a position retained in the 25 millimeter embryo, while in those of 28 and 3 I millimeters, it is nearer the last-named sulcus. The displacement, which is dorsomesal along the sloping roof of the maxillomanclibular plane, becomes dorsal when the vertical cheek is formed.

That the advance of the keel of the paroticl along the oral epithelium assists the dorsal displacement of its orifice is highly probable. The proliferation keel extends craniad in line with the border of its flange. This line intersects that of the buccal sulcus at an acute angle, so that its production craniad diverges from the ventrally curving sulcus. As the paroticl advances, therefore, it deviates from the sulcus dorsomesad. The degree of shifting attributable to this factor apjears to be extremely small.

In the 25 millimeter embryo the region of the parotid attachment is slightly convex towards the oral cavity. In the embryo of 30 millimeters the convexity has increased and lengthened to form a sagittal ridge limited dorsad by the superior alveobuccal sulcus, and ventrad by the subparotid sulcus, a mere angle here in the caudal portion of its extent. In the 51 millimeter embryo the ridge extends from the parotid orifice to the region of the orbital angle. Upon it open, in addition to the parotid, the ducts of the three orbital glands, from which circumstance it may be termed the stomal ridge. The subparotid sulcus is still a mere angle, and has ceased to be continuous 
craniad with the remnant of the buccal sulcus, which is confined to the postangular portion of the vestibule. In the 70 millimeter cmbryo the stomal ridge is better defined, and at its rentral limit the subparotid sulcus has deepened to a well-marked furrow (Fig. I14).

The Sprout of the Parotid. - The inception of this sprout has already been described in the embryos of $12.5^{-1} 3.5$ millimeters. The dircction of its distal growth is determined first by the position of the flange and later mainly by the masseter muscle. The flange is itself ventrolaterally inclined and, broadening caudad, causes its free border to diverge caudolaterad from the buccal sulcus. The growth of the sprout is in the resultant of thesc directions, ventrad, caudad, and laterad. In embryos of 14 and 15 millimeters (Figs. 4i, 43-45) the bud is retort shaped with a gradually lengthening neck; its direction is dominantly ventrad. It is first in relation with the facial vein, which is grooved dorsad to receive it. About it is a plexus of capillaries connected with the rein, which dorsad communicate with the opthalmic vein through the deep facial vessel. While both limbs of the plexus contribute to this connection, the communication in the earlier cmbryos ( $I_{3}-I_{5}$ millimeters) is freest on the lateral aspect of the parotid. In later stages the mesal loop is cnlarged and the lateral loses its connection with the orbital vessels. The deep facial is formed mesad of the duct, while the lateral capillaries are organized into the superficial facial vein. This condition is established in embryos of $16-17$ millimeters, and is retained in the adult, where the duct passes between these ressels, but separated from the deep facial by the border of the masseter. The topography of the proximal segment of the duct is shown in Figs. roo-ror.

In the most advanced of the 15 millimeter embryos the cnlarged fundus has passed beyond the facial vein and reached the sloping border of the massetcr. From this point its growth has a very definite path, which the sprouts of the various embryos follow, apparently without deviation, but at quite unequal rates. An idea of the difference in size, which may obtain between parotids in cmbryos in which the other oral derivatives are of corresponding development, may be gained by a comparison of the two 15 millimeter embryos figured (Figs. 44, 45). Similar discrepancies are present in all stages, sometimes even on the two sides of the same embryo. No attempt has, 
therefore, been made to establish a rigid chronology of the growth of the sprout. The path followed extends along the sloping border of the masseter nearly to its ventral limit. Just before reaching this, howcver, it turns to the lateral surface of the muscle near, but not actually at the ventral margin. It now grows horizontally caudad until the caudal borcler is reached. Here the secondary branches are directed dorsad as well as caudad towards the cartilage of the external auditory meatus. This position of the duct may be termed inframuscular, the definitive position in ungulates.

The surface of the masseter where the cluct lics against it is faintly grooved. About the enlarged fundus of the bud the mesenchyme is slightly thickened and shows a concentric arrangement of its elements. After the sprouts of the second and third order have appeared, a very slight change of like nature can be observed about them, and the same is true of late stages when the branches have become numerous. The degree of thickening is so small that with a low power the branches seem to lie free in an almost unattered mesenchyme, in marked contrast to those of the submaxillary and greater sublingual gland, which are surrounded by a conspicuous and well-circumscribed condensation. In part this may be explained by the relatively small bulk of the parotid, which markedly lags behind the submaxillary in development, but it can hardly be entirely so accounted for. In the adult the parotid has a far looser structure and lacks a capsule in the strict sense of the term.

The secondary sprouts appear as small knoblike irregularities of the surface of the enlarged extremity of the primary bud. They are regularly present in the 18 millimeter cmbryos, when the growth has reached the sagittal midthird of the muscle. In some of these the secondary sprouts have attained a length of $20-40 \mu$. These branches are not numerous ( $5-7)$; they are directed at first caudad, continuing the line of the duct. In a few cases in which they were studied they were found to vary in number and arrangement, not only from embryo to embryo, but from sicle to side of the same embryo. In the 25 millimeter embryo the branches are retromasseteric and pointing dorsad towards the ear.

Recurrent branches of the parotid were present in two embryos, arising from the anlage of the duct inmediately in front of its division. In the 20 millimeter embryo, No. $8_{3}$ (Fig. 104, 99), on the left side a 
solid slender branch was directed mesad, craniad, and slightly ventrad, from the mesal side of the duct, close to the border of the masseter, as though seeking its ental surface. A short distance craniad a second small sprout was found, also directed mesad. Both arise in rełation to the cranial third of the muscle. In embryo No. I +4 , of 3 I millimeters length (Fig. 105.99), again on the left side, two recurrent sprouts are present. They are subequal and solid, scarcely enlarged at their extremities, and arise close together from the ventromesal aspect of the paroticl duct, opposite the middle third of the masseter. They correspond both in their relation to the masseter and to the parotid duct to the variant ventral accessory lobules of the adult cat (Part $\mathrm{V}$, Fig. 5, 6, 7).

The duct gradually changes its inframuscular for a transmuscular position. The proximal segment of the duct is first affected. In the 25 millimeter embryo this has a straight course from the mouth to the border of the masseter, which it crosses near the junction of its lower and middle thirds. From this point it inclines ventrad in a gentle curve. In the 35 millimeter embryo (Fig. 106) the duct has a longer straight segment, which extends a little obliquely over the first third of the muscle, crossing about halfway between the dorsal and rentral borders. It then curves ventrad; its branches are retromasseteric, the lowermost at the level of the ventral border of the muscle. The duct is straight, but slightly inclined ventrad in its whole course in the embryos of $5 \mathrm{I}$ and of 70 millimeters, and placed nearer the dorsal than the ventral border of the muscle.

The masseter has increased its sagittal dimensions markedly during this process, and no doubt its lengthening may play a rôle in taking up the slack in the duct, but from the nature of the displacement of the duct, which is progressive craniocaudad, it would seem that changes in the general topography of the region, perhaps associated with the development of the alveolar processes and the consequent modifications of the cheek and masseter, must be reckoned with as factors in this change of level.

Throughout development the duct presents a pale center in section; here the cells stain faintly, and have pyknotic nuclei. Their pallor increases in later stages and often simulates a lumen. When an actual lumen is formed, these cells disappear. A lumen is present 
in a portion of the duct in embryos of $3 \mathrm{I}$ millimeters. In the 34 millimeter embryo it extends from the orifice into the primary branches. In this embryo the lumen is continued to the surface of the oral epithelium by a channel, among the cells of the stratum corneum, but lacking an intrinsic wall. It is difficult to see how such a passage should form save under the influence of the flow of fluid. As the epithelium of the gland shows no histogenetic changes and its burls are solid, the only obvious source of such a fluid is the liquefaction of the central cells.

\section{TIIE URBITOPAROTID INTERVAL AND ITS DERIVATIVES}

Between the parotid anlage and the orbital inclusion a segment of the buccal sulcus more or less completely escapes inclusion in the folds of these anlages; this is the orbitoparotid interval (Fig. 163. 15). With the separation of the orbital inclusion its caudal boundary is lost. It is desirable, however, in view of variant sprouts which appear in the course of the buccal sulcus, to distinguish between the region where the sulcus is obliterated to form the inclusion, and the portion which escapes folding; in other words, between the secondary buccal sulcus and the orbitoparoticl interval. The late embryonic and adult conditions of the furrows (Fig. I65), when the secondary buccal (I a) is directly continuous with the alveobuccal sulcus (25) without point of demarcition, and further the obliteration of the greater part of the buccal sulcus in the remorleling of the vestibule, efface the early landmarks, and render impossible an exact determination of the caudal limit of the interval. The sprout of the first orbital gland, which appears shortly after the separation of the cranial process of the inclusion, which, for reasons to be given later, is with a high degree of probability to be assigned to the secondary buccal sulcus, is yet so near the cranial extremity of that furrow as to make it possible that it is itself a derivative of the orbitoparoticl interval. In these circumstances the error in taking it as the approximate caudal limit of the interval is small. The interval becomes, therefore, in stages subsequent to the separation of the inclusion, the sagittal distance between the parotid and the first orbital sprout. Still later the orbital sprout arlvances by the formation and constriction of a keel at the expense of, and encroaching upon, the interval; its duct comes to have a proximal segment of 
secondary formation parallel to the oral epithelium and lodged in the stomal ridge, and a distal portion, the product of its sprout, which is dorsally directed towards the orbit. The change of direction corresponds to the site of the early sprout, and should strictly be taken as the caudal limit of the interval, which, therefore, in the adult corresponds to the stomal ridge, from the parotid orifice caudad to its termination. The ventrolateral limit of the ridge is a furrow, the persistent sulpparotid sulcus, while the ridge itself, occupying the interval between the superior alveobuccal sulcus and this furrow, corresponds in position to the obliterated portion of the buccal sulcus. In late periods of development (70 millimeters and later) it becomes the site of diffuse gland formation, as does also the subparotid sulcus. In the adult the orifices of these glands are occasionally visible with a lens, but their bodies are hardly more than microscopic. They appear, further, to be highly variable. In view of their late appearance and simple development they have been considered as diffuse glands, and as they are not associated with the buccal sulcus, but formed after its reduction, they have been distinguished from the orbitoparotid sprouts proper, which are sulcal in origin and early in development. In the adult they open upon the stomal ridge between the parotid and the first orbital gland, and in the line connecting their orifices. From the standpoint of its derivatives, therefore, the interval is chiefly interesting in this segment, for here alone are variants developed early, here alone do they obtain cven moderate size, and here also they may lose their connection with the oral epithelium, or that of the parotid, and become included in the mesenchyme. The smaller, more caudal derivatives, as well as by their secondary position the first three orbitals, represent a link and largely efface the distinction between the derivatives of the superior alveobuccal and those of the buccal sulcus, so that here the elements of the two furrows come into actual juxtaposition, and may form a gland mass (zygomatic or facial "gland") usually of minute proportions, but which, nevertheless, in the adult presents the same possibilities of confusion and the same difficulties of interpretation, on other than embryologic grounds, as the massa sul,lingualis of man.

The orbitoparotid interval, thus defined, appears first in embryos of 12 millimeters, with the establishment of the parotid flange at the 
postangular bend. This is but a short distance craniad of the orbital angle where the orbital fold is still adrancing; the sagittal segment of the buccal sulcus is extremely short, and the interval between the two folds, which are as yet incomplete, is correspondingly minute and tends to be encroached upon by the folds. Nevertheless, in the lessdeveloped embryos of this stage (Nos. 100, 107, 217) it is present, and has a length varying between 27 and $50 \mu$. Here the sulcus, while presenting in section a high degree of angularity of the ental contour of its fundus and an appreciable narrowing of its lumen, is not actually reduced to a fissure, nor is a flange present, until the tapering cranial process of the inclusion is reached. In embryo No. 78 the parotid on the right side is a flange $100 \mu$ in length, increasing to a maximum and as gradually diminishing in breadth; a minute fissure indents its base which, deepening and widening craniad and caudad, reduces the flange and restores the lumen of the buccal sulcus. An interval of $60 \mu$ separates the flange from the orbital inclusion. On the left side the parotid has the same structure, with the difference that caudad the flange, while reduced in width, is not wholly lost, but extends into continuity with the orbital inclusion. Here we have an early example of what has been termed the orbitoparotid bridge, a condition occurring as an unusual variant in embryos between 12 millimeters and I $_{5} .5$ millimeters in length (Fig. .4). In embryo No. 263, the most advanced of the embryos rated at I 2 millimeters, a similar bridge is present on both sicles. These embryos, as has been pointed out. form a small series illustrative of the early condition of the parotid and consequently of the orbitoparotid interval. In the less advanced (Nos. I00, 107, 217 ) the interval is present; its absence in the older embryos (Nos. 78 one side, and 203) is, then, a secondary condition due to the extension of the folds at a rate exceeding that of growth in the sagittal segments of the buccal sulcus. The primitive independence of the parotid is further shown by the shape of its flange, which, broadening to a maximum, undergoes a decline towards the interval, so that even in cases where this is bridged and the parotid is continuous with the orbital inclusion, it cannot be interpreted as a simple extension of the latter fold, but appears distinctly as an added or annexed element. The orbitoparoticl interval is, therefore, a residuum of unfolded sulcus, tending from the first to be encroached upon by its limiting folds, and regu- 
larly undergoing a diminution of length caudad proportional to the length of the cranial process. This boundary is, therefore, subject to fluctuating variation. Craniad, on the other hand, the interval gains to the degree that the parotid advances, its flange being destroyed in the process of freeing the duct. In cases where the reduction of the fold is not total, a remmant may be left attached to the buccal sulcus, in a position analogous to the postglandular flange of the submaxillary. This eventually disappears, but first may serve as a starting point of an orbitoparotid sprout.

Caudad the interval is limited by the cranial process of the orbital inclusion, until its separation from the oral epithelium takes place. This occurs in embryos ranging from 15 to 19.5 millimeters in length. During the period of its attachment the fold continues to advance, so that the length of the cranial process varies with the time of its separation. An attempt was made to determine the cranial limit of the orbital fold in embryos between 16.5 and 21 millimeters. For this purpose the only available and not wholly satisfactory landmark is the deep facial vein. This is, relative to the region in question, a large structure, and has the further disadvantage of undergoing a shift caudad during development, but this is very slight in degree during the period here in question. The difficulty of its size may to some extent be overcome by dividing its total width at the level of the sulcus into halves. Four positions of the tip of the orbital inclusion may be distinguished with reference to the vein, prevenous, venous I. II, corresponding to the cranial and caudal halves of the vein, and postvenous. The attached and free processes are tabulated separately.

TABLE I

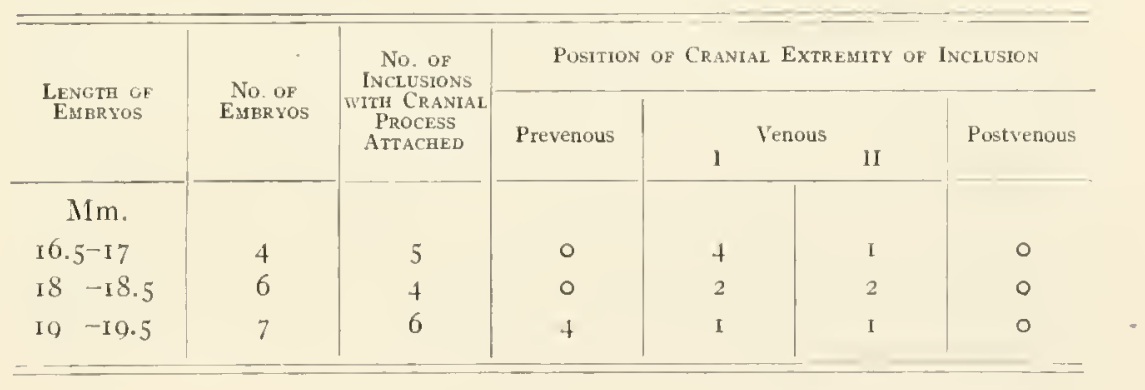


TABLE II

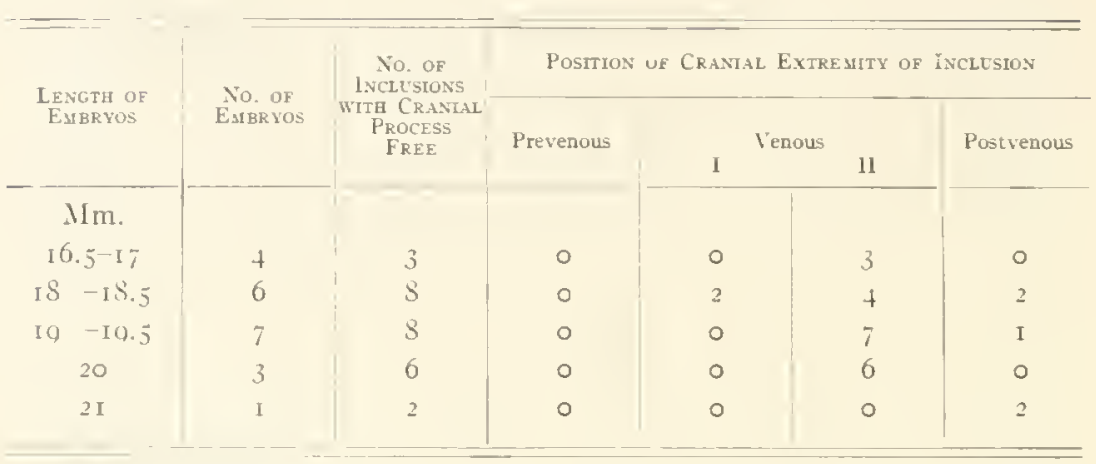

From the first table it is apparent that the orbital fold regularly advances to the plane of the deep facial vein, and in a majority of cases to its cranial half, while in the larger embryos in which the attachment is retained it has a decided tendency to advance beyond the vein. The maximum of advance is attained in the 19.5 millimeter embryo (No. 277). where the attached tip of the inclusion is at the level of the border of the masseter, only $57 \mu$ caudal to the parotid, while the distance from the parotid to the deep facial vein is $267 \mu$.

In the second table it is seen that a large majority of the free inclusions also extend to the plane of the rein, but that as development proceeds they tend to assume a postvenous position (embryo of 2 I millimeters). This is true of the late stages of the inclusion also. A long and tapering cranial process is characteristic of the inclusions which extend to the cranial half of the vein or farther, whether free or attached, while in those of postvenous position the process is rudimentary. It is possible that the position and shape of the process may in some cases depend upon a premature separation, before the fold has made any considerable advance. In the 15 millimeter embryo (No. 216) the cranial process is short, but already constricted, at its junction with its flange (Fig. 45) and evidently on the point of separation. On the other hand, the inclusions may, and probably do in many cases, shorten after separation, either by retraction, or by reduction of the cranial process. If embryos of the same length are compared in the two tables, the attached inclusions in general are found to extend farther craniad than those that are free. In many of 
DEVELOPAENT OF SALIVARY GLANDS IN TIE DOMESTIC CAT 253

the embryos where the inclusions are free, a remnant of the flange may be found attached to the buccal sulcus opposite the cranial half of the vein or in a prevenous position. Evidently the fold has been of average length, but the inclusion after separation has shortened. The rate at which this is accomplished gives ground to infer that the inclusion is really under some tension from growth of the sulcus, to which it is attached only by its extremities. This may also be a factor in its ventral displacement during this period. In the 2 I millimeter ambryo the cranial process is already rudimentary and separated by an interval of $107 \mu$ from the vein; in older embryos it can scarcely be said to be present, the inclusion terminating with a rounded knob, the pars lata, near the orbital angle.

It thus appears that the middle of the deep facial vein is passed by the majority of orbital inclusions, and that the postrenous position, while possibly in some cases primary, is, as a rule, acquired by reduction of the cranial process. The vein may, therefore, serve as the normal caudal limit of the orbitoparotid interval, subsequent to the separation of the inclusion and until the sprout of the first orbital is formed. This sprout at its inception is found in the plane of the deep facial vein, but in all of our material lies craniad of the tip of the orbital inclusion. The time of its appearance varies; it may be present in embryos of I8.5 millimeters, but may be absent even as late as in 20-2 I millimeter embryos. It is clear that the sprout is situated close to the junction of the secondary buccal furrow with the superior alveobuccal, but it is hardly possible, and perhaps hardly desirable, to make a definite assignment of it to either. In one or two cases when the sprout was present, the sulcus of the interval showed a slight flange prevenous in situation. If this could with certainty be interpreted as a remnant of the flange of attachment of the cranial process, the orbital sprout would have to be assigned to the secondary buccal sulcus. But the flanges in question may equaliy well be ascribed to a remnant of a previously complete orbitoparotid bridge, or even to the postglandular flange of the parotid.

If the deep facial vein be taken as the average caudal limit of the interval, the cases of prevenous extension of the inclusion must be considered as encroachments upon its territory on the part of the orbital fold which, as has been stated, may advance within $57 \mu$ of the parotid. 
In a very small minority of cases the folds are continuous and the interval is effaced by an orbitoparotid bridge. This has already been described in the 12 millimeter embryos. It was found complete but five times in our material; the oldest embryo in which it was retained intact was 15.5 millimeters in length. In embryo No. 127 an almost complete bridge is interrupted close to the parotid by a small incisure (Fig. 43). Cases in which the lumen of the buccal sulcus is reduced in the whole extent of the interval, but without the formation of a - flange, are more frequent. In these the lumen is fissurelike, the fundus markedly acute, and frequently (leflected ventrad (Fig. 56). For the rest there is regularly a marked angularity of the fundus of the sulcus over part or the whole of this segment, suggesting a tendency to a fold. In length, in the degree of folding, in the presence of incomplete keels, and the formation of sprouts, the intervals vary widely and are frequently asymmetrical. In this respect almost every embryo has an individuality of its own.

While the two folds of the buccal sulcus, the orbital and the parotid, are from their inception separate and only rarely become continuous, there is yet evidence to show that this independence has been derived from a more primitive condition, where a continuous fold involved the cranial as well as the caudal segment of the buccal sulcus. The slender rodlike condensation of the mesenchyme ventral to the floor of the maxillomandibular plane, extends in embryos of 12 millimeters from the angulus oris to the orbital angle. Corresponding to it the epithelium of the floor is elevated to form a rilge parallel to the buccal sulcus, which extends to the postangular bend, usually not quite to the border of the masseter. The condensation in the mesenchyme gradually becomes indistinct and is lost, but can in the majority of embryos of $14^{-3} 5$ millimeters still be recognized between the parotid flange and the cranial process of the inclusion; occasionally it persists in a part of its course in embryos of $17-18$ millimeters. In the cases where an orbitoparotid bridge was formed the condensation was well marked. There is further a continuous epithelial thickening along the fundus of the buccal sulcus in its whole extent. This becomes incorporated in the folds of the parotid and of the orbital inclusion. In the interval it is gradually thinned, but is not wholly lost until after the separation of the cranial process. 
While the material and the means of forming a continuous fold are thus present, we are naturally led to seek the occasion of its interruption. This, I believe, is to be found in the space requirements of the masseter muscle. Its anlage is a condensation in the mesenchyme shield-shaped in section (Figs. $36-38,73$ ) and at first continuous with that of the zygoma. In embryos of 13.5 millimeters the myoblasts can be distinguished and begin to be separated by a line of less dense tissue from the fibroblasts of the latter. The ental surface of the masseter is nearly sagittal in direction, at least from the orbital angle craniad. The dorsal border is approximately horizontal. To it the cranioventral or sloping border, which is broad and rounded, ascends obliquely, with the result that the muscle has a tapering extension along the zygoma. This border crosses the buccal sulcus in the orbitoparotid interval. Here, also, the muscle comes closest to the sulcus, which, from the orbital angle to the postangular bend, has a straight course, nearly sagittal, but with a slight lateral deviation, while from the postangular bend to the angulus oris the sulcus is obliquely transverse (Figs. 35. 97). The sulcus is then passing craniad of the border of the muscle with a lateral sweep, at the point where the latter ascends dorsal to it. The tapering prolongation of the masseter along the zygoma lies dorsal to the maxillomandibular plane in the region of the parotid (Figs. 5I-55). The approximation of suicus and muscle is here also appreciable in the region of the interval (Figs. 56-57). It must be borne in mind that at the stage we are considering, $12-13.5$ millimeters, the sagittal segment of the sulcus is still short, the folds separated only by a minute interval (Figs. 31, 34), which markedly increases in succeeding stages (Figs. 4I, 43-45). That the muscle is close enough to make its presence felt upon the sulcus through the intervening mesenchyme, is shown by the ventral deflection of the parotid flange, of the orbitoparotid bridge when present, and of the cranial prolongation of the orbital inclusion itself.

The anlage of the masseter, as of the other muscles of mastication, defines itself close to the trunk of the mandibular nerve and thence extends craniad, overlapping more and more of the buccal sulcus as it does so. The direction of growth being sagittal, the muscle is brought into more intimate relations with the laterally diverging sulcus as it advances, and a juxtaposition of its sloping border with the 
orbitoparotid interval is established in embryos of $\mathrm{I}^{-1} 3$ millimeters. At this period the parotid fold is established, and the orbital fold is still confined to the region of the orbital angle. The sagittal segment of the sulcus now lengthens, but the muscle maintains its relative position. The orbital fold continues to advance, diminishing in breadth towards the border of the muscle, where in the large majority of cases the process comes to a stop, and the orbitoparotid interval gives rise to no fold. In the embryos of our series of the period of 10.5 to 19 millimeters, in which the advance of the fold attains its maximum, not one inclusion extended beyond the border of the muscle, and only in a single instance to that point. The factors favoring and impeding the extension of the fold over the orbitoparotid interval must be balanced with some nicety, for in many cases an imperfect bridge is here formed, and the influence of the masseter suffices only for the ventral deflection of the flange or fold and not its complete suppression. The variations may well depend upon slight differences in the rates of advance of the fold or muscle, which latter may fail to come within acting distance until a flange is already present, in which case it can only deflect it ventrad and slowly cause its reduction, instead of primarily inhibiting its formation. As the masseter is a mammalian neomorph, the fold, the development of which it impedes, must be referred to promammalian forms. It is present both in the embryo and adults of the lizard and turtle as an open. foldlike extension of the oral cavity laterad and dorsad towards the muscles of mastication, with which it establishes intimate relations, while into its roof open the cauclal members of the series of superior labial glands.

\section{THE ORBITOPAROTID GLANDS}

Orbitoparotids are sprouts derived from the buccal sulcus between the parotid and the orbital inclusion, or in the case of older embryos between the parotid and the first orbital anlage. They are usually of small size and confined to the triangle, bordered mesad by the oral epithelium, laterad by the parotid, and caudad by the masseter. A very few tend to enlarge beyond these narrow contines, passing toward the lateral or mesal surface of the muscle. Those that do not attain so large a size may yet, within the triangle, manifest a definitive se- 
lection of one or other of these lines, following either the parotid duct along its mesal surface or else, directed caudad close to the oral epithelium, seck the orbital path. A very few, to be considered in detail, seem to vacillate between these alternatives. A large majority follow the parotid, as the orbital path appears to be unfavorable on account of its contracted limits and the long distance that must be traversed, before room for expansion can be found. As regards the attaclument of the sprout there are three possible sites: viz. the angle between the parotid and the oral epithelium, the parotid duct, the oral epithelium itself. The element in a few cases loses its connection altogether and is found embedded in the mesenchyme as an orbitoparotid inclusion.

In 69 embryos between I 2.5 and 70 millimeters, counting each side separately, the orbitoparotid element was found 49 times, as follows:

From the angle between the parotid and the buccal sulcus, 13 .

From the parotid duct, 5 .

From the buccal sulcus, 26.

As an inclusion, 5 .

In the younger embryos the sprout is regularly at the angle between the parotid and the oral epithelium, springing from the intermediate portion of the parotid flange. After 14 millineters this condition is rare. Its latest occurrence is at 19 millineters. When we consider that the parotid attachment advances craniad, and that the duct is freed by a reduction of the intermediate portion of the flange, it is evident that a sprout cannot long retain this position, but must either be carried laterad with the duct or left behind as the parotid advances if it retains its connection with the buccal sulcus. In its earlier stages the orbitoparoticl is simply a thickening of the intermediate portion of the flange, not yet extending free into the mesenchyme, as, for example, in the I 3.5 millimeter embryo (Figs. 34, 40). In slightly older embryos it forms a minute projection caudad for a section or two, as in the 15 millimeter embryo of Fig. 45. In embryo No. 127 (Fig. 43) may be seen the mode in which this position is lost. The orbitoparotid bridge is interrupted by a narrow oblique incisure close to the parotid, leaving a slightly thickened portion of the flange attached to the parotid. In the fragment remaining attached to the sulcus we have the possibility of a second sprout, realized only once in our series in embryo No. 249 of I8.5 millimeters (Fig. 99). Of the two cases of 


\section{DEVELOPMENT OF SALIVARY GLANDS IN THE DOMESTIC CAT}

late retention of the angular position, occurring in 19 millimeter embryos, one is evidently a condition of late origin. Nuch of the intermediate portion of the flange has been lost, but the narrow fragment remaining is not flat and compressed, as is usual, but of convex outlines. There is no free sprout. In itself the section is not convincing, but in view of the fact that just this appearance is constant in cases where a free sprout is attached to the flange, it must be considered as an orbitoparotid in its inception. It is interesting to note that Chievitz figures the attachment of the parotid in one of his human embryos with this enlargement of the intermediate portion of the flange. The second case occurs in embryo No. So. Here the orbitoparotid is large, $I_{40} \mu$ long, and extends along the mesal side of the parotid duct as far as the facial vein, in the gutter of the dorsum of which it rests. The position of the attachment can only be accounted for by supposing that the orbitoparotid has been able to advance at the same rate as the parotid itself. The supposition is not difficult, for frequently the orbitoparotid is keeled, and sometimes the caudal sections of the keel are constricted at their base, repeating in miniature the later stages of the parotid attachment.

The attachment to the parotid duct is infrequent. It is always to its mesal side and, within the proximal third of the promasseteric segment of the duct. These elements tend to take a course midway between the parotid and the buccal sulcus (Fig. 99) a direction which, if continued, would cause them to abut directly upon the broad border of the masseter. None of them is large enough to do this, and the position would seem to be an unfarorable one for development. Exactly how far caudad an orbitoparotid can take origin from the duct cannot be determined. Chievitz reported a case in man where the cranial process of the orbital inclusion (his entomasseteric duct) was continuous with the parotid at the border of the masseter. Similar connections have been reported by Elizabeth Weishaupt in the pig, and are present in one pig and one cherrotain of our series. Had an orbitoparotid spruut of angular position been present in one of the embryos, it would have been attached to the parotid duct at the junction of its promasseteric and transmuscular segments. Evidently, therefore, the range of the orbitoparotid extends over the whole promasseteric portion of the duct. On the other hand, efllorescent lobules may 
involve the whole transmuscular portion (Part V, Fig. I3). In view of these facts a sharp distinction can hardly be maintained between the accessory parotid lobules and orbitoparotids draining into the main duct, while the latter through the sprout of angular position are serially continuous with those that arise from the oral epithelium in the course of the orbitoparotid interval.

These constitute the third class of orbitoparotids, which are by far the most numerous in our series and the only ones present in embryos of more than 20 millimeters length, although in the adult representatives of the other types are found occasionally (see Part V, p. I64). They are most numerous close to the parotirl, not infrequently as far caudad as the middle of the interval, rare in the third quarter, while none was observed in the fourth. They are frequently attached to small crests, but whether these are remnants of the orbitoparotid flange or proliferation keels cannot in individual cases always be determined. Some certainly are remnants of the flange, being pointed at their distal extremity and constricted at the attachment of the sprout. Others are rounded at their free margin and constricted at their attachment only in their caudal sections. That these are keels of proliferation and serve to advance their sprouts seems probable, from the retention of the angular position in embryo No. So and the greater frequency of the element in the cranial half of the interval even in late stages. The keels vary in length from 27 to $80 \mu$. The sprouts may follow either the parotid or the orbital path, the more cranial inclining to the former, the more caudal to the latter direction of growth. From the greater frequency of the cranial position the parotid line is far the more usual. In two cases what looks to be a sort of vacillation on the part of the sprout occurs. In embryo No. 252 of I 9 millimeters, a sprout arising from the oral epithelium a short distance caudad of the parotid approaches that duct until no mesenchyme can be seen between them, but bends mesad in its caudal segments towards the buccal sulcus without, however, coming very near it. An interesting case occurs in the 70 millimeter embryo on the left side (Fig. I 7). Arising from the stomal ridge midway between the parotid and first orbital orifices, the sprout extends caudad as a solid slender rod of cells for a distance of $420 \mu$, diverging very slightly from the oral epithelium. It lies laterad to the first orbital duct, extending beside it to a point $\mathrm{s} 20 \mu$ caudad of the 
border of the masseter, where it terminates without enlargement. At the border of the muscle it gives off laterad a large retort-shaped bud,

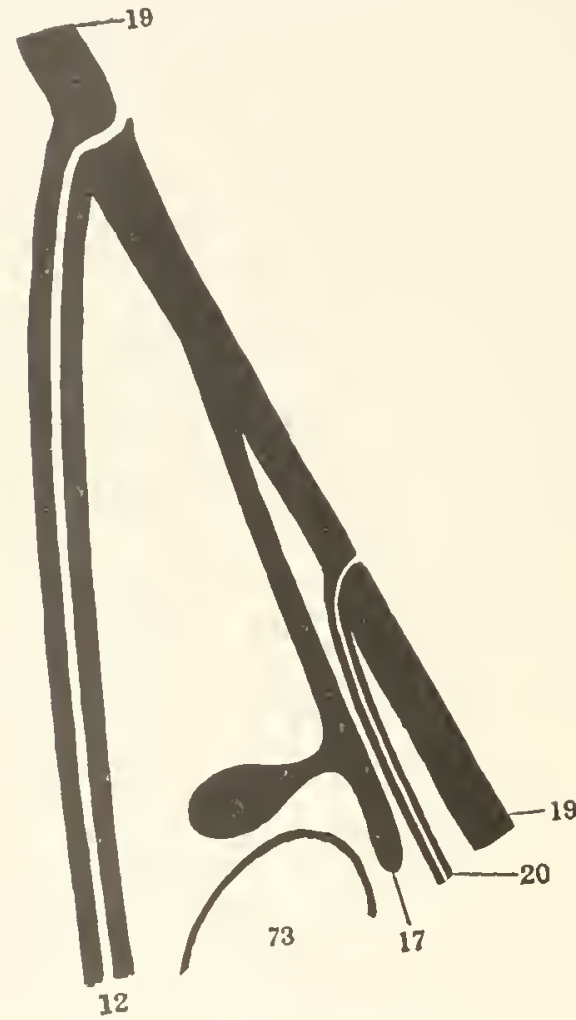

Fig. II7. Graphic reconstruction of the orbitoparotid element in the 7o millimeter embryo. Columbia Cullection, No. 27o.

12. Parotid duct

77. Orbitoparotid anlage.

Ig. Epithelium of stomal ridge.

20. First orbital duct.

73. Masseter muscle. which lies close to the muscle, projecting horizontally at right angles to the direction of the cell cord from which it arises. Here it would seem as though the orbital path had been tried and abandoned in favor of the freer ectomasseteric course.

This obitoparotid is the largest in our series. In general the length of the sprouts is far less than this, varying between $\mathrm{I} 3 \mu$ and $80 \mu$ as a rule. The largest of those taking the ectal path along the parotid occurs in embryo No. 21 of the Princeton Collection (Fig. 97, 17). Here on the right side it extends to the masseter, following its sloping border almost to its veutral limit. It lies directly in the line of the border, deviating neither mesad nor laterad. It has a length in the sections of I $80 \mu$.

The orbitoparotids in general stain deeply and resemble the basal cells of the oral epithelium. Some show a faint pallor of the center, which, it is to be presumed, is due to the same process as elsewhere in the salivary anlages. They are all cylindrical in shape and rarely show even a slight degree of enlargement of the tip, from which it niay be inferred that the process of 
DEVELOPMENT OF SALIVARY GLANDS IN THE DOMESTIC CAT 261

proliferation is not very active. Only the one described in the 70 millimeter embryo has a branch.

A few are constricted at their attachment to the oral epithelium. In a very few the constriction is completed, and the orbitoparotid, separated from the oral epithelium, lies isolated in the mesenehyme, and becomes an inclusion. Five cases were found in the embryos of our series.

The earliest is in the 18.5 millimeter embryo, No. 249, on the left side (Fig. 98,18 ). It is a smatl, cylindrical solid mass of cells, deeply staining throughout and placed elose to the buccal suleus, on the level of which it lies. Its cranial extremity approaches the oral epithelium, only a minimal quantity of mesenchyme intervening. Caudad the separation is somewhat greater. It is situated behind the middle of the orbitoparotid interval, which in this embryo has a definite caudal limit in the sprout of the first orbital gland. In its whole length it is promasseteric, that is. lies cranial of the plane in which the sloping border of the muscle crosses the buccal sulcus, which I lave termed the masseteric point. Reckoned by sections, its measurements are as follows :-

Length, $10 \mu$.

Distance from parotid attachment, $160 \mu$.

Distance from the masseteric point, $120 \mu$.

Distance from first orbital, Iо7 $\mu$.

Length of orbitoparotid interval, $277 \mu$.

On the opposite side of this embryo, in a nearly symmetrical position, is an orbitoparotid sprout constricted at its attachment and, in view of the condition just described, evidently on the point of separating from the oral epithelium (Fig. 99, I7).

In the 2 I millimeter embryo, No. 242, a slightly larger inclusion is present on the right side. This also is solid, but has a pale center, and tapers to a point caudad. It follows the direction of the buceal sulcus, close to which it lies, and is entirely promasseteric. Its dimensions follow:-

Length, $53 \mu$.

Distance from parotid attachment, $\mathrm{I} 60 \mu_{\text {。 }}$

Distance from masseteric point, $93 \mu$. 
In the 25 millimeter embryo, No. 147 , the inclusion is also on the right side, and has the same appearance in the sections. It is circular, deeply staining except for the pale center, and tapering caudad. In this embryo it lies near the parotid duct, the course of which it follows. Its measurements are :-

Length, $9 \circ \mu$.

Distance from parotid attachment, $225 \mu$.

Distance from masseteric point, I $65 \mu$.

In the 28 millimeter embryo, No. 408 , the inclusion which is on the left side tapers at both ends. It is solid with a pale center. It follows the line of the buccal sulcus, taking a course that, continued, would be parallel to the orbital sprouts; for $60 \mu$ it extends caudad of the masseteric point and lies under cover of the muscle. Its extremity is just craniad and slightly to the lateral side of the deep facial vein:-

Length, $100 \mu$.

Distance from parotid attachment, $280 \mu$.

In the 5 I millimeter embryo, No. 104, the inclusion attains its maximum size for our series. It is on the left side close to the parotid duct. the course of which it follows on its ental aspect. Its cranial extremity is blunt and inflated, containing a lumen for $60 \mu$ (Fig. 1 ro, $I \&$, page 242). Caudad it narrows abruptly, but is continued as a long, slender object, diminishing gradually to a point. In this portion it is rather poorly and diffusely stained, the cell outlines are indistinct, the nuclei are pale. Its dimensions follow:-

Length, $273 \mu$.

Distance from parotid orifice, $273 \mu$.

Distance from masseteric point, $147 \mu$.

It remains to consider the occurrence of these several types of orbitoparotid elements a little more narrowly in reference to the ages of the embryos in which they are present. The sprout in the angular position alone is found in embryos of less than I 5 millimeters. It does not occur in any of the series above 19 millimeters. If the series is divided into three groups on this basis, the results nay be tabulated as follows: 
DEVELOPHENT OF SALIVARY GLANDS IN THE DOMESTIC CAT 263

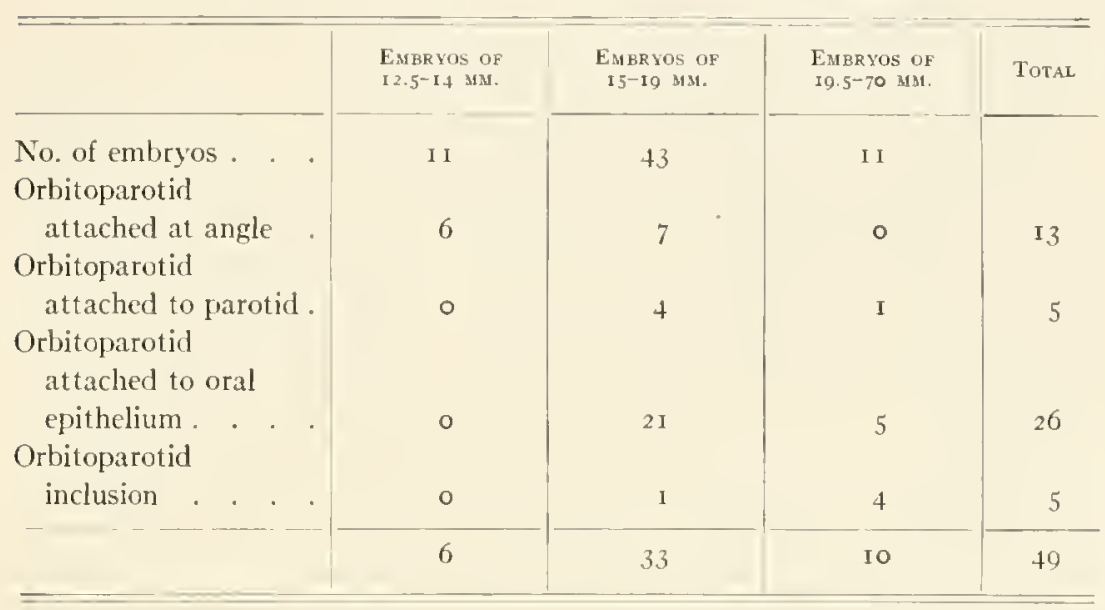

It so happens that the two smaller groups are almost one-fourth of the larger group in number. For purposes of comparison their number of sprouts may be multiplied by four without introducing an error greater than is inherent in the smallness of the series itself. On this basis the table is as follows:-

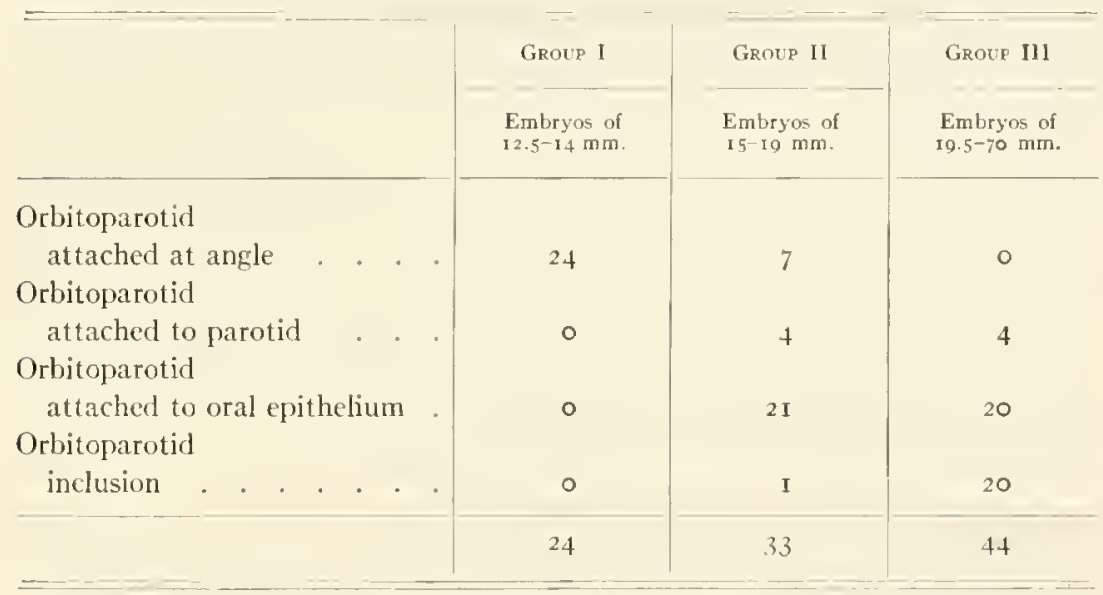

Compared thus, it is evident that there is a production of new sprouts not only in the intermediate embryos of group II, but also in the third group, making it probable that sprouts continue to be produced 
in later stages of development, which the frequency of orbitoparotids in the adult would indicate (Part V. page 164).

Turning now to the occurrence of the several varieties of orbitoparotids in the three groups, the first is seen to be wholly composed of those of angular position. That this is not the only site of the manufacture of orbitoparotids appears from a comparison with group II. For granted that the embryos of this group were equipped with twenty-four orbitoparotids at their entrance upon this period, and that the seven angular sprouts are all of new formation, an unnecessary concession, there are still two sprouts in excess, which cannot be accounted for by displacement of the original sprouts of group I along the parotid or along the buccal sulcus, and which, therefore, must have originated in one or other of these positions. The statistics of the third group strengthen this view. Angular sprouts are no longer formed, the intermediate portion of the flange having disappeared. And yet there is an excess of eleven elements to be accounted for. Further in this group a large number have been reduced to inclusions. In the adult no inclusion has yet been found, and again the proportion of orbitoparotids has increased.

It would appear, therefore, that orbitoparotid elements are formed during the late stages of development, as well as the early, and at an increasing rate. Their site is certainly the oral epithelium. The possibility of their formation from the parotid duct nust also be granted, for some of the inclusions of group III lave a parotid course, and yet the elements of this position have not decreascd proportionately. If the recurrent branches of the duct shall ultimately prove to be orbitoparotids, a high degrec of productivity must be conceded to this source. Of whatever nature they shall prove to be, a formation of these branches also in late periods of development must be taken into consideration, on account of their frequency in the adult.

\section{THE ORBITAL GLANDS}

The topography of the early anlages of these elements differs but slightly from that of the glands of the adult. It will facilitate the account of their development briefly to recapitulate the conditions in the adult, for the details of which the reader is referred to Part $V$. The 
DEVELOPMENT OF SALIVARY GLANDS IN THE DOMESTIC CAT 265

glandular mass of the orbit presents its base to the orat cavity in the mesal part of the triangle, between the masseter laterad, the internal pterygoid mesad, and the margin of the hard palate craniad. This area appears pale in cats in which the pigmentation of the epithelium is not excessive, the orbital gland mass and suborbital fat being here close to the transulcent mucosa. It may conveniently be termed the triangle of the orbital glands, although they occupy only its mesal half, the remainder corresponding to the delicate suborbital fat in which the glands are embedded. The massa orbitalis is composed of several elements which diminish in size caudad. Three are well developed in the cat and have ducts prolonged craniad in the mucosa to orifices considerably in advance of their respective bodies. These ducts pierce the buccinator to bend craniad into a course which carries them obliquely along the stomal fold, a ridge extending from the parotid orifice caudad to the tuberosity of the superior maxillary, where it turns mesad and caudad, diminishing in size as it approaches the triangle of the orbital glands, where it stops. The first duct opens close beside the last cusp of the carnassial, the second just behind the molar, and the third a very short distance further caudal, at the point where the deep facial vein crosses the lateral angle of the triangle of the glands. It is, then, the third orbital which in the adult corresponds to the vein; in this point the embryo presents differences which are described below in detail. Between the orifices of these larger orbital ducts a few minute mucous glands open along the ridge. All of the ducts open laterad to the internal pterygoid and are, therefore, to be assigned to the vestibule, and in particular to its short postdental portion, which by reason of the obliquity of its lateral wall is narrowing rapidly toward the fauces.

A corresponding contraction of the cavity occurs in the embryo from an early period, at the point where the buccal sulcus begins its mesal sweep, and at the same time begins its descent from the crown of its sagittal arch. It was found convenient to designate this region of changing direction the orbital angle, from its relation to the broad portion of the orbital inclusion. Here also the superior dental ridge dwindles and finally ends. In this region the anlage of the first orbital gland appears as a solid ridge of cells projecting from the dorsal wall of the buccal sulcus close to, but not at, its fundus (Fig. I46, 20). The 
time of its formation varies in rather wide limits; it is present at 18.5 millimeters in embryo No. 249 (Figs. 98, 99, 20). In one of the 19 milli.neter cmbryos it is again present. In the three embryos of 20 millimeters of our series it is present only in two. In all these the anlage is bilateral and presents the same general characters. The oral epithelium has well-defined periderm and basal layers; the latter alone gives rise to the anlages. There is no evidence of folding, and no fissure is present. In section the anlages are deeply staining, of approximately hemispheric contours, and are slightly longer than broad, from $27-40 \mu$ in the section counts. Here, then, the first event is clearly an act of proliferation.

With reference to the superior dental ridge the position of the laterally placed anlage varies in these embryos. In those of 18.5 and 19 millimeters and in one of the 20 millimeter embryos there is a short sagittal interval between the termination of the dental ridge and the keel of the first orbital gland. It is not more than $40 \mu$ at the most and has disappeared in the second of the 20 millimeter embryos, the termination of the dental anlage and the beginning of the orbital appearing in the same section.

In all of these embryos the first orbital is situated in advance of the orbital inclusion, from the tip of which it is separated by a variable sagittal interval. The inclusions are now free from the oral epithelium except for their caudal extremities. Their anterior processes are short conical continuations of the partes latæ, which now have circular cross-sections and are distinguished from the partes cylindricæ by their size alone. The question of the origin of the first orbital anlage, whether from the superior alveobuccal or the secondary buccal sulcus, has been rliscussed in connection with the orbitoparotid interval. The early anlages are in the plane of the deej facial vein which approximately marks its caudal limit, and it was shown that in the embryos here in question, the relation of the sprout to the orbital inclusion is readily explained by the reduction of the anterior process subsequent to its separation from the oral epithelium. Further, the sprout is postdental in position, while the orbital inclusion regularly in early stages extends beyond the extremity of the dental ridge. As none of our series possesses a first orbital coexisting with a still attached anterior process of the inclusion, an absolute assignment of the gland cannot be 
made. Clearly it is close to the junction of the two sulci and as the interval between it ind the parotid spronts may produce as variants orbitoparotid clements, it is apparent that we are dealing with a series of glands in process of separation into parotid and orbital groups, and that the interval in the cat is not yet absolute. The point of prime importance in the site of the first orbital is its entomasseteric position, as contrasted with the promasseteric situation of the parotid and orbitoparotids, which evidently determines its direction of growth along the only path permitted, caudad and dorsad into the orbit. As further the border of the masseter atdvances slightly relative to the buccal sulcus during development, the time of the appearance of a sprout has some influence in determining its direction of growth, those of late appearance having less chance of escaping the embrace of the muscle. As the glandiferous activity of the marginal cavity, in contrast to that of the alveolingual region, is accelerated craniad and later extends to its caudal portion, it is evident that early appearance and cranial position here coöperate to achicve an ectomasseteric position for some of the elements, while later establishment and coincident caudal site determine the selection of the orbital path, the masseter in each case being the chief factor in determining the topography of the glands, as by its apposition to the oral epithelium it is responsible for the sterile, or nearly sterile, interval between the analges of the parotid and orbital elements of the buccal sulcus series.

The direction of least resistance for the growth of an entomasseteric sprout is already strictly determined by the relations of adjacent parts. Dorsad is a dense mesenchyme condensation, horizontally placed and by its mesal border coming into close relation to the oral epithelium, the anlage of the alveolar process and maxillary tuberosity; laterad is the deep facial vein ascending into the orbit under cover of the masseter and the anlage of the zygomatic arch (Fig. 102, 95). The interval between these structures and the buccal sulcus is filled with loose mesenchyme which, caudal to the alveolar process, is widely continuous with that of the orbit, to reach which the sprout of the first orbital must extend itself a relatively considerable distance caudad, before it may turn dorsad and find room to expand.

In the 2r millimeter embryo the orbital has lengthened to a short crest along the dorsal wall of the buccal sulcus, and now extends 
craniad as far as the end of the superior dental anlage. The advance of the duct is thus early initiated. In its caudal sections the anlage appears constricted at its attachment, but as yet none of it is free from the oral epithelium.

In the 25 millimeter embryo the first orbital forms a keel I $33_{3} \mu$ in length, but with its extremities still in the same relative position, craniad at the end of the dental ridge, caudad at the level of the deep facial vein where it crosses the sulcus. It is composed of deeply staining cells resembling those of the basal layer of the oral epithelium, forming a small solid keel constricted caudad along its line of attachment, but not yet free in any part of its extent. Its growth, therefore, has only sufficed to keep pace with the general lengthening of the oral cavity, and no independent progress has been made as yet. In this embryo the tip of the orbital inclusion slightly overlaps the anlage at its caudal extremity.

In the 28 millimeter embryo some advance has been made. Three orbitals are present on the right side, two on the left. On both sides the second lies opposite the deep facial vein. On the right side the first orbital has a total length of $320 \mu$, of which all but one section $(20 \mu)$ belong to the attachment. This begins as a low keel near, but not at, the fundus of the buccal sulcus, as in the earlier embryos. It gradually increases in height caudad, and in its last third is constricted at its base. In a fer sections near its cranial extremity a minute fissure indents the base of the flange. It has been seen that the fissure was not present in the earliest stages of the anlage, which, therefore, does not owe its inception to a flange. Two interpretations of such a fissure are possible and perhaps not mutually exclusive. First, it may be due to the movements of the cells incident to proliferation and the formation of the keel; second, it may be a rudimentary fragment of the superior alveobuccal sulcus which in this region becomes continuous with the secondary buccal. This is the region of transition between the segment of the mouth which retains the maxillomandibular plane as a permanent element of the oral cavity, and that which suppresses a portion of it as the orbital inclusion. The transition is craniad of the orbital angle, corresponding to the cranial process of the inclusion. Here, then, small irregularities of the developmental process might be expected to occur. 
DEVELOPIENT OF SALIVARY GLANDS IN THE DOMESTIC CAT 269

The keel of the first orbital is lateral and almost parallel to the dental ridge for $240 \mu$ of its extent; the remaining $67 \mu$ of the attachment are postdental. The distance of the free fundus of the sprout from the termination of the ridge $(80 \mu)$ corresponds precisely with that of the early anlages of the $18.5^{-20}$ millimeter embryos. The keel hats advancel and lengthened while the sprout has retained its primitive position. It is, however, entirely craniad of the deep facial vein, which is now crossing the sulcus more obliquely as well as at a more caudal point. With reference to the sulcus the caudal portion of the keel of this anlage is now of fundal position, while the prolongation cranial diverges from the sulcus. The fundal position is secondary, for all the early anlages are parietal, and so goes to show that the fundus of the secondary buccal sulcus continues to shift at this period. In view of the position of the sprouts of the second and third orbitals (vide infra) this interpretation is preferable to the assumption that the site of the anlage is variable, even within such narrow limits. The free tip of the orbital now lies just at the notch between the palate condensation and that of the tuberosity of the maxillary; between them the path is free to the orbit.

The first orbital of the left side corresponds in site and length, and in the indentation of the base of its keel by a minute fissure in a few of its cranial sections. The process of constriction is, however, much more advanced; I00 $\mu$ only are attached, $220 \mu$ are free. This is a good instance of the independence in rate of the processes of proliferation and constriction.

The second orbital on the riglyt side springs from the angle between the first and the oral epithelium. Like its fellow of the left side, and the third orbital, it is fundal in position. Both are moderately advanced in development. The second has a length of $200 \mu$, of which 80 are free and form a rather thick dorsally directed sprout, which is directed towards the orbit on the mesal surface of the deep facial vein. The element of the left side corresponds closely, but a considerable interval $(100 \mu)$ separates it from the first orbital. On this side the constriction and separation of the first anlage have been accelerated.

The third orbital is present only on the right side. It has a length of $100 \mu$, of which $60 \mu$ are free, and is interposed between the second 
orbital and the secondary buccal sulcus. The attachment is a short keel, fundal in position, constricted at its base, and extending craniad to the angle between the second orbital and the sulcus. It is interesting to note that on the right side of this embryo, each member of this series bears to the preceding member a relation almost identical with that borne to the parotid by the orbitoparotid, when it occupies the angular position.

The 3 I millineter embryo is but little more advanced. Three orbital elements are present on each side, diminishing in size caudad, and all are now attached to the roof of the oral cavity well mesal to the fundus of the buccal sulcus. The first is represented by a keel, which becomes constricted at its base and is finally continued into a free cord of cells as it is followed caudad. The anlage is solid throughout. It diverges dorsad and laterad at a very acute angle from the oral epithelium, a small quantity of mesenchyme intervening, and terminates opposite the beginning of the second orbital in a slightly enlarged extremity. The total length is $285 \mu$, of which $120 \mu$ are free. The anlage lies craniad of the facial vein, except for its caudal sections. The keel now overlaps the dental ridge for $225 \mu$.

The second orbital begins as a keel in the angle between the free extremity of the first and the oral epithelium. It has a total length of ISo $\mu$, of which go $\mu$ are free. The anlages overlap for $30 \mu$, and the second is slightly mesal in position. In structure and direction it is an almost exact copy of the first. and lacks the thicker sprout of the 28 millimeter embryo. The mesenchyme in which it lies is widely continuous with that of the orbit. The deep facial vein lies lateral to it, and between them appears the cranial extremity of the orbital inclusion. The third orbital bears nearly the same relation to the second that the second bears to the first, inserted between its fundus and the oral epithelium, slightly to the mesal side. Its total length is $45 \mu$, of which $15 \mu$ are free. It is overlapped in its whole extent by the second orbital.

These three elements appear to have essentially the same history, their anlages appearing as solid keels which are subsequently freed by constriction; they differ collectively from such keeled glands as the parotid and submaxillary in the late appearance of an actively growing sprout, so that the keel here makes a long advance before the sluggish 
sprout begins its distal growth. The comparison again suggests that sulcal position, when accompanied by the formation of a flange, accelerates the development of the sprouts.

The comparison of the 28 millimeter and $3 \mathrm{t}$ millimeter embryos is illustrative of the variations in the rate of growth, so frequently observed in the development of the salivary glands.

The 34 and 35 millimeter embryos show a continuation of the same processes. In the latter the first orbital is relatively small (Fig. 107, 20) and situated close to the border of the masseter. The second is of larger size and of almost vertical direction. The third is also directed dorsad and of a size about equal to the first. In all the other embryos of our series the first orbital is appreciably the largest of the series.

Important changes in the topography of this portion of the mouth are now initiated, a vertical portion of the cheek is forming with the reduction of the buccal sulcus and the appearance of superior and inferior alveobuccal furrows. The vertical wall of the cheek defined by these sulci diminishes in height caudad, and in the plane of the second orbital the inferior sulcus ascending towards the superior becomes shallow and finally disappears, without reaching the funnelshaped contraction of the faucial region. The secondary buccal sulcus persists, and to its dorsal wall are attached the third and second orbital sprouts, craniad of which it becomes continuous with the superior alveobuccal sulcus. Just ventrad of this sulcus the wall of the cheek presents a convexity to the oral cavity, the anlage of the ridge upon which the parotid and, subsequently, the orbitals open. It is as yet of small sagittal extent and does not reach the first orbital, which is attached to the cheek in line with the ridge, but caudal to it. About midway between the parotid and first orbital, on the left side. an orbitoparotid springs from the oral epithelium, close to which it turns caudad, taking the direction of the orbital elements (Figs. Io6I08, I7). This behavior of the orbitoparotid is again suggestive of a primitive continuity of the orbital and parotid series.

In the 51 millimeter embryo the stomal ridge has extended caudad, and now all three orbital ducts are attached to its summit, in line with the parotid orifice, which is at its cranial extremity (Fig. 109, 20-22). After a course along the ridge, for a distance diminishing from the first to the third, they cross the secondary buccal sulcus and enter 
the orbit, where all have numerous short branches, those of the third order terminating in retort-shaped enlargements. The bodies of the glands are disposed in an oblique row, the first lateral and cranial, and overlapping the second, as that in turn does the third at the caudomesal end of the series. They are surrounded by an area of moderately dense mesenchyme, which gradually merges into the loose tissue at the bottom of the orbit. All of the ducts have pale centers except in their smaller branches and at their attachments, which still preserve a keel-like form.

The first element is distinctly the largest. Its duct is attached to the crest of the stomal ridge opposite the interval between the last and penultimate dental anlages. Its duct diverges gradually from the epithelium and farther caudad is ectal and dorsal to that of the second urbital (Figs. min-II3, 20). As it turns dorsad to enter the orbit it forks, and these primary branches continue dorsad for some distance before secondary sprouts appear. They supply craniolateral and caudomesal lobes of about equal size.

The duct of the second element $(2 I)$ begins opposite the last dental anlage, and turns dorsad at a slightly more caudal point than the first. Caudomesal to the body of the first, it divides dichotomously into branches studded with solid sprouts. A considerable number of the third order are present.

The third orbital (22) is distinctly smaller, its duct shorter and arising from the oral epithelium beneath the body of the second gland, at an interval appreciably greater than that between the first and second. In the orbit its duct is irregularly enlarged, and gives off several thick short secondary branchés.

The general relations of the bodies of the glands are little changed. Lateral to the first is the deep facial vein; the orbital inclusion on a more ventral level terminates in the plane of the second element.

In the 70 millimeter embryo the three orbitals, while greatly enlarged, offer no material changes in disposition (Fig. 114,20-22). The stomal ridge is prominent and forms an elongated convexity immediately below the superior alveobuccal furrow from the orifice of the paroticl to the plane of the body of the first orbital, where it gradually disappears. Its ventral margin is marked against the plane of the check by a shallow furrow which extends from the parotid orifice to that of the third orbi- 
tal. Along the crest of the stomal ridge open, at nearly equal intervals, the parotid, an orbitoparotid, and the three orbitals, whose general disposition in comparison with the embryo of 51 millimeters shows only increased growth along the lines there established, without the appearance of any new features. The anlages are solid; in the ducts the centers are very pale and in some places a minute cleftlike lumen secns to be present. Attention has a ready been called to the difficulty of determining the presence of small lumina in the salivary anlages; the rather thick sections of this embryo do not afford grounds for a definite statement, but suggest that the lumina are being formed as discontinuous clefts between the pale axial cells of the ducts. At their oral extremities the ducts are attached by shorter keels than in earlier stages, markedly constricted at their bases in all except the most cranial sections, which would seem to indicate that their period of adrance is drawing to a close. The keels are solid and deeply staining; there is no appearance of a channel among the cells of the thick stratified oral cpithelium, as in the case of the inferior alveobuccal glands, to continue their drainage lines to the surface, which would seem to agree with the apparent lack of continuous lumina in the ducts, as such channels through the epithelium are probably formed under the influence of the flow of fluid incident to the removal of the central cells.

Three additional orbital sprouts are now present, arising in series from the secondary buccal sulcus ventral to the bodies of the orbital glands (Fig. I I 4, 23). They are short solid sprouts springing from the basal layer of the epithelium of the secondary buccal sulcus on its dorsal aspect, and directed dorsad or dorsocaudad towards the orbital mass. They are separated by a distinct interval from the diffuse glands of the fauces, and in situation and direction of growth correspond so closely with the first three orbitals that they seem properly to be interpreted as belated nembers of this series. They are here simple sprouts and show at their origin no appearance of keels. In the adult it will be remembered that the orbital mass at its caudomesal extremity comprises several small elements, resting against the oral epithelium, whose ducts open directly into the vestibule at the caudal extremity of the stomal ridge, and beyond it on the surface of the glandular triangle.

The orbital mass, thercfore, represents a serics of like elements, the 
cranial members of which are accelerated in development and of preponderating size in the adult. They are the product of the second phase of activity of the caudal portion of the marginal cavity after it has thrown off the orbital inclusion, which has been seen to represent its primitive fundus. A point of interpretation arises here. As has been seen, the secondary buccal sulcus is continuous craniad in the older embryos of this series with the superior alveobuccal sulcus. This sulcus is of late formation, and produced by a simple process of folding between the dental ridge and the buccal sulcus, which is ventrally displaced and finally obliterated as the vertical cheek is formed. Behind the border of the masseter its representative is the orbital inclusion. Now from the continuity of the secondary buccal sulcus with the superior alveobuccal, it would seem that the orbital inclusion is the equivalent of the maxillomandibular plane lateral to the alveobuccal sulcus, and that being lost, the secondary buccal sulcus is really the equivalent of the alveobuccal with which it is continuous. If this interpretation is valid, the orbital glands are homodynamous with the glands of the superior alveobuccal sulcus, that is, superior "molar or buccal" glands, as these terms are commonly used (Fig. 165).

The elements appear in the course of the secondary buccal sulcus in its postdental segment; three acquire more cranial orifices, their ducts being carried forward by keels of proliferated epithelium, as is usual with the large salivary glands. The orbitals afford an interesting series of the degree of this process, which diminishes from the first orbital to the third, and is apparently lacking in the more caudal elements. It further establishes beyond doubt that such advances may be made without relation to a sulcus, and therefore are sometimes, and with a high degree of probability always, the results of a proliferation, and not the separation of the border of a flange as such, even when the proliferation advances along this border.

\section{THE GLANDS OF THE ALVEOLINGUAL REgION}

Here are developed the submaxillary, the greater sublingual, and a few representatives of the lesser sublingual series of glands. The submaxillary is formed in the course of the lingual sulcus, which serves also as a line for the advance of its keel. The greater sublingual arises 
from a kecl of proliferation attached to the epithelium of the alveolingual region, at a small but perfectly distinct interval, lateral to the lingual sulcus. At no time has it any contact with the submaxillary, but is from its inception and throughout its development an absolutely independent element. Both glands are established first in the neighborhoor of the submaxillary ganglion, and subsequently extend craniad along the lingual sulcus and the floor of the alveolingual region, following their separate lines at somewhat different rates, but so that the submaxillary is always in advance of the greater sublingual. At a late period (embryo of 70 millimeters) the lesser sublingual series is represented by a few sprouts in the caudal portion of the furrow, which forms the lateral boundary of the plica sublingualis, the homologue of which in man is the site of the early members of this series (Rivinian, glands, glandulæ sublinguales minores). Three independent glandiferous lines are thus distinguishable, a mesal, intermediate, and lateral, yiclding, respectively, the submaxillary, greater sublingual, and lesser sublingual glands, and in the order named. The cat presents the glands of this region, not indeed in their lowest terms, for all three lines are represented, but in a schematically simple form. The derclopmental process, in contrast to that of the buccal sulcus series, is also remarkably uniform and fixed.

\section{THE SUBMAXILLARY GLAND}

The lingual sulcus, as has been said, appears in separate segments, one craniad in what is subsequently the frenular region, and one near the submaxillary ganglion. The intermediate region of the sulcus is at first represented only by a rounded angle, where the epithelium of the tongue meets that of the floor of the alveolingual region (Figs. 22-24), which gradually becomes acute (Fig. 122), without attaining any depth or having parallel walls. This condition is attained in the majority of embryos of 55 millimeters, but the intermediate segment tends to be shallower than the more cranial and caudal portions of the sulcus. In a few cases, on the other hand, it never becomes more than an angle or may even be entirely absent in embryos of 18 to ig millimeters. This fact, it will be seen, has some importance in determining the nature of the process, which gives rise to the submaxillary duct. 
As we are here about to follow a development remarkably fixed in type, and subject only to slight variations in its rate as a whole, and to an equally small degree in the relative rates of its component processes. it will be convenient simply to report the findings in individual embryos, which are taken as representative of arerage conditions for their several lengths. In each the right side is described.

II millimeter embryo, No. 213 (Figs. II $8-121$ ). - The tongue at its tip is triangular in section and continued as a diminishing ridge in the gutter between the ends of the mandibular processes. At its sides it is definerl by shallow concarities which, near the tip and in the region of the lingual nerve, become angular, and form distinct boundaries between the tongue and the alveolingual regions. Near the lingual crossing the angle becomes more acute (Fig. I20), and caudad shows a minute vertical keel of epithelium (Fig. 121) which seems to be a remnant of the primitive thickening, which extends from the buccal sulcus to the lateral tongue swelling. It is to be noted that we are dealing with a very early condition of the sulcus before it has advanced beyond the condition of an angle in any considerable portion of its course, and that the keel referred to antedates the appearance of the actual sulcus.

II.5 millimeter embryo. Mo.256 (Figs. 23-30). - The sulcus presents cranial, intermediate, and caudal segments, the latter two alone being shown in these figures. The cranial segment has become very deep; it is directed mesad and ventrad, undermining the tongue, to a degree which increases craniad, until eventually- it meets its fellow of the opposite side, and the tip of the tongue is thus freed from the floor of the mouth for a short distance. As the sulci of the two sides deepen, they also become broader, and near this confluence the tongue is connected to the floor of the nouth only by a narrow strip of mesenchyme which intervenes between the broad fundi of the sulci. The cranial border of this fold is vertical, and in the section in which the sulci unite, disappears in its whole extent. At this stage, therefore, the cranial border of the frenulum or plica mediana corresponds with the confluence of the sulci. This relation is maintained to the stage seen in the 17 millimeter embryo, after which new conditions are established. The internediate segment of the sulcus is angular, becoming more acute as the region of the lingual nerve is approached (Figs. 
23-25). Immediately in front of the nerve a minute crest appears at the fundas (Figs. 26-27) which is solid and deeply staining. At the lingual crossing (Fig. 28) this has increased in height, but retains the ventromedian inclinations of preceding sections. Caudad it is larger, convex mesad, but with a general vertical direction (Fig. 29), eventually thickened at its margin (Fig. 30). In these sections its base is indented by a small fissure, which in the last is prolonged as an axial pale line rather more than through half the width of the anlage.

12 millimeter embryo, No. $7^{8}$ (Figs. 122-128). - This embryo is hardly more advanced than that of Ir.5 millimeters. It is almost perfectly oriented in the transterse plane. which renders unnecessary the after all not very difficult task of allowing for obliquity in sections where it is desired to distinguish between a keel and a flange. The sections are $20 \mu$ in thickness; alternate ones of the anlage of the right side are given, together with one of the intermediate segment of the sulcus, 100 $\mu$ prelingual in situation. In this section (Fig. I22) the sulcus is a slightly deepened angle, its epithelium very slightly thickened. The lingual sections show a flange or blind fold with a pale axial streak, gradually increasing to a maximum (Figs. 123-125) and as gradually decreasing caudad (Figs. 126-128). The maximum is attained in the region of the submaxillary ganglion; the latter from its situation and size is seemingly able to account, at least in part, for the apposition of the walls of the fold. Craniad of the lingual nerve the flange gives place to an angular sulcus with a keel attached. The keel alone was present in the I millimeter embryo, and extended over the whole of this region. It therefore forms the actual free border of the flange, which has simply carried it ventrad as the folding occurred. The keel here forms, also, the cranial continuation of the fold, a transition occurring near the lingual crossing.

No stages occur in our series intermediate between the conditions observed in the I millimeter embryo and those of the II.5 and 12 millimeter embryos. In none of them does the lingual sulcus appear as a deep open furrow, nor show a gradual reduction of its lumen by approximation of its walls, such as occurs in the parotid. The formation of this segment of the sulcus and its reduction to form the submaxillary flange appear, therefore, to be coincident and to constitute a single process. 


\section{DEVELOPMENT OF SALIVARY GLANDS IN TIIE DOMESTIC CAT}

I2.5 millimeter embryo, No. 264. - The flange is lingual and postlingual in position. It retains its wavelike form, coming gradually to a maximum and then declining. It is also concave laterad. In these features it closely resembles the anlage of the 12 millimeter embryo. It is, however, of greater depth and more thickened at the border in its sections of greatest breadth. This is the beginning of active proliferation, which from its site is referable to the minute ked that antedated the flange, and was carried ventrad in its formation as its free border.

13.5 millimeter embryo, No. 189 (Figs. 36-3.8). - In these sections is shown the topography of the alveolingual region. The intermediate region of the sulcus is angular, its epithelium thickened to a slight keel at the fundus (Fig. 36). Caudad the sulcus is reduced to a flange which has a considerable depth at the lingual crossing (Fig. 38 ). Here the bulky submaxillary ganglion lies lateral to the flange, and the nerve carrying an extension of its ganglion, sweeps in an arch ventrad of the anlage to reach the tongue. Caudad of the nerve the anlage shows a great increase in size, its enlarged fundus being directed ventrad and slightly laterad, toward a moderately well circumscribed arca of dense mesenchyme (Fig. 39). Ventrad of the alveolingual region is a sagittal tract of mesenchyme, limiterl laterad by Meckel's cartilage, mesad by the genioglossus, and rentrad by the mylohyoid muscle (Fig. 37). These, save the cartilage, which is inclosed in the ossification of the mandible, are permanent relations and narrowly confine the space available for glandular development. Caudad, beyond the border of the mylohyoid, this supramylohyoid mesenchyme becomes continuous with the dense area just mentioned, through the broad interval between the hypoglossal nerve and Meckel's cartilage (Fig. 39). The lingual nerve and its ganglion are near the caudal border of the mylohyoid, and the proliferation center of the submaxillary, just cauclal to the lingual crossing, is close to the junction of the two areas of mesenchyme. Its subsequent growth takes place in both directions, distad into the mesenchymal condensation, and proximad along the prelingual segment of the lingual sulcus.

In the section of greatest breadth (Fig. 39) three regions can be recognizcd in the anlage, defined by very slight constrictions; ventrad is the enlargement of the sprout; dorsad a portion of the flange at- 
tached to the lingual sulcus; while between is an intermediate element, which from its position appears to correspond to the dorsal accessory submaxillary of the human embryo. The dorsal element is the postglandular flange, which after the separation of the duct for a time persists along the lingual sulcus, but eventually is reduced and disappears. As yet these elements are rather vaguely defined, especially the junction of the postglandular flange with the intermediate element, which is as yet more of a change of direction or a kink in the anlage than an actual constriction.

In a second embryo of 13.5 millimeters the submaxillary has undergone important changes and the anlage of the greater sublingual has appeared. A series of third sections is given in Figs. I29-138. It is seen that the anlage has lengthened enormously and in a direction craniad of the lingual nerve; the advance of the duct has, therefore, begun. In the degree of this process, not in its nature, the embryos between 13.5 and ig millimeters show a wide range of variation. In the individual under consideration the gain is rather large, and in this respect it is distinctly in advance of its stage. Turning now to the structure of the anlage, in the region of the lingual crossing (Fig. 135), it is seen to be a flange directed ventrad and slightly laterad in close proximity to the nerve, and possibly in consequence of the presence of the nerve, presenting a slight kink in its middle as though pressed upon. The postglandular flange and intermediate elements are not very clearly defined. Craniad (Figs. 131-134) the flange diminishes in width, loses its kink, but retains its lateral deflection from the fundus of the sulcus. The fissure indents its base increasingly and becoming wider an open lingual sulcus is formed (Fig. 130), to the fundus of which the anlage is attached. Finally, the attachment becomes parietal and its folcllike character is lost; in Fig. 129 it appears as a solid projection of epithelium of the lateral wall of the sulcus near, but not at, its fundus. This character is retained by the cranial tip of the anlage until the duct comes to rest, a constantly increasing interval separating it from the fundus of the sulcus in later stages.

Caudad the separation of the duct has begun. This is accomplished by a solution of continuity in the flange in such a way that a portion, the postglandular flange, is always left attached to the lingual sulcus (Figs. $136,137,3^{I}$ ). This retains a fissure at its base, but rapidly 
diminishes caudad, so that in a few sections both flange and sulcus have disappeared (Fig. I38).

The sprout has lengthened and is directed ventrad, caudad, and laterad, toward the mesenchymal thickening (32) which it has now reached (Fig. I38). In this course it passes caudad of the lingual nerve and its ganglion, which accompanies it with a sheathlike extension (Fig. I 37,49$)$. The extremity of the sprout is enlarged, retort shaped, and lies at about the level of the caudal border of the mylohyoid.

The model of a submaxillary corresponding in general to this, but with a less degree of cranial extension of its duct - a process variable in its rate - is shown in Fig. I 39 from an embryo of 15 millimeters. The anlage has lost the wavelike form of its earlier stage, and is now a somewhat triangular object with a concave caudal border. The sprout is attached to the region of greatest wiclth of the flange, and thus is seen to correspond to the early thickening of the margin which appears at a similar point. Craniad the ventral border ascends rapidly to the lingual sulcus, where it extends but little beyond the lingual crossing. The portion of the flunge caudal to the attachment of the sprout presents two slight constrictions, which partially divide it into an element attached to the lingual sulcus, the postglandular flange, and a portion intermediate between that and the sprout. The greater sublingual anlage is also present to the lateral side of, and separate from, the submaxillary, immediately dorsal to the lingual nerve (33).

We may now, on the basis of these findings, attempt an interpretation of the processes at work in the formation of the submaxillary anlage. The order of events is: first, the separation from the general placodelike thickening of the oral epithelium of a keel extending along the caudal and the greater part of the intermediate segments of the lingual sulcus; second, the formation in the region of the submaxillary ganglion of a flange; third, its extension craniad, diminishing the while, until in the intermediate segment of the sulcus it finally ceases to be formed and only the ket persists; fourth, the displacement of the keel to a lateral parietal position.

The early solution of continuity in the epithelial thickening of the floor of the mouth is associated with the rapicl expansion of the area. A gap between the alveolingual thickening and the inferior dental anlage is established in the period of 9.5 to ro millimeters. In embryos 
of to to 12 millimeters there is a slight diffuse thickening in the region of the submaxillary ganglion and a minimal keel along the as yet angular lingual sulcus; in embryos of 12 to 13 millimeters the keel becomes indistinguishable in the course of the intermediate segment of the sulcus.

Meanwhile, caudal to the lingual nerve and opposite its bulky ganglion, a flange is formed. This has, at first, a wavelike form with its maximum leight opposite the submaxillary ganglion, thence diminishing equally craniad and caudad. Its cranial extremity, at first, is in the vicinity of the lingual crossing. The ventral border is first thickenerl at the point where the flange is highest.

The advance beyond the lingual crossing is begun in one of the 13.5 millimeter embryos, and new conditions are established at the cranial end of the anlage. The flange stops and gives place to a keel. This differs from the flange in involving the basal cells alone, instead of the whole thickness of the epithelium, and, further, it is parietal and not fundal in attachment. The advancing submaxillary has reached a point in the intermediate segment of the lingual sulcus, which ceases to be reduced to a flange, but instead deepens to an open sulcus with nearly parallel walls and a distinct lumen. The keel of the submaxillary is attached to the lateral wall near, but not at, the fundus, from which it diverges as it proceeds craniad. This condition is present in embryos of 15 millimeters. It thus appears that the angular boundary between the tongue and the alveolingual gutter is deepened, as the tongue enlarges, to an open sulcus in the cranial portion of its course, while caudad a flange is formed in the vicinity of the bulky submaxillary ganglion, opposite which the process is at a maximum. The ganglion may, therefore, be looked upon as the cause of the formation of the flange. Craniad the flange is smaller, the fissure at its base deeper, until a point is reached where the compressing influence of the ganglion is no longer felt, and an open furrow results. The flange is composed of two layers of epithelium, lateral and mesal, in apposition by their periderm strata, the bulging nuclei interlocking and obscuring the line of contact of the layers, while the faintly staining cell bodies produce the pale axial streak of the sections. The flange is fundal in position. Could it be opened along its perislerm axis, the lingual sulcus would be restored, and it is reasonable to expect that 
the preformed keel would be found at its fundus. This element, however. ceases to be distinguishable from the flange as soon as the latter is formed. It is only an inference that it retains its morphogenic individuality, and. constituting the free border of the flange, is the actual site of proliferation which gives rise to the submaxillary duct. The sections of the 13.5 millimeter embryo, No. 78 (Figs. 1 26-1 27), show this early proliferation rather on the lateral aspect of the flange, and suggest that even here there is a slight tendency to shifting of the fundus as the sulcus deepens and consequent displacement of the keel to a parietal position, such as occurs to an increasing degree craniad.

We have now to enter upon the question of the mode of formation of the flange, and at the outset it must be borne in mind that there is here no reduction by compression of an open sulcus to produce a secondary flange, as in the case of the parotid and orbital inclusion. Here the flange is primary. That it is the result of proliferation uncomplicated by folding is a supposition little in harmony with its structure. The fissure that indents its base is too deep and constant to be regarded as a mere concomitant of rapid proliferation, and is, further, always continuous with the periderm axis. It is difficult, also, to interpret this periderm as developer in situ secondarily, for it is present from the inception of the flange. Above all, the gradual reduction of the flange craniad is accompanied by a deepening of the fissure, the walls of which are continuous with the layers of the flange. Granted that the anlage is a true flange, it is yet certain that it is not produced by apposition of the walls of a primarily open sulcus. There are here two alternatives, accelerated growth in the epithelium inmediately adjacent to the as yet angular lingual furrow on both sides, or a process of inrolling of the epithelium of the tongue and alveolingual region towards their common boundary, the lingual sulcus. An antecedent necessity in either case is the presence of factors tending to prevent the free expansion of the region, and so leading to the production of a sulcus or fold. This condition is satisfied in the relation of the tongue to the palate processes and in particular to the roof of the mouth between them. Here, as His has pointed out, the growth of the tongue is resisted. and the organ as a whole tends to sink ventrad between the alveolingual gutters as development proceeds. They in turn are limited laterad by the enlarging region of the alveolar pro- 
DEVELOPHENT OF SALIVARY GLANDS IN THE DOMESTIC CAT $28_{3}$

cesses. An opposition of forces thus engendcred produces beside the tongue a sulcus, and where the additional factor of compression by the submaxillary ganglion is present, a flange. But the flange far exceeds in depth the open sulcus which continues it craniad. While this may be assigned solely to the more active and earlier established growth of its layers, there are certain facts which render probable that it is assisted by a greater degree of inrolling of epithelium from the tongue and alveolingual gutter. The tongue as it is followed caudad diminishes in its elevation above the level of the gutters, while they, too, narrow as the region of the flange is approached. The latter is plainly apparent to one running over the sections, but from the absence of an alveolar sulcus in the cat it is less conspicuously evident than in the human embryo (Part II, Figs. 4, 6-I9). Indirect evidence to the same effect is afforded by the adult condition of the Rivinian glands in both forms. These develop lateral to the submaxillary at first, and subsequently the caudal members of the series become dorsal to the submaxillary line and continuous with the isthmian elements (Webcr's gland). The most plausible cxplanation scems to be a shift mesad of primitively lateral parts, which is precisely what the inrolling of alveolingual surface epithelium into the submaxillary flange would entail. In this displacement, areas of surface epithelium primitively close to the sulcus would occupy ventral (aboral) positions in the flange, while more lateral elements would be dorsal.

The anlage established, we have now to consider its cranial advance, the separation of its duct, and the extension distad of its sprout.

The advance has been seen to depend in part upon the continuation of the flange beyond the lingual crossing, in part upon the presence of the primitive keel. The transition is very gradual between these two regions of the anlage, but is always prelingual. In older embryos the nerve crosses in two divisions; the transition is usually nearer the smaller cranial branch in the period of $\mathrm{I}^{-1} 7$ millimeters. The flange diminishes, giving place to an open sulcus with a fundal keel; this becomes parietal and finally stops altogether. The conditions typical of an anlage of this period are shown in the model of a 16 millimeter embryo (Fig. 140). A slight tendency of the keel to become parietal in the early anlage has bcen referred to. In the region of the intermediate segment of the lingual sulcus this becomes pronounced, 
and increasingly so craniad. Here we are dealing with a process already observed in the case of the parotid and of the orbital inclusion, which was there attributed to unequal growth in the walls of the sulcus and consequent shifting at its fundus. In the case of the lingual sulcus there appears to be a further element in the nature of inrolling. We have now reached a point where this is unequal as regards the mesal and lateral walls of the sulcus, the contribution from the tongue exceeding that from the alveolingual region, either absolutely or in eapacity for growth. The alveolingual region broadens slightly, which farors the view of a lessened inrolling. In any event the keel has now become parietal. It does not extend now as a recognizable element along the cranial segment of the sulcus, but gradually is formed in a caudocranial direction, advancing by slow and unequal increments from stage to stage.

This advance by a keel, which is not fundal, but lateral parietal in position, is characteristic of all the later stages of the anlage. As the sections are followed craniad the flange diminishes gradually. From the first the anlage has been a keel of thickened epithelium to which a flange has been added. The keel forms the free border of the compound structure, and proliferating occasions the enlargement of the border of the flinge and gives rise to the free-growing sprout. The proliferation extends craniad, using the flange as a guide or scaffold. But the lingual and prelingual segments of the sulcus have begun to deepen, tending to drive the fundus deeper, or rather to form a new fundus mesad of the keel, which, therefore, assumes a parietal position in the lateral wall. The lateral bend of the anlage (Fig. 137), with its consequent displacement of the free border, also favors the change by altering the direction of the line by which the proliferation is advancing, and causing it to impinge upon the lateral wall of the sulcus. The direction of this line is craniad and slightly dorsard that of the fundus almust horizontal. The keel of proliferation continuing, this line becomes more and more dorsally placed in the lateral wall as the process advances craniad, and, until it comes to rest, is in each successive stage carried farther from the fundus. This in late stages causes it to open upon the summit of the plical sublingualis, the mesal surface of which is the lateral wall of the lingual sulcus.

In the 20 millimeter embryo, No. $24 \mathrm{I}$, and in a few others of about 
DEVELOPMENT OF SALHVART GLANDS IN THE DOMESTIC CAT $28_{5}$

this period, a smatl keel is present attached to the lateral wall of the lingual sulcus in its cranial segment, unconnected with the submaxillary keet. In this embryo on the right side it extends from the frenular section to $\mu$ caudad. It is in line with the submaxillary keel, but separated from it by a wide sagittal interval. The same formation occurs in the human embryo both in the submaxillary and sublingual lines. Here, then, we have the possibility given of the formation of the duct by fusion of distinct elements. Yet this departure from the norm cannot be considered of more than slight degree. In the advance of this duct, and of others, we are dealing with a process of proliferation which advances craniad, not a bodily displacement of material. As the duct advances the latent glandiferous functions of more cranial segments of the oral epithehim are successively aroused, and the keel is formed by the activity of the segments to which it is attached. In these outlying keel formations we meet merely a disturbance of the time element; epithelium destined to produce a keel proliferates at an earlier period than is usuat. In this there is a strong suggestion that the ducts are advancing along glandiferous lines, which in some ancestral form yielded series of small glands, the crowded anlages of which are now compounded and fused to form the duct. An occasional recrudescence of their ancient independence fincts expression in the accelerated appearance of a portion of the keel, as in the case here considered, which is no more than a slight disturbance of the rhythm of the process, a deviation from the strict sequence of events in time.

That the proliferation process of the submaxillary is in reality independent of the lingual sulcus, and that its duct is in no sense its separated fundus, is shown clearly in a few enbryos where the intermediate segment of the sulcus fails to advance beyond a condition of slight angulation. In Fig. I 50 the usual condition of the intermediate segment is shown in a ig millimeter embryo. There is a deep lingual sulcus directed ventromesad and the keet of the submaxillary is attached to its lateral wall. In Fig. I47, also from a 19 millimeter embryo, the same region is shown. The lingual sulcus is reduced to a mere angle, lateral to which the submaxillary keel is attached to the floor of the alveolingual region Here is clear evidence that the sulcus as such does not supply the material for the advance of the duct. 
The duct formed by proliferation in the border of the flange and continued craniad by proliferation in the lateral wall of the lingual sulcus, is freed by a process of constriction, advancing craniad from the caudal border of the flange. This is begun in some of the 13.5 millimeter embryos. Just caudad of the lingual nerve, the solid duct is free (Fig. I36). Here there persists along the lingual sulcus a remnant of the flange, the postglandular flange (3I). This represents the caudal portion of the primitive flange, which escapes destruction in the freeing of the duct. It is precisely analogous to the inconstant postparotid flange, but unlike that element is never in any of our embryos the source of a sprout. It is constant in embryos of 20 millimeters and under. In embryos of I 8 millimeters and less it extends from the angle of junction of the duct and lingual sulcus caudad to the lingual crossing. In older embryos it is rapidly reduced in a caudocranial direction, and in those of more than 20 millimeters it is altogether absent. With it disappears, also, the lingual sulcus, and the alveolingual region passes without demarcation by an even curve into the side of the tongue (Figs. 144, I46). The caudal segment of the sulcus then seems to form only in the interests of the submaxillary, and as soon as the duct has made its advance hastens to disappear.

The sections at the lingual level in embryos of $\mathrm{I} 3 \cdot 5^{-1} 5$ millimeters (Fig. IfI) throw some light upon the nature of the constriction. Here the flange projects ventrolaterad from the sulcus and enters into close relations with the lingual nerve. The flange is twice kinked and slightly bent at the kinks as though pressed upon by the nerve. Three areas are distinguishable, a dorsal one continuous caudad with the postglandular flange $\left(3_{I}\right)$, a ventral one continuous with the freegrowing sprout (30), and an intermediate element (30a) which behaves differently at different periods. In embryos of $13.5^{-1} 5$ millimeters, when separation is initiated, the flange of the submaxillary has a triangular contour (Fig. I39) with a concave caudal border. The intermediate portion of the flange corresponds to the crown of this curve. In sections passing through the anlage close to the border the flange has the appearance shown in Fig. I36. In immediately succeeding sections the postglandular flange, adhering to the sulcus, is separated by a considerable gap from the free duct, which lies almost vertically below it. In many cases there is no sign of an intermediate 
element. The mesenchyme between the duct and the flange is somewhat denser than elsewhere in the vicinity, an appearance in the case of the parotid associated with the destruction of the intermcdiate element. On the other hand, it is possible that at this stage the free duct is formed as yet solely by the distal growth of the sprout, and the concavity of the caudal boider of the flange may possibly be due to the traction of the sprout upon the flange; the thickening in the mesenchyme may be antecedent to the development of a gilp in the flange. The caudal border retains this character while it remains postlingual in position (embryos of ${ }_{1} 5^{-16}$ millimeters). When the separation has advanced farther along the sulcus and has reached the lingual crossing, the type changes slightly (Fig. 142). There is still the dorsal kink between the intermediate element and the postglandular flange. But the whole flange having narrowed, these elements, especially the intermediate, are much smaller. There is only a slight constriction between the duct and the intermediate element, and the actual break occurs between the intermediate element and the postglandular flange. In this region, therefore, the intermediate element persists attached to the duct and is not destroyed as farther caudad. The appearances at this stage suggest strongly the condition of the parotid, in which an orbitoparotid is situated at the angle where the duct joins the mouth. This type is usual up to the stage of 20 millimeters. In a minority of cases the break occurs at the dorsal border of the duct, and the intermediate element is left attached to the postglandular flange. The intermediate element never, in the cat, gives rise to sprouts, nor does it long remain visible. The duct soon loses its slightly hourglass shape, becomes oval, and finally circular in section, and the intermediate element is completely effaced. Its early disappearance and morphogenetic insignificance in the cat may account for the irregularities in its behavior in the process of separation. Its presence has been recorded in the human embryo; and in the ardult primate, the dorsal accessory submaxillary of Huntington is probably its derivative.

A third type of separation characterizes embryos from 20 millimeters to 35 millimeters in length. The attachment now is a simple keel, constricted at its base in its caudal sections, while the duct is freed simply by the deepening of the constriction; the intermediate element is no longer present (Fig. 143). The anlage now extends far 
craniad of the lingual crossing; the separation has likewise advanced through the whole extent of the flange and reached a point where the attachment is by means of the proliferation keel. No flange being present, there can be no intermediate element. The duct with a circular orifice is first found in our series in the embryo of ${ }_{5} \mathrm{I}$ millimeters.

The advance of the duct is rather slow and somewhat unequal in early stages. The whole mouth is lengthening, and the advance of the keel is not able to maintain itself against this greater growth. Its cranial extremity, while successively farther in advance of the lingual crossing, is separated from the cranial end of the lingual sulcus by an increasing distance. The following measurements were taken upon the right side of well-oriented embryos. They refer only to the attachment of the anlage; its sprout and free duct are not considered. The confluence of the two lingual sulci in these embryos corresponds to the frenulum. The lingual crossing has been explained to refer only to the fibers of the nerve, and in stages where two branches are present, to the larger caudal one. The distance between these two points affords an index of the growth of the region as a whole. With regard to the submaxillary keel, its caudal end is easily recognized; craniad it diminishes so gradually that it is not easy to tell exactly in what section it stops; another observer might easily add a section to the counts, or take one alway. The sections are 1.3.3 $\mu$ in thickness.

\begin{tabular}{|c|c|c|c|c|}
\hline EMBRYO & 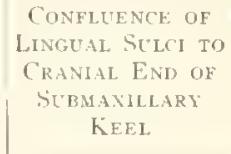 & $\begin{array}{l}\text { LENGTH OF SUB- } \\
\text { MAXILLARY AT- } \\
\text { TACHMENT }\end{array}$ & $\begin{array}{c}\text { END of SubmaxillaRy } \\
\text { Keel To Lingual } \\
\text { Crossing }\end{array}$ & $\begin{array}{c}\text { CONFLIENCE OF } \\
\text { LINGUAL SULCI } \\
\text { TO LINGUAL } \\
\text { CROSSING }\end{array}$ \\
\hline & $\mu$ & $\mu$ & $\mu$ & $\mu$ \\
\hline No. 223 & & & & \\
\hline $\begin{array}{l}13.5 \mathrm{~mm} . \\
\text { No. } 216\end{array}$ & 267 & 245 & $-13.3^{*}$ & 547 \\
\hline $\begin{array}{l}\text { I } 5 \mathrm{~mm} . \\
\text { No. } 259\end{array}$ & 246 & 267 & o & $5+7$ \\
\hline I $7 \mathrm{~mm}$. & 320 & 293 & 13 & 626 \\
\hline
\end{tabular}

These are merely individual measurements from embryos that were

* The distal extremity of the keel is I $3.3 \mu$ caudal to the lingual nerve. 
considered fairly typical of their groups. The most variable measurement was that of the length between the confluence of the sulci and the lingual crossing. In this respect the embryos between 13.5 and I 6 millimeters may be said to be perfectly lawless. The measurement seems to bear little relation either to the general development of the mouth or of the submaxillary in particular. The embryos No. 223 and No, 216 were chosen because they coincided in this dimension, which makes apparent the slight gain of the submaxillary attachment. The i 7 millimeter embryo shows a well-marked advance of the anlage, which, however, is not sufficient to offset the lengthening of the sulcus. The separation has now begun to advance beyond the lingual crossing.

In embryos of 1 8-20 millimeters the constriction advances rapidly though unevenly, but is sufficient to reduce the length of the keel, gaining considerably upon the proliferative process. In these embryos the frenulum has altered its shape. It no longer has a vertical border rising from the confluence of the sulci, but has become a large crescentic fold concave craniad with cornua forming ridges on the ventral surface of the tongue and on the floor of the mouth. Craniad of the section in which the tongue becomes free, the plica mediana extends as a diminishing rilge between the lingual sulci. The section in which the tongue becomes free is here termed the frenular section, and as it undergoes a relative displacement caudad it is not a useful point to measure from, as the distance between it and the submaxillary diminishes by its own displacement, as well as by the advance of the anlage. The keel of the anlage reaches this section in the 28 millimeter embryo. In the following measurements the confluence of the sulci at the extremity of the plica mediana is again used in preference to the frenular section.

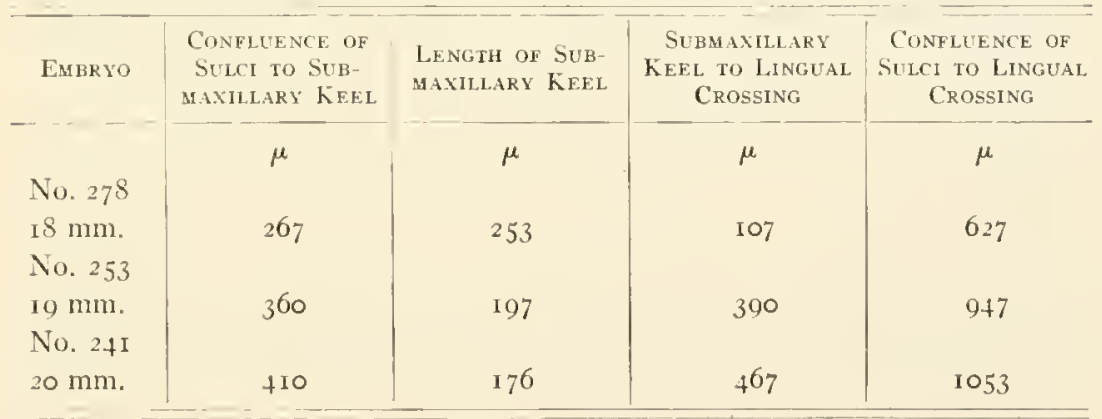


The prolifcration and constriction advance steadily from the lingual crossing, but the constriction more rapidly. In the is millimeter embryo the proliferation has gained upon the sulcus, which has made no advance upon the I 7 millimeter embryo. Here, again, we have evidence that the formation of the duct is by a process independent of the sulcus, since it may lengthen while the sulcus is at a standstill.

During the period between 20 and 30 millimeters the duct continues to advance by the formation and separation of a keel, and during the latter part of this period at a rate sufficient to gain upon the lengthening of the region and to approach the cranial end of the lingual sulcus. In the $5^{\mathrm{I}}$ millimeter embryo the attachment is circular; there is no sign of a keel, and the duct, so far as intrinsic processes are concerned, has come to rest.

The following measurements show a progressive and absolute advance from the lingual crossing. The distance between the keel and the confluence of the sulci indicates a fluctuating balance of growth between the region as a whole and the proliferation of the keel, inclining now to favor the one, now the other, but finally the growth of the keel predominates and the duct makes a relative as well as an absolute advance.

\begin{tabular}{|c|c|c|c|c|}
\hline EMBRYO & $\begin{array}{c}\text { Confluence of } \\
\text { Lingual Sulci to } \\
\text { SubMaxillary } \\
\text { KeEl }\end{array}$ & $\begin{array}{l}\text { Length of Stub- } \\
\text { MAXILLARY KEEL }\end{array}$ & $\begin{array}{c}\text { SUbMiniLiary } \\
\text { KEEL TO LINGUal } \\
\text { CRossing }\end{array}$ & $\begin{array}{l}\text { Total: Conflu- } \\
\text { ENCE OF SUlCi to } \\
\text { Lingual Crossing }\end{array}$ \\
\hline & $\mu$ & $\mu$ & $\mu$ & $\mu$ \\
\hline $\begin{array}{l}\text { No. I } 47 \\
25 \mathrm{~mm} . \\
\text { No. } 408\end{array}$ & 160 & 93 & 1039 & 1292 \\
\hline $\begin{array}{l}28 \mathrm{~mm} \text {. } \\
\text { No. I } 44\end{array}$ & 40 & 100 & 1080 & 1220 \\
\hline $\begin{array}{l}31 \mathrm{~mm} . \\
\text { No. } 10.4\end{array}$ & 45 & 30 & 1950 & 2025 \\
\hline $51 \mathrm{~mm}$. & I 80 & 42 & 3402 & 36.33 \\
\hline
\end{tabular}

The constriction on the whole gains upon the proliferation, and the keel, which indicates the balance between these two processes, is 
shortened in the later stages. Here we may note that the length of the keel in no wise expresses the activity of the proliferation, for these short kcels arc advancing absolutely more rapidly than the long oncs of earlier cmbryos. In the light of these conditions the cxtremely small epithclial plates at the angulus oris cannot be used as evidences of a small degrce of fusion between the maxillary and mandibular processes. They indicate rather approximately equal rates in the process of fusion and in that of reduction of the epithclium.

In the 20 millimeter embryos the attachment of the submaxillary keel was to the latcral wall of the lingual sulcus, a short distance from its fundus. This parietal position it maintains, but the distance between the fundus and the attachment increases, in part owing to a deepening of the sulcus, in part to growth in breadth of the whole region.

Lateral to the lingual sulcus the floor of the mouth becomes convex; the convexity has a latcral limit in the circumflex sulcus which appears concomitantly. The elevation is the plica sublingualis. In the 20 millimeter embryos it is slight in degree and limited to the frenular region. Later it extends caudad and in the embryo of 70 millimeters almost reaches the lingual crossing. The still later reduction of the caudal portion of the fold and its undermining by the sulcus, does not fall within the period covered by the cmbryos of our series. In the adult it is reduced to little more than a papilla, on which the ducts of the submaxillary and greater sublingual open, situated close to the symphysis, and attached to the plica mediana, traction upon which will elevate it sufficiently to show that it is frce of the floor of the mouth.

The attachment of the duct to the lateral wall of the lingual sulcus causes it to be situated upon the plica as soon as the latter appears. Gradually it is carried craniad and gains an orifice near the cranial end of the plica. At first located on its mesal surface, in the 5I millimeter embryo it has rcached the summit of the convexity.

The distal growth of the submaxillary is exceedingly vigorous. Its bud is a large, solid, retort-shaped object from the first. In the I4 millimeter embryos its extremity is at the border of the mylohyoid; in the more advanced embryos of 15 millimeters it has reached the center of its mesenchymal area. In the $16-16.5$ millimeter embryos 
it has several branches, which are given off from the convex aspect of the duct and have a dominantly caudal direction (Fig. I40). Throughout the period covered by our series the submaxillary far exceeds in volume the other salivary glands. The mesenchymal condensation which is common to it and the greater sublingual is a retort-shaped object (Fig. 106), the neck of which enters the interval between the digastric muscle and Meckel's cartilage, when, becoming less definite, it is continuous with the supramylohyoid mesenchyme. Its fundus rests against the lateral surface of the digastric, ventral of the masseter at its caudal angle, where it comes close to the branches of the parotid. The two glands in these sections present a marked contrast in appearance, the parotid sprouts lying free in almost unaltered mesenchyme (of a capsule or common condensation there is no trace), while the branches of the submaxillary are contained in a dense and sharply circumscribed area of very richly nucleated young connective tissue.

The mesenchymal condensation antedates the emergence of the sprout from the mylohyoid girdle. In the early stages its outline is a little vague, and there is a zone of transition to the less dense surrounding tissue. The limits gradually become better defined, and in late stages receive further emphasis from a series of circumferential lymph spaces.

\section{THE GREATER SUBLINGUAL GLAND}

Of the primitive epithelial placode of the floor of the mouth a porion persists in the vicinity of the submaxillary ganglion. After the appearance of the submaxillary flange, it forms a diffuse thickening of the alveolingual fold, best marked near its middle and fading off towards the tongue and alveolar process. In the midst of this area the anlage of the greater sublingual appears as a rather indefinite sagittal ridge. It is present in one of the embryos of 12 millimeters (Figs. 127.33), in two of 13.5 millimeters, and in two of the 14 millimeter embryos. In all of these the periderm and basal layers are well defined, and the ridge of the greater sublingual (Figs. $153^{-15} 6.33$ ) is seen to be composed of the basal cells alone, which project beyond the general surface of the epithelium and suffer some disturbance of their regular arrangement. The periderm passes uninterrupted over the ridge; there is no fissure. Ventral to the ridge is a slight diffuse thickening 
of the mesenchyme. The anlage is separated by a distinct interval from the lingual sulcus, equal to about half the width of the gutter at this point, and the epithelium diminishes in thickness towards the sulcus, so that the two anlages cannot in any sense be considered continuous. This independence of the greater sublingual is absolute and maintained throughout development.

In the 13.5 millimeter embryo, No. 223 (Figs. 133-I35), the ridge, which has a sagittal length of $107 \mu$, extends to the lingual crossing. In the two embryos of 14 millimeters, Nos. 122 and 127 , the anlage is of the same character, but shorter. In the first it has a length of $6_{3} \mu$ and stops $13 \mu$ caudad of the lingual nerve; in the second it reaches the plane of the nerve and measures $90 \mu$.

In the 13.5 millimeter embryo, No. 189 (Fig. I 39), the greater sublingual is larger than in the foregoing; its cranial extremity has advanced beyond the lingual crossing. It is relatively broad for its height and bulky as contrasted with the anlages of the other salivary glands. It is at its maximum caudad, thence diminishing craniad, where the keel ceases to project from the ectal surface of the epithelium, and is replaced by a rather ill-defined thickening of the epithelium of the alveolingual region. This may be slightly concare. The anlage is clearly a product of proliferation, arising out of a diffuse thickening, unassisted by fold or fissure.

In embryos of $15-17$ millimeters the anlage increases in depth and width; its caudal portion becomes constricted at the base along the line of its attachment. The cranial extremity continues to merge insensibly with the diffuse thickening of the gutter and shows little tendency to advance, in only a few cases passing the lingual crossing and then only by a few micra. Some of the sections of the keel now show a slight indentation of their base. The fissure is always minute, a mere line in the oral portion of the epithelium and never so deep as the thickness of the epithelium at the sides of the kecl. It is not often present at the extremities of the crest, and never, apparently, is formed by the deepening of the concavity craniad of the keel. It would seem, rather, to be an invagimation fissure due to some slight shifting of cells incichent to the active proliferation of the kech. In no part of the line followed by the greater sublingual is there ever a preformed sulcus. 
In embryos of is millimeters* the greater sublingual begins to adrance, forms a free-growing sprout, and separates a portion of its duct from the alveolingual epithelium by the continuance of the constriction already initiated at its caudal extremity.

The advance takes place along a line converging slightly towards the lingual sulcus, but never joining the keel of the submaxillary: The cranial extremity retains the character of a gradual subsidence into a more diffuse thickening. In embryos of $19-20$ millimeters the termination is more abrupt, the thickening less marked. With regard to the latter, it will be remembered that primitively it covers the whole alveolingual region, and yet at the time just prior to the establishment of the greater sublingual, it has become confined to the portion of the gutter caudal to the lingual crossing. In succeeding stages it reappears in a limited area in advance of the keel of the anlage with which it merges. A similar sequence of events characterizes, also, the advance of the submaxillary, but here the thickening is a sharply circumscribed, almost linear keel. Both glands appear in regions where the diminishing thickening has not wholly disappeared, and form their anlages out of its remains, the submaxillary partially, the greater sublingual wholly. The advance of both glands proceeds over an area from which the thickening has vanished, but as they advance a localized area of the epithelium recovers its powers of relatively rapid proliferation and supplies the material for the ducts. The more diffuse condition of this element in the line of the greater sublingual may indicate a less degree of fixity in its line, or may have reference to the late efflorescence of its duct (Figs. Iog. II4).

The interpretation of this anlage as a keel and not a flange is strengthened by its mode of separation. Almost from the first a constriction is present in its caudal sections close to its attachment to the oral epithelium, which, deepening, cuts off the entire keel. No portion of it is left adherent to the epithelium, and there is no intermediate portion destroyed in the process. Throughout, its separation resembles the late stages of the parotid and submaxillary glands, and on a larger scale the process of duct formation of the three cranial orbitals. With them it constitutes a class intermediate between sulcal

* The I6.5 millimeter embryo of Fig. I 40 agrees in the development of the greater sublingual with the I 8 millimeter embryos. 
-flanged glands like the parotid and submaxillary, and simple diffuse glands, such as the inferior alveobuccal, which are merely sprouts. It is keeled, but not sulcal; its formation is without the assistance of a fold.

Arlvancing along the floor of the alveolingual region, it lags slightly behind the submaxillary. The following measurements are the same as those given for the submaxillary and from the same embryos, with the addition of the sagittal distance between the cranial ends of the two anlages, to show the lag of the greater sublingual.

\begin{tabular}{|c|c|c|c|c|c|}
\hline EMBRYo & $\begin{array}{c}\text { Confluence of } \\
\text { Lingual Sulci } \\
\text { to Lingual } \\
\text { Crossing }\end{array}$ & $\begin{array}{l}\text { CONFLUENCE OF } \\
\text { LINGUAL SULCI } \\
\text { TO GREATER SUB- } \\
\text { LINGUAL KEEL }\end{array}$ & $\begin{array}{c}\text { LENGTH OF } \\
\text { GREATER } \\
\text { SUBLINGUAL } \\
\text { KEEL }\end{array}$ & $\begin{array}{l}\text { CaUdal End of } \\
\text { Greater SUbLin- } \\
\text { GUal KeEl to } \\
\text { Lingual Crossing }\end{array}$ & $\begin{array}{l}\text { SAGITTAL lNTER- } \\
\text { VAL BETINEEN } \\
\text { CRANIAL ENDS OF } \\
\text { SUBMAXILL ARY } \\
\text { AND GREASER } \\
\text { SUBLINGUAL. } \\
\text { KEELS }\end{array}$ \\
\hline & $\mu$ & $\mu$ & $\mu$ & $\mu$ & $\mu$ \\
\hline $13.5 \mathrm{~mm}$. & 547 & 480 & 107 & - & 165 \\
\hline I $5 \mathrm{~mm}$. & 547 & +40 & 107 & 0 & 104 \\
\hline $17 \mathrm{~mm}$. & 627 & 520 & 107 & 0 & 200 \\
\hline I $8 \mathrm{~mm}$. & 627 & 404 & So & 5.3 & 227 \\
\hline Ig $\mathrm{mm}$. & 947 & 600 & 8o & 267 & 240 \\
\hline $20 \mathrm{~mm}$. & 1053 & 665 & I 20 & 268 & 255 \\
\hline
\end{tabular}

These measurements show a progressive distancing of the greater sublingual by the submaxillary. The former remains stationary to the period of 18 millimeters. Then an advance is begun, which becomes rapid at ig millimeters. The separation begins at the same time and is somewhat variable in rate, but on the whole such as not materially to reduce the length of the keel. Like the orbitals the greater sublingual is slow in the initial stages of its development, in contrast to the submaxillary and parotid. It would seem, therefore, that the sulcal position associated with formation of flanges, while not qualitatively altering the process of gland development, which is always proliferation, yet in some way favors the early appearance of the anlage and accelerates its growth. This, once initiated, proceeds at a rate unaffected by the presence or absence of a sulcus. Here may be cited the conditions in the 19 millimeter embryo, No. 253 
(Figs. 144, I 45). On the left the lingual sulcus is absent except in its cranial segment, which the anlage of the submaxillary has not yet reached. On the right the intermediate portion is well developed, yet the two submaxillaries have reached corresponding points in their adrance, and distance the greater sublingual to the same degree.

In the stages represented by the embryos between 20 and 5I millimeters length the duct continues its advance by the same process, the proliferation of a keel and its separation by constriction, and it continues to lag behind the submaxillary. The keel in these embryos is usually indented by a slight fissure on its oral surface at least in some of its sections. The degree varies from a slight concavity to a fissure which in a very few cases causes the anlage to resemble a flange; a good example of this maximum condition is shown in Figs. I4S, 151. Only rarely does the fissure extend through the whole length of the flange and it is almost uniformly absent from the most cranial sections, which thus continue to resemble the early condition of the anlage. While these fissures are at any stage inconsiderable in sagittal extent as well as depth, and always confined to the keel, which is itself short, yet in a composite of the whole period of advance of the greater sublingual, they would serve to plot a line extending from the middle of the gutter at the lingual crossing to a cranial point nearer the mesal than the lateral boundary of the region. corresponding in position and direction to the intermediate sulcus of the human embryo.

In the embryo of $5 \mathrm{I}$ millimeters the keel has disappeared, and the Jumen of the duct can be followed to the oral epithelium. Being lateral in situation, it reaches the convexity of the plica sublingualis earlier than the submaxillary, and in the 70 millimeter embryo is attached to its lateral aspect.

The adrance of the greater sublingual in the period between 25 and 51 millimeters is shown by the table on following page, the same points of measurement having been used as in the preceding one.

The distal growth of the greater sublingual is sluggish for a long period. In embryos of $\mathrm{I} 7$ millimeters the caudal extremity of the keel is enlarged and spherical. In those of 18 millineters it forms a short, horizontally directed sprout, which grows distad below the alveolingual gutter to the mesal side of the lingual ganglion, which is grooved to receive it, and against which its fundus rests. In the embryos of 


\begin{tabular}{|c|c|c|c|c|c|}
\hline ЕмHRYO & $\begin{array}{c}\text { CONFLUENCE OF } \\
\text { LiNGUAL SUlCi } \\
\text { To LINGUAL } \\
\text { CROSSING }\end{array}$ & $\mid \begin{array}{c}\text { Confluence of } \\
\text { Lingual Sulct } \\
\text { to Greater } \\
\text { Sublingual Keer }\end{array}$ & $\begin{array}{l}\text { LENGTH OF } \\
\text { GREATER SUb- } \\
\text { EINGUAL KEEL }\end{array}$ & $\begin{array}{c}\text { CAUDAL END of } \\
\text { GREATER StBLIN- } \\
\text { GUAL KEEL TO } \\
\text { LINGUAL CROSSING }\end{array}$ & $\begin{array}{l}\text { SAGITTAL INTER- } \\
\text { VAL BETWEEN } \\
\text { CRANLAL } \\
\text { ENDS OF SEB- } \\
\text { MA UILARY AND } \\
\text { GREATER SUB- } \\
\text { LINGUAL KEELS }\end{array}$ \\
\hline & $\mu$ & $\mu$ & $\mu$ & $\mu$ & $\mu$ \\
\hline $25 \mathrm{~mm}$. & I 292 & I 86 & 93 & 1015 & 26 \\
\hline $28 \mathrm{~mm}$. & 1220 & 100 & I 20 & 1000 & 60 \\
\hline $3 \mathrm{I} \mathrm{mm}$. & 2025 & 315 & 45 & 1665 & 270 \\
\hline $51 \mathrm{~mm}$. & 3633 & 204 & 42 & 3297 & 105 \\
\hline
\end{tabular}

19 and 20 millimeters, while it has passed the ganglion, its enlarged extremity is still within the embrace of the mylohyoid muscle, but has begun to turn ventrolaterad towards the interval between the digastric and the cartilage of Meckel. At 25 millimeters it has entered the submaxillary mesenchyme and has begun to branch freely. The type is monoporlial. In the 35 millimeter embryo it extends caudad almost as far as the submaxillary, dorsomesal to which it lies; the ducts for some distance are separated by a sheathlike prolongation of the submaxillary ganglion upon the duct of the same name. This general relation is retained in the embryo of $5^{1}$ millimeters and of 70 millimeters. In later stages the greater sublingual suffers relative reduction, for in the adult it cannot be said to extend beyond the digastric upon the dorsal surface of which it is molded, and it has lost its caudal extension mesad of the submaxillary, which it overlaps to only a slight degree. Both glands have altered in shape, as is shown by comparing the elongated pyriform mass of the 35 millimeter cmbryo (Fig. 106) with the almost reniform submaxillary of the adult. Their sagittal extent is relatively less, their vertical diameter increased.

The supramylohyoid portion of the greater sublingual is present in the 5 I millimeter embryo as a series of short sprouts incrusting the duct caudad of the lingual crossing (Fig. 109, 34). In the 70 millimeter embryo these are larger and extend slightly beyond the lingual nerve (Fig. 114, 34).

The ducts of the submaxillary and greater sublingual glands pursue a. nearly horizontal course beneath the epithelium of the alveolingual 
region. There is a very slight inclination ventrad, and an equally slight one laterad, as far as the lingual crossing. Here the direction changes by a rounded curve, ventrad, laterad, and caudad, into the mesenchyme which incloses their sprouts. The Bartholinian duct is

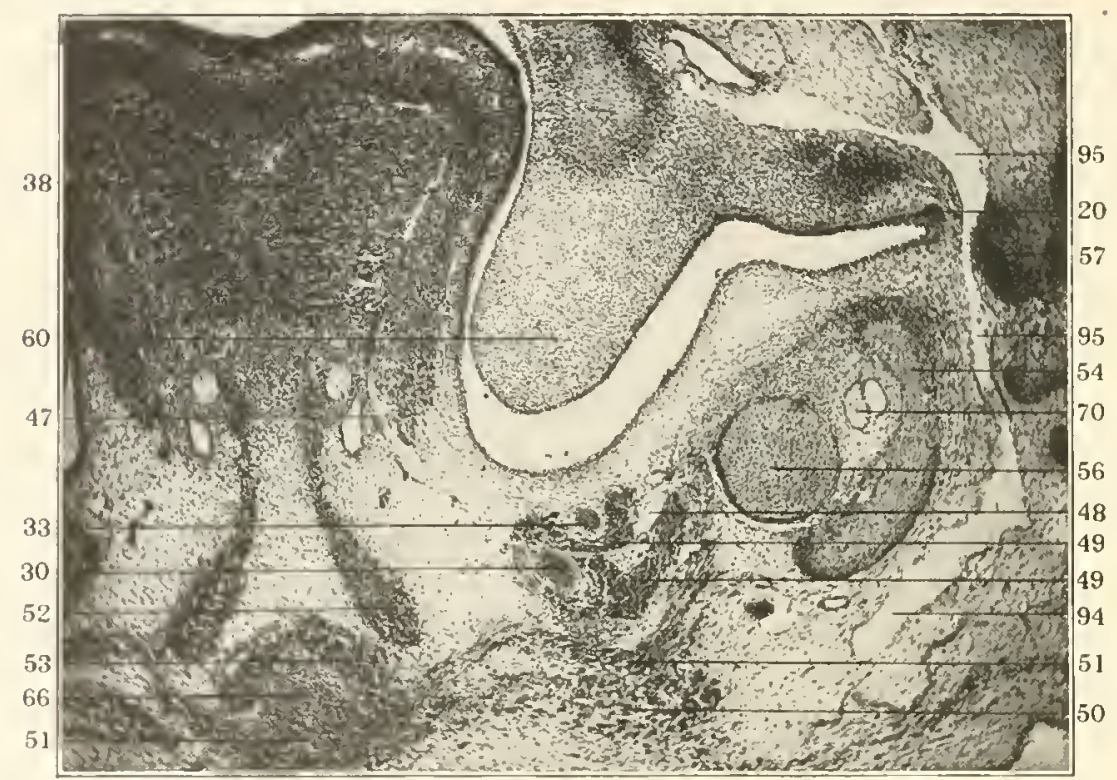

Fig. I 46 . Frontal section of the oral cavity passing through the submaxillary ganglion of a to millimeter embryo. Columbia Collection, No. 249. Left side, $X \mathrm{II}_{5}$, reduced to $\frac{1}{2}$.
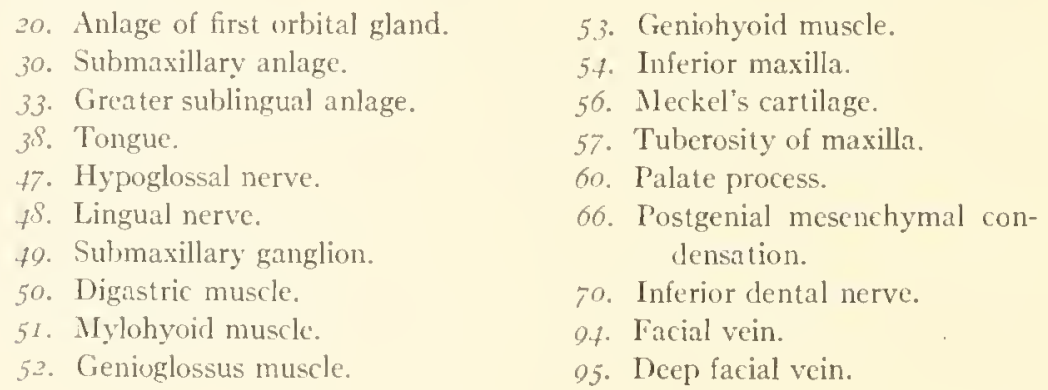

lateral as far as the lingual crossing, as was to be expected from the position of its keel, but it is also dorsal, and tends to interpose itself between the submaxillary duct and the orat epithelium; this is in part 
due to a mesal displacement of the greater sublingual, in part to a sinking ventrad of the submaxillary duct, the distance between which and the oral epithelium increases more rapidly than the corresponding interval for the greater sublingual. Caudad of the lingual nerve, as the sprouts enter the interval between Meckel's cartilage and the digastric, the relation changes. The greater subingual, continuing more horizontally and more directly caudad in the older cmbryos, crosses the submaxillary duct on its dorsal aspect from its lateral to its mesal side, and thence is continued along the mesal aspect of its branches in the dorsal portion of the condensation, and this, as has been said, to a degree far exceeding the adult overlapping of the two glands. The crossing of the ducts seems to be due to the direction taken by the more active submaxillary sprout, which carries it into the ventral and lateral portions of the mesenchyme condensation. These portions being preëmpted, the greater sublingual, when it begins its tardy growth, finds room for expansion only in the dorsomesal part of the area.

At the lingual crossing the ducts enter into intimate and complex relations with processes of the submaxillary ganglion. The large body of the ganglion retains its position lateral to the ducts. It surrounds the submaxillary duct with a cylindrical sheath and receives the greater sublingual between two processes of its mesal surface which nearly, though never quite, surround it (Fig. r 46). The ganglionic sheath upon the submaxillary duct follows it far beyond the mylohyoid, and persisting longest on its dorsomesal aspect, intervenes for a considerable distance between it and the greater sublingual duct.

THE DIFFUSE GLANDS OF THE MOUTH

By diffuse glands are meant such as are developed as simple sprouts, either from the general surface of the oral epithelium or in the course of a sulcus. The class comprises the following groups and series:-

I. The inferior alveobuccal glands, "molar gland."

2. The glands of the stomal ridge.

3. The caudal members of the orbital series.

4. The lesser sublingual glands, glandulae sublinguales minores, or Rivinian elements.

5. The isthmian and faucial glands.

6. The palatine glands. 
Of all these only the inferior alveobuccals are present in the embryos of our series less than 70 millimeters in length.

The inferior alveobuccal glands are present in the course of the sulcus of the same name in some of the embryos of 17 millimeters; in those of 18 millimeters they are constant. The sulcus at this time is a broad, shallow convexity between the buccal sulcus and the inferior dental anlage. It attains its maximum near the angulus oris and thence diminishes in both directions. The region in a 19 millimeter embryo is shown in Fig. I 44. The glands in their inception are small hemispheric elevations composed of basal cells. They are at first few in number and arranged in a single slightly irregular row. A second row is soon addled; this may be present in embryos of I8-18.5 millimeters or still lacking in embryos of 19 millimeters (Fig. 144). The sprouts are at first attached close together in the deepest part of the concavity of the sulcus. In the 25 millimeter embryo (Fig. I $_{5} \mathrm{~S}$ ) they have begun to elongate, and form small solid cylinders with very slightly enlarged rounded extremities. The sprouts are directed ventrolaterad. In the embryos above 3 I millimeters they usually fork at a little distance from the mouth, though some always lack this division. In the 28 millimeter embryo secondary branches are present. In the 35 millimeter embryo there is a pale axial line in the duct; a lumen is present in the $5 \mathrm{I}$ millimeter embryo. Here the stratum corneum is thick, and a narrow channel without proper wall continues the lumen through it to the surface. The cells adjacent to this passage contain a small quantity of pigment. In the 70 millimeter embryo a few of these passages were present in the epithelium only, terminating in the layer of basal cells, or in rery small cellular projections from its ectal surface. These had not the regular hemispheric contour of early sprouts; their appearance suggested degeneration.

While these glands are evidently formed by a simple process of sprouting, their orifices become gradually transferred to the lateral wall of the sulcus. In the 25 millimeter embryo the concavity is somewhat deeper (Fig. 158). In the embryo of 50 millimeters the sulcus is angulate at its fundus (Fig. I59); in that of 70 millimeters it is a deep $V$-shaperl cleft (Fig. 160). In the same embryos the attachment of the glands are seen to be shifted dorsad on the lateral 
wall of the sulcus. In the $5 \mathrm{r}$ millimeter embryo the anlages of the mesal row are still fundal, the lateral are parietal, in position. In the 70 millimeter embryo both are parietal and at some distance from the fundus. In the adult these glands open about midway between the fundus and margin of the lip. The sprouts never show any formation of keels at their attachments, and a great part of this displacement occurs after they have acquired a lumen. The process must therefore be referred to the conditions of growth in the sulcus itself, which produce a rolling of the epithelium at the fundus as the sulcus deepens. Here is a clear case of the assumption of a secondary parietal pusition by simple glands, which bears out the argument for a like process in the more difficult cases of such keeled glands as the parotid and submaxillary.

In the ig millimeter embryo (Fig. I44) the series extends approximately the whole length of the sulcus. This arrangement is maintained in subsequent stages (Figs. I06, I09, I14) and in the adult. That this is accomplished by the addition of new members at the cranial end of the series is rendered probable by the smaller size of the sprouts in this position.

The glands of the stomal ridge are present only in the 70 millimeter embryo. The ridge extends, diminishing in size, from the parotid orifice to the orbital angle. Dorsad it is limited by the superior alveobuccal sulcus; ventrad by the subparotid furrow, which is actually no more than a slightly deepened angle, defining the ridge from the vertical plane of the cheek. On the ridge in the line of its greatest prominence open the ducts of the parotid and orbital glands, and on the left side, also, of an orbitoparotid. The sprouts of the ridge glands are attached to the surface of the ridge near the ventral sulcus just mentioned (Fig. II6). They are all advanced beyond the stage of the hemispherical anlage, and exist as short cylinders rounded and very slightly enlarged at their extremities. On the left side there were four, viz. one immediately ventrad of the first orbital, two approximately below the second, near the caudal end of the furrow. and a fourth in a corresponding position near the third orbital orifice (Fig. II4). The first of these is the largest. Its duct runs caudad, diverging slowly from the mouth to near the border of the masseter; here it turns rather abruptly laterad, immediately ventrad of the bud 
of the orbitoparotid (Fig. I 7 ), which it strikingly resembles. It is of nearly the same size, and in its well-marked retort shape bears evidence of being a bud of great activity. Should such an element fulfil its possibilities, it would in the adult impose as an orbitoparotid, by reason of its orifice upon the stomal ridge and the position of its fundus ventrad of the sloping border of the masseter, between the superficial and deep facial veins. It is to be noted that in the small series of adults such an element was of much greater frequency than the orbitoparotid of the embryo. Notwithstanding the smallness of this series, the discrepancy was rather disconcerting. It may be explained by the possibility of late development of such an element as this, which can hardly at present be distinguished from an orbitoparotid in the adult. If the ridge gland could be shown to retain the primitively more ventral position of its orifice on the ridge, it might be recognized; otherwise I fail to see how these elements can be distinguished.

In this connection another element of the adult may be referred to. Infrequently, so far as our present knowledge extends, there is to be seen on the stomal ridge a small glandular orifice ventrad of, or even craniad of, that of the parotid (Part V, Figs. 1, 2). It is possible that this may represent the enlargement of some later established element of this series at the cranial end of the ridge. It is evident that we shall not arrive at a complete solution of the problems of this region, until the pussibilities of development of the ridge glands are understood.

The lesser sublingual glands are represented in the 70 millimeter cat by three sprouts on each side (Fig. 114, 36). They are hemispherical, resemble the basal layer of the oral epithelium in the character of their cells, and are attached to the watls of the circumflex sulcus near its fundus. This furrow is of late appearance and slow development in the cat. In the 19 millimeter embryo of Fig. It+ the plica sublingualis is present as a slight convexity of the floor of the alveolingual region beside the frenulum. Its mesal border is defined by the lingual sulcus. Laterad a faint furrow appears and gradually extends caudad, nearly reaching the lingual crossing in the 70 millimeter embryo. In the cat the furrow appears merely complimentary to the plica sublingualis, and not in any part of its extent a primitive sulcus. 
It therefore corresponds with the late-formed circumflex furrow in the human embryo, which is the site of the early lesser sublingual sprouts (Rivinian elcments). These glands of the cat must, therefore, be interpreted as more caudal members of the same series, the cranial portion being here suppressed. The sprouts are prelingual in situation (Fig. II4) and, what is of greater import, are separated by a wide interval from the diffuse glands of the isthmus, with which they are continuous in the adult, forming a small corpus glandulare in the anterior pillat of the fauces, which extends ventrad and craniad into the alveolingual region, to a point a few millimeters in advance of the lingual nerve. The condition in this embryo proves the continuity to be of secondary and late acquisition, and enables us to recognize the complex nature of the body.

The isthmian and faucial glands are numerous, especially caudad (Fig. I I4), where they are thickly scattered over the whole lateral wall from the lingual to the secondary buccal sulcus. Along the latter they are most numerous. Here a ridge is formed resembling the stomal ridge, with which, however, it is not continuous. Its dorsal limit is the secondary buccal sulcus, its ventral a wcll-defined furrow. Along both these sulci the hemispherical sprouts of the faucial glands are numerous. They diminish towards the orbital angle and are not continuous with either the lesser sublingual or alveobuccal series.

The pulutine glands are continuous with the faucial series at the secondary buccal sulci. They are rather numerous and scattered over the whole surface of the palate, but less thickly toward the median line. All are alike in structure, small hemispheric projections, composed of basal cells alone.

The caudal members of the orbital series must be reckoned among the simple diffuse glands. In the 70 millimeter embryo three are present (Fig. I 4 , 23) as short solid cylinders projecting from the dorsal wall of the secondary buccal sulcus near its fundus. In the adult the ducts of these elements run direct from their bodies to their orifices, without turning craniad to a sagittal course in the submucosa, as do those of the first three members of the series. Here, then, we find a gland series transitional in character between the keeled elements with alvancing ducts and the simple sprouts of the diffuse glands. The first three in diminishing degree belong to the class of 
the parotid, submaxillary, and greater sublingual; the caudal members appear to be no more than simple sprouts. Yet it is likely that when older embryos are examined some slight degree of advance will be found to occur in the fourth and perhaps the fifth, the keel formation diminishing gradually and continuously throughout the series, instead of making an absolute default at the third orbital.

\section{SUMNARY}

I. After the appearance of the palate process, the oral carity may be divided into three portions: the circumlingual space, the alveolingual region, and the marginal carity. which are, respectively, mesal, ventral, and lateral to the palate process.

The whole marginal cavity and the floor of the alveolingual region are lined by a thickened epithelium. This placode, at first continuous with the expansion of the carity and in proportion to its degree, becomes resolved into sagittal strips separated by areas of thinner epithelium. Thus the anlages of the salivary glands and the dental ridges arise from a common placode. Caudad the lateral expansion of the mouth is limiter by the mandibular nerve and the quintus muscles, in particular the masseter, with reference to which the marginal carity is divisible into an entomasseteric segment, where development is modified and retarded, and a promasseteric segment where growth is free. At the border of the muscle is a region of transition.

2. The modifying effects of these relations are most pronounced upon the lateral border of the mouth, the buccal sulcus, and the adjacent purtion of the marginal cavity. the maxillomandibular plane. The latter is reduced in its entomasseteric portion to a blind fold or flange, the orbital inclusion, which is finally separated from the oral epithelium and embedded in the mesenchyme along the ental surface of the masseter and internal pterygoid muscles. The glandular derivatives of the plane resolve themselves into three groups, promasseteric, masseteric, and entomasseteric, comprising, respectively. the parotid, the orbitoparotids, and the orbital glands. The direction of their growth is also determined by the masseter, the parotid ectomasseteric, the orbitoparotids usually pro- or infra-masseteric, the orlbitals entomasseteric. 
3. From the buccal sulcus are formed the orbital inclusion, the parotid, and inconstant orbitoparotid clements.

The orbital inclusion is a fold extending craniad from the plane of the mandibular nerve, and reaching the angulus oris in embryos of I 0.5 millimeters; with the lengthening of the buccal sulcus it becomes relatively displaced caudad and assumes an entomasseteric position. The first formed portion is cylindrical, pars cylindrica; at the orbital angle it broadens, pars lata, and is thence continued forward as a variable tapering cranial process. This rarely extends as far as the border of the masseter, but exceptionally may be prolonged as an orbitoparotid bridge to the parotid (Fig. I64). The inclusion becomes constricted at its attachment to the oral epithelium, from which it separates first at the junction of the pars lata and the pars cylindrica, while its extremities remain longer attached. It finally undergoes displacement laterad towards the quintus muscles. At the orbital angle the pars lata is in contact with the buccomasseteric nerve, a relation which the inclusion permanently retains. Lateral to the nerve a variable lateral process is devcloped. There are evidences of independent growth in the inclusion, in the presence of sprouts in its cylindrical portion in the 70 millimeter embryo, less certainly, also, at its caudal extremity and in the lateral process (Fig. I65).

The parotid appears as a minute fold, separate from the orbital inclusion at its inception, but at times becoming sccondarily continuous with it (Figs. I63, I64) through an orbitoparotid bridge. The "fold is reduced to a flange, which assumes a triangular shape. At its free angle a process of proliferation is initiated, which extends distad as a sprout below the border of the masseter, and also advances proximad along the free border of the flange and ultimately along the oral epithelium in front of the flange, forming a keel, which becomes constricted and freed and ultimately produces the promasseteric portion of the parotid duct. The sprout gives rise to the remainder of the duct system and the epithelium of the gland. Primarily inframuscular, the duct secondarily acquires a transmuscular position. The attachment of the anlage to the oral epithelium is at first fundal, but later becomes dorsal parietal, the buccal sulcus forming a new fundus (subparotid furrow) ventral to the anlage (Fig. I64).

The orbitoparotid elements are sprouts formed in the orbitoparotid 
interval. They may arise from the parotid flange in the angle between the duct and the oral epithelium, or from either the oral epithelium or the duct itself. Their bodies, usually of small size, are confined to the triangle between the mouth. the parotid duct, and the masseter muscle. In this confined space they may be parallel to the parotid, or to the oral epithelium, or have an intermediate direction. Very rarely larger sprouts tend to escape either towards the orbit or along the inframasseteric path. In a few cases these elements were found separated and forming inclusions.

The parotid, orbitoparotid, and the sprouts referred to in the course of the orbital inclusions, evidently constitute a series of buccal sulcus

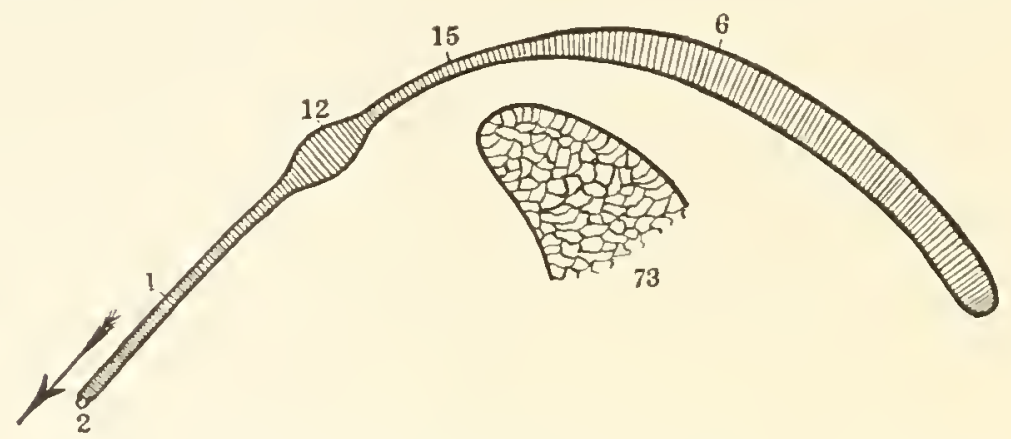

FIG. I63. Sihema of buccal sulcus and its derivatives, early stage.

- I. Buccal sulcus.

2. Angulus oris.

12. Parotid anlage.

0. Orbital inclusion.

15. Orbitoparotid interval.

73. Masseter muscle.

derivatives modified in development by the presence of the masseter (Fig. I65).

4. The vestibule is formed by a remodeling of the maxillomandibular plane. In this process the buccal sulcus is largely effaced, and dorsal and ventral limits (alveobuccal sulci) are formed for the new carity by a simple process of folding in the roof and floor of the mouth. With the appearance of the alveobuccal sulci, two sagittal strips of epithelium are defined, intervening between them and the buccal sulcus (Wangenstreifen, Chievitz), which are destined to form the lining of the cheek. Of these the ventral is much the wider, corresponding to the greater expansion of the floor of the maxillomandib- 
ular plane as contrasted with the roof, and is accordingly the major component of the cheek. Caudad the alveobuccal sulci converge towards the orbital anlage. Here the buccal sulcus has been reduced in the formation of the orbital inclusion, and a new lateral border acquired by the marginal cavity, the secondary buccal sulcus. This becomes continuous with the superior alveobuccal sulcus (Figs. I64, 165, I $a$ and 25). The orbital inclusion, therefore, corresponds to the

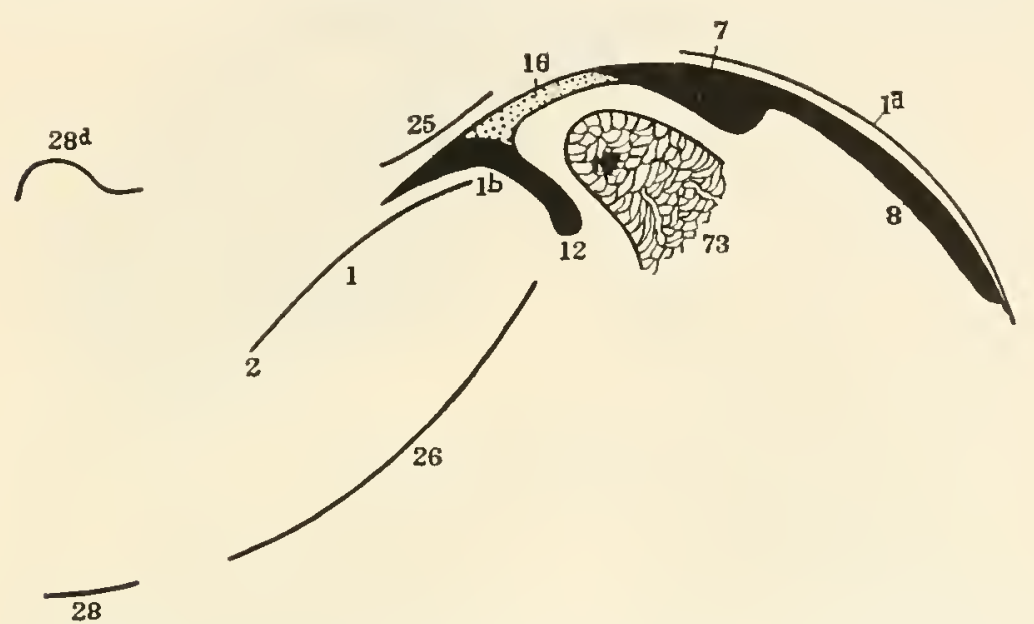

Fig. I64. Schema of buccal sulcus together with the alveobuccal and alveolabial sulci, intermediate stage.

I. Buccal sulcus.

Ia. Secondary buccal sulcus.

Ib. Subparotid sulcus.

2. Angulus oris

7. Orbital inclusion, pars lata.

8. Orbital inclusion, pars cylindrica.
12. Parotid anlage.

16. Orbitoparotid bridge.

25. Superior alveobuccal sulcus.

26. Inferior alveobuccal sulcus.

28. Infcrior alveolabial sulcus.

28a. Superior alveolabial sulcus.

73. Masseter muscle.

dorsal Wangenstreifen on the roof of the mouth precisely, so far as the dorsal lamina of its fold is concerned. The ventral alveobuccal sulcus disappears near the border of the masseter. It is, therefore, impossible to make so precise an evaluation of the ventral lamina of the inclusion, in terms of the ventral Wangenstreifen. The subparotid condensation in the mesenchyme is lateral to the inferior alveobuccal sulcus; in early stages it extends caudad to the inclusion, and lies imme- 
diately ventrad of the cranial process and pars lata. It would secm, therefore, that not the whole of the Wangenstreifen is included in the ventral lamina. The lining epithelium of the cheek thus appears as the expansion of parts immediately adjacent to the buccal sulcus.

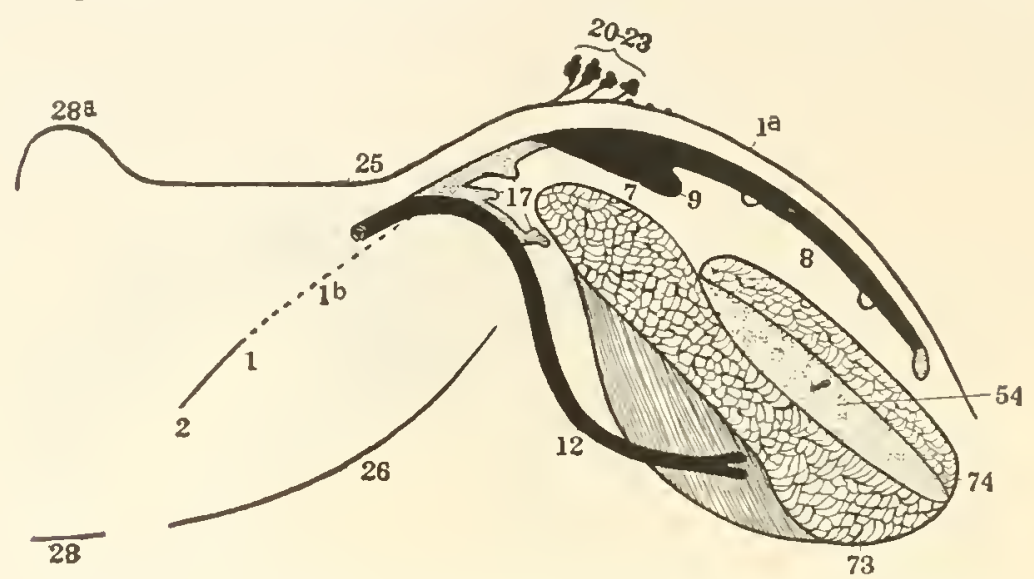

F1G. I65. Schema of alveobuccal and alveolabial sulci, late stage.

I. Buccal sulcus.

Ia. Secondary buccal sulcus.

Ib. Subparotid sulcus.

2. Angulus oris.

7. Orbital inclusion, pars lata.

8. Orbital inclusion, pars cylindrica.

Q. Lateral process of orbital inclusion.

12. Parotid anlage.

17. Orbitoparotid sprout.

20. First orbital gland.
21 . Second orbital gland.

22. Third orbital gland.

23. Caudal orbital glands.

25. Superior alveobuccal sulcus.

26. Inferior alveobuccal sulcus.

28 . Inferior alveolabial sulcus.

2 $\delta$. Superior alveolabial sulcus.

54. Inferior maxilla.

7.3. Masseter muscle.

74. Internal pterygoid muscle.

Like the rest of the marginal cavity their development is modified and retarded where they are in relation to the masseter.

5. The orbital glands arise in the course of the secondary buccal sulcus in a dorsal parietal position. They are the results of a process of proliferation unaccompanied by flange formation. The first three form keels which advance craniad and are separated by constriction from the oral epithelium to form the ducts. The caudal members of the series appear to be simple sprouts. As the secondary buccal sulcus is evidently equivalent to the superior alveobuccal with which it becomes continuous, its glands are homodynamous with superior 
alveobuccal glands and may, therefore, be directly compared with the superior labial series of reptiles.

6. The inferior alveolabial glands are a series of simple sprouts in the course of the sulcus of the same name, and are equivalent to the inferior labial glands of reptiles.

7. Reichel interpretcd the parotid as equivalent to an hypertrophied gland of the superior labial series. As the segment of the buccal sulcus from which it arises is not present in sauropsida, this homology requires qualification. In view of the continuous placode which occupics the marginal cavity of mammalian embryos, and the evolution of separate anlages incident to its expansion, it would seem that in this placode was contained material equivalent to both dorsal and ventral alveobuccal sulci and their derivatives; that, in general, expansion and separation of the anlages precede their activation, but that the parotid, being accelerated, develops in the fundus of the buccal sulcus out of material which has not yet been absolutely assigned either to the dorsal or the ventral gland line, and appears, therefore, ontogenetically as a neomorph of intermediate position, yet in its subsequent shift to a dorsal parietal position and in ultimately coming to open upon a common stomal ridge with the orbital glands, it manifests its closer affinity to the dorsal line, which is also reflected in the less degree of expansion of the dorsal Wangenstreifen, as compared with the ventral. It should, therefore, be interpreted as a displaced portion of the dorsal series, owing its inception and independence to processes incident to formation of the cheek and consequent léngthening of the buccal sulcus of the mammalia.

8. The glands of the alveolingual region are the submaxillary, the greater sublingual, and the lesser sublinguals. The submaxillary anlage appears as a low keel of epithelium at the fundus of the lingual sulcus, a persistence of the mesal border of the primitive placode. A flange is then formed in the segment of the sulcus caudal to the lingual nerve, and the keel is carried ventrad as its free border. The flange becomes triangular, and proliferation is initiated at its free angle; there results a distal free-growing sprout and the formation of a crest proximad, which, advancing along the flange, reaches the fundus of the sulcus. Later, as the sulcus deepens the lengthening crest assumes a parietal position in its lateral wall. The duct is formed by the constriction and separa- 
tion of the crest of proliferation. In the region of the flange rudimentary structures appear (Figs. I41, I42), a postglandular flange representing its attached border, and an intermediate portion, which is usually allot ted to the duct. Both are ephemeral in the cat, and have not been found to give rise to sprouts.

The greater sublingual gland is the result of a process of proliferation initiated caudal to the lingual nerve, lateral to, and distinctly separate from, the submaxillary anlage, of which it is perfectly independent throughout development. It appears as a ridgelike thickening in the midst of a remnant of the primitive placode, and advances as a keel along the floor of the alveolingual region. Its duct is freed by constriction. The distal sprout is relatively late in assuming active growth.

The lesser sublinguals in the 70 millimeter embryo are represented by three hemispherical sprouts in the prelingual segment of the circumflex sulcus (Fig. 1 I4). The gland field of the alveolingual region resolves itsclf into three sagittal gland lines: mesal, the submaxillary, intermediate, the greater sublingual, lateral, the lesser sublinguals.

9. In the 70 millimeter embryo (Fig. II 4 ) the simple sprouts of the small diffuse glands of the mouth are for the first time present. These are the lesser sublinguals, the caudal members of the orbital series, the glands of the stomal ridge, isthmian, faucial, and palatine glands.

IO. As regards the developmental process, the salivary glands are either simple sprouts, or in addition to the sprout have keeled extensions along the oral epithelium. The latter are termed complex glands, and are regarded as equivalent to condensed rows of simple sprouts. To this class belong the parotid, the submaxillary, the greater sublingual, the first three orbitals, and possibly some of the orbitoparotid elements. Two glands of this class are in early development associated with a flange, the parotid and submaxillary. Their permanent structure is like that of the other glands, the result purely of proliferation. The flanges seem only to accelerate their development, as shown by their early appearance and rapid growth, and serve to guide the crests which give rise to the ducts. In contrast to the flanged glands, the growth of the sprouts of the other complex glands is late in beginning (greater sublingual, orbitals I. II, III). 
1I. The anlages at the salivary glands are all at first solid. Later their central cells stain feebly and have pyknotic nuclei. The lumina are late in appearance, and at first are small, discontinuous clefts which later become continuous. During this process the central cells disappear.

\section{ANNOTATION OF LEADERS IN ALL FIGURES}

I. Buccal sulcus.

Ia. Secondary buccal sulcus.

Ib. Subparotid sulcus.

2. Angulus oris.

3. Postangular segment of buccal sulcus.

7. Postangular bend.

5. Orbital angle.

6. Orbital inclusion.

7. Pars lata of orbital inclusion.

8. Pars cylindrica of orbital inclusion.

9. Lateral process of orbital inclusion.

IO. Cranial process of orbital inclusion.

II. Separating sulcus.

12. Parotid anlage.

I3. Subparotid condensation.

I4. Periparotid condensation.

I5. Orbitoparotid interval.

I6. Orbitoparotid bridge or flange.

17. Orbitoparotid sprout.

I8. Orbitoparotid inclusion.

19. Stomal ridge.

Iga. Glanrls of stomal ridge.

2o. Anlage of first orbital gland.

21 . Anlage of second orbital gland.

22. Anlage of third orbital gland.

23. Anlages of caudal orbital glands.

24. Inferior alveobuceal glands.

25. Superior alveobuccal sulcus.

26. Inferior alveobuccal sulcus.

27. Diastemal fold.

28. Inferior alveolabial sulcus.

$28 a$. Superior alveolabial sulcus.

29. Lingual sulcus.

30. Submaxillary anlage.

30a. Intermediate element. 
31. Postglandular flange.

32. Submaxillary condensation in mesenchyme.

33. Greater sublingual anlage.

34. Supramylohyoid portion of greater sublingual.

35. Circumflex sulcus.

36. Lesser sublingual glands.

37. Faucial glands.

38. Tongue.

39. Frenulum

fo. Lateral tongue swelling.

fi. Tuberculum impar.

42. Craniolingual plane.

43. Palatolingual plane.

4. Alveolingual region.

75. Palatomandibular plane.

f6. Maxillomandibular plane.

77. Hypoglossal nerve.

48. Lingual nerve.

49. Submaxillary ganglion.

50. Digastric muscle.

51. Mylohyoid muscle.

52. Genioglossus muscle.

53. Geniohyoid muscle.

5t. Inferior Maxilla.

55. Inferior alveolar process.

56. Meckel's cartilage.

57. Tuberosity of maxilla.

58. Zygoma.

59. Maxillary process.

6o. Palate process.

OI. Mandibular process.

62. Ectopalatine sulcus.

63. Palate bone.

64. Superior dental anlage.

65. Inferior dental anlage.

60. Postgenial mesenchymal condensation.

67. Mandibular nerve.

68. Maxillary nerve.

69. Buccomasseteric nerve.

7o. Inferior dental nerve.

71. Fifth nerve.

72. Gasserian ganglion.

73. Masseter muscle.

7t. Internal pterygoid. 
75. Buccinator muscle.

76 . Fauces.

77. Pharynx.

78. Median dorsal sulcus of pharynx.

79. Nasal fossa.

So. Septum nasi.

$\delta_{I}$. Lateral nasal cartilage.

82. Nasal sulcus.

$\delta_{3}$. Lateral nasal process.

84. First entodermal pouch.

85. Nasopharynx.

86. Tubotympanic sulcus.

87. Hypophysis.

88. Eyc.

8g. Periorbita.

go. Ophthalmic vein.

91. Epiglottis.

Q2. Trachea.

93. Facial nerve.

9f. Facial vein.

95. Deep facial vein.

g5. Plica sublingualis.

97. Ilyoid bar.

gS. Esophagus.

9.. Recurrent branch of parotid. 




\section{EXPLANITION OF FIGURES}

All the following figures of reconstructions and sectims are based upon material in the Embryological collection of Columbia University with the exception of Figs. 46 and 97 , which are from embryo No. 21 of the P'rinceton Collection. For permission to study and reconstrue this embryo my acknowleelgements are due to Professur C. WI. F. Mcclure.

\section{Platis NLI-XLIL}

FIgs. I-S. Camera lucida outlines of the oral cavity of an 8.5 millimeter embryo. Columbia Collection, No. 2.8. Frontal transwerse sections taken at inturvals of $\mathrm{r} 33 \mu, \times$ So, reduced to $\frac{1}{6 .}$.
2. Angulus oris
fer. Latcral tongue swelling.
t1. Tuberculum impar.
50. Maxillary process.
OI. Mandibular process.
67. Manclibular nerve.
$7 I$. Trigeminal nerve.
7.9. Median clorsal sulcus of pharynx.
Sz. Nasil sulcts.
3 3. Lateral nasal process.
$s_{4}$. First entudermal prouch
ine. Tubotympanic sulcus.
15. Hypophysis.
97. Hyoid bar. 


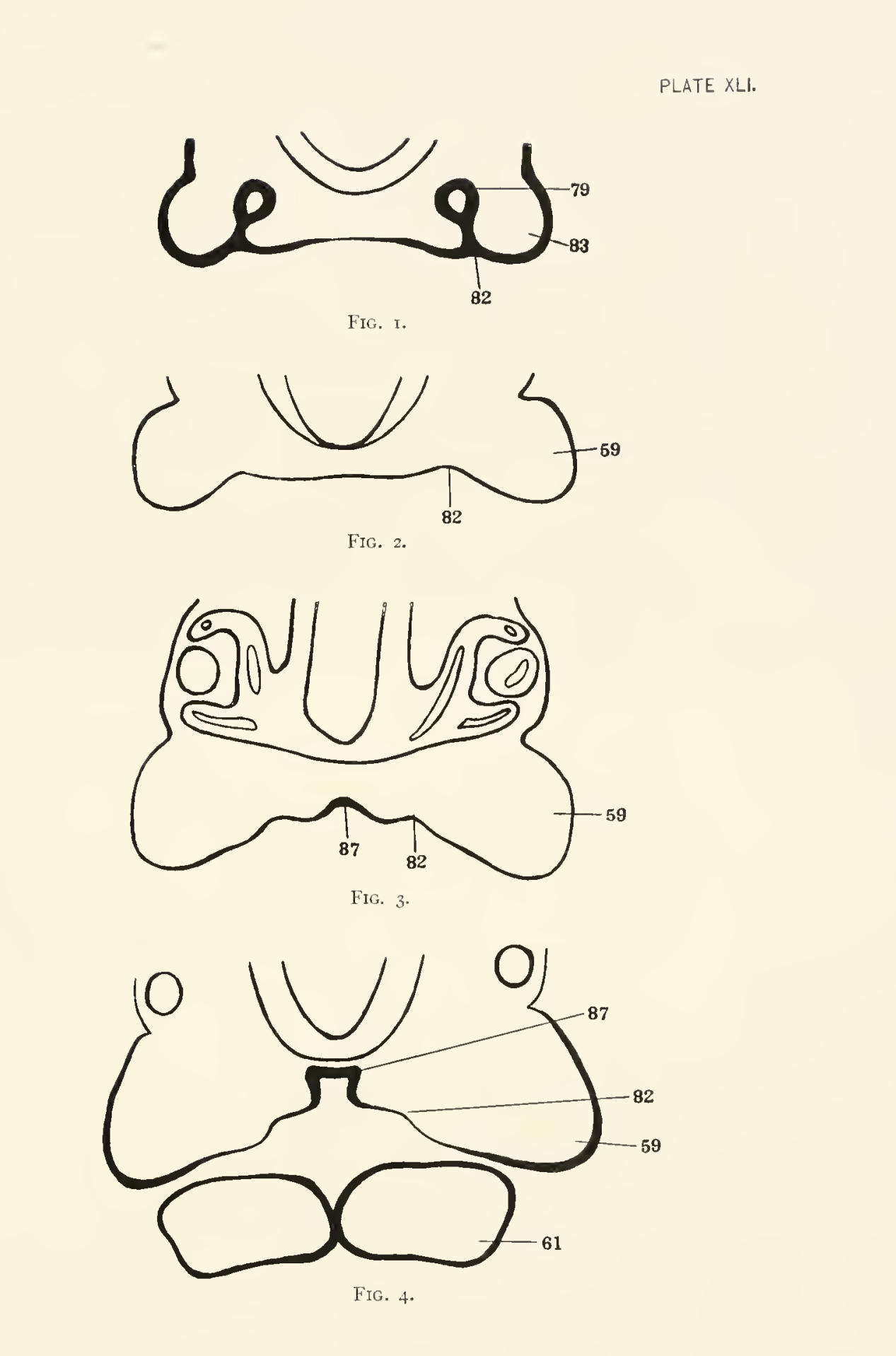




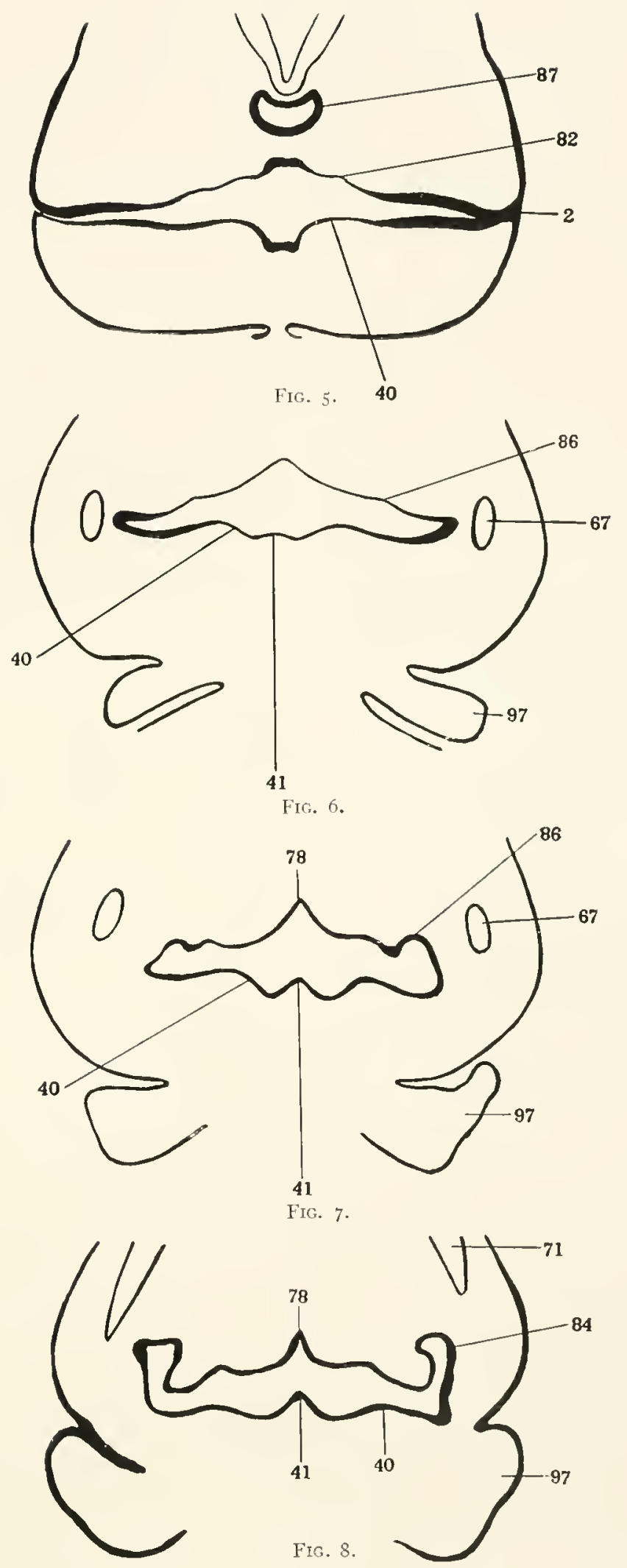


\section{PLATE, XLIII}

FIti, 0. Camera lucidia outline of the oral epithelium in frontal section of a to millimeter embryo. Columbia Collection, No. 237, at the plane of the anguli oris, $X$ So, reduced to $\frac{1}{6}$.

FI6. Io. The same. Frontal section in the plane of the mandibular nerves, $\times$ So, reduced to ?

Fig. Ir. Camera lucida outline of the oral epithelium in frontal section in the plane of the mandibular nerves, from the 10.5 millineter embryo. Columbia Collection, No. I $20, \times 80$, reduced to $\frac{1}{6}$.

2. Angulus oris.

6. Orbitil inclusion.

fo. Lateral tongut swelling.

71. Tuherculum impar.

0o. Pillate process.

67. Mandibular nerve.

6). Maxillity nerve.

$7 I$. Trigeminal nerve.

72. Gasserian ganglion.

86. Tubotympanic sulcus.

S7. Hypophysis. 
PLATE XLIII.

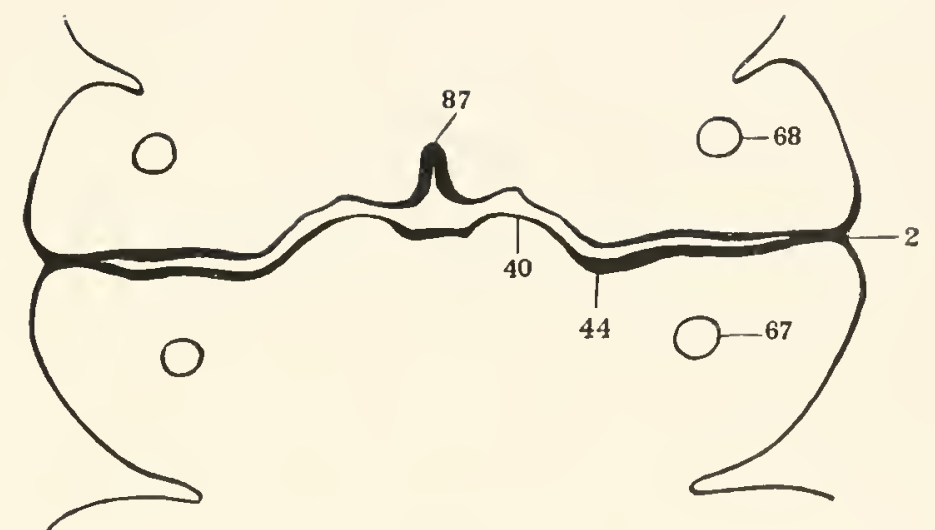

FIG. 9.

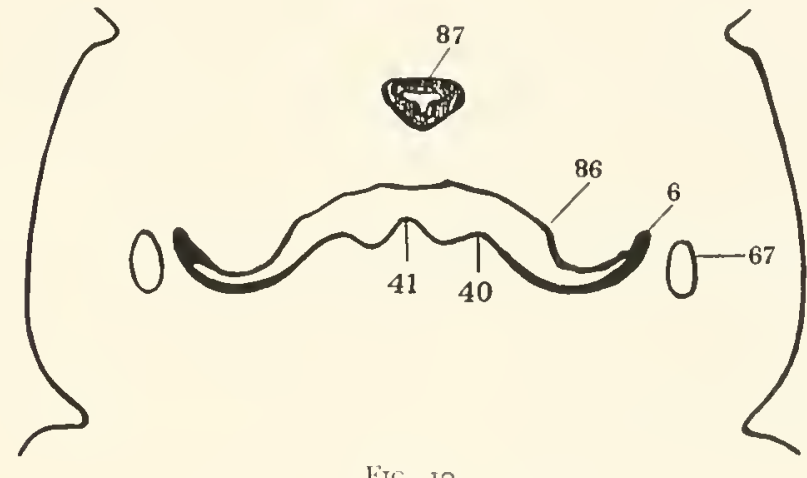

Fis. Io

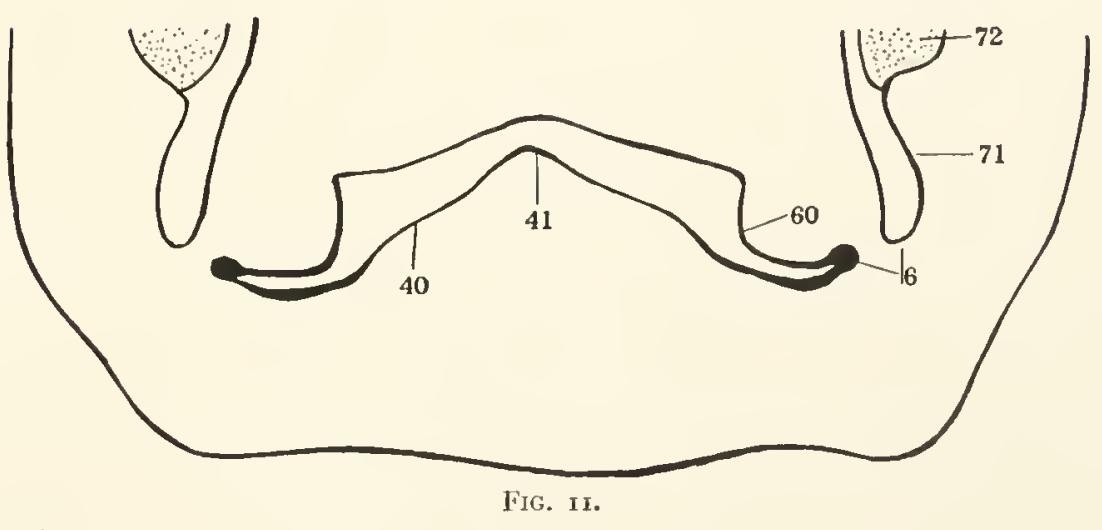


PLATE XLIS

FIGS. 12-14. Camera lucida outlines of the oral epithelium in frontal section, at the angulus oris, at the orbital angle, and in the caudal segment of the buccal sulcus, from an II.5 millimeter embryo. Columbia Collection, No. 25 I. $\times$ So, reclucet to $\frac{1}{6}$.

7. Orbital inclusion, pars lata.

8. Orbital inclusion, pars cylindrica.

29. Lingual sulcus.

4.9. Lingual nerve.

5n. Meckel's cartilage.

6o. Palate process.

62. Ectopalatine sulcus.

$\hat{f}_{t}$. Superior dental anlage.

65. Inferior dental anlage.

6-. Nandibular nerve.

68. Maxillary nerve.

69. Buccomasseteric nerve. 
PLATE XLIV.
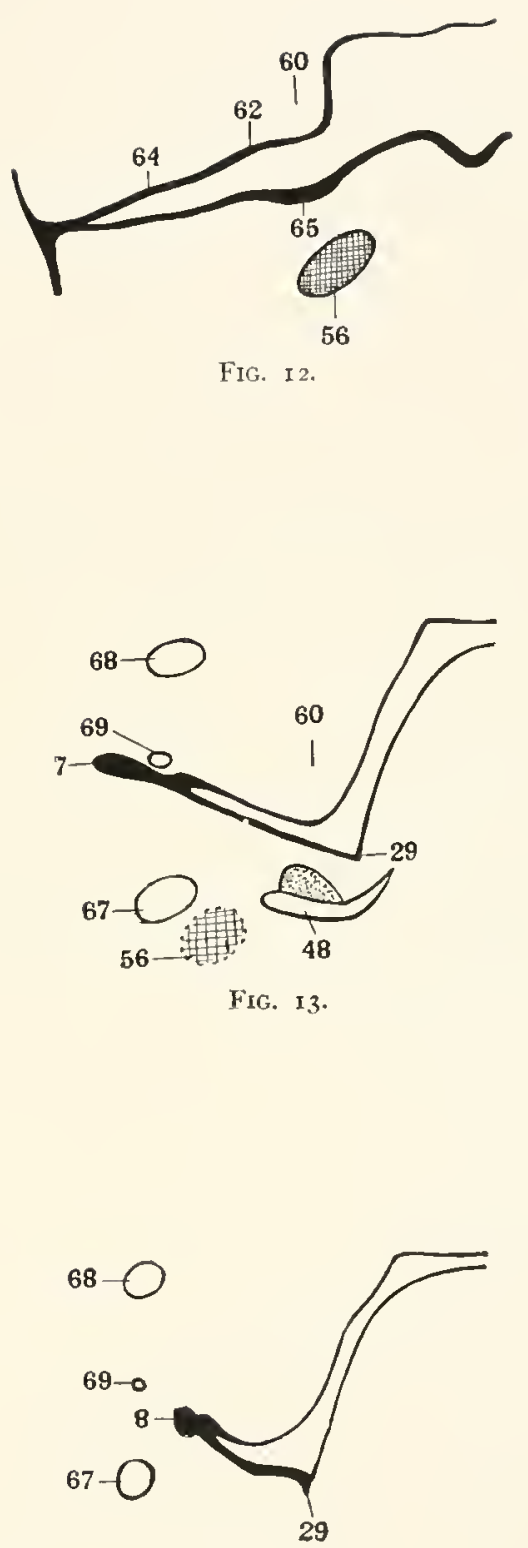

Fig. I4. 


\section{Plate XLV}

Figs. I5-17. Camera lucirla outlines of the oral epithelium in frontal section at the angulus oris, orbital angle, and in the caudal portion of the buccal sulcus, trom an embryo of a 2.5 millimeters. Cloumbia Collection, No. $20+<$ So, reduced to $\frac{1}{12}$.

1. Buccal sulcus

2. Ingulus oris

7. Orbital inclusion, pars lata.

8. Orbital inclusion, frars cylindrica.

29. Lingual sulcus

30. Submaxillary anlage.

t2. Craniolingual plane.

43. Palatolingual plane.

45. Palatomandibular pline.

th. Maxillomandibular plane.

to. Sulumaxillary ganglion.

5\%. Meckel's cartilige,

6o. Palate process.

62. Ectopalatine sulcus.

6.- Mandibular nerve.

6.8. Maxillary nerve.

6o. Buccomasseteric nerve.

7.3. Masseter muscle. 


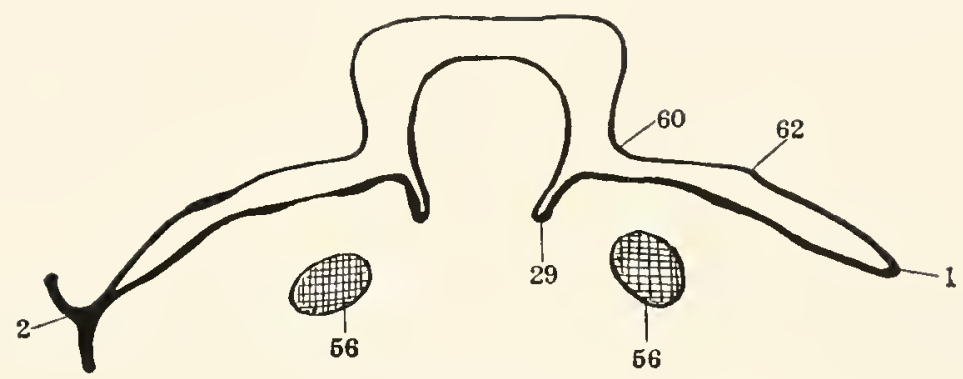

FIG. I5.
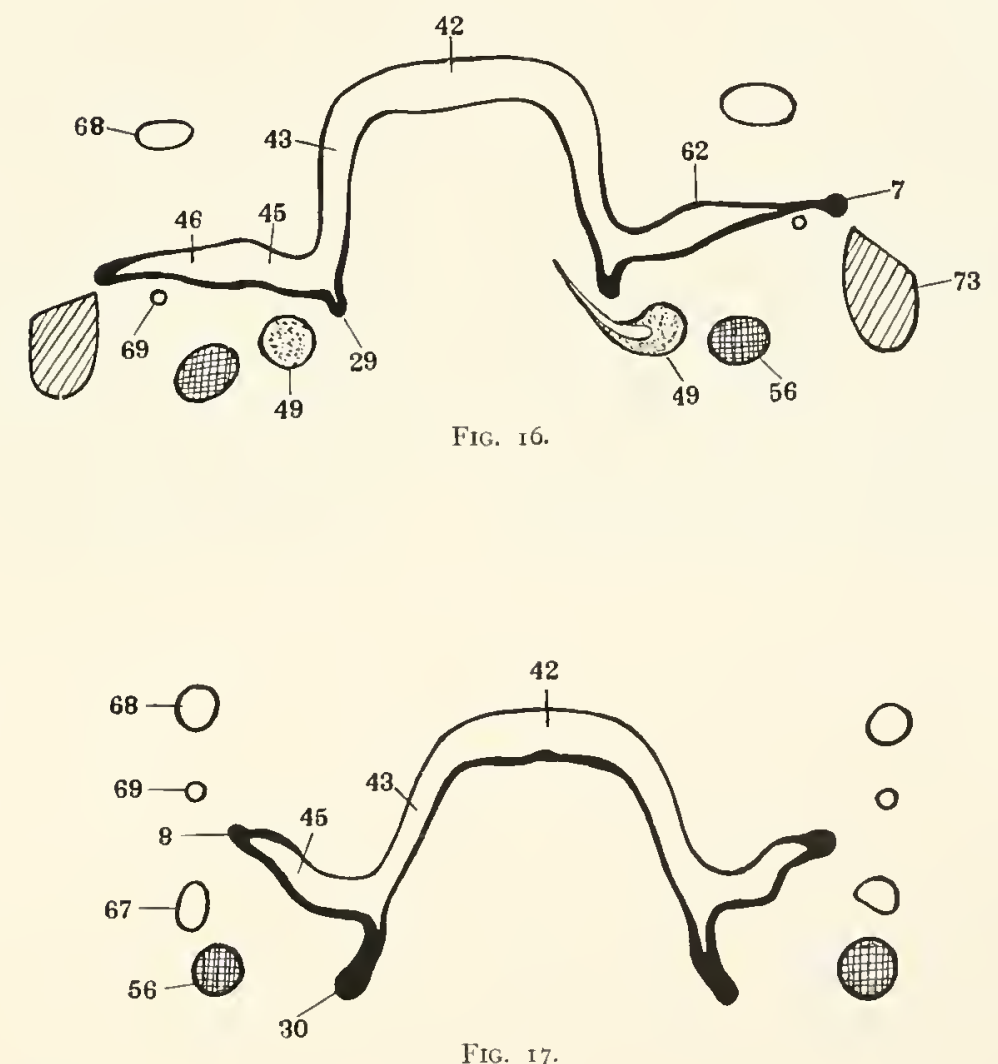


\section{Plate XlVI}

FIG. IS. Photomicrograph of frontal section in the plane of the mandibular nerve, from an embryo of a millimeters. Columbia Collection, No. 26.8 , $X$ II 5 , reduced $10 \%$.

Fur. 19. Photomicrograph of frontal section in the plane of the mandibular nerve, from an embryo of 9 millimeters. Columbia Collection, No. 1o6, $\times 115$, reduced to $\%$. 


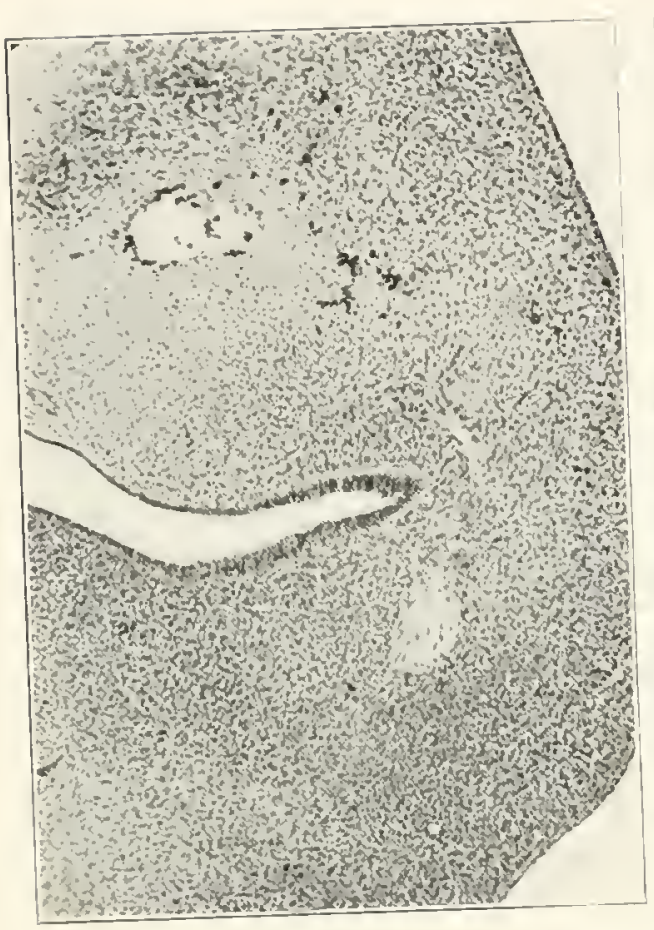

Fig. IS.

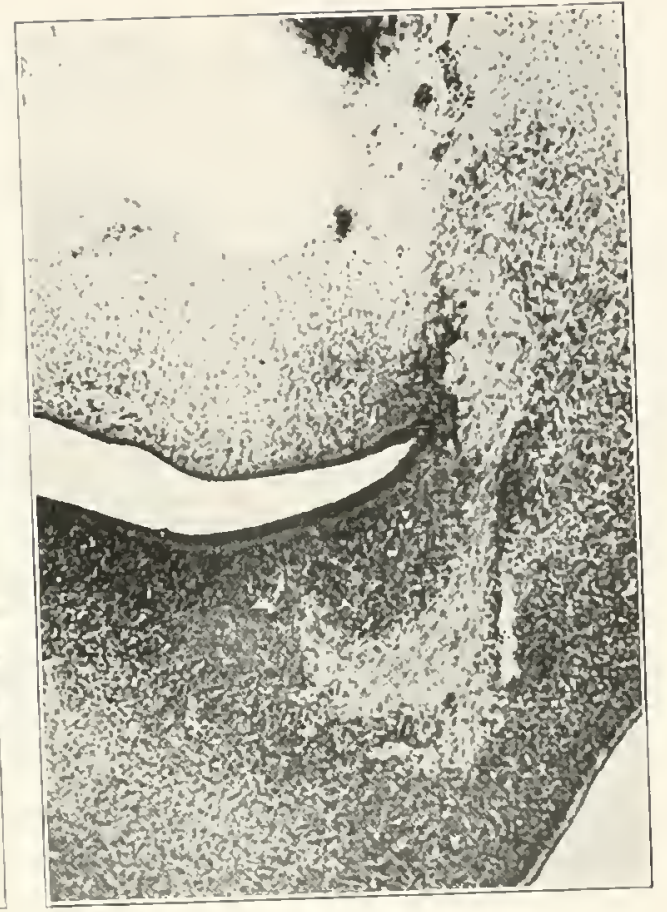

Fic. 19. 
Plate xlyi

FIG. 20. Photomicrugraph of frontal section in the plane of the mandibular nerve, from an embryo of $10 \mathrm{~mm}$. Columbia Collection No. $120, \times 100$, reduced to $\frac{2}{3}$. 


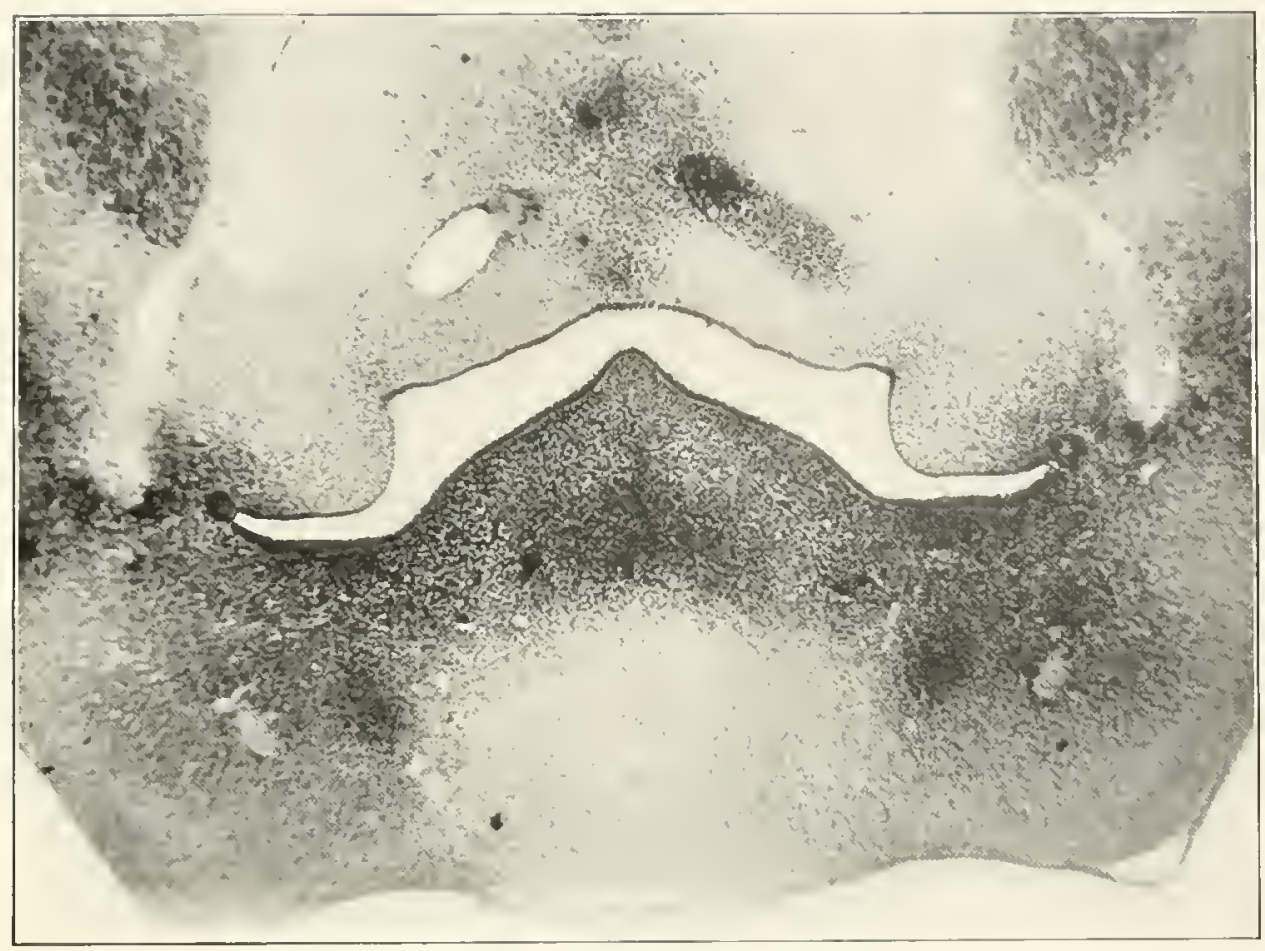

Fig. 20. 


\section{Plate XLI'III}

FIG, 2I. Reconstruction of the ectal surface of the oral epithelium of a Io millimeter embryo. Columbia Collection, No. I $\mathrm{I}_{3}, \times 600$, reduced to ${ }_{4}^{1}$. FIg. 22. Frontal section of the broader portion of the orbital fold of the same embryo, at the site indicated in the preceding figure, $X$ II5, re'duced to $\frac{1}{2}$.

2. Angulus oris.

6. Orbital inclusion

7. Orbital inclusion, pars lata.

70. Lateral tongue swelling.

7I. Tuberculum impar.

74. Alveolingual region.

6o. Palate process

67. Mandibular nerve.

S6. Tubotympanic sulcus. 

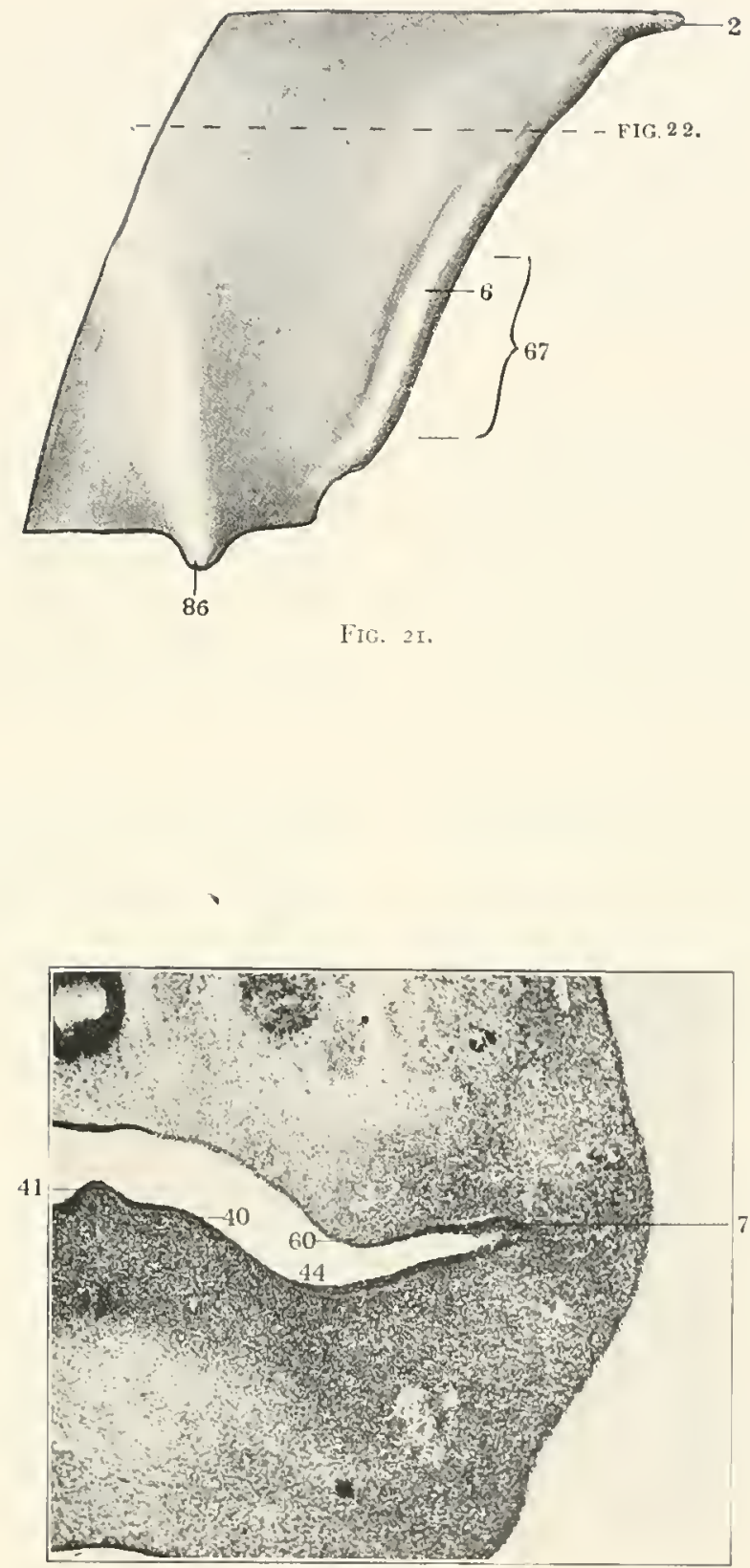

FIG. 22 


\section{Plate NLIS}

FIGS. 23-30. Frontal sections of the marginal cavity and alveolingual region of an ir. 5 millimeter embryo. Columbia Collection, No. 256. Slide 7, sections $12,17,22,26,27,34,42,4 t$. Thickness of sections, $13.3 \mu$, $X_{\text {I I } 5}$, reduced to $\frac{1}{2}$.

2. Angulus oris.

7. Orbital inclusion, pars lata.

S. Orbital inclusion, pars cylindrica.

v. Orbital inclusion, lateral process.

1.3. Subparotid mesenchymal condensation

20. Lingual sukus.

3\%. Submaxillary anlage.

4. Aveolingual region.

45. Lingual nerve.

44. Submaxillary ganglion.

50. Mleckel's cartilage.

64. Superior dental anlage.

6\%. Inferior dental anlage.

0o. Buccomasseteric nerve.

70. Inferior dentill nerve.

73. Masseter muscle. 


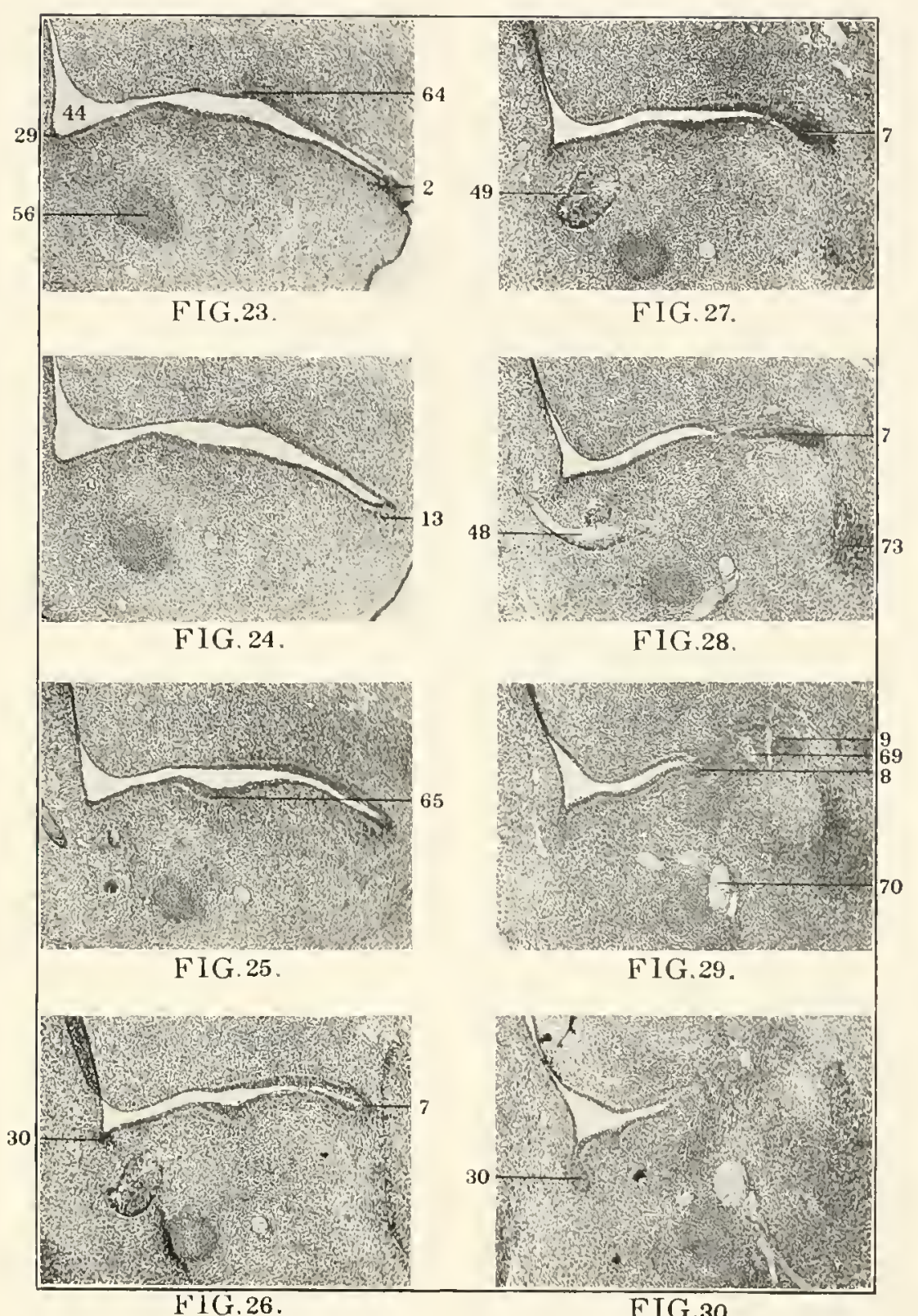

FIG.30. 
PLATE I,

FIG. 3I. Reconstruction of the ectal surface of the epithelium of the left buccal sulcus in al 13 millimeter embryo. Columbia Collection, No. 107, $\times 300$. Dorsal view, rerluced to $\frac{1}{2}$.
Ia. Secondary buctal sulcus.
2. Angulus uris.
4. Postangular bend.
7. Orbital inclusion, pars latat.
8. Orbital inclusion, pars cylindrica.
11. Separating sulcus.
I2. Parotid anlage.
15. Orbituparotid interval. 


$$
7
$$


PLATE LI

FIGs. 32 and 33. Frontal sections of a 1,3 millimeter embryo. Columbia Collection, No. $16_{7}$, at the levels indicated in the precerling figure showing tears in the periderm of the orbital inclusion causing it to resemble an open fold, $\times 300$, reduced to $\frac{3}{1}$

Ia. Secondary buccal sulcus.

8. Orbital inclusion, pars cylindrica.

I1. Separating sulci. 


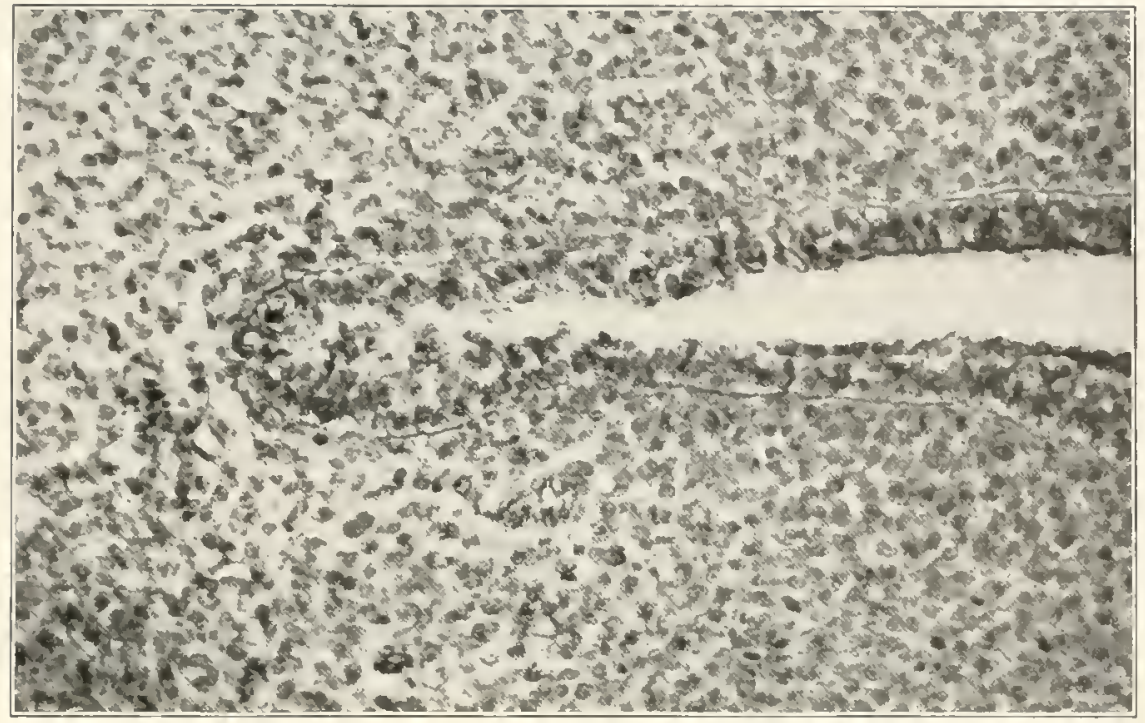

Fig. 32.

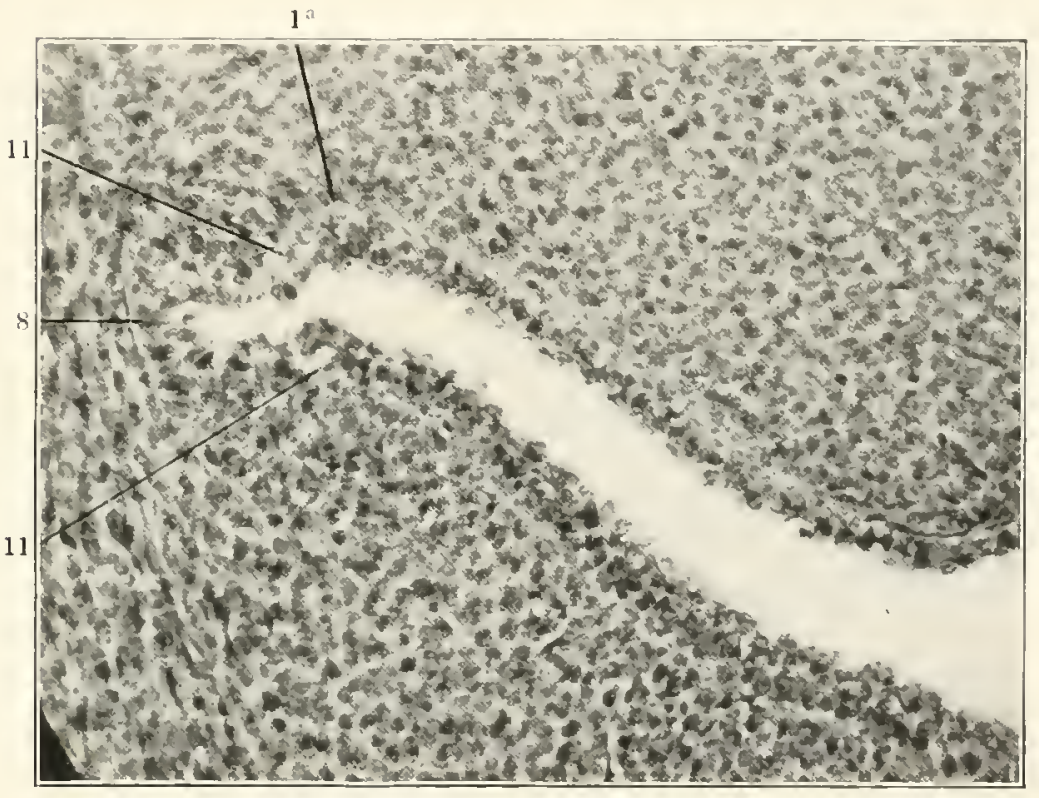

FIG. 33. 
FIG. 34. Reconstruction of the ectal surface of the epithelium of the left buccal sulcus of an embryo of $1,3.5$ millimeters. Columbia Collection, No. I $89, \times 300$, reduced $\frac{1}{2}$. Dorsal view.

Fig. 35. Same embryo. Reconstruction $f$ the ectal surfac of the oral epithelium. Dursal view. $\times 45$, actual size.

2. Angulus oris

7. Postangular bend.

7. Orbital inclusion, pars lata.

8. Orbital inclusion, pars cylindrica.

II. Dorsal separating sulcus.

12. Parotid anliage.

15. Orbitoparotid interval.

IT. Orbitoparotid sprout.

62. Eectopalitine sulcus.

ho. Buccomasseteric uerve.

s. First entorlermal pouch.

87. Hypophysis. 


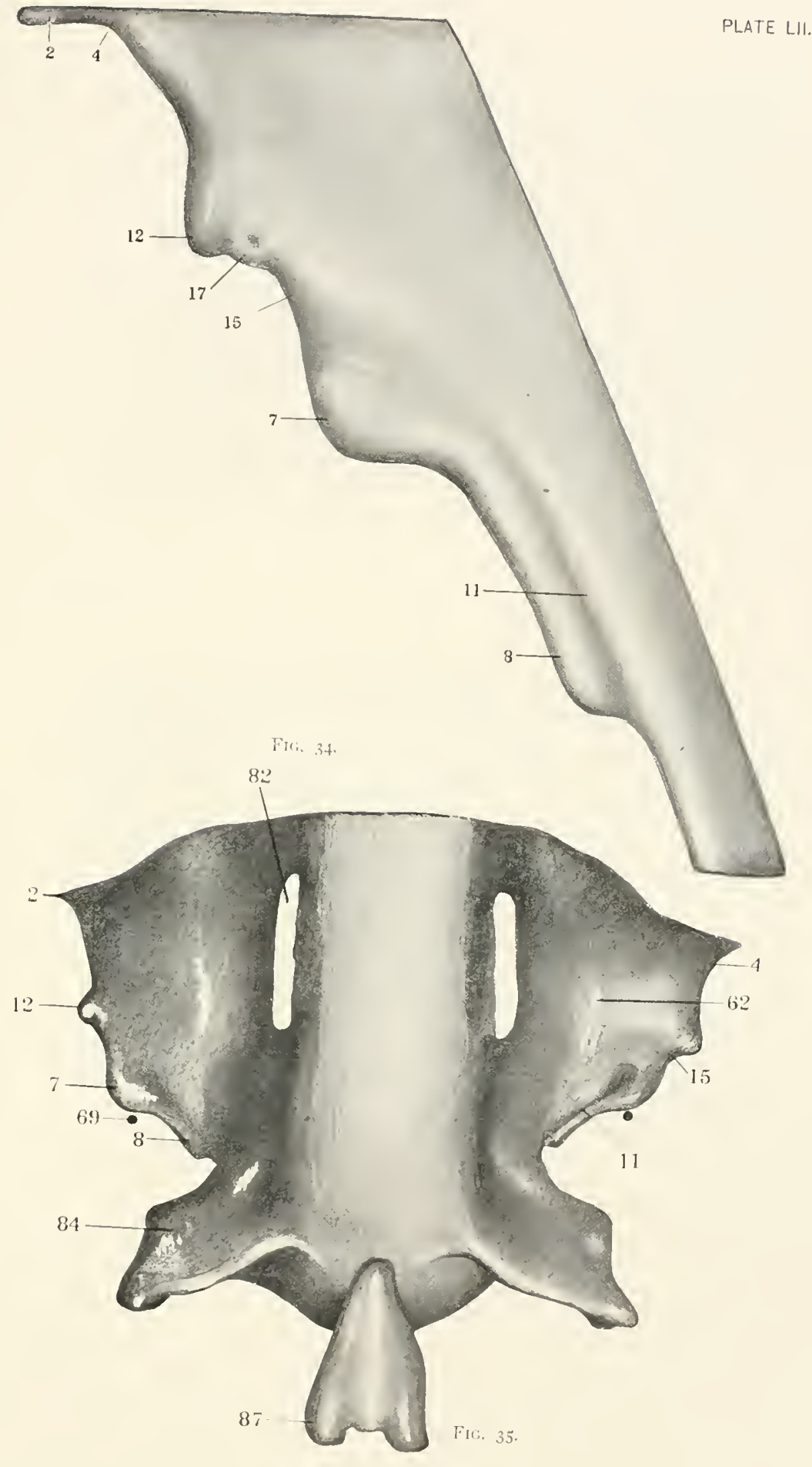


Plite LIII

Figs. 36 and 37. Same embryo as Figs. 34 and 35. Frontal sections of head passing through parotid anlages $(.36)$ and through the partes latae of the orbital inclusions $(37), \times 35$, reduced $\frac{9}{10}$.

58. Zygoma.

73. Masseter muscle. 


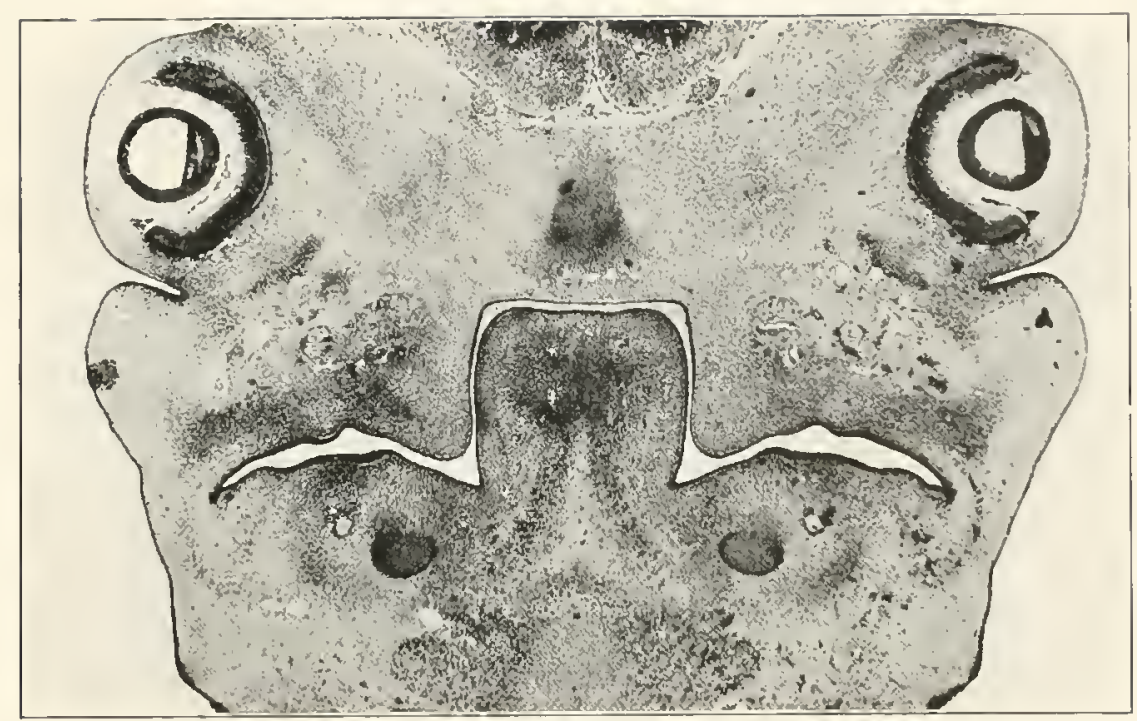

Fig. 30 ,

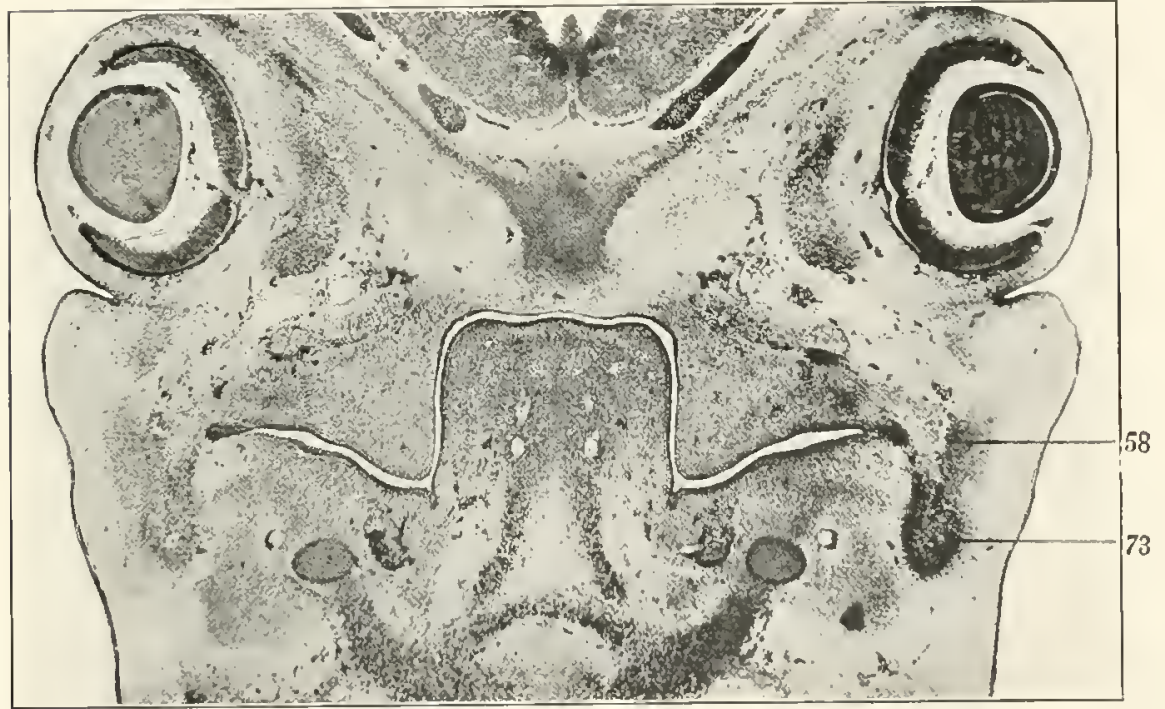

Fici. 37. 
Plate LIV

Figs. 38 and 30. Same embryo as preceding figures. Frontal sections passing through the lingual crossing ( 38 ) and the submaxillary anlage (39), $\times$ 35. reduced to "i'.

30. Submaxillary anlage.

ti. Hypoglossal nerve.

4. Lingual nerve. 


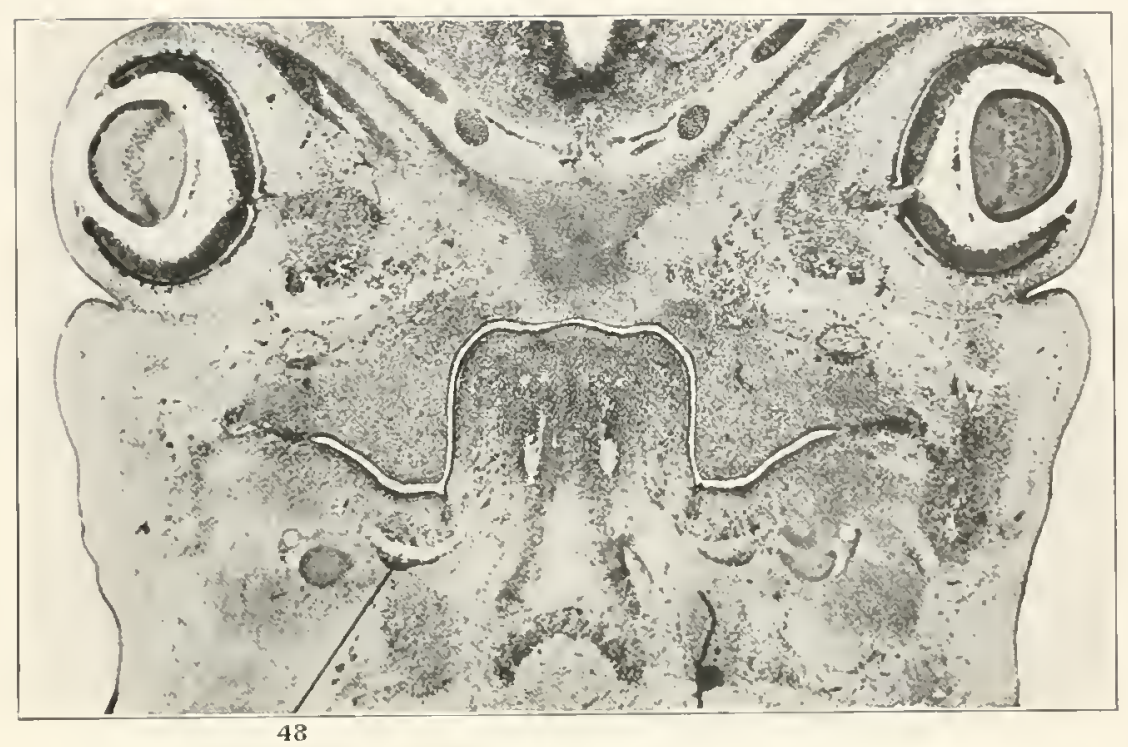

FIG. 38 ,

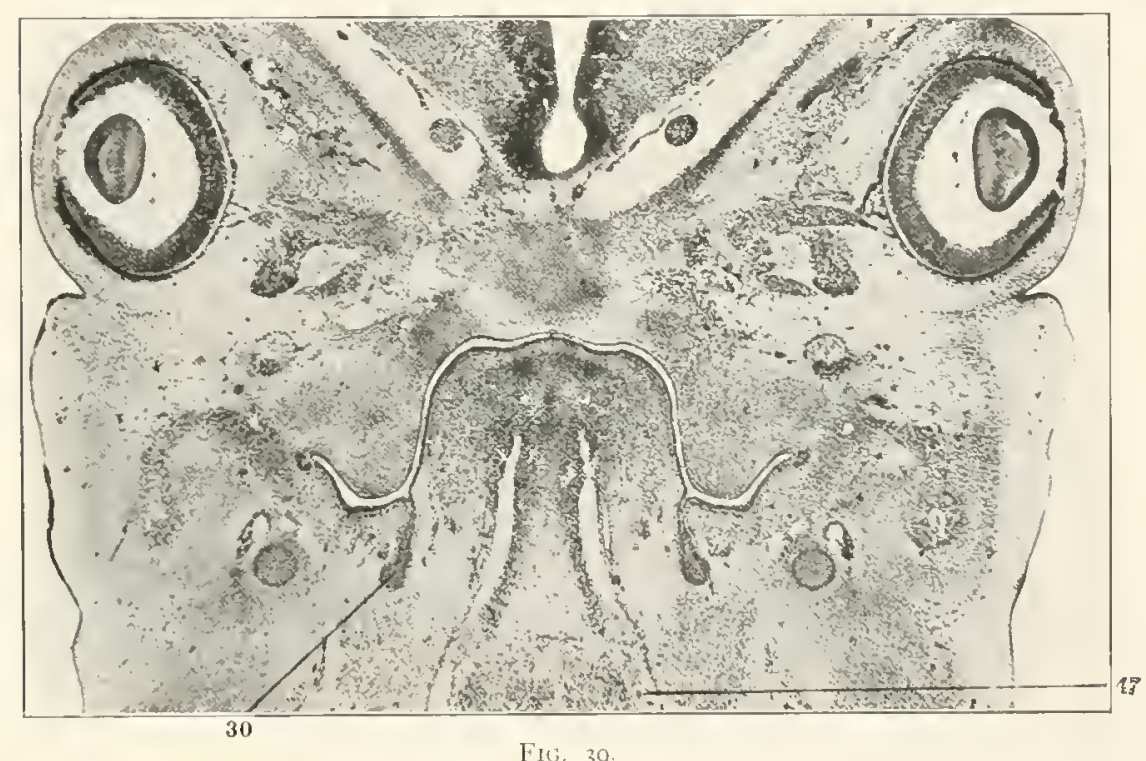




\section{Plate L $V^{\prime}$}

Fig. 40. Same embryo as preceding. Parotid and orbitoparotid of left side. An enlarged detail of Fig. $30, \times 350$, reluced to $\frac{3}{4}$.

FIG. 4t. Reconstruction of the ectal surlace of the epithelium of the right buccal sulcus in a it millimeter embryo. Columbia Collcetion, No. $211, \times 300$, recluced to $\frac{1}{4}$.

I. Buccal sulcus.

2. Angulus oris.

7. Orbital inclusion, pars lata.

8. Orbital inclusion, pars cylindrica.

12. Parotid anlage.

15. Orbitoparotid interval. 
PLATE LV.

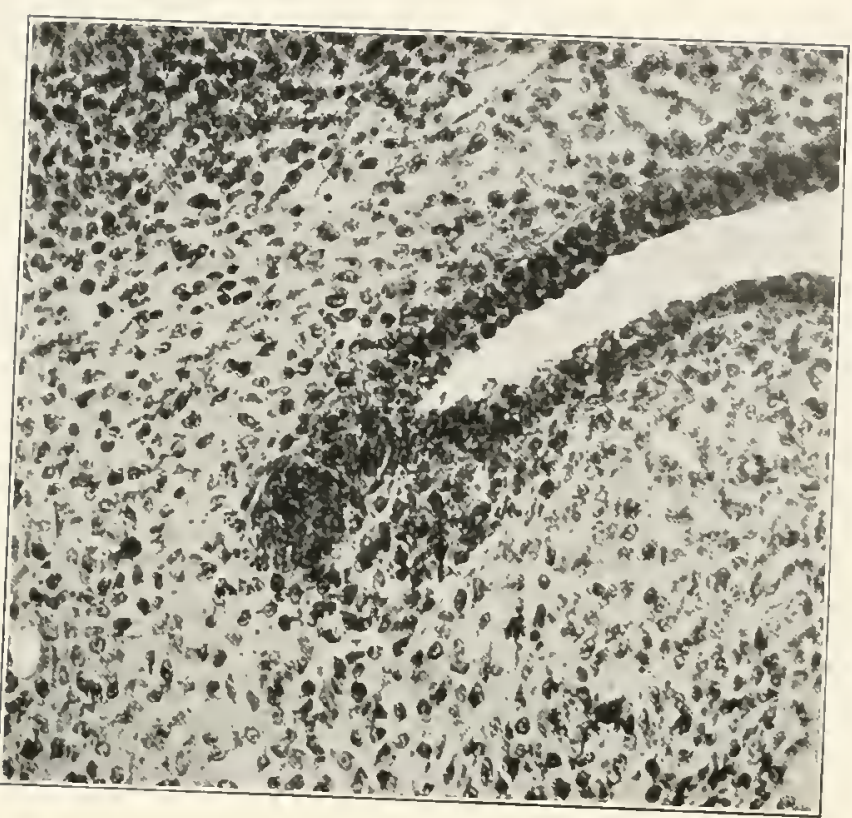

Flc. 40.

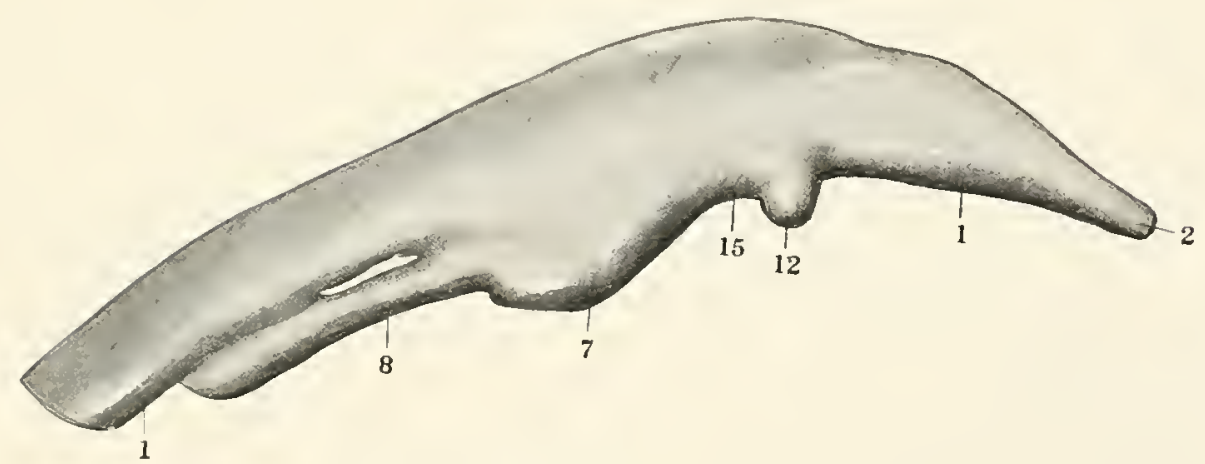

FIG. 4 I. 
Pite Lit

FIG. 42. Section of the pars lata of the orbital inclusion in the same embryo $\times 3+0$, reduced to 3 .

FIG. +3. Reconstruction of the ectal surface of the epithelium of the right buccal sulcus in a $1+$ millimeter embryo. Columbia Collection, No. $127, \times 300$, reduced to $\frac{1}{1}$.

I. Buccal sulcus.

2. Angulus oris.

7. Orbital inclusion, pars lata.

8. (Orbital inclusion. pars cylindrica.

12. P'arotid anlage.

I6. Orbitoparotid Hange.

I\%. Orbitoparotid sprout attached to parotid. 

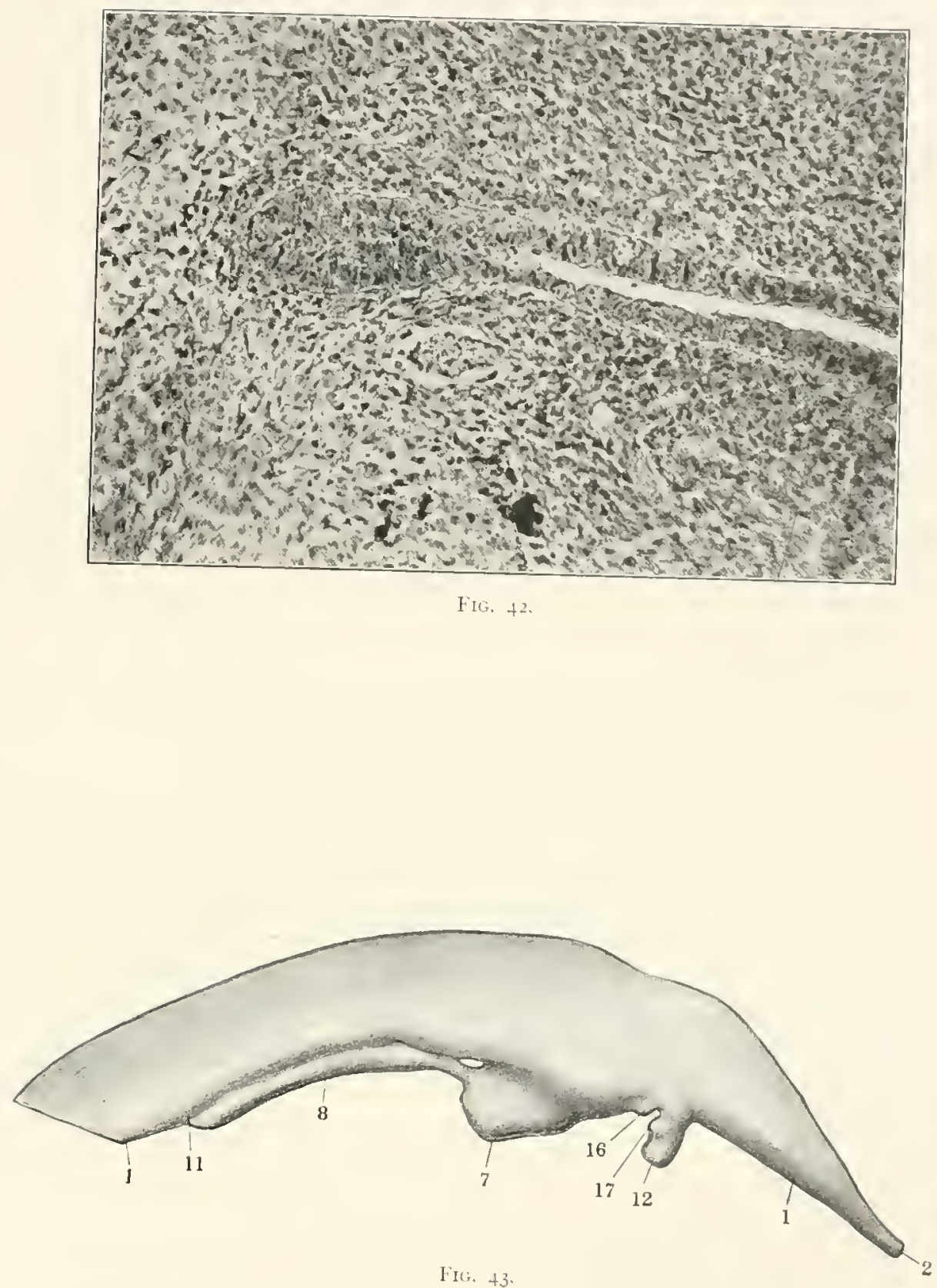


\section{Plate LiII}

FIG. 44. Reconstruction of the ectal surface of the epithelium of the right buccal sulcus in a 15 millimeter embryo. Columbia Collection, No. 2rg $\times 300$. reduced to $\frac{1}{4}$.

FIG. 45. Reconstruction of the ectal surface of the epithelium of the left buccal sulcus in a 15 millimeter embryo. Columbia Collection, No. 2r6, X 300 , reduced to $\frac{1}{1}$.

I. Buccal sulcus.

2. Ingulus oris.

7. Orbital inclusion, pars lata.

8. Orbital inclusion. pars cylindrica.

9. Orbital inclusion, lateral process.

10. Orbital inclusion, crutial process.

I3. Parotid anlage.

15. Orbitoparotil interval.

I6. Orbitoparoticl bridge.

$I_{7}$. Orbitoparoticl sprout.

64. Superior dental anlage. 

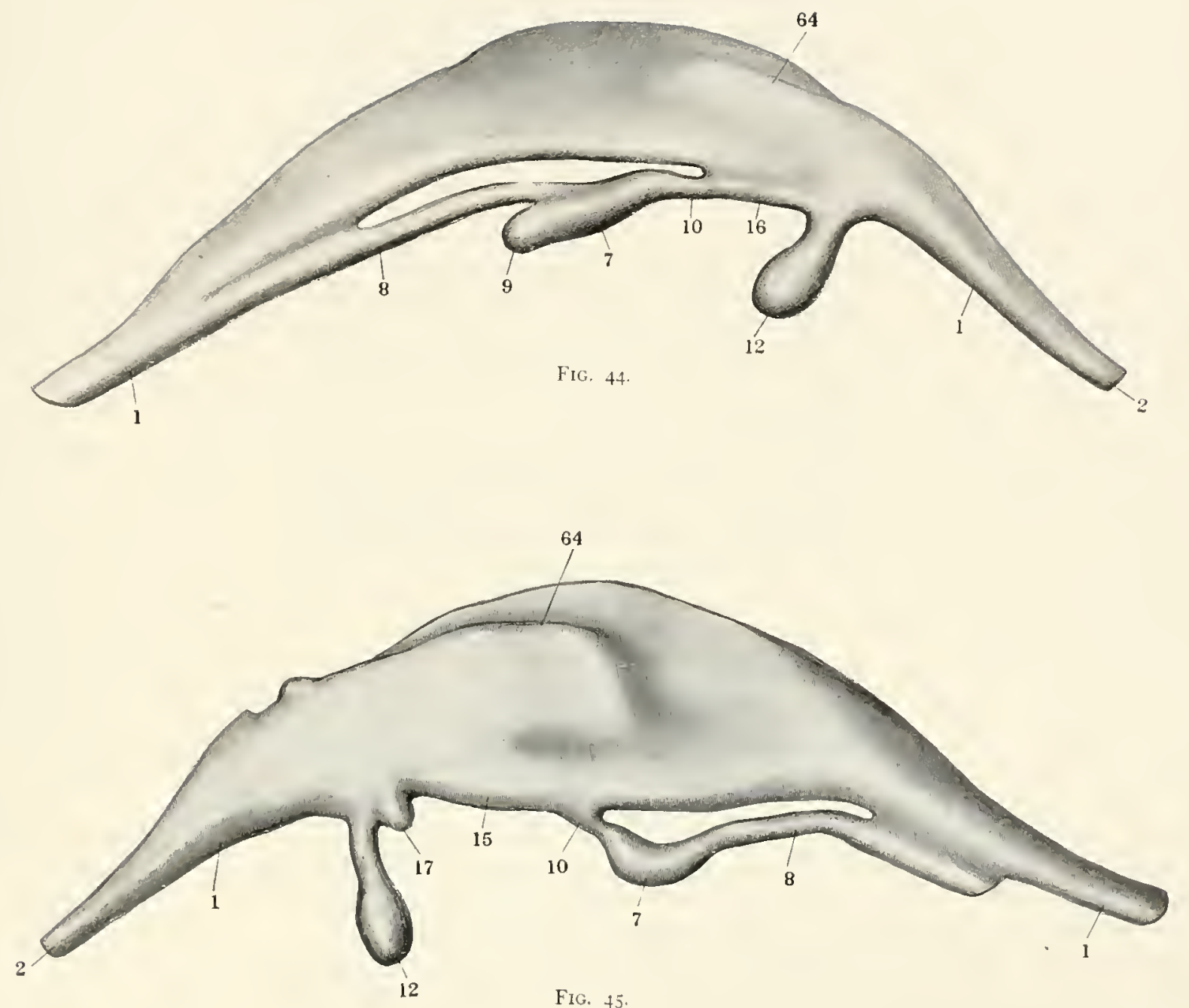

FIG. 45. 


\section{Plate LitII}

FIG. 46. Frontal section of the right parotid fold in a 12 millimeter embryo. Columbia Cullection, No. $100, \times 400$, reduced to $\frac{3}{4}$.

FIG. 47. Frontal section of the right parotid foll in a 2 millimeter embryo. Columbia Collection, No. $217, \times 100$, reduced to 3.

FIG. 48. Frontil section of the right parotid foll in a 12 millimeter embryo. Columbia Collection, No. 263 , ' $\times 400$, refluced to ${ }_{4}^{3}$. 


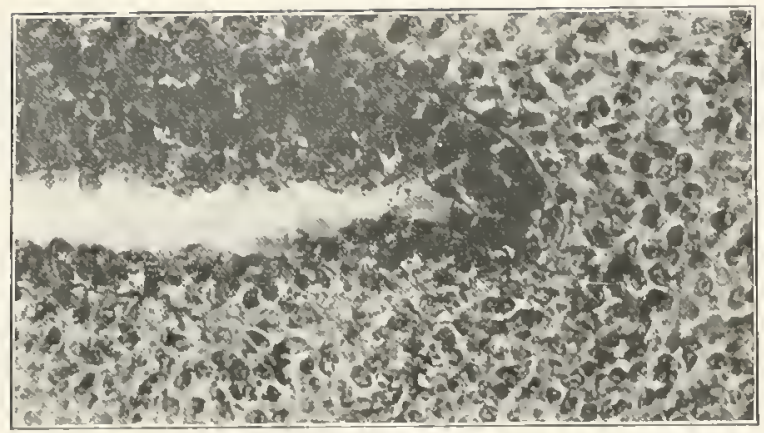

FIG. 40.

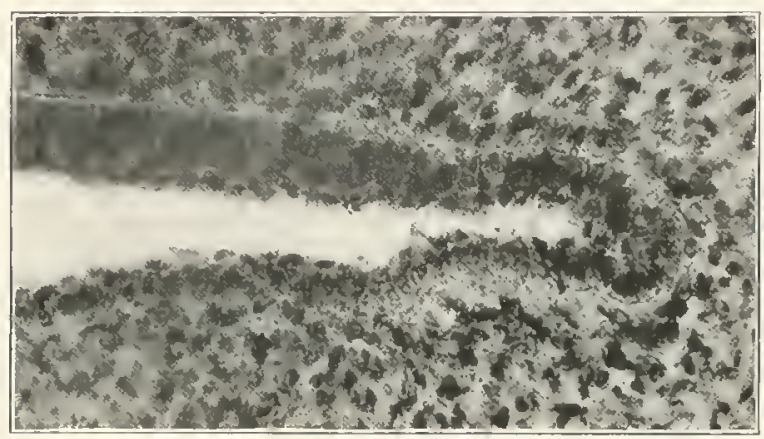

IIG. 47

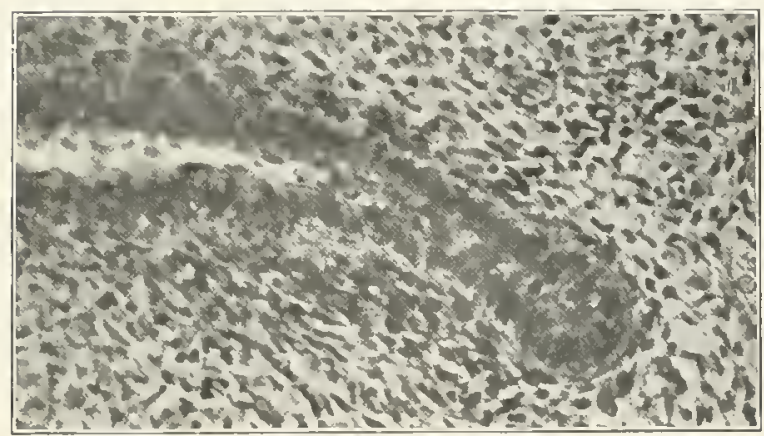

FiIG. $4^{8 .}$ 


\section{Plate LIX}

FIGs. 40-57. Right parotid anlage of a 13.5 millimeter embryo. Columbia Collection, No. 189. Serial sections, $X \mathrm{II}_{5}$, reduced to $\frac{1}{2}$.

I. Buccal sulcus,

12. Parotid anlage.

20. Inferior alveobuccal sulcus.

50. Neckel's cartilage.

62. Ectopalatine sulcus.

6. Superior dental anlage.

65. Inferior dental anlage.

7o. Inferior dental nerve. 


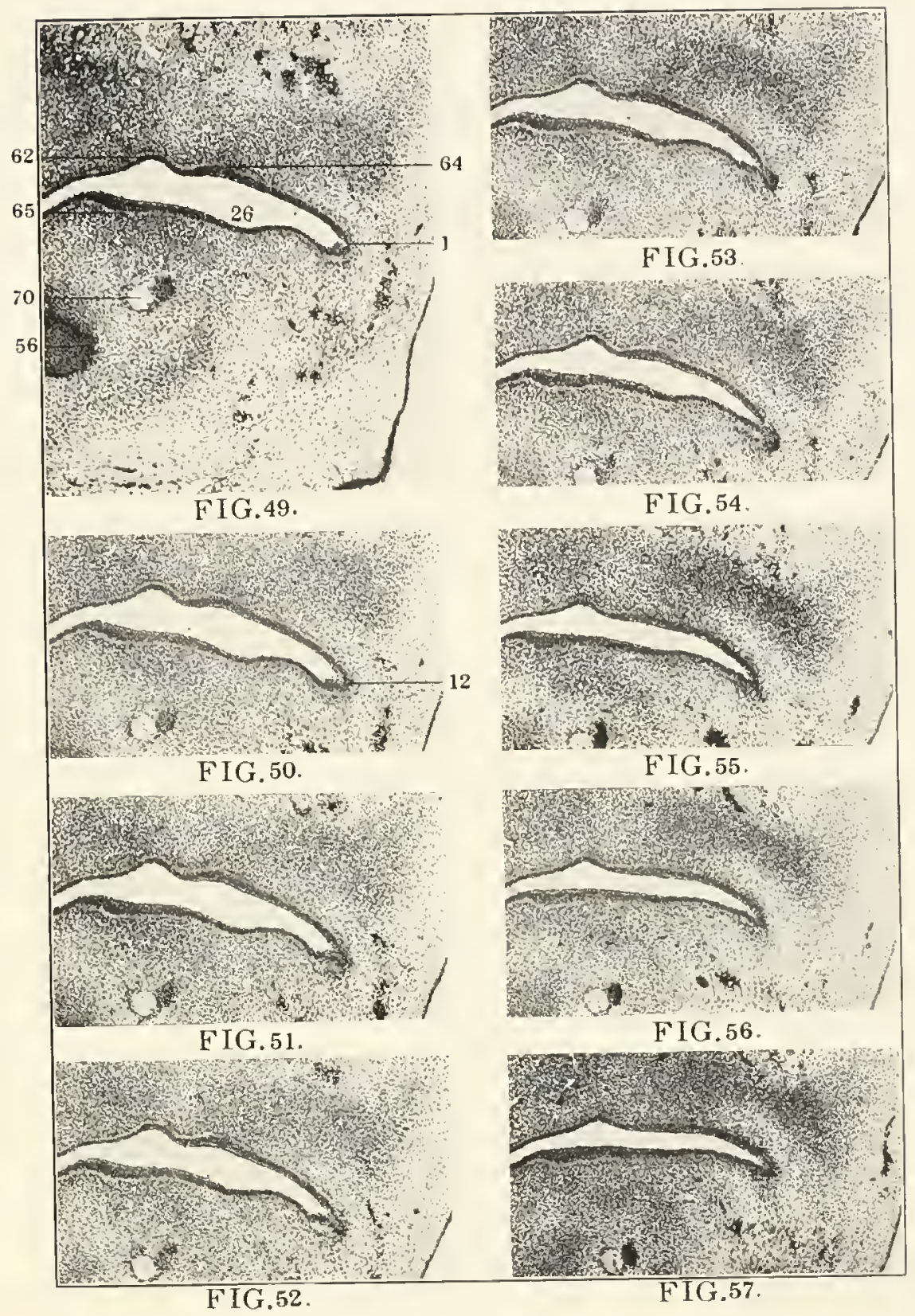




\section{PLATE L.S}

FıGs, $58-61$. Right parotid anlage of a 13.5 millimeter embryo. Columbia Collection, $X_{0}, 223$. Series of alternate sections, $X \pm 15$, recluced to $\frac{1}{2}$.

I2. P'arotid anlage.

I3. Subparotit cundensation of mesenchyme.

2\%. Inferior alveoluuccal sulcus.

29. Lingual sulcus.

35. Tongue.

73. Palatolinguat plane.

4. Mreolingual region.

45. Palatomaxillary plane.

46. Mandilutumaxillary plane.

57. Inferior maxilla.

56. Neckel's cartilage.

60. Palatc process.

62. Ectopaliatine sulcus.

67. Superiur ilental anlage.

65. Inferion rental anlage.

-o. Inferior dental nerve.

7.3. Nasscter muscle and zygoma.

0.1. Facial vein. 
PLATE LX.

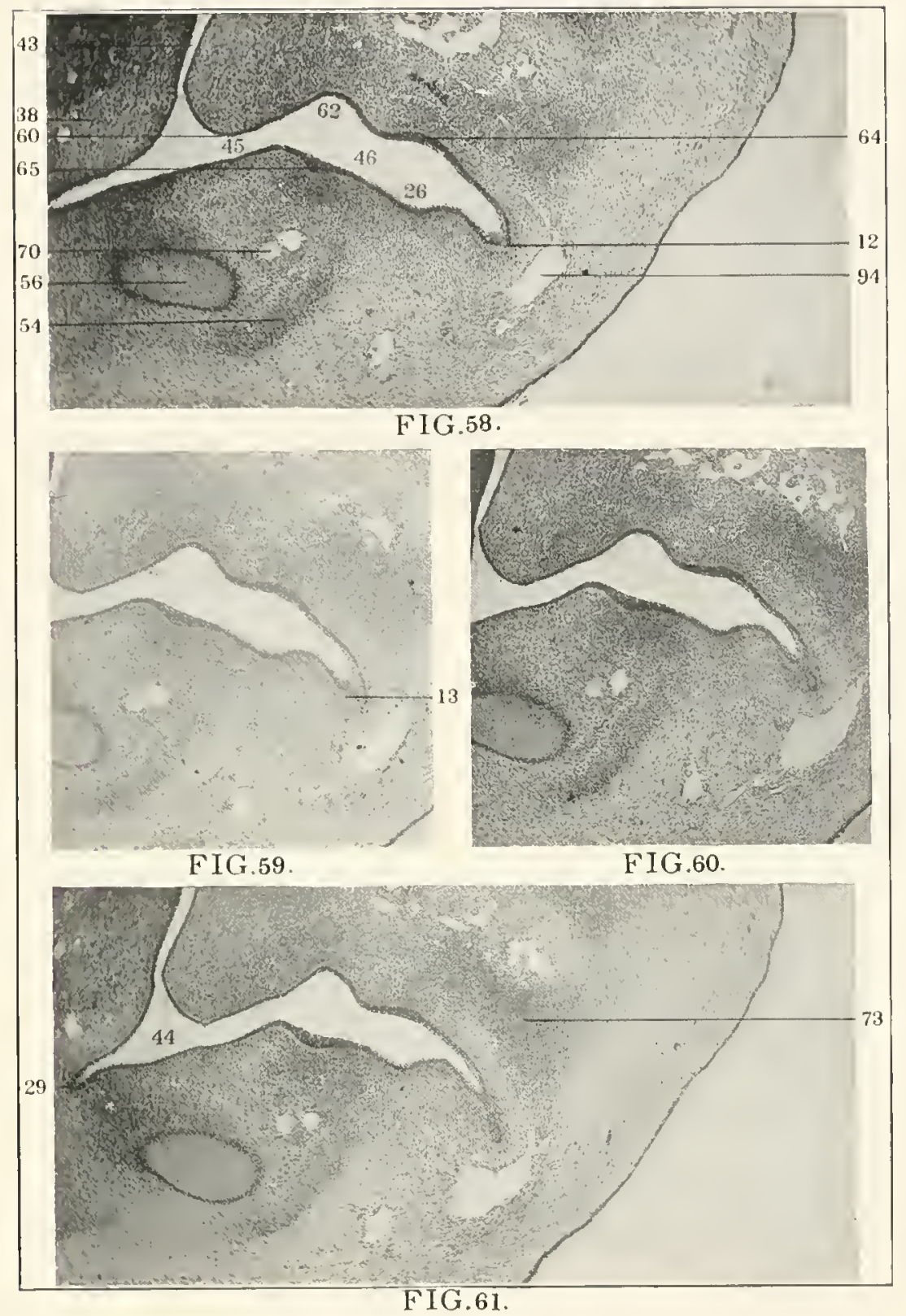


Plate LiI

FIGS. 62-65. Alternate sections continued from preceding, $X$ I I 5 , reduced to $\frac{1}{2}$. 16. Orbitoparotid flange.

95. Deep facial vein. 


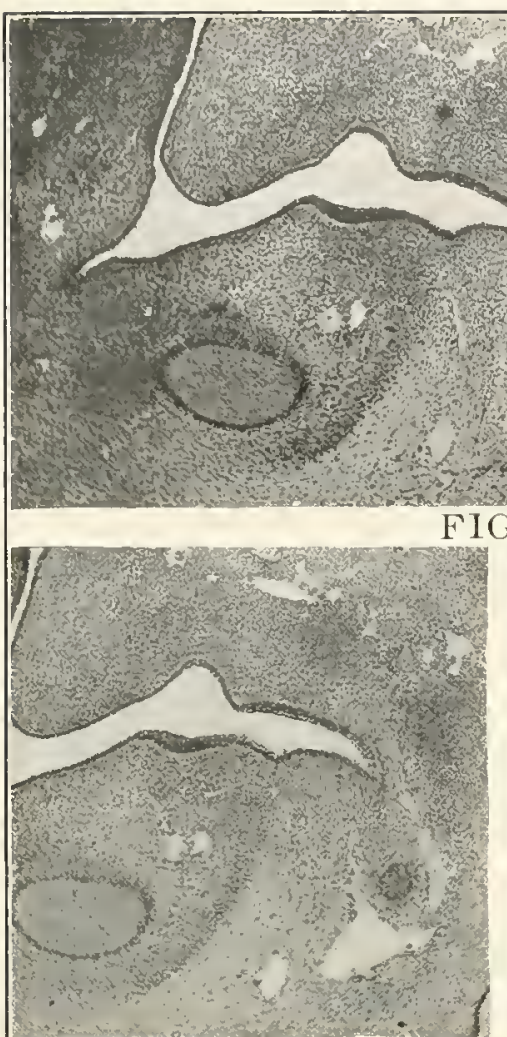

FIG.63

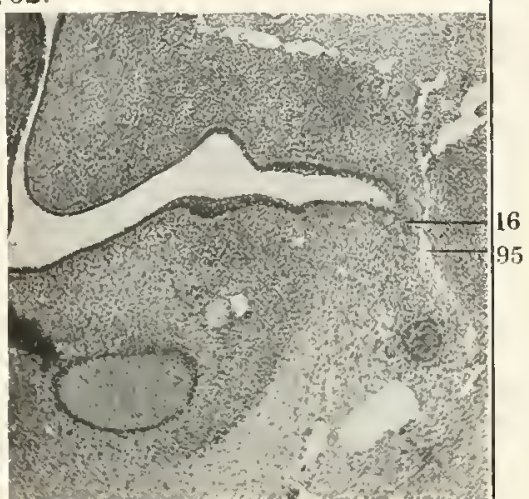

FIG.64

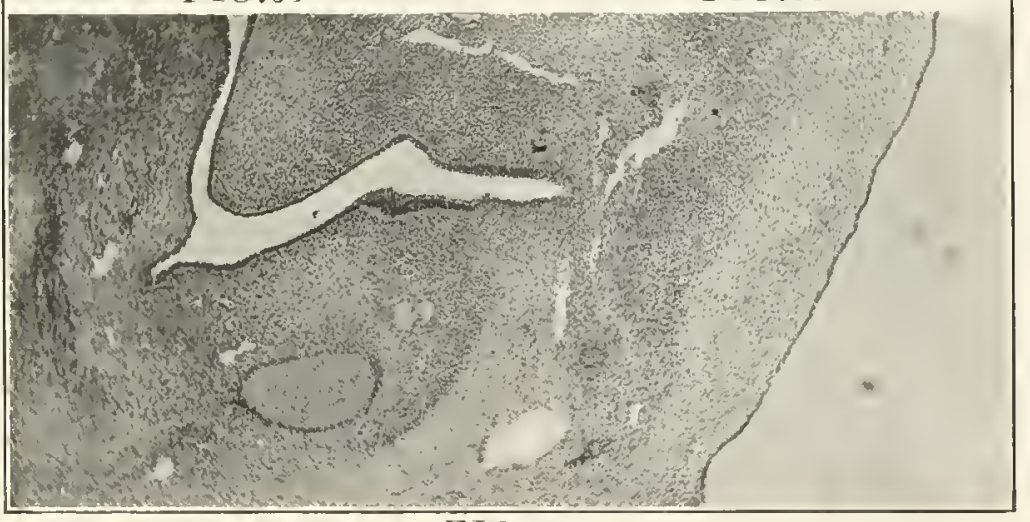

FIG.65. 
Plate L.il

Figs. 66-73. Right parotid anlage of the $1_{5}$ millimeter embryo of Fig. 44. Columbia Collection, No. 219. Contmuous serial sections, $\times$ i I5, reduced to $\frac{1}{2}$.

I. Buccal sulcus.

Ib. Subparotid sulcus.

12. Parotid anlage.

26. Inferior alveobuccal sulcus.

45. Palatomandibular plane.

th. Maxillomandibular plane.

5h. Mechel's cartilage.

62. Ectopalatine sulcus.

of. Superior dental anlage.

65. Inferior dental anlage.

7o. Inferior dental nerve.

73. Masseter muscle.

97. Facial vein. 


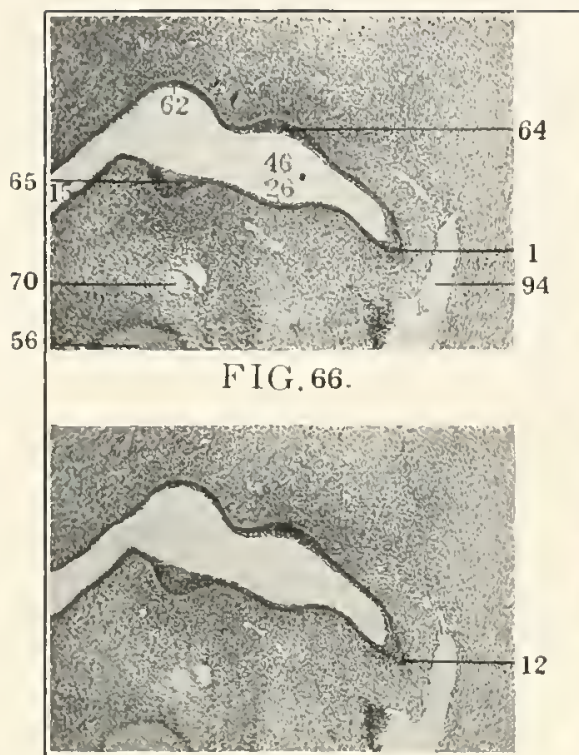

FIG.67.

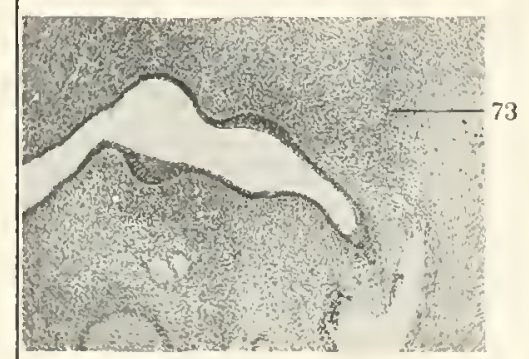

FIG. 68.

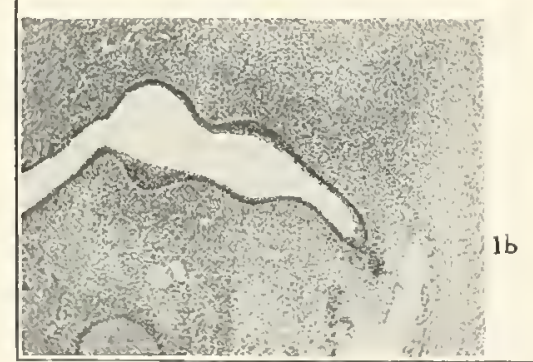

FIG.69.

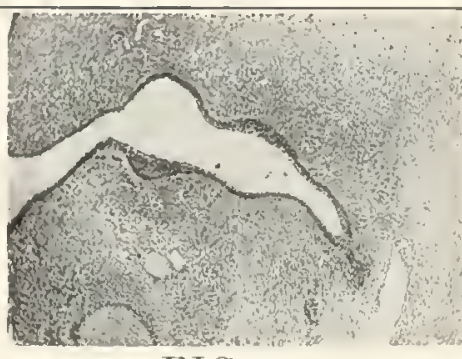

F IG. 70 .

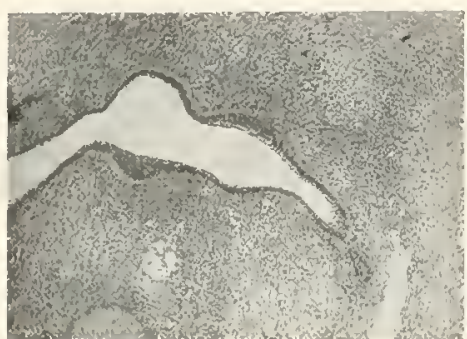

FIG.71.

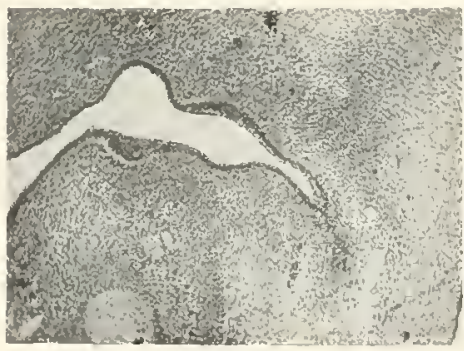

FIG.72.

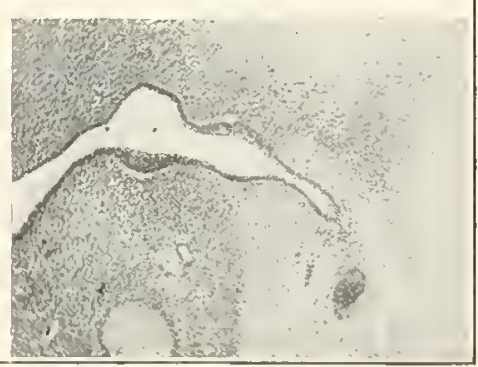

F IG.73. 


\section{Plate LXIS}

FIGS. 82-S7. Right parotid anlage of a 105 millimeter embryo. Columbia Collection, No. $27 \%$. Series of alternate sections, $X$ in 5 , reduced to $\frac{1}{2}$.

I. Buccal sulcus.

I2. Parotid anlage.

17. Orbitoparotid sprout.

25. Superior alveobuccal sulcus.

26. Inferior alveobuccal sulcus.

45. Palatomanclibular plane.

46. Maxillomantibular plane.

54. Inferior maxilla.

56. Meckel's cartilage.

63. Ectopalatine sulcus.

6. Superior dental anlage.

65. Inferior dental anlage.

70. Inferior dental nerve.

9. Facial vein. 


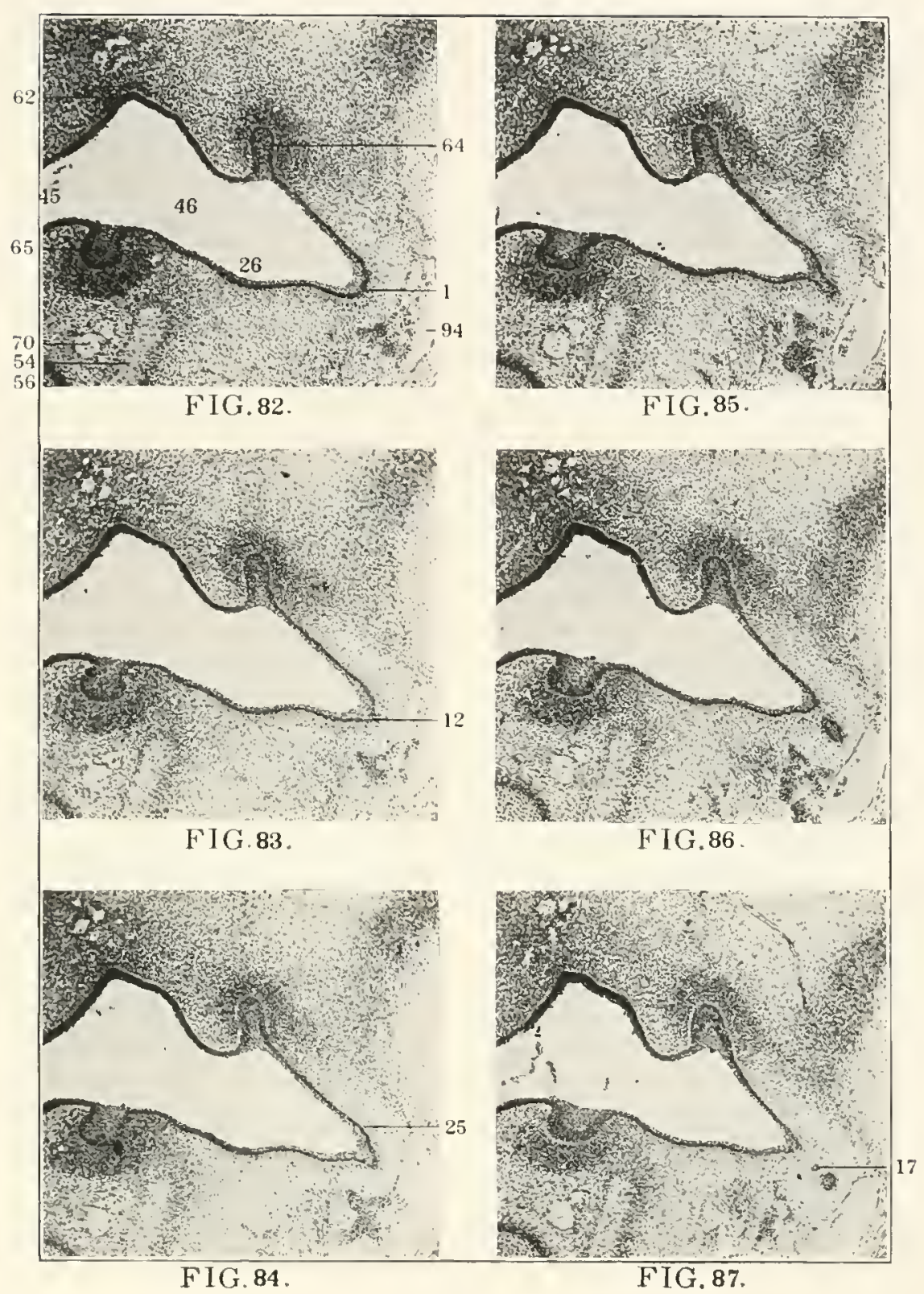




\section{Plate Lxy}

Figs. 88-0.4. Right parotid attachment of a 20 millimeter embryo. Columbia Collection, No, $2+1$. Continuous series of sections, $X$ I I 5 , reduced to $\frac{1}{2}$.

Ib. Subparotid sulcus.

12. Parotid crest.

24. Inferior alveobuccal glands.

25. Superior alveobuccal sulcus.

26. Inferior alveobuccal sulcus.

38. Tongue:

f6. Maxillomandibular pline.

54. Inferior missilla.

56. Meckel's cirtilage.

6. Superior dental anlage.

05. Inferior dental anlage.

70. Inferior dental nerve.

97. Facial vein. 


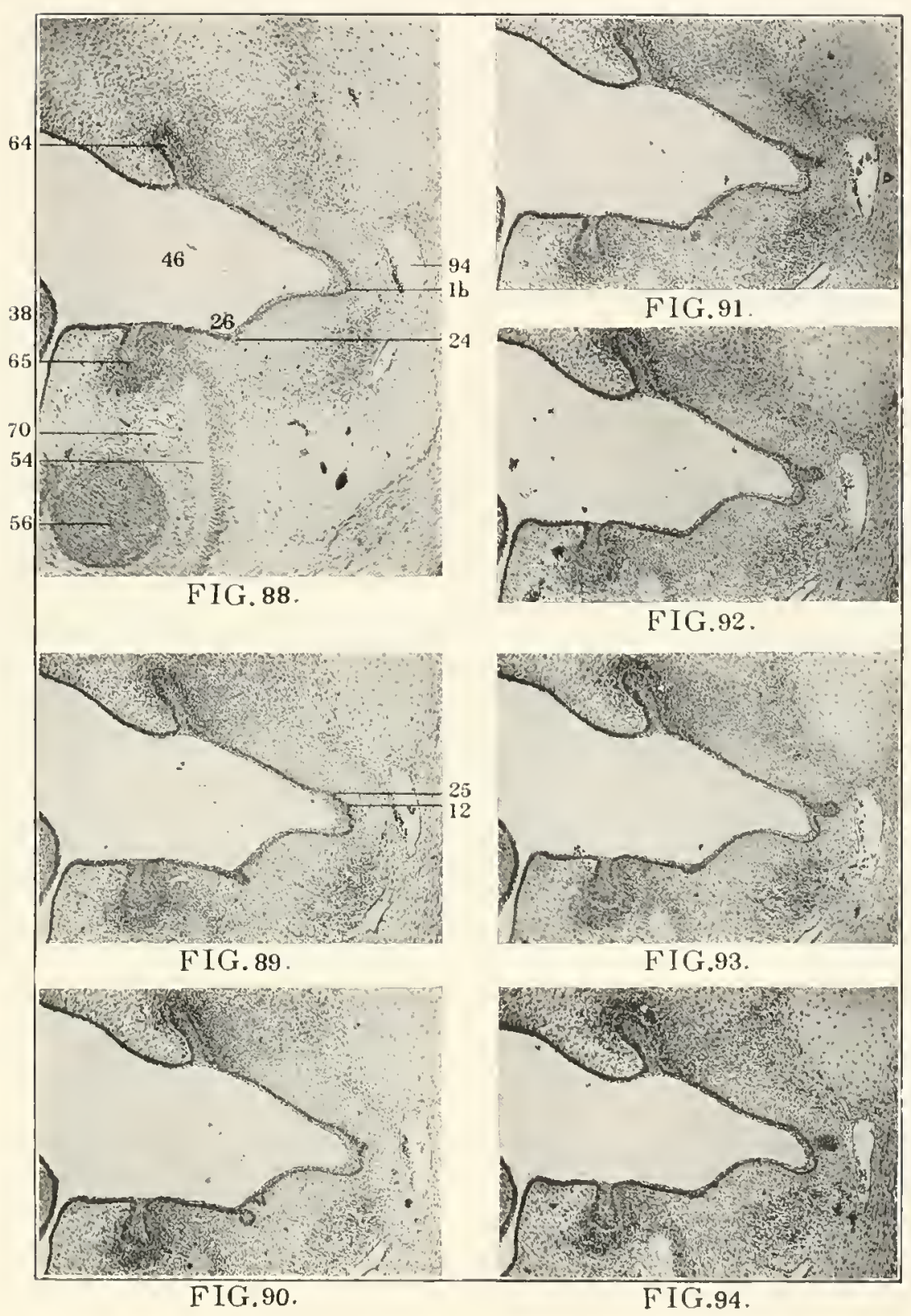




\section{Plate LXIT}

FIG. 06. Reconstruction of the ectal surface of the oral epithelium of an 18 millimeter embryo. I'rinceton Collection, No. 2I. Lateral view, $\times 45$, actual size.

2. Angulus oris.

6. Orbital inclusion.

12. Parotid anlage.

17. Orbitoparotid sprout.

30. Submaxillary anlage.

33. Anlige of the greater sublingual gland.

44. Alveolingual region.

Sf. First entodermal pouch.

87. Hypophysis.

92. Trachea.

gS. Esophagus. 


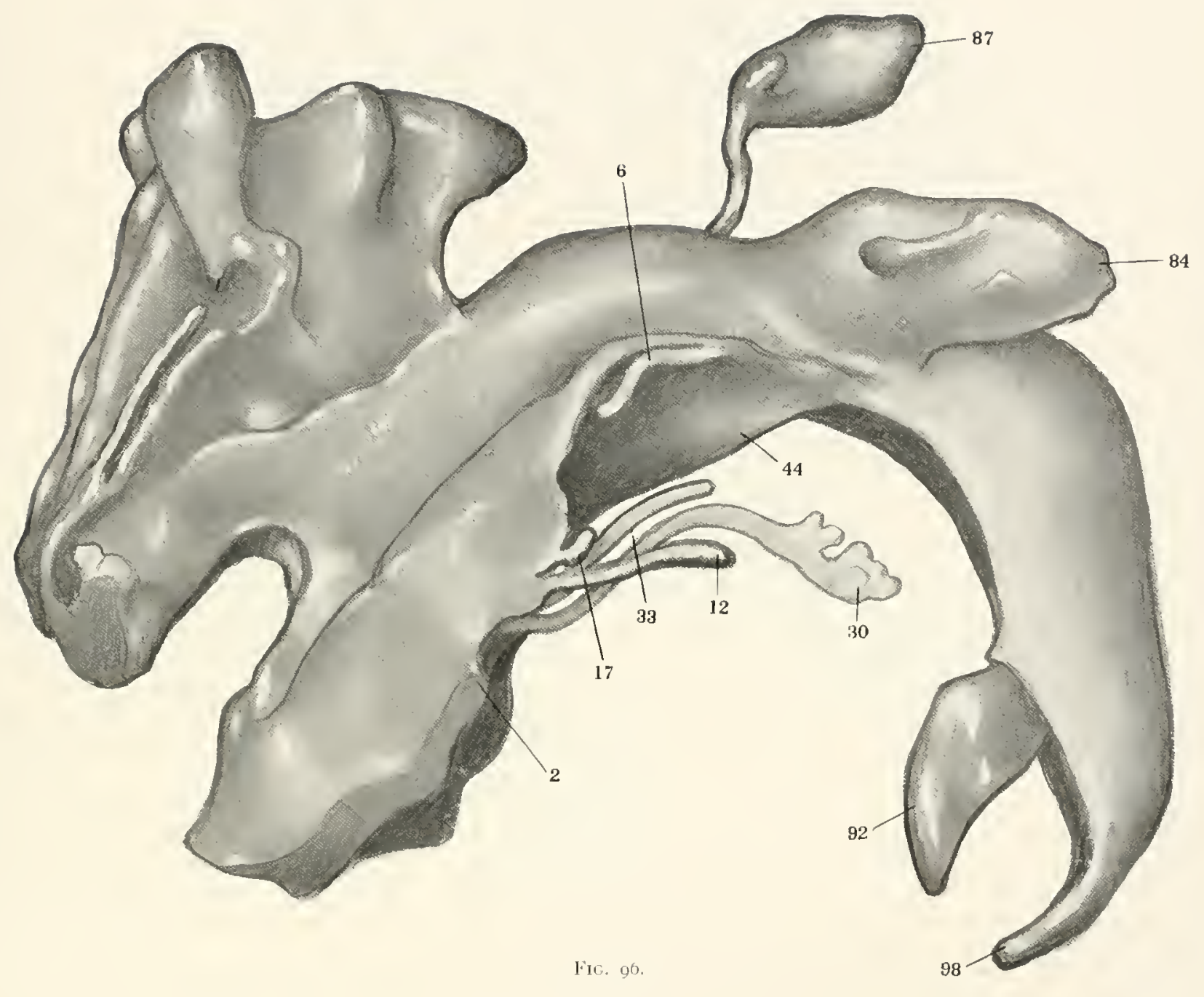




\section{PLate LAl11}

FIG. 97. The same reconstruction as Fig. 96. Dorsal view, $\times 45$, actual size. The scale is the same as that of the reconstruction of the 13.5 millimeter embryo in Fig. 35.

2. Angulus oris.

7. Postangular bend.

5. Orbital angle.

6. Orbital inclusion.

I2. Parotid anlage.

$I_{7}$. Orbitoparotirl sprout.

62. Ectopalatine sulcus.

6.4. Superior dental rirlge.

8. First entodermal pouch.

87. Hypophysis. 
PLATE LXVII.

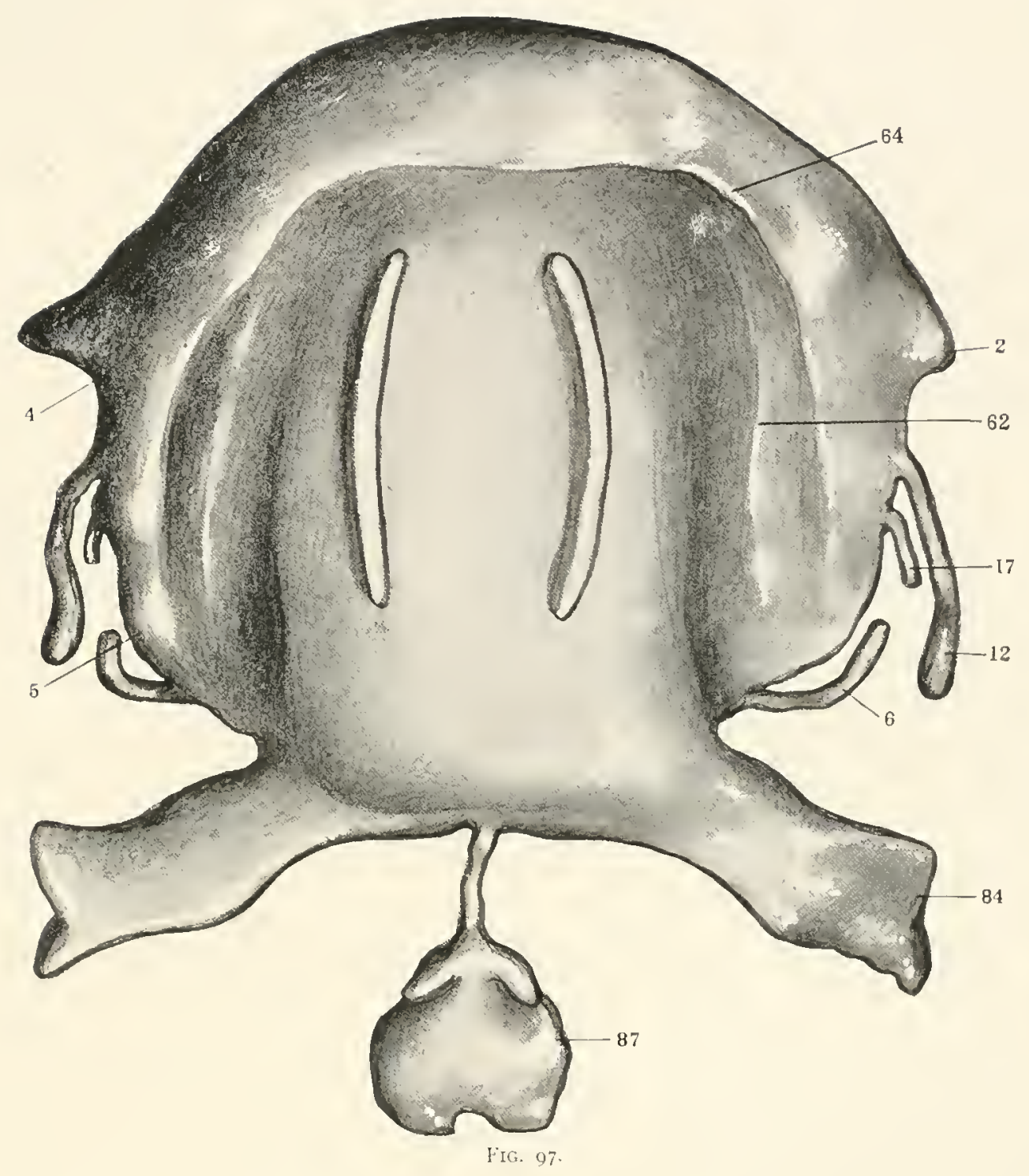




\section{Plate Lxi'ili}

FIG. QS. Reconstruction of the ectal surface of the epithelium of a portion of the left buccal sulcus of an 18.5 millimeter embryo. Columbia Collection, No. $249, X$ I 14 , reduced to $\frac{2}{5}$.

FIG. 9o. The same, right sicle.
5. Orbital angle.
6. Orbital inclusion.
12. Parotil anlage.
17. Orbitoparoticl sprout.
Is. Orbitoparotis inclusion.
20. Anlage of first orbital gland. 


$$
\text { 揞 }
$$




\section{Pl.tTe L.ils}

FIGS, Ioo-ro3. Camera lucida drawings of frontal sections of the right side of the same embryo as Figs. of and oo, at the levels indicated in Fig. Q9, $\times 85$, reluced to $\frac{1}{2}$. In Fig. Ioz the tip of the cranial process is indicated by a dotied circle ventral of the fuccal sulcus and mesad of the deep facial vein (95). This position is frequent at this stage. Is is seen from Fig. 09, in this embryo the process in question was rudimentary. To this extent the figure is schematic. In Fig. Io3 the oullines of a number of sections of the orbital inclusion have been superimposed. The level of the basic section is shown in Fig. 99.

I. Buccal sulcus.

ra. Secondary buccal sulcus.

7. Orbital inclusion. pars lata.

8. Orbital inclusion, pars cylindrica.

I2. Parotid anlage.

14. Periparotid mesenchymal condensation.

17. Orbitoparotill sprout.

20. Anlage of first orbital gland.

30. Sulbmaxillary anlage.

32. Submaxillary mesenchymal condensation.

3.3. Greater sublingual anlage.

38. Tongue.

72. Craniolingual plane.

43. Palatolingual plane.

47. Mveolingual region.

45. Palalomandibular plane.

4). Maxillomandibular plane.

t7. Hypoglossal nerve.

78. Lingual nerve.

40. Sulumaxillary ganglion.

50. Digitstric muscle.

5I. Mylohyoid muscle.

52. Cinioglossus muscle.

53. Cieniohyoid muscle.

57. Inferior maxilla.

50. Mcekel's cartilage.

57. Tuberosity of maxilla.

58. 7ygoma

6o. P'alate process.

6z. Ectopalatine sulcus.

o. Superior dental anlage.

6.5. Inferior dental anlage.

7o. Inferior dental nerve.

73. Masseter muscle.

ft. Internal pterygoid muscle.

79. Nisul fossa.

8o. Nasial seprum.

$S_{1}$. Littcral thmoidal cartilage

SR. Eye.

ge. Ophthalmic rein.

97. Facial vein.

95. Deep facial vein. 


\section{PLATE LXX}

FIG. I04. Composite frontal section of the 20 millimeter embryo. Columbia Collection, No. $8_{3}$, in which several sections of the recurrent parotill branches (q9) have been superimposed, $\times 85$, reduced to $\frac{1}{2}$.

FIG. 105. Composite frontal section of the 31 millimeter embryo. Columbia Collection, No. 14t, in which several sections of the recurrent parotid branches have been superimposed, $\times \$_{5}$, reduced to $\frac{1}{2}$.

Ia. Secondary buccal suicus.

6. Orbital inclusion.

12. Parotid anlage.

29. Lingual sulcus.

30. Submaxillary anlage.

33. Greater sublingual anlage.

3.S. Tongue.

f). Lingual nerve.

49. Submaxillary ganglion.

50. Digastric muscle.

51. Mylohyoid muscle.

52. Genioglossus muscle.

53. Geniohyoil muscle.

5t. Inferior maxilla.

56. Meckel's cartilage.

58. Zygoma.

59. Alveolar process.

no. Palate process.

63. Palate bone.

70 . Inferior dental nerve.

73. Masseter muscle.

-7. Internal pterygoid muscle

85. Nasopharynx.

99. Recurrent branch of parotid. 

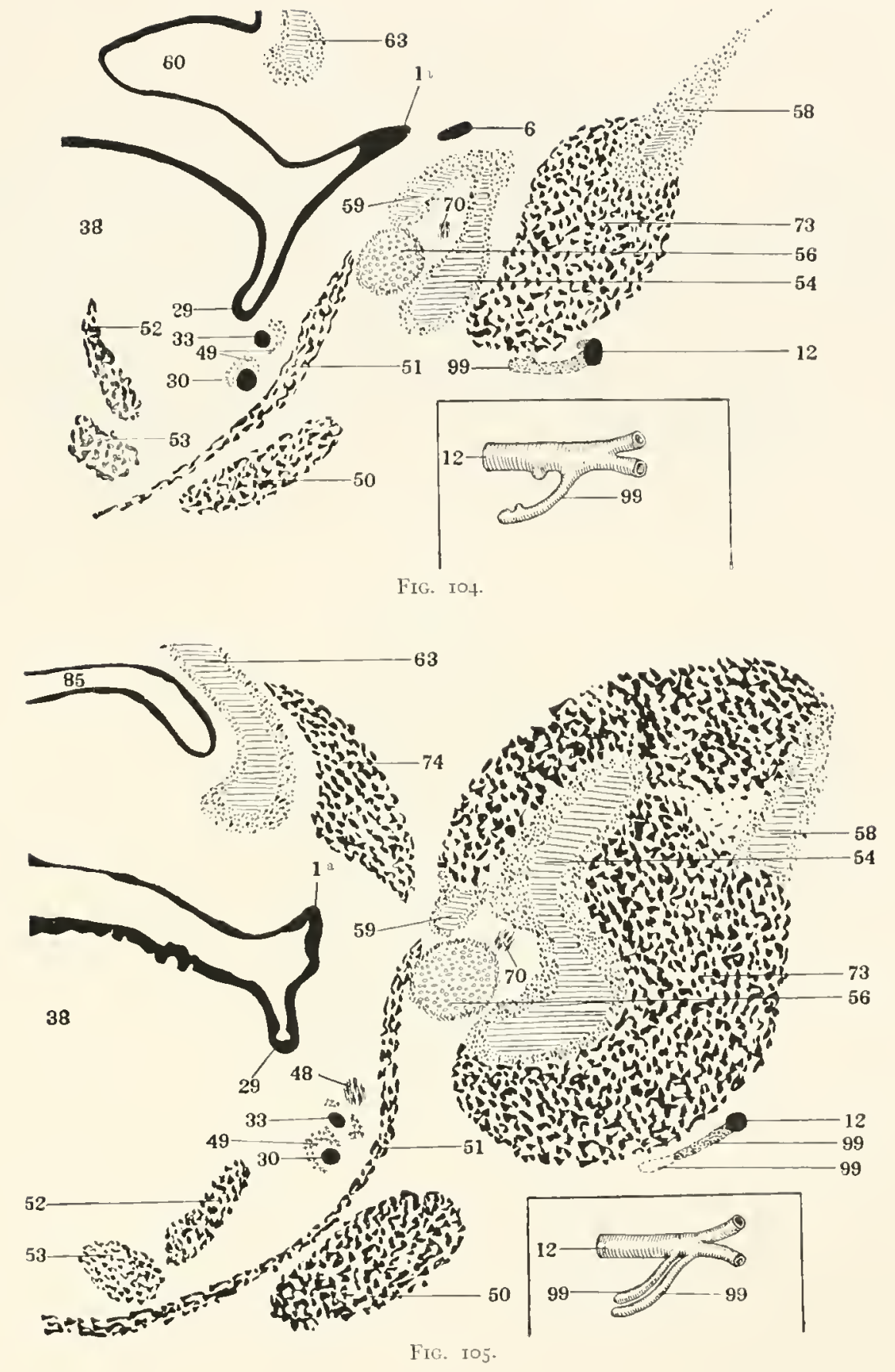


\section{Plate LXy}

FIG. Io6. Reconstruction of a portion of the oral epithelium of the 35 millimeter embryo. Columbia Collection, No. 9o. V'entrolateral view, $\times 80$, reduced to $\frac{1}{2}$.

FIG. 107. Schema of dorsal view of the same reconstruction, $\frac{2}{3}$ actual size, showing the derivatives of the buccal sulcus.

2. Angulus oris.

6. Orbital inclusion.

I2. Parotid.

17. Orbitoparotid.

20. Anlage of first orbital gland.

21. Anlage of second orbital gland.

22. Anlage of third orbital gland.

24. Inierior alveobuccal anlages.

30. Submaxillary duct.

32. Submaxillary condensation in the mesenchyme.

33. Greater sublingual duct.

54. Inferior maxilla.

56. Meckel's cartilage.

6. Superior dential anlage.

73. Masseter muscle. 

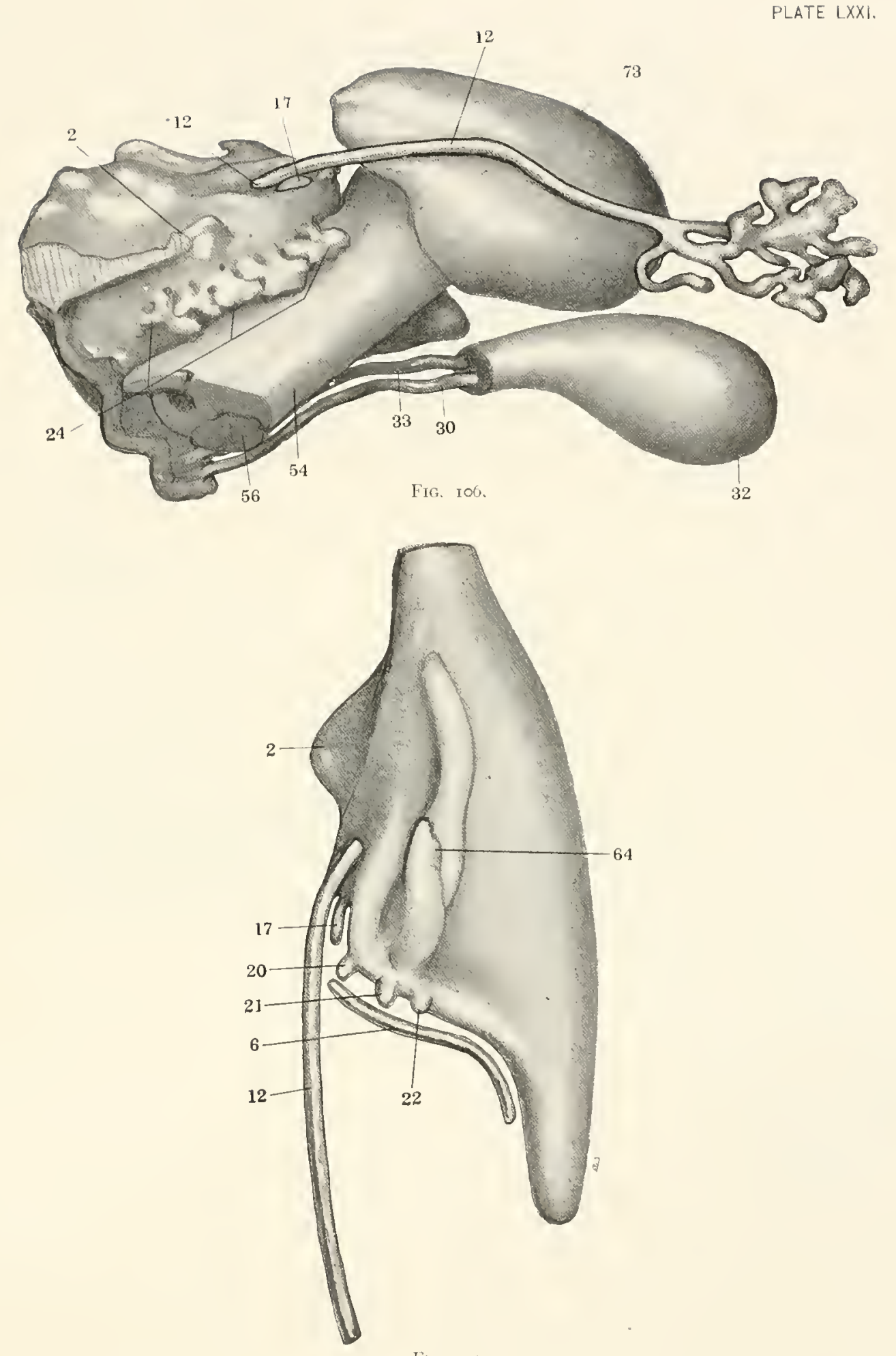

F1G. 107. 


\section{Plate Lxyi}

FIG. toS. Photomicrograph of the parotid and orbitoparotid of the 35 millimeter embryo. Columbia Collection, No. po. Horizontal section, $X$ II 5 , reduced to ${ }_{2}^{1}$.

FIG. IOo. Schema of oral epithelium and glandular anlages of the left side of the 5I millimeter embryo. Columbia Collection, No. ro.t. From a wax reconstruction.
2. Angulus oris.
6. Orbital inclusion.
I2. Parotid.
17. Orbitoparotid sprout.
IS. Orbitoparotid inclusion.
20. Anlage of first orbital gland.
$2 I$. Anlage of second orbital gland.
22. Anlage of third orbital gland.
27. Diastemal folk.
2S. Inferior alveulabial sulcus.
284. Superior alveolabial sulcus.
29. Lingual sulcus.
30. Submaxillary gland and duct.
33. Greater sublingual gland and duct.
31. Efflorescent lobules of greater sublingual duct.
38. Tongue.
5t. Inferior maxilla.
65. Inferior dental anlage. 


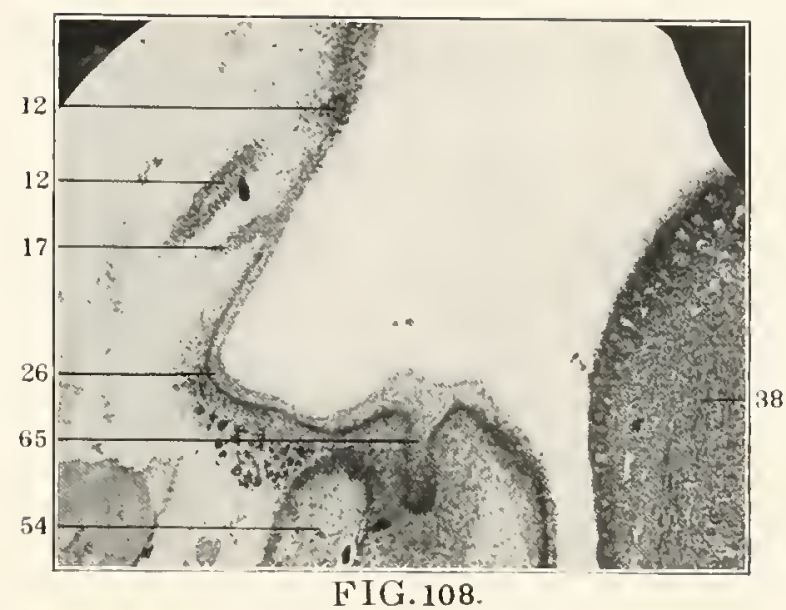

PLATE LXXII

FIG. 108 .

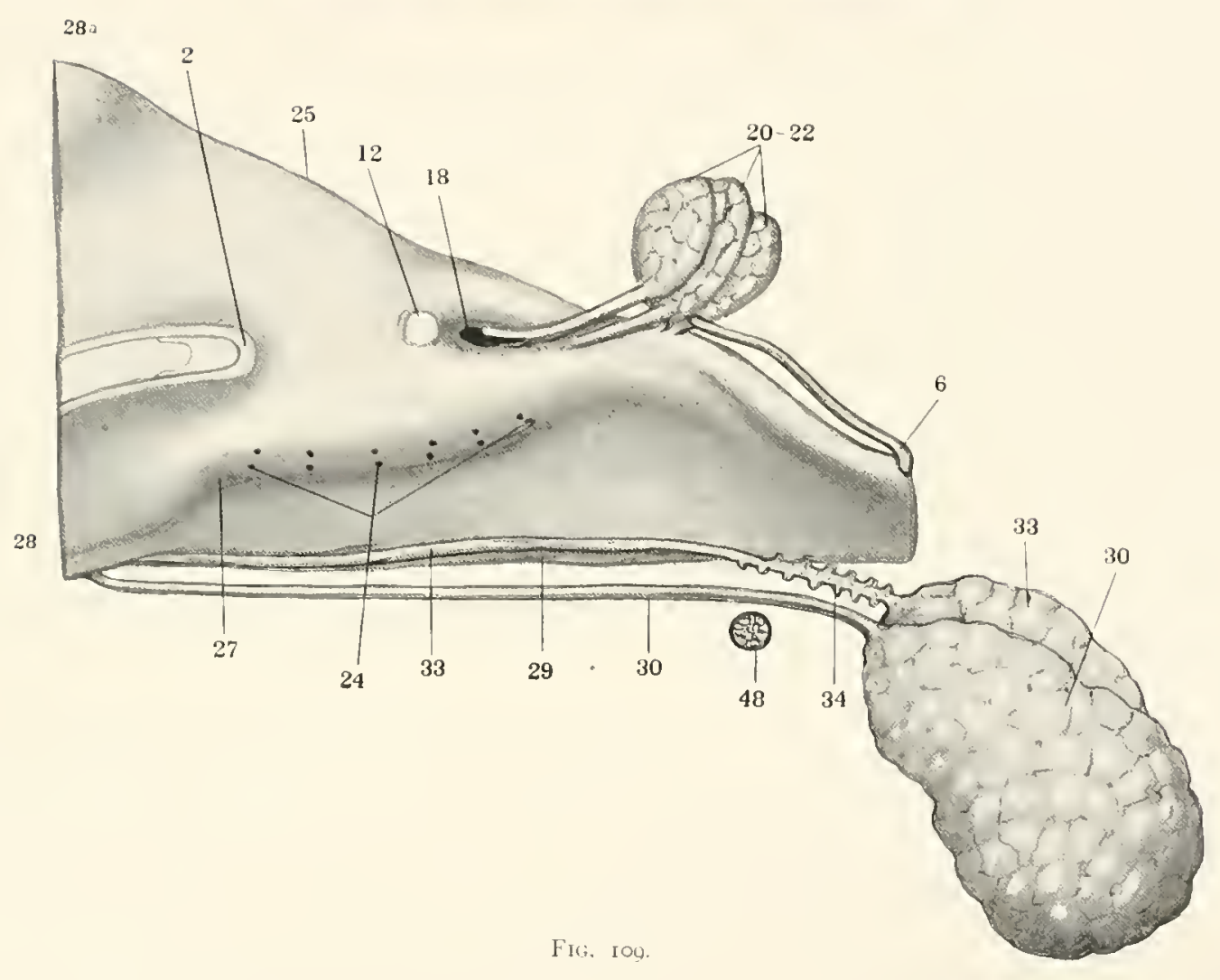




\section{Plate LAXIII}

Fig. II . Camera lucida drawing of a frontal section passing through the attachment of the thirl orbital gland near its cranial extremity, in the $5 \mathrm{r}$ millimeter embryo. Columbia Collection, Nu, 104, $\times 8_{5}$, reduced to $\frac{1}{2}$.

FIG. 112 . The same. Section passes through the caudal extremity of the attachment of the third orbital gland, $\times 85$, reduced to $\frac{1}{2}$.

Fig. I I3. The same. A more caudal section through the budy of the second orbital gland, $\times s_{5}$, reduced to $\frac{1}{2}$.

6. Orbital inclusion.

12. Parutid.

20. Anlige of first orbitul gland.

2I. Anlage of second orfital gland.

22. Inlage of third orbital gland.

30. Submaxillary anlage.

33. Greater sublingual anlage.

37. Supramylohyoid portion of greater sublingual.

39. 'longue'.

19. Lingual nerve.

40. Submaxillary ganglion.

50. Digastric muscle.

jI. Mylohyoid muscle.

52. Genioglossus muscle.

53. Geniohyoid musele.

54. Inferior maxilla.

55. Inferior alveolar process.

53. Meckel's cartilage.

5?. Lygoma.

63. Pialate bone.

64. Superior dental anlage.

65. Inferior clental anlage.

$S_{I}$. Lateral thmoidal cartilage.

85. Naso plarynx.

Ss. Eye.

So. Periorlyta.

oo. Ophthalmic vein.

43. Facial nerve

44. Facial rein.

45. Deep facial vein. 



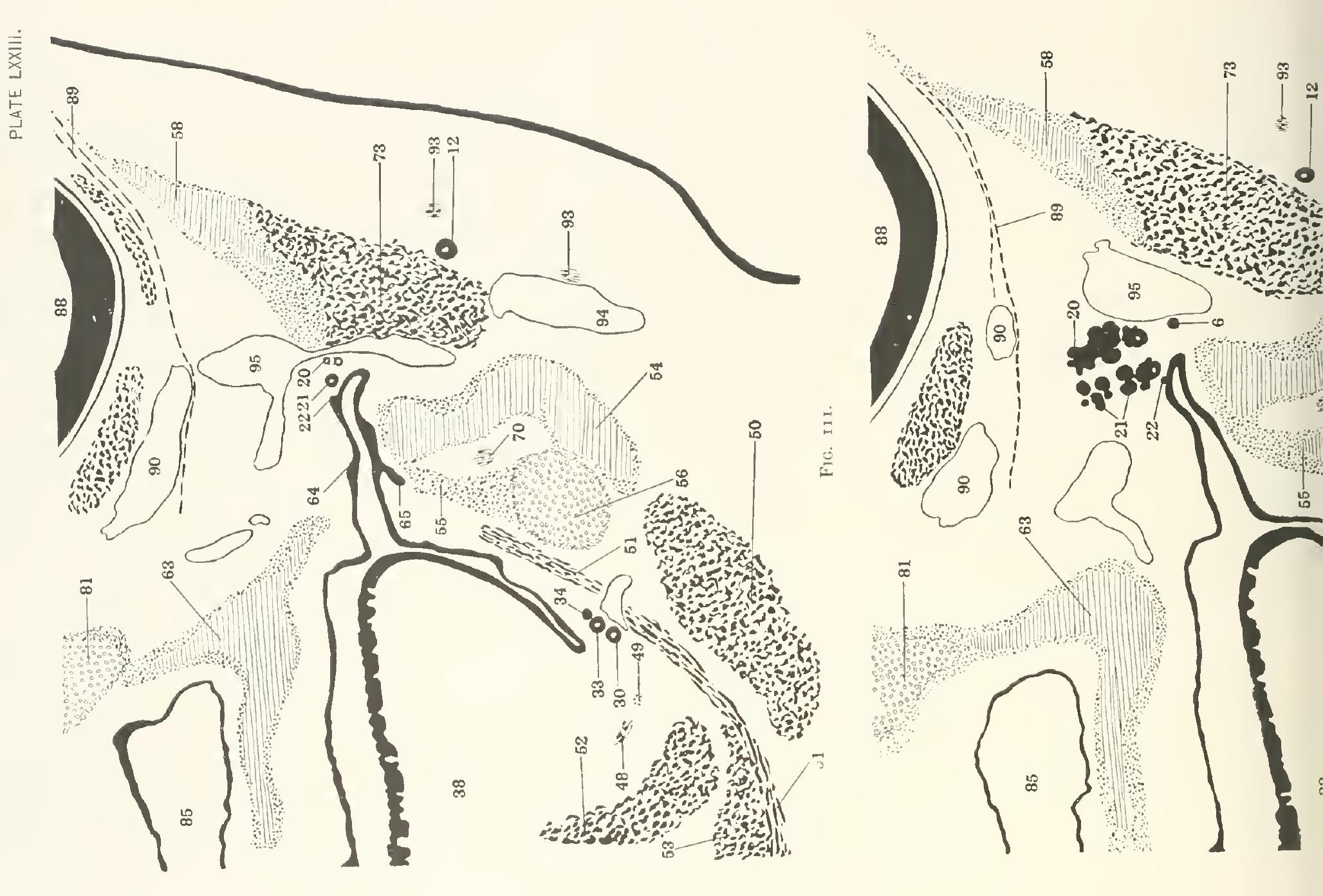




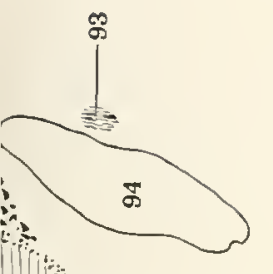

:

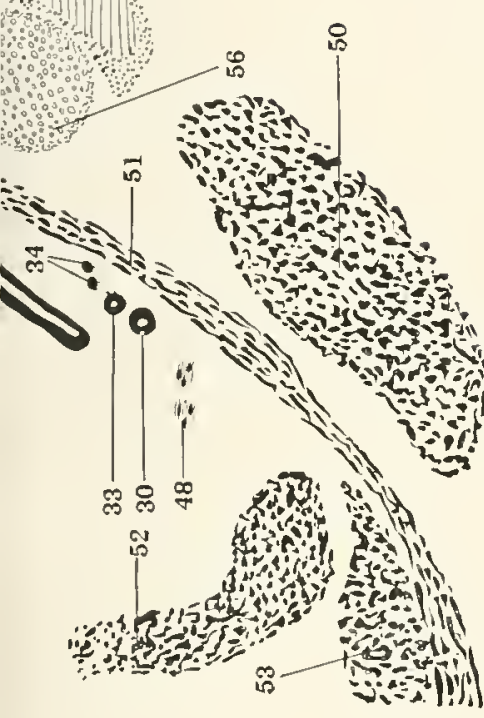

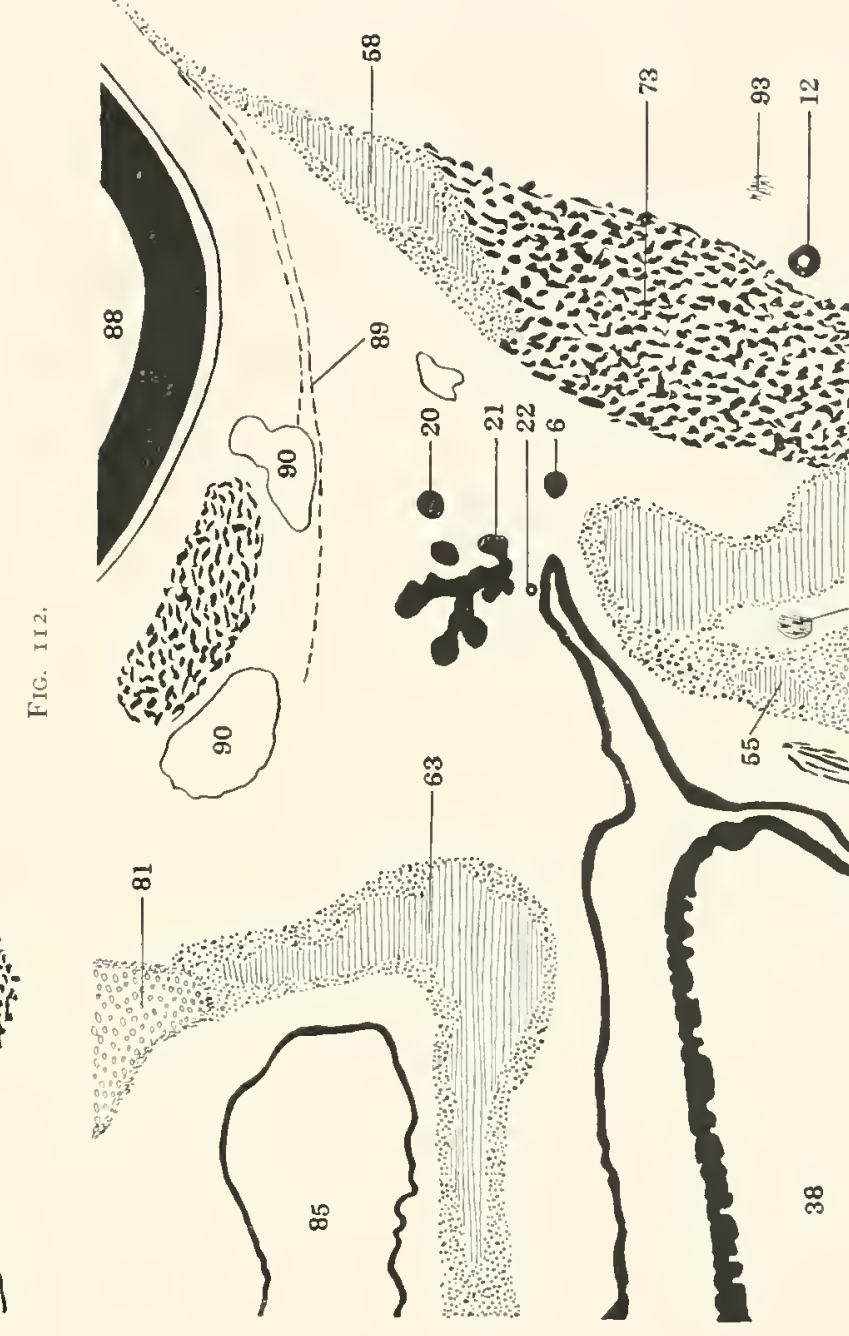

$\infty$ 




\section{PLATE LXXIV}

FIG. II. Schema of the oral epithelium and the glandular anlages in the ;o millimeter embryo. Columbia Collection, No. 270. From a graphic reconstruction.

Fic. I 5. Same embryo. Frontal section through the orifice of the parotid duct, $\times 70$, reduced to $\frac{1}{3}$

FIG. II6. Same embryo. Frontal section through the first orbital duct close to its orifice, $x ; 0$, reduced to $\frac{1}{2}$.

Ia. Secondary buccal sulcus.

Ib. Subparotid sulcus.

2. Angulus oris.

6. Orbital inclusion.

12. Parotid.

I7. Orbitoparotid sprout.

ro. Stomal ridge.

19a. Glands of stomal ridge.

20. First orbital gland.

21. Second urbital gland.

22. Third orbital glancl.

23. Cautial members of the orbital series.

21. Inferior alveubuccal glands.

25. Superior alveobuccal sulcus.

26. Inferior alveobuceal sulcus.

2.). Inferior alveolabial sulcus.

2. $\$$ a. Superior alveolabial sulcus.

30. Submaxillary duct.

3.3. Greater sublingual duct.

37. Eftlorescent lobules of the greater sublingual duct.

3n. Lesser sublingual glands.

f. . Lingual nerve.

56. Meckel's cartilage. 

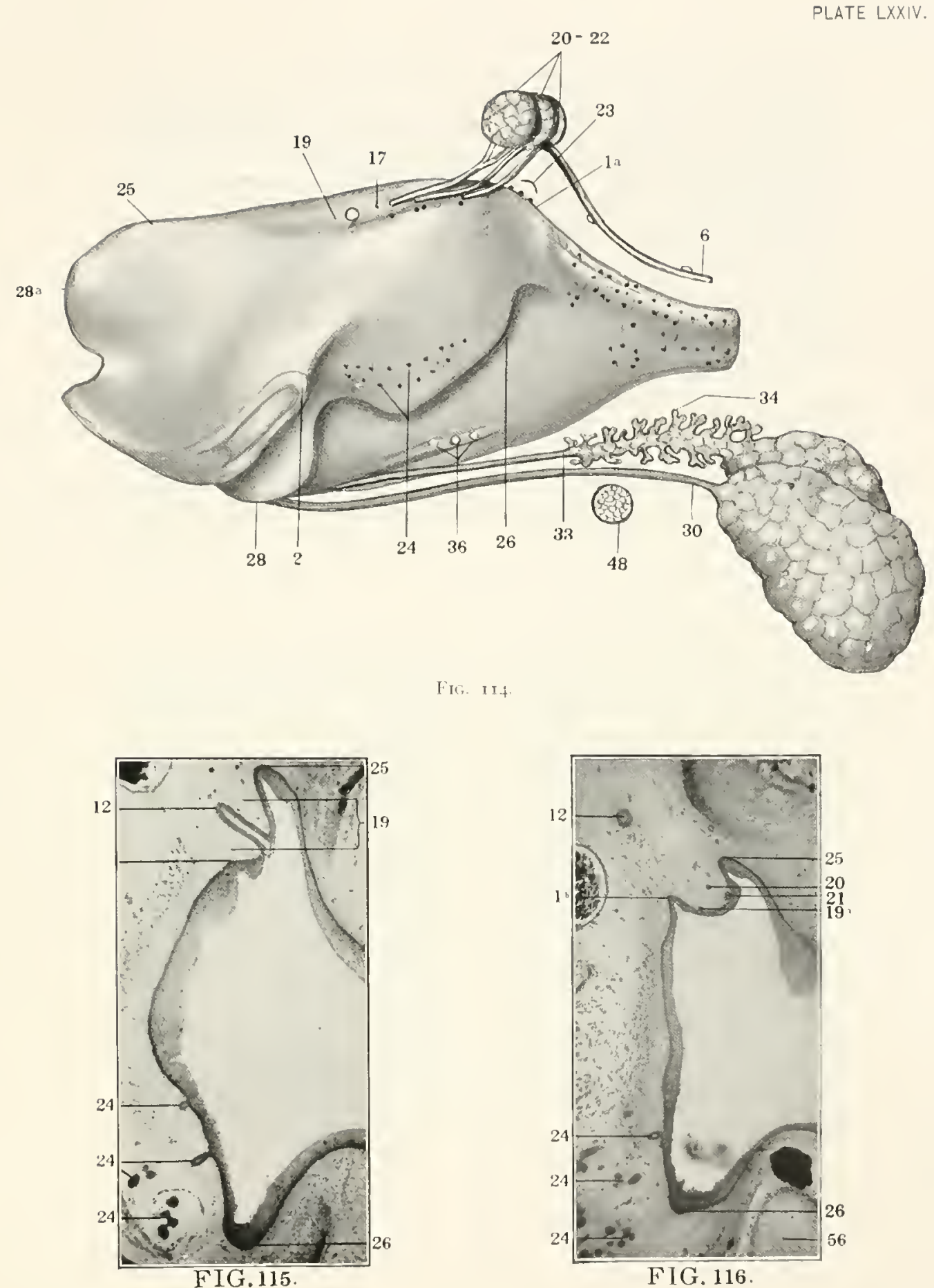


\section{PLATE LXIT}

FIGS. II8-I2I. Sections of the alveolingual region of an I m millimeter embryo. Columbia Collection, No. 213. Every third section. Thickness of sections $13.3 \mu, X \mathrm{II}_{5}$, reduced to $\frac{1}{2}$.
29. Lingual sulcus.
30. Submaxillary anlage.
7o. Latteral tongue swelling.
ft. Tuberculum impar.
43. Pialatolingual plane.
t4. Alveolingual region.
45. Palatomandibular plane.
4h. Nasillomantlibular plane.
f. I Iypoghossal nerve.
4). Lingual nerve.
4). Submaxillary ganglion.
$5 \%$. Meckel's cartilage.
65. Inferior dental antage.
7o. Inferior dental nerve. 


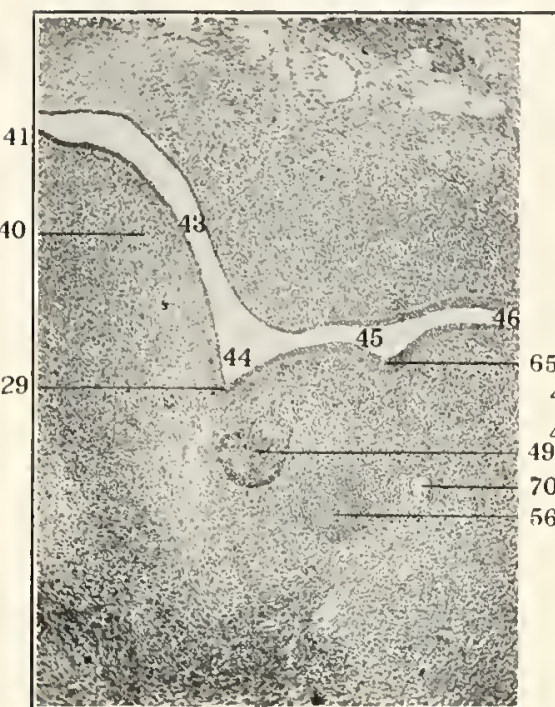

FIG. 118.

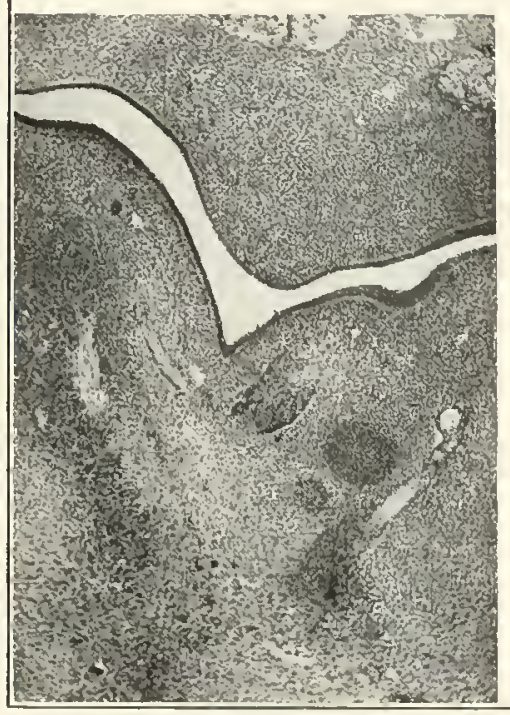

FIG. 119.

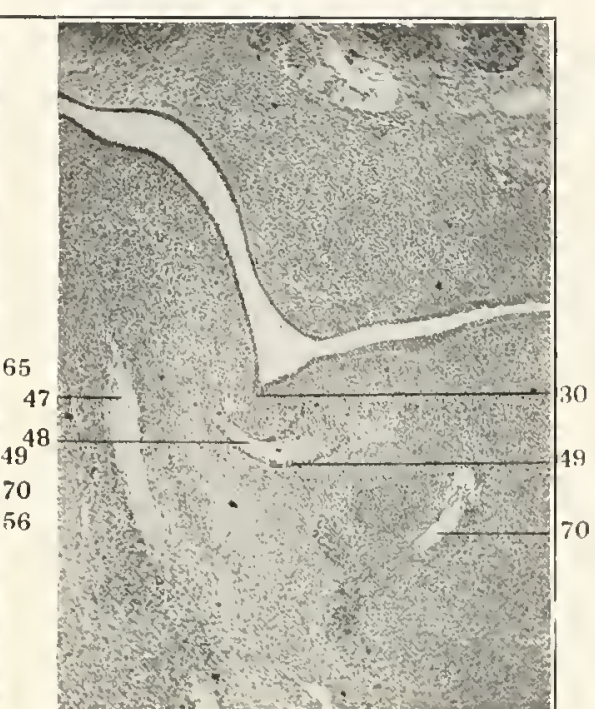

F IG. 120 .

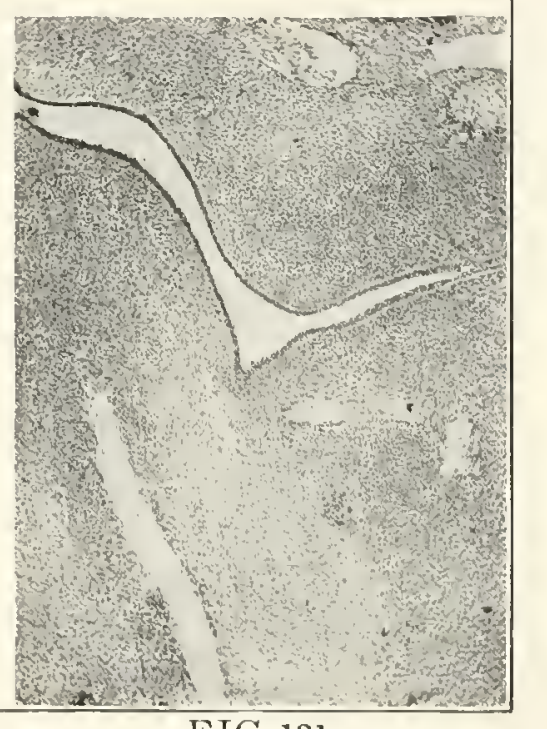

FIG.121. 
PLATE: LXXYI

FIGS. 122-128. Sections of the alveolingual region of a 12 millimeter embryo. Columbia Collection, No. -8 . Fig. 122 is $100 \mu$ craniad of the lingual crossing; Figs. 12,3-128 are alternate sections. Thickness of sections $20 \mu, \times 115$, recluced $\frac{1}{2}$.

\$. Orbital inclusion, pars cylindrica.

29. Lingual sulcus,

30. Submaxillary inlage.

3.3. Anlage of greater sublingual gland.

73. Palatolingual plane.

15. Lingual nerve.

10. Submaxillary ganglion.

5: Mechel's cartilage.

7). Inferior dental nerve

7ł. Internal pterygoid muscle. 


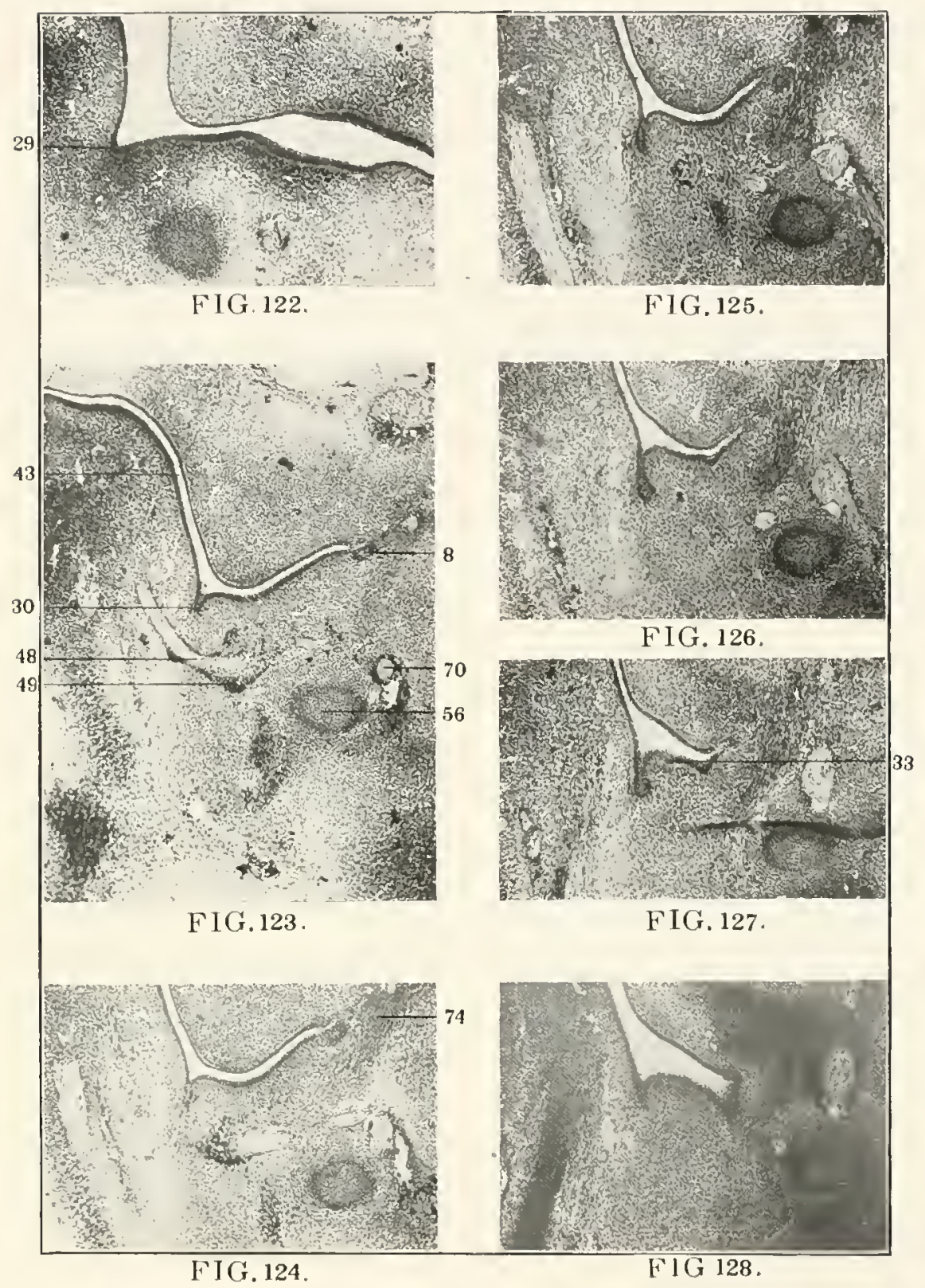




\section{PLATE LXYVII}

FIGS. I 20-I3 8 . Sections of the alveolingual region of a I 3.5 millimeter embryo. Columbia Collection, No. 223. Every third section. Thickness of sections $13.3 \mu, X$ I I 5 , reduced to $\frac{1}{2}$.

FIGS. 1 20-132.
20. Lingual sulcus.
30. Submaxillary anlage.
3. 5 . Tongue.
42. Craniolingual plane.
4.3. Palatolingual plane.
44. Alveolingual region.
45. Palatomandibular plane.
4h. Maxillomandibular plane.
49. Submaxillary ganglion.
50. Digastric muscle.
5I. Mylohyoid muscle.
52. Genioglossus muscle.
57. Inferior maxilla.
50. Meckel's cartilage.
6o. Palate process.
62. Ectopalatine sulcus.
万4. Superior dental anlage.
65. Inferior dental anlage.
68. Maxillary nerve.
7o. Inferior dental nerve. 


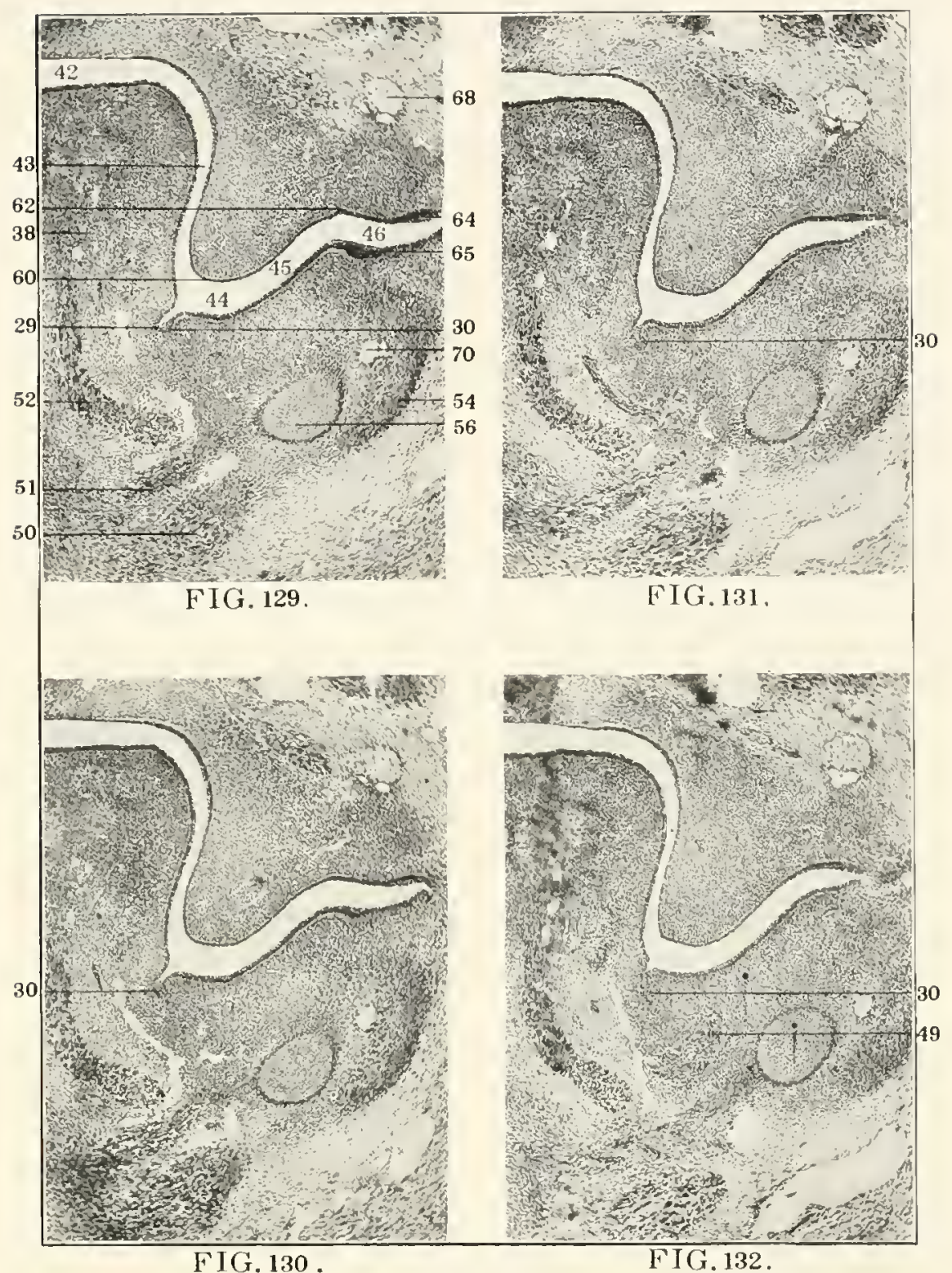


PLATE LXXTIII

FIGs. $133^{-13}$. Continus from the preceding.

3. Submaxillary anlage.

30 . Intermediate element of submaxillary tlange.

3i. Postglandular flange.

32. Submaxillary mesenchymal conrlensation.

3.3. Anlage of greater sublingual.

4. Lingual nerve.

49. Submaxillary ganglion. 


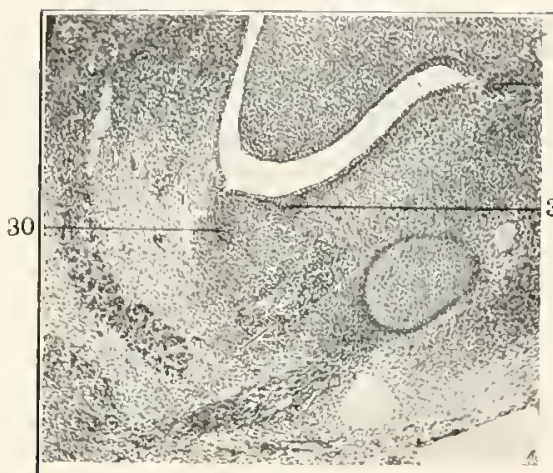

FIG. 133

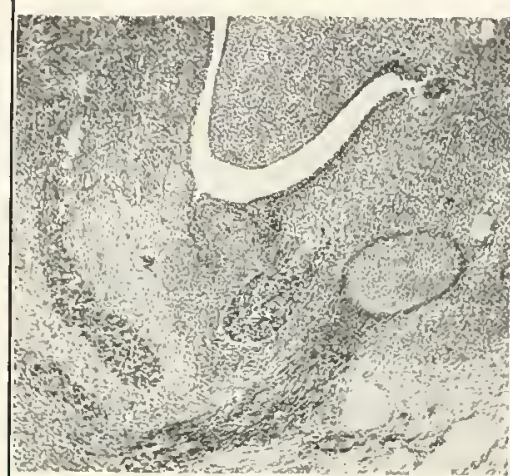

FIG.134.

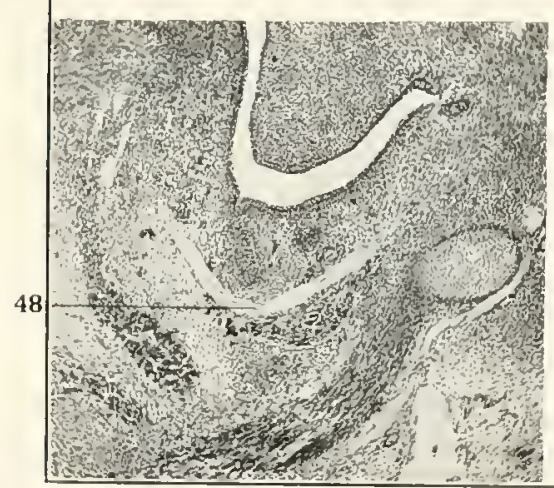

FIG.135.

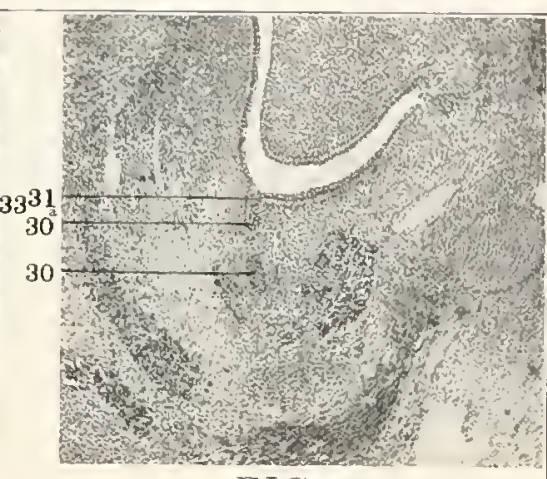

FIG.136.

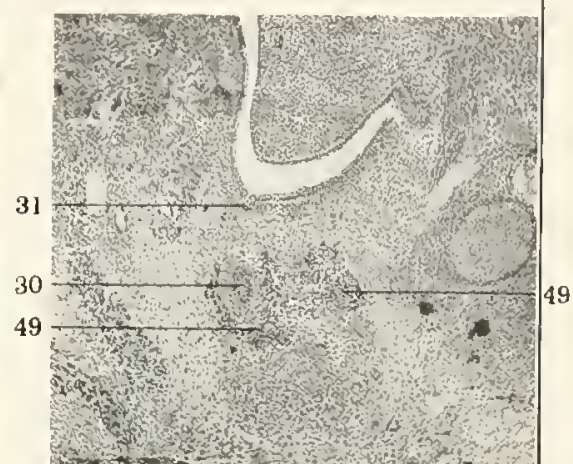

FIG. 137 .

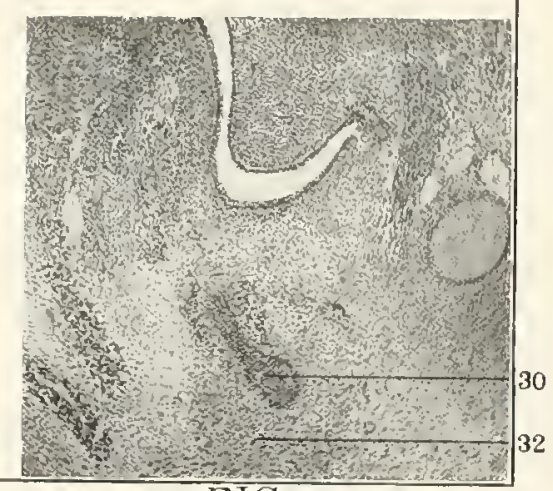

FIG.138. 


\section{Plate LXXix}

FIG. I30. The submaxillary and sublingualis major anlages in a 13.5 millimeter embryo. Columbia Collection, No. I80. Right side. From a wax reconstruction, $\times 75$, reduced to $\frac{1}{2}$.

FIG. I40. The submaxillary and sublingualis major anlages in a 16,5 milhmeter embryo. From a wax reconstruction, $\times_{75}$, reduced to $\frac{1}{2}$.

20. Lingual sulcus.

30. Submaxillary anlage.

31. Postglindular flinge.

33. Greater sublingual anlage.

74. Epithelium of alveolingual region.

4.5. Lingual nerve. 


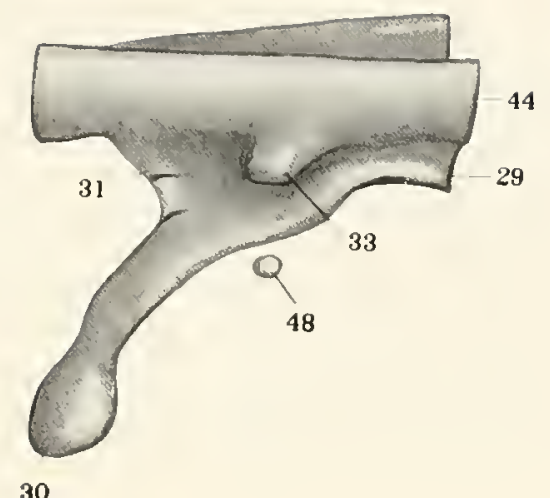

FIG. 139

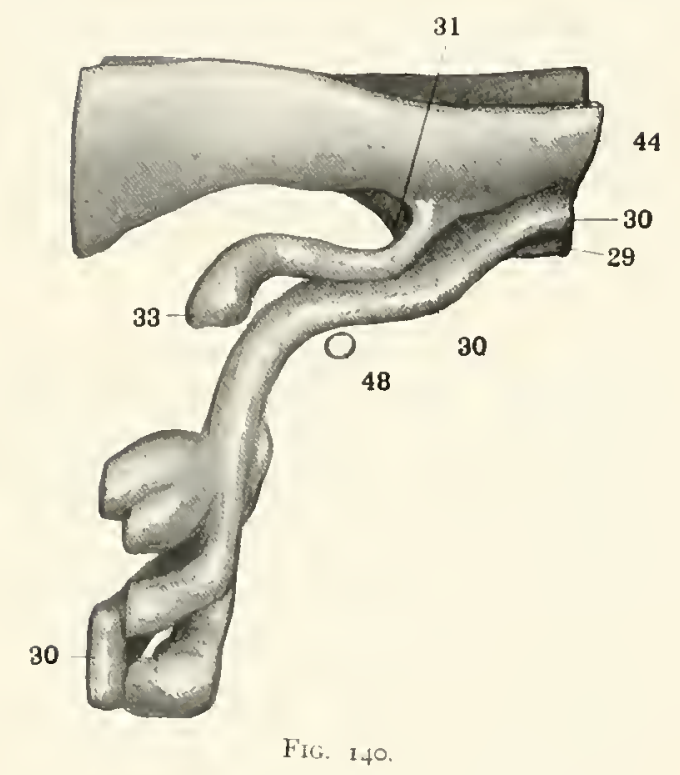


PLATE LXXY

FIG. If $\mathrm{I}$. The attachment of the submaxillary anlage in a if millimeter embryo. Columbia Collection, No. $210, \times 115$, reduced to $\frac{1}{2}$.

FIr. 142. The attachment of the submaxillary anlage in an is millimeter embryo. Columbia Collection, No. 278, $x+15$, reduced to $\frac{1}{2}$.

FIG. 143. The attathment of the submaxillary anlage in a 21 millimeter embryo. Columbia Collection, No. $2+2, \times 115$, reduced to $\frac{1}{2}$.

8. Orbital inclusion, pars cylindrica.

29. Lingual suleus.

30. Submaxillary anlage.

300 . Intermediate element of submaxillary flange.

31. Postglandular flange.

33. Crest of greater sublingual.

35. Circumflex sulcus.

39'. 'Tongue.

t3. Palatolingual plane.

47. Alveolingual region.

45. Palatomandibular plane.

4. Maxillomandibular plane.

ti. Hypoglussal nerve.

4). Lingual nerve.

49. Submaxillary ganglion.

50. ligastric muscle.

5I. Mylohyoid muscle.

52. Geniolnyoid muscle.

53. Geniuglossus muscle.

54. Inferior maxilla

50. Meckel's cartilage.

6o. Palate process.

65. Inferior dental anlage.

70. Inferior dental nerve. 
PLATE LXXX.

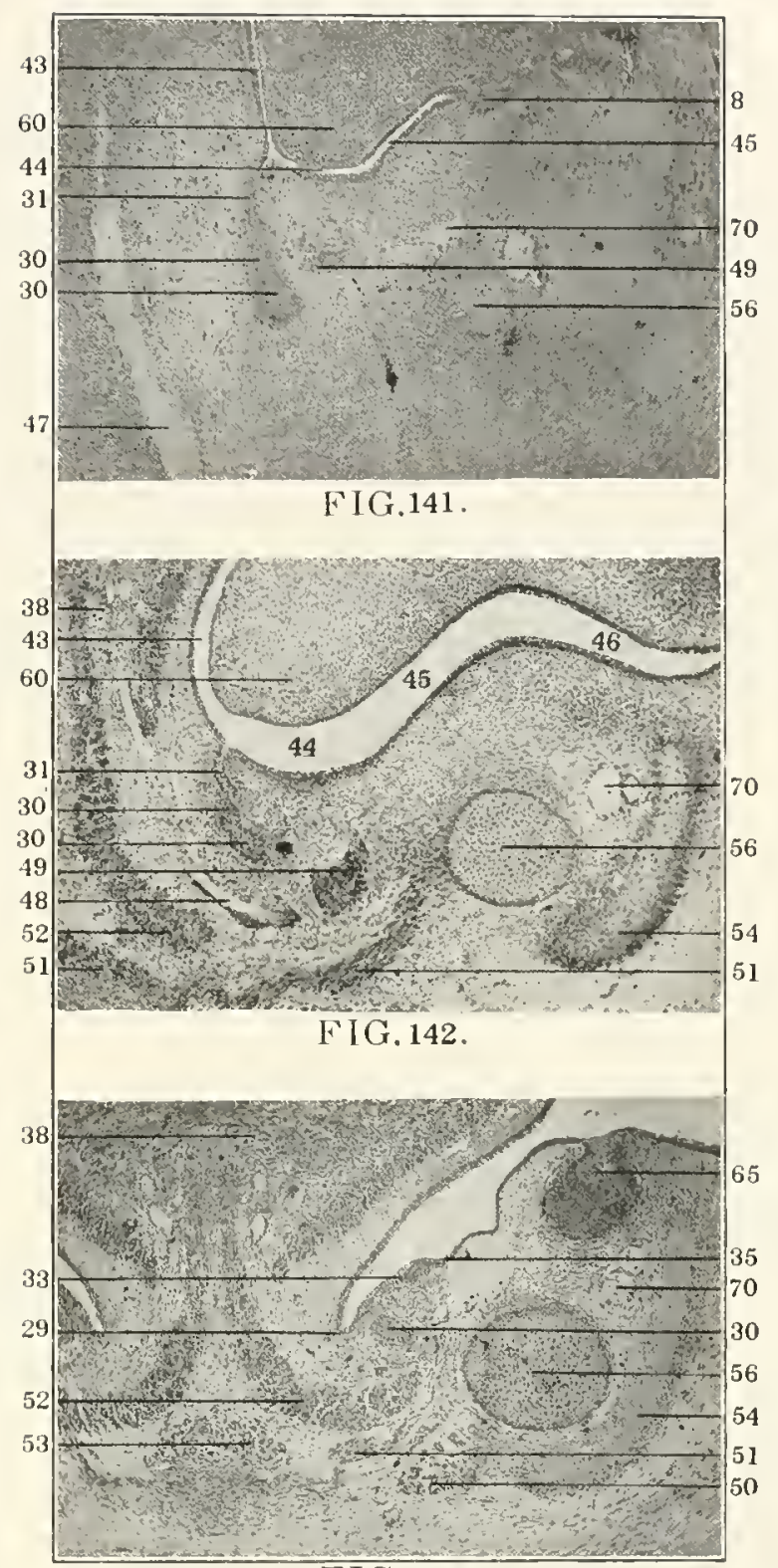

FIG.143. 


\section{PLATE LAXXI}

FIG. If4. Reconstruction of the alveolingual region and adjacent parts of the mouth of a 10 millimeter embryo. Columbia Co.lection, No. 253 Left side, $\times 55$, reduced to $\frac{1}{2}$.

FIG. I45. The same recunstruction, right side.
5. Orbital angle,
6. Orbital inclusion.
I2. Parotid.
27. Inferior alveobuccal glands.
30. Submaxillary gland.
33. Greater sublingual gland.
38. Tongue.
39. Frenulum.
t9. Submaxillary ganglion.
50. Digastric muscle.
5I. Mylohyoid muscle.
52. Genioglossus muscle,
65. Inferiur dental anlage.
on. I'ostgenial mesenchymal condensation.
7.3. Masseter muscle.
23. Tracheat.
g6. Plica sublingualis.
9.5. Esophagus. 

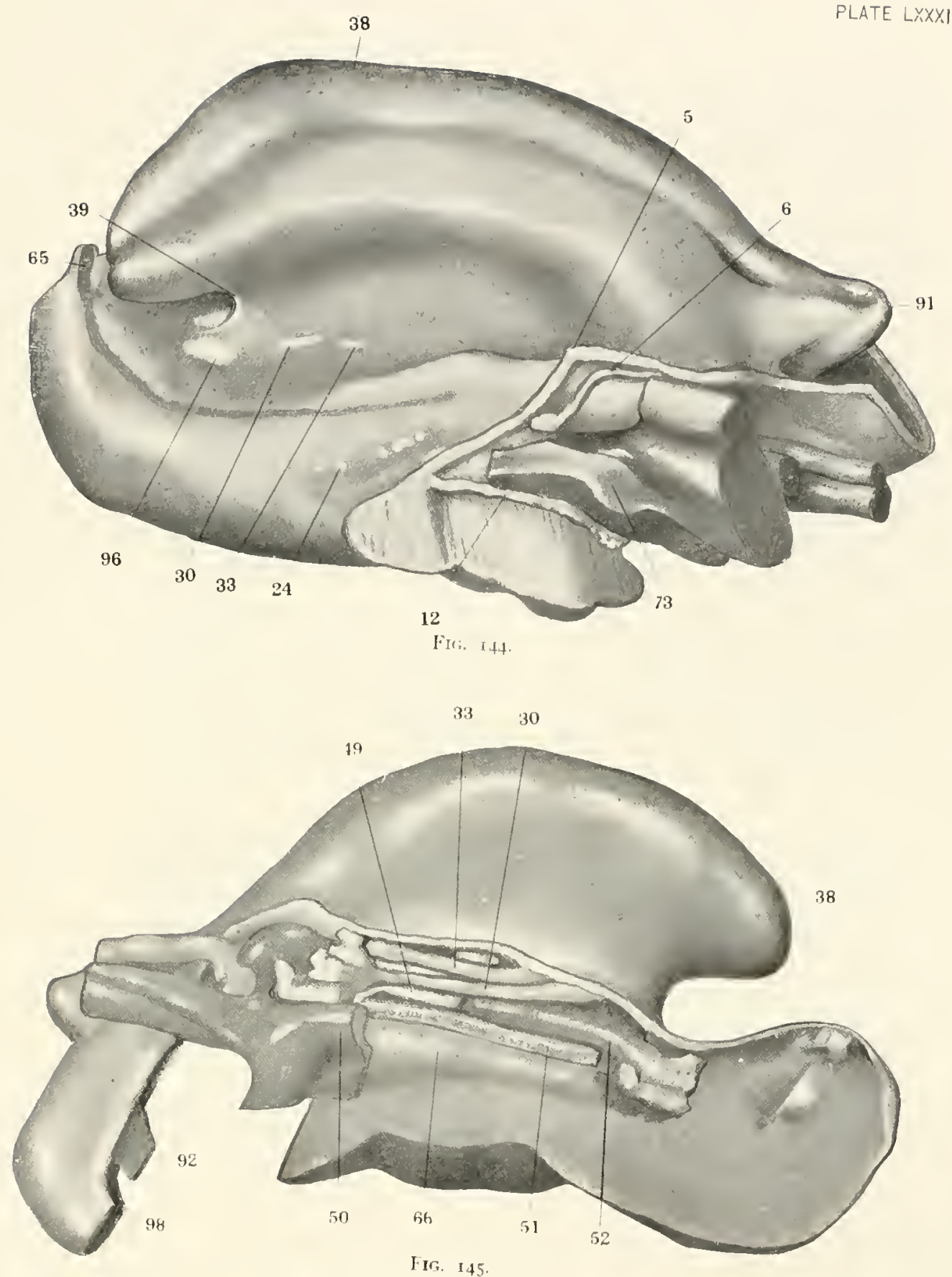


\section{PLAFE LXXYI}

FIGS. I47-I 49. The attachment of the submaxillary duct in a io millimeter embryo. Columbia Collection, No. 253. Serial sections at intervals of 40 ancl $20-\overline{7}, \times$ ir 5 , reduced to $\frac{1}{2}$.

Figs. I 50-152. The same in another io millimeter embryo. Columbia Collection, No. 276 . Serial seetions at intervals of 13.3 and $133 \mu, X_{115}$, reduced to $\frac{1}{2}$.

29. Lingual sulcus.

30. Submaxillary anlage.

30\%. Intermediate clement.

31. Postglandular flange.

3.3. Greater sublingual anlage.

39. Tongue.

t3. Palatolingual plane.

47. Mveolingual region

45. Patatomandibular plane,

th. Maxillomanelibular plane.

51. Mylnhyoid muscle.

52. Geniogtossus muscle.

53. Geniohyois muscle.

5ł. Inferior maxilla.

5ో. Meckel's cartilage.

f). Palate process.

62. Ectopalatine sulcus.

6f. Superior dental anlage.

65. Inferior dental anlage.

70. Inferior dentil nerve. 


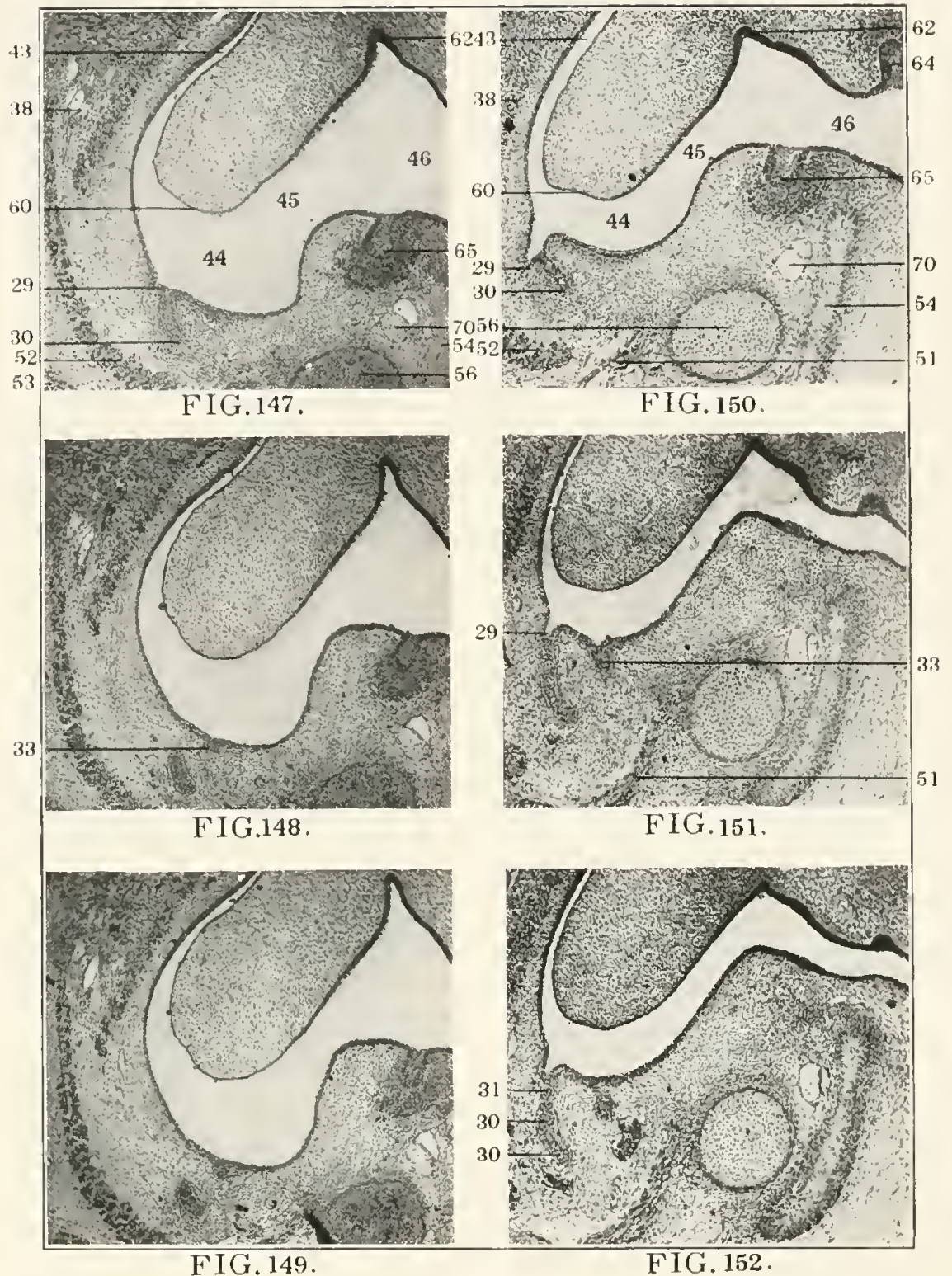




\section{PLATE LXXXIII}

FIGs. I53-I56. Sections of the alveolingual region of a If millimeter embryo. Columbia Collection. No. I22. showing an early stage of the anlage of the sublingualis major. Serial sections. X II 5 , reduced to $\frac{1}{2}$.

3'. Submaxillary anlage.

33. Greater sublingual anlage.

75. Lingual nerve.

79. Submaxillary ganglion.

5x. Mylohyoid muscle

52. (ienioglossus muscle.

i 3. Geniohyoir muscle.

$5^{\circ}$. Meckel's cartilage.

7. Inierior dental nerve. 


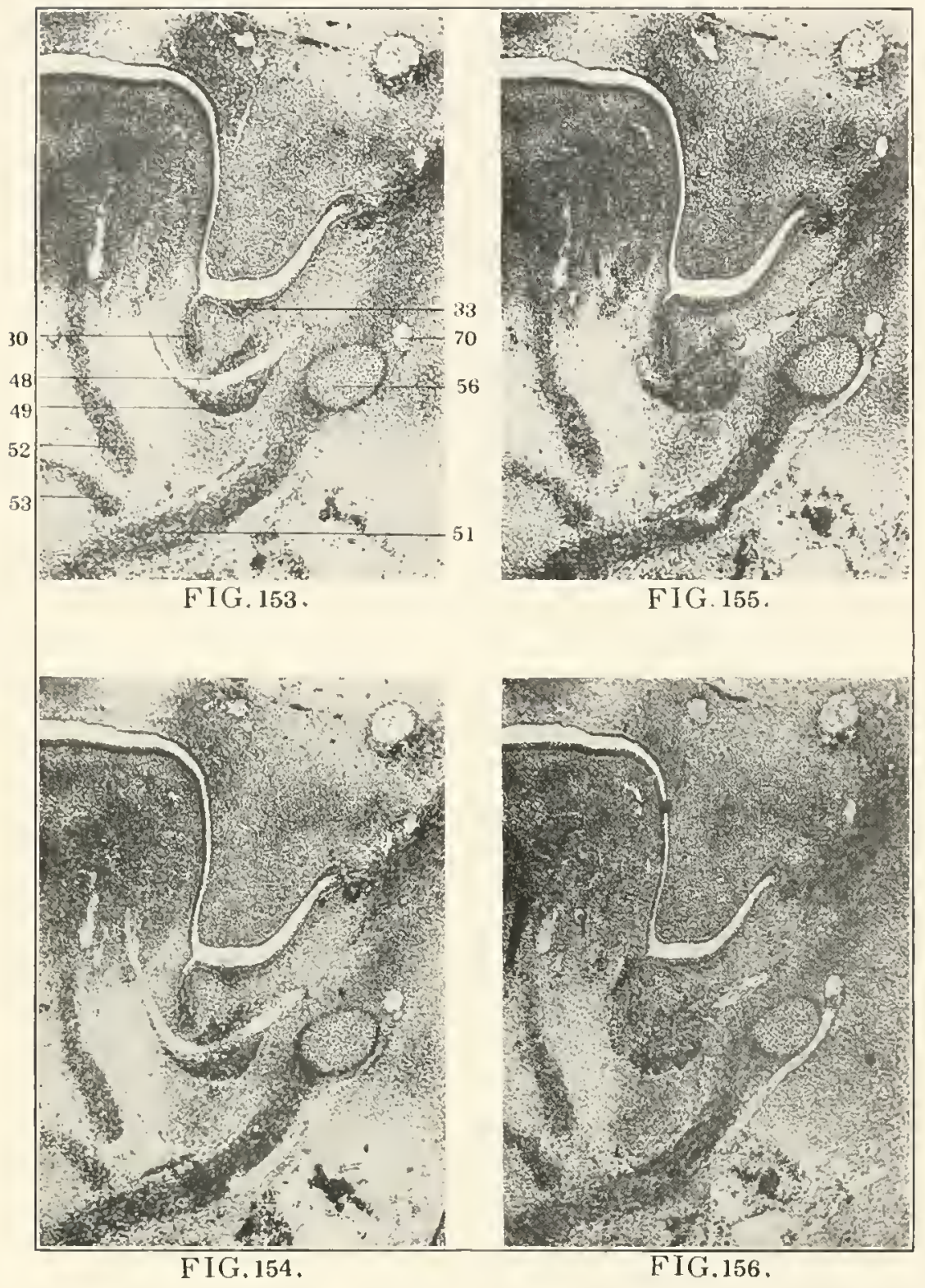




\section{Plate LAXXY}

FIG. I6r. Section showing sprout of a lesser sublingual in the to millimeter embryo. Columbia Collection, No. $270, \times 60$, reduced to $\frac{1}{2}$.

FIG. I62. Detail of the same, $X$ I I $_{5}$, reduced to $\frac{1}{2}$,

3). Submaxillary duct.

33. Greater sublingual cluct.

34. Efflorescent sprout of greater sublingual duct.

35. Circumflex sulcus.

3h. Lesser subiingual sprout.

50. Digastric muscle.

5x. Mylohyoid muscle.

52. Genioglossus muscke.

54. Inferior maxilla.

56. Meckel's cartilage.

65. Inferior dental anlage.

7o. Inferior dental nerve.

go. Plica sublingualis. 
PLATE LXXXV.
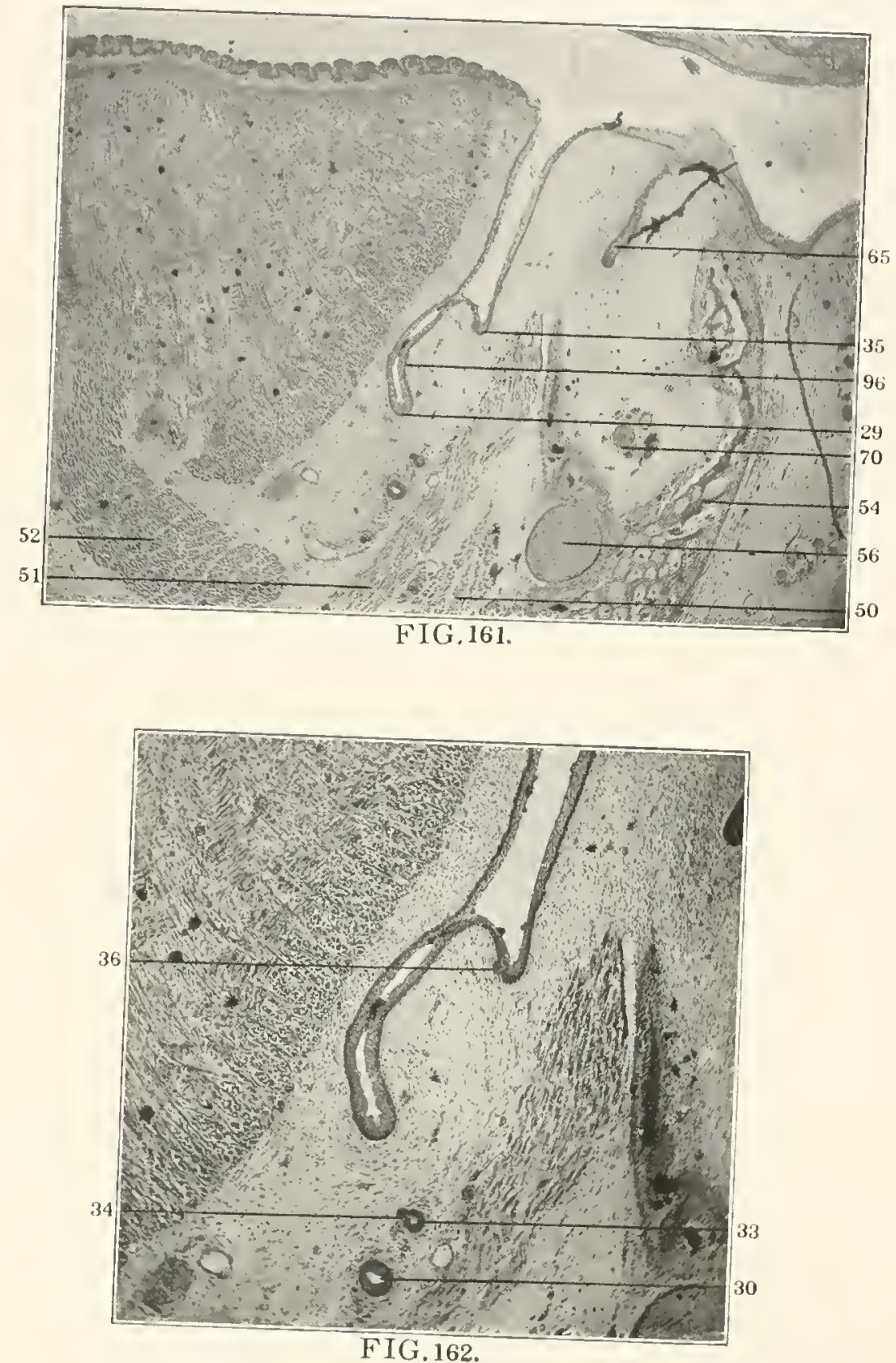


$$
\text { - - }
$$


PART VII

THE ANATOMY OF THE SALIVARY GLANDS IN SOME
MEMBERS OF OTHER MAMMALAN ORDERS

MARSUPIALS, INSECTIVORES, RODENTS, AND

UNGULATES

\section{By Churchill Carmalt}

IN the following account a limited number of species of Marsupials, Insectivores, Rodents, and Ungulates have been selected for illustration and description from a large amount of available material. Previous accounts of the salivary organization in the domestic and laboratory animals, and in many of the wild forms, have been published, notably by Cuvier, Meckel, Owen, Ranvier, and, more recently, by Illing and Zumstein. Reference to these publications is here omitted, because a general review of the salivary literature follows in Part VIII of this volume.

\section{MARSUPIALIA}

Fig. i. Didelphis Marsupialis - V'irginia Opossur.

Princeton University Morphological Museum, No. 456.

This marsupial presents an extremely simple and generalized type of mammalian salivary organization approaching rather closely the conditions encountered in the average arctoid carnivore (cf. Part $\mathrm{V}$ ).

I. The retromasseteric parotid (5), moderate in extent, fits with a concave margin around the caudal circumference of the external auditory canal and concha. The caudal excursion of the gland does not extend beyond the facial vein and its companion lymplatic nodes ( $\mathrm{IO}$ ).

The parotid duct (5) is simple in its entire long course across the masseter. 
2. A group of superior alseobuccal or molar glands ( $f$ ) begins caudad of the parotid duct terminal and arches around the angle of the mouth, without being prolonged into an inferior alveobuccal series (cf. the disposition of the alveobuccal glands shown in Canis familiaris, in Fig. 7 , and Taxidea americana, Fig. I2, Part V).

3. The submaxillary gland $(I)$ occupies the usual retro- and submandibular position of the carnivore and is divided into several larger lobules. The duct $(I)$ is simple throughout and opens by an independent parafrenular orifice.

4. The greater sublingual gland (2) is a small polyhedral mass embedded in the ventrocephalic border of the submaxillary gland. The duct, carrying two minute glandular sprouts, crosses to the dorsal border of the submaxillary duct and then continues, in company with the same, to the plica sublingualis, under cover of the lesser sublingual glands.

5. The lesser sublingual glands (3) form a narrow uniform band extending from the symphysis menti caudad, across the lateral aspect of the submaxillary and greater sublingual ducts, and arching thence dursomesad into the ventral palatine arch.

Fig. 2. Petauroides Volans - Flying Phalanger.

Columbia University Morphological Museum, No. 2 I 4 I.

I. The parotid gland $\left(5 a, 5^{b}\right)$ has an oblong, expanded form and is situated entirely in the subauricular and cervical region. The slightly reduced terminal portion fills the triangular interval between the sternomastoid, pectoral, and cephalohumeral muscles. The duct ascends obliquely to its termination.

2. The submaxillary $(I)$ forms a small compact mass fitted into the recess between sternomastoid, digastric, and the infrahyoid muscles, along the cephalic margin of the parotid. The duct is simple.

3. A small narrow band of lesser sublingual glands (3) overlies the lateral aspect of the submaxillary duct near its termination.

\section{INSECTIVORA}

Fig. 3. P'teropus Scapulatus - Fox Bat.

Columbia University Morphological Museum, No. 2002.

I. The parotid gland (5) lies entirely retromasseteric. The dorsal border is fitted around the extemal auditory meatus. Ventrad the 
gland teminates in two processes separated by a deep notch. The cephalic prolongation covers the corresponding portion of the submaxillary duct (1). The narrower caudal process is longer and extends into the neck overlying the sternomastoid muscle.

The parotid duct occupies the ungulate position on the mesal surface of the mandibular angle and internal pterygoid muscle, turning thence dorsad along the cephalic margin of the masseter to the buccal orifice.

2. The submaxillary gland $(I)$, of triangular shape, and composed of several loosely connected lobes, lies in the lower cervical region, in the supraclavicular fossa, its base corresponding to the entire length of the clavicle.

The long, slender submaxillary duct $(I)$ ascends on the sternomastoid, and reaches the oral floor by passing under cover of the ventral prolongation of the parotid, continuing thence forward to the plica sublingualis. In this long course the duct is simple without lateral derivatives.

3. The lesser sublingual glands (3) form a slender mass on the lateral aspect of the terminal portion of the submaxillary duct.

I could, in this specimen, find no indication of a greater sublingual duct and gland. I am under the impression that a specimen of Pteropus contained in the Princeton Museum shows a small Bartholinian gland closely embedded in the dorsal border of the submaxillary gland, with a slender duct accompanying the submaxillary duct to a separate parafrenular orifice.

[Note By EDIToRs:- On inquiry the presence of a greater sublingual gland in a specimen of Pteropus contained in the Princeton collection was ascertained.]

Fig. 4. Scalops Aquaticus - American Mole.

Columbia University Morphological Museum, No. I962.

In this insectivore all three major salivary glands, parotid, submaxillary, and greater sublingual, are present.

They have all shifted from the facial, inter-, and sub-mandibular regions caudad to the level of the pectoral girdle.

The parotid (5) appears divided into two main lobes.

The greater sublingual gland is entirely under cover of the lateral portion of the submaxillary $(I)$. Only its duct (2) is exposed on the 
right side of Fig. 4 by division and reflection of the right cephalohumeral muscle.

\section{RODENTIA}

Fig. 5. Sciurus Carolinensis - Gray Squtrrel.

Columbia Iniversity Morphological Museum, No. I946.

I. The parotid (5), the largest single gland, extends from the masseteric region to the supraclavicular fussa. Its caudal margin rests on the cephalic border of the pectoralis major.

2. The submaxillary gland $(t)$ is a globular mass embedded, at the hyoid level, in the mesal border of the parotid.

3. The greater sublingual gland is placed between the cephalolateral pole of the submaxillary and the adjacent cephalomesal surface of the parotid. The course of the submaxillary $(I)$ and greater sublingual (2) ducts to the plica sublingual's is shown on the left side of Fig. 5, after reflection of the mylohyoid.

4. A small group of lesser sublingual glands (3) covers the lateral aspect of the terminals of the submaxillary and greater sublingual ducts.

5. Lateral to the symphysis a small collection of inferior alveobuccal glands $(7)$ is encountered.

Fig. 6. Ceflogenty Pica-Paca

Princeton University Morphological Museum, No. 1305.

I. Parotid gland (5). A compact irregularly quadrangular mass fitted closely around the ventral and cephalic margins of the external ear. Stenson's duct, emerging irom the upper third of the cephalic border, curves under cover of the zygomatic arch to its buccal orifice.

2. Immediately cephalad of the parotid duct terminal lies a separate small oblong gland (4) with relatively long duct $(4 a)$. In Fig. 6 the $z y-$ gomatic arch has been detached and reflected to show this structure, which I have not encountered in this condition in any other mammal. It is evidently a derivative of the superior alveobuccal series of the usua' mammalian type, but characterized by combination of the individual components into a definite gland with a common duct.

3. Submaxillary gland $(I)$. A compact globular mass situated in the cligastric space, its border slightly overlapped by the adjacent angle of the parotid. 
4. The greater sublingual gland (2) forms a small mass embedded in the cephalic margin of the submaxillary.

The submaxillary and greater sublingual ducts run closely connected, under cover of lingual nerve and lesser sublingual glands, to separate orifices on the parafrenular papilla.

5. The lesser sublingual glands (3) form a relatively large mass which begins some distance behind the orifices of the submaxillary and greater sublingual ducts and extends caudad to abut directly against the body of the greater sublingual gland. The glands are characterized by unusually large and distinct openings of their ducts on the lesser sublingual (Rivinian) ridge. Further, the caudal extremity of the gland mass turns dorsomesad, so that the submaxillary and greater sublingual ducts, crossed in this situation by the lingual nerve, lie for a short distance after emerging from their respective glands on the lateral aspect of the lesser sublingual mass. They then turn over the oral border of the same to its mesul surface, which they follow forward in the rest of its extent. Their terminal segments, as stated, pass forward beyond the lesser sublingual mass to their separate orifices.

Fig. 7. IYYdrochcerus CAPYBARA - C.IPYBARA.

Princeton University Morphological Museum, No. 1025.

I. The parotid (5) is in the form of an inverted $\mathrm{T}$, the extremity of the vertical branch fitting around the circumference of the external auditory meatus. The expanded horizontal portion lies in the suband retro-mandibular region, its cephalic division supporting the submaxillary gland from below. The large intraglandular divisions of the parotid duct run, for the most part, on the superficial aspect of the gland, ascending to a point on the cephalic margin of the vertical segment of the gland from which the main duct emerges, on a level with the external auditory meatus. Stenson's duct (5) runs, without lateral derivatives, straight across the masseter muscle to its termination.

2. The submaxillary gland $(I)$ is relatively small and rests on the cephalic division of the horizontal parotid arm. An accessory submaxillary gland $\left(I^{\prime \prime}\right)$, close to the main body of the gland, empties into the beginning of the submaxillary duct. The latter is simple, its ter- 
minal portion covered laterally by the greater sublingual gland and duct.

3. The greater sublingual gland (2) is an oval mass composed of two divisions, each draining by a separate duct, which unite into a single canal at the cephalic end of the gland.

The greater sublingual gland is confined to the central portion of the alreolingual area, the caudal extremity barely extending beyond the point of intersection of the submaxillary duct and lingual nerve. There are no distinct lesser sublingual glands.

As previously stated (ci. supra. Part I, p. I6). the structure of the greater sublingual gland in this animal. and the absence of the group of separate lesser sublingual glands. suggests that the latter have been included in the building up of the double greater sublingual element. In other words. Hydrochorus may represent a type in which all the available separate glandular components of the alveolingual field are appropriated in the development of composite larger glands with separate ducts. A further unfolding of the greater sublingual element might assign the value of a separate gland and duct to each of the two components encountered in this form. In this case the alveolingual area would. in the adult, present three distinct major glands. the median submaxillary, intermediate greater sublingual. and a lateral element, representing the usual group of lesser sublingual sprouts, united into a definite gland with separate duct. Such a condition has not as yet been encountered among the mammalian types exanined, but Hydrochœrus forms an approach to its attainment.

Two further examples of this form, contained in the Columbia University Collection, both show the same composite formation of the greater sublingual gland and the complete absence of a lesser sublingual group.

Fig. S. Hristrix Afric.e-Acstralis - Africts Porclpine. Princeton University Morphological Museum, No. I 40.

I. The parotid gland ( 5 ) is very large extending from the subauricular position cephalad around the duct haliway across the masseter, and caudad into the neck, increasing in breadth caudo-cephalad. Several distinct lobules on the deep surface of the cephalic border come into intimate relation with the submaxillary and greater sublingual glands. 
2. The submaxillary $(I)$ and greater sublingual (2) glands occupy the digastric area, below and behind the mylohyoid. Their simple ducts run forward in company, under cover of the lesser sublingual mass, to separate parafrenular openings.

3. The lesser sublinguals (3) occupy the central and caudal districts of the lateral alveolingual field as a compact trapezoid mass.

Fig. 9. Fiber Zibethicus - MIUSkRat.

Princeton University Morphological Museum, No. 460.

I. The parotid $\left(5 a, 5^{b}\right)$ is clongated in the cephalo-caudal direction and partially subdivided by a deep vertical groove along the ectal surface. In the interval between its concave cephalic border and the ventral margin of the external auditory canal is lodged the globular gland of the eyelid (6), whose duct ( $6 a)$ ascends obliquely cephalad over the zygomatic area and carries near its termination two accessory paraductular gland masses. The parotid duct (5) is simple, without associate derivatives.

2. The submaxillary gland $(I a, I b)$ is single, almond shaped, lodged in the suprahyoid region near the median line, the glands of opposite sides being nearly in contact.

3. The cephalic pole of each submaxillary gland is capped dorsally by a lymph node (Io), intervening between it and the adjacent parotid, and ventrally by the small, but distinct, greater sublingual gland (2).

Submaxillary and greater sublingual ducts $(I, 2)$ are simple, extend around the mylohyoid border to the mesal surface of the lesser sublingual mass, and terminate by separate parafrenular orifices.

4. The lesser sublingual glands (3) form a compact mass, with tapering cephalic extremity, occupying the central and caudal portions of the lateral alveolingual district, and covering in the area of their extent the lateral aspect of the submaxillary and greater sublingual ducts.

Fig. io. Arctomys Monax - Ground Hog.

Princeton University Morphological Museum, No. 886.

I. The parotid (5), extremely reduced in the dorso-ventral and correspondingly elongated in the cephalo-caudal diameter, forms a long, narrow mass, extending from the caudal border of the external auditory meatus to the submaxillary fossa. The parotid duct (5) is simple and runs a long course over the masseter to its buccal orifice. 
2. The submaxillary gland $(I)$ is composed of several large loosely connected lobes, and the greater sublingual gland (2) is embedded on its cephalolateral surface. Submaxillary (I) and greater sublingual (2) ducts take the usual course and terminate in independent parafrenular openings.

3. The lesser sublingual glands (3) form a solid rectangular mass with very distinct individual duct openings on the Rivinian ridge.

\section{UNGULATA}

The typical Ungulates are characterized by the following features in their salivary organization :-

I. Only two of the three components of the typical mammalian alveolingual area are fully developed, as the submaxillary and lesser sublingual glands.

The greater sublingual or Bartholinian gland is usually absent. On the other hand, the lesser sublingual group is extensively developed.

2. The submaxillary gland is large and prolonged dorsocephalad, under cover of the parotid, from its usual submandibular position into the retromandibular and subauricular area.

3. Stenson's duct emerges from the ventrocaudal portion of the gland and arches below masseter and mandibular angle, or under cover of the latter and of the internal pterygoid, to the ventral border of the masseter, along which it ascends to its point of intersection with the deep facial vein and the facial nerve trunks, where it turns at right angles through the buccinator fibers to its terminal orifice.

These generalized Ungulate salivary characters are illustrated in the following three preparations:-

Fig. it. Antelope Cervicapra - Antelope.

Princeton University Morphological Museum, Nu. I 463.

I. The trapezoid parotid gland (5) is slightly prolonged at the caudoventral angle upon the emerging duct. The latter curves along the border of the masseter and mandible, ascends along the ventral margin of the muscle, and turns alove the comnissure at right angles to its terminal segment through buccinator and alveobuccal mucosa (5). 
2. The submaxillary gland $(I)$ lies below and behind the mandible, largely under cover of the mesal surface of the parotid gland. Its simple duct, eovered in the normal position by the caudal border of the lesser sublingual mass, and crossed obliquely by the lingual nerve, courses forward to the parafrenular opening.

3. The lesser sublingual group (3) is exposed in Fig. I I by resection of the body of the mandible, and is formed by a densely crowded mass of individual glands which extends from the plica sublingualis caurlarl, crossed on its lateral aspect by the lingual nerve, and then turns dorsomesad, under cover of mandibular ramus and internal pterygoid muscle, into the anterior palatine arch and the soft palate.

Fig. I2. Bos Taurus - Calf.

Columbia University Morphological Museum, No. 21 54

The preparation shows the superficial exposure of parotid gland and duct (5).

The elongated group of the upper and lower alveobuccal glands $(4,7)$ are fully developed.

Fig. I3. Equts Caballus - Horse.

After a fresh dissection.

The vertically elongated parotid $(5)$ is divided by incisures into four main lobes.

The duct arehes mesad of the prolonged mandibular angle, emerging at the ventral margin of the masseter, along which it ascends to its point of engagement in the buceinator. The submaxillary gland $(I)$ is relatively small, is placed largely under cover of the caudal portion of the parotid, but does not project beyond its dorsal margin.

ANNOTATIONS OF LEADERS IN ALL FIGURES

I. Submaxillary gland and duct.

$I^{\prime \prime}$ Accessory submaxillary gland.

Ia. Left submaxillary gland.

Ib. Right submaxillary gland.

2. Greater sublingual gland and duct.

3. Lesser sublingual glands and ducts.

4. Superior alveobuccal or molar glands.

ta. Superior alveobuccal or molar duci. 
324 SALINARY GLANDS IN MARSUPIALS, INSECTIVURES, RODENTS

5. Parotid gland and duct.

5a. Left parotid gland.

jo. Right parotid gland.

6. Eyelid gland.

6i. Eyelid duct and accessory glands.

7. Inferior alveobuccal or molar glands.

$\delta$. Facial nerve.

q. Zygomatic arch.

10. Lymphatic nodes.

II. Thyroid gland. 



\section{PLATE LXISII}

Fig. I. Didelphis Marsupisis - I irginia Oposstum.

Princeton University Morphological Museum, No. 450 .

$I, I$. Submaxillary gland and duct

2. Greater sublingual gland.

3. Lesser sublingual glands.

4. Superior alveobuccal or molar glands.

3. 3. P'arotid gland and duct.

IO. Lymphatic nudes. 
PLATE LXXXV!.

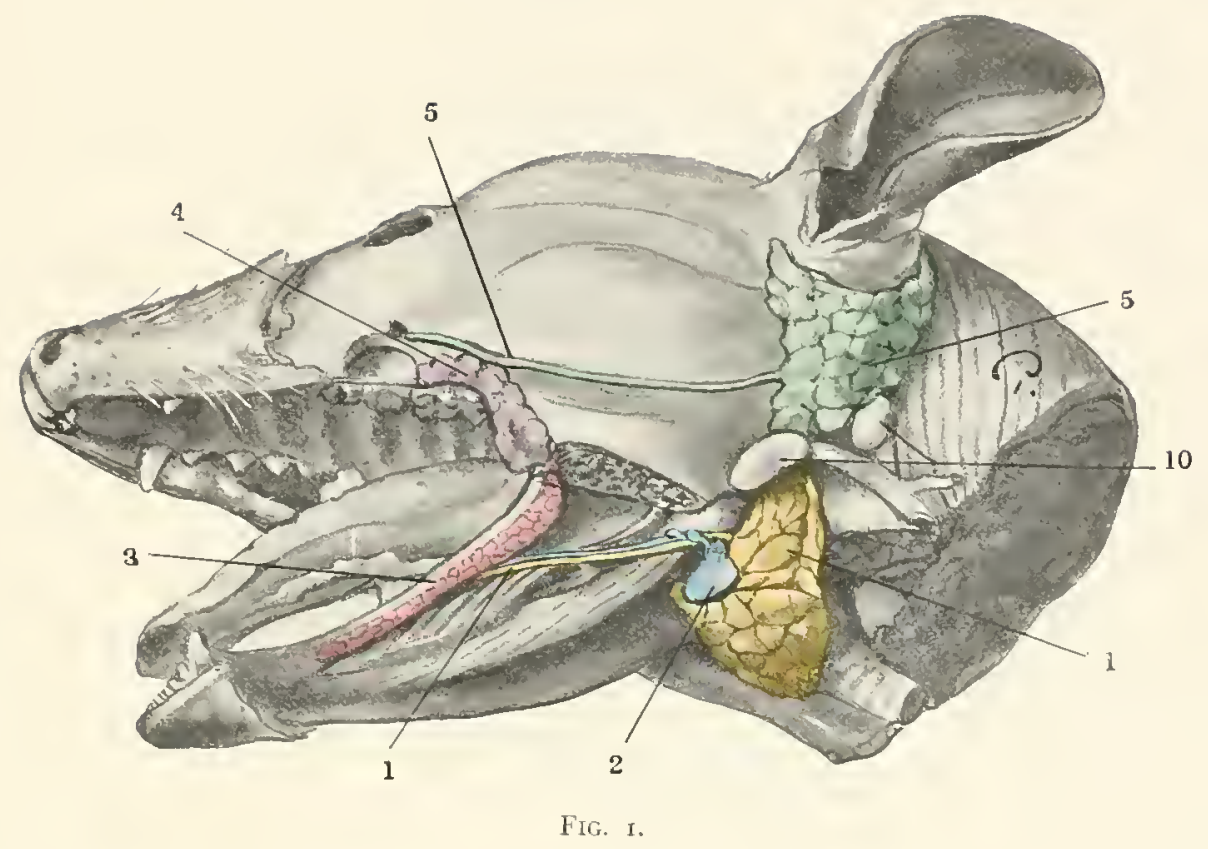




\section{Plate Lxyetil}

Fig. 2. Petauroides Volans - Flying Phalanger.

Columbia University Morphological Museum, No. 2I +1.

I. Submaxillary gland.

3. Lesser sublingual glands.

5. Parotid duct.

5a. Left parotid gland.

$5 b$. Right parotid gland. 
PLATE LXXXYII

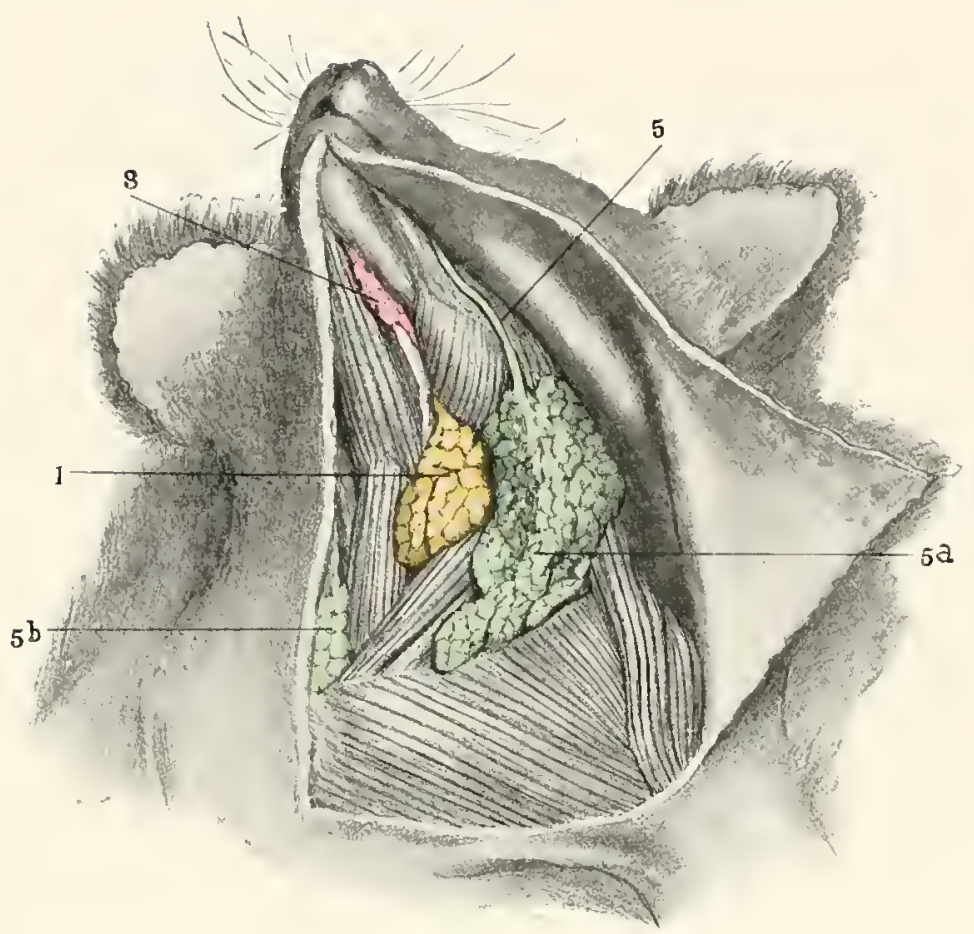

FIG. 2. 
PLATE LAXXIIII

Fic. 3. P'tFropt's Scipllates - Fox Bat.

Columbia University Morphological Museum, No. 2002.

$I, I$. Submaxillary gland and duct.

3. Lesser sublingual glands.

5. Parotid gland.

s. Facial nerve. 
PLATE LXXXVIII.

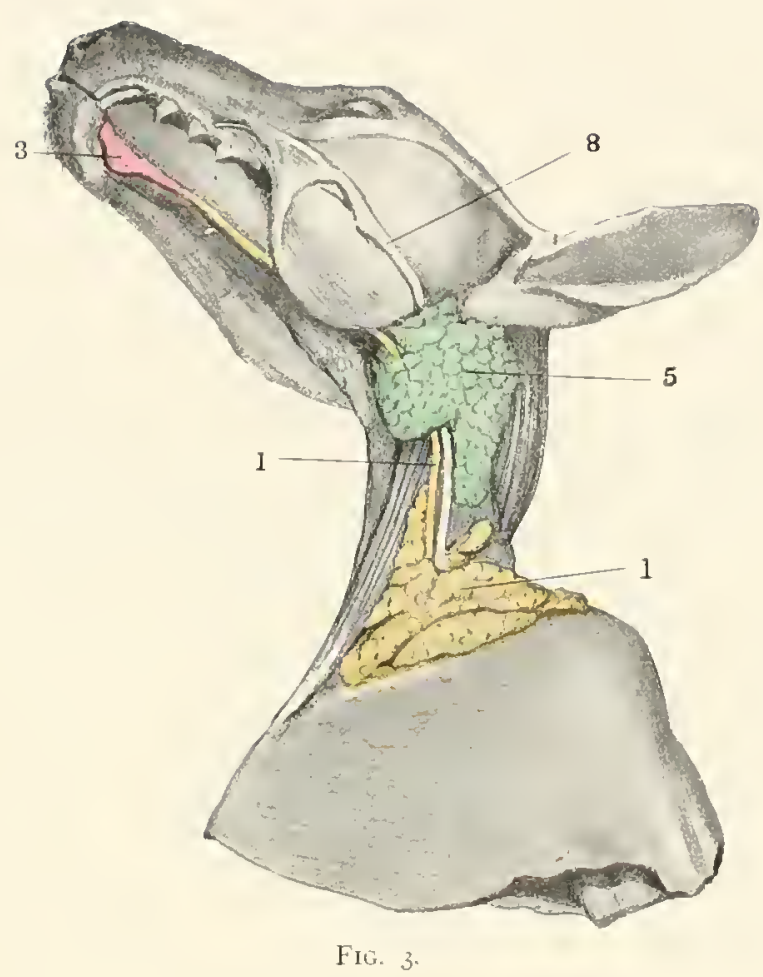




\section{PLATE LXXXIX}

Fig. 4. Scalops Aquaticts - Commox Mole.

Columbia L'niversity Morphological Museum, No. 1962.

I. Submaxillary gland and duct.

2. Greater sublingual duct.

5, 5. Parotid gland. 
PLATE LXXXIX.

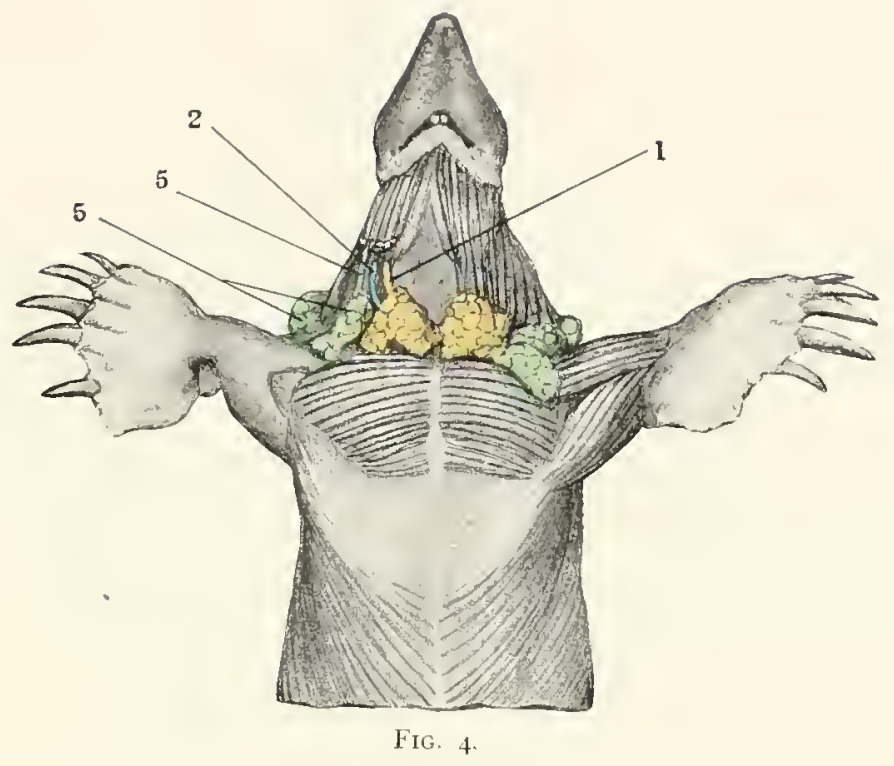


PLATE XC

Fig. 5. Sciurus Chrolintagis - Griy Soutril

Columbia University Morphological Museum, No. 1946.

$I, I$. Stumaxillary gland and duct.

2. Creater suhlingual gland and duct.

3. Lesser sublingual glands.

5. 5. Parotid gland and duct.

7. Inferior alveotuccal or molar glands. 

Plate ICI

Fig. 6. Calogenys Paca-Paca.

Princeton University Morphological Museum, No. I305.

$I, \imath$. Submaxillary gland and duct.

2, 2. Greater sublingual gland and duct.

3. Lesser sulblingual glands.

7. Superior alveobuccal or molar gland.

fil. Superior alvenbuccal or molar duct.

5. 5. P'arotil gland and duct.

g. Zygomatic arch.

10. Lymphatic nodes. 
PLATE XCl.

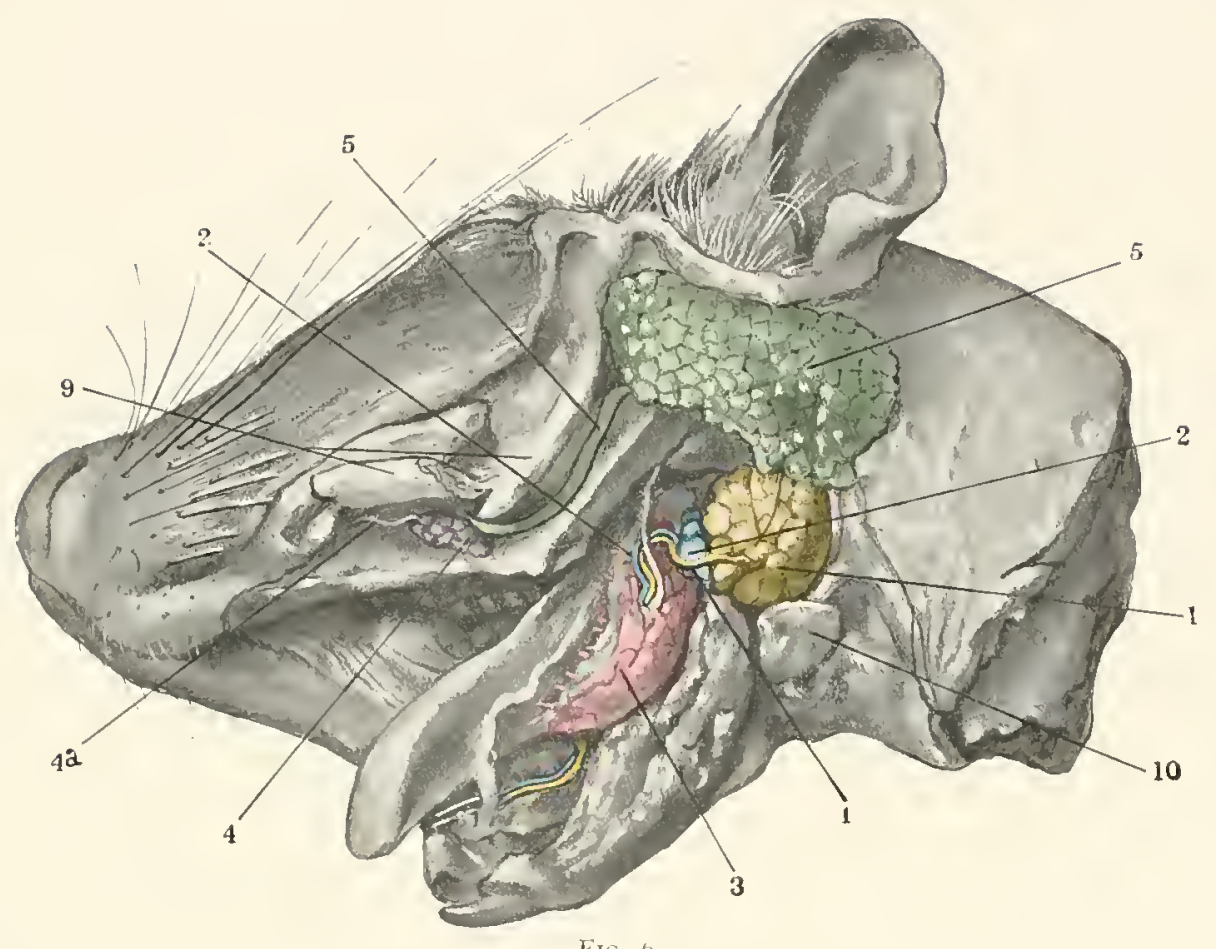

II IG. 0 . 


\section{PLATE XCII}

Fig. $;$. Hydrocheres Capibara-Capybar.

Princeton University Morphological Museum, No. I0z5.

$I, I$. Sulmaxillary gland and duct.

$I^{\prime \prime}$. Accessory submaxillary glind.

2 2. C. Greater sublingual gland and duct.

5, 5. Parutid gland and duct. 
PLATE XCII.

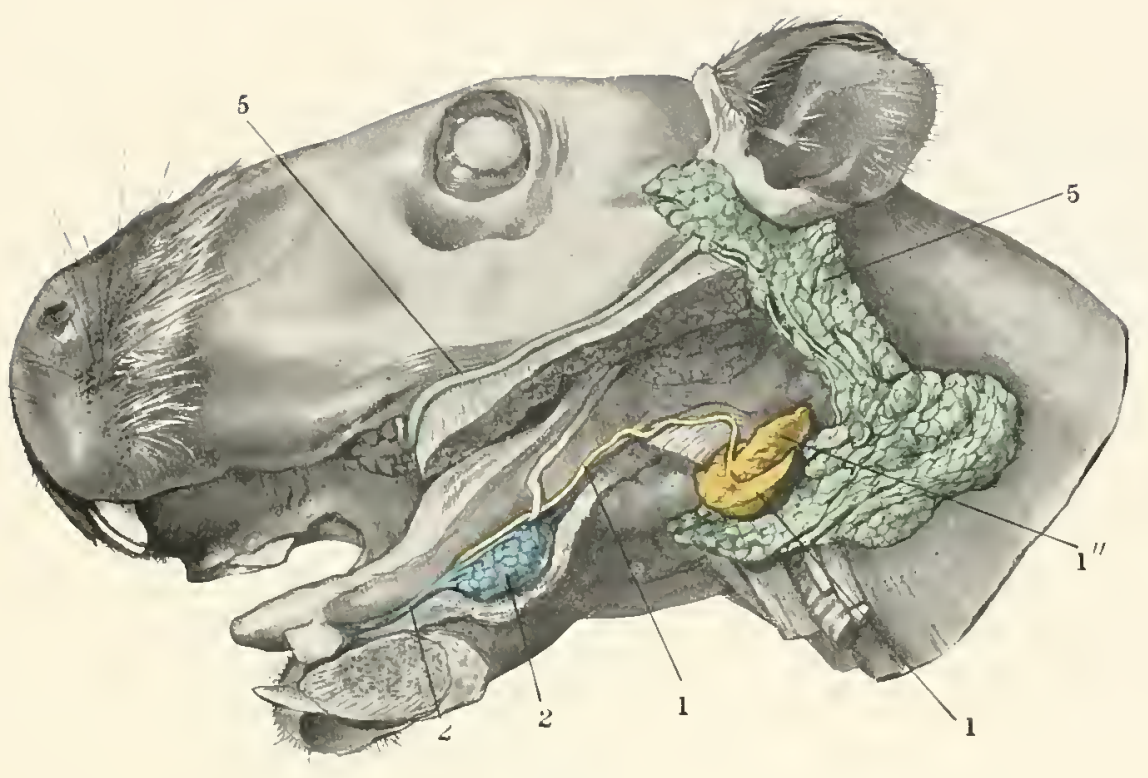

FIG. 7. 


\section{PLATE YCIII}

Fig. 8. Hystrix Africe-Australis-African P'orCupine. Princeton University Morphological Museum, No. I 440.

$I, I$. Submaxillary gland and duct.

2, 2. Greater sublingual gland and duct.

3. Lesser sublingual glands.

5. 5. Parotid gland and duct. 


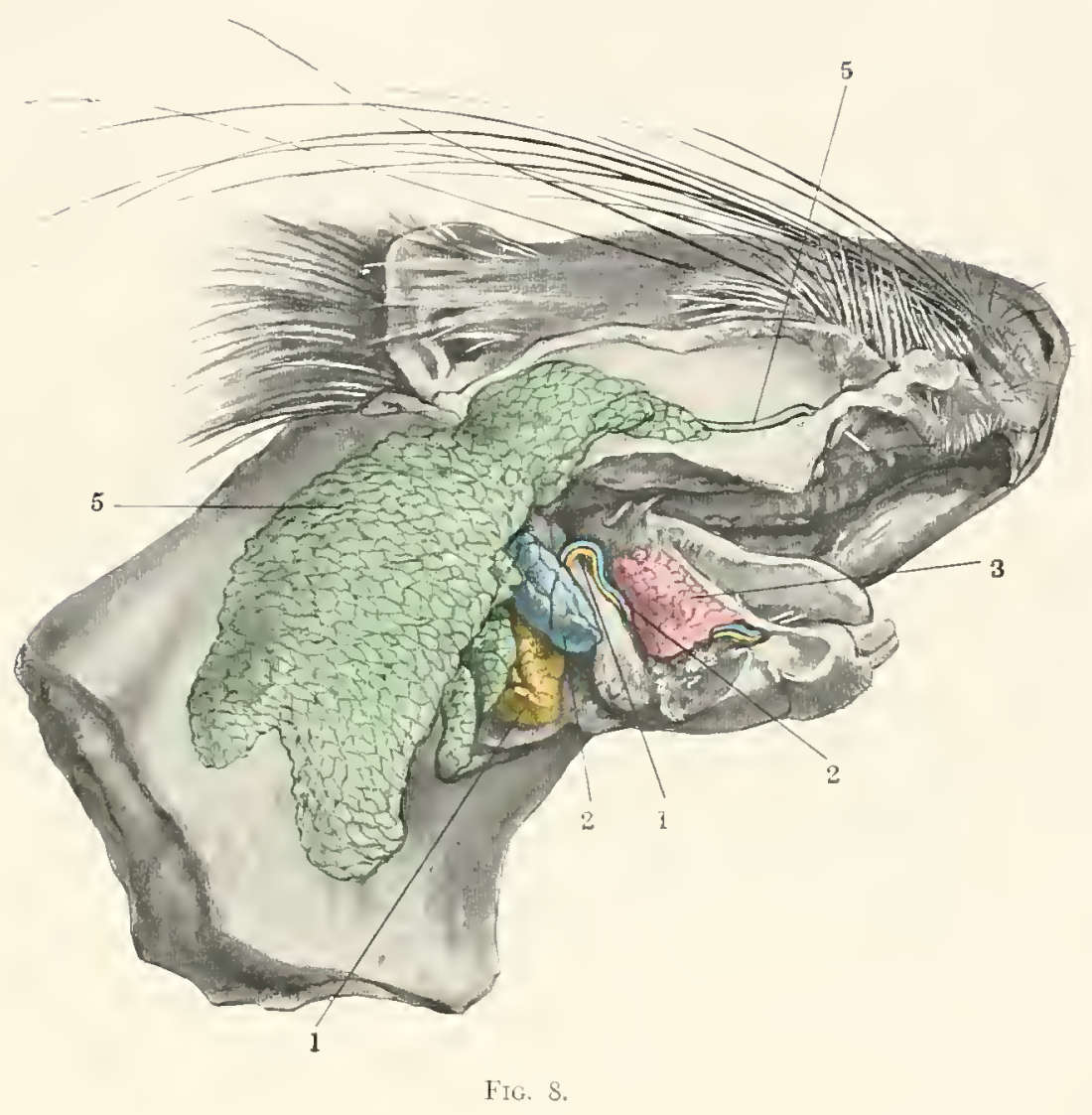




\section{Plate XCIV}

Fig. o. Fiber Zibethicus - MUskrat.

Princeton University Morphological Mluseum, No. 460.

I. Submaxillary cluct.

fa. Left submaxillary gland.

Ib. Right submaxillary gland.

2,2. Greater sublingual gland and duct.

3. Lesser sublingual glands.

5. Parotid duct.

5it. Left parotid gland.

jb. Right parotid gland.

6. Eyelid gland.

oa. Duct of eyclid gland and accessory glands.

10, Io. Lymphatic nodes. 
PLATE XCIV.

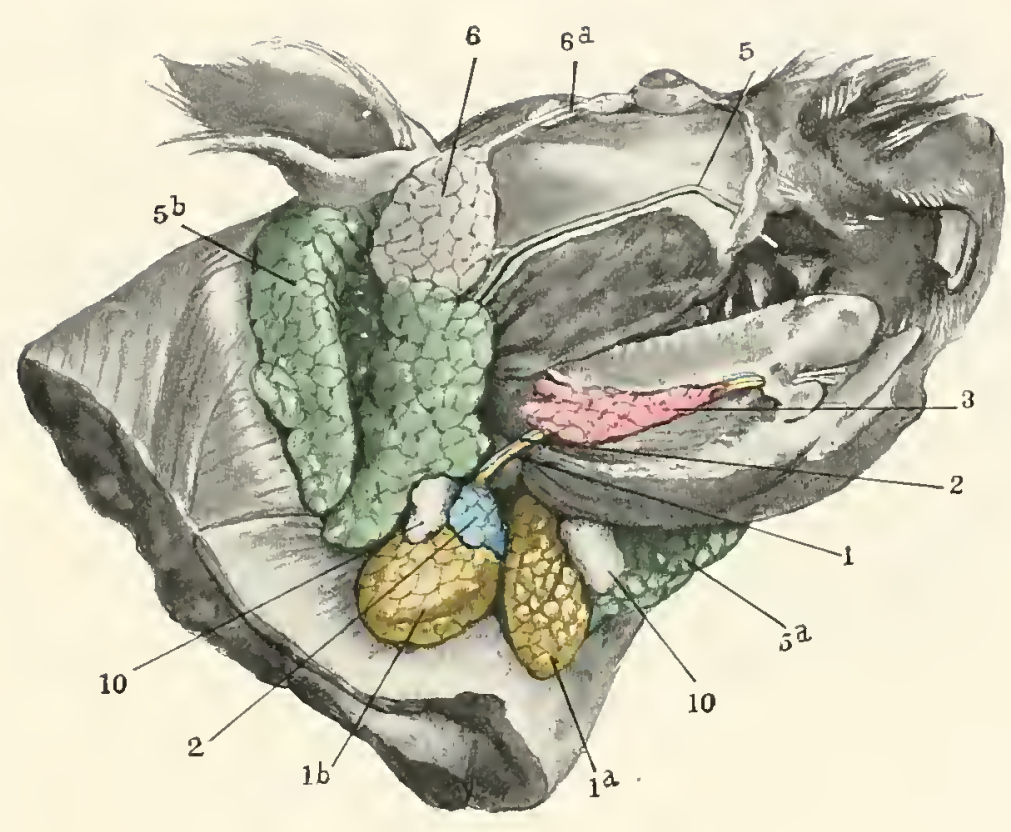

FIG. 9. 
Plate $\mathrm{MCV}$

Fig. io. Arctomys Monix-Ground Hog. Princeton University Morphological Museum, No. S86.

$I, I$. Submaxillary gland and duct.

2. 2. Greater sublingual gland and duct.

3. 3. Lesser sublingual glands and ducts.

5. 5. Parotid gland anil duct. 
PLATE XCV.

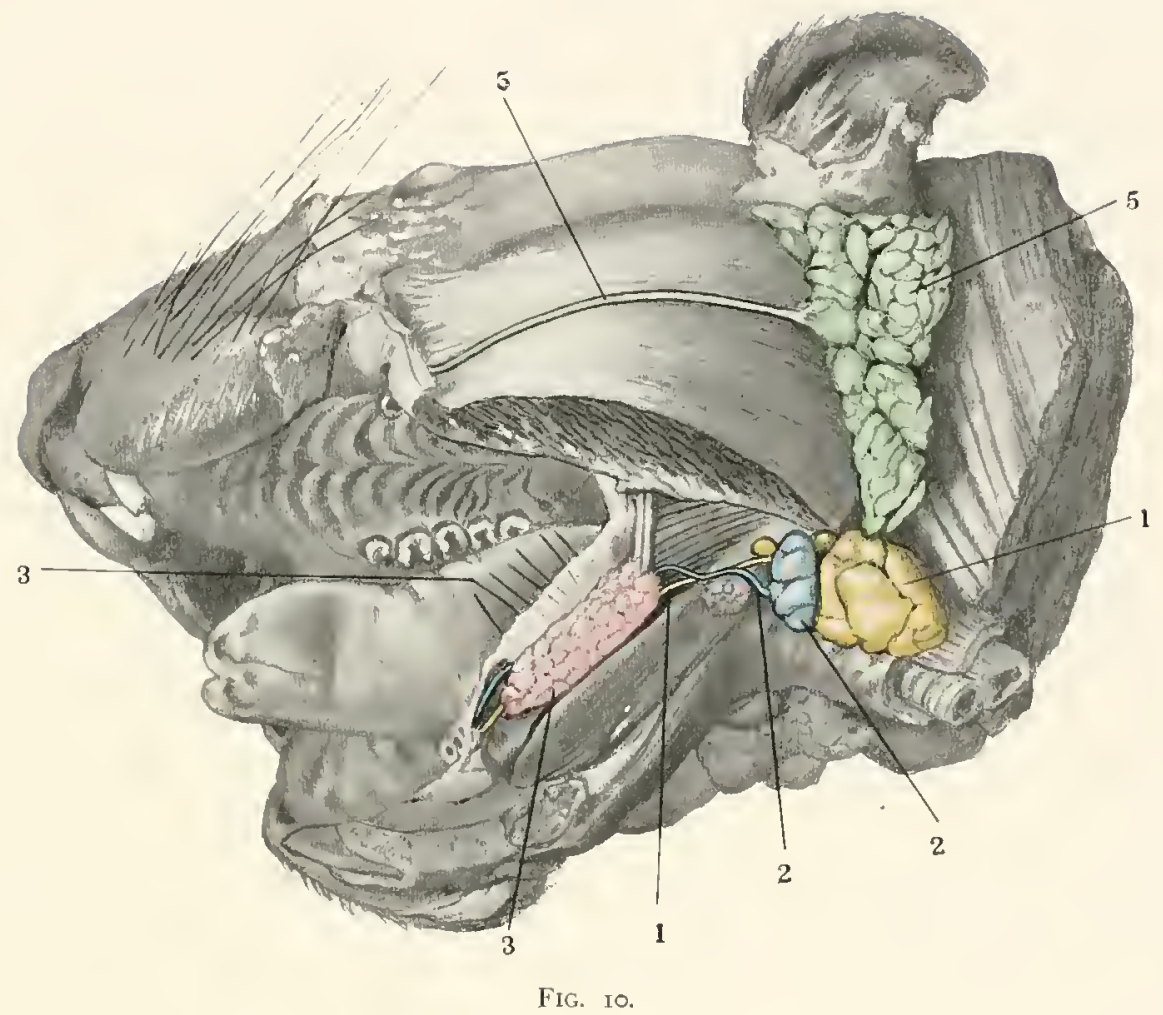




\section{Plate XCli}

Fig, it. Antelope Cirvicapra - Antelope.

Princeton University Morphological Museum, No. I 463.

$I, I$. Sulmaxillary gland and duct.

3. Lesser sul,lingual glands.

5. 5. P'arotil gland and duct.

II. Thyroid glant. 


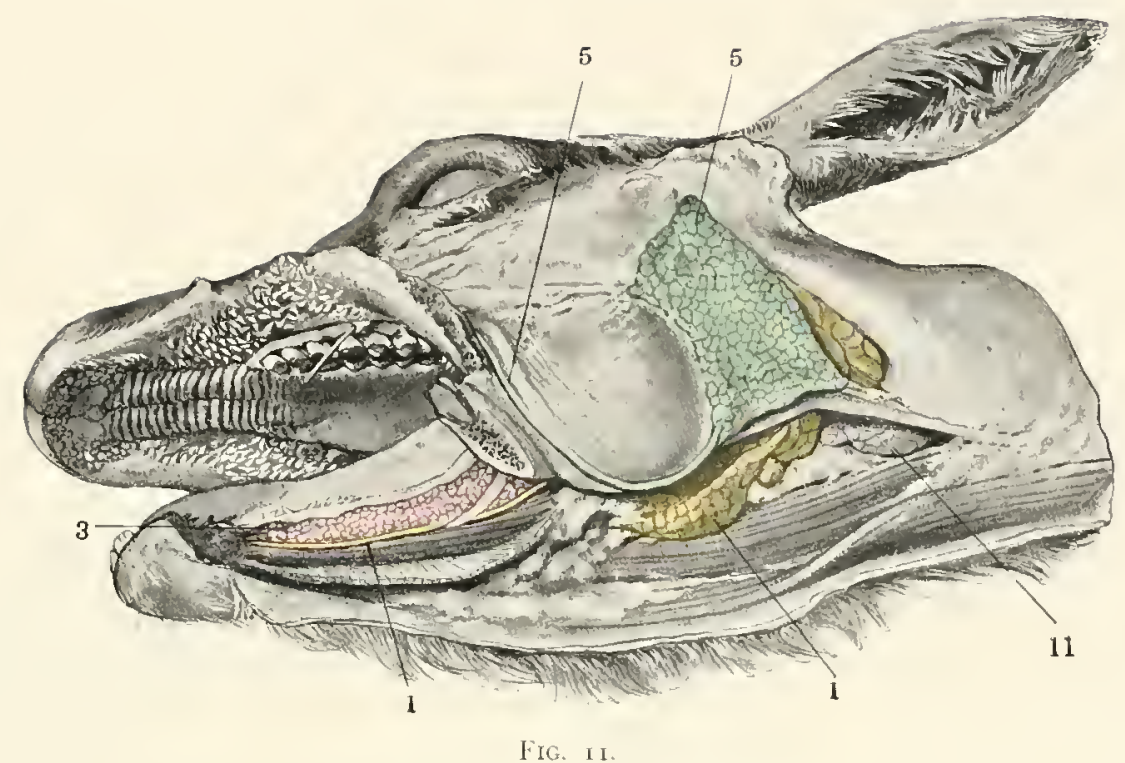




\section{Plate XCTII}

Fig, I2. Bos Taurus - Calf

Columbia University Morphological Museum, No. 2153.

r. Submaxillary gland.

4. Superior alveobucial or molar glands.

5. 5. Parotid gland and duct.

7. Inferior alveobuccal or molar glands.

8. Facial nerve. 
PLATE XCVII.

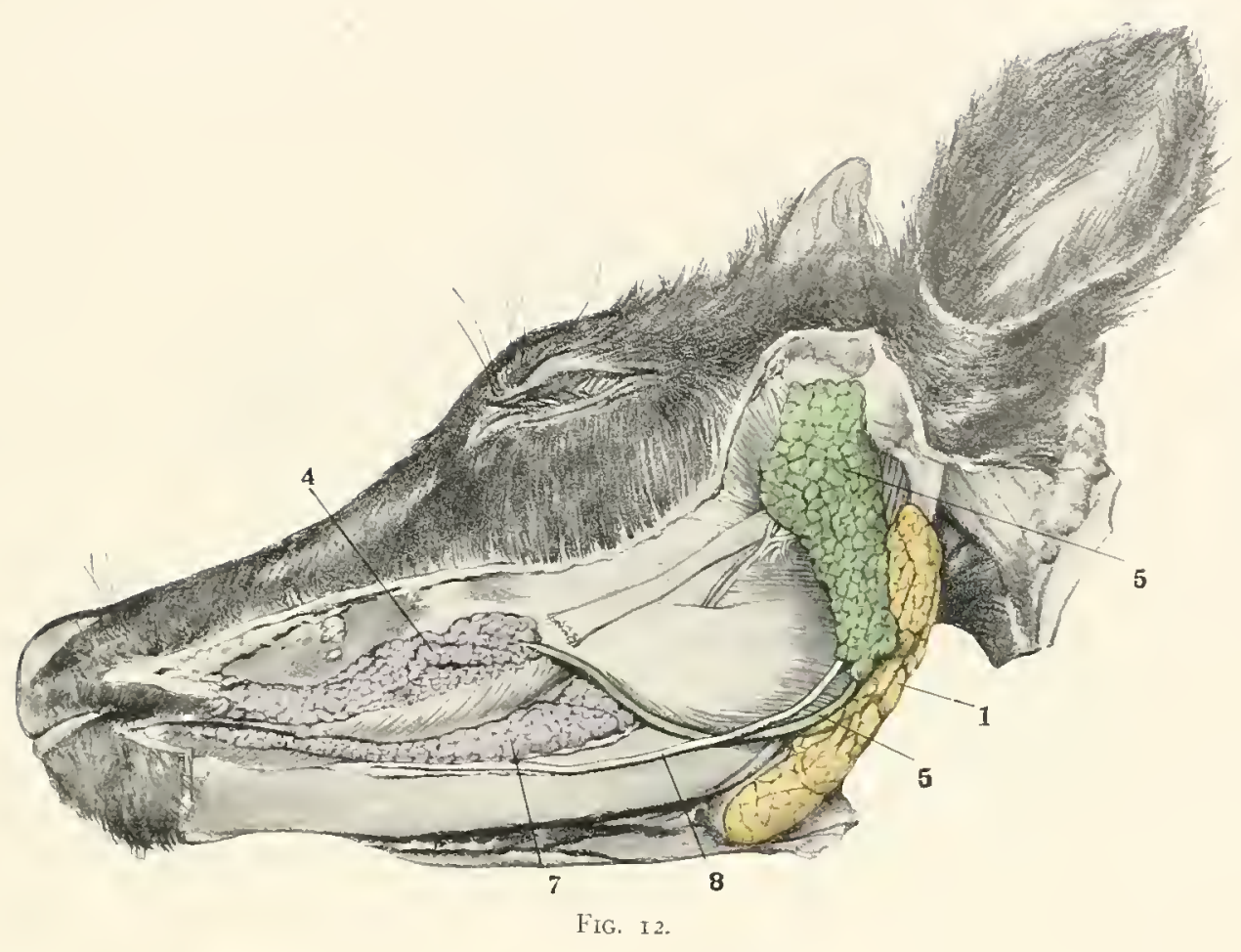


Plate XCIIII

Fic. 13. Lquls caballus- - Horse.

From a fresh dissection.

$I$, $I$. Submaxillary gland and duct.

5, 5. I'arotid gland and duct. 
- 

PART VIII

THE MAMMALIAN ALVEOLINGUAL SALIVARY AREA, WITH SPECIAL REFERENCE TO THE DEVELOPMENT OF THE GREATER SUBLINGUAL GLAND OF THE PIG, TOGETHER WITH A REVIEW OF THE LITERATURE

\section{By H. von W. Schulte}

OF the glands of the alveolingual region the submaxillary has been most successfully investigated, and alone has received a consistent treatment in the literature. With regard to the others much confusion has obtained both in respect to their number and as to their mutual relations, the result in large part of the difficulty of the problems involved, but complicated by the misfortune of an uncritical and inconsistent nomenclature. The relations of these glands in man are especially intricate, owing, first, to the compression and consolidation of the several elements in correlation with the reduction of the mandible, and, second, to the inconstancy of the Bartholinian element, so that here the analysis of the gland complex, on anatomical grounds, is rendered almost impossible of successful accomplishment. The preoccupation of anatomists with this form, however justificd by practical considerations, has served to retard the solution of these problems, by diverting attention from types of easier analysis, and depriving of its due weight evidence derived from the study of the lower mammals. The unsatisfactory state of our knowledge of human conditions is illustrated by the BNA, Glandula sublingualis, Ductus sublingualis major, Ductus sublinguales minores. Here the concept "gland" itself is vague, and the error is made of taking the secondary coaptation of the connective tissue as the criterion of glandular entity, irrespective of the number of epithelial gland individuals present, as indicated by a plurality of ducts. In consequence of a like mode of thinking, the 
statements of the older writers are ambiguous in their use of the term "sublingual," which may" be applied to either the Bartholnian or the Rivinian elements, or vaguely to a gland mass in which both are included, as is still the custom of human anatomists.

Cuvier seems to have been the first to recognize the composite nature of the sublingual mass, but largely through the misconception of Meckel his results failed to effect a lasting improvement. In the pig he described, in addition to the submaxillary, two sublingual glands, the first narrow and elongated, with a single duct accompanying that of the submaxillary, the second of more cranial position draining by eight or ten ducts in a row. With this analysis the results of Reichel, Chievitz, Zumstein, Illing, Carmalt, Huntington, and Silvester are in substantial agrement, and have further established its general validity for the mammalia. We may, therefore, recognize as typical of the alveolingual region the presence of two large glands and a series of small elements as follows:-

I. Glandula submaxillaris BNA; maxillaire, Cuvier.

2. Glandula sublingualis major, corresponding to the Ductus sublingualis major of the BNA; greater sublingual gland, Bartholinian gland; première sublinguale, Cuvier; Glandula sublingualis, Chievitz; Glandula sublingualis Bartholini s. monostomatica, Illing; retrolinguale. sublinguale, according to its relation to the lingual nerve, Ranvier; Glandula retrolingualis, Zumstein.

3. Glandule sublinguales minores, corresponding to the Ductus sublinguales minores of the BNA; lesser sublingual glands, Rivinian glands; deuxième sublinguale, Cuvier; Glandulæ alıeololinguales, Chievitz; Glandula sublingualis Rivini s. polystomatica, Illing; Glandula sublingualis, Ranvier. Zumstein, Hammar; Glandes sublinguales accessoires, Bujard.

By massa sublingualis (Drüsenconglomerat der gessammten Gl. sublingualis autorum, Chievitz) is meant an aggregate of these glandular elements in a common connective tissue investment, as in man, where the lesser sublinguals, the Bartholinian element when present, and frequently supramylohyoid lobules of the submaxillary, are so conjoined.

With regard to the definition of these several elements, it must be premised that their topographical relations are only of approximative 
value, and serve rather to express the usual development of the glands than as absolute morphologic criteria. There is, again, substantial agreement as to the submaxillary, which Zumstein defines by its general inframylohyoid position and its orifice upon the caruncula sublingualis, where the caruncle is developed. While it is true that the body of the submaxillary lies in large part below the level of this muscle, the position is better expressed as caudal (posterior); its duct extending beyond the border of the muscle and turning through the interval between the digastric muscle and the mandible, secures for its ultimate arborization the usual situation below the angle of the jaw, from which it derives its name. While the borly of the gland, so far as our present knowledge extends, is always ectal to the digastric, in many forms a much more caudal point is reached, the body being cervical or even thoracic in position (Owen, Carmalt, Huntington, Silvester). The duct may present a supramylohyoid efflorescence of small lobules, the dorsal and rentral accessory submaxillaries (Huntington). Their ducts are usually short and open respectively into the dorsum and venter of the main duct; a caudal member of the ventral series may have a recurrent duct. Less frequently a dorsal element, the secondary submaxillary (Huntington), is present; its duct joins that of the submaxillary after a course of variable length in contact with it dorsally.

The sublinguales minores are a series of small glands which, when completely developed, extend from the salivary caruncle along the alveolingual gutter to the arcus palatinus and there ascend to become continuous with the isthmian and palatine glands, as in man and a number of other primates (Huntington). The caudal members not infrequently are suppressed, and the series may stop at (Zalophus, Silvester), or in front of (rat, Ranvier) the lingual nerve, a condition less common than has been supposed. On the other hand, only the caudal members may be present. When this is the case, two possibilities offer: the series may extend into continuity with the isthmian glands and appear as a continuation of this group (cat, Carmalt); or the isthmian group may be suppressed, the arcus palatinus totally free of glands, and the lesser sublinguals represented only by a few small elements in the vicinity of the lingual nerve (wolverine, Carmalt).

The sublingualis major rarely extends beyond the digastric muscle, upon the posterior belly of which its fundus is molded. Laterad, 
partially escaping the confinement of the muscle, its extremity is in contact with the submaxillary at, and dorsal to, its hilus and to a slight degrec on its mesal surface. In cases in which the submaxillary is cervical or thoracic, the greater sublingual may also extend beyond the digastric and retain its relation to the submaxillary. Frequently this element is of less development, entirely supramylohyoid or even prelingual in situation. It may be absent (rabbit, Chievitz), or inconstant (man). Its orifice is usually close to that of the submaxillary on its lateral aspect, or slightly caudal to it. In Macropas giganteus (Silvester) it is a full centimeter caudad of the orifice of the larger gland. It sometimes opens into the submaxillary duct, a condition not rare in primates (Huntington), and may be variable in this respect (man).

Ranvier confused the problem of the relations of sublinguales minores and sublingualis major, by arbitrarily establishing the lingual nerve as a line of demarcation between the two, defining the former as prelingual in position, the latter as retrolingual (hence the name). This division led him to interpret the Bartholinian element (sublingualis major) as an hypertrophied Rivinian gland, notwithstanding the fact that Chievitz had alrearly described its development both in man and in the pig, and had demonstrated beyond peradventure that it is not of this nature. What doubt might reasonably still exist as to its independence could only concern the nature of its relation to the submaxillary (vide infra). Further, as Zumstein pointed out, Ranvier's position is untenable both from the known existence of intermediate forms of the sublingualis major, and from the fact that such a landmark as the lingual nerve could only be an inclex of the degree of development of the glands in question. For it is obvious that the product of a sagittally directed sprout such as that of the sublingualis major will terminate in front of, at, or behind a given transverse level according as it is of small, moderate, or large development. In man the element is small and prelingual; the same is true of many primates (Huntington). The situation of the fundus at the level of the lingual nerve is, from the smallness of the landmark, necessarily less frequent than the prelingual and retrolingual positions, which from their greater extent permit a wider degree of variation within their limits. The fundus is at this level in Zalophus (Carmalt, Silvester); the extension of a gland of 
retrolingual position forward beyond this level is frequent, as, for Finally, the sublingulich condition it is figured by Ranvier hinself. attain a cervical position, ajor may extend beyond the digastric and though recognizing the invalidity Tragulus (Silvester). Zumstein, alto make a special case of the lum of Ranvier's criterion, yet prefers it as Ranvier had done to the liuman Bartholinian gland, assigning the developmental evidence to the contrary, absolutely disregarding Zumstein then contrary.

Zumstein then raises the question of the possibility of the extension caudacl of the Bartholinian element by further growth, into a retrolingual
position. In this case, he suggests, it might be which of the two, the sublingualis element, was actually present. There or an hypertrophied Rivinian ting the possibility of such a phenomenon are excellent grounds for admitpeculiar development of these elements was not lnence. While the naturally assumed to be derived from simplet known they were quence the orifice of a gland was taken to be the point, and in conseto offer the most important evidence of its statue point first formed, and question the variations of the orifice of the inclependent, now into the sublingualis major, now perplexity. As a matter of fact, it disturbed no night well have caused goes to show that men's instincts may be better than their logic.
Further, Chievitz had described two position lingualis major in different forms, asitions of the anlage of the subbe explained, would imply the a discrepancy which, unless it could mediate between the submaxillary presence of two elements interone, now the other, was developed; lesser sublinguals, of which now developmental evidence elsewhered; but as Zumstein disregarded influenced his views. His position, it seems unlikely that these facts who, influenced by his knowledge really reflects the error of Reichel, find in the mammal the representative sauropsid conditions, sought to sublingual glands of reptiles, and so was of the anterior and posterior the alveolingual gutter into cond so was led to divide the products of not be shown to have exerted a direct infal groups. While he cancriteria of the latter belong to the gener influence upon Ranvier, yet the Reichel, and Zumstein, while aware of point of view which governed absolute and arbitrary division of the of the inadmissibility of Ranvier's 
view the submaxillary and sublingualis major as essentially caudal, the Iesser sublinguals as cranial, in origin. Assigning the Bartholinian element to the latter group, the problem for him is the possibility of the invasion of the caudal (posterior) field, by an overgrown element of the cranial (anterior) series, which then would simulate the sublingualis major.

While the extrinsic relations of these glands are thus expressive mainly of their degree of development, the intrinsic or reciprocal relations of their ducts, especially in the supramylohyoid portion of their course, have a high degree of morphologic importance, and though shifted from their early position in the embryo, yet retain what is essential in the primitive relationships.

Reichel in a section from an adranced embryo (rodent, probably rat, of $\zeta$ centimeters) in which the definitive topography was already attained, shows the elements oriented in a dorsoventral plane. The most ventral is the duct of the submaxillary, of intermediate position that of the sublingulis major, while the sprouts of the lesser sublinguals are interposed between the latter and the epithelium of the alveolingual gutter. In the adult the bodies of these glands lie lateral to the two ducts as far caudad as the lingual nerve, where they gradually become dorsal as the series extends into the arcus palatinus; in some cases the mass extends to the mesal side of the ducts or even presents a gutter in which they are lodged (Huntington); but the orifices of their ducts in any case are arranged in rows along the alveolingual gutter dorsal to the horizontal ducts of the large glands. The duct of the sublingualis major is in contact with that of the submaxillary, and is directly dorsal in the greater part of its course. Near its orifice it deriates to its lateral side, and caudad where the gland extends to the digastric, it crosses the submaxillary dorsally to gain its mesal surface. In cases in which the Bartholinian element is small and lies lateral to the submaxillary, its duct may be lateral throughout, retaining the embryonic position (man). When a secondary submaxillary is present, its duct is interposed between the main duct and that of the sublingualis major. The dorsal position of the duct of the sublingualis major is often orerlooked in dissections, from the ease with which it can be displaced laterad. In all of Ranvier's illustrations it is so represented, but Zumstein, working with serial sections, established 
the dorsal relation for a large number of mammals, and his results have been confirmed and exended by recent observers. The sublingualis major thus appears essentially as an intermediate element between the lesser sublingual series and the submaxillary complex, while all three correspond evidently to sagittal and not transverse divisions of a primitive gland field.

Reichel occupies a position in a way intermediate between that of the anatomist and the embryologist, for while formulating his inquiry in the spirit of a morphologist, he sought its solution in the facts of embryology. The problem for him was purely one of homology what glands are present in mammals, and to what glinds of lower forms are they equivalent? The embryological problem proper, the nature of the developmental process, can hardly be said to fall within his plan. His work is remarkable for extent of information, critical insight, and the power of brilliant generalization, and productive of results, which, after due allowance for the intellectual virtue of the man himself, redound to the credit of the method of morphology, as compared with the methods of the half-morphologists and their hampering self-limitation to the partial field either of anatomy or of embryology.

Reichel's work forms, therefore, a convenient approach to the more special study of the developmental process. After a critical analysis of the data afforded by comparative anatomy, in which he detected the prevalent confusion of the sublinguales minores and major, he prescnts an exceedingly condensed report of his findings in a few embryos (he examined many) and then formulates his conclusions, recognizing the Rivinian and Bartholinian elements as distinct glands, variable in the degree of their development in different forms. The anlage of the submaxillary he located in a furrow beside the developing tongue (sulcus lingualis); the sublingualis major he assigns to a parallel and ectal sulcus; the sublinguales minores arise, also, from these same furrows in series, but caudal to the larger sprouts of the two complex glands. These observations were made upon a "rather young embryo of the mouse." The relation of the submaxillary and the greater sublingual ducts is correctly given, but the caudal position and the sulcal relations here assigned to the lesser sublinguals are, at first sight, extremely perplexing (vide infra). But few other data are given. The larger ducts are stated to move forward and acquire prefrenular 
orifices, but the mode of this shift is not described. The presence of the sublingualis major and its numerous side branches is noted in the dog and pig. In a figure taken from a rodent embryo of 51 millimeters (he calls it a mouse, but has evidently confused his material as Chieritz pointed out) he shows the elements in their adult relations, the lesser sublinguals dorsal, then the sublingualis major, and ventrally the submaxillary. Finally, in a rabbit embryo of 56 millimeters he states that all three elements are present, and on this observation founds his inference that the anlages are constant, but that that of the sublingualis major may be suppressed in later stages. Chievitz found no Bartholinian element in the rabbit, and suggested that Reichel had mistaken for it the most anterior of the lesser sublinguals, an error which his description of the mouse embryo shows he had no means of avoiding. The explanation of this is difficult only if we assume that the "rather young "embryo in question was what a modern investigator would so designate. Reichel seems to have had - at least he reported - no very young embryos. Assuming the mouse in question to have advanced considerably in development, the description is comprehensible, which it certainly is not, if it be taken to apply to an early stage. On this assumption the lateral furrow beside the tongue would be the sulcus circumflexus, which limits the plica sublingualis in front and at the side. This appears in man and in the cat before the ducts reach the transverse plane of the frenulum, and the Bartholinian duct is attached to the plica near, but not actually in, the circumflex sulcus. In man and the cat this furrow gives origin to the early sprouts of the diffuse Rivinian glands, in man close to, in the cat far caudal to, the attachment of the Bartholinian duct. In later stages the number of these glinds is increased by sprouts of more mesal position. from the surface of the plica sublingualis (Chievitz), from the lingual sulcus itself (Reichel), and in forms in which the lesser sublinguals become continuous with the isthmian group, additional elements must be formed from the oral epithelium mesal to this sulcus. This condition has not yet been reported in an embryo. It is not, therefore, necessary to accuse Reichel of an error of observation in his assignment of the lesser sublinguals to a position caudal to the attachment of the anlages of the larger glands, but it is unfortunate that the length of this embryo was not stated. 
These findings had an unfortunate theoretical consequence. Conceiving the lesser sublinguals to be characterized by a caudal (posterior) position, Reichel accepted Leydig's homology and made them equivalent to the posterior sublingual glands of reptiles.

Wenn Lexdig den mit dem ductus Bartholinianus mündenden Theil der glandula sublingualis der vorderen, den mit zahlreichen ductus Rivini mündenden hintern Theil der hintern Unterzungendrüse der Ophidier parallel stellt, so kann ich nur dem zweiten Theil dieser Behauptung zustimmen, während ich gegen den ersten geltend machen muss, dass die vordere Unterzungendrüse der Ophidier nicht mit einem einzigen Gange muindet, dass somit der mit dem ductus Bartholini mündende Theil ṇur einem einzigen dieser Drüschen homolog sein kann.

The sublingualis major and submaxillary are then taken to be the equivalents of single diffuse glands, greatly hypertrophied, a conclusion which is open to doubt, both on comparative (Huntington) and developmental grounds, and the transverse division of the field has been seen to be fruitful in misconceptions.

The view that even the large salivary glands develop as simple sprouts found general acceptance in the early eighties. Kölliker in the second edition of his Grundriss states expressly:-

Die Speichedrüsen entwickeln sich nach dem Typus der schon früher besprochenen Thränendrüsen und Milchdrüsen und sind anfangs nichts als cylindrische, am Ende leicht verbreiterte, solide Sprossen der tieferen Epithelialschichten der Mundhöhle, welche von einer Mesodermschicht, einer Fortsetzung der Mucosa, umgeben sind (Fig. $234 \mathrm{sm}$ ).

In the figure referred to he shows the submaxillary crossing the lingual nerve, its fundus surrounded by a conspicuous condensation of the mesenchyme.

Reichel did not advance beyond this conception of the development of the salivary glands; in fact, it is the basic assumption in his principle of gland homology.

Bei der Beurtheilung, ob zwei Drüsen zweier verschiedener Thiere einander homolog seien oder nicht, wird man somit weniger auf die Lage der Drüse, als auf die Art und Weise ihrer Ausmündung Werth zu legen haben, da der Ort der Ausmündung uns zugleich sicher die Stelle bezeichnet, von der aus sich die Drüse gebildet hat.

So deeply rooted had the idea of development by simple sprouting become, that as late as IgOI, after the results of His and Chievitz had 
long been available, Gegenbauer expressly states "that we must take the orifices of glands to be the portions first formed." If it thus seems that anatomists are somewhat impervious to information derived from the developmental field, and persist in the endeavor to solve the problems of morphology without the aid of ontogeny, the case is hardly better with the embryologist, who sometimes seems unaware that problems of homology exist at all. The effects of one-sidedness are as unfortunate in the one liscipline as in the other, and appear as conspicuously from the developmental as from the comparative standpoint. It was the merit of Carmalt to perceive the importance of a return to the larger method of morphology, and he was on the point of beginning a developmental stucly of the salivary glands, when his useful and stimulating labors were brought to an untimely close.

Before examining the developmental literature, it will be convenient to define the sulci of the alveolingual region, Regio alveolingualis, which itself forms the zone of junction between the circumlingual space and the marginal portion of the oral cavity, and corresponds to the crest of the palate process. Its floor, the alveolingual gutter (sulcus aheololingualis, Chievitz, Hammar), is a concavity extending from the tongue laterad to the region of the akveolar process. It presents four sulci, which vary in degree of development in embryos of different forms.

I. Sulcus lingualis (Schulte). This appears to be constant. In it three segments may be distinguished, cranial, intermediate, and caudal, the last correspondling topographically to the submaxillary ganglion; and serving as the point of inception of the submaxillary antage. This furrow defines the alveolingual region against the tongue. Its course is in general sagittal, but its cranial segment turns mesad beside the frenulum, in front of which it is confluent with its fellow of the opposite side. In time of appearance it antedates the other sulci of this region.

2. Sulcus alveolaris (Schulte); sulcus sublingualis (His). This forms the lateral boundary of the alveolingual gutter. In man it is deep and cleftlike (His). It has a nearly sagittal course, beginning at a point caudad of the lingual nerve and extending beyond the symphysis. Its anterior extremity crosses Meckel's cartilage dorsally and, reaching a point lateral to the cartilage, gradually is lost. This portion 
is ephemeral, beginning to be effaced at 22 millimeters. The caudal portion of the sulcus is reduced next, and finally the whole from behind forward. In the pig the sulcus has the same general history, but is in embryos of I -19 millimeters a rather shallow concavity; in the cat it is retarded and rudimentary.

3. Sulcus intermedius (Schulte). In the figures of His and Chievitz this appears as a shallow indentation of the alveolingual gutter, between the lingual and alveolar sulci. In a human embryo of 20 millineters it is an oblique furrow extending from the region of the submaxillary ganglion about halfway to the frenulum. Its caudal extrenity approaches the alveolar sulcus, its cranial the lingual, without joining cither. A minute epithelial keel is attached to its fundus. In an embryo of 22 millimeters the furrow had disappeared, but the keel, though reduced, was still present. Its significance is problematic.

4. Sulcus circumflexus (Schulte). The development of this furrow is complementary to that of the plica sublingualis, which it bounds at the side and in front, where it is confluent with the lingual nerve. It extends gradually caudad in man, becoming confluent with the alveolar sulcus. In the cat, apparently, it is independent throughout its existence; its caudal extremity extends beyond the lingual nerve. It gives rise to the early sprouts of the lesser sublingual series in man and in the cat.

His (' 8 ) was the first to appreciate the peculiarity of the mode of formation of the ducts of the larger salivary glands. He added to Reichel's localization of the submaxillary anlage in the lingual sulcus its precise situation in reference to the lingual nerve, finding it to be just caudal to the point at which the nerve turns ventrad of the sulcus to enter the tongue. Unfortunately he mistook the pale center of the anlage for a lumen, and was thus led to infer that its advance took place by a bridging over of the sulcus. His assignment of the sublingual gland to the alveolar sulcus is plainly stated to be conjectural, nor is it possible from the context to tell whether the supposition has reference to the Bartholinian or to the Rivinian elements.

Two years later Chievitz published his admirable and important paper. The opening paragraph is interesting in its expression of the attitude of this first-rate investigator towards his subject, and the matter-of-course way in which a sound, but often over- 
looked, principle of morphology is enunciated. He notes that in the case of the salivary glands, as in many others, attention has at first been directed to adult conditions, and then to the earliest stages of development, "Es giebt jedoch in Lebenslaufe dieser Organe einen mittleren Abschnitt, über welchen man gewöhnlich mit einem Sprunge hinwegsetzt. Es war meine Absicht, eine solche Strecke durch stufenweise Beobachtung durchzumachen, aber zuerst musste ich mich natürlich mit dem zu beiden Enden dieser Strecke liegendem Terrain persönlich bekannt machen. . . ." He then gives a concise summary of the literature and his own observations upon adult material (man, pig, ox, rat, dog, cat, and rabbit). He used the celloidin corrosion method of Schiefferdeker, and wax injections of the ducts as a preliminary to dissection. His conclusions are in accord with the observation of Cuvier and the results of Reichel, as to the presence of two glands and a gland series in the alveolingual region, which he designates respectively: Glandula submaxillaris, Glandula sublingualis, Glandulæ alveololinguales (lesser sublinguals). He further finds the massa sublingualis (das Drüsen conglomerat der gesammten Glandula sublingualis autorum) to be compounded of the lesser sublinguals, the Bartholinian element, and sometimes "ein contingent . . . welches von einigen aus dem Ductus Wharton. kommenden Aesten herstammt. Solche sind von Meckel erwähnt; ich habe selbzt sie selten aber sicher, mittels Injection durch den Ductus Wharton. constatirt. In einem Falle, wo ich einen solchen Ast auf der einen Seite beobachtete, fand sich ausserdem beiderseits eine Gl. sublingualis s. str." (i.e. a sublingualis major). He then reports in detail his findings in a series of pig embryos ( 7 millimeters 7 centimeters), and a series of human embryos (6 weeks to 12 weeks), together with brief, but important, observations upon individual embryos of the mouse and rabbit. His results may be briefly summarized. In both man and the pig he found the submaxillary arising from the lingual sulcus caudal to the lingual nerve, and thence advancing by means of an epithelial keel, subsequently freed by constriction. From the primitive anlage growth proceeds proximad as a crest, distad as a free-growing sprout, which enters and divides in the circumscribed mesenchyme condensation, which forms so conspicuous an object in sections of the submaxillary. He further noted the intimate relations of the duct to the submaxillary 
ganglion. The anlage is solid throughout and subsequently acquires a lumen. The lesser sublinguals of the pig he found in an embryo of 5 centimeters as short, unbranched plugs in a row lateral to the ducts of the larger glands. They arise from the surface of the alveolingual region, not from furrows, and are not associated with an epithelial crest. His figure of their condition in a 7 centimeter pig is well known and often reproduced. They are shown lateral to the ducts of the submaxillary and greater sublingual glands, which extend horizontally in contact, the submaxillary being ventral, while the lesser ducts are directed vertically and attached to the oral epithelium chorsal to the larger ones. In man their history differs somewhat. In an embryo of Io weeks they arise from a lateral furrow of the alveolingual gutter, from the fundus of which a solid epithelial keel projects ventrad. To this are attached a few short, rounded sprouts. He also notes the presence of two other sprouts which he assigns to this series, one from the lingual sulcus, one from the plica sublingualis. In an embryo of $\mathrm{I}_{2}$ weeks $\mathrm{II}^{-} \mathrm{I} 3$ sprouts in a row were present on each side, the first close to the lateral side of the orifice of the submaxillary. They now arise from the lateral surface of the plica sublingualis. The sublingualis major in the pig arises, in the youngest embryo described, as a crest from the side of that of the submaxillary. Distad the crest is continued as a free-growing sprout, proximad it advances, and, separating by constriction, produces the horizontal portion of the duct. In man it has a similar history. From the account of its development in these two forms the sublingualis major would appear to be a lateral derivative of the submaxillary, but not a simple branch, for its advance is provided by a keel, and in the adult it may have a separate orifice.

The findings in a 9 millimeter embryo of a mouse tend to cast doubt upon so simple a solution of the problem of the sublingualis major.

Die Submaxillaris ging aus der Furche zur Zeite der Zunge ziemlich weit hinten ab; das hintere Ende hatte schon kleine Knospen abgegeben; in dem vorderen Theile des Ausführungsganges ist ein Lumen entstanden, welches auf der rechten Seite mit der Mundhöhle communicirt, während es linkerseits noch abgeschlossen ist. Die Sublingualis ist durchweg massiv. Während wir sie aber bei den früher beschriebenen Formen von der Submaxillarisanlage ausgehend sahen, geht sie bei der Maus selbstständig von dem Mundboden aus und zwar von der Bodenfläche des Sulcus alveololingualis - nicht von den diese Fläche seitlich begrenzenden 
Furchen. Die cylindrische Drüsenanlage geht vorn aus einem niedrigen Epithelkamm hervor und geht dann, massiv unter der Oberfläche freiliegend nach hinten um ungetheilt, abgerundet zu enden.

In the embryos of the rabbit Chievitz reports his inability to find the anlage of the sublingualis major. The concluding portions of his paper are concerned with the late changes in the anlages, in particular with the histiogenesis of their epithelium. Chievitz does not discuss his findings except in relation to the number of elements present, and the composition of the massa sublingualis, as has been noted, and yet his results are of the highest theoretical importance and form a basis for new interpretations and new problems in the morphology of the salivary glands. (I) From the standpoint of development the glands may be divided into those formed in toto as simple sprouts, and those supplied with advancing keels, which secondarily separate from the oral epithelium to form ducts. Only to those of the first class can the old criterion of the orifice be directly applied. (2) As glands of the second class are not the product of simple sprouts, it becomes pertinent to inquire what interpretation can be made of them, and, in particular, of their keels; whether, in other words, they ought not to be compared to a plurality, a condensed row of simple elements, rather than to a single gland, hypertrophied. (3) With regard to the analysis of the glands of the alveolingual region, the work of Chievitz confirms and emphasizes the distinction between the sublingualis major and the sublinguales minores, by the discovery of the peculiar development of the former, but at the same time raises unexpectedly the question of its relation to the submaxillary. A number of alternatives offer: if it be taken, and the assumption is natural, that the site of the anlage is an absolute index of the status of a gland, we must conclude that here is evidence of the presence of two different elements, one a lateral associate of the submaxillary (man, pig), and one an independent derivative of the alveolingual gutter (mouse). It will be noted that this view differs toto celo from the distinction of Ranvier between the human Bartholinian element and the retrolingual, for here the division of the fiell is sagittal, there transverse, and further the resemblance in position of the anlages in man and the pig, proves the inconsequence of a distinction between these glands in the adult on the basis of their relation to the lingual nerve. Nor did Zumstein 
raise the question of the possibility of the presence of a second gland in this region, on the grounds of the difference in position of this anlage in different forms. He has in mind simply the abstract possibility of an enlargement of one of the lesser sublinguals to such a size that, extending to a retrolingual position, it might be confused with a retrolingual (sublingualis major). It is remarkable that embryologists have accepted or overlooked the two sites of origin of the sublingualis major with as much indifference as anatomists have the two sites of the orifice of this gland.

The alternative to the admission of two glands is to show that the differences in the site of the anliges of the sublingualis major are inessential, and, in particular, that its approximation to the submaxillary is secondary. The evidence that this is the case in the pig will be presented in detail (vide infra). Here it is desirable to note that the condition of this anlage in Chievitz's earliest reported embryo is considerably advanced, and that the stage of its inception is not covered in his investigation.

The results of Chievitz confirm the sagittal division of the alveolingual gland field, already made on comparative grounds: mesal is the submaxillary advancing along the lingual sulcus; lateral are the lesser sublinguals (sulcus cireumflexus) at first associated with a keel, later opening diffusely upon the surface of the plica; of intermediate position and uncertain status is the sublingualis major, agreeing in mode of development with the submaxillary, to which it may or may not be attached, but if attached, yet retaining some independence in the possession of a keel by which its advance is made.

The remaining literature is concerned with the developmental process exclusively:

Hammar (oI) in a brief note records a submaxillary in a human embryo of 13.2 millimeters as

cine leistenförmige Verdickung des Epithels, welche aboralwärts am deutlichsten ist und hier etwas angeschwollen ungefähr in der Mitte der Rinne mit einem stufenähnlichen Absatz endet. Dies ist die Anlage der Gland. submax.

Durch einem oralwärts fortschreitenden Abschnürungsprocess wird sie von der Rinne losgetrennt, wobei aus der Stufe eine flaschen- oder kolbenförmige Anlage des Drüsenkörpers (Embryo I 7 und 18.5 millimeter) aus der Leiste aber der lange Drüsengang hervorgeht. 
In his summary he states:-

Dic Ohrspeicheldrüse wirl als eine Furche dem Boden der W'angenrinne entlang angelegt, welche Furche durch Abtrennung in ihrer grössten Ausdehnung als Rohr frei gemacht wird.

Dic Submaxillarisclrüse wird in fast ähnlicher Wcise, obwohl als eine solicle, an ihrem aboralen Ende verdickte Leiste dem Borlen der Arcololingualrinne entlang angelegt und gleichfalls später abgetrennt.

It would seem, therefore, that Hammar recognized the inception of the anlage as associated with the formation of a fold, not in the sense of a bridging over of the sulcus (His), but as the apposition of its walls to form a blind fold or flange. I have elsewhere expressed my doubt of the correctness of Hammar's observation upon the parotid, and my reasons for holding that his description really refers to the orbital inclusion.

In an embryo of 24.4 millimeters he found five lesser sublingual sprouts, but not associated with a crest. The Bartholinian element is not described.

Sudler ('O2) briefly notes the solidity of the submaxillary anlage, as against the description of His, and its appearance before that of the parotid, Hammar to the contrary.

Göppert ('02) gives an excellent figure through the oral cavity of a mouse embryo, in which the sublingualis major is at tached to the floor of the alveolingual region lateral to the sulcus lingualis. The duct of the submaxillary is free at this level, so that the Bartholinian element is at this stage cauclal, as well as lateral, to the attachment of the larger gland.

Bujard ('I 1) describes in detail the conditions of the anlages in a human embryo of about ten weeks and notes, further, an observation of Paulet upon the parotid and submaxillary in an embryo of 14.7 millimeters. In this the anlages have the form of globular buds suspended at the extremities of short epithelial crests, which represent their ducts. The larger embryo is described in detail, on the basis of reconstructions. The submaxillary has already assumed its definitive relations. Bujard records the presence of a small lobule arising from the venter of the duct just before its division into three primary branches. This he terms the accessory submaxillary lobule: it is equivalent to the ventral accessory submaxillary of Huntington. With regard to the other glands his conclusions are as follows:- 
La sublinguale et les glandes alvéolo-linguales sont par contre aux premiers stades de leur développement. Dans la première, la longeur et la différenciation marquée du canal excréteur sont hors de proportions avec un corps glandulaire tout juste élauché; c'est là le reflet du mode de bourgeonnement primaire des glandes salivaires, lequel est l'apparition précoce du canal, qui se dessine parfois même avant le corps (parotide d'après Hammar). Chez le fœetus humain de ro semaines environ, ce mode primitif est déjà effacé pour la parotide et la sousmaxillaire, par la ramification de ces glandes: il est encore évident dans la sublinguale.

La crête glandulaire primitive se retrouve encore dans le fait que les bourgeons des glandes alvéolo-linguales sont tous encore dépendant d'une liste épithéliale commune, très haute par place.

The lesser sublinguals, five in number, arise from a common crest attached to the oral epithelium along the line of a faint furrow, which appears to be the sulcus circumflexus. A sixth smaller sprout in line with these, but not attached to their crest, is denominated Glandula buccalis. That the ducts of the larger salivary glands antedate their sprouts in time of appearance is more than questionable. The clear description of the relations of the lesser sublinguals to their crest of origin is confirmatory of Chievitz's report, in connection with which it must be taken to outweigh Hammar's statement to the contrary. The crest is important as representing a transition between the simple sprouts of the later diffuse glands and the keels of the submaxillary and sublingualis major. To the diffuse glands of the lesser sublingual series must be assigned the Glandula buccalis of Bujarrl.

Elsewhere in the work of which this paper forms a part, I have recorded some observations upon the development of these glands in the cat. The sublingualis major appears as an independent anlage (Fig. I), as in the mouse, and retains its independence throughout development. The inception of the submaxillary is attended with the formation of a flange, attached to, and representing a portion of, the lingual sulcus just caudal to the lingual nerve crossing; yet the conclusion seemed to be warranted that the definitive structures of the gland were derived by a proliferation, begun in the border of the flange and thence advancing along the lingual sulcus, so that duct and sprout appeared as the result of a common process. The same, except that there is no flange, is true of the sublingualis major. In the separation of the submaxillary, remnants of the flange remain attached to the lingual sulcus as a postglandular flange, and to the duct of the submaxillary, the 
intermediate element; both disappear without giving rise to sprouts. The lesser sublinguals appeared very late in the caudal portion of the sulcus circumflexus. With reference to the site of inception, the submaxillary is mesal, the sublingualis major intermediate, the sublinguales minores lateral. Secondarily, the duct of the sublingualis major becomes interposed between that of the submaxillary and the oral epithelium. 'The flange of the submaxillary is produced by' an apposition of the epithetium on the two sides of a lingual furrow, which is at first a mere angle between the tongue and the alveolingual gutter; the appearance of a vertical flange seemed to indicate some degree of shifting mesad of the epithelium of the gutter, and rentrad on the part of the epithelium of the tongue.

In the human embryo of 20 millimeters, submaxillary, sublingualis major, and sublinguales minores were present. The submaxillary had a much deeper flange than in cat embryos of equiralent development. In its separation a postglandular flange and an intermediate element were present; the latter in this, and in an embryo of 22 millimeters, showed some evidence of independent sprouting. The Bartholinian element in the younger embryo was attached to the flange of the submaxillary, but was prolonged forward along the lingual sulcus by a keel of its own. On the two sides its disposition differed in reference to the line of separation of the submaxillary duct. on one remaining attached to the duct, on the other to the postglandular flange. In the older embryo it was present on one side onty, and was attached to the duct of the submaxillary. Three lesser sublinguals arose from a small crest attached to the circumflex sulcus.

In view of the greater height of the submaxillary flange in the human embryo, as compared with that of the cat, it seemed reasonable to infer here a greater mesal shift of the epithelium of the atveolingual gutter, which, could it be proved to occur, would account for the juxtapostion of the submaxillary and Bartholinian glands. Indirect evidence to this effect seemed to be afforded by the narrowing of the alveolingual region as a whole in the vicinity of the flange.

The association of the early sprouts of the lesser sublingual glands with a continuous, but evanescent, keel of epithelium presents an advance in organization, in comparison with a gland field of simple independent sprouts. Were the cranial members of such a series re- 
duced to rudiments and the caudal sprout accelerated, we should have an anlage resembling that of the sublingualis major, where a sprout of caudal position is continued forward by an epithelial keel. In the case of this gland in the cat, there is a late efllorescence of the duct with small sprouts, which could be interpreted as a late assumption of glandiferous activity on the part of the retarded and coalesced elements of the keel. In this connection it is interesting to note that the keels are not always formed continuously from behind forward, but small outlying fragments may appear in line with, but in advance of, the extremity of the main keel, which thus presents discontinuities in its proliferation, as though its elements retained some independence. Such interruptions are infrequent, but occur in the keel of the Bartholinian element on both sides in the human embryo of 20 millimeters, and in the submaxillary on one side. They also have been observed in the keel of the submaxillary in the cat. This is in brief the developmental evidence, which prompts the interpretation of the larger keeled salivary glands in terms of a series of simple glands, rather than as hypertrophied equivalents of individual elements. The line of advance of a duct would thus appear as a selected strip, crystallized, as it were, out of a more primitive diffuse field. The presence of a sulcus, or, more particularly, a flange, would appear as an accelerating factor in the development of sprouts, rather than a necessary condition of such an organization as is here contemplated, for the flanged glands (submaxillary, parotid) anticipate in appearance and exceed in development the glands which are only provided with keels (sublingualis major, orbitals I, II, III), but agree with them in the formative process, which for both is proliferation, advancing craniad for the proximal portion of their ducts, proceeding distad into the mesenchyme for the remainder of their epithelium. The comparative evidence for this view, which is abundant, has been presented elsewhere (Huntington).

We thus conceive the ghand field of the alveolingual gutter organized into sagittal glandiferous lines, mesal the submaxillary, intermediate the sublingualis major, while laterad persists the diffuse gland field of the lesser sublinguals, in which organization has proceeded no farther than the abortive keel, which connects the early members of this series. It might be expected that such divisions as these would not 
always be absolute, that not all of the material of the mesal portions of the field would in all cases be incorporated into the lines of the submaxillary and sublingualis major, but that in some embryos rudiments of glands might appear between the duct lines and the diffuse field of lesser sublinguals. In the 20 millimeter embryo such were present along the intermediate sulcus and also between it and the lingual furrow in the form of small epithelial thickenings, like short ridges, but not enlarged at their distal (aboral) extremity, as is the case in active sprouts.

It remains to consider the process by which these several elements become oriented in the dorsoventral plane, so that the primitively mesal submaxillary becomes ventral, the lesser sublinguals dorsal, while the Bartholinian element retains its intermediate position. This is accomplished by the concomitant displacement ventrad of the submaxillary duct after its separation from the oral epithelium, and the mesal shift of the Bartholinian duct, while the elevation of the lateral portion of the alveolingual region, attending the enlargement of the alveolar process and the appearance of the arcus palatinus, accounts for the dorsal position of the orifices of the Rivinian glands. This rearrangement of the several elements affords a clue to the apparent discrepancies in the history of the Bartholinian element in its relation to the submaxillary gland, its attachment to which, in such forms as man and the pig, being conceivably no more than the result of a mesal displacement of such an independent anlage as occurs in the cat, accomplished secondarily by a movement in toto of the epithelium of the alveolingual region. This supposition is further supported by the formation of a blind fold or flange along the lingual sulcus, incident to the appearance of the submaxillary anlage; the material for this must evidently be derived, so far as its lateral lamina is concerned, from the surface epithelium of the alveolingual gutter. Could a form be found in which the Bartholinian proliferation was established prior to the formation of the submaxillary flange, actual proof of the shift might be forthcoming. In view of the fact that in the earliest of the pig embryos described by Chievitz ( 22 millimeters) the anlages of both glands had attained a considerable size, and, further, that the flange or crest of the submaxillary was of great depth, it seemed desirable to examine younger embryos, with a view of ascertaining 
the early condition of the sublingualis major, and especially the nature of its relation to the submaxillary. Through the kindness of Professor C. F. II. McClure, who permitted me to make use of the beautiful embryos of the Princeton Collection, I have been able to secure the necessary data to demonstrate the primitive independence of the sublingualis major, and its displacement mesad with the formation of the submaxillary flange, to the lateral lamina of which it is for a time attached.

In a pig of 15 millimeters (Princeton Collection, No.21 I) the submaxillary anlage alone is present. The lingual sulcus has (leep cranial and caudal scgments, corresponding respectively to the regions of the frenulum and of the submaxillary ganglion, which are connected by a shallower intermediate portion. In its whole extent its epithelium is thickened slightly at the fundus. While thus agreeing in general conformation with that of the cat, the lingual sulcus of the pig is characterized by its great depth caudal to the lingual nerve (Fig. 2, 4). Here it is an open $V$-shaped furrow directed ventrad and slightly laterad in the sections. Its lateral wall passes at a rounded, but nearly right, angle into the floor of the alveolingual region. The thickened epithelium of the fundus assumes the form of a small keel at the lingual crossing (7), which, increasing in size, attains a maximum I $20 \mu$ caudal to the nerve and thence diminishes as gradually, but can be followed as far as the origin of the first entodermal pouch. In its sections of maximum size the epithelium of the submaxillary anlage is slightly constricted at its junction with the lingual sulcus. A periderm layer is everywhere present in the mouth, but cannot be followed into the anlage; the fundus of the sulcus, while acute, does not show clear evidence of compression. If the anlage is interpreted as due to enlargement of the submaxillary keel, that is, as the result of a process of proliferation. in toto in this stage, as far dorsad as the constriction in subsequent stages, no gross error will be made; but it is difficult, if not impossible, to make an absolute distinction between flange and prolifcration in the pig, because the staining properties of periderm and basal cells are so nearly identical that the former cannot be recognized with certainty in the fully formed flange. Such a deep open lingual sulcus as here affords attachment to the submaxillary proliferation is never seen in the cat, in which a flange is present before the prolifera- 
tion is at all marked. The alveolar sulcus is a shallow concavity, lined with thickened epithelium. It has a general sagittal course, but approaches the lingual sulcus caudad, where the latter becomes deep.

In a second embryo of 15 millimeters (Princeton Collection, No. 210) the submaxillary is slightly more advanced in development, and the anlage of the sublingualis major has appeared. The beginning formation of a flange by the apposition of the walls of the lingual sulcus is indicated; the sulcus is somewhat less deep and its fundus has more the character of a fissure: the solid epithelium of the submaxillary anlage is increased in height ( $\mathrm{Fig} .3,7$ ). In profile the anlage is wavelike; it is postlingual in situation; lateral to it is the bulky submaxillary ganglion. The lateral lip of the lingual sulcus has the same contour as in the preceding embryo. Here the anlage of the sublingualis major appears as a solid ridge subhemispherical in section (Fig. 3. 11). It has a length of $75 \mu$. The cranial extremity is ro5 $\mu$ behind the lingual nerve, the caudal is opposite the deepest portion of the submaxillary. The anlage diminishes craniad, where it is attached about midway between the lingual and alveolar sulci, to the convex floor of the alveolingual region. It is thus absolutely independent of the submaxillary, which it only approaches caudad in the region where the flange has begun to be formed. The alveolar sulcus resembles that of the preceding embryo. Meckel's cartilage is now better clefined craniad, and the termination of the sulcus is directly dorsal to it.

In an embryo of I6 millimeters (Princeton Collection, No. 217) there are important changes. The anlage of the submaxillary has increased in size and now has a triangular profile, its caudal border being nearly vertical, a conformation which recalls Hammar's description of its early condition in man. In section (Fig. 4) the lingual sulcus is seen to be still deep, its fundus fissure-like. The epithelium of the submaxillary (7) has increased in size, is retort shaped, and is slightly constricted as it joins the sulcus. $A$ periderm line in its axis can hardly be distinguished. The anlage of the sublingualis major has a length of $105 \mu$; its cranial extremity extends to within $40 \mu$ of the lingual nerve. Its caudal extremity retains its position in the lateral lip of the lingual sulcus, while craniad and in the greater part of itscourse it is attached to the lateral wall of the sulcus near its funclus (Fig. +. II). It is evident, therefore, that incident to the formation of the 
submaxillary flange there has been a shifting or inrolling of epithelimm and that with this the sublingualis major has been carried mesad. The atveolar sulcus remains unchanged, save that its cranial extremity now crosses Meckel's cartilage dorsally.

In an embryo of 17 millimeters (Princeton Collection, No. I67) the anlages have increased considerably in size. That of the submaxillary is a solid triangle of epithelium, thickened at its free margin, with a nearly vertical caudal border, and a tapering point craniad. Its advance along the lingual sulcus has begun, and it now reaches to the cranial border of the lingual nerve as it passes beneath the alveolingual gutter. The anlage has a length of $165 \mu$; its free angle is at the level of the submaxillary ganglion (Fig. 5, 15 ). There is as yet no free sprout. Caudal to the vertical border of the anlage a low postglandular flange extends for a few sections along the lingual sulcus, representing the rudiment of the caudal portion of the early anlage. The lingual sulcus caudal to the nerve is now reduced to a shallow furrow, little more than an angle at the meeting of the tongue and the alveolingual region. Here the anlage of the sublingualis major is attached lateral to the submaxillary with which it is in contact. It is a solid ridge $135 \mu$ in length. Craniad it extends to the lingual nerve; caudad it reaches beyond the vertical border of the submaxillary and is attached lateral to the postglandular flange, to which it bears, the same relation as farther craniad to the submaxillary anlage. As the lingual nerve is approached the lingual sulcus resumes its lumen, or, more correctly, it has not here been reduced to a flange. In section it is $\mathrm{V}$-shaped, of moderate depth. The proliferation keels of the anlages have independent attacluments, the submaxillary just mesal, the sublingualis major just lateral, to the fundus. The condition resembles that of the prelingual portions of these keels in the human embryo of 20 millimeters.

The nature of the changes in the lingual sulcus is apparent from a comparison of Figs. 4 and 5. The deep furrow of the younger embryo has been obliterated by the apposition of its walls to the level of the sublingualis major, and in consequence the flange of the submaxillary has increased in depth. Dorsal to the sublingualis major the sulcus seems to have opened wider than before, and its walls meet at a right angle. The alveolar sulcus is shallower, a temporary condition, as 
though its epithelium were drawn upon in the changes affecting the lingual sulcus. A new furrow (I2) has appeared on the side of the tongue dorsal to the lingual sulcus, which evidently corresponds to a shallow concavity of the younger embryo.

In an embryo of 19 millimeters (Princeton Collection, No. I68) the sublingualis major is more intimately related to the submaxillary; a narrow plate of epithelium now serves to attach both anlages to the lingual sulcus (Fig. 6, 9). This contains no visible periderm, and yet its interpretation as a flange produced by foldling together of the walls of the lingual sulcus seems justified on comparison with the conditions in the embryo of 17 millimeters (Fig. 5). It can be seen that the lingual sulcus has become deeper and more like a fissure, while the distance between its fundus and the supralingual furrow (I2) dorsad, and the alveolar sulcus laterad, has diminished. At the same time the attaclyment of the sublingualis major has been carried from the sulcus itself into the resulting flange. It thus appears that the connection of the two anlages in the pig is purely secondary, and is occasioned by the closure of the lingual sulcus, which in producing the flange of the submaxillary draws into itself material from the surface of the tongue and the floor of the alveolingual gutter. The portion of the sulcus thus affected is caudal to the lingual nerve (Figs. 6-8); opposite the nerve the sulcus retains its lumen, and the prolongations of the anlages are attached as in the 17 millimeter embryo. The flange ventral to the attachment of the sublingualis major has increased in height (compare Figs. 5 and 6); this is evidentiy the result of growth in the flange itself, the increment supplied by continued infolding being relatively small, as appears from the size of the plate dorsal to the sublingualis major.

In front of the lingual nerve the epithelium at the fundus of the lingual sulcus is slightly thickened. At the cranial border of the nerve the epithelial plate of the submaxillary appears, and rather aloruptly acquires a considerable depth, projecting ventrad from the sulcus. The sagital length of its attached border is $\mathrm{i} 20 \mu$. The depth of the flange increases rapidly caudad and at its maximum (Fig. 6) extends slightly. ventracl of the submaxillary ganglion. The caludal border is nearly vertical. The angle at which it joins the ventral margin presents a pyriform enlargement, the sprout, which is on the point of beginning 
its independent growth in to the mesenchymal condensation, which is now well defined. Caudal to the vertical border a well-marked postglandular flange extends along the lingual sulcus for $60 \mu$ (Fig. 8, 8).

The crest of the sublingualis major has a sagittal length of 215 $\mu$. It increases gradually for $75 \mu$ and then more gradually declines (Figs. $6,7,8)$. It is attached in its first section to the lingual sulcus lateral to the keel of the submaxillary, then to the flange of the submaxillary, behind this to the postglandular flange, and for a caudal section or two to the lingual sulcus, which regains its lumen beyond the flanges.

In a second embryo of 19 millimeters (Princeton Collection, No. I04) a more advanced stage of the anlages has been attained. The sprouts are growing distad freely, that of the submaxillary into its mesenchyme condensation, that of the sublingualis major has descended to the level of the lingual nerve. The flange of the submaxillary has largely disappeared and the duct is free as far as the lingual crossing. Its attachment extends a short distance in front of the nerve, and is effected by a narrow epithelial plate common to it and the sublingualis major. The combined anlages have in section the form of an inverted $\mathrm{Y}$, the stem representing the closed lingual sulcus, the mesal arm the submaxillary, the lateral the sublingualis major. It is evident that as the keels extend craniad the folding of the sulcus also continues, and that the anlages are only continuous with one another through the medium of the flange which replaces the lingual sulcus.

We have now followed the development of the sublingualis major to the period at which Chicvitz begins his account, and have shown that the position ascribed to it by this investigator is secondary, and due to the inrolling of the alveolingual epithelium incident to the formation of the submaxillary flange. It is possible that this is the explanation of its condition in man also, where Chievitz describes its attachment to the submaxillary in an eight weeks embryo: "Von dem oben erwähten epithelkammartigen Gebilde geht an dessen äusserer Fläche ein kurzer rundlicker Forsatz ab, welchen ich, namentlich gestützt auf eine bei einem älteren Embryo gemachte Beobachtung, als die Anlage einer Glandula sublingualis deute."

The anlage is evidently still minute and is so represented in his seventh figure. This, in view of the condition occurring in the pig, does 
not argue against the interpretation of its position here also as secondary. At the same time if an inrolling incident to the formation of the submaxillary flange occurs, and the evidence seems ample that it does, it is clear that the site of the antage of the sublingualis major will depend upon the rate of the inrolling and the time at which this proliferation begins. It is, therefore, abstractly possible that in cases where a considerable degree of inrolling occurs, or where the sublinguals major is late in initiating its proliferation, the anlage might appear primarily attached to the flange of the submaxillary, but none the less would its epithelium be of lateral provenience. There is no difficulty, on the evidence afforded by the mouse, cat, and pig, in interpreting the sublingualis major as an independent derivative of the alveolingual epithelium, characterized by the intermediate position of its anlage and duct, between those of the submaxillary and of the lesser sublingual glands.

Two types of development of the sublingualis major may, therefore, be defined on the basis of our present knowledge :-

I. The anlage appears as a proliferation crest attached to the alveolingual epithelium, lateral to the lingual sulcus and the anlage of the submaxillary, from which it is separate and absolutely independent throughout development. This type occurs in the cat, and, apparently, in the mouse (Reichel, Chievitz, Göppert).

2. The anlage arising in the same way becomes approximated to that of the submaxillary secondarily, being displaced mesach and drawn into the flange of the larger gland. It is to be noted that in this case it is attached to the flange, and not to the keel of proliferation which forms its free border. In front of the flange it too advances by means of a kecl, and has an independent attachment to the lingual sulcus. When the sulcus is obliterated, a common flange is formed, along which both submaxillary and sublingualis major advance independently. This type is found in the pig; it is likely that it also occurs in man, but as yet the evidence is incomplete.

The relation of the anlage of the Bartholinian element to the flange of the submaxillary does not directly determine the nature of its definitive debouchment, whether into the duct of the submaxillary or by an independent orifice, nor is it possible at present to estimate the factors which effect this difference. In both man and the pig the 
sublingualis major is annexed by the submaxillary flange, yet in the pig it regularly has a separate orifice, while in man the condition is variable. In both the sublingualis major makes its advance by an independent keel, continued along the lingual sulcus close to, but not perfectly distinct from, that of the submaxillary. There is, then, material for an independent duct to be formed by the constriction and separation of the lateral keel. On account of the proximity of the two keels the supposition of their occasional fusion is not difficult, but is unsupported by any evidence. On the other hand there are differences in the anlages of the sublingualis major, in man and the pig, which suggest another explanation. It has been seen that in the latter the sublingualis major is attached to the postglandular flange, and that it retains this attachment when the flange of the submaxillary is disrupted to free the larger duct. In man (human embryo of 20 millimeters) this condition obtains on one side; on the other the cleft passes dorsal to the Bartholinian anlage, which is attached to the free duct of the submaxillary. Further, in this embryo there are gaps in the crest of the Bartholinian element on both sides. It is suggested that the attachment to the separating submaxillary duct may so disturb the alignment of the sublingualis major that its proliferation fails to supply the gap and its independent line of advance is lost, with the result that its duct becomes tributary to that of the submaxillary.

It remains to mention derivatives of the alveolingual region mesal to the submaxillary. Our knowledge of their development is still extremely meager. Chievitz described a sprout at the cranial end of the lingual sulcus, which is apparently referable to the apical gland of the tongue. In the 20 millimeter human embryo of the Columbia Collection, there is attached to the mesal lamina of the submaxillary a triangular anlage, similar in structure to the keel of the sublingualis major. In the 22 millimeter embryo this seems to be represented by a more cranially attached plug, which arises from the fundus of the lingual sulcus (Part II, Figs. 4, I I, I 2, 2 I). The attachment has probably been shifted craniad by a process of constriction, such as frees the keels of the submaxillary and greater sublingual glands. The association of this anlage in the earlicr stage with the flange of the submaxillary is very likely due to the shift of epithelium incident to the formation of the flange. 
Of the development of the caudal members of the lesser sublingual series, which in some forms extend into continuity with the isthmian glands, and of the elements which are placed mesal to the large ducts, such as IV'eber's gland in man, we have at present no information. Their morphologic status has been described elsewhere in this work (Parts 1 and III).

\section{SUMMARY}

I. The gland complex of the alveolingual region, on both comparative and developmental grounds, admits of division into sagittal components, the submaxillary, the sublingualis major, the sublinguales minores. Primitively these are arranged in a horizontal plane, the submaxillary mesal, the sublingualis major intermediate, the sublinguales minores lateral; in the course of development they become oriented in a dorsoventral plane, retaining their reciprocal relations; the submaxillary becomes ventral, the sublingualis major remains intermediate, the orifices of the sublinguales minores become dorsal.

2. A gland cannot be defined absolutely by the site of its orifice nor is it yet certain that the point at which proliferation begins is an absolute criterion. In view of the fact that gland development here takes place in a shifting plate of epithelium, it is evident that the site of an anlage in the transverse plane is the resultant of the rate of the shift and the time at which proliferation is initiated. In determining the status of a gland its whole developmental history must be borne in mind. The topography of the adult is indicative mainly of the degree of development of the element; a higher degree of morphologic inportance attaches to the intrinsic relations of the ducts in the supramylohyoid portion of their course. In view of the existence of mixed glands, the general character of their secretory epithelium cannot afford a criterion of their morphologic status.

3. The submaxillary and sublingualis major can be interpreted as equivalent to pluralities of simple glands, rows of which have been condensed to form the ducts. These elements manifest some independence in the formation at times of outlying segments of the keels, and at times of a late efflorescence of the ducts. This interpretation affords an explanation of the otherwise perplexing ontogenetic appearance of these mammalian neomorphs, which long antedate their 
phylogenetically older companions. If, however, $\mathrm{tl}$ cy are composites of these same elements, their priority in appearance indicates merely the acceleration of a portion of a common gland field. The presence of a sulcus seems to favor the appearance of the anlages, in that the sprouts associated with flinges grow more rapilly (submaxillary and parotid) than those without (sublingualis major, orbitals), but that it is not essential to the process of condensation, which gives rise to a keeled gland, is shown by the history of the sublingualis major and the litrger orbital glands.

4. The glandiferous epithelium of the alveolingual gutter tends thus to produce diffuse simple sprouts. This tendency in carly stages is repressed in the mesal (lingual sulcus) and intermediate areas. Here the keels of the submaxillary and sublingualis major are formed. The potentiality of these areas is not exhausted in the production of these ducts, as is shown in man by the appearance of other rudiments, and as may be inferred by the presence of simple diffuse glands in the adult opening mesad to the ducts of the large glands (Huntington).

5. The submaxillary is a sulcal, flanged, keeled gland. Its prolifcration is initiated caudal to the lingual crossing, in the transverse plane of the submaxillary ganglion. It advances along the border of its flange to reach the fundus of the lingual sulcus, to the lateral wall of which its keel is subsequently displaced. The duct is freed by constriction and separation of its keel. The lumen is acquired secondarily. In the region of the flange the duct is freed by a solution of continuity in the flange, portions of which persist for a time attached to the lingual sulcus, the postglandular flange, and to the submaxillary duct, the presumptive anlages of the second submaxillary and the dorsal accessory submaxillaries, respectively.

6. The sublingualis major is a keeled gland, not sulcal and, therefore, lacking a flange. Its proliferation is initiated caudal to the lingual nerve. Its keel is attached to the floor of the alveolingual gutter and advances on the lateral side of the submaxillary. It may remain separate from the submaxillary throughout development (cat), or be carried by an inrolling of the epithelium of the gutter into the submaxillary flange (pig). This circumstance does not determine the position of its orifice, which is independent in the pig, where its keel retains its independence, and when the submaxillary duct is freed, remains 
attached to the postglandular flange. The debouchment of this gland into the submaxillary, possibly depends upon the adherence of its anlage to the submaxillary duct at the time of its separation, with, in addition, the presence of interruption in the keel of the sublingualis major.

7. The sublinguales minores are derived from simple sprouts. In their highest development they extend from the caruncula salivaris to the arcus palatinus, where they may be continuous with the isthmian glands. The anterior or posterior members of the series may be suppressed. In man the earliest sprouts appear in the course of the circumflex sulcus, and are associated with an epithelial keel. This condition, which is evanescent, is intermediate between that of separate sprouts and the keels of the larger glands. Later they have been found arising diffusely from the surface of the plica sublingualis. This formation proceeds from before backwards along the gutter, lateral to the ducts of the larger glands. The later stages of their development, in particular their origin from the mesal portion of the gutter, require investigation. Reichel has described their attachment to the lingual sulcus caudal to the submaxillary. In the pig they are stated to arise diffusely from the first. In the cat the anterior members of the series are suppressed. The earliest sprouts arise from the circumflex sulcus near the lingual nerve.

8. The apical gland in man, or one of its elements, appears to be a keeled gland arising from the mesal lamella of the flange of the submaxillary. This position may be secondary. It advances by the constriction and the separation of its keel.

\section{BIBLIOGRAPHY}

Bujard, Eug. IgI. Réconstruction plastique des glandes salivares d'un foetus humain de to semaines environ. Anat. Anzeiger, Bd. $38,4,5$.

Chievitz, J. H. 1885. Beiträge zur Entwickelungsgeschichte der Speicheldrüsen. Arch. f. Anat. u. Physiol. Anat. Abt.

Cuvier. isio. Vorlesungen über vergleichende Anatomie. Leipzig.

Gegenbaurr, Carl. 1898 . Vergleichende Anatomie der Wirbelthiere. Leipzig.

Göppert, E. 1902. Die Entwickelung des Mundes und der Mundhöhle mit Drüsen und Zunge. Hertwig's IIndbuch der Entwickehungsgesh, d. 2, Th. I.

Hammar, J. August, inol. Notiz über der Entwickelung der Zunge und der Mundspeichddrüsen beim Menschen. Anat. Anzeiger, Bd. I9. 
IIs, W. I 885 . Anatomie menschlicher Embryonen. Th. 3. Leipzig.

IlLING, G. ro04. Vergleichende Makroskopische und Mikroskopische Untersuchungen über die Submaxillaren Speicheldrüsen der Haussäugetiere, Anatomische llefte, 26 Band, Heft $\frac{2}{3}$.

Kol.Liker, A. 1884. Grundriss der Entwickelungsgeschichte des Menschen und der Höheren Tiere. Leipzig.

Meckel, J. F. i 829 . System der vergleichenden Anatomie. Halle.

()WEN, R. IS6S. The Anatomy of Vertebrates. London.

Ranvier, L. i886. Étude anatomique des glandes connues sous le nom de sousmaxillaire et souslinguales chez les mammifères. Arch. de Phys. Norm. ef Path.

Rf.ICHEl, I'. I $88_{3}$. Beitrag zur Morphologie der Mundhöhlendrüsen der Wirbelthicre. Morph. Jahrowh. Vol. 8.

Zumstein, J. J. isgr. U'ber die U'nterkieferdrüsen Säuger. Marburg.

Loewential, N. igiz. Ueber die Stellung der sogennanten Gl. retrolingualis nach entwieklungsgeschichtlichen Befunden. Anat. Anzeiger, Bd. f2. No. I6.*

ANNOTATION OF LEADERS IN ALL FIGURES

I. Alveolingual region. 4. Lingual sulcus.

2. Circumlingual space. 5. Alveolar sulcus.

3. Marginal cavity. 6. Submaxillary flange.

7. Submaxillary proliferation, keel or duct.

8. Postglandular flange.

9. Flange common to submaxillary and sublingual major.

IO. Intermediate element. II. Sublingualis major.

I2. Supralingual sulcus. A furrow present in embryos of 17 millimeters and over, parallel and clorsal to the lingual sulcus, at first caudal to the lingual nerve, later extending craniarl.

13. Juxta-alveolar sulcus. A furrow present in embryos of 17-19 millimeters, parallel and lateral to the alveolar sulcus and situated caudal to the lingual nerve.

14. Lingual nerve.

I7. Meckel's cartilage.

15. Submaxillary ganglion. I8. Palate process,

16. Hypoglossal nerve. 19. Tongue.

* It is a matter of regret that, as the text of the papers here published was completed in February 19r2, we were unable to make use of Loewenthal's findings, and discuss his conclusions in the body of this work. He holds the Gl, retrolingualis (greater sublingual gland) to be it second or accessory submaxillary, on account of the resemblance of their development, and the position and time of appearance of their anlages. In that he thus sharply distinguishes between the greater sublingual and the Rivinian series, we are in full agreement, but are not able to go so far in the other direction as to view the gland in question as a submaxillary derivative. We have not felt the necessity of recognizing in this region but two glandular entities, the submaxillary and the lesser sublingual series, to one or other of which the greater sublingual (retrolingual) must be assigned. Our reasons for interpreting it as an independent coördinate entity have been given at lengtlı in the preceding papers. 




\section{Plate MCIX}

FIg. I. Transverse coronal section through the lingual crossing of the left side of a cat embryo of it millimeters. Columbia Collection, No. I22. Slicle 10, row 2 , section $1, \times 1$ I 5 , reduced $\frac{1}{2}$.

FIG. 2. Transverse coronal section through the anlage of the submaxillary gland of the left side of a pig embryo of 15 millimeters. P'rinceton Collection, No. 2I1. Slide 0, row I, section I. This section is $120 \mu$ caudal to the lingual crossing, $X$ I I 5 , reducet $\frac{1}{2}$.

FIG. 3. Transverse coronal section through the anlages of the submaxillary and sublingualis major of the left side of a pig embryo of 15 millimeters. Princeton Collection, No. 2ro. Slide 6, row 3, section 1. This section is $150 \mu$ caudal to the lingual crossing, $\times 115$, reduced $\frac{1}{2}$.

FIg. 4. Transverse coronal section through the anlages of the submaxillary and sublingualis major of the left sicle of a pig embryo of i6 millimeters. Princeton Collection, No. $21 \%$. Slide 7 , row 1 , section 6 . This section is $60 \mu$ caudal to the lingual crossing, $X 1_{5}$, reduced $\frac{1}{2}$.

I. Alveolingual region.

2. Circumlingual space.

3. Marginal cavity.

4. Lingual suleus.

5. Mveolat sulcus.

6. Submaxillinry tlange.

7. Submaxillary prohferation, keel or duct.

II. Sublingualis major.

I2. Supralingual sulcus. I furrow present in embryos of 17 millimeters and over, parallel and dorsal to the lingual sulcus, at first caudal to the lingual nerve, later extencling craniad.

14. Lingual nerve.

I5. Sulmaxillary ganglion.

16. Hypoglossal nerve.

17. Meckel's cirrtilage.

I. P. Palate process.

19. Tongue. 
PLATE XCIX
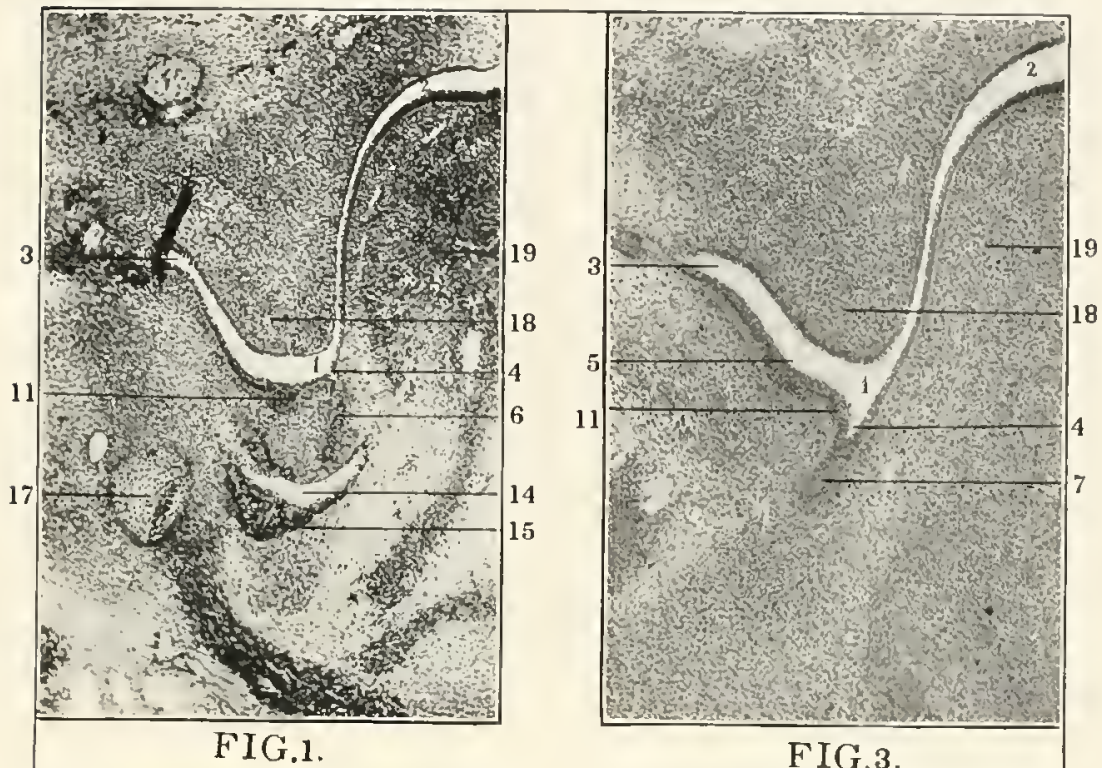

FIG.3.

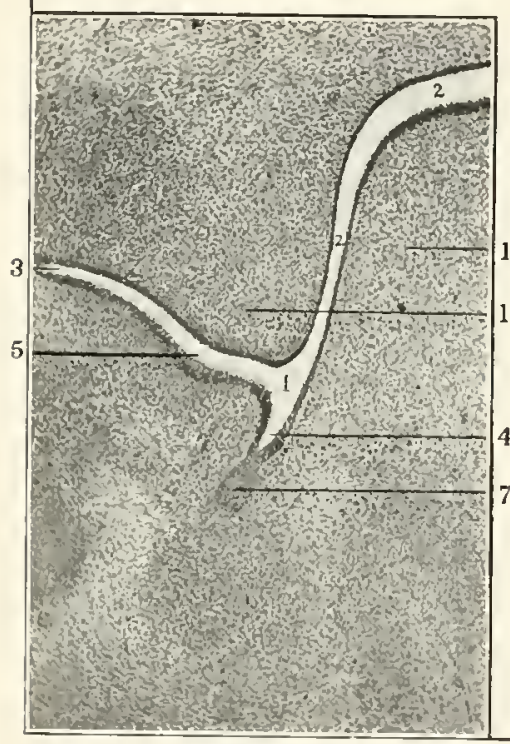

FIG.2.

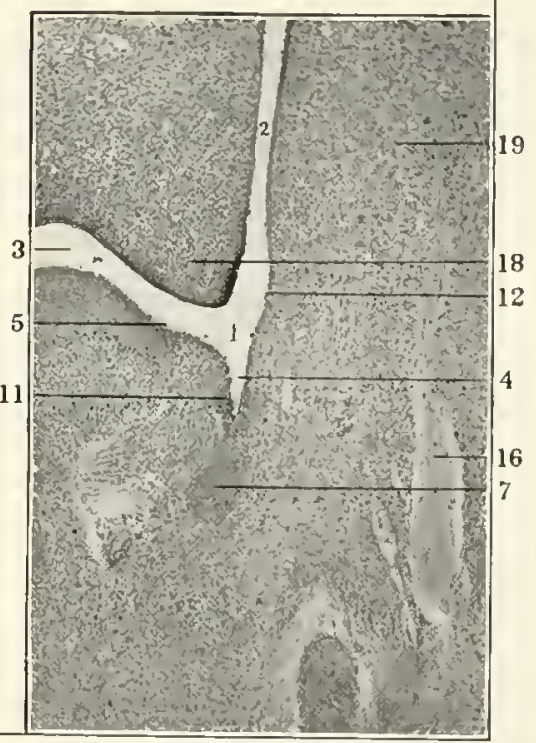

FIG.4. 


\section{Plate C}

FIG. 5. Transverse coronal section through the anlages of the submaxillary and sublingualis major of the left side of a pig embryo of $\mathrm{I} ;$ millimeters. Princeton Collection, 10. 167. Slide 10 , row 1 , section 8 . This section is $45 \mu$ caudal to the lingual crossing, $X$ i 15 , reduced $\frac{1}{2}$.

Figs. 6, 7. S. Three successive coronal sections through the anlages of the submaxillary and sublingualis major of the left side of a pig embryo of ro millimeters. Princeton Collection, No. 168. Slide 13, row 2, sections 5.4 .3 . The section of Fig. 6 is $30 \mu$ caudal to the lingual crossing, $X$ I 15 , reduced $\frac{1}{2}$

I. Alveolingual region.

2. Circumlingual space.

3. Marginal cavity:

4. Lingual sulcus.

5. Areolar sulcus.

7. Submaxillary proliferation, keel or duct.

f. Postglandular flange.

9. Flange common to sulımaxillary and sublingualis major.

ro. Intermediate element.

11. Sublingualis major.

I2. Supralingual sulcus

I.3. Juxta-alvenlar sulcus. A furrow present in embrrons of 17 -ro millimeters, parallel and lateral to the alveolar sulcus and situated caudal to the lingual nerve.

14. Lingual nerve.

I5. Submaxillary ganglion.

16. Hypoglossal norve.

I7. Meckel's cartilage.

18. Palate process.

IQ. Tongue. 
PLATE C.

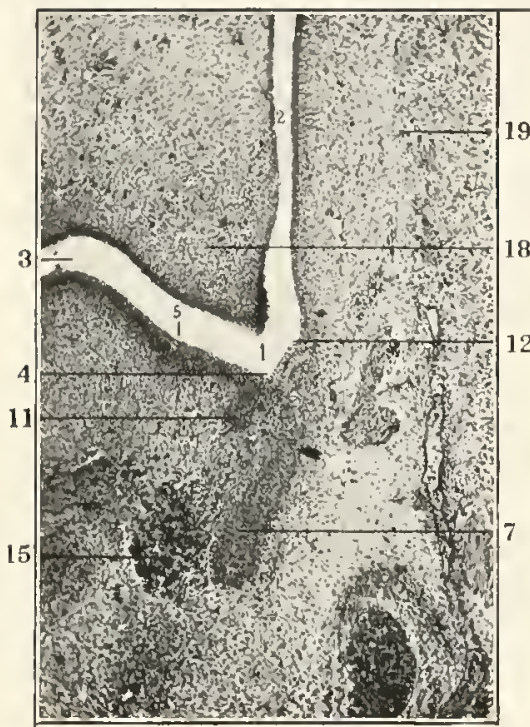

FIG.5.

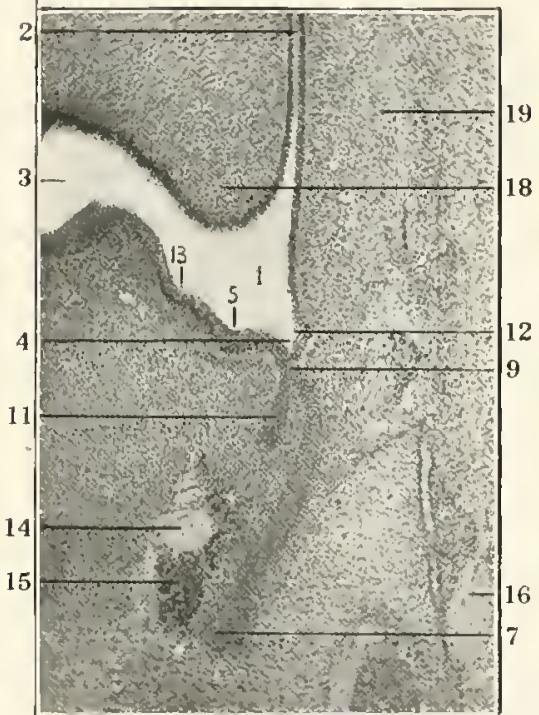

FIG.6.

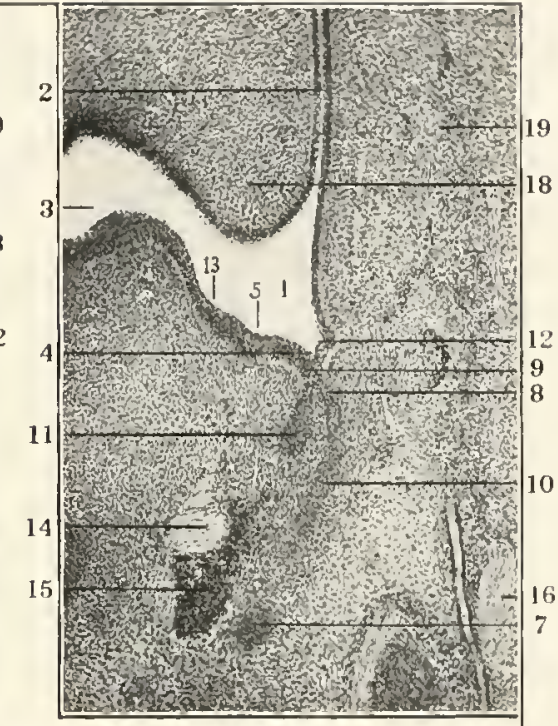

FIG.7.

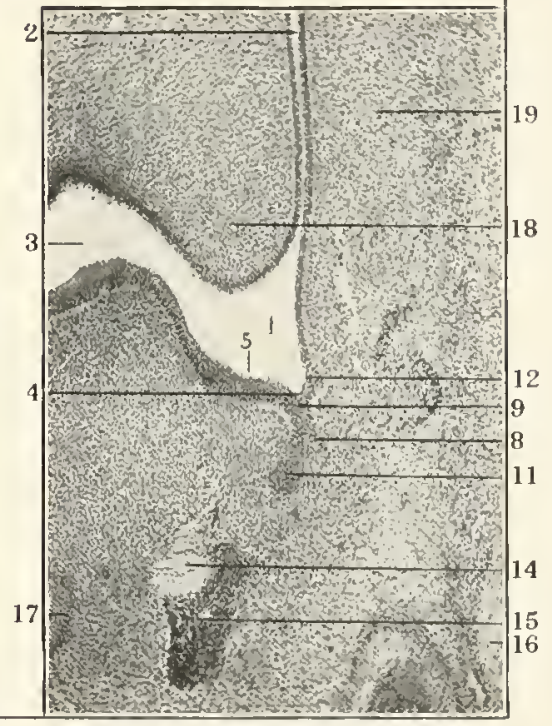

FIG.8. 




\section{INDEX}

Accessory parotid gland, 74; in Cynocephalus Alveolingual salivary organization, primate, hamadryas, 85

Accessory submaxillary gland or glands, 75, 90, $01,0596,104,110,100$

Irlenoid follicles. Peritonsillar, 22

Niveobuccal and alverolabial sulci in man, 0 ; in the cat, $160-62,230-72,308$

Alveoluccal or molar glands, The inferior, in carnivora, 157-58, 188; of the cat, 166, 209ro, $274,299,300-1$; of lioness. I 09 ; of the dog, 171; of Thibetan bear, 172; of the badger, $175 ;$ of the glutton, $170-77$; of sealion. 180

Alveobuccal or molar glands, The superior, in man, 6, II, 22: in the cat, 274; in the opossum, 3in: in the calf, 323

Alveobuccal sulcus, The inferior, of the cat, 160 $62,209 \cdots 10,238-73$

Alveohuccal sulcus, The superior, of the cat, I $00-62,237-43,274$

Alveolabial glands, The inferior, 309; in gray squirrel, 3 I 8 ; in calf, 323

Alveolahial sulci, The, $238 \quad 39,240$

Alveolingual area, Narrowing of caudal portion of, I33: topographical divisions of the 136 37

Aveolingual derivatives, I IO-I I

Alveolingual glands, 5,7, I $2-2 \mathrm{I}, 28,76-77$, I 5556 ; of the cat, 160-60, 274-75; developmental processes of the, $341-44$; rearrangement of the elements, $311-15 ;$ complex of the 352

Mveolingual glandular development, Mecbanical factors in, $133-30$

Meaning of analytical study of $137-30$

Alveolingual sulcus, of Chievitz, 2S, 190-200

Analysis of adult primate sub- and inter-mandibular salivary complex, 137-55; meaning of analytical sturly, I37-39; groups and divisions, I39, I +1 I, I 45, I 46 , I 50, I $52-53$

Anatomy of the aduit human salivary glands (Chtrchill Caralat), 5-23

Anatomy of the salivary glands in some members of other mammalian orders (CHu RCHLL CARMALT), 315-24

Anatomy of the salivary glands in the carnivora (Churchill Carmalt), 155-90

Angulus oris, The, $30-32,160,161,233,204$. $200-9,224,240$; fusion at the, 215

Anlage, Hammar on inception of the, 60, 340 Anlage of a right parotid, 229-30; solid, 231 ; structure of, 235

Anlage of buccal sulcus, 29, 30; a lumen in, 32 ; in Paulet's embryo, $14-17,33-3.4$; of parotid in 4 embryos, $f 1$; study of, necessary, 44 ; development of, 45 ; separate, 243

Anlage of the greater suhlingual, 105, 203-94

Anlage of the masseter, 226, 255

Anlage of the submaxillary, $48-52,55,60$, 105 $278-84,300$; solidity of, $49,51-52$

Anlage, primary, Development of the, ro6, II I8

Anlages of glands of the alveolingual region, 100

Anlages of the dental ridges, 203, 236, 304

Anlages of the lesser suhlinguals, 50-57, 105

Anlages of the orbital glands, 2 10

Alveolingual region, The, 5, 26; its sulci and their derivatives, $40-00$, I I0-I I; summary, no70, 115; bibliography, 70-71; annotation of learlers, $71-72$; in lower primates, $74,106-7$; in the cat, 199-200, 304; glands of the, 309Io ; gland complex, 352

Alveolingual salivary area, the primate, Genetic interpretation of (GEO. S. Huntington), I I 5- 55

Alveolingual salivary complex in lower primates, Schema of, in individual species, 00-10, I 1054 ; in adult human, $154-54$

Alveolingual salivary development, Genetic theory of, I22 33: mechanical factors influ encing, $333-36$; detailed analysis of salivary complex, I $37-55$

Anlages of the salivary glands, Formation of the 32-33: thrce attached to lingual sulcus, 51 52 ; variations in development of, $06-67,31$ I

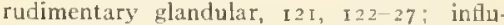
ences modifying the, I33-35; solid, I92: relation of, to oral cavity, r 93 ; terms used in description of, 199; shifting of the oral, 215: arise from placode, 30.1

Inlages of the tongue 200

Anlages of the zygoma, 228

Innotation of leaders in all figures, $22-23,71-$ 72, I I 3, I $80-90,3$ I I-I3, 32324,355

intelope, Salivary glands of the, $322-23$

Anthropoitea, Salivary glands of $80-83$

Apical gland of the tongue, $5,17,47,53,67,60$ 351,354 
Arctomys monax, 321

Arcus palatinus, Glands of the, $7,18,23,108$ Associate parotid glands, 83

Ateles hybridus, Salivary glands of, 90, 100, 108, I 10,152

Ateles sp.?, Salivary glands of, $91-92,94,96,97$, 101 " 108,100, I10, III, I $48-40,153$

Auditory canal, The external, 23

Aulmann, G., on divisions of the mouth, 199

Baboons, The, 20, $83-80,109$

Badger, The salivary glands of the, $173-76$, i 84 , I $S_{5}$

Bartholinian element, Inconstancy of the, 325 ; Ranvier's confusion over the, 328-29

Bartholinian gland. The, or greater sublingual, 13, 24, 15- 17 ; Chievitz on origin of, 28; a component of the sublingual gland, 29; in Bujard embryo, 59, 326; confusion over, 32S29. Sec also Sublingual gland, The greater.

Bibliography of human salivary glands, 70-71

Bibliography of manmalian alveolingual salivary area, 35.4-55

Bibliography of salivary glands in the camivora, I 80

Blandin-Nuhn or "apical" gland of the tongue, $5,17,47,53$

Bos taurus. 323

Buccal sulci, The, important, 196-97; divergence of, 201

Buccal sulcus, the, Development of in human embryos, 31-42; two constants in, $42-46$; summary, 69

Buccal sulcus, the, Development of, in the cat, 29-30, 196-08, 20.4-8; derivatives of, $210-77$ : the orbital inclusion, $210-23$; the parotid $224-48$ : the orbitoparotid interval, $245-56$ : the orbitoparotid glands, $250-66$; the orhital glands, 264-7+; summary, 304-0

Buccal sulcus, The secondarv, 202, 200, $210,217$. $238-41$; an interpretation. 274; summary, $307-8$

Bujard, Eug., on embryos, 25; description of enbryo of 5 cent., to; embryo of ro weeks, 5 cent. 58-59; on the glands in two embryos, $3.10-41,354$

Calf, Salivary glands of the, 323

Canals, Conducting, 128

Canis familiaria, sef $\mathrm{Jog}$

Capybara, Salivary glands of the, 319-20

CARMALT, CHCRCHILL, The anatomy of the salivary glands in some members of other mammalian orders, 315-24

Carmalt, Churchill, The anatomy of the salivary glands in the carnivora, $155^{-00}$

Carmalt, Churchile, Contribution to the anatomy of the adult human salivary glands. 5-23; death of, 25; results of, 326; on the submaxillary, 327 ; the work of, 334
Carnivora. Anatomy of the salivary glands in the, $155-90$

Cat, domestic, Development of the salivary glands in the (H. von W. Schulte), I91-313: The oral cavity, 195-209; glands of the vestibule, 209 -10; the orbital inclusion, 210 23; the parotid, 224-48; the orbitoparotid interval and its derivatives, $248-56$; the orbitoparotid glinds, 256 0.4 ; the orbital glands, $26.7-74 ;$ glands of the alveolingual region: the submaxillary, 275-92; the greater sublingual, 292-09; the diffuse glands of the mouth, 290-304; summary, 29-31, 30.4-11: annotation, 31 I-I3

Cat, Study of the, I55: description of the silivary glands of the, $159-69,183,184$, I 55

Cavum oris proprius, of the cat, I 59, 16

Cebidix, Salivary glands of the, $80-02,94,96$

Cercopithecidie, Salivary glands of, $83-89,94$

Chauveau and Arloing, I 99

Cheek, Formation of the 205, 24

Chievitz, J. H., on embryos, 25-26; on sulcus alveolingualis, 26,28 ; description of $\mathrm{em}$ bryo of, of eight weeks, $38-39,50-51$; embryo of ten wecks, 40; of two embryos of 12 weeks each, 41 ; embryo of 6 weets, 49 50; embryo of Io weeks, 58 ; of 12 weeks, 50 ; on formation of ducts, 191; alveolingual sulcus of, $190-200$; on formation of the cheeks, 241 ; on orbital inclusion, 258; results of, 320, 339; on Bartholinian element, 328, 329; on Reichel, 332 ; summary of work of, 335-39; 354 ; on alveolingual field, 339

Chimpanzee, A variant, I $47-48$

Circumflex sulcus, The, 56, 67

Circumlingual region in the cat, 200

Cologenys paca, 318

Columbia Collection, Description of embryo No. 229, of $7.5 \mathrm{~m} ., 31-32$; embryo No. 325 of $20 \mathrm{~m} .34-38$; of No. 3. 39; alveolingual region of No. 325, 51-55; of No. 3, 55-58; embryos in the, $192-93$

Complex glands, 310

Cranial process, The, 222

Craniolingual plane, The, 200

Cuvier, on seals, I80; $180,315,354$; Chievitz in accord with, $33^{6}$

Cynocephalus babouin, Salivary glands of, 82 $83,97,101-2,103-0,1+2-43,144$

Cynocephalus hamadryas, Salivary glanels of, 9. $85-80,94,96,97,101-2,108-9,1+2-43,144$

Cynocephalus porcarius, Parotid complex of, 8

Cynocephalus sphinx, Salivary glands of, $9,83-$

89, 04, 97, IOI-2, $108-9, I_{42}, 144$

Dental ridges, Anlages of the, 203-4

Development, selective, Progressive tendencies in, IIO-2I

Developmenta] process in alveolingual region regular, 275 
Didelphis marsupialis, 315

Diffuse glands defined, 19.4; development of the 290-304

Dog, Study of the salivary glands of the, 155 , 157, 170-71: fifty examined, $\times 50$

Dorsal accessory submaxillary glands, I3-14, 6.4, 75

Duct of Bartholin, 28, 76, I I

Ducts, Formation of, 37, 43, 191-92; by union of anlages, Ins

Ducts of Rivinus, 28,76

Ductus Stenonianus, $4^{2}$

Ductus sublinguales minores, 28,77, II, 325 320

Ductus sublingualis major, 28,325

Ectopalatine sulcus, The, 35 ; of the cat, 201-3, 209

Ellenberger and Baum on orbital glands in the $\operatorname{dog}, 157,189$

Embryonic conditions, Two important, illus trated, I $10-20$

Embry"onic selection, I $37-38$

Embryos, human, Salivary glands examined in, 25-26; exhibit complex organization, 25: series of examined, $3 I^{-1}$

Embryos, Various, examined by Chievitz, 336

Entomasseteric duct of Chievitz, 33.40, ror

Epithelial crest (Chievitz), 67-68, 215

Equus caballus, 323

Evolution, Line of, Ing; tendencies in, progressive, II -2 I

Face, formation of the, 205,241

Facts established by Schulte, i i 7-22

Faucial glands, 15, 22. See also Isthmian gland

Felis domestica, see Cat

Felis leo, Salivary glands of the, $100-70$

Fiber zibethecus, 321

Figures, Annotation of leaders in all, $22-23,71-$ 72, I 3 . I $89-90,311-13.323-24.355$

Fixation by Zeuker's solution, 193

Flange, Definition of, 27, r94: sprout from, 30: changes in the, 231 35; in IJammar's embryo, $60-63$; of the suhmaxillary, $05,280-82$; formation of the, $28_{2}-83$; and parotid, 70, 225 , 230

Flanges of the salivary glands, The, 3 Io

Fold, transformed into a cylinder of cells, 3 I, 32 ; the anlage of the parotid, 32, 33, 44; not yet observed in man, $37-38$

Fox bat, Salivary glands of the, 316-I7

Fundal, term of position, 20-27, I94

Gegenbaver, Carl, on the tongue, 199; on orifices of glands, $334 ; 35$.

Genetic interpretation of the primate alveolingual salivary area (GEO. S. IluntIngton) I : 5-5 55

Gland, Limitation of the term, 28 ; continuous process in formation of, 37; vague concept of the, 325-26; . cannot be defined absolutely. 352

Gland sprouts, T'erms defining position of, 26-27 Glandes sublinguales accessoires, 326

Glandiferous sulci, The, 200

Glands, Annotation oI, in all figures, $22-23,7 \mathrm{E}$ 72, i 33, I $89-90,311-13,32324,355$ Glands of the alveolingual area, arcus palatinus, and soft palate, $5,7,12-2 \mathrm{I}, 28,70-77$

Glands of the alveolingual region in the carnivora, 155-50: in the cat, 106-60,27.4-75: summary, 309-10; confusion regarding, 325 ; results of Chievitz's observations on, 338-39

Glinds of the stomal ridge, $210,273,209,301^{-2}$ Glands of the vestibule, $20-10$ : The orbital in clusion, 20-30; the parotid, 30; the orbitoparotids, 30-3I; should he referred to their origin, 48 ; in the carnivora, $156-58$; in the cat, Ibo-60, 209-74

Glands, Polystomatic, 28

Glands, Separate small, of the lingual, labial and pharyngeal regions, 7,22

Glandula buccalis (Bujard), 341

Glandula Nuckü, II, I57, I 7 I, I 80

Glandula orbitoparotis, 157

Glandula parotis, $156-57$

Glandula retrolinguatis, 11 r, 326

Glandula sublingualis, $28,325,326,336$

Glandula sublingualis major, $20,70,155-56,326$ Glandula sublingualis monostomatica, 28,76 , I 1

Glandula sublingualis Rivini, s. polystomatica, 28 , 76, I I, 326

Glandula sublingualis, s. Bartholini, II

Glandula suhmaxillaris, I 1 0, I 55, 326, 336 Glandulae alveobuccales inferiores, $157^{-} 58$ Glandule alveolinguales, $76,326,336$

Glandule et ductus Rivini, II

Glandule isthmiane, 156

Glandulx orbitales, I 57

Glandula sublinguales minores, $29,76,77$, I I 156,326

Glandular combinations, Possibilities in, $122-33$ : not suhject to chance, 137-39: plus a determining factor, 139

Glandular ducts, Continuous, I 1 7-1

Glandular masses, Paraparotid separate, 7, 10-II

Glandular trigone, The, in the cat, 150,160

Glutton, The salivary glands of the, $176-79,183$, I 85

Göppert, E., 70; figure of oral cavity of a mouse embryo, 340 ; 354

Ground hog, Salivary glands of the, 321-22

Gulo luscus, The salivary glands of the, $170-70$

Hammar, J. August, on embryos, 25; on sulcus buccalis, 20, embryo of $8 \mathrm{~mm}$. 31 : embryo of I1.7 m., 32-33; embryo of $17 \mathrm{~m}$., 34; embryo of IS.5 m., 39; embryo of $24.4 \mathrm{~m}$., 39 ; the 


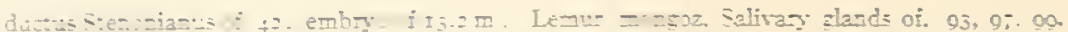

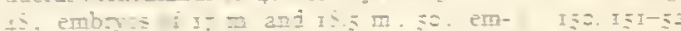

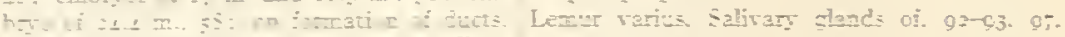

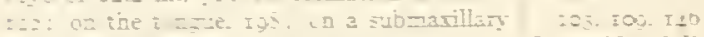

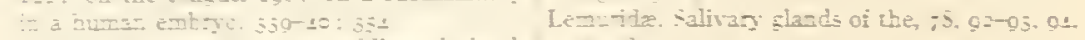

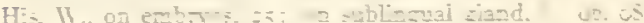

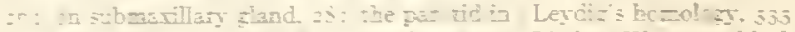

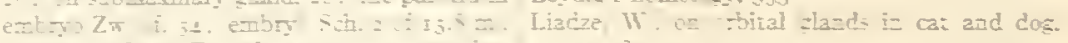

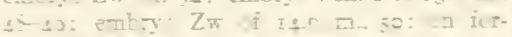

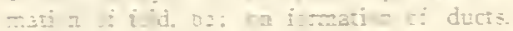

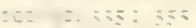

H :-se. Salis alan is at the. :

I5-. ISO

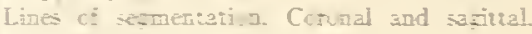

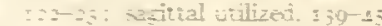

Lingual a:ca. The $135-30$

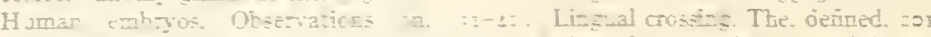

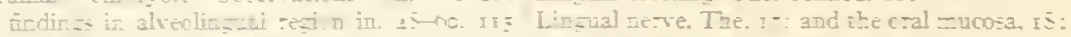

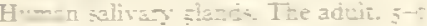

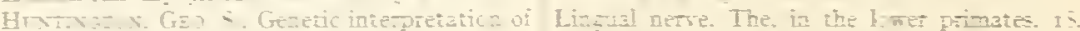

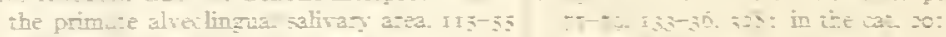

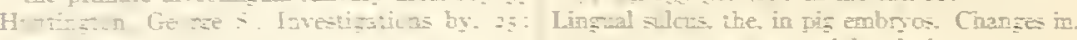

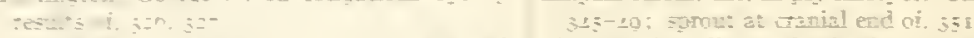

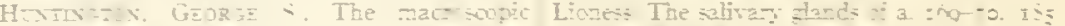

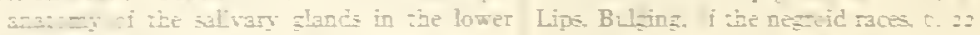
primutec. $-3-5=3 \quad$ a

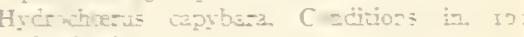
ziz-is $0.5: 0-0$

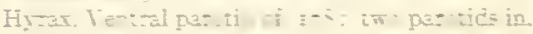

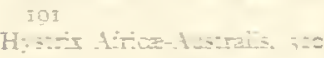

T11ing. (x- -

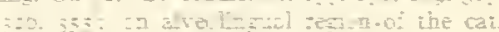

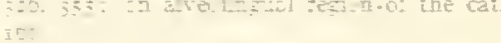

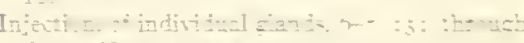
Euci rifes. -2 , t:

I-

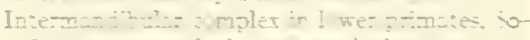

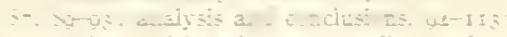

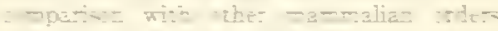

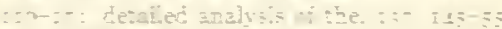

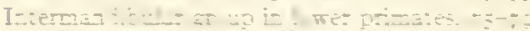

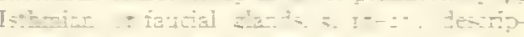

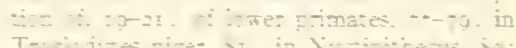

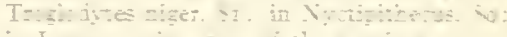

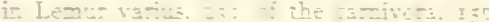
$\because i^{2}$ e

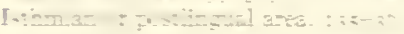

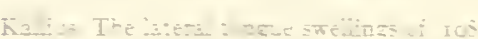

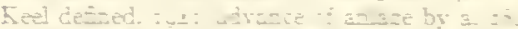

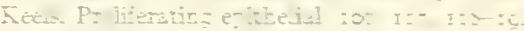
250

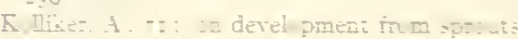

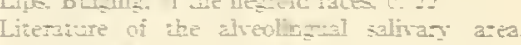

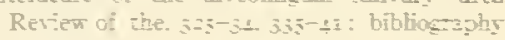
izisiz:

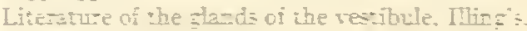
Iรา

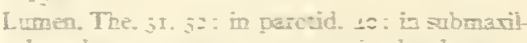
lesy duct so $5:-55,5-53.150$ : development

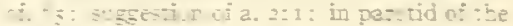

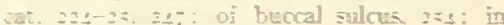

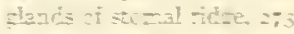

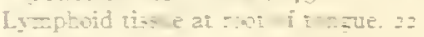

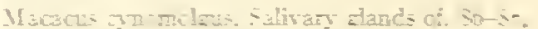

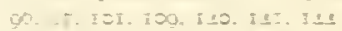

Mucaci- nemesinus. S-lisang glands of. E;- -o

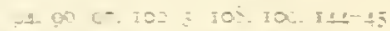

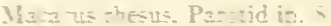

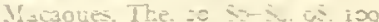

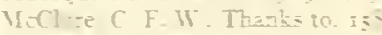

Mach pas gisan:eui. The steate: sublingual i= $=-2$

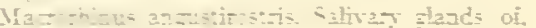
I $\ .<$

Mam-zalian akm -gual salivay area. The

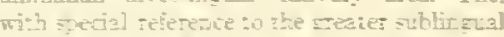

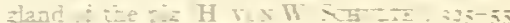

$I=-$ Deselwoment it the salivar glasds in

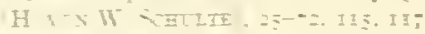

Mandibia: retse. The : - $^{-}$

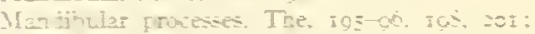

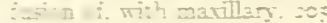

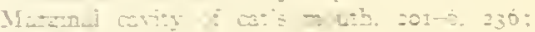

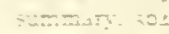

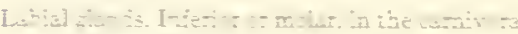

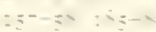

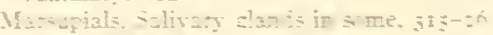

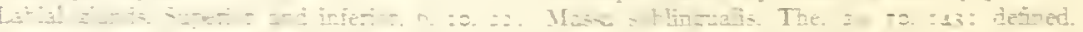
wa

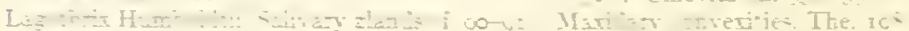

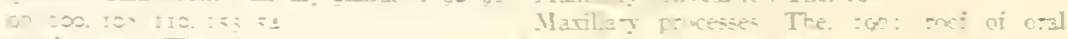

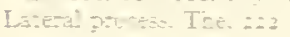

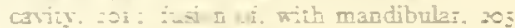


Maxillomandibular plane, The, 20r, 202-4, 205, Orbitoparotil inclusions, 30, 42 200,304

Maximow, $7+$

Mechanical conditions, Influence of, $121-22$, 13336

Orbitoparotid interval, The, $30,43,44$; glands developed in, 75; and its derivatives in the cat, 225, $248-50$

on glands of he the seals, 180 ; 315 ; on (18) $189,315,355$

cartilige, 46, 47, 56

Mephitis putida, The salivary glands of the, I 73

livart. St. G., on parotid gland, 157,160 , I 89 the zyognatic gland of, 19

Molar glands, The, of Ward, I 1, 210. See also Alveobuccal glands, Labial glands

Moldenhauer named sulcus lingualis, 26; the tubotympanic sulci of, 195

Mole, Imerican, Salivary glands of the, 317-18

Morphological Museum of Columbia Iniversity 74. See Columbia Collection

Morphological Museum of Princeton, 8, 74, I58, I 79

Mouth. See Oral cavity

Muscles, Annotation of, in all figures, 23

Muskrat, Salivary glands of the, $32 \mathrm{I}$

Nomenclature, Difficulties of, $26,7+$

Nuck, A., discovered orbital gland, I I, I 57, 171 ; I 89

Nuhn-Blandin gland, sec Blandin-Nuhn

Nyctipithecus trivirgatus, Salivary glands of $89,94,96,9 S, 99$, I 10, 150-5 I

Opossum, Virginia, Salivary glands in the, 315-

Oral cavity, The, in embryos of cats, 105-209; longitudinal growth of, 205 ; recapitulation of details, 208 9 ; summary, 304

Orbital angle, The, $35,203,204$

Orbital fold, Rise of, $204,211,212,224$; cranial limit of, 251-52; advance of, 256

Orbital glands, 5-6, 7, 10- II, 22, 75; annotation of, 22 ; in the carnivora, 157 ; of the cat, sho$61,164-05,210,264-74$; of lioness, 160 ; in the dog, $170-71$; of badger, 175-70: of the glutton, 176; in sea-lion, ISo; observations, I 56, I 88

Orbital glands of the cat, $210,26+-74$; a point of interpretation, 27.; summary, 308-0

Orbital inclusion, The, 29,41 ; wide distribution of, $42-43$; summary on, $69,305-8$; development of, in the cat, 197-98,205, 206, 208 , 209, 210-23: pars cylindrica, 2II, 2I6-19. 305; pars lata, 21 2, 216-I8, 221-22, 305: structure of, 223

Orbitoparotid bridge, The, $30,226,232,250$

Orbitoparotid gland. The, a constant element in the carnivora, I57; of the cat, I64; of procyon, $172-73$; of the glutton, 176,278 : in constant and small, i $86-87$; i 88

submaxillary, 327; 355

Paca, Salivary glands of the $318-19$

Palate, soft, Glands of the, 7,18

Palate process, Rudiment of the, 198; contact of tongue with, 199; roof of cavity, 201, 200, 24.3. 30.4

Palatine area, $135-36$

Palatine glands, 5, 17-21, 22; of the cat, 100 , $299,303^{-4}$

Palatolingual planes, The, 200

Palatomandiluular plane, The, 201, 202, 200

Parietal, term of position, 27, 194

Parotid fold of Ilammar, Evidence for, incomplete, 31, 33-34

Parotid gland, Accessory, of lower primates, $74-75$

Parotid gland, The, 5-6, 7-1 $\mathrm{I}$; accessory parotid glands, 8-9,74-75; separate glandular masses, ro-11; annotation of, 22; sulcus giving origin to, 26,30 ; the earliest described +2 ; question of origin of, 44 ; addition of
proximal segment to, $45-46$; development of, 70 ; of lower primates, $7 f$; in individual species, So 94: Of Simia satyrus, 80; of Troglodvtes niger, $8 \mathbf{r}$; of Cynocephalus sphinx, 83 ; hama dryas, 85-86; of Macacus, $80-88$; of Nyctipithecus, 89 ; of Ateles hybridus, 90; of Lagothrix, 90 ; of Ateles sp. ?, or : of Lemuridx $92,93,94$; of the carnivora, $156-57$; of the cat, I00; of lioness, $\mathrm{I} 69$; of the dog. I 70 of Thibetan bear, I7I-72; of raccoon, I72; of skunk, 173; of badger, 173; of glutton, 176. 177; in sea-lion, 179: observations, is 1$82,18+-85,188$; primitive independence of 250 ; in tying phalanger, 316 ; of fox bat, $316-17$; in American mole, 317 ; of the gray squirrel, 318 ; of the paca. 318 ; in capybara, 319; in African porcupine, 320 : in muskrat, 321 ; in ground hog, 321; trapezoid in antelope, 322 ; in calf, 323 ; in horse, 323

Parotid gland of the cat, Development of the 162-64, 204, 206, 210, 224-48; summary, 233 305-8, 310; Reichel on the, 309; a complex gland, 310

Parotid group in lower primates, $74-75$

Parotid. The retromasseteric, in the opossum, 315

Parsons, on the parotid gland, 6

Paulet, J. L., on embryos. 25; description of embryo of $14.7 \mathrm{~m} ., 33-34.49-50,340-41$; the ductus Stenonianus of, 42

Orbitoparotid glands, The, of the cat, 204, 210, Petauroides volans, 316 256-64; summary, 305-8, 3i0

Phalanger, Jlying, Salivary glands of the, 316 
Pharyngeal area, 135-36

Pharyngeal glands, 5, 22

Pharyngeal tubercle, The, 23

Pig enbryos in Princeton collection examined hy Schulte, $345-50$

Plica fimbriata, The, $47,50,51$

Plica sublingualis, The, 57, 59, 69, 332

Pohlmann, A. 11., on cats, 19.4: on the formation of the mouth in cats, 205

Porcupine. African, Salivary glands in the, 320

Postlingual or isthmian area, $135-36$

Prelingual area, Divisions of the, $135-30$

Primates, lower, Genera and species of, examined, 73

Primates, lower, The macroscopic anatomy of the salivary glands in the GFO \& HzyTisciton). 73-IIs

Primates, Parotid development in, 8,9 ; observations on, 25. See Parotid gland

Procyon lotor. The salivary glands of a, 172-73 Procyonidix, Meckel on parotid in, 178

Proliferation, 37. 44-46, 57, 61-63, 65, 70; along edge of a solid fold, 234,274 ; keel of, 284,288 of the submaxillary, $285-86,290$; gland development always by, 295; 305, 309, 310, 3.15, $350,351,352,353$

Proparotid convexity, The, 35

Pteropus scapulatus, 3 I6

Putorius, Zumstein on alveolingual region in, $173-79$

Rabbit, Greater sublingual absent in, 328,332 Raccoon, The salivary glands of $a, 172-73,181$ 185

Ranvier, L., 74; retrolingual gland of, 70,79 , 1 I $2,145-46,149,189,320$; studies of, 155 $315,327,338$; inaccurate, I $56,328-20 ; 355$

Regio alveolingualis, 26; sulci of the, $334-35$

Reichel, on the parotid gland, 300; results of studies of, 326; on the relations of the sublingual and submaxillary glands, $330-33$; on sprouts, 333; Chievitz in accord with, $336 ; 355$

Reighard and Jennings, on parotid gland, I57; I 89

Retrolingual, Impropriety of term, I I 2

Retrolinguale (Kanvier), 76, I I2, 326

Rivinian, The, or lesser sublingual clands, 16, I 7 $21,28,20,77$. See Sublingual glands, The lesser

Rodentia, Salivary glands of some, 3 I \&-22

Salivary development, A general dogma of, It $6-17$; facts of, established by Schulte, $117-25$

Salivary glands, Contribution to the anatomy of the adult human (C. CARMaLT), 5-23

Salivary glands in man. Development of the (H. voN II'. SCHULTE), 25-72: The glands of the vestibule, 20-3I; observations on human embryos, $3 \mathrm{I}-4 \mathrm{I}$; discussion of findings, $42-60$; summary, 60-70; bibliography, 70-7I

Salivary glands in the carnivora, Anatomy of the (C. Carmalt), 155-90

Salivary glands in the domestic cat, The development of the (H. VON $\mathrm{II}^{*}$. SCHLLTE), 104, 105. $122,1 \mathrm{OI}-3 \mathrm{I} 3$

Salivary glands in the lower primates, Macroscopic anatomy of the (GEO. S. HUNIINGTON) 73-113: Terminology; 74-79: description of individual species, So-03; analysis and conclusions, 93-113; annotation in figures, 113

Scalops aquaticus, 317

Schiefferdeker, Celloidin corrosion method of, 330

Schulte, H. von II. The development of the salivary glands in man, 25-73, 79. IO4, II 5 II Schulte, H. vos $W$., The development of the salivary glands in the domestic cat, 104, 105, $122,101-313$

Schulte, $H$ vox W. The mammalian alveolingual salivary area, with special reference to the greater sublingual gland of the pig, 325-55

Schulte, II. von W., Facts established by, ir $7-$ 22

Sciurus Carolinensis, 318

Sea-lion, Californian, The salivary glands of the. I $79, \mathrm{IS}_{3}, \mathrm{I} \mathrm{S}_{4}, \mathrm{I} 85, \mathrm{I} S \mathrm{~S}$

Seals, Cuvier on glands absent in, 180

Secondary submaxillary gland and duct, The, $14^{-15}, 75^{-70}, 90-91,91-92,95,104,108,110$, II $2,145^{-} 46$

Segmentation, Lines of, 122

Selection. Slight changes in, 129; embryonic, $137-3 \mathrm{~S}$

Separating sulci defined. 21

Silvester. C. F., Preparations of, in Museum at Princeton. 158; 180; results of, 326, 327; on greater sublingual in Tragulus, 320

Sinia satyrus, Salivary glands of, 9, So-81, 94 . $96,97,98,101,109,110,140,141$

Socia parotidis, 40, 74. See also Accessory parotid

Sprout from epithelial flange, 60: of the first orbital gland, 248: from stomal ridge, 259-60 Sprouts, of orbitoparotids, $30-31$; establishment of, 43: starting-points for, 70; from anlages, 105-0; of the orbital glands, 160 ; of the paretid. I $S_{I}, 229-32,245-47,259$; continued production of orbitoparotid, $263-64 ;$ additional urbital, 273; of inferior alveobuccal rlands, 300: of lesser sublinguals, 303, 310 : views regarding development from, 333-34; production of. 35.3

Squirrel, gray, Salivary glands of the, 3 is

Stenson's duct, $7,8,9$; in lower primates, 74. 85, 85; in paca, 318 ; in capybara, 310 ; in Ungulata, 322 
Stomal ridge, The, in the cat, I60, I65-66, 2 10, Sublingual group, Lesser, 76-79, I I 8-21, I 45 271,273 ; in lioness, 169 ; in the dog, 170; in Sublinguale, Deuxième, Première (C11vier), 326 Thibetan bear, $171-72$; in badger, 173 ; of Sublinguales minores, 28 glutton, i 76

Structures, miscellaneous, Annotation of, 23 Sublingualis major, 28,336

Submandibular complex in lower primates, $88-$ Sublingual gland, The greater, or Bartholinian 89 ; analysis of, $137-45$ gland, $5,13,14,15-17,18,22,28,29,51,59$, Submandibular group in lower primates, $75-76$ 69 , I1 3,320 ; Ilis on origin of, 26 ; a complex, I I0

27-29, 310: development of the, 65-67,70: Submaxillary duct, The, 57-58, 75; relation of relation of to the lesser, II 3 ; cause of variable occurrence of, s 20 ; relation of, to submaxillary; $130,138,333$; in the carnivora, $155-56$; of the cat, $167-08,292-99,309$; of lioness, 169 ; of dog, 17r; of Thibetan bear, 172; of raccoon, I73; of skunk, 173; of badyer, 174: absent, 175 ; observations on, $180,183,188$; in opossum, 316 ; in American mole, 317 18; of gray squirrel, 3 Is; in paca, 319 ; in hyolrochorus, 16, 320; in African porcupine, 321 ; in muskrat, $32 \mathrm{I}$; von Schulte and others on, 327-30; in man, 328-29; Chievitz on, 33739: primitive independence of, $345-50$; development of, in pig embryos, $345-52$; interpretation of, 352-53; described, 353-54

Sublingual gland, The greater, and duct, in lower primates, $76-77$, So-92, 96-99, 100-13, 328; in Simia satyrus, $80-8 \mathbf{I}$; in Truglodytes niger, $82 ;$ in Cynocephalus babouin, 84 ; hamadryas, $80 ;$ in Macacus, 87,80 ; in Ateles, sp.?. 92; in Lemurvarius, 92; facts in development of, $117-18$; interpretation, I 18 19; variable development of, 120-21; without derivatives, $139-41$; union of duct with submaxillary, 146-50; default of, I 50-5t

Sublingual glands, The lesser, or Rivinian, I3, I 4 , $16,17-21,29,59,326$; development of, $67-68$, $69-70,104,106,118$; in the carnivora, 156; of the cat, I 68,299, 302-3, 300, 327; of lioness, 170; of dog, I7I; of Thibetan bear, 172 ; of raccoon, 173; of skunk, 17.3; of badger, 174; of glutton, 177 ; in sea-lion, 179 ; observations, 186, I88; in opossum, 316 ; in flying phalanger, 316 ; in fox bat, 317 ; in gray squirrel, 318 . in paca, 319; in African porcupine, 321; in muskrat, $32 \mathrm{I}$; in Ungulata, 322; in antelope, 323; von Schulte and others on, $327 ;$ rela tions of, to the greater, 328-32; Reichel on, 333; Chievitz on, 337; derived from simple sprouts, 354

Sublingual glands, The lesser, and ducts proper, in lower primates, $76-79,80-03,97-113$; in Simia satyrus, $8 \mathrm{I}$; in Troglodytes niger, $82-$ 83 ; in Cynocephalus sphinx, $8,3-84$; in Cynocephalus babouin, $85 ;$ in hamadryas, 86 ; in Macacus cynomolgus, 87 ; nemestrinus, 89; in Nyctipithecus, 89 ; in Ateles hybridus, 90 ; in Lagothrix, 91 ; in Ateles, sp.?, 02 ; in Lemurs, 93; facts in development of, in 8 ; Sulcus alveololingualis (Chievitz), 26

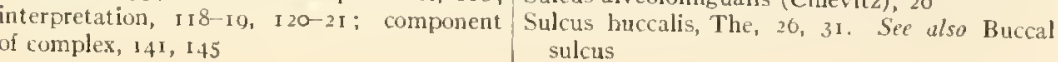

to greater sublingual, i 30

Submaxillary gland, The, 5, 12-15; accessory glands and ducts, I2, I $3-14,15,20,75$; secondary, $32,14-15,75$; annotation of, in all figures, 22; furrow giving origin $t 0,26$; in the embryos, 4 S-59; Chievitz on origin of, $50-5 I$; development of, $60-65,69,70$; in the carnivora, $155 i$ of the cat, $160-67,275^{-92}, 300$, 3 fo: of the lioness, 160 ; of the $\operatorname{dog}, 17 \mathrm{I}$; of Thibetan bear, 172; of raccoon, 173; of skunk, 173; of badger, 174; of glutton, 177 ; in sea-lion, 179; observations, I8 $1,183-8.4$. IS8; in opossum, 316; in flying plaalanger, 316 ; in fox bat, $317 ;$ in American mole, 317 ; in gray squirrel, 318 ; in paca, 318; in capybara, $319^{-20}$; in African purcupine, 321 ; in muskrat, 321 ; in Ungulata, 322 ; in antelope, $323 ;$ in horse, 323 ; Cuvier on, in pig, 326: substantial agreement on, 327 ; Chievitz on, $330-37$; interpretation of, $35^{2-53}$; described, 353

Submaxillary gland and duct and associated structures in lower primates, $75-76,77,80-93$. 95-90; in Simia satyrus, 80; in Troglodytes niger, 81 S $S_{2}$; in Cynocephalus sphinx, 83 ; babouin, 84; hamadryas, 86 ; in Macacus, 87, 88; in Nyctipithecus, 89; in Ateles hybridus, 90: in Lagothrix, 9o-u1; in Ateles Sp.?, OI-92; in Lemurs, 92-93 ; summary, 99I13; facts of development of, I I 7 ; without derivatives, $139-41$; accessory glands, $142-$ I 45; a secondary, 145-46, I54a; union of duct with sublingual, $1+40-50$

Subparoticl sulcus, The, 2.44

Sudler, Mervin T., on embryos, 25; embryo CLX of, 48; embryo CLAIV of 10 ; bryos XLIII and XXII of 50 ; on formation of ducts, 192; on sulidity of submaxillary anlage, 3 to

Sulcal glands defined, 194

Sulci, glandiferous, Confused nomenclature of, 26; terminology suggested for, 26; of the alveolingual region, $4^{6-70}$

Sulci of the alveolingual region defined, $334-35$ Sulcus alveobuccalis, $157-58$

Sulcus alveolaris, The, 26, 46-47, 58; defined, $334-35$ sulcus 
Sulcus circumflex. The, 332, 341; (Scbulte) Variation, Range of, in lower primates, 25; along detined, 335 Sulcus intermedius (Schulte), 20, 55; defined,

335 Ventral accessory submaxillary glands, $13-14$, submaxillary line, 66, 112 57.09 ; in the cat, 200; defined, 334 Sulcus sublingualis (His), 26. $334-35$

Ventral accessory submaxillary glands, $13-14$, $29,75,155$

Symington, Tupographical anatomy of the sali. Vessels and nerves, Annotation of, in all figures, vary glands, o 


\section{COLUMBIA UNIVERSITY PRESS}

Columbia University in the City of New York

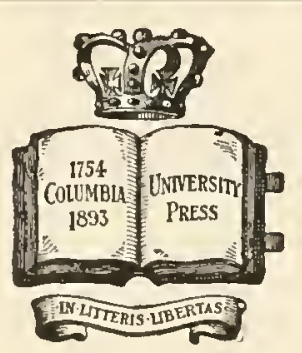

The Press was incorporated June 8,1893 , to promote the publication of the results of original research. It is a private corporation, related directly to Columbia University by the provisions that its Trustees shall be officers of the University and that the President of Culumbia University shall be President of the Press.

The publications of the Columbia University Press include works on Biography, History, Economics, Education, Philosophy, Linguistics, and Literature, and the folluwing series:

Columbia University Contributions to Antbropology.

Columbia University Biological Series.

Columbia University Studies in Cancer and Allied Subjects.

Columbia University Studies in Classical Philology.

Columbia University Studies in Comparative Literature.

Columbia University Studies in English.

Columbia University Geological Series.

Columbia University Germanic Studies.

Columbia University Indo-Iranian Series.

Columbia University Contributions to Oriental History and Philology.

Columbia University Oriental Studies.

Columbia University Studies in Romance Philology and Literature.

Blumenthal Lectures. Hewitt Lectures.

Carpentier Lectures. Jesup Lectures.

Julius Beer Lectures.

Catalogues will be sent free on application.

LEMCKE \& BUECHNER, Agents 30-32 WEST 27th ST, NEW YORK 


\section{COLUMBIA UNIVERSITY PRESS}

Columbia University in the City of New York

\section{Scientific Features of Modern Medicine}

By FREDERIC S. LEE, Ph.D.

Dalton Professor of Physiology, Columbia University

Cloth, $12 \mathrm{mo}$, pp. vii +183

Price, $\$ 1.50$ net

$I^{N}$ this volume, the author, who is a member of the Faculty of the College of Physicians and Surgeons, Culumbia University, presents in clearcut and non-techuical language an account of modern medical achievements and aims. The chapters are as follows: -

A Sketch of the Normal Human Boly

The Nature of Disease. Methods uf Diagnosing Disease

Methors of Treatix; Disease

bacterla AND Protozod and their Relation to Disease

The Treatient axl the Prevextion of Infectious Diseases

The Problem of Cancer and other Prublems

FEATLRES OF MIUDERN SIRGERY

The Rôle of Experimext In Medicine. The Public and the Medical Prufession

The book throughout is marked by poise and sanity, and admirably accomplishes its purpose to illustrate the genuinely scientific character of modern medicine, it great change from the medicine of the past and its hopeful outlook for the future.

\section{Education and Preventive Medicine} By NORMAN E. DITMAN, M.D. 8vo, paper, pp. 73

Price, 25 cents net

$\Lambda \mathrm{N}$ interesting account of the achievements of sanitary science in the past and a plan for securing still greater results in the future.

LEMCKE \& BUECHNER, AgENTS 30-32 WEST 27 th ST., NEW YORK 

. 




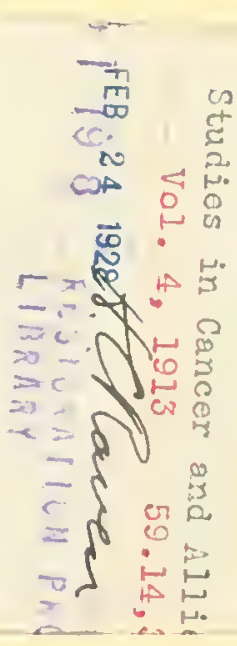


